\title{
REFRAMING IMMIGRANT RESISTANCE
}

ALLIANCES, CONFLICTS, AND RACIALIZATION IN ITALY

Teresa M. Cappiali 
"Brilliantly theorized and rigorously researched, Reframe Immigrant Resistance draws from and makes critical contributions to research on European and North American migration, social movements, and critical race studies. Teresa Cappiali's comparative analysis of migrant mobilizations, alliances, and intra-movement tensions will be widely read and the definitive book on immigrant rights activism in Italy."

Chris Zepeda-Millán, University of California, Los Angeles (UCLA), USA

"This is by no means a detached book, but one that is engaged and is engaging in research that addresses extremely relevant issues in migration studies-namely, migrant struggles and activism within civil society, with the support of some political allies. The arguments are empirically grounded through an original conflict-based and multi-sited methodology, where knowledge is produced through the author's participation within immigrant communities, making it clear that these spaces of resistance are local. Even if it is contextualised in Italy, this book illustrates one of the most silent emancipatory struggles in this second decade of 21 st century and makes an important contribution to the literature on inclusion and democracy and on justice in our contemporary migratory societies."

Ricard Zapata-Barrero, University Pompeu Fabra, Barcelona, Catalonia, Spain

"Theoretically provocative and empirically rich, this volume helps our understanding of migrant struggles by considering the meaning of migration, recognizing their agency, making their voices heard, considering their practices, and the alliances but also the tensions that often emerge in a broad field of action."

Donatella della Porta, Scuola Normale Superiore, Italy

"Based on a thorough theoretical construction and on a meticulous empirical work in four Italian cities, this book examines immigrant political mobilization in a social context marked by a strong racialization. A must read for students and scholars interested in exploring the changing dynamics of immigrant politics, immigration political mobilization and citizenship in Italy and in Europe."

Marco Martiniello, University of Liège, Belgium 

$\because$ Taylor \& Francis http://taylorandfrancis.com 


\section{Reframing Immigrant Resistance}

This book focuses on the political participation and grassroots mobilization of immigrants and racialized communities in the European context. Based on extensive data collected in Italy, it explores the role that alliances among pro-immigrant groups play in shaping political participation, asking why and how immigrant activists mobilize in hostile environments, why and how they create alliances with some white allies rather than others, and what might explain variations in forms of political participation and grassroots mobilization at the local level. Using social movement, critical race, and post-colonial theories, the author examines the ways in which both institutional and non-institutional actors, including immigrant activists, become involved and compete in the local arena over immigration and integration issues, and assesses the mechanisms by which both conventional and non-conventional forms of participation are made possible, or obstructed. By placing immigrant activists at the center of the analysis, the book offers a valuable and novel insider perspective on political activism and the claims-making of marginalized groups. It also demonstrates how pro-immigrant groups can play a role in racializing immigrant activists. A study of the effects on participation in social mobilization of coalitions, conflicts, and racialization processes among pro-immigrant groups and immigrant activists, this volume will appeal to scholars of sociology, political science, and political sociology with interests in migration, ethnic and racial relations, social movements, and local governance.

Teresa M. Cappiali is a Vinnova MSCA-Seal of Excellence Fellow and a researcher at the Raoul Wallenberg Institute of Human Rights and Humanitarian Law in Sweden. She specializes in migration, the politics of migration, racism, and anti-racism from an intersectional approach. 


\section{Research in Migration and Ethnic \\ Relations Series \\ Series Editor: \\ Maykel Verkuyten, ERCOMER \\ Utrecht University}

The Research in Migration and Ethnic Relations series has been at the forefront of research in the field for ten years. The series has built an international reputation for cutting edge theoretical work, for comparative research especially on Europe and for nationally-based studies with broader relevance to international issues. Published in association with the European Research Centre on Migration and Ethnic Relations (ERCOMER), Utrecht University, it draws contributions from the best international scholars in the field, offering an interdisciplinary perspective on some of the key issues of the contemporary world.

Other titles in the series

Intra-State Immigrants as Sub-State Nationalists

Lived Experiences in the Basque Country

Nick Hutcheon

Family Migration and the Path to an Occupation

The (Early) Experiences of Skilled Taiwanese and Chinese 'Wives'

Chieh Hsu

\section{Reframing Immigrant Resistance}

Alliances, Conflicts, and Racialization in Italy

Teresa M. Cappiali

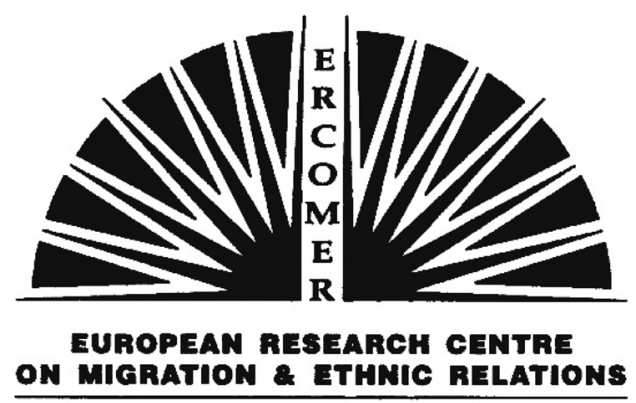

For more information about this series, please visit: www.routledge.com/sociology/ series/ASHSER1136 


\section{Reframing Immigrant Resistance}

Alliances, Conflicts, and Racialization in Italy

\section{Teresa M. Cappiali}


First published 2022

by Routledge

2 Park Square, Milton Park, Abingdon, Oxon OX14 4RN

and by Routledge

605 Third Avenue, New York, NY 10158

Routledge is an imprint of the Taylor \& Francis Group, an informa business

(C) 2022 Teresa M. Cappiali

The right of Teresa M. Cappiali to be identified as author of this work has been asserted in accordance with sections 77 and 78 of the Copyright, Designs and Patents Act 1988.

The Open Access version of this book, available at www.taylorfrancis. com, has been made available under a Creative Commons Attribution-Non Commercial-No Derivatives 4.0 license.

Trademark notice: Product or corporate names may be trademarks or registered trademarks, and are used only for identification and explanation without intent to infringe.

British Library Cataloguing-in-Publication Data

A catalogue record for this book is available from the British Library

Library of Congress Cataloging-in-Publication Data

A catalog record for this book has been requested

ISBN: 978-1-138-57724-4 (hbk)

ISBN: 978-1-032-20017-0 (pbk)

ISBN: 978-1-351-26740-3 (ebk)

DOI: $10.4324 / 9781351267403$

Typeset in Times New Roman

by Apex CoVantage, LLC 
Ai miei genitori, Gianni e Giovanna, che mi hanno insegnato ad interessarmi sempre agli altri, ad aprire gli orizzonti e a sognare un mondo migliore

To my parents, Gianni and Giovanna, who taught me to always be interested in others, to broaden my horizons and to dream of a better world 

$\because$ Taylor \& Francis http://taylorandfrancis.com 


\section{Contents}

List of figures $\quad \mathrm{x}$

List of tables $\quad$ xi

List of abbreviations and acronyms xii

Note to the reader xiii

Acknowledgments $\quad \mathrm{xV}$

Introduction

1 The Italian context and methodology 29

2 A theoretical model of local dynamics: alliances and $\begin{array}{ll}\text { conflicts in context } & 55\end{array}$

3 Civic participation in a city of intercultural dialogue $\quad 80$

4 Multiple forms of participation in a stronghold of the left 111

5 Political contention amid the rise of the Northern League 152

6 Obstructing participation in a stronghold of the Catholic Church 192

7 Political racialization and resistance 220

$\begin{array}{lr}\text { Conclusion } & 249\end{array}$

Appendix A Research design and methodology 272

Appendix B List of interviews conducted in Reggio Emilia 288

Appendix C List of interviews conducted in Bologna 290

Appendix D List of interviews conducted in Brescia 293

Appendix E List of interviews conducted in Bergamo 295

Index 297 


\section{Figures}

2.1 Overview of the theoretical model of local dynamics 


\section{Tables}

1.1 Main immigrant communities in Italy (2012) 30

1.2 Comparison of the four cities 46

2.1 Three approaches to inclusion and their implications for participation 65

2.2 Local dynamics and participation of immigrant activists in the $\begin{array}{ll}\text { four cities } & 73\end{array}$

$\begin{array}{lll}7.1 & \text { Ideology and approaches to inclusion } & 259\end{array}$

7.2 Alliances and participatory variations in the four cities 260

\section{Appendix A}

Table 1 The largest immigrant communities in each region by country of origin (2012)

Table 2 Comparison of two regions (1998-2013) 275

$\begin{array}{lll}\text { Table } 3 \text { Summary of the fieldwork } & 278\end{array}$

Table 4 Summary of interviews with immigrant activists 280 


\section{Abbreviations and acronyms}

ACLI: Christian Association of Italian Workers (Associazioni Cristiane Lavoratori Italiani)

CGIL: Italian General Confederation of Labor (Confederazione Generale Italiana del Lavoro)

CGIL-FIOM: Metalworkers' Federation (Federati Impiegati Operai Metallurgici della CGIL)

CISL: Italian Confederation of Workers' Trade Unions (Confederazione Italiana Sindacati Lavoratori)

CNEL: National Council for Economics and Labor (Consiglio Nazionale dell'Economia e del Lavoro)

COBAS: $\quad$ Confederation of Basic Committees (Confederazione dei Comitati di Base)

CUB: $\quad$ Unitary Base Confederation (Confederazione Unitaria di Base)

DC: $\quad$ Christian Democrats (Democrazia Cristiana)

DS: $\quad$ Democrats of the left (Democratici di Sinistra)

PCI: $\quad$ Italian Communist Party (Partito Comunista Italiano)

PD: $\quad$ Democratic Party (Partito Democratico)

PDL: $\quad$ People of Liberty (Popolo della Libertà)

PRC: Communist Refoundation Party (Partito di Rifondazione Comunista)

UDC: $\quad$ Union of the Center (Unione di Centro)

UIL: $\quad$ Italian Labor Union (Unione Italiana del Lavoro)

USB: $\quad$ Base United Unions (Unione Sindacale di Base) 


\section{Note to the reader}

This book is the result of a collective endeavor. Its knowledge has been produced with the immigrant activists I have interviewed. The most important insights conveyed here are not mine; rather, they emerge from the various perspectives of the immigrant activists whom I met during my journey. The influential Indian feminist scholar, Uma Narayan, calls this phenomenon "epistemic advantage." She argues that, while it is possible for non-members of marginalized groups to understand systems of oppression and domination, it is both "easier and more likely for the oppressed to have critical insights into the conditions of their own oppression than it is for those who live outside these structures" $(1989,264$; emphasis mine). Moreover, though immigrant activists are often a minority within immigrant communities, they are not isolated individuals. On the contrary, activists share collective experiences with the larger immigrant communities they work with and for. Through their engagement, they devote countless time and energy to the immigrant communities, listening to their suffering and needs, helping them find solutions to their problems, and sensitizing them to their rights and duties in the receiving society. Therefore, immigrant activists are a key entry point to study processes of othering and resistance from an epistemic point of view. Their engagement in their communities - and in Italian political life - gives them critical insights not only into their own situation but those of many immigrants they have encountered and helped during their journey and who are part of their networks and lives. In this respect, the insights presented here are the sum of multiple individual and collective perspectives distilled during my research.

As a critical scholar focusing on migration, racism, and anti-racism, I cannot dissociate this work from my own endeavors to end injustice. This book is, therefore, for the immigrant activists I have met during my research and all the immigrants living in Italy. Dedicated to the passionate and inspiring people I have met and without whom this book would not exist, this work supports their cause, hopefully helping to improve their conditions by translating what they have taught me during the many months I spent with them.

Informed by the points of view of those whose mobility is constrained and punished, this study has changed my way of seeing the world and issues of inclusion and exclusion. To migrate today means different things to different groups of people. This variation in migratory experience is especially acute if one compares 
that of a white person from the "Global North" to that of a person of color from the "Global South." My own "partial vision" of a white woman who has largely benefitted from the global mobility infrastructure (Spijkerboer 2018) has been enriched by the complexity of views of many immigrants (women and men) with different origins who are stuck in a system built on racial inequality, which constrains the mobility and disciplines the bodies of racialized groups within and across countries. The results presented herein offer readers an opportunity to listen to the suffering and feel empathy with the struggles of the many immigrant activists who experience some of the worst forms of institutional racism in contemporary democracies. Hopefully, the readers will be motivated to learn more about the issues explored in this study and to seek ways to properly address them. 


\section{Acknowledgments}

This book and its most important insights were possible thanks to the great generosity and love of many people whom I have met during my $\mathrm{PhD}$ studies in Canada and my extensive field research in Italy. Special thanks go to all the wonderful people I met during my fieldwork and who helped me to conduct my empirical research. I am grateful to have met with so many inspiring politicians, trade unionists, NGO members, and Italian activists, who dedicate their lives to improving immigrants' human rights. Even though this book includes some important criticisms in attempting also to understand what could have been done better, it is undeniable that immigrants' lives in Italy could have been much worse now were it not for the people who are truly committed to defending their rights. I am especially grateful to the "gatekeepers" who offered invaluable guidance, material, and contacts, and the 101 people who agreed to participate in face-toface interviews. Without their time and insights, I would never have been able to formulate the questions needed to bring to light the pressing issues addressed in this book. In this regard, I am most indebted to the immigrant activists I interviewed, who offered their precious time and support. I continue to be inspired by their passion and tireless work toward improving their rights and preparing Italy, my home country, for a more inclusive and tolerant democracy. It breaks my heart to know that while I was welcomed and given the possibility to thrive in Canada, they faced discrimination and violation of their basic human rights in the country where I was born. I hope that my understanding of this structural injustice will help me contribute to making their experiences visible in this book and in my future work.

This book constitutes a further development of my PhD dissertation, which was defended at the Université de Montréal in Canada. The generosity and true commitment to academic integrity and excellence as well as meritocracy of the many people who accompanied me on this journey have made me a better academic and a better person. My dissertation would never have come to completion without the support of two wonderful mentors: my main supervisor, Jane Jenson, and cosupervisor, Pascale Dufour. Prof. Jenson's patience and tireless encouragement have been a constant source of support. What seemed an impossible task, and an overly ambitious project, became surprisingly feasible. Prof. Jenson is an excellent supervisor, and I couldn't have found a more suitable person for the task. 
I am also grateful to Prof. Dufour, who helped me orient my thoughts toward a more sociological approach. I owe her a great deal for many aspects of this work, and I am so happy that she helped me to develop aspects of my research that are relevant to social justice. I thank you both for believing in me and in this project.

I would also like to express special thanks to Prof. Éléonore Lépinard, who pushed me to go forward, to believe in myself, and helped me refine my sociological inclinations. I followed Prof. Lépinard's sage advice at the beginning of my $\mathrm{PhD}$ and I ended up working on something I was really passionate about. My overall development as an academic has been influenced by her passion. I am so glad to have had her support for so many years and to have discovered what critical sociology is really about.

I am greatly indebted to Prof. Jeffrey Reitz, who has offered wonderful support during my visiting fellowship in the Centre of Ethnic, Immigration, and Pluralism Studies at the University of Toronto between 2013 and 2015. Prof. Reitz is not only a great teacher and scholar, but also, and most importantly, an inspiring human being. I would like to thank him for believing in me and my research, and for believing in a more inclusive and just world.

I want to thank the wonderful people in the Department of Political Science at the Université de Montréal, who welcomed me in the first place, and who made this journey possible and extremely pleasant. Special thanks go to Prof. JeanFrancois Godbout and Prof. Christine Rothmayer, who gave me great advice and encouraged me in many invaluable ways. I will never forget your kindness and professional support. I also thank all the Faculty in the Department of Political Science for standing up for tolerance and respect for diversity and equality, and for believing in meritocracy and hard work. Quebec has taught me how to be a better person and a citizen of the world.

I am also thankful to IRTG Diversity who offered me financial, intellectual, and moral support in the last two years of my PhD. Thanks to Prof. Laurence McFalls and Prof. Ursula Lehmkuhl, and all the professors and $\mathrm{PhD}$ students who are part of this wonderful team. I would especially like to acknowledge my bowling buddiesLucio, Alice, and Rebecca. I will never forget our wonderful training and leisure trips at Otzenhausen. I miss you all very much.

My $\mathrm{PhD}$ offered me a chance to develop within an inspiring environment, made so by the presence of funny and loving colleagues. I have made some of the most beautiful friendships in the world. I am grateful to my very special friends, Martin, Merouan, Mona, and Waeza. I hope there will be other opportunities to spend time with you all, imagining and recreating our own political space of freedom. Thank you for being in my life.

During my $\mathrm{PhD}$ studies, I was extremely lucky to spend several months in the Centre on Social Movement Studies (COSMOS) at the European University Institute in Florence as a visiting research fellow in 2013 and 2014. Here, I was exposed to the most current research in the fields of migration and social movements, and I was given the opportunity to receive constant feedback on my data collection and analysis. The same goes for the great opportunity to be a visiting researcher in the Department of Government (Fall 2015) and in the Mario Einaudi 
Center for International Studies (Spring 2016) at Cornell University. I am thankful to Michael Jones-Correa, who invited me in the first place and who gave me valuable advice on my project, and to David B. Lipsky, who encouraged me to become a better academic.

Furthermore, I am grateful that while completing this book, life brought me to Italy and then to Sweden. In both countries, I was exposed to different disciplines and scientific approaches, helping me to expand my horizons. During my Postdoctoral Fellowship at Collegio Carlo Alberto, Turin, I received the most relevant advice and support from my great mentor, Tiziana Caponio. I was delighted to get feedback from the members of FIERI (Forum Internazionale ed Europeo di Ricerche Sull'immigrazione): Giovanna Zincone, Ferruccio Pastore, Irene Ponzo, and Andrea Pogliano. I am also grateful for the friendship and academic support of Davide Barrera, Moreno Mancosu, and Monica Ferrín Pereira.

In Sweden, my colleagues and students in the Department of Gender Studies at Lund University have provided a refreshing environment in which I found new ways of looking at and researching intersectionality, racism, human rights, and resistance. I thought I had learned the basic approaches to knowledge production until I met the wonderful feminist and anti-racist colleagues and students at Lund. They have convinced me that there is no "good science" without a true commitment to social justice and equality. I have been inspired to be more courageous and explicit about the role of research in the reproduction of power relations and to be suspicious of research that, despite its claims, does not benefit the communities on which it is done. Had I met them before, I would have been able to refine my thinking and understanding of the interlocking forms of oppression that the immigrant activists I interviewed have to go through. Yet, even though I wish I had met them earlier, I was lucky to meet them during the final phase of writing this book. I am indebted to them for having been able to "see" the empirical data with fresh eyes and, fortunately, through the lens of critical, emancipatory research. This has allowed me, as bell hooks would say, to theorize activism and resistance from the margins, and to offer a more nuanced and pluralistic perspective of the communities with whom and for whom I have conducted this research. My special thanks also go to Diana Mulinari, Helle Rydström, Lena Karlsson, Irina Schmitt, Maja Sager, Cristian Norocel, Marta Kolankiewicz, Rebecca Selberg, Jens Rydström, Terese Anving, and Sara Goodman. I am also grateful for the friendship and support of the PhD students, Riya Raphael and Mikael Karlsson, and the most inspired and engaged students I could have ever dreamed of: Maria Levin, Yvonne Jila, Maliha Shermuhammad, Jonelle Twun, and Merethe Riggelsen. I am grateful too for the support and new collaborations with the RWI (Raoul Wallenberg Institute of Human Rights and Humanitarian Law) in Lund. Special thanks go to a friend and great intellectual-activist, Michael McEachcrane, and to the most inspiring international human right lawyers, RWI's Director Morten Kjaerum.

Last but not least, I am greatly inspired and revived by the intellectual exchanges and friendships with people I have met during my academic career. Particular thanks go to Maria Tonini, Monica Cabarcas, and Catia Gregoratti, who are great academics and anti-racist feminists. And, of course, I am grateful to my good 
friends and colleagues, Juan Carlos Triviño-Salazar and Johanne Jean-Pierre, and the most inspiring academic and friend, Chris Zepeda-Millàn. Without his support, this book would never have come to fruition.

By way of closing, I would like to offer a tribute to all the activists who have fought and continue to fight around the world to improve human rights for immigrants. My greatest thanks go to the most inspiring Italian human rights activist, trade unionist Aboubakar Soumahoro (originally from Côte d'Ivoire), who agreed to be interviewed twice during my data collection, despite his busy schedule. Some of the most important insights of the book are owed to him. I am also greatly indebted to Raymon Dassi (in this book anonymized as Donald R.), who helped throughout my entire research and read parts of my final manuscript. I owe him some of the insights on how political racialization works in Italian politics. 


\section{Introduction}

\section{Racialization and immigrant mobilizations: the case of Italy after the 2008 financial crisis}

This book presents an in-depth study of immigrant activism and struggles in Italy, with a particular focus on conflicts and alliances with Italian pro-immigrant groups in four Italian cities in the North: Reggio Emilia, Bologna, Brescia, and Bergamo. It examines how immigrants and new citizens of migrant background have sought to improve their human rights situation and bring an end to the suffering, labor exploitation, and injustice inflicted on them and their families by institutional racismor what some authors have called the "Italian apartheid" (Perrocco 2003). In particular, this book focuses on the demands that racialized immigrants and new citizens (or "people of color") - meaning non-white women and men, mostly from non-European countries, especially from countries in the "Global South"-make with the help of Italian "white" supporters - leftist political parties, trade unions, NGOs, the Catholic Church, and the grassroots radical left-to challenge racial inequality in their country of residence. ${ }^{1}$ The book examines the complicated issue regarding the inclusion of immigrants in society by looking at several activist mobilizations around immigration issues that took place in urban settings in Italy in 2010 and 2011, as a result of the deterioration of immigrants right after the 2008 financial crisis and the introduction of new restrictive immigration laws in 2008 and 2009 (Oliveri 2012, 798). What were these immigrants' demands? How were they framed by these groups with the supports of Italian pro-immigrant groups? In this study, I define "inclusion" of immigrant groups as the efforts made by the state and a plethora of actors - including anti-racist and pro-immigrant groups - to promote recognition of immigrants' fundamental rights and substantial achievement of parity and (racial) equality.

While focusing on the specific case of Italy, a key border country of the European Union, the book speaks to immigrants' struggles for rights in Western democracies more broadly. The mobilizations that took place in Italy were not isolated phenomena but part of a more general trend. In the past two decades, a substantial amount of literature has documented a new era of institutional racism promoted by more restrictive official policies of immigration and integration and discourses and practices of exclusion of immigrants (especially, but 


\section{Introduction}

not exclusively, of "non-white," "poor" immigrants from the "Global South") (de Haas et al. 2020). This new shift, combined with the rise of anti-immigrant political parties and widespread xenophobia, has led to the construction of targeted immigrant groups as a "social threat," and to state-supported practices of criminalization and marginalization (d'Appollonia 2015; El-Tayeb 2011). As Raissiguier $(2010,4)$ observes, "global economic transformations, the construction of Europe, increasing national anxieties and the economic crisis" have all contributed to the emergence of a "hegemonic discursive and material practice" which defines immigrants and racialized communities of migrant background as Others. These include immigrant offspring, who are constructed as "second-class citizens" (El-Tayeb 2011). Moreover, some groups of immigrants (especially the undocumented ones) are constructed as "impossible subjects" of the nationstate, and as people with no rights (see also Nicholls 2013; De Genova 2010). Powerful processes of exclusion and marginalization have become widespread (d'Appollonia 2015) and these have impacted immigrants and racialized groups of migrant background differently, depending on their race, ethnicity, religion, citizenship status, gender, and class (El-Tayeb 2011).

In response to these developments, several pro-immigrant actors and immigrant groups with different statuses and identities have mobilized in Europe and North America. Some protests have exposed a variety of issues concerning the deterioration of immigrants' rights, including the passing of restrictive citizenship and migration legislations and the reinforcement of the regime of deportation (della Porta 2018; Nicholls and Uitermark 2016; Raissiguier 2010; Voss and Bloemraad 2011; Zepeda-Millán 2017). Other demonstrations were responses by racialized groups with migrant backgrounds (e.g., Arabs, Blacks) to the general societal rise of xenophobic and racist attitudes toward them (d'Appollonia 2015). Moreover, many immigrant workers - both documented and undocumented-have organized and unionized at the national and local levels in response to the drastic deterioration of their labor rights (Adler et al. 2014; Anderson 2010b; Milkman 2011; Doellgast et al. 2018). Many mobilizations developed in response to the global financial crisis of 2008 and involved immigrants who saw their rights undermined by changes to both migration and labor laws. More recently, many refugees and their supporters have organized across Europe in response to hostilities during the so-called "refugee crisis" of 2015 (Ataç 2016; della Porta 2018; Steinhilper 2018; Steinhilper and Ataç 2019).

Focusing on the case of Italy, this study explores why and how immigrants and racialized communities make rights claims in democratic yet often racially hostile and exclusive societies. It asks: How can vulnerable immigrants and racialized groups mobilize for their rights at a historical conjuncture particularly hostile to their claims? Using the rich data on immigrant mobilizations in Italy I collected during my research between 2013 and 2014, I seek to enhance the current scholarship on immigrant activism: to theorize and provide new empirical knowledge about immigrant activism beyond the specific case of Italy.

Italy is the perfect case to analyze immigrant activism in hostile environments. Between 2010 and 2011, several immigrant mobilizations swept throughout Italy. 
The mobilizations were carried out by immigrants and racialized communities of immigrant origin and Italian "native-born" (or "white") pro-immigrant supporters of different political orientations (Oliveri 2012; Cappiali 2019). These actions were sparked by two main structural changes: the global financial crisis of 2008 and the passing of measures restricting immigrants' rights in Italy. The two changes exacerbated the already poor conditions of immigrant rights across the country (Cappiali 2019). The economic crisis increased nationalist hostility to immigration and escalated immigrants' criminalization in public discourse. Moreover, while the economic crisis hit the Italian population more broadly, immigrant workers were disproportionately impacted (OECD 2014). ${ }^{2}$ The mobilizations were also in response to two anti-immigrant measures passed in 2008 and 2009 by the right-wing government - the so-called "Security Package" (Pacchetto Sicurezza) (Laws 125/2008 and 94/2009). These measures reinforced the country's institutional racism promoted by the infamous Bossi-Fini Law (or Law 189/2002). This law was introduced in 2002 by the right-wing majority, and it is considered especially tough on immigrant workers as it frames immigrant presence in Italy as a labor force, as "non-deserving" and as a security problem (see also Caponio and Graziano 2011). Combined with labor precariousness and unemployment, this legal framework placed precarious immigrant workers into illegality and further marginalized immigrant groups (Cannella 2010; Triandafyllidou and Ambrosini 2011).

Immigrant mobilizations started with a key symbolic event on January 7, 2010. After two workers were injured by three Italian mobsters, hundreds of undocumented immigrants, exploited as orange-pickers by the Italian Mafia, organized a protest in Rosarno, in the Southern region of Calabria. The protesters launched an urban battle that lasted several days - fueled by immigrants' will to resist extremely unjust working conditions. The intense protests became a national symbol of resistance to exploitation and encouraged new protests across the country in the following two years (Cappiali 2016, 2019; Oliveri 2012; Ragusa 2011).

Directly referring to the protest of the orange-pickers in Rosarno, on March 1, 2010, a national strike of immigrants, called "A day without us: The strike of migrants," was organized by an anti-racist movement - composed of coalitions of church-based, left-wing civil society organizations, and radical left organizationsand many immigrant workers and associations who formed the Committee of the First of March (Comitato Primo Marzo). The event saw thousands of people take to the streets for organized sit-ins, demonstrations, and strikes (Oliveri 2012; Cappiali 2019). This was the first strike of immigrant workers in the country at the national level, and the organizers managed to coordinate its actions in several large and mid-sized cities from the South to the North-Bologna, Genoa, Trieste Brescia, Mantua and Basso Mantovano, Milan, Padua, Rome, Turin, Naples, Bari, and Palermo. The action brought 300,000 people to demonstrate in the streets and prompted many workers to strike (Cappiali 2019; Cobbe and Grappi 2011). National in scope, the event exposed important geographical variations among the pro-immigrant and immigrant groups - and the alliances and conflicts between groups with different ideological affiliations - across the country (Cappiali 2019). 
As a result of these differences, immigrants' participatory outcomes and levels of visibility were also different across contexts.

Also in 2010, national and local authorities responded negatively to the thousands of undocumented immigrants employed in the underground economy who had applied for mass regularization of their status. So, inspired by the occupation of the crane by Italian workers, nine undocumented immigrants climbed onto a crane in Brescia in Northern Italy in November 2010 (Cappiali 2016). Some immigrants occupied a crane for several weeks. Part of a larger mobilization of hundreds of immigrants, supported especially by the city's radical left, the protesters wanted to expose the state's failure to regularize most of the immigrant workers who had applied, holding Brescia's right-wing administration accountable for raising the requirements and slowing down the regularization process. Immigrants and their supporters called this the "swindle amnesty," because they felt that the state used this mass regulation to steal money from immigrant workers, but with no actual intent to regularize their employment status. For several months, they organized demonstrations and occupied a public space in front of the Prefecture, the governmental office that issues permits to immigrants and where their applications were processed (Cappiali 2016).

Known later as the "Struggle of the crane" (Lotta della gru), this mobilization became famous among anti-racist organizations across the country because of its intensity and endurance. It was described as symbolic not only of the struggle against exploitation and unjust treatment of undocumented immigrants, but also of immigrants' self-determination, courage, and ability to resist institutional racism (Cappiali 2016; Mometti and Ricciardi 2011). Because of its disruptive character, moreover, this dramatic event represented the peak of the protests in 2010. It marked a very contentious and polarized moment, attracting the attention of national and international media. What is more, it triggered a national debate on the deplorable living and working conditions of many immigrant workers across the country - not least in the rich cities of the North.

Other, less contentious mobilizations also took place during the same twoyear period. On September 9, 2011, the city of Reggio Emilia, in Northern Italy, launched the national campaign "Italy is me, too! For the rights of citizenship" (L'Italia sono anch 'io! Per i diritti alla cittadinanza). The campaign's goal was to collect enough signatures to present two popular legislative propositions to Parliament. The first proposition sought a change in the citizenship law, which was considered particularly restrictive. Based on jus sanguinis (or "right of blood"), the law excludes children of non-EU immigrant parents from citizenship status. ${ }^{3}$ The change would instead apply a "moderate" jus soli ("right of soil") principle, allowing many second-generation immigrants born or raised in the country and excluded from naturalization criteria to become Italians with full rights. The second proposition focused on granting non-EU citizens, who had been residents in Italy for several years, the right to vote in local elections. ${ }^{4}$ The campaign was also created in response to the growing climate of intolerance that followed the financial crisis, and which was reflected in the legislation and in the dominant criminalizing discourses on immigration. For this reason, it was as much a cultural 
battle to reshape the debate on immigration, which had become almost completely monopolized by the main anti-immigrant party, the Northern League. Moreover, many left-wing mayors across the country participated in the initiative with the support of civil society organizations. Even though the campaign did not succeed in pressuring the parliament to change the citizenship law and to promote local voting rights, the committee achieved its goal of collecting enough signatures to send the propositions to the Italian Parliament and to prompt a new debate on the level of discrimination in the legislation.

The striking variations between the mobilizations described above reveal important differences in the geographical context as well as in the immigrant characteristics of immigrant activists, Italian organizations, and the claims to rights that were made. Here the question I ask is: what are the factors that explain these variations? By analyzing four selected local contexts, this book will explain these variations. In particular, it will unveil why and how some mobilizations take place in some cities and not in others, as well as why and how some immigrants are more visible than others within mobilizations. I will show that such variations are largely affected by ideological affiliations of pro-immigrant groups supporting immigrant claims and by alliances with immigrant groups.

\section{A new approach to study mobilizations in context}

This study fills major lacunae in our current understanding of the civic and political participation of immigrants and racialized communities and their rights claims in hostile environments - going beyond the case of Italy. In recent years, research focusing on why and how immigrants become civically and politically active in hostile environments has expanded. This research has provided new knowledge about immigrant mobilizations in receiving societies, highlighting the key role of immigrant activists and their supporters in resisting institutional racism and oppression and, in some cases, improving their living and working conditions. Despite the important contributions of this research, there are some crucial gaps that this book seeks to rectify. In particular, our current understanding of why and how immigrants' civic and political participation and rights claims vary across geographic locations is inadequate. Studies often focus on geographical variations of some forms of participation and rights claims of immigrant groups (e.g. rights of residency vs. campaigns against racism) or some immigrant groups (undocumented immigrants vs. immigrant youth), but there is little research that approaches these mobilizations by taking into account the entire participatory spectrum. To address this issue, I will ask the question of why some immigrant groups mobilize in some specific cities and others in other contexts, why and how they create alliances with some pro-immigrant actors, and not with others, and why and how do their right claims and mobilization vary.

My main argument is that immigrant activists' rights claims and patterns of civic and political participation are affected by the composition of coalitions and conflicts between immigrant activists and their pro-immigrant supporters. While national factors (such as a change in legislation and in the economic conditions) 
matter, they are not enough to explain the variations in immigrant mobilizations observed, for instance, in Italy after the financial crisis. This is why we need to zoom in on local dynamics to understand these variations. The nature of immigrant claims (e.g., radical vs. moderate) and the ability of immigrants to mobilize in adverse contexts and with very scares resources depends very much on configurations of powers in city and the coalitions and alliances that are created by immigrant activists and pro-immigrant actors. These latter provide not only resources but also framing opportunities. How local actors with different ideological affiliations understand and "frame" immigration and integration issues affect alliances and forms of participation in cities. Appropriation of the immigrants' cause and processes of othering by potential allies also have a relevant impact in shaping alliances with immigrant activists and participatory trajectories. Immigrant activists are key players and have a significant role in shaping local dynamics, as they engage with resources and framing promoted by pro-immigrant actors and engage with some groups rather than others, contributing to legitimizing or de-legitimizing pro-immigrant actors in cities.

At the heart of this book is therefore a challenge to common knowledge that presupposes that pro-immigrant groups systematically advance immigrant's rights agenda. Pro-immigrant actors frequently adopt opportunistic approaches, including paternalistic or instrumental attitudes toward immigrant activists, and this study offers substantial empirical evidence of the ambivalence of these actors and especially on how they often tend to marginalize immigrant activists - with many insisting on speaking on their behalf. Moreover, my approach, which puts immigrant activists at the center of the analysis, allows to address an important gap in migration studies. The literature tends to depict immigrants as passive subjects. By looking at how immigrant activists perceive and act upon the opportunities and constraints of civic and political participation promoted by pro-immigrant supporters, I expand our understanding of how immigrants promote their own inclusion, by focusing on demands concerning the equal treatment and access to their fundamental rights.

The study offers both relevant theoretical and empirical contributions. Migration scholars sometimes claim that immigrant groups are too vulnerable and lack the skills and resources to mobilize and compete with other powerful actors (Caponio 2006). An uneven distribution of resources and power and, concomitantly, immigrants' competition with stronger, more well-established pro-immigrant actors with greater resources, contribute to the marginalization of immigrant groups (Triviño-Salazar 2018). Some scholars, however, note that immigrants' marginalization is an effect of mechanisms of othering reflected in how pro-immigrant groups see and construct (wittingly or unwittingly) immigrants as "outsiders" or inferior others (Cappiali 2017; El-Tayeb 2011; Pojmann 2006; Raissiguier 2010). Focusing on this aspect, scholars find that some allies tend to victimize immigrants and adopt opportunistic approaches, including paternalistic or instrumental attitudes that silence immigrants (Cappiali 2017; Cissé 1999; Pojmann 2006; Siméant 1998; Raissiguier 2010). Finally, authors looking into the role of allies in shaping immigrant mobilizations find that marginalization may occur at the level 
of meaning construction. Nicholls (2013) and Yukich (2013), for instance, demonstrate that movements fighting for the regularization of undocumented immigrants construct discursive distinctions between "deserving" and "undeserving" immigrants, promoting a positive narrative for the regularization of some immigrants, constructed as legitimate subjects, while excluding others. All in all, this scholarship calls for a closer look at how pro-immigrant groups may silence immigrant voices. As I will show, mechanisms of marginalization can be powerful among pro-immigrant actors, even with different ideological orientations and views about immigrant rights, shaped by traditional conflicts, interactions, and struggles for legitimacy within the discourses that decide who is an immigrant and how she/he is to be included in society.

\section{An ethnographic approach to study interactions of actors in cities}

The empirical analysis of local dynamics and the mechanisms and factors that explain civic and political participation and rights claims of immigrant activists is based on rich first-hand data collected in four Italian cities in two rich regions in the North-Reggio Emilia and Bologna in Emilia-Romagna and Brescia and Bergamo in Lombardy - between 2013 and 2014, for a period of 14 months (between February-November 2013 and May-August 2014). I conducted extensive field research (about two and a half months in each city) and collected a total of 118 in-depth, semi-structured interviews. Of the total interviews, 43 were conducted with Italians (e.g., local authorities, members of key third-sector organizations, trade unions, Catholic organizations, political party officials, grassroots organizations, and several radical left organizations), and 57 with immigrant activists (e.g., foreignborn individuals active in Italian or immigrant associations, political parties, trade unions, and radical left organizations) (for more details, see Table 4, Appendix A). The rest of the interviews were conducted in other cities, such as Rome, Milan, and Turin, where key pro-immigrant and immigrant activists were based. Twelve were conducted with key Italian actors and six with key immigrant activists relevant at the national and regional level (for more details, see Tables 3 and 4, Appendix A). ${ }^{5}$

The analysis focuses on competing discourses and practices of multiple actors in the years following the global financial crisis (2008-2013), a period in which a rise in hostilities and racism toward immigrants and racialized minorities were especially pronounced. In order to offer an overview of the historical context, I use a timeframe of 15 years (1998-2013) (cf. Chapter 1). Moreover, I used an ethnographic approach (Bray 2008; Lichterman 2002) to identify which actors matter case by case and a snowball method to contact the interviewees. In each context, I mapped key local actors and dynamics that shaped variations in participation and rights claims. I compared the perceptions and motivations by pro-immigrant and immigrant groups, and I highlighted the role played by frames and political competition among a wide range of actors in promoting or hindering (in)formal participation of immigrant groups in local fields of power. 


\section{Theoretical contribution}

Theoretically, I propose to enlarge our conceptualization of the local contexts of immigrant activism by analyzing the interactions between pro-immigrant groups with different political orientations and immigrant activists in cities. By using social movement and critical social theory to build on existing scholarship on citizenship and migration, particularly the inclusion of immigrants in cities, the book offers a new conceptualization of the local political arena. I have developed a theoretical model of local dynamics to understand the features and relationships at work in cities and how conflicts and alliances between pro-immigrant and immigrant groups determine immigrants' participatory routes. To this end, I adopt an actor-oriented approach to grasp how a multiplicity of pro-immigrant and immigrant groups shapes participation. I show that civic and political participation and grassroots mobilizations are made possible or obstructed by the interactions of these various actors and how immigrants respond in turn. This model analyzes the complex configurations of actors in cities, explaining why and how these distinct actor combinations shape the various trajectories and outcomes of immigrant rights activism across cities in ways that were not possible before (see Chapter 2).

Some of these dynamics, I argue, have been largely overlooked by the dominant approach in the field of migration, namely the political opportunity approach (Ireland 1994; Soysal 1994; Koopmans and Statham 2000; Koopmans 2004; Giugni and Passy 2004), which is why we still lack in the migration literature a stronger theorization of context that allows us to explain why and how immigrants mobilize in specific settings, create alliances with some actors and not others, and mobilize differently across cities (see Chapter 2). While important analyses in this field document why and how institutional actors promote some forms of participation, such as participation in associations (Caponio 2006) or in political parties (Garbaye 2005; Triviño-Salazar 2018; Zapata-Barrero et al. 2017), we lack knowledge of how multiple local actors - institutional and non-institutionalshape both conventional and non-conventional politics via their interactions in various settings. This is why we need to consider what actors are local dynamics are most relevant in each geographical context - both top-down and bottom-up dynamics - and look at why and how they impact various civic and political form of immigrant participation and rights claims (cf. Penninx et al. 2004).

I use an inductive approach to examine why, how, and which actors interact and promote immigrants' civic political participation in the selected cities. This means that I look into the role of all the actors involved in the process of inclusionadministrations, the Catholic Church, trade unions, and civic and political organizations created by Italians' and/or immigrants' activists - and all the forms of participation promoted in each city. As the analysis of this book will reveal, this comprehensive approach allows to better grasp interactions among organizations in each city and how they affect various participatory outcomes.

Moreover, to analyze interactions between pro-immigrant and immigrant groups, I use the concept of political racialization (Cappiali 2017). ${ }^{6}$ This concept explains the role that pro-immigrant actors play in producing differential 
inclusion in their organizations and, consequently, in receiving society more generally. Political racialization explains how pro-immigrant actors have partially included immigrants in the political sphere but in a relationship of subordination. This relation of power is "differential" insofar as the pro-immigrant groups deploy complex mechanisms of inclusion and exclusion that result in the subaltern inclusion of the migrant activists in their organizations. Through structural and discursive devices, they construct people of migrant background (both immigrants and racialized minorities) as inferior Others on the basis of their perceived difference, the presumed backwardness of the migrant population relative to Italians (Però 2007), and through their tendency to speak for them. These mechanisms are based on ascribed characteristics of ethnic, racial, and religious affiliations, and usually involve a "native-born" or "white" European population addressing a "non-native" and "non-white" group of people (El-Tayeb 2011). In short, pro-immigrant supporters contribute to producing the otherness of the migrant population through their discourses and practices - a political process of racialization - by reinforcing the binary narrative that distinguishes between "us" and "them."

\section{Reconceptualizing cities: an actor-oriented approach}

The rich data collected reveal a complexity of factors and mechanisms accounting for political variations in modalities of political action and mobilizations at the local level. I have developed a theoretical model of local dynamics that examines civic and political participation as a continuum. Much research on immigrant activism tends to study different forms of immigrant participation separately. My theoretical model, instead, considers forms of participation as a continuum (cf. Martiniello 2005). The model also strives to include all the potential alliances in the analysis so as to see why and how some alliances and some types of mobilizations are developed in some local settings and not in others. Therefore, I adopt a broad definition of participation, considering multiple forms of civic and political participation, observing how they are linked. I include in my definition participation in civic channels, such as involvement in immigrant associations and in pro-immigrant associations and, and examine whether such involvement has implications for political participation. While I agree with Eliasoph (2012) that civic participation, including in the volunteering sector, is always political (as it affects directly and/or indirectly the political sphere), in my analysis I keep the question open about whether civic participation by immigrant activists is seen as "political" by immigrant and pro-immigrant actors in each context. Here, I am particularly interested in the question of depoliticization of immigrant organizations through processes of ethnicization, for instance, which tend to focus on ethnic identity and culture and to neutralize the political role of immigrant associations (Torrese 2010).

Moreover, I consider political participation in multiple conventional channelsfor instance, in consultative bodies and trade unions - and in non-conventional channels - such as protests and demonstrations - and consider how immigrant activists combine these different channels. Martiniello $(2005,3)$ defines political 
participation as "the active dimension of citizenship. It refers to various ways in which individuals take part in the management of the collective affairs of a given political community." Following Martiniello, and in order to map the different incentives offered to immigrant activists, I define political participation in an expansive sense and include both conventional and non-conventional channels. ${ }^{8}$ I use the term "political channels" to refer to the opening of opportunities for the exercise of political rights by people of migrant background. Channels of political participation here are intended broadly, and they refer to four dimensions that promote incentives for:

1 Parallel Channels (i.e., Consultative bodies, created for non-EU immigrants with no voting rights);

2 Conventional or formal participation (i.e., voting and standing for election, volunteering for political campaigns, signing petitions, belonging to activist groups, and serving in public office);

3 Non-conventional or informal participation (i.e., strikes, supporting boycotts, and protests);

4 Illegal participation (i.e., activities that break the law, such as the illegal occupation of a public space).

The broad definition of participation I offer here makes a distinction between "political participation" and "political incorporation." The latter term is often linked to formal citizenship and it identifies integration mainly in formal terms (Hochschild and Mollenkopf 2009; Hochschild et al. 2013). Scholars who use this definition have tended to focus on the levels of naturalization and formal participation in conventional politics (see, e.g., Bloemraad 2006), mainly in the electoral system, through voting and running for election. My understanding of participation goes beyond this definition. I concentrate instead on "citizenship in practice," and especially the meaning that immigrant activists give to inclusion and participation. As barriers to citizenship and formal participation are growing across Europe, we need to have a more articulated grasp of multiple forms of participation and how immigrant activists redefine the meaning of inclusion from below. Studying participation as a continuum, moreover, avoids the assumption that participation is rigidly associated with the status of immigrants in the receiving society. To understand participation from the point of view of activists of migrant background, I examine how they perceive and seize the opportunities, conventional and non-conventional, available to them. For this reason, I avoid focusing on one specific form of participation and instead explore how immigrants utilize both institutional and non-institutional channels of participation and observe why and how participation de facto takes place in specific contexts.

Moreover, the theoretical model of local dynamics articulates two key concepts"local realm of immigration" and "approaches to inclusion." As I will explain further in Chapter 2, together with other factors, these two concepts provide a new conceptual framework to theorize the importance of local contexts. They allow me to reconceptualize the local context in a dynamic, flexible way to include top-down 
and bottom-up dynamics and to grasp how these dynamics impact multiple forms of civic and political participation and rights claims of immigrant activists across cities.

The first concept is the "local realm of immigration." The concept of "realm" refers to a structured space of relations created by the involvement of local actors on issues of immigration and immigrant inclusion. It postulates that local dynamics on these matters are the result of interaction between these actors. This concept moves us beyond the idea that the context is a given to identify both which actors matter and how they promote inclusion in different local arenas by way of their interactions (Cappiali 2018). Through this concept, the focus is not on the configurations of power and local actors in general but on which actors matter in specific local contexts and how they mobilize to promote immigrants' inclusion. Beyond simply identifying actors, it offers a particular way of thinking about their roles in framing and structuring opportunities and constraints for immigrant participation through their discourses and practices. Moreover, the concept allows one to grasp variations across cities, precisely because it does not determine in advance what actors matter when it comes to immigration/inclusion issues. Instead, it leaves such questions open to empirical investigation: what actors matter, how, and to what extent - these are the result of complex interactions.

The second key concept of the model is "approaches to inclusion." This concept identifies not only on what local actors do to encourage immigrants' greater inclusion in society but also on how and why they do so (see Cappiali 2018). It refers to how local actors understand and frame migration and the inclusion of people of migrant background, based on ideological and strategic considerations, and how this understanding affects their discourses and practices. It is not just concerned with what actors do to promote inclusion (e.g., what type of local policies or services have been created), but how they do this. In this respect, the concept speaks to how immigrants are constructed as a "subject of inclusion" through discourses and practices by pro-immigrant groups. Through this construction, we can grasp why and how local actors frame and promote a certain approach to include immigrants and what type of inclusion they facilitate or hinder. Examining approaches to inclusion reveals how power is involved to legitimize the work of pro-immigrant groups in the local realm of immigration and why and how immigrant voices are encouraged, channeled, or marginalized in specific ways. The approaches they adopt, in turn, affect (directly or indirectly) the civic and political participation of immigrants, as well as their rights claims, and which groups of immigrants and rights claims are more likely to be made visible in the city.

The study of the four cities presented here identifies three main approaches to inclusion, namely, assistance, intercultural, and political rights promotion. As I will explain in Chapter 2, these approaches are largely shaped by the ideological affiliations of local actors promoting the inclusion of immigrants. Moreover, the model includes four interacting factors affecting immigrant participatory trajectories and rights claims (cf. Figure 2.1, Chapter 2). These factors are: (1) the institutional context, focusing on configurations of actors in each city; (2) the realm of immigration and interaction of approaches to inclusion, that is discourses and 


\section{Introduction}

practices actors adopt to promote immigrant activism in each given context; (3) civic and political channels of participation opened by pro-immigrant actors; (4) engagement of immigrant activists and alliances they decide to create to local actors in city. The factors identified in the model allow us to explain in a significant way the important variations across the four cities (cf. Table 2.2, Chapter 2). As I will explain in Chapter 2, the model allows to go beyond deterministic accounts of cities and to grasp the role of both top-down and bottom-up dynamics promoted by a plurality of actors. It accounts for conflicts and alliances between proimmigrant groups and immigrant activists and explains variations in immigrant activists' civic and political participation and rights claims. The two key concepts of the model - the local realm of immigration and approaches to inclusionin particular, help us understand how actors' understanding of immigration issues has a substantial impact on what kind of inclusion and of participation is promoted in each city. The model shows the role of ideological and strategic positioning of local actors and their interactions in affecting approaches to inclusion, and the types of alliances they developed with immigrant groups and the type of activism they encourage. The empirical chapters will give evidence of how the model works and offer robust results that justify the use of the model beyond the cases presented in this book.

\section{Empirical contribution}

The empirical portion of this study offers an in-depth analysis of the local dynamics in four medium-sized cities - Reggio Emilia, Bologna, Brescia, and Bergamo in two regions in Northern Italy, Emilia-Romagna and Lombardy-to evidence of how the model works. I zoom in on local dynamics that explain important variations across the four cities and look precisely at processual interactions among local actors that produce these variations. The analysis identifies the involvement of pro-immigrant and immigrant actors in each local context, examines the alliances and conflicts between them, and highlights how local dynamics have shaped the forms of civic and political participation and rights claims of immigrant activists. Each chapter brings in the perspective of some key immigrant activists to examine their role by analyzing their discourses and practices. I conclude each chapter by highlighting the implications of the findings in each city and note their broader relevance for understanding immigrant activism beyond the specific case analyzed.

The study shows how alliances between racialized immigrants and new citizens of migrant background and other collective actors - particularly political parties, the Catholic Church, trade unions, NGOs, and grassroots radical left organizations and immigrant groups - affect the ability of immigrant activists to mobilize and the content of their claims. By looking at these alliances and coalition work, we can better understand immigrant activism in context. Ideological and political conflicts - as well as the different "framings" of working and living conditions of immigrants in the receiving society—shape opportunities and constraints for participation and coalitions between immigrants and "white" organizations. At a time when local politics are highly contentious arenas for immigration issues, these actors 
have become even more important. This has had an impact on how traditional and new pro-immigrant groups respond to hostile environments and support immigrants and racialized communities. By centering on immigrant activists' strategizing, mobilizing, and coalition work, I argue that we can seize the ambivalent role that pro-immigrant collective actors play in defending, but sometimes also disempowering and watering down the efforts of immigrants and racialized communities make to promote their rights.

Moreover, the book uncovers how activists perceive and seize the opportunities available to them, including why and how they create alliances with some local actors and challenge others, and how they expose and challenge barriers to their inclusion, which are also imposed by pro-immigrant actors. The analysis breaks with the idea that immigrants are passive subjects. Instead, I shed light on the agency of immigrants to shape alliances, transform local dynamics, and mobilize in contexts where they are constrained by uneven fields of power. Emphasizing the role of immigrant activists helps shed light on how they shape local dynamics by interacting with other actors in a stronger position of power. Accordingly, I seek to explain the variation in forms of civic and political participation of immigrant groups in highly hostile environments. To this end, I adopt an interdisciplinary approach and address the main limitations of migration studies, including three main areas of research: citizenship and migration studies; social movement theories; and critical social theories applied to citizenship, migration, and racial/ ethnic relations, as I will further explain in Chapter 2. By combining the strengths of each area of research, I hope to offer a fine-grained analysis of the local dynamics of immigrant activism that has not been done before.

This book shows how, through their mobilizations at the individual and collective level, immigrant activists strategically engage in multiple forms of civic and political participation, even amid the most hostile contexts, to promote their rights and create political change. Though immigrant activists are a minority within migrant communities (Martiniello 1993), they challenge their allies, especially the latter's processes of othering of immigrants. Because of their social and personal skills, in most cases, they mediate between their communities and the receiving society, promote change, and determine alliances.

\section{Redefining key concepts in the field of migration}

In this study, I propose to reformulate some of the major concepts largely adopted in the field of migration in Europe. I do so in light of the insights drawn from my methodology from below and the use of critical theories.

This study critically engages with the broad category of "immigrants" widely used in both academic and political debates in Italy and beyond. I hold that we need to scrutinize this broad category. While it is a pertinent term in Italian society and public discourses, it is important to understand its meaning in context. In Italy, it is often invoked to construct a sense of a national "us" native-born Italian, versus "them" immigrants who came to the country. As many interviews of this book will show, the category is widely used by people of migrant background 


\section{Introduction}

(including new citizens) to talk about their everyday "immigrant" experience, and to position themselves politically and socially within Italian society.

By problematizing this concept, this book seeks to illustrate how it has largely hidden rather than exposed real groups of people who are socially and politically distinct, especially non-EU immigrants and racialized communities. These distinctions are often made invisible by academic research. In the book, the word "immigrants" refers mostly to non-EU immigrants (often referred to, in a derogatory way, as extra-comunitari) coming from different countries outside of Europe, especially from the "Global South" (e.g., Moroccans, Pakistanis, Senegalese). These groups are racialized as "people of color" or non-white. Most immigrants in Italy move from low-income countries, and immigrants are often considered "low-skilled" and perform "low-skilled" jobs. As Calavita (2005b) asserts, the construction of immigrants as marginalized Others is produced and reinforced by legislations that exclude immigrants and labor market demand for "low-skilled" jobs, including those in the underground economy. These workers lack social mobility and often remain at the margins of society. In the case of Italy, distinctions are made between EU and non-EU immigrants, both in the public discourse and in the manner in which immigrants perceive themselves.

The status of many EU immigrants in Italy comes with several rights. Most European immigrants come from Eastern Europe; Romanians are the most significant group numerically. However, this does not always position them in an equal footing in Italian society. Eastern Europeans and they are also racialized and they usually undertake mostly low-paid and precarious jobs. The construction of immigrant groups as marginalized Others has shifted over the years in public discourse and society. During my empirical research, it became clear the category of "immigrants"mostly used by both pro-immigrant supporters and immigrant groups - is more salient when referring (mostly implicitly) to non-EU immigrants and their offspring.

Throughout the book, I use the term "racialized immigrants" and "racialized communities" rather than the more widely used concept in the European migration literature of "ethnic minorities" to refer to people of color, both non-EU immigrants and new citizens of migrant background who are originally from non-EU countries. I highlight what is often erased in the European literature on migration: most groups targeted by immigration policy, as well as discussed in public and academic discourses on immigration and "integration" in Europe, are people of color - non-EU or non-white immigrants (El-Tayeb 2011). The concept of "ethnic minorities" is unable to grasp the mechanisms at play in Italy and it erases the role of racism in society. The term focuses on cultural differences - often expressed by focusing on the concept of "ethnicity" - and erases the processes of othering. The racism and exclusion constructed through law, discourses, and practices prevent people of color (immigrants and new citizens), especially those from countries of the "Global South," from being granted full rights in Italy. The concept of racialized is useful because it emphasizes the processual nature of attributing meaning to the corporeal dimension of human bodies (Omi and Winant 2015). Finally, I prefer the term "communities" because it is less normative than "minorities," as it is a concept that conveys more explicitly some neutrality. In recent years, many 
anti-racist scholars and activists have moved away from using the term "minority," which discursively reproduces the idea that immigrants are in a position of subordination in the receiving society. It is argued that the term "minorities" does not correspond to the numerical representation of these groups, because racialized non-white people actually constitute a global majority.

As will become clear throughout the book, this study has implications for the concept of "integration" used by academics, policy-makers, and practitioners. As with "assimilation" and "incorporation"-mostly used in the North American context-I contend that "integration" (a concept largely used in migration studies in the European context) is loaded with normative biases. For this reason, I prefer to replace it with the concepts of "inclusion" and "exclusion." The literature on migration tends to depict receiving societies as homogenous and to see "integration" as a process through which each immigrant becomes part of these societies by learning how to adapt. However, this approach tends to underestimate the role that immigrants and racialized communities have played in transforming these societies through their presence and activities (Glick Schiller and Çağlar 2011). This tendency has often failed to account for the transformations that have de facto taken place as a result of many years of mass migration (El-Tayeb 2011). Moreover, by embracing methodological nationalism (Wimmer and Glick Schiller 2002), authors who invoke these concepts assume (implicitly or explicitly) the societal cohesion of the receiving society and raise questions about the "integration" of immigrants whenever they do not fit into a preconceived definition of national culture and community (Bauböck 2006). Thus, their "integration" and sense of "belonging" is defined in terms of how much they feel part of the national community (Bloemraad 2006), and how much they are able to "integrate" into the fabric of society.

As interviews with immigrant activists show, their narratives and experiences speak to a critical approach toward "integration" and how it conceives a need for them to "fit" into society, especially a society that calls on them to comply with narrowly defined roles, which create barriers to their inclusion. I hold that, focusing on both how the state and institutional actors at the national and local level "incorporate" or "integrate" the migrant population, and the ways in which immigrants feel that they belong, serves a performative function. From this perspective, the various approaches adopted to think about immigrants" "integration" in society - multicultural, intercultural, universalist, etc.- despite their differences, can have a performative function because they tend to naturalize the idea that immigrants are separate entities that need to be "integrated" while, paradoxically, affirming a fictitious homogeneity of the receiving society. This approach presents a dichotomous understanding of receiving societies, reproducing an "us versus them" discourse in academic research and policy-making, which results in the assumption that immigrants are objects of policies and passive subjects. Moreover, this mechanism, I argue, erases the fact that "immigrants" are already deeply embedded in the national and local contexts in which they reside and are involved in power struggles over discourses on immigration even before their arrival in receiving society. Moreover, if we connect this issue to the problem of 
historical colonialism, white supremacist ideology, and the current structural inequalities that keep racialized groups at the bottom of the racial hierarchy globally and within specific societies, it appears clear how the issue of immigration and inclusion of many racialized groups in Western societies is intertwined with racism and racialization process, and how the West constructs its Others (El-Tayeb 2011; Palmi 2020; The Black Mediterranean Collective 2021).

Thus, to break with normative assumptions, I opt for the less normative concepts of "inclusion" and "exclusion." Doing so uncovers a range of overlooked processes by which immigrant groups have, or are prevented from having, access to material, political, and cultural resources. These crucial resources allow immigrant groups to interact on an equal footing with other actors in the receiving society (Bloemraad 2006). Practices in receiving societies, such as restrictive immigration laws and citizenship regimes, serve not to exclude the migration population, but rather to include them within specific relations of subordination that result in "differential" or "subordinated inclusion" of the migrant population vis-à-vis the labor market (Calavita 2005a). ${ }^{9}$ Such analyses explain the persistence and salience of exclusionary practices and unequal treatment on the basis of constructed racial difference, showing why and how some immigrants and racialized groups are marginalized across time and space, despite different models of inclusion promoted in various geographical contexts.

Critical citizenship and border scholars also highlight that, rather than excluding immigrants, migration laws and devices for migration control are designed to produce processes of differential or subaltern inclusion (Oliveri 2015; Anderson and Hughes 2015; Anderson 2010a). That is, discourses and practices shape differential paths of economic and social inclusion of immigrants and racialized communities in receiving societies, because they preclude immigrants from pursuing certain paths. The permitted paths, in turn, often result in a concentration of specific "ethnic" or "racial" groups in marginal or unequal socioeconomic positions (Chaudhary 2015). The question of who is an "immigrant" at a given time and space is central. As Anderson (2010a) and De Genova (2010) explain, the construction of immigrants - and their different categories - as outsiders has a sociopolitical function of legitimizing the exclusion of specific groups from accessing full rights. The most emblematic example is that of "illegal" migrants who are denied most rights and are constructed as "impossible subjects" (Ngai 2004; see also Anderson 2010a; De Genova 2010). The prevalence of negative constructions of different categories of immigrants in public debates-for example, the migrant as poor, marginalized, a threat-involves an asymmetrical power relationship between immigrants and the receiving society and state.

Thus, the concepts of inclusion and exclusion used in the book account for forms of civic and political participation and rights claims that go beyond immigrants' attempts to become part of the social fabric of a receiving society. Indeed, many claims, for instance, address issues related to labor exploitation in the global context. The concepts identified here open an empirical investigation into the multiple ways people of migrant background understand and define inclusion and the pathways to civic and political participation: practices and discourses from below and new perspectives on their role as immigrants from the "Global South" 
struggling for their rights in the "Global North." I claim that the conditions for civic and political participation need to be understood in a "flexible" manner. Such participation cannot be reduced to the official "incorporation regime" put in place by the state, precisely because there are multiple possibilities available out there. Why and how immigrant activists engage in the local context depends on how they interpret and interact with the opportunities and constraints available in specific times and spaces.

Mainstream debates on models of integration in Europe often tend to erase racism or treat it as a secondary aspect of inclusion processes (Bulmer and Solomos 2019). As Mulinari and Neergaard (2017) explain, quoting American sociologists Bonilla-Silva and Baiocchi (2001), the dismissal of racism as a principle of social organization in the social sciences reveals that these disciplines "have followed rather than challenged what they conceptualise as 'white racial common sense.' Protected by a myth of neutrality and objectivity, social sciences follow understandings of racism in their analysis of inequality as relegated to a secondary status" (Mulinari and Neergaard 2017, 88-89). This criticism, the authors go on to argue, can be directed toward a large part of European scholarship on migration. In my view, this can also be said of models of integration across countries and cities (e.g., assimilationist, multicultural, intercultural). Such research often erases the function of racism in society and ignores structural obstacles that prevent immigrants from becoming citizens with full rights.

I follow Goldberg (2006) in this regard when he explains that European denials lie at the heart of contemporary "racial Europeanization." Goldberg argues that racial Europeanization is part of a "European self-conception emerging from the continent's response to its history, especially the Holocaust." Racial Europeanization is based on a desire to see race no longer exist as a category in Europe. The result is not to eliminate race as a category of being in the world: indeed, it continues to shape European social relations and social life. Tomlinson $(2013,256)$ points out the actual result:

Goldberg warns that suppressing discourses about racisms in turn suppresses the availability of conceptual tools that will allow people to recognize, analyze, and debate what might count as structural racisms and how racial differences can be negotiated effectively. Suppressed also are the tools to examine the dominant discourses and narratives that crystallize identities, that frame races and cultures as totalities that are closed and unchanging (Balibar 2009). Goldberg and others argue that disciplinary frameworks serve to reinforce these discourses rather than call them into question.

(Balibar 1991)

Finally, I make a conceptual distinction between "pro-immigrant supporters" and "allies." While supporters can be any group that acts in favor of greater immigrant rights in society, allies are groups and organizations that have created networks and alliances with immigrants and who are recognized as such by immigrants 
themselves. I ask why, how, and under what conditions immigrant supporters become allies. Such questions need to be addressed not just by academics, but also by activists and organizations who are interested in improving the rights of immigrants. The lack of critical analysis of the role of "native-born" or "white" pro-immigrant supporters, especially though not exclusively in the European context, is continuous with Europe's colonial past and its denial of how post-colonial and race issues still shape our societies (Gilroy 2005; Lépinard 2020). One of the main goals of this book is to openly address mechanisms of silencing by proimmigrant groups and how processes of othering and racialization have shaped their relationships with immigrant groups. This is particularly the case for more conservative pro-immigrant groups - such as the Catholic Church - but it is also applicable to most sections of the left in Italy, moderate and radical groups alike. In this respect, the book has important implications for current research on immigrants' inclusion beyond the case of Italy, as it addresses an understudied, yet very important aspect, of responses by pro-immigrant supporters to immigrants and their resistance to fully address the implications that come with considering non-EU immigrants as equal to the European population.

\section{Outline of the book}

In Chapter 1, I sketch out the Italian context in which immigrant mobilizations took place and present methodology. The description will give the reader a sense of the highly hostile context in which immigrant activists and their supporters mobilize to ask for greater immigrant rights. It will offer an overview of the conditions under which immigrant civic and political participation and inclusion in Italy is made possible or is obstructed by institutional racism and the hostile climate that triggered the mobilizations that took place in 2010 and 2011. Subsequently, I present briefly the methodology I used to conduct my research. The methodological section will show how the four cities selected for this study allow to control for specific local variations and to draw robust conclusions about my findings.

Chapter 2 introduces the theoretical model of local dynamics I have developed to explain the link between local dynamics and variations in civic and political participation of immigrant activists. The chapter first introduces the literature I use to explain why we need to reconceptualize cities. I focus on three main literatures: migration studies, social movements, and critical social theory. I proceed with a presentation of the theoretical model of local dynamics and anticipate how the model will help inform the analysis of the rich empirical material collected in each city and further analyzed in the empirical chapters. The chapter closes with an overview of local dynamics in the four cities analyzed in this study to illustrate how the model is able to explain significant local variations in forms of participation of immigrant activists.

Chapters 3 through 6 present four empirical studies of the cities of Reggio Emilia, Bologna, Brescia, and Bergamo, illustrating how the theoretical model works. Each empirical chapter is divided into four parts. The analysis starts with 
the description of one key mobilization that took place in the years between 2010 and 2011, when important pro-immigrant mobilizations emerged in many Italian cities, after the financial crisis that started in 2008 and the introduction of new restrictive immigration laws in 2008 and 2009. I identify the local actors, including immigrant activists, involved in the organization of the events and draw attention to the local dynamics in order to explain why and how these mobilizations took place as they did. I highlight the unique features of the city that may explain why and how specific local dynamics affect alliances and participatory outcomes of immigrant and racialized groups.

More specifically, Chapter 3 focuses on the city of Reggio Emilia. In Italy, this city is considered one of the best examples of how local actors can promote interculturalism from above. Its role is recognized both at the national and international levels. Accordingly, Reggio Emilia is the city of intercultural dialogue, as key local actors - the institutional left-wing authorities, trade unions, lay organizations of the left - tend to promote an advanced approach to interculturalism. The chapter begins with a description of the campaign "Italy is me, too! For the rights of citizenship" that was launched in 2010 by the left-wing administration in cooperation with lay and church-based civil society organizations, as well as migrant communities. The campaign spread in many cities across Italy. Its goal was to collect enough signatures for two popular legislative propositions. The first proposition concerned the introduction of the jus soli principle to grant citizenship to children born in Italy to immigrant parents; the second focused on granting non-EU citizens the right to vote in local elections. Using this example and asking why this campaign was launched in Reggio Emilia, I identify the actors involved in the mobilization, their characteristics, as well as the forms of participation and demands that were made by these pro-immigrant actors and immigrant groups. In line with the theoretical model of local dynamics presented in Chapter 2, this empirical chapter connects the role of local actors in promoting inclusion and explain why and how immigrant activists, and especially second-generation immigrants, participate mainly in formal civic channels, and why they create alliances with institutional actors rather than other actors, such as trade unions and other left actors. I show that the local administration in Reggio Emilia is a main actor in promoting the inclusion of immigrants in the city via an advanced approach to interculturalism. It also shows how specific local dynamics shape the ways in which immigrant groups mobilize and make claims in the city. I explain how civic forms of participation are encouraged over others, why there are few channels for political participation, and how this has an impact on which immigrant activists are made "visible," as well as the ways in which some immigrant activists mobilize and strategically make specific rights claims rather than others. Because the local administration and the political parties strongly encourage their participation from above, the most visible immigrant activists in the city are new Italian citizens and immigrant youth.

Chapter 4 focuses on the city of Bologna, the city of multiple forms of participation. It starts with a brief description of the 2010 "A day without us: The strike of migrants." This event was characterized by a plethora of leftist civil society 
actors and significant participation of immigrant workers and associations. The organizers emphasized the key role of immigrant workers in the country's economy and sought to expose the fact that existing laws were racist and produced immigrants' "illegality." Bologna was one of the Italian cities with a high level of participation in the national strike and demonstrations. What is more, the strike was organized entirely from below, without the support of trade unions. Drawing links between specific interactions among local actors and the approaches to inclusion that prevail in the city, this chapter shows why and how this mobilization had such a great impact in Bologna in particular and why immigrant activists were so visible and involved in the organizations. The analysis shows that in the absence of institutional intervention from left-wing administrations in more recent years, left-wing actors have encouraged two approaches - interculturalism and political rights promotion-from below. Several channels have been opened by civil society organizations and radical left actors over the years and this has created the conditions for immigrant activists to grow in the city. The analysis also shows conflicts and complex alliances between pro-immigrant groups and immigrant activists. Despite their discourses on the need to include immigrants, leftwing actors in Bologna have often marginalized immigrants' voices, often in more subtle ways but sometimes overtly too. Nonetheless, it also reveals how a plethora of actors of the left promoting participation have offered greater opportunities for immigrants to create their own political trajectory and to emerge as relevant political players. Immigrants have created their own channels of participation and have formed alliances with several institutional and non-institutional left-wing actors, including trade unions, grassroots organizations, and radical left actors. As the interviews with immigrant activists will show, in some cases, the obstacles imposed by pro-immigrant organizations of the left have presented important opportunities to create alternative ways to participate and to make rights claims. As a matter of fact, immigrant activists participate in various ways and, in many cases, their activities overlap. This is also because they have more choices in allying with several pro-immigrant groups, depending on their immigrant status and working conditions. Finally, I also explain how conflicts between moderate and radical left-wing actors are also problematic as they prevent many immigrant activists from shaping local dynamics.

Chapter 5 moves on to the case of Brescia, the city of political contention. This chapter starts with a description of the "Struggle of the crane," a protest organized in 2010 by undocumented immigrants and radical left actors calling for the regularization of thousands of undocumented immigrants working in the underground economy. The protest resulted in a radicalization of the forms of immigrants' political participation. There was no similar protest in the country in terms of duration, intensity, and immigrants' visibility. The protest was triggered by the overt anti-immigrant policies introduced by the local right-wing administration with a strong presence of the anti-immigrant party, the Northern League, and it exposed important conflicts between key pro-immigrant organizations in the city - the Catholic Church and trade unions - and immigrant activists allied with the radical left. The chapter investigates why immigrant activists mobilized 
in a particular way by drawing links between specific interactions among local actors and the approaches to inclusion that prevailed in that city. Here, the "visible" immigrant activists were mostly vulnerable and precarious immigrant workers, enrolled in radical trade unions of the metalworkers, the CGIL-FIOM, and non-unionized undocumented migrants. Examining the discourses and practices of key actors, including immigrant activists, I unveil the role of conflicts and alliances in the city, and particularly the role of the radical left in promoting the participation and rights claims of vulnerable immigrants. The analysis reveals that, in the absence of interventions by local authorities, two actors have promoted inclusion on immigrants in the city: The Catholic Church and the radical left, including the more radicalized branch of the left-wing trade union-the GCIL-FIOM. While the dominant actor in the city, the Catholic Church promotes a dominant assistance approach to inclusion, the radical left and the more radicalized branch of the left-wing trade union encourage a political rights promotion approach in non-conventional channels. These latter are important challengers of the Catholic Church and their role in the city largely affects the approaches to inclusion developed in the city. In particular, in the absence of conventional channels to participation promoted by institutional actors (as it is in the case of Reggio Emilia) or more moderate actors from the civil society (as it is the case in Bologna), the particular configuration of actors in Brescia has contributed to the creation of a migrant social movement in the city, and the development of alliances between radical left actors and immigrant activists. The chapter further demonstrates why and how the "visible" immigrant activists are mostly made up of vulnerable and precarious immigrant workers, enrolled in radical trade unions of the metalworkers, the CGIL-FIOM, and non-unionized undocumented migrants, and why they are so active in the city.

Chapter 6 focuses on the city of Bergamo, the city of assistance. Here, local dynamics and the absence of relevant moderate and radical left-wing actors help to explain why, in contrast to all the other cities, participation is almost non-existent. The most powerful actor, the Catholic Church, followed by other key actors in the city - trade unions and church-based organizations, including those of the leftpromote an almost exclusive assistance approach. Here there are some more radical left actors, but they are very weak. As such, there are no major challengers to the dominant approach in the city. This in turns results in an almost complete lack of civic and political incentives on the part of local actors. In addition, when these incentives arise from immigrant activists themselves, they are almost completely obstructed. The chapter will further identify the mechanisms by which there is such a limited participation by immigrant activists in the city, in striking contrast to the other three cities studied. Among other factors, processes of racialization and co-optation of immigrant activists are particularly pronounced and clearly show how the Catholic Church and other organizations in the city blocked immigrants' participation here more than elsewhere. The chapter offers an opportunity to delve deeper into the role of the Catholic Church in the realm of immigration in Italy. It examines the strong impact of the approach to inclusion developed by the Catholic Church and its allies_-predominantly based on assistance - on the 


\section{Introduction}

implications for the political silencing of other competing organizations, not least immigrant groups. Zooming in the specific local dynamics in Bergamo, it shows why and how the dominant role of the Catholic Church and the lack of strong challenges of the left result in the exclusive promotion of the assistance approach to inclusion, the lack of alliances between local actors and immigrant organizations and weak participatory channels available for immigrant activists. The chapter also analyzes the discourses and practices of selected immigrant activists to offer an insider perspective on the main obstacles they face and the frustration their experience for their extreme marginalization in the city.

Chapter 7 focuses on the political racialization of immigrant activists by proimmigrant actors and resistance to it. It does so by analyzing immigrants' perceptions of, and responses to, opportunities and barriers to participation imposed by pro-immigrant actors across cities. The analysis critically deploys selected interviews with immigrant activists to investigate why and how pro-immigrant groups have produced immigrants' otherness through their discourses and practices-and how immigrant activists have resisted them. It demonstrates the range of perspectives among immigrant activists with respect to the meaning of inclusion and participation in the receiving society and their different strategies of resisting processes of racialization by pro-immigrant actors. The findings show that immigrant activists undergo heavy processes of othering, not only from the state and state institutions but also from the Italian pro-immigrant groups. These powerful processes largely affect why and how they become involved in a receiving society the way they do and whether and to what extent they decide to ally with some pro-immigrant supporters rather than others. In particular, their alliances and participatory trajectories are shaped by complicated processes of political racialization and strategies adopted to resist them. Immigrant activists' discourses and practices are not targeted at the exclusionary practices of the state and its multiple ramifications as well as the anti-immigrant language of anti-immigrant parties, but in fact reveal strong criticisms of the discourses and practices of pro-immigrant groups. Their critiques exhibit the frustration as well as important efforts to push pro-immigrant actors to reconsider their approaches to the inclusion of immigrants and to do a better job in improving their rights and favoring their inclusion in society by eliminating barriers to support racial equality. The striking similar criticism emerging from immigrants' interviews with different political orientations and active in different cities is particularly telling because it shows that, to a certain extent, political racialization cut across ideological lines among actors and across differences between leftist, more progressive cities, and Christian Democrats, or more conservative ones.

Finally, the concluding chapter summarizes the contribution my research makes to the study of civic and political participation of immigrant activists in receiving societies. Discussing the book's theoretical and empirical contributions, it stresses that connections I have drawn between the multiplicity of local pro-immigrant actors and forms of participation in Italy should be applied to future research that seeks to understand immigrant activism in receiving societies beyond the case of Italy. I argue that my theoretical model of local dynamics should be integrated 
into future comparative studies to better grasp the complex role of pro-immigrant groups in encouraging or obstructing immigrant inclusion in hostile environments. The chapter ends with a presentation of the implications of this research for the wider literature, as well as my recommendations for new avenues of research and for the future of the anti-racist movement in Europe.

\section{Notes}

1 In order to simplify my task, in this book I use the broad categories of "immigrants" and "people of migrant background" interchangeably to refer to non-EU immigrants with different legal status, including new citizens, who have acquired formal citizenship. I also use "immigrant activists" and "activists of migrant background" to refer to people of migrant background who are activists, including new citizens. When necessary, I specify immigrants' status and country of origin as well as the type of activism in which they engage. Beyond the more general terms described earlier, for analytical purposes, I use more distinct words, such as "new citizens," "first-, second- and thirdgeneration immigrants," "undocumented immigrants," etc. when needed to specify their citizenship status. As I set out in this Introduction, in many countries, European citizens of migrant background are externalized by the continuous definition of them as "immigrants" (El-Tayeb 2011). I am aware of the limitations of this terminology and its contribution to the construction of new members of the European communities as others. This note is one of acknowledgment.

2 In Italy, the economic crisis has hit migrants the hardest, as it has in most EU countries (OECD 2014). According to the report of the Italian Ministry of Labor and Social Policies $(2014,13)$, among the sectors most affected by the economic crisis were those in which migrants often work, such as the construction and the manufacturing sectors.

3 See Chapter 2 for more information on the Italian citizenship law.

4 In opposition to EU citizens, virtually non-EU citizens have no local voting rights in Italy (Groenendijk 2008). In order to guarantee the promotion of some basic civic and political rights, in 1992, the Council of Europe adopted the Convention on the Participation of Foreigners in Public Life at the Local Level (Council of Europe 1992) with the aim of encouraging the active participation of foreign residents in the life of the local community and the development of its prosperity by enhancing their opportunities to participate in local public affairs. Italy ratified the Convention in 1998 with the TurcoNapolitano Law.

5 Unless otherwise noted, all translations from Italian to English of interviews and other visual, oral, and written material used in the book, are my own.

6 In the article (Cappiali 2017), I examine why and how the Italian left produces political racialization and I note that by systematically preventing immigrant activists from taking the floor and determining their own trajectories within their organizations, the left has contributed to producing and reinforcing immigrants' marginalization in the receiving society. I also examine how, despite such marginalization, immigrant activists have challenged political racialization through their activism.

7 For conventional politics, the most important literature is that of the political behavior approach, which focuses on electoral politics. The goal of this scholarship is to understand why and how individuals vote. An assumption of this literature is that we need to explain why individuals choose to take on the cost of participating. This need for an explanation is especially pressing when it comes to new citizens of migrant background, because research shows that they are less likely than the "native population" to participate. Many studies have concentrated on this striking "turnout gap" (Voss and Bloemraad 2011). Another aspect that emerges within this literature is the existence of an "ethnic vote." As Martiniello notes, this behavior has often been taken as obvious. 


\section{Introduction}

But it is not obvious, and we can explain it by looking at the contextual factors that have contributed to its development (2005, 8-9). In non-conventional politics, a growing subfield of migration scholarship has been exploring why and how migrants in vulnerable conditions (such as undocumented migrants and asylum seekers) participate in strikes, protests, and mass mobilizations (Nicholls 2014, 24; Voss and Bloemraad 2011, 22; Zepeda-Millán 2017). It is one of the main claims of this book that we can gain new, important insights if we study the different forms of participation without assuming the participatory behavior of immigrant groups, depending on their immigrant status.

8 It is important to note that scholars do not agree on how we should distinguish between conventional and non-conventional politics. In this reconstruction, I follow Martiniello's typology of forms of political participation (2005), in order to offer a map and classify the various forms of participation and rights claims in cities.

9 Some authors have explained how specific practices in receiving societies, such as restrictive immigration laws and citizenship regimes, serve not to exclude the migration population, but rather to include them within specific relations of subordination that result in "differential" or "subordinated inclusion" of the migrant population vis-à-vis the labor market (Mezzadra and Neilson 2010; see also Anderson 2010a). Here, I used the concept of "differential inclusion," but with different analytical purpose than that of Mezzadra and Neilson (2010).

\section{References}

Adler, Lee H., Maite Tapia, and Lowell Turner, eds. 2014. Mobilizing Against Inequality: Unions, Immigrant Workers, and the Crisis of Capitalism. Ithaca: Cornell University Press/ILR Press.

Anderson, Bridget. 2010a. "Migration, Immigration Controls and the Fashioning of Precarious Workers' Work." Employment and Society 24 (2): 300-317.

Anderson, Bridget. 2010b. "Mobilizing Migrants, Making Citizens: Migrant Domestic Workers as Political Agents." Ethnic and Racial Studies 33 (1): 60-74.

Anderson, Bridget, and Vanessa Hughes. 2015. Citizenship and its Others. London: Palgrave MacMillan.

Ataç, Ilker. 2016. "Refugee Protest Camp Vienna: Making Citizens through Locations of the Protest Movement." Citizenship Studies 20 (5): 629-646.

Balibar, Étienne. 1991. "Is There a Neo-Racism?" In Race, Nation, Class, edited by Étienne Balibar and Immanuel Wallerstein, 17-28. New York: Verso.

Balibar, Étienne. 2009. "Europe as Borderland." Environment and Planning D: Society and Space 27: 190-215.

Bauböck, Rainer. 2006. Migration and Citizenship: Legal Status, Rights and Political Participation. Amsterdam: Amsterdam University Press.

Bloemraad, Irene. 2006. Becoming Citizens: Incorporating Immigrants and Refugee in the United States and Canada. Berkeley and Los Angeles: University of California Press.

Bonilla-Silva, Eduardo, and Gianpaolo Baiocchi. 2001. "Anything but Racism: How Sociologists Limit the Significance of Racism." Race and Society 4: 117-131.

Bray, Zoe. 2008. "Ethnographic Approaches." In Approaches and Methodologies in Social Sciences: A Pluralist Perspective, edited by Donatella della Porta and Michael Keating, 296-315. Cambridge: Cambridge University Press.

Bulmer, Martin, and John Solomos, eds. 2019. Migration and Race in Europe. New York: Routledge.

Calavita, Kitty. 2005a. Immigrants at the Margins: Law, Race, and Exclusion in Southern Europe. Cambridge: Cambridge University Press. 
Calavita, Kitty. 2005b. "Law, Citizenship, and the Construction of (Some) Immigrant 'Others'.” Law \& Society Review 30 (2): 401-420.

Cannella, Giovanni. 2010. "La Condizione Giuridica dei Lavoratori dopo il 'Pacchetto Sicurezza'." In Immigrazione e Sindacato. Lavoro, Cittadinanza e Territoti. VI Rapporto, edited by Francesco Carchedi, Francesca Carrera, and Giovanni Mottura, 41-56. Roma: Ediesse.

Caponio, Tiziana. 2006. Città italiane e immigrazione. Discorso pubblico e politiche a Milano, Bologna e Napoli. Bologna: Il Mulino.

Caponio, Tiziana, and Paolo R. Graziano. 2011. "Towards a Security-Oriented Migration Policy Model? Evidence from the Italian Case." In Migration and Welfare in the New Europe, edited by Emma Carmel, Alfio Cerami, and Theodoros Papadopoulos, 105-120. Bristol: The Policy Press.

Cappiali, Teresa M. 2016. "Activism of Immigrants in Vulnerable Conditions and RadicalLeft Allies: A Case Study of Italy's Struggle of the Crane." Journal of Ethnic and Migration Studies 42 (15): 2508-2527.

Cappiali, Teresa M. 2017. “'Whoever Decides for You without You, He is Against You!' Immigrant Activism and the Role of the Left in Political Racialization." Ethnic and Racial Studies 40 (6): 969-987.

Cappiali, Teresa M. 2018. "Local Actors and Approaches to Integration: What is their Impact on Immigrants' Political Participation?" In The Routledge Handbook on the Governance of Migration and Diversity in Cities, edited by Tiziana Caponio, Ricard Zapata-Barrero, and Peter Scholten, 136-149. New York: Routledge.

Cappiali, Teresa M. 2019. "Ideological Affiliations, Conflicts, and Competing Mobilization Frames: The Role of Pro-Immigrant Allies in Shaping Immigrant Struggles for Greater Rights." International Migration Review 53 (3): 869-899.

Chaudhary, Ali R. 2015. "Racialized Incorporation: The Effects of Race and Generational Status on Self-Employment and Industry-Sector Prestige in the United States." International Migration Review 49 (2): 318-354.

Cissé, Madjigène. 1999. Parole de sans-papiers. Paris: La Dispute.

Cobbe, Luca, and Giorgio Grappi. 2011. "Primo marzo, percorsi di uno sciopero inatteso." In La normale eccezione. Lotte migranti in Italia, edited by Felice Mometti and Maurizio Ricciardi, 55-90. Rome: Edizioni Alegre.

Council of Europe. 1992. Convention on the Participation of Foreigners in Public Life at Local Level. http://conventions.coe.int/Treaty/Commun/QueVoulezVous. asp?CL=ENG\&NT=144 (Accessed June 20, 2015).

d'Appollonia, Ariane Chebel. 2015. Migrant Mobilization and Securitization in the US and Europe: How Does it Feel to Be a Threat? London: Palgrave Macmillan.

De Genova, Nicholas. 2010. "The Deportation Regime: Sovereignty, Space, and the Freedom of Movement." In The Deportation Regime: Sovereignty, Space, and the Freedom of Movement, edited by Nicholas De Genova and Nathalie Peutz, 33-65. Durham, NC: Duke University Press.

de Haas, Hein, Stephen Castles, and Mark J. Miller. 2020. The Age of Migration: International Population Movements in the Modern World (6th ed.). New York: Guilford Press,. della Porta, Donatella, ed. 2018. Solidarity Mobilizations in the "Refugee Crisis": Contentious Moves. London: Palgrave Macmillan.

Doellgast, Virginia, Nathan Lillie, and Valeria Pulignano, eds. 2018. Reconstructing Solidarity: Labour Unions, Precarious Work and Politics of Institutional Change in Europe. Oxford: Oxford University Press.

Eliasoph, Nina. 2012. The Politics of Volunteering. Cambridge: Polity Press. 
El-Tayeb, Fatima. 2011. European Others: Queering Ethnicity in Post-National Europe. Minneapolis: University of Minnesota Press.

Garbaye, Romain. 2005. Getting into Local Power: The Politics of Ethnic Minorities in British and French Cities. Oxford: Blackwell.

Gilroy, Paul. 2005. Postcolonial Melancholia. New York: Columbia University Press.

Giugni, Marco, and Florence Passy. 2004. "Migrant Mobilization between Political Institutions and Citizenship Regimes: A Comparison of France and Switzerland." European Journal of Political Research 43: 51-82.

Glick Schiller, Nina, and Ayşe Çağlar, eds. 2011. Locating Migration: Rescaling Cities and Migrants. Ithaca: Cornell University Press.

Goldberg, David Theo. 2006. "Racial Europeanization." Ethnic and Racial Studies 29: 331-364.

Groenendijk, Kees. 2008. Local Voting Rights for Non-Nationals in Europe: What We Know and What We Need to Learn. Washington, DC: Migration Policy Institute.

Hochschild, Jennifer L., and Jacqueline Chattopadhyay, Claudine Gay, and Michael JonesCorrea, eds. 2013. Outsiders No More? Models of Immigrant Political Incorporation. Oxford: Oxford University Press.

Hochschild, Jennifer L., and John H. Mollenkopf, eds. 2009. Bringing Outsiders In: Transatlantic Perspectives on Immigrant Political Incorporation. Ithaca: Cornell University Press.

Ireland, Patrick. 1994. The Policy Challenge of Ethnic Diversity: Immigrant Politics in France and Switzerland. Cambridge, MA: Harvard University Press.

Koopmans, Ruud. 2004. "Migrant Mobilisation and Political Opportunities: Variation among German Cities and a Comparison with the United Kingdom and the Netherlands." Journal of Ethnic and Migration Studies 30 (3): 449-470.

Koopmans, Ruud, and Paul Statham, eds. 2000. Challenging Immigration and Ethnic Relation Politics: Comparative European Perspective. Oxford: Oxford University Press.

Lépinard, Éléonore. 2020. Feminist Trouble. Intersectional Politics in PostSecular Times. New York, London: Oxford University Press.

Lichterman, Paul. 2002. "Seeing Structure Happen: Theory-Driven Participant Observation." In Methods in Social Movement Research, edited by Bert Klandermans and Suzanne Staggenborg, 188-145. Minneapolis: University of Minnesota Press.

Martiniello, Marco. 1993. "Ethnic Leadership, Ethnic Communities' Political Powerlessness and the State in Belgium." Ethnic and Racial Studies 16 (3): 236-255.

Martiniello, Marco. 2005. "The Political Participation, Mobilization and Representation of Immigrants and their Offspring in Europe." In Migration and Citizenship: Legal Status, Rights, and Political Participation, edited by Rainer Bauböck, 52-64. Amsterdam: IMISCOE.

Mezzadra, Sandro, and Brett Neilson. 2010. "Borderscapes of Differential Inclusion: Subjectivity and Struggles on the Threshold of Justice's Excess." In The Borders of Justice, edited by Étienne Balibar, Sandro Mezzadra, and Ranabir Samaddar, 181-203. Philadelphia: Temple University Press.

Milkman, Ruth. 2011. "Immigrant Workers, Precarious Work, and the US Labor Movement." Globalizations 8 (3): 361-372.

MinistryofLaborandSocialPolicies.2014.Quartorapportannual.Gliimmigratinelmercatodel lavoro italiano. www.integrazionemigranti.gov.it/Attualita/News/Documents/IV_RAPPORTO _MDL_ITA_ENG_ALTRELINGUE/IV_Rapporto_annuale_MdL_immigrati_ 2014.pdf (Accessed June 30, 2015).

Mometti, Felice, and Maurizio Ricciardi, eds. 2011. La normale eccezione. Lotte migranti in Italia. Rome: Edizioni Allegre. 
Mulinari, Diana, and Anders Neergaard. 2017. "Theorizing Racism: Exploring the Swedish Racial Regime.” Nordic Journal of Migration Research 7 (2): 88-96.

Ngai, Mae. 2004. Impossible Subjects: Illegal Aliens and the Making of Modern America. Princeton: Princeton University Press.

Nicholls, Walter J. 2013. "Making Undocumented Immigrants into a Legitimate Political Subject: Theoretical Observations from the United States and France." Theory, Culture \& Society 30 (3): 82-107.

Nicholls, Walter J. 2014. "From Political Opportunities to Niche-Openings: The Dilemmas of Mobilizing for Migrant Rights in Inhospitable Environments." Theory \& Society 43 (1): 23-49.

Nicholls, Walter J., and Justus Uitermark. 2016. Cities and Social Movements: Immigrant Rights Activism in the US, France, and the Netherlands, 1970-2015. London: Wiley-Blackwell.

Oliveri, Federico. 2012. "Migrants as Activist Citizens in Italy: Understanding the New Cycle of Struggles." Citizenship Studies 16 (5-6): 793-806.

Oliveri, Federico. 2015. "Subverting Neoliberal Citizenship: Migrant Struggles for the Right to Stay in Contemporary Italy." ACME: An International E-Journal for Critical Geographies 14 (2): 492-503.

Omi Michael, and Howard Winant. 2015. Racial Formation in the United States: From the 1960s to the 1990s. New York: Routledge.

Organization for Economic Cooperation and Development (OECD). 2014. Lavoro per gli immigrati. L'integrazione nel mercato del lavoro in Italia. OECD Publishing. www.oecd. org/els/lavoro-per-gli-immigrati-9789264216570-it.htm (Accessed September 10, 2016).

Palmi, Tommaso, ed. 2020. De-colonizzare l'anti-razzismo. Per una critica della cattiva coscienza bianca. Milan: Deriveapprodi.

Penninx, Rinus, Karen Kraal, Marco Martiniello, and Steven Vertovec, eds. 2004. Citizenship in European Cities: Immigrants, Local Politics and Integration Policies. Aldershot: Ashgate.

Perrocco, Fabio. 2003. "L'apartheid Italiano.” In Gli immigrati in Europa. Diseguaglianze, razzismo, lotte, edited by Pietro Basso and Fabio Perocco, 211-233. Milan: FrancoAngeli.

Pojmann, Wendy. 2006. Immigrant Women and Feminism in Italy. Aldershot: Ashgate.

Ragusa, Stefania. 2011. Le Rosarno d'Italia. Storie di ordinaria ingiustizia. Firenze: Vallecchi.

Raissiguier, Catherine. 2010. Reinventing the Republic: Gender, Migration, and Citizenship in France. Stanford: Stanford University Press.

Siméant, Johanna. 1998. La cause des sans-papiers. Paris: Presses de Sciences po.

Soysal, Yasemin Nuhoglu. 1994. Limits of Citizenship: Migrants and Post-National Membership in Europe. Chicago: University of Chicago Press.

Steinhilper, Elias. 2018. "Mobilizing in Transnational Contentious Spaces: Linking Relations, Emotions and Space in Migrant Activism." Social Movement Studies 17 (5): 574-591.

Steinhilper, Elias, and Ilker Ataç. 2019. "Contentious Subjects: Spatial and Relational Perspectives on Refugee Mobilizations in Europe." In Handbook on Critical Geographies of Migration, edited by Katharyne Mitchell, Reece Jones, and Jennifer L. Fluri, 345-357. Cheltenham: Edward Elgar.

The Black Mediterranean Collective, ed. 2021. The Black Mediterranean. Bodies, Borders and Citizenship. Cham, Switzerland: Palgrave Macmillan.

Tomlinson, Barbara. 2013. "Colonizing Intersectionality: Replicating Racial Hierarchy in Feminist Academic Arguments.” Social Identities 19 (2): 254-272. 


\section{Introduction}

Torrese, Eugenio. 2010. Oltre il binomio welfare-immigrazione. Un'esperienza locale: l'Agenzia per l'Integrazione. Milano: Franco Angeli.

Triandafyllidou, Anna, and Maurizio Ambrosini. 2011. "Irregular Immigration Control in Italy and Greece: Strong Fencing and Weak Gate-Keeping Serving the Labor Market." European Journal of Migration and Law 13 (3): 251-273.

Triviño-Salazar, Juan-Carlos. 2018. "The Politics of Immigration Locally: Alliances between Political Parties and Immigrant Organizations." Ethnic and Racial Studies 41 (9): $1728-1746$.

Voss, Kim, and Irene Bloemraad, eds. 2011. Rallying for Immigrant Rights: The Fight for Inclusion in 21st Century America. Berkeley: University of California Press.

Wimmer, Andreas, and Nina Glick Schiller. 2002. "Methodological Nationalism and Beyond: Nation-State Building, Migration and the Social Sciences." Global Networks 2 (4): 301-334.

Yukich, Grace. 2013. "Constructing the Model Immigrant: Movement Strategy and Immigrant Deservingness in the New Sanctuary Movement." Social Problems 60 (3): 302-320.

Zapata-Barrero, Iris Dähnke, and Lea Markard, eds. 2017. Immigrant Incorporation in Political Parties: Exploring the Diversity Gap. London: Routledge.

Zepeda-Millán, Chris. 2017. Latino Mass Mobilization: Immigration, Racialization and Activism. Cambridge: Cambridge University Press. 


\section{The Italian context and methodology}

\section{Institutional racism and the hostile context in Italy}

Like other Southern European countries such as Spain, Greece, and Portugal, Italy unexpectedly became an immigration country in the first half of the $1980 \mathrm{~s}$, after having been almost exclusively an emigration country since the beginning of the century (Kosic and Triandafyllidou 2005,5$).{ }^{1}$ Only thirty years later, Italy has become home to one of the largest migrant populations in the EU (Ministry of Labor and Social Policies 2014). According to official sources, in 2013, Italy had the fourth-highest number of migrants in absolute numbers (more than four million) and had a relatively high percentage of migrants on a per capita basis $(7.4 \%)$ (Ministry of Labor and Social Policies 2014, 13). Statistics on the characteristics of the migrant population suggest that, notwithstanding the financial crisis, the migrant population was heading toward greater stabilization in Italy (Caritas/ Migrantes 2012, 443). In 2011, the total population of Italy was $60,820,764$ and the proportion of migrants (EU and non-EU citizens) was about $8.2 \%$ of the total population. Of the total foreign population, non-EU citizens were around $68 \%$ and $\mathrm{EU}$ around $29 \%$. In addition to the migrant population, 546,340 foreigners became new Italian citizens from 2003 to 2013. Also, the presence of migrants who were minors was $23.9 \%$ of the migrant population. Finally, the number of people holding a long-term permit (Carta di soggiorno) amounted to more than $52.1 \%$. Moreover, the migrant population of Italy is highly diverse. Though the five largest migrant communities-Romanians, Albanians, Moroccans, Chinese, and Ukrainians - represent more than $50 \%$ of the total number, the migrant population includes people from four continents (Istat 2013). Table 1.1 presents an overview of the main migrant groups.

Migrants are mainly employed in "low-skilled" and low-paid jobs, often in the underground economy, and suffer from exploitation and discrimination. According to the $\operatorname{OECD}(2014,20), 44 \%$ of the "regular" migrant population working in Italy in 2012 were employed in non-qualified or semi-qualified jobs, in contrast to only $15 \%$ of native Italians. ${ }^{2}$ Migrant laborers with valid work permits mainly work in the service sector (57\%) and industrial sector $(29.6 \%)$. In the service sector, they are mainly employed by private citizens as caregivers and domestic servants, and by enterprises such as restaurants and hotels. In the industrial sector, 
Table 1.1 Main immigrant communities in Italy (2012)

\begin{tabular}{lrr}
\hline Origin & Total (approximate) & $\%$ \\
\hline Total foreign population & $5,011,000$ & 100.0 \\
\hline Non-EU residents & $3,637,800$ & 73.4 \\
EU residents & $1,334,800$ & 26.6 \\
1. Romania (EU) & 951,100 & 21.7 \\
2. Morocco & 437,500 & 10.0 \\
3. Albania & 412,700 & 9.4 \\
4. China & 213,600 & 4.9 \\
5. Ukraine & 192,300 & 4.4 \\
6. Philippines & 139,800 & 3.2 \\
7. Moldavia & 130,800 & 3.0 \\
8. India & 123,700 & 2.8 \\
9. Peru & 97,600 & 2.2 \\
10. Poland & 95,900 & 2.2 \\
11. Tunisia & 93,200 & 2.1 \\
12. Egypt & 91,900 & 2.1 \\
13. Bangladesh & 88,500 & 2.0 \\
14. Ecuador & 84,400 & 1.9 \\
15. Sri Lanka & 83,700 & 1.9 \\
16. Senegal & 79,000 & 1.8 \\
17. Pakistan & 77,500 & 1.8 \\
18. Nigeria & 74,400 & 1.7 \\
19. Macedonia & 56,600 & 1.3 \\
20. Bulgaria & 50,000 & 1.1 \\
Other origins & 813,300 & 18.4 \\
\hline
\end{tabular}

Source: Istat (2013)

they are mostly employed in construction and manufacturing (OECD 2014, 20). Also, $8.5 \%$ are employed in the agricultural sector. Some migrants are also selfemployed in small enterprises, which represent $7.8 \%$ of the total enterprises in Italy (Ministry of Labor and Social Policies 2014). A relevant number of "regular" migrants are also employed in the underground economy.

Like all southern European countries, "the underground economy has long been well-rooted in Italy" (Reyneri 1998b, 86) and both documented and undocumented migrants participate in it extensively. Already in the 1980s and 1990s, Reyneri noted that, "all local surveys of immigrants show a huge proportion of irregular employment, even among those who could have a regular labor contract, since they hold residence and work permits" (1998b, 87).

In Italy, people are considered "irregular" (or "illegal") when they enter without documents, or when they reside in the country after the expiration of their visa (Fasani 2009, 13). The phenomenon is widespread and is deeply linked to the underground economy (Calavita 2005a; Reyneri 1998a). Research has shown that the underground economy and demand for labor are crucial pull factors (Reyneri 1998a). Reyneri also explains that rather than being the cause of the underground economy in Italy (and elsewhere in Southern Europe), irregular immigration is one 
of its results (Reyneri 1998a). Since the 1980s, left-wing and right-wing governments in Italy have approved seven amnesties to legalize undocumented migrants. These amnesties have been one of the main instruments of Italian immigration policies (Mantovan 2007, 43; Kosic and Triandafyllidou 2005). Research shows that "More than a half of the documented migrants currently residing in Italy have obtained legal status through one of the[se] mass regularizations" (Fasani 2009, 13). In total, around 1,760,200 migrants have been regularized with the amnesties, making Italy the country in Europe with the highest number of people regularized through this method (Fasani 2009, 13).

Moreover, the phenomenon of undocumented migrants is not only structurally linked to the underground economy, but it is also produced and reinforced by the current legislation. As Fasani (2009, 16-17) and Calavita (2005a, 74) explain, migration policy (interacting with economic factors) produces irregularity. Calavita $(2005 \mathrm{a}, 74)$ adds that the legislation, by producing "illegality," constructs migrants' marginalization, and this nourishes a circle of exclusion through the confinement of this vulnerable population to the margins of the Italian economy. What is more, "their location in the economy reproduces . . . otherness from within, as immigrants' status as an underclass of workers with substandard wages and working conditions impedes their full membership in the national community" (Calavita 2005a, 74).

Recent research shows that labor exploitation is widespread not only for nonEU citizens but for EU citizens as well, such as the Romanians working in the construction sector (OECD 2014). The International Organization for Migration (IOM) has denounced the high level of exploitation linked to the underground economy in Italy, especially in the agricultural sector in the southern regions of Campania, Apulia, and Sicily (IOM 2010). Amnesty International (2012) points out that exploitation in the agricultural sector is widespread in the rest of Italy. Finally, the journalist Ragusa (2011) documents the situation of extreme exploitation in the regions of the North, such as Veneto, Lombardy, Emilia-Romagna, and Tuscany.

A wide corpus of research has examined the negative effects of the current Italian immigration regime on the exclusion of immigrants and racialized communities. Existing works have shown how different immigrant and racialized groups face several legal and social obstacles. In the past two decades, immigration laws have focused on the "temporariness" of immigrants and have contributed to constructing many non-EU immigrants and their offspring as second-class citizens (Calavita 2005a). Moreover, since the beginning of the 2000s, Italy moved toward an immigration regime based on exclusion and "institutional racism" (Basso 2010, 391), or a new form of "Italian apartheid" (Perocco 2003, 221). Looking at the economic marginalization of immigrant workers, Calavita describes this situation as an "economy of otherness" in which immigrants are subordinated to a system that benefits from their work while conceding them very limited rights (Calavita 2005b, 415).

The presence of immigrants in the country is also ambiguously justified only for some categories of workers, in particular domestic workers (the so-called "colf e badanti"), and thus most other immigrant workers are not considered worthy of 
staying in Italy (Triandafyllidou and Ambrosini 2011). In line with this thinking, the law restricts family reunifications and limits the conditions under which immigrants can reside in the country or request a long-stay permit (Triandafyllidou and Ambrosini 2011). Moreover, configured as economic "threats" and "criminals," irregular immigrants are exposed to extensive criminalization and inferiorization. This context makes immigrants with different statuses very vulnerable and exposes them to similar forms of stigmatization and labor exploitation.

Looking at the impact of the 2008 financial crisis, research has shown that sectors with the greatest concentration of immigrants, particularly construction, manufacturing, and services, were heavily affected. Between 2008 and 2010, for example, the number of unemployed immigrant workers in Italy significantly increased $(+64.2 \%$ ), and unemployment rates doubled (from $6.9 \%$ in 2008 to $13 \%$ in 2010) (Ministry of Labor and Social Policies 2014). This increase was much higher than that seen among "native-born" Italian workers, whose unemployment rates shifted from $6 \%$ to $8.7 \%$ (ibid.). Not surprisingly, as a result of immigrant workers' precarious conditions, labor exploitation among migrants also increased across the country in the years following the financial crisis (Amnesty International 2012; IOM 2010).

Immigrants' employment conditions are worsened by restrictive legislation (Triandafyllidou and Ambrosini 2011), which play a role in disciplining the labor force (Oliveri 2018; Palidda 2011). One law, in particular, the so-called BossiFini Law (or Law 189/2002) introduced in 2002 by the right-wing majority, is especially tough on immigrant workers as it frames an immigrant presence in Italy exclusively as a labor force and failed to promote long-term integration (see also Caponio and Graziano 2011). With the introduction of a new work visa, the contratto di soggiorno, the Bossi-Fini Law establishes a strict link between the permit of stay and the work contract. According to this visa program, immigrants working in the country can renew their permit for a two-year period only if they have a long-term work contract (Triandafyllidou and Ambrosini 2011, 264). A particularly problematic aspect of this legislation is its failure to account for the flexible nature of Italy's labor market or the difficulty in finding and keeping a regular job contract in a country with a widespread underground economy. The labor market offers almost exclusively temporary work contracts, especially in the sectors where immigrant workers are mostly employed, such as construction, agriculture, care, catering, and cleaning services (ibid.). For these reasons, the law has been criticized by human rights groups for creating immigrant illegality (it is easy to lose legal status under these circumstances) and enhancing the power of employers who are more likely to exploit immigrants in the underground economy (Oliveri 2012, 802).

There were other legislative developments in the years that preceded the mobilizations that followed the financial crisis of 2008, as described in the Introduction of the book. The newly elected right-wing Italian government introduced two new controversial measures in 2008 and 2009 to fight "illegal" immigrants in the so-called Security Package (Pacchetto Sicurezza), or Laws 125/2008 and 94/2009. As many Italian scholars have observed (Cannella 2010; Caponio and 
Graziano 2011; Triandafyllidou and Ambrosini 2011), introducing a felony charge for "illegal entry and stay in the country" criminalized undocumented immigrants working and living in Italy. Moreover, these laws also affected immigrant workers with legal status by exposing them to state control, surveillance, and blackmail in the labor market (Cannella 2010).

The discriminatory effects of the legislative framework presented above fall into four broad categories. First, the current legislation creates juridical precariousness for immigrants. By shortening the permit of stay and by requiring greater documentation for work permits, the law redoubles the "bureaucratic burden," thereby making immigrants "subjects of the administration" (Caponio et al. 2012, 3). Second, the closer link between residence and work established by the legislation produces "institutionalized irregularity" (Calavita 2005b, 413). As Kosic and Triandafyllidou (2005) point out: "The gap between the planned legal quotas, the demand for foreign labor and the immigration pressure from non-EU countries continuously reproduce large numbers of undocumented immigrants" (12). The problems date back to the first comprehensive law on migration introduced by a left-wing government in 1998, the so-called Turco-Napolitano Law. Quoting Zincone, Fasani (2009, 16-17) explains,

the lack of adequate possibilities for legally accessing the Italian labor market"... the policy of closing the front door of legal entry, while keeping the back door of illegal entry half open ..." (Zincone 1998)- has played a major role in increasing undocumented stocks and flows.

In spite of its attempt to end "irregularity," the Bossi-Fini Law has not been able to solve this problem. On the contrary, it has increased the production of irregularity (Triandafyllidou and Ambrosini 2011, 264). Third, the problem described earlier produces, in turn, labor precariousness and economic marginalization. According to Calavita, in Italy, "[e]conomic marginality is . . institutionalized through law" (Calavita 2005b, 415). Cannella (2010, 41-45) underscores that the precarious juridical status of non-EU workers in Italy has effects not only on the irregular immigrants but also on regular immigrants. While the strong link between the permit of stay and permit of work established by the Bossi-Fini Law contributes to the vulnerability of immigrant workers who could be easily blackmailed, the Security Package's introduction of the felony of clandestinity further aggravates the situation. Cannella explains that the "greater the vulnerability, the greater the probability that immigrants will accept the worst working conditions, low paid jobs, work in very bad conditions and in impossible hours, and in places where there is lack of security" $(2010,45)$. Fourth, through the current legislation, both regular and irregular immigrants are criminalized, inferiorized, and constructed as people with no rights and as "outsiders" (Basso and Perocco 2003, 7). The Law constructs "regular" immigrants in Italy "only and exclusively" in economicutilitarian terms under the principle of the Jus Laboris, "that is, being subordinated to being active" and productive in the labor force (Perocco 2003, 219; Basso and Perocco 2003, 18-19). 


\section{The Italian context and methodology}

In addition to the discriminatory nature of the legistation on immigration, the Italian citizenship regime is particularly exclusionary when it comes to citizenship acquisition for non-EU nationals and has been noted for its extraordinary slowness (Kosic and Triandafyllidou 2005, 20). Italian legislation on citizenship is regulated by Law 91/1992. The law is mainly based on jus sanguinis, which favors the acquisition of Italian citizenship for citizens who have Italian "blood," rather than those who are born in the country (jus soli). There are very limited cases in which one can acquire citizenship on the basis of the jus soli principle. One such exception is if an individual born in Italy has no parents or the parents are stateless or unknown (Art. 1, comma 1, letter B Law 91/1992). Migrants who want to naturalize may do it in one of the following ways: (1) They may be naturalized automatically, if they have at least one Italian parent, regardless of their place of birth, or if one of the parents of a minor becomes an Italian citizen. (2) They may request citizenship under certain conditions, such as having been born in Italy or continuously residing in Italy until they are 18 years of age. The citizenship application must be submitted within a year after the 18th birthday. (3) They can apply for citizenship if they are married to an Italian. Before the foreign spouse can apply for naturalization, the couple must have been married for three years if they reside abroad or six months if they live in Italy. (4) Individuals can request Italian citizenship if they have lived in Italy for at least 10 years (four years for EU citizens), and have no penal precedents and adequate economic resources.

It has been argued that the law is exclusionary in at least three main ways: (1) Individuals have to wait a very long time to apply for citizenship - 10 years - and this is aggravated by the slow bureaucratic process: it can take up to three or four years to receive an answer from the institutions, which extends the waiting time to 13 or 14 years (Kosic and Triandafyllidou 2005, 22-23). (2) Based on the principle of the jus sanguinis, the law slows down the processes of inclusion of migrant children, who are considered migrants until they can apply for citizenship at the age of 18, unless their parents acquire Italian citizenship when they are still minors. Finally, (3) "Children born in Italy to undocumented immigrants are themselves undocumented” (Calavita 2005b, 413).

\section{The "racist wave": exclusionary practices and discourses}

In addition to the exclusionary legal framework, public discourse on immigration issues has brought about a "racist wave." Increasingly racist and discriminatory discourses and practices have been put in place by Government institutions, representatives of political parties, the police, and private citizens (Kosic and Triandafyllidou 2005). Above all, the rise of the main anti-immigrant party (the Northern League) has contributed to the spread of discriminatory discourses and practices toward immigrants at both the national and local levels (Ambrosini 2013). In particular, the Northern League has contributed to the spread of discriminatory discourses and practices towards immigrants at both the national and local levels (Ambrosini 2013) and has politicized the discourse on migration, openly suggesting a link between irregular immigration and criminality. ${ }^{4}$ 
The most emblematic examples of this racism have been the multiple attacks on a member of the Democratic Party, Cécile Kyenge, a Congolese-born Italian. Right after her nomination as Minister of Integration during the government of Enrico Letta (2013-2014), she became the target of several racist attacks by members of the Northern League. One of the most blatant examples was when Roberto Calderoli, the then-European Senator and member of the Northern League, in July 2013, claimed that Minister Kyenge reminded him of an orangutan. A few days after Calderoli's slur, during a speech in a meeting of the Democratic Party, members of the far-right neo-fascist party, the New Force (Forza Nuova) threw bananas at Minister Kyenge. ${ }^{5}$ This last episode stimulated an intense national debate and the Left in power has unsuccessfully asked the Senator to leave the Senate. ${ }^{6}$

Discrimination against immigrants is not new in Italy. Research shows that discrimination is experienced in the housing market (Baldini and Federici 2011) and in the workplace (OECD 2014, 32). The mass media have also played a major role by promoting a negative and stereotyped image of immigrants (Mantovan 2007, 42; Bellu 2015). Anxiety about immigrants was already rising by the end of the 1990s (Diamanti and Borbignon 2001) and increased throughout the 2000s (Ambrosini 2013). As Kosic and Trindafyllidou $(2005,18)$ anxieties by the native population have been fueled by Italian media's focus "on issues of criminality and illegal entry and reproduces images of 'threat' to the national public order." In the last few years, while these anxieties are still produced by mainstream media, but racism and discrimination are also spilling over in social media (Caponio and Cappiali 2017). Also, over the years, Italy has not adopted adequate measures to identify and combat discrimination, making it difficult to assess their scope and effect (OECD 2014, 108-109).

The climate of intolerance put in place by political leaders in the $2000 \mathrm{~s}$ has also affected other institutions, such as the police, and a number of different political parties, including some of the main left-wing local administrations which have adopted also some discriminatory ordinances (Bellinvia 2013). Expressions of racism have also increased among the Italian population. Research shows that immigrants and racialized communities are victims of discrimination in the housing market (Baldini and Federici 2011) and in the workplace (OECD 2014, 32). Kosic and Trindafyllidou $(2005,16)$ observe that, since the 1990 s, "Italian public attitudes, initially characterized by 'social tolerance' towards immigrants, have given way to hostile and xenophobic behavior." The emergence of a public anxiety over the issue of immigration has resulted in the perception of immigrants as suitable scapegoats for the problems of Italy. Ambrosini $(2013,140)$ highlights that just before the 2008 elections, when the Northern League achieved its greatest electoral success, "the share of Italian citizens who considered immigrants a threat to security exceeded the threshold of 50\%." Moreover, according to several projects conducted by the Pew Research Center (2007, 2016), Italians are constantly concerned with immigration issues and in 2015, 73\% said that immigrants (especially from the Middle East and North Africa and from Eastern European countries) had a bad impact on their country. Furthermore, several studies show 
that acts of discrimination towards migrants and racialized communities are quite high, placing Italy among the countries that discriminate the most in Western Europe (FRA 2011). Despite this problem, Italy has not yet adopted adequate measures to counteract these anti-immigrant trends, making it difficult to assess their scope and effect (OECD 2014, 108-109). Research done by international organizations such as the IOM and Amnesty International indicates that since immigration laws are "ineffective and open to abuse" (Amnesty international 2012, 13), they expose immigrants to exploitation and institutional discrimination with very little chances to contrast them (IOM 2010,3).

By the end of 2010, at the local level (especially in the North), the Northern League was able to implement policies which promoted various forms of social, economic, and cultural exclusion. According to Ambrosini (2013), there were unprecedented in the history of the Italian Republic. As he explains, in some cities in the North, some of the most infamous discriminatory ordinances concerned: (1) cultural exclusion, such as the prohibition on playing cricket in the parks or using public spaces; (2) social exclusion, for example, limiting access by the migrant population to specific services; and (3) security exclusion, by reinforcing surveillance and by banning gatherings in public spaces. ${ }^{7}$ In this general context, one of the most blatant expressions of racism by local authorities came from a member of the Northern League: the mayor of Treviso (Veneto Region), Giancarlo Gentilini, nicknamed "the Sheriff" because of his policies against Roma immigrants. Gentilini was the mayor of Treviso between 1994 and 2003 and then between 2003 and 2013. In Italy, he was famous for his open expressions of racism. Among his most infamous comments were the following: "The extra-comunitari [the non-Europeans]? One should dress them as hares and do 'pim pim pim' with the rifle!" This climate of intolerance has also affected other institutions, especially the police, and members of political parties, including the main left-wing party (Bellinvia 2013), who have borrowed some of the anti-immigrant parties' discourses or have remained silent of some key issues, for fear of the "electoral cost" (Caponio 2006, 92). What is more, despite the strong evidence of the presence of institutional, elite, and everyday racism, the denial and lack of a juridical and political framework to address these issues remains one of the most problematic aspects of Italian democracy today (Khoum 2010).

The developments described earlier led to the further deterioration of immigrant rights in the two years prior to the mobilizations between 2010 and 2011. The mobilizations and protests by immigrants and pro-immigrant organizations in several localities across the country were in large part triggered by the developments described earlier (Cobbe and Grappi 2011; Oliveri 2012; Cappiali 2016, 2019). As will be shown in the empirical chapters of this book, throughout Italy, multiple pro-immigrant actors with a wide range of political affiliations - regional and local administrations, lay NGOs, the Catholic Church and church-based NGOs, traditional trade unions, and grassroots organizations - have advocatedsometimes successfully, other times less so - to improve the working and living conditions of immigrants and racialized communities (see also Cappiali 2019). 


\section{Pro-immigrant actors in promoting inclusion in Italy}

\section{Responses by leftist trade unions and political parties}

It is commonly recognized that the Left holds many responsibilities in the failure of integration of immigrants and racialized communities in Western democracies, especially because of its ambiguous approach to the issue of immigration (Casseron 2007; Raissiguier 2010). In this respect, Italy shares many similarities with other European counterparts (Mantovan 2007; Però 2007; Pojmann 2006; Cappiali 2017a). Left-wing organizations in Italy have been recognized as crucial actors in the governance of migration, especially in the first decade of mass migration (Mottura and Pinto 1996). Not only they presented themselves as progressive and welcoming (Però 2007), but they also invested concretely on immigration issues beyond their rhetoric. Yet, despite these important initiatives, there is also significant evidence supporting the responsibilities of the left in the "integration crisis" in Italy. Major setbacks of the Left in approaching immigration issues have contributed to marginalizing immigrants and racialized communities, making the integration crisis not only a right-wing's fault. In the following I present a brief overview of some of the responses to immigration by main left-wing actors in Italy.

Facing the lack of adequate immigration and integration policies at the national level, left-wing non-state actors, trade unions and political parties dealt with immigration issues in an informal and pragmatic way as the phenomenon evolved. While they offered assistance in the first years of immigration, they have developed several strategies to include immigrants in society since the 1990s. Moreover, leftwing organizations have made several visible efforts to encourage the civic and political participation of immigrants in the social and political life of the country, by opening platforms for participation and increasing the level of immigrant representations in their organizations (Kosic and Trindafyllidou 2005; Cappiali 2015).

The main traditional trade union in Italy, the "Communist" CGIL (Italian General Confederation of Labor-Confederazione Generale Italiana del Lavoro), for instance, has played the greatest role in promoting immigrants' inclusion, and in particular immigrant unionization and rights claims (Mottura 2010). There are also other two big trade unions in Italy: the Catholic CISL (Italian Confederation of Trade Unions-Confederazione Italiana Sindacati Lavoratori) and the Socialist UIL (Italian Union of Labor-Unione Italiana del Lavoro). The work on immigration of the CISL is also very important in Italy, while the work of the UIL is more marginal than the other two main organizations.

In contrast to the attitudes of trade unions in other European countries, especially from the North - which were unwelcoming if not hostile during the first phase of immigration (Penninx and Roosblad 2000, 5) - the CGIL offered assistance and support to the newcomers since they first began arriving in the 1980s (Mottura and Pinto 1996; Mantovan 2007). The CGIL is the strongest trade union in Italy, with the highest number of people enrolled $(5,775,962)$. Here, the number of immigrant workers in this organization is the highest among all the trade unions $(410,127)$, representing $15.5 \%$ of the total active workers enrolled in the CGIL. ${ }^{9}$ 
The CGIL also created specific structures to promote the political activism of immigrant workers. ${ }^{10}$ By the end of the 1980s, the CGIL created specific "Offices for Migrants" or "Offices for Foreigners" (Uffici immigrati or Uffici per stranieri) within each territorial unit of the organization, the so-called Chambers of Labor (Camere del Lavoro). These offices were intended not only to offer services but also to encourage the political participation of immigrant workers. In order to do so, the CGIL instituted the Migrant Coordination Organization (Coordinamento Migranti), a platform at the national level that sought to encourage immigrants to participate in the organization at the decisional level (Marino 2010, 346-348). Additionally, depending on the choice of the territorial branches, some Migrant Coordination Organizations (Coordinamento Migranti) were also created at the local level (Marino 2010). ${ }^{11}$ Additionally, the CGIL has provided specific units for the defense of immigrant rights in the workplace, which were managed by the federations of categories. Mottura and Pinto (1996) underscore that it was the first union in Italy to organize meetings with foreigners to discuss their specific problems. Moreover, the union has actively attempted to enhance the visibility of immigrant workers in its organization. Already in 2000, the CGIL had 160 immigrant representatives in the workplace (delegates-delegati), 3 national directors (dirigenti), and two secretaries of category (the CGIL-FIOM (metalworkers) of Biella, in Piedmont (North of Italy), and the FILLEA (construction workers) of La Spezia in Liguria (North of Italy) (Mantovan 2007).

The center-left parties have also worked on the subject of immigration since the end of the 1990s, due in large part to the influence of Livia Turco, one of the key figures of the party. One can identify three main phases of the emergence of the theme of immigration within the main left-wing party. ${ }^{12}$ The first phase took place between 1996 and 1999, when the then main moderate left-wing part of Italy, DS (Democrats of the Left-Democratici di Sinistra) pushed for the approval of the first comprehensive law on immigration, the Turco-Napolitano Law (see Zaslove 2006). The second phase started in 2001. Livia Turco was elected again as a member of the opposition, and she promoted the creation of Brothers of Italy (Fratelli d'Italia), a structure of the party that aimed to favor the inclusion of immigrants (see Democratici di Sinistra 2004). With this organization, in 2002, in response to the approval of the Bossi-Fini Law, she launched a campaign, "Brothers of Italy: Immigration is a richness for you, too!" ("Fratelli d'Italia. L'immigrazione è una ricchezza anche per te"), at the national level to sensitize the Italian population to the importance of seeing immigration in a positive light. ${ }^{13}$ Unfortunately, not only was the campaign not able to grasp the attention of the Italian public opinion but it was also confined within a group of insiders and experts on immigration and failed to reach the attention of its own political party. So event then the DS was silent on the theme and did not introduce immigration issues in its agenda as it was not yet among its priorities.

The third phase of the moderate left-wing party was promoted by the new party the Democratic Party (Partito Democratico). Today Democratic Party is the main social-democratic party in Italy. It was created on October 4, 2007, by former members of the Democrats of the left (heirs of the Italian Communist Party) and the Democracy is Freedom Party, a small party with Catholic roots. The new 
phase developed between 2009 and 2013, in response to the rise of the Northern League. At that time, the political party realized that it was important to talk about the theme and to raise public awareness. To this end, in 2010 the Democratic Party encouraged the creation of the National Forum on Immigration, a platform aiming to promote the participation of citizens (Italian and immigrants) interested in the theme of immigration. Through the Forum, the Party also engaged in many campaigns to enhance the awareness of the Italian population. Gradually, at the regional and local level and through the Forum, the Democratic Party supported the creation of Provincial Forums of Immigration. ${ }^{14}$ This was most successful in those regions where the party was well established, such as Lazio and EmiliaRomagna. Within three years, the Party in the Emilia-Romagna Region created a Forum in almost every province. Additionally, it developed one of the most solid networks with a great level of coordination, thanks to the creation of a Regional Forum. Among the results of the work done by the Forum in Emilia-Romagna was the promotion of a leadership of migrant background in the party. During the national election of 2013, when the left-wing coalition won the elections, two main members of the Forum in Emilia-Romagna were elected in the Parliament: Cécile Kyenge (at the time, the person in charge of the Regional Forum and a municipal councilor in the city of Modena) and Khalid Chaouchi (the president of the GMI (Young Muslims of Italy_Giovani Mussulmani d'Italia) and one of the key members of the Forum of Reggio Emilia).

It is important to note that the most important work by the moderate left has been done in some cases at the regional of local level. Some left-wing Regions, for instance, have promoted inclusion, by challenging the Bossi-Fini Law. The first to do so was the left-wing government of the Emilia-Romagna Region, which introduced the Regional Law n. 5, approved on March 24, 2004, to promote social integration of immigrants (Region Emilia-Romagna 2004). ${ }^{15}$ This law defines Italy as a multiethnic society and makes explicit the need for Regional authorities to support intercultural exchanges and integration, including measures against discrimination. It also promotes basic service delivery without making distinctions between documented and undocumented immigrants. Finally, the Region acknowledged the importance of promoting immigrants' political rights at the local level and encourages debate in this direction. ${ }^{16}$ In 2005, the Berlusconi government tried to stop the implementation of the Regional law of Emilia-Romagna by defining it as "unconstitutional." However, in 2005, the Italian Constitutional Court decided in favor of the region Emilia-Romagna. The approval of the Regional law in Emilia-Romagna encouraged other left-wing regions to do the same: Abruzzi (13/12/2004, Law n. 46), Friuli (4/3/2005, Law n. 5. suppressed in 2008), Liguria (20/2/2007, Law n. 7), Latium (Law 10/2008), Tuscany (law 29/2009), Marche (law 13/2009), Apulia (4/12/2009, Law n. 32), and Campania (law 6/2010) (Rossi et al. 2013; OECD 2014).

In addition to these regional interventions, some local authorities also responded to the climate of racism and exclusion and promoted integration at the local level. Some of the most progressive experiments by left-wing local authorities toward the inclusion of immigrants took place in the Emilia-Romagna region. As I will show in Chapter 3, the city of Reggio Emilia, for instance, that had stood out for 
its assistance to irregular immigrants and was also known for its welcoming environment (Turco 2005) moved toward more comprehensive approaches to integration during the second half of the 2000s (Cappiali 2015). In this city in particular efforts were made in the direction of interculturalism, by encouraging cultural exchanges in schools, hospitals, etc., and through the development of mixed and immigrant associations. Elsewhere in Emilia-Romagna and in other regions, some cities promoted also political rights through the creation of parallel institutions, such as the consultative bodies (e.g., Bologna and Modena) (Cappiali 2015).

\section{Responses by the radical left}

European scholars who have focused on the study of the sans-papiers movements have highlighted the crucial role of the radical left in supporting undocumented immigrants in their struggle for recognition both at the national and local level (Siméant 1998; Nicholls 2013). Like in many other European countries, radical left organizations are crucial allies of immigrants and refugees in vulnerable conditions in Italy (Mantovan 2007, 179-180). Radical left organizations represent a complex world of grassroots organizations typically distinguished from mainstream political parties. They are further left than mainstream political parties and represent a complex world of grassroots organizations that have very different views. In Italy, some radical left organizations are historically associated with the Communist Refoundation Party (PRC, Partito Rifondazione Comunista), while other organizations are dissociated from any party and claim extra-parliamentary trajectories of political action (Cosseron 2007). ${ }^{17}$

Radical left organizations in Italy have been particularly active around issues of housing, working conditions and amnesties, mainly between the 1980s and 1990s. In the 2000s, however, they attempted to develop a more structured antiracist movement after Genoa 2001. This was the first attempt in the country to organize the movement at the national level. At this point, the radical Left had several national and international objectives, including the closure of detention centers and the detachment of the stay permit from the work permit. Moreover, when the Bossi-Fini Law was introduced in 2002, these organizations mobilized for its abolition. The Law was considered as, among other things, a means of exploiting immigrants. Because in many respects this proved to be the case, the radical Left organizations were able, in some cases, to create coalitions with more moderate actors (Cappiali 2015). In more recent years, the situation for immigrants has grown worse, due in large part to the financial crisis and the Bossi-Fini Law's linking of the permit to stay with the permit to work. In this context, radical Left organizations have mobilized to fight for the rights of immigrants, particularly those who have lost their jobs, houses, and often their permit to stay. ${ }^{18}$ In the second half of the 2000s, the anti-immigrant movement lost its momentum, because of internal conflicts. As De Nardis $(2011,36)$ explains, with the fall of the Romano Prodi's left-wing government in 2008 and the ejection of the communists from the Italian Parliament, there was a severing of the "close bond between 
the movement of global justice and the Communist Refoundation Party." In this specific historical juncture, therefore, the PRC and the radical organizations split.

In 2006, when a left-wing coalition won the elections again for the first time since the last defeat in 1999, the hope that the government led by Romano Prodi would help to re-launch the anti-racist movement was soon dissolved with the fall of the government and the success of the right-wing parties (with a strong presence of the Northern League) in the elections of 2008. In the election of 2006, there was an attempt to create a large coalition of the left and the radical left through the Party L'Ulivo, led by Romano Prodi (Cosseron 2007, 10). However, as De Nardis $(2011,36)$ has explained, with the fall of the Prodi government in 2008 and the rejection of the communists from the Italian Parliament, there was a de-restructuration of the radical left and the end of the "close bond between the movement of global justice and the Communist Refoundation Party."

The radical left organizations mobilized early on the issue of immigration. Yet, a more structured anti-racist movement in Italy was organized only in the 2000s during the G8 of Genoa, when the Social Forum created a Table for Migrants to discuss issues linked to immigration. This was the first attempt to organize the movement at the national level. However, soon ideological conflicts began to surface between the PRC and the radical organizations, and among radical left actors themselves. These conflicts reflected major differences in the ways these organizations interpreted the phenomenon of immigration and the actions that went with it (Cobbe and Grappi 2011). Additionally, because the left-wing government in power since 1998 established the link between the permit to stay and the work permit with the Turco-Napolitano Law and introduced the CIE, or the Centers of Identification and Expulsion (Centri di identification e espulsione) and the control of borders, an open conflict emerged in those years between the radical and the moderate left on the issue of immigration. Among other things, the radical left supported the idea of "no borders" and "free movement" and challenged the legitimacy of the state in controlling the movement of people through legal means. In 2006, when a left-wing coalition won the elections again for the first time since the last defeat in 1999, the hope that the left-wing government led by Romano Prodi would help to re-launch the anti-racist movement was soon dissolved with the fall of the government and the success of the right-wing parties (with a strong presence of the Northern League) in the elections of 2008. However, some radical left organizations in Italy have been able to mobilize over the years. At the national level, one of the main organizations is the Project Melting Pot Europe: For the Promotion of the Rights of Citizenship (Progetto Melting Pot Europa. Per la promozione dei diritti di cittadinanza), based in one of the strongholds of the radical left in Italy (Padua) and associated with the political area of the disobedient ones (see Cosseron 2007) At the local level, there are also some radical left organizations that have developed their own unique trajectories, and even though they are considered a reference for the Italian movement, they are not national organizations. Two organizations are particularly strong: the Migrant Coordination Organization of the Province and City of Bologna (Coordinamento 
Migranti della Provincia e città di Bologna) (see Chapter 4) and the association Rights for All (Diritti per Tutti) in Brescia (see Chapter 5).

As I will show in the empirical chapters, during several months of fieldwork I conducted in Italy in 2013 and 2014 researching about the role of the Left in including immigrants in Italy, what emerged above all things was a great disappointment and a sense of detachment of immigrant activists from the Left (see also Cappiali 2015, 2016, 2017b). One aspect of criticism that emerged was the internal conflicts of the Italian Left on the issue of immigration. One Italian citizen of Moroccan origin I interviewed in 2013 summarized very well a point that has emerged in almost all the interviews: "The whole left is guilty of several setbacks. They have transformed the immigration issues in a reason to be divided" (Interview in Reggio Emilia, 11 July 2013). Several immigrant activists I have interviewed have expressed the same concerns.

These conflicts explain in part why the left was unable to have an effective impact on the integration of immigrants in Italy. The first conflict is between the radicaland the center-Left, over two main measures introduced with the Turco-Napolitano Law in 1998 and it is still at the heart of many of the disagreements between the radical- and the center-Left today: (1) the establishment by the left-wing government of a link between the permit to stay and the work permit that did not exist in previous laws and (2) the creation of an expulsion system, including the institution of detention centers. These two measures clash with the radical Left's refusal to limit the freedom of movement of people and to link their rights to immigrants "economic function" in receiving society. The second major conflict is between the radical Left organizations and the main left-wing trade union, the CGIL. In particular, a major problem arose in 2006, when Italian trade unions agreed to collaborate with the Berlusconi government. One of the conditions of this collaboration was that immigrants renewing their permits of stay would now have to go through a much more cumbersome, bureaucratic process. One of the main criticisms that has been made of the trade unions is that, since then, these organizations have been overwhelmed with bureaucratic procedures, and have not been able to do politics and organize migrant workers around issues linked to their rights.

Beyond internal conflicts, another aspect I have suggested in my own work is the political marginalization of immigrants in the left-wing organization (Cappiali 2017a). This topic will be further analyzed in the empirical chapters of the book. Building on the work by Però (2007) who identified a discrepancy between the left's inclusive discourses and its exclusionary practices and a systematic use of paternalistic and instrumental attitudes in one of the strongholds of the left, Bologna, I will show that, not only the left failed to treat immigrants and racialized communities equally, but it also contributed to their systematic political racialization. This term refers to a mechanism whereby political actors, in order to legitimize their work on immigration, create alliances with immigrant groups and include immigrants in the political sphere, but in a relationship of "ethnic" or "racial" subordination. In most cases, left-wing organizations confine the responsibilities of immigrant activists in aspects that concern only immigrants and immigration issues. In most cases, they are asked to deliver service for other 
immigrants. The reasoning behind these practices is that left-wing organizations need immigrants to legitimize their work on immigration but they try to prevent them from having a say in things that concern the agenda of the organization, including on immigration issues. A recent research by Mottura et al. (2010) on the representation of immigrant activists in the main Italian left-wing trade union, the CGIL, supports this view. The author suggests that there are systematic internal barriers within the trade union that prevent immigrant workers from reaching roles of responsibilities within the organization.

Therefore, the role of the Italian left in promoting the inclusion of immigrants has been quite ambivalent. This is due to a mix of slow adaptation to change, a tendency to use the immigration issue for instrumental and political reasons, and an unwillingness to treat immigrants on an equal footing.

\section{Responses by civil society organizations}

It is important to mention that, composed of a complex world of associations with different political backgrounds, civil society organizations also play a key role in Italy. While in the Christian-Democrat territories, the Church and church-based organizations tend to have more power than non-Catholic lay organizations, in Communist territories it is the networks of lay organizations and left-wing organizations and co-operatives that occupy the space of the civil society organizations. The Catholic Church (diocese and Caritas), church-based organizations (parishes) and lay organizations of Catholic orientation (e.g., ACLI) have been very important in replacing the state during the first phase of immigration to Italy and promoting an assistance approach by providing social services and shelter to immigrants, by advocating for the improvement of immigrants' conditions, and by lobbying for the improvement of immigrants conditions through participation in the local tables of negotiations and campaigns of sensitization (cf., e.g., the "Italy is me, too!" campaign in Chapter 3).

As Zaslove $(2006,19)$ highlights: at the beginning of the immigration process (in the 1980s), Italian civil society organizations "provided help to immigrants before there was adequate legislation and they lobbied the government to increase the legal status and to grant the social and civil rights to immigrants." Over the years, third-sector organizations have also been crucial in fighting against discrimination, particularly in those territories where the Northern League had a strong influence (such as Lombardy and Veneto), and in lobbying for greater inclusion of people of migrant background in the receiving society. They also responded vigorously to the increasing vulnerability caused by the financial crisis.

At the national level, Caritas has been the major expression of the involvement of the Catholic Church in the realm of immigration. Among other things, in 1991, through the Center of Study and Research/Immigration Statistic Dossier (Centro Studi e Ricerche IDOS/Immigrazione Dossier Statistico), the director of Caritas of Rome promoted the creation of an annual statistical study of the phenomenon of immigration in the Lazio Region in order to fill the statistical lacuna left by the public authorities. In 2004, the Dossier became a national project. At the territorial level, there is a Caritas in virtually every diocese. ${ }^{19}$ Since the 1980 s, through 
the territorial Caritas, the Dioceses created new helpdesks to answer the specific needs of immigrants. These were commonly attached to the existing Center of Listening (Centri di Ascolto). In territories where the diocese was very influential, it created specific centralized offices to offer services. ${ }^{20}$

Like the Catholic organizations, lay organizations of the left are stronger in territories where they belong to the dominant political culture. For this reason, one can observe different roles by similar local actors across Italian territories (Campomori 2008; Mantovan 2007). In some territories where they are particularly strong, third-sector organizations of the left have been able to create strong networks of solidarity and collaborate with each other to better provide services in the city (assistance approach), promote intercultural dialogue (intercultural approach), and (sometimes) to promote political participation through political rights.

As it will appear clear in this book, civil society organizations were in some cities among the most important actors in shaping the local context and immigrants' participation and rights claims in each city.

\section{Research design and methodology}

The analysis of this book focuses on competing discourses and practices of multiple actors in the years following the global financial crisis (2008-2013), a period in which a rise in hostilities and racism toward immigrants and racialized communities was especially pronounced. In order to offer an overview of the historical context, I use a timeframe of 15 years (1998-2013). In 1998, with the TurcoNapolitano Law, the Italian government recognized for the first time that immigration was a structural phenomenon, and gave regional and local actors power over the implementation of local policies (Campomori 2008; Caponio 2006). Thus, 1998 is a starting point to examine how these actors mobilized around issues of immigration over time, how they promoted inclusion and how they shaped civic and political participation of immigrant and racialized communities.

This study investigates the mechanisms and factors that explain civic and political participation and rights claims of immigrant activists in four Northern Italian cities: Reggio Emilia, Bologna, Brescia, and Bergamo. The case selection is constructed by identifying the most similar cases taking into account Italian civic traditions (Putnam 1993) and political sub-cultures (Campomori 2008; Messina 2001). It is based on the selection of the independent variable (contextual factors) rather than the dependent variable (outcomes) in order to control for contextual variations. Geddes (1990) has eloquently argued that selecting cases on the basis of outcomes on the dependent variable biases the conclusions. Today, this is common knowledge in the sub-field of comparative politics in political science and political sociology, especially in studies focusing on social movements and participatory trajectories. Following this reasoning, I selected cities on the basis of several considerations about variations and similarities with respect to context, rather than variations of mobilizations and immigrant participatory trajectories (for more details, see Appendix A). 
The research design builds on existing comparative studies in the migration literature on European cities that account for the relevance of regional and local variations explaining immigrants' civic and/or political participation in receiving societies (Ambrosini 2012; Campomori 2008; Caponio 2006; Garbaye 2005; Marques and Santos 2004; Morén-Alegret 2002; Penninx et al. 2004). Recent literature has shown that local context matters especially when national policies of inclusion are lacking (Caponio and Borkert 2010; Penninx et al. 2004; Garbaye 2005; Morén-Alegret 2002; Pilati 2010). Yet the regional level still remains underexplored (some exceptions are the works of Campomori and Caponio 2013). My research does not address this gap directly, but it takes into account regions in its design to control for multi-level variations. While the choice of making comparisons in a single country stemmed from the idea of controlling for variations at the national level, the selection of four cities in two regions was based on the need to control for regional variations and to concentrate specifically on local dynamics (for more details, see Appendix A). To this end, I used a systematic cross-case comparison of four cities in two regions of Northern Italy: Emilia-Romagna and Lombardy.

Through a cross-regional comparison of two traditionally Communist cities and two traditionally Christian-Democrat cities with the same political orientation and to consider intraregional variations (Caponio 2005, 2006; Garbaye 2005; Però 2007). As my empirical analysis reveals, the model of local dynamics in Chapter 2 explains these variations in cities with similar political sub-culture. ${ }^{21}$

To control for contextual variations within the same political sub-culture, I selected two traditionally Communist cities - Reggio Emilia and Bologna - in Emilia-Romagna, and two traditionally Christian-Democrat cities-Brescia and Bergamo - in Lombardy, building on research undertaken on cities in Italy (Campomori 2008; Caponio 2006; Mantovan 2007). The selection of cities was based on their institutional variations, which I determined, in part, by their political subculture and the political orientation of local administrations, such as progressive or left-wing in traditionally Communist cities, and conservative or right-wing in traditionally Christian-Democrat cities. In addition, I considered the strength of civil society organizations (e.g., left-wing trade unions and NGOs in traditionally Communist cities and Catholic trade unions and organizations in traditionally Christian-Democrat cities). This selection process accounts for the presence of key challengers to established actors - the radical left organizations in one of the two cities of each political sub-culture (Bologna and Brescia). The existing literature considers sub-culture and political orientation as major factors in determining models of inclusion at the local level (Campomori 2008; Caponio 2006). While the first refers more precisely to the political sub-culture (Communist vs. Christian Democrat), the second refers to the political leaning of the local administration (left vs. right). The sub-culture is generally more stable, as it refers to specific relationships between the public and private sectors (Campomori 2008; Messina 2001), while the political orientation can vary. In recent years, there have been important variations in the political orientation of local administrations where, for instance, right-wing administrations have run Communist cities that were considered to be the main strongholds of the left (e.g., Bologna; see also Caponio 


\section{The Italian context and methodology}

2006). These changes have been greatly affected by the politicization of the issue of migration at the local level (Castelli Gattinara 2016).

Furthermore, the selection of the four cities accounted for the high size of the immigration population in each city and the degree to which migrant communities were economically and socially included, according to official statistics (cf. Table 1.2; for more details, see Appendix A).

Despite these similarities, the four cities differ with respect to the role of local actors, which is, to a certain extent, linked to the political sub-culture of the region. Table 1.2 presents the main differences between the four cities from 1998 to 2013.

Table 1.2 Comparison of the four cities

\begin{tabular}{|c|c|c|c|c|}
\hline & $\begin{array}{l}\text { Reggio } \\
\text { Emilia }\end{array}$ & Bologna & Brescia & Bergamo \\
\hline $\begin{array}{l}\text { Political } \\
\text { orientation } \\
\text { of local } \\
\text { administrations }\end{array}$ & $\begin{array}{l}\text { 1998-2013: } \\
\text { Centre-left }\end{array}$ & $\begin{array}{l}\text { 1998-2013: } \\
\text { Centre-left, } \\
\text { except for } \\
\text { 1999-2004 } \\
\text { (right-wing } \\
\text { coalition) }\end{array}$ & $\begin{array}{l}\text { 1998-2008: } \\
\text { Centre-left } \\
\text { 2008-2013: } \\
\text { People of } \\
\text { Freedom and } \\
\text { Northern } \\
\text { League } \\
\text { 2013-2018: } \\
\text { Democratic } \\
\text { Party }\end{array}$ & $\begin{array}{l}\text { Alternation } \\
\text { in power: } \\
\text { Centre-right } \\
\text { and right- } \\
\text { wing (People } \\
\text { of Freedom } \\
\text { and Northern } \\
\text { League) }\end{array}$ \\
\hline Total population & 163,928 & 380,635 & 188,520 & 115,072 \\
\hline $\begin{array}{l}\text { No. of immigrants } \\
\text { and percentage } \\
\text { compared to the } \\
\text { total population }\end{array}$ & $\begin{array}{l}25,687 \\
\quad(15.7 \%)\end{array}$ & $51,771(13.6 \%)$ & $31,888(16.9 \%)$ & $15,833(13.8 \%)$ \\
\hline $\begin{array}{l}\text { The largest } \\
\text { immigrant } \\
\text { communities in } \\
2012\end{array}$ & $\begin{array}{c}\text { China } \\
(3,437) \\
\text { Albania } \\
(3,149) \\
\text { Morocco } \\
(2,626) \\
\text { Ghana } \\
(1,984) \\
\text { Ukraine } \\
(1,795) \\
\text { Romania } \\
(1,531) \\
\text { Moldova } \\
(1,512) \\
\text { Nigeria } \\
(1,108) \\
\text { Egypt }(927) \\
\text { Sri Lanka } \\
(801)\end{array}$ & $\begin{array}{l}\text { Romania }(6,856) \\
\text { Philippines } \\
\quad(5,133) \\
\text { Bangladesh } \\
(4,935) \\
\text { Moldova }(4,558) \\
\text { Morocco }(3,792) \\
\text { Ukraine }(3,163) \\
\text { China }(3,032) \\
\text { Pakistan }(2,803) \\
\text { Albania }(2,509) \\
\text { Sri Lanka } \\
(1,355)\end{array}$ & $\begin{array}{l}\text { Pakistan } \\
(3,296) \\
\text { Moldova } \\
(2,923) \\
\text { Ukraine } \\
(2,633) \\
\text { Romania } \\
(2,626) \\
\text { Albania } \\
(2,146) \\
\text { India }(2,027) \\
\text { China }(2,016) \\
\text { Egypt }(1,803) \\
\text { Bangladesh } \\
(1,753) \\
\text { Philippines } \\
(1,390)\end{array}$ & $\begin{array}{l}\text { Bolivia }(3,001) \\
\text { Morocco } \\
(1,440) \\
\text { Ukraine } \\
(1,390) \\
\text { Romania } \\
(1,360) \\
\text { Albania } \\
(1,060) \\
\text { China }(919) \\
\text { Bangladesh } \\
(866) \\
\text { Senegal }(462) \\
\text { Ecuador }(418) \\
\text { Philippines } \\
(398)\end{array}$ \\
\hline
\end{tabular}

Source: Istat 2013; Caritas/Migrantes 2012; www.comuni-itaiani.it; www.regione.emilia-romagna.it; www.regione.lombardia.it; www.comunediblogna.it 
One can observe the distinctions between the cities by way of their political orientation. While Reggio Emilia was always governed by the center-left between 1998 and 2013, Bologna experienced an alternation in power between 1999 and 2004, when it was governed by a center-right coalition, but it was mostly governed by leftwing administrations. On the other hand, while Brescia was governed by the centerleft from 1998 to 2008 and then by a right-wing coalition with a strong Northern League presence between 2008 and 2013, Bergamo experienced the alternation in power between left-wing and right-wing administrations earlier. In the empirical chapters, the impact of these differences on local dynamics is made clearer.

In order to account for local dynamics in each context, I use an inductive approach and prioritize pro-immigrant organizations in each city. Most of the actors I identify had mobilized around the issue of immigration since the first arrival of immigrants in the 1980s and 1990s and were still the main actors when I was doing my research (Kosic and Triandafyllidou 2005, 26; Mantovan 2007). Some of these actors were the main left-wing party; the Democratic Party (Partito Democratico); the main traditional left-wing trade union CGIL, the Italian General Confederation of Labor (Confederazione Generale Italiana del Lavoro); the CGIL-FIOM, the Metalworkers' Federation of the CGIL (Federati Impiegati Operai Metallurgici della CGIL); the CISL, the Italian Confederation of Workers' Trade Unions (Confederazione Italiana Sindacati Lavoratori). I also looked into the main organizations of the Catholic Church and the main anti-racist organizations of different political orientations within the radical left.

Other actors I looked at had gained power in more recent years, especially after the economic crisis. When relevant, I followed the activities of grassroots trade unions, such as the USB, the Base United Unions (Unione Sindacale di Base) and COBAS, Confederation of Basic Committees (Confederazione dei Comitati di Base), organizations that had expanded, especially among more vulnerable workers, in the 1980s and 1990s (Gall 1995). In recent years, they have been mobilizing around issues of housing and immigrants' deplorable working conditions (Cappiali 2016, 2017a). ${ }^{22}$ The USB and the CUB are the most structured base organizations. However, base unionism encompasses many other organizations, such as the Confererazione Cobas, CUB, USI-AIT, SLAI Cobas, and SI Cobas. Some of these organizations also engage with immigrants' struggles in the workplace. At the time of my fieldwork, only the USB had created a more structured branch that is exclusively engaged with immigrants.

As mentioned already in the Introduction, in addition to the rich data collected through document analysis and observant participation, this study relies on the in-depth analysis of 118 semi-structured interviews. I used a snowball sampling method to identify most interviewees, starting with key Italian and immigrant leaders and members of the most visible groups mentioned earlier. Most interviews were explorative in nature, but some of them were ad hoc. Some key actors were interviewed more than once or offered support during and after the field research. I triangulated the interviews with participant observation of 60 key events in the four cities and across the country, and archival research of national and local newspapers, websites, and official and unofficial documents produced by local organizations. Several activists shared their personal files and archives 
(visual and written material), including newspapers they had collected during some key events they had organized in 2010 and 2011 and in other periods. I supported my analysis with second-hand sources, including pamphlets of protests and other events, and books produced by significant grassroots organizations and activists (for more details, Appendix A).

After presenting the Italian context and the methodology, I now turn to the theoretical model I have developed to explain conflicts and alliances among proimmigrant and immigrant actors in cities.

\section{Notes}

1 Several parts of the Italian context have been published previously in Cappiali (2017b).

2 These percentages would increase if one were to include the undocumented immigrants, who are largely concentrated in the Southern regions.

3 "Italy Condemned for 'Racist Wave'.” $B B C$. May 28, 2008. http://news.bbc.co.uk/2/hi/ europe/7423165.stm (Accessed June 25, 2015).

4 Ambrosini $(2013,140)$ pinpoints that during the national elections in 2008, "issues of security and the struggle against illegal immigration dominated the campaign and contribute considerably to the overwhelming victory of the Center-Right, which promised 'no more illegal immigration on the doorstep'."

5 See the articles: A. Whitnall. "Defamation Case Opened Against Racist Italian Senator Roberto Carderoli as Abuse of Black Minister Continues." The Independent. July 18, 2013. www.independent.co.uk/news/world/europe/defamation-case-opened-againstracist-italian-senator-roberto-calderoli-as-abuse-of-black-minister-continues-8717391. html (Accessed June 25, 2015); S. Scherer. "Roberto Calderoli, Italian Politician, Compares First Black Minister Cecile Kyenge To Orangutan.” The Huffington Post. July 14, 2013. www.telegraph.co.uk/news/worldnews/europe/italy/11058867/Italian-politicianclaims-he-has-been-cursed-after-orang-utan-remark.html (Accessed June 25, 2015); G. Mezzofiore. "Italian Court Opens Investigation into Roberto Calderoli's Orangutan Slur." International Business Times. July 17, 2013. www.ibtimes.co.uk/italy-opensinvestigation-calderoli-s- racist-orangutan-491340 (Accessed June 25, 2015).

6 See the article: www.stranieriinitalia.it/attualita-calderoli_kyenge_orango_il_ministro_ basta_offese_lega_rifletta_17474.html (Accessed June 25, 2015).

7 Ambrosini $(\overline{2013}, 147)$ explains that the prohibition on playing team games in the park is an example of

[O]pposition to the expression of other cultural features: this includes the prohibition of playing the game of cricket in public parks (Brescia), according to a new regulation that prohibits all team games and other activities, but whose main goal was to suppress an activity that is very popular among Pakistani and Indian immigrants, which produced substantial gatherings on public holidays.

For a complete analysis of these ordinances see Ambrosini 2013. The author identifies five types of exclusion: civil, social, cultural, security, and economic (Ambrosini 2013, 142).

8 R. Franceschi. "Delirio razzista di Gentilini (Lega Nord)." March 2, 2009. www. youtube.com/watch? $\mathrm{v}=\mathrm{bA}-\mathrm{f9}$ i8DYmk (Accessed June 25, 2015). "Leprotti, vagoni piombattie gay. Le 'frasicelebri' dello Sceriffo.” Corriere del Veneto.June 10, 2013. http:// corrieredelveneto.corriere.it/veneto/notizie/politica/2013/10-giugno-2013/leprotti-vagonipiombati-gay-frasi-celebri-sceriffo-2221580964729.shtml (Accessed June 25, 2015).

9 It is important to note that the memberships of these organizations have recently been declining, due at least partly to the financial crisis. See Matteo Trebecchi. 2015. "La crisi taglia le tessere sindacali. Giù gli iscritti fra edili e mecaninci." Il Corriere della Sera. January 29, 2015. http://archiviostorico.corriere.it/2015/gennaio/29/ 
crisi_taglia_tessere_sindacali_Giu_co_0_20150129_9a9d89d0-a780-11e4-a7b96f88 $\overline{6} 246 \mathrm{~d} 6 \overline{5} \mathrm{e} \cdot \mathrm{shtml}$ (Accessed May $10 \overline{10}, \overline{2017}$ ).

10 The percentage of the immigrant workforce that is unionized is even higher than that of Italians in relative terms. In 2011, around $45 \%$ of immigrant workers in Italy were enrolled in a union, compared to around $27 \%$ of the Italian population (Caritas/ Migrantes 2012).

11 Marino explains that the need to create a Migrant Coordination Organization at the regional and local level was officially expressed in 1991 during the XXII Congress of the CGIL, and was formalized in 1992. She describes these organizations as follows:

Composed of immigrants, union delegates, functionaries and workers . . . the Migrant Coordination Organizations aim to favor the participation of immigrants. Their composition guarantees a close contact with the workplace through the union delegates elected by the workers (migrants and not). These figures [i.e. the union delegates] are central in the relationship between immigrant workers and the union, because they function as an active link between the union organization and the workplace.

(Marino 2010, 349; my translation)

It is important also to note that the CGIL was the only traditional trade union to create these organizations.

12 I owe the reconstruction of these phases to the Assessor of Cohesion and Security of the municipality of Reggio Emilia (Interviews in Reggio Emilia on March 3, 2013 and on May 10, 2013).

13 See M. Iervasi. “'Fratelli d'Italia,' DS al fianco degli immigrati. Lo slogan della campagna contro il ddl Bossi-Fini diventerà il nome di una struttura del partito per tutti gli stranieri." L'Unità. January 31, 2002. http://cerca.unita.it/ARCHIVE/ $\mathrm{xml} / 40000 / 36114 . \mathrm{xml}$ ?key $=$ Maristella + Iervasi\&first $=1101 \&$ orderby $=0 \& \mathrm{f}=$ fir (Accessed May 15, 2017).

14 See the official document of the Democratic Party approved on February 26, 2008, on the Forums: article 24, Chapter VI, p. 15. www.partitodemocratico.it/allegatidef/ Statuto\%20PD44883.pdf

15 Regional Law, n. 5/2004 "Norme per l'integrazione sociale dei cittadini stranieri immigrati." http://demetra.regione.emilia-romagna.it/al/monitor.php?urn=er:assemblealegi slativa:legge:2004;5 (Accessed May 27, 2016). Once can also look at the official site of the Emilia-Romagna Region: http://sociale.regione.emilia-romagna.it/immigrati-estranieri/norme/legge-5-2004 (Accessed May 10, 2017).

16 At the time of the formulation of the law, during the regional debate, the possibility of introducing the right to vote for immigrants without citizenship was also discussed, and then dropped out. I owe this insight to the person in charge of immigration policy of the region Emilia-Romagna (Interview in Bologna, July 15, 2013).

17 For an articulated definition of the radical left and its role as a key political actor in Europe, see Cosseron 2007.

18 This reconstruction is mainly based primary sources. I interviewed the main Italian and immigrant members of the anti-racist movement at the national and local levels and collected several documents produced by these organizations.

19 The diocese is an administrative district under the supervision of the bishop. In Italy, the diocese usually corresponds more or less to the territory of the provinces.

20 Even though there is a great territorial variety in the level of investment of Caritas in the processes of inclusion of immigrants, due to different political positions of the main representatives, there is a common interest among all the local Caritas organizations in assisting migrants in Italy.

21 It is also important to explain here the reason why I did not select a region and cities from the South or from the Centre of Italy. Unlike Caponio (2006) and Campomori (2008), and Campomori and Caponio $(2013,2014)$ who tried to represent the "main three areas 
of Italy" by selecting three cities on the basis of their geographic position (Caponio, for instance, selected Bologna for the North, Rome for the Centre, Naples for the South), I opted for a selection on the basis of similarities and also on the stable political orientation of the regions. This choice allowed me to isolate some key factors which could not be controlled in the Centre and South of Italy in which more unstable economies, low levels of industrialization and unionization, a great number of irregular workers, just to name a few, would have immensely affected the reliability of my comparison.

22 The birth of the base trade unions in Italy dates back to 1969-1970, during the Hot Autumn ("Autunno caldo") when masses of workers supported by the radical left opposed decisions taken by the traditional unions. At that time, workers struggled to gain more rights and pressured traditional trade unions to push for the improvement of working conditions. During the struggles, workers organized themselves into Factory Councils (Consigli di fabbrica), which were democratic bodies made up of representatives elected by workers in the workplace, independent of their union membership. The factory councils were strongly criticized by groups of the extra-parliamentary left who accused them of wanting to restrain activism by workers. However, workers themselves wanted the councils to exist and took part in them. It was in this general atmosphere that base trade unions began to develop as autonomous organizations. They developed as a mass organization, able to stand as an alternative to the traditional unions and as a place where those discontented with traditional unions could encounter political militants with an experience of the revolutionary left.

\section{References}

Ambrosini, Maurizio, ed. 2012. Governare città plurali. Politiche locali di integrazione per gli immigrati in Europa. Milano: FrancoAngeli.

Ambrosini, Maurizio. 2013. "'We are Against a Multi-Ethnic Society': Policies of Exclusion at the Urban Level." Ethnic and Racial Studies 36 (1): 136-155.

Amnesty International. 2012. Italy: Exploited Labour: Migrant Workers in Italy's Agriculture. December 18. www.amnesty.org/en/documents/EUR30/020/2012/en/ (Accessed May 27, 2016).

Baldini, Massimo, and Marta Federici. 2011. "Ethnic Discrimination in the Italian Rental Housing Market." Journal of Housing Economics 20: 1-14.

Basso, Pietro, ed. 2010. Razzismo di Stato. Stati Uniti, Europa, Italia. Milan: FrancoAngeli.

Basso, Pietro, and Fabio Perocco, eds. 2003. Gli immigrati in Europa. Disuguaglainze, razzismo, lotte. Milano: FrancoAngeli.

Bellinvia, Tindaro. 2013. Xenofobia, sicurezza, resistenza. L'ordine pubblico in una città "rossa." Il caso di Pisa. Milano: Mimesis edizioni.

Bellu, Gian Maria, ed. 2015. Notizie di Confine. Terzo rapporto Carta di Roma. www. cartadiroma.org/wp-content/uploads/2015/12/Rapporto-2015_-cartadiroma.pdf

Calavita, Kitty. 2005a. Immigrants at the Margins: Law, Race, and Exclusion in Southern Europe. Cambridge: Cambridge University Press.

Calavita, Kitty. 2005b. "Law, Citizenship, and the Construction of (Some) Immigrant 'Others'." Law \& Society Review 30 (2): 401-420.

Campomori, Francesca. 2008. Immigrazione e cittadinza locale. La governance dell'integrazione in Italia. Roma: Carocci.

Campomori, Francesca, and Tiziana Caponio. 2013. "Competing Frames in Immigrant Integration in the EU: Geographies of Social Inclusion in Italian Regions." Policies Studies 34: 163-179.

Campomori, Francesca, and Tiziana Caponio. 2014. "Migrant Reception Policies in a Multilevel System: Framing and Implementation Structures in the Italian Regions." In 
Politics of Immigration in Multi-Level States. Governance and Political Parties, edited by Eve Hepburn and Ricard Zapata-Barrero, 130-149. London: Palgrave Macmillan.

Cannella, Giovanni. 2010. "La Condizione Giuridica dei Lavoratori dopo il "Pacchetto Sicurezza." In Immigrazione e Sindacato. Lavoro, Cittadinanza e Territoti. VI Rapporto, edited by Francesco Carchedi, Francesca Carrera, and Giovanni Mottura, 41-56. Roma: Ediesse.

Caponio, Tiziana. 2005. "Policy Networks and Immigrants' Associations in Italy. The Cases of Milan, Bologna and Naples.” Journal of Ethnic and Migration Studies 31 (5): 931-950.

Caponio, Tiziana. 2006. Città italiane e immigrazione. Discorso pubblico e politiche a Milano, Bologna e Napoli. Bologna: Il Mulino.

Caponio, Tiziana, and Maren Borkert, eds. 2010. The Local Dimension of Migration Policymaking. Amsterdam: Amsterdam University Press.

Caponio, Tiziana, and Teresa M. Cappiali. 2017. "La perdurante questione dei rifugiati e dei migranti" [The persistent question of refugees and immigrants]. In Politica in Italia. Edizione 2017. I fatti dell'anno e le intepretazioni, edited by Alessandro Chiaramonte and Alex Wilson. Bologna: Il Mulino.

Caponio, Tiziana, and Paolo R. Graziano. 2011. "Towards a Security-Oriented Migration Policy Model? Evidence from the Italian Case." In Migration and Welfare in the New Europe, edited by E. Carmel, A. Cerami, and T. Papadopoulos, 105-120. Bristol: The Policy Press.

Caponio, Tiziana, Ferruccio Pastore, and Roberta Ricucci. 2012. "Amministrare l'immigrazione. La difficile simbiositra burocrazia e cittadini stranieri." Rapportidiricerca Fieri. http://fieri.it/2012/09/19/rapporto-di-ricerca-amministrare-limmigrazione-2/

Cappiali, Teresa M. 2015. "Activism and Participation Among People of Migrant Background: Discourses and Practices of Inclusiveness in Four Italian Cities." Political Science. Doctoral diss., Unpublished. Université de Montréal, Montreal. https://papyrus. bib.umontreal.ca/xmlui/handle/1866/13579

Cappiali, Teresa M. 2016. "Activism of Immigrants in Vulnerable Conditions and RadicalLeft Allies: A Case Study of Italy's Struggle of the Crane." Journal of Ethnic and Migration Studies 42 (15): 2508-2527.

Cappiali, Teresa M. 2017a. “' 'Whoever Decides for You without You, He is Against You!' Immigrant Activism and the Role of the Left in Political Racialization." Ethnic and Racial Studies 40 (6): 969-987.

Cappiali, Teresa M. 2017b. "An Italian 'Integration Crisis': The Role of the State and Political Actors in Excluding Immigrants and Ethnic Minorities." In Italy from Crisis to Crisis: Political Economy, Security, and Society in the 21st Century, edited by Matthew Antony Evangelista, 168-198. New York: Routledge.

Cappiali, Teresa M. 2019. "Ideological Affiliations, Conflicts, and Competing Mobilization Frames: The Role of Pro-Immigrant Allies in Shaping Immigrant Struggles for Greater Rights." International Migration Review 53 (3): 869-899.

Caritas/Migrantes. 2012. Immigrazione Dossier Statistico 2012. Rome: Anterem.

Castelli Gattinara, Pietro. 2016. The Politics of Migration in Italy. Perspectives on Local Debates and Party Competition. New York: Routledge.

Cobbe, Luca, and Giorgio Grappi. 2011. "Primo marzo, percorsi di uno sciopero inatteso." In La normale eccezione. Lotte migranti in Italia, edited by Felice Mometti and Maurizio Ricciardi, 55-90. Rome: Edizioni Alegre.

Cosseron, Serge. 2007. Dictionnaire de l'extrême gauche. Paris: Larousse.

Democratici di Sinistra. Area Comunicazione e Formazaione Politica. 2004. Immigrati e Italiani: Il future è convivenza. Convegno del Dipartimento Welfare. Ufficio Immigrazione. Roma, 20-21 febbraio 2004. 


\section{The Italian context and methodology}

De Nardis, Fabio. 2011. "The Failure of the Radical Left Project in Italy: The Case of the Refoundation Communist Party (PRC)." Journal of Politics and Law 4 (2): 36-48.

Diamanti, Ilvo, and Fabio Bordignon. 2001. "Sicurezza e opinione pubblica in Italia." Rassegna Italiana di Sociologia 1: 115-136.

European Union Agency for Fundamental Rights (FRA). 2011. European Union Minorities and Discrimination Survey, Main Results Report. Vienna: European Union Agency for Fundamental Rights. http://fra.europa.eu/sites/default/files/fra_uploads/663-FRA-2011_ EU_MIDIS_EN.pdf

Fasani, Francesco. 2009. Country Report Italy. Country report prepared under the research project CLANDESTINO Undocumented Migration. Counting the Uncountable. Data and Trends across Europe, funded by the 6th Framework Programme for Research and TechnologicaldevelopmentunderPriority 7, 'CitizensandGovernanceina Knowledge-BasedSociety,' Research DG, European Commission. http://irregular-migration.net/typo3_upload/ groups/31/4.Background_Information/4.4.Country_Reports/Italy_CountryReport_ Clandestino_Nov09_2.pdf

Gall, Gregor. 1995. "The Emergence of a Rank and File Movement: The Comitati di Base in the Italian Worker's Movement." Capital \& Class 19 (1): 9-20.

Garbaye, Romain. 2005. Getting into Local Power: The Politics of Ethnic Minorities in British and French Cities. Oxford: Blackwell.

Geddes, Barbara. 1990. "How the Cases You Choose Affect the Answers You Get: Selection Bias in Comparative Politics." Political Analysis 2: 131-150.

International Organization for Migration (IOM). 2010. "Stagione amara": Rapporto sul sistema di ingresso per lavoro stagionale e sulle condizioni dei migranti impiegati in agricultura in Campania, Puglia e Sicilia. December 2010.

Istat. 2013. Gli stranieri al 15o Censimento della Popolazione. www.istat.it/it/files/2013/12/ Notadiffusione_stranieri20122013.pdf

Ministry of Labor and Social Policies. 2014. Quarto rapport annual. Gli immigrati nel mercato del lavoro italiano. Italy. www.integrazionemigranti.gov.it/Attualita/News/Documents/IV RAPPORTO_MDL_ITA_ENG_ALTRELINGUE/IV_Rapporto_annuale_MdL_immigrati_ 2014.pdf

Khouma, Pap. 2010. Noi italiani neri. Storia di ordinario razzismo. Milan: Baldini Castoldi Dalai.

Kosic, Ankica, and Anna Triandafyllidou. 2005. Active Civic Participation of Immigrants in Italy. Country Report prepared for the European Research Project POLITIS. Oldenburg. www.ubi-oldenbrug.de/politis-europe

Mantovan, Claudia. 2007. Immigrazione e Cittadinanza. Auto-organizzazione e Partecipazione dei Migranti in Italia. Milan: FrancoAngeli.

Marino, Stefania. 2010. "Le strutture specifiche per la rappresentanza dei lavoratori migranti: un confronto tra Italia e Olanda." In Immigrazione e Sindacato. Lavoro, cittadinanza e territori. VI Rapporto, edited by Francesco Carchedi, Francesca Carrera, and Giovanni Mottura, 337-352. Roma: Ediesse.

Marques, M. Margarida, and Rui Santos. 2004. "Top-Down and Bottom-up Reconsidered: The Dynamics of Immigrant Participation in Local Civil Society." In Citizenship in European Cities: Immigrants, Local Politics and Integration Policies, edited by Rinus Penninx, Karen Kraal, Marco Martiniello, and Steven Vertovec, 107-125. Aldershot: Ashgate.

Messina, Patrizia. 2001. Regolazione politica dello sviluppo locale. Torino: Utet.

Morén-Alegret, Ricard. 2002. "Gobierno Local e immigracion extranjera. Aproximacion a los casos Barcelona y Lisboa durante los anos 90.” Migraciones 11: 25-81. 
Mottura, Giovanni. 2010. "Immigrazione e crisi economica. Spunti di riflessione per una future ricerca." In Immigrazione e Sindacato. Lavoro, cittadinanza e territori. VI Rapporto, edited by Francesco Carchedi, Francesca Carrera, and Giovanni Mottura, 25-40. Roma: Ediesse.

Mottura, Giovanni, Silvia Cozzi, and Matteo Rinaldini. 2010. Uscire da Babele. Percorsi e problemi del rapporto tra sindacato e lavoratori immigrati. Rome: Ediesse.

Mottura, Giovanni, and Pietro Pinto. 1996. Immigrazione e cambiamento sociale. Strategie sindacali e lavoro straniero in Italia. Rome: Ediesse.

Oliveri, Federico. 2012. "Migrants as Activist Citizens in Italy: Understanding the New Cycle of Struggles." Citizenship Studies 16 (5-6): 793-806.

Oliveri, Federico. 2018. "Racialization and Counter-Racialization in Times of Crisis: Taking Migrant Struggles in Italy as a Critical Standpoint on Race." Ethnic and Racial Studies 41 (10): 1855-1873.

Organization for Economic Cooperation and Development (OECD). 2014. Lavoro per gli immigrati. L'integrazione nel mercato del lavoro in Italia. OECD Publishing. www.oecd. org/els/lavoro-per-gli-immigrati-9789264216570-it.htm (Accessed September 10, 2016).

Palidda, Salvatore. 2011. "The Italian Crime Deal.” In Racial Criminalization of Migrants in the 21st Century, edited by Salvatore Palidda, 164-175. Milan: Agenzia X.

Penninx, Rinus, Karen Kraal, Marco Martiniello, and Steven Vertovec, eds. 2004. Citizenship in European Cities: Immigrants, Local Politics and Integration Policies. Aldershot: Ashgate.

Penninx, Rinus, and Judith Roosblad, eds. 2000. Trade Unions, Immigration and Immigrants in Europe 1960-1993. Amsterdam: Berghahn Books.

Però, Davide. 2007. Inclusionary Rhetoric/Exclusionary Practices: Left-Wing Politics and Migrants in Italy. Oxford: Berghahn.

Perocco, Fabio. 2003. "L'apartheid Italiano." In Gli immigrati in Europa. Diseguaglianze, razzismo, lotte, edited by Pietro Basso and Fabio Perocco, 211-233. Milan: FrancoAngeli.

Pew Research Center. 2007. The Pew Global Attitudes Projects. www.pewglobal. org/2007/10/04/world-publics-welcome-global-trade-but-not-immigration/

Pew Research Center. 2016. Report: Europeans Fear Wave of Refugees will Mean More Terrorism, Fewer Jobs. www.pewglobal.org/2016/07/11/europeans-fear-wave-of-refugeeswill-mean-more-terrorism-fewer-jobs/

Pilati, Katia. 2010. La partecipazione politica degli immigrati: Il caso di Milano. Rome: UNAR.

Pojmann, Wendy. 2006. Immigrant women and feminism in Italy. Burlington: Ashgate/ Aldershot.

Putnam, Robert D. 1993. Making Democracy Work: Civic Traditions in Modern Italy. Princeton: Princeton University Press.

Ragusa, Stefania. 2011. Le Rosarno d'Italia. Storie di ordinaria ingiustizia. Firenze: Vallecchi.

Raissiguier, Catherine. 2010. Reinventing the Republic: Gender, Migration, and Citizenship in France. Stanford: Stanford University Press.

Region Emilia-Romagna. 2004. Legge Regionale n. 5/2004 "Norme per l'integrazione sociale dei cittadini stranieri immigrati." http://demetra.regione.emilia-romagna.it/al/ monitor.php?urn=er:assemblealegislativa:legge:2004;5 (Accessed May 27, 2016).

Reyneri, Emilio. 1998a. "The Role of the Underground Economy in Irregular Migration to Italy: Cause and Effect?” Journal of Ethnic and Migration Studies 24 (2): 313-331. 


\section{The Italian context and methodology}

Reyneri, Emilio. 1998b. "The Mass Legalization of Migrants in Italy: Permanent or Temporary Emergence from the Underground Economy?" South European Society and Politics 3 (3): 83-104.

Rossi, Emanuele, Francesca Biondi dal Monte, Massimiliano Vrenna, eds. 2013. La governance dell'immigrazione. Diritti, politiche e competenze. Bologna: Il Mulino.

Triandafyllidou, Anna, and Maurizio Ambrosini. 2011. "Irregular Immigration Control in Italy and Greece: Strong Fencing and Weak Gate-Keeping serving the Labor Market." European Journal of Migration and Law, 13 (3): 251-273.

Turco, Livia. 2005. I nuovi Italiani. L'immigrazione, i pregiudizi, la convivenza [The New Italians. Immigration, Prejudice, and Cohabitation]. Milano: Mondadori.

Zaslove, Andrej. 2006. "The Politics of Immigration: A New Electoral Dilemma for the Right and the Left?" Review of the European and Russian Affairs 2 (3): 10-36.

Zincone, Giovanna. 1998. "Illegality, Enlightenment and Ambiguity: A Hot Italian Recipe." South European Society and Politics 3 (3): 43-82. 


\title{
2 A theoretical model of local dynamics
}

\author{
Alliances and conflicts in context
}

In this chapter, I present a theoretical model of local dynamics, focusing on alliances and conflicts in context, to examine the complexity of immigrant mobilizations and forms of participation of immigrant activists in cities. This model, I argue, helps explain the link between local dynamics and variations in civic and political participation of immigrant activists. The chapter starts with a description of the three main literatures this study draws from and contributes to - namely, migration studies, social movements, and critical social theory. Subsequently, I proceed by introducing my theoretical model of local dynamics, by reconceptualizing cities through an actor-oriented approach. The model I have developed articulates two key concepts: namely the local realm of immigration and approaches to inclusion. I define these two concepts and explain how they allow constructing the theoretical model. Subsequently, I set out how four key factors and mechanisms identified work dynamically together to shape the forms of participation and rights claims in the four cities. While I have developed the model through an inductive approach to the field and a comparative analysis of the four cities, I present the model prior to the empirical chapters to demonstrate its analytical leverage in understanding the diverging outcomes beyond the cities analyzed. The empirical chapters that follow will illustrate how the model works in the four cities and give evidence of its relevance. It is my claim that the theoretical model can be used to study alliances and conflicts around immigration issues in other cities in Italy and beyond.

\section{Explaining alliances and immigrant activism}

\section{Beyond the political opportunity approach in the migration field}

Over the past three decades, the literatures on citizenship, migration studies, and social movement theories concerned with immigrant activism have shown that the receiving society plays an important role in shaping the institutional and political opportunities for participation and mobilization (Bloemraad 2006; Ireland 1994; Koopmans 2004; Soysal 1994). This framework, known as the institutional or political opportunity approach, shows that context matters and that immigrants' participation trajectories are shaped by "political opportunities," particularly 
institutional factors, such as legislative, institutional, and/or political discourses and practices of inclusion (e.g., immigration and labor laws). These factors are relevant in shaping civic participation, including the formation and characteristics of immigrant associations (Martiniello 2009; Pilati 2010), conventional politics such as voting and running for elections (Hochschild et al. 2013), and less conventional politics like protests and grassroots mobilizations (Koopman and Statham 2000; Giugni and Passy 2004). ${ }^{1}$

Moreover, the same literature has been further enriched by what has been called the "local turn" in the study of migration (Penninx et al. 2004). In particular, scholars in the fields of political sciences and sociology have examined how local political opportunities and constraints can explain variations of civic and political participations of immigrant groups across cities. Much of this research focuses on the role of institutional actors and top-down dynamics. It explains that participatory forms and mobilizations are characterized by a great variety of responses that differ depending on specific local political opportunities (Koopmans 2004; Garbaye 2005; Caponio 2006; Morales and Giugni 2011).

The main contribution of this approach is to explain that an "open" institutional context, when incentives are offered by institutional actors, are key in promoting immigrants' civic and political participation at the national and local levels (Ireland 1994; Giugni and Passy 2004; Koopmans 2004; Morales and Giugni 2011; Hochschild et al. 2013). Closed and hostile national environments, on the contrary, raise structural barriers to the civic and political participation of immigrants and new citizens. From this perspective, mobilizations of vulnerable immigrant groups in hostile environments are deemed unlikely, as immigrants are exposed to increased surveillance and tough deportation regimes, and the cost of mobilization becomes prohibitively high (della Porta 2018; Nicholls 2014; Oliveri 2012; Siméant 1998).

As Voss and Bloemraad (2011) observe, from a political opportunity perspective, the mass mobilizations of Latinos that began in 2006 in the United States, in response to the introduction of restrictive immigrant legislations, were "theoretically puzzling." Scholars using the political opportunity approach would have predicted a lack of participation, because under these circumstances, opportunities for participations would be minimized by fear, state repression, and anti-immigrant rhetoric (Koopmans 2004; Giugni and Passy 2004). Yet, counter-intuitively, the Latinos' mobilization reveals that the presence of a major "threat" can trigger mobilizations on the part of vulnerable immigrants and their pro-immigrant supporters, encouraging the development of new alliances and forms of participation as well as new demands for inclusion (Zepeda-Millán 2017; cf. Nicholls 2014, 24). In particular, there is growing research demonstrating that immigrant mobilizations occur precisely in response to hostile actions, such as detention and deportation (Nyers and Rygiel 2012), the criminalization of the undocumented by new legislation (Cappiali 2016; Zepeda-Millán 2017), and increases in immigrant exploitation during economic recessions (Oliveri 2012, 2018). Prohibitory changes, this research suggests, activate the will of immigrant groups to fight to improve their rights, because they affect the lives and working conditions of 
immigrants and their families (Cappiali 2016; Nicholls 2013; Oliveri 2012; Raissiguier 2010; Siméant 1998; Zepeda-Millán 2017).

While the political opportunity approach helps us explain how institutional or top-down dynamics affect why immigrant groups may or may not mobilize and how, it explains bottom-up dynamics less well. Bottom-up dynamics are complex interactions by multiple actors, particularly civil society organizations (e.g., the Catholic Church, trade unions, grassroots organizations, and radical left organizations) and immigrant groups, that shape participation and rights claims. I argue that we need to complement the top-down, institutional perspective with a bottom-up, actor-oriented approach. Doing so helps us analyze the conflicts and alliances between multiple actors (immigrant activists and pro-immigrant groups) and their impact to account for variations in participation outcomes. As I show in the following section, pro-immigrant groups can play a crucial role in aiding immigrant mobilizations as their symbolic and material resources reduce the cost of mobilization (Zepeda-Millán 2017; della Porta 2018) and can, at the same time, hinder or affect negative immigrant claims for greater rights, via mechanisms of silencing and marginalization.

\section{Social movement research: ideology, conflicts, and alliances in hostile environments}

The field of social movements exposes limitations of the political opportunity approach used in the migration field, and it better theorizes the interaction between structural and agential factors (Tilly and Tarrow 2015). As some leading scholars in the field argue, while structural factors can trigger mass mobilizations (della Porta and Diani 2011), they cannot fully explain how alliances among mobilized groups are constructed and why mobilizations vary across contexts (Tarrow 2011). I turn, therefore, to the scholarship in the field of social movements focusing on the role of agential dynamics.

Studying social movements illuminates interactions among actors and the processes of coalition building, meaning construction, and alliances with outsider actors like political parties and trade unions (della Porta and Diani 2011; Tarrow 2011). Using a network theory perspective, several scholars point to the importance of mobilizing structures and the web of organizations that makes mobilization possible (della Porta 2018). Diani and McAdam (2004), for example, observe that activists develop complex networks and that the nature of their relations affects their ability to mobilize. In other words, how different groups interact, create coalitions, and seek compromises around common goals strongly influence mobilizations (della Porta and Diani 2011, 226). Movements are often composed, however, of many organizations pursuing profoundly different strategies and goals (Diani 1997; Benford and Snow 2000). As Benford (1993) notes, "frame disputes" within movements can lead to their weakening and sometimes even block coalitions from forming between groups who, in principle, have shared goals. These dynamics and power struggles are further complicated when these interactions and conflicts involve the promotion of rights of more vulnerable 
groups - such as immigrants in receiving societies. These latter are often found in a "weaker" position and their goals and demands can be silenced by the struggle for legitimacy of pro-immigrant actors (Cappiali 2019).

Studies focusing more specifically on immigrant social movements show that, under similar national and local conditions, immigrant mobilizations may take place in some urban settings but not in others, suggesting that something other than institutional factors is impacting immigrant collective action (Monforte and Dufour 2011; Steinhilper 2021). In these instances, the creation of alliances between pro-immigrant and immigrant groups is crucial. Research shows that, by offering material and symbolic support, pro-immigrant groups in a receiving society play a vital role in opening up opportunities for immigrant participation and in determining favorable mobilization outcomes (Cappiali 2016, 2019; della Porta 2018). These supporters, moreover, become crucial allies and play a key role in developing positive narratives about the role of immigrants in receiving societies, especially when public opinion and political actors turn toward nativist and xenophobic rhetoric framing immigrants as an "economic burden" or "security threat" (d'Appollonia 2015). Their efforts, therefore, represent what Nicholls (2013) calls "niche openings," which favor mobilizations even amid constraining and hostile environments. As della Porta $(2018,4)$ explains, "Networks of supporters are particularly relevant for the mobilizations around resource-poor groups in protest campaigns often involving broad coalitions of various players, interacting in different settings, reflecting some characteristics of already mobilized social movements." The presence of "allies" can also increase individuals' expectations of succeeding and, thus, immigrant willingness to mobilize in the first place, even though their status and vulnerability remain the same. With the support of a strong "platform of advocacy," immigrants in very vulnerable conditions may be ready to face the most challenging environments and even risk deportation (Raissiguier 2010; Cappiali 2016). ${ }^{2}$

While previous research investigates why and how pro-immigrant groups matter in advocating for immigrant rights, especially when vulnerable immigrants succeed in mobilizing under very hostile context (Monforte and Dufour 2011; Cappiali 2016; de Graauw 2016), there is less knowledge of the ways in which pro-immigrant groups may hinder immigrant rights claims and mobilizations. Yes, this is an important question if we want to understand variations in political mobilizations as well as how these mobilizations occur (Cappiali 2019). Ideological and political conflicts - as well as the different "framings" of working and living conditions of immigrants in the receiving society - undermine possibilities for participation and coalitions between immigrants and "native-born" organizations (Mantovan 2007; Cappiali 2019). Also, studies suggest that immigrant allies frequently adopt opportunistic approaches, including paternalistic or instrumental attitudes toward immigrant activists, and there is empirical evidence that these actors often tend to racialize immigrant activists — with many insisting on speaking on their behalf (Cappiali 2017, 2019).

Moreover, previous research suggests that bringing heterogeneous groups together becomes even more challenging when mobilizations are organized for 
and with vulnerable groups, as supporters are often divided along ideological lines regarding the best strategies to end a group's exclusion or exploitation (Cappiali 2019; della Porta 2018; Zamponi and Castelli Gattinara 2020). Studies show that alliances are not easy to create and maintain; they are often complicated (Cappiali 2019) and involve difficult negotiations and conflicts around framing the issues of migration (Nicholls 2013), as well as the silencing and marginalization of immigrant activists (Cappiali 2017, 2019). These groups can obstruct immigrants' participation and claims by adopting processes of tokenism and neutralization (Martiniello 2005), by disempowering immigrant organizations, and by instrumentalizing them for political purposes (Cappiali 2017). The literature on social movements and intersectional coalitions, moreover, shows that structural privilege and disadvantage (as well as recognition or denial of power dynamics and privileges) influence the dynamics within the same coalition (Evans and Lépinard 2020). Lépinard (2020), in particular, pushes research in the field of social movements and migration, by providing sound evidence of the saliency of "racialization" of non-white feminist activists by feminist groups. She analyzes the key role of asymmetrical power relations between "white" and racialized feminists and how racialized feminist challenge "white" feminists' denial of greater recognition in the feminist movement.

In this book, I will build on this field of research to examine how immigrant activism is affected by power dynamics and complex interactions with "white" groups, and under what conditions they are able to speak for themselves and shape their own struggles in their interaction and conflicts with their supporters. In order to do so, I turn to critical social theories, and especially critical race and postcolonial studies.

\section{The othering of immigrants by pro-immigrant actors and resistance}

This study applies a critical lens to citizenship and migration and race and ethnic relations to study interactions between immigrant activists and their Italian supporters. "Critical" social theories are epistemological postures and strategies of analysis of political and social relations that scrutinize the role of ideology, power, and domination in producing unequal treatment and marginalization in societies. Dynamics of inclusion and exclusion are shaped by unequal and hierarchical power relations, including the positions of actors and their interactions in receiving societies (Lépinard 2020). Immigrant and racialized activists resist these processes and promote their inclusion in society through their activism (Cappiali 2017; Lépinard 2020).

Race, intersectional, and post-colonial studies explain the persistence and salience of processes of othering by showing why and how some groups are marginalized across time and space, as well as how they can resist the discourses and practices that oppress them (Evans and Lépinard 2020; Lépinard 2020). By looking at oppression of immigrants and racialized groups via their own perspectives and experiences one can theorize power and processes of othering from below (see, e.g., Bilge and Collins 2018; Sager 2011; Mulinari 2015). Moreover, the 
same epistemological position offers a unique opportunity to theorize the resistance and agency of marginalized groups (Bilge and Collins 2018; Sager 2011; Mulinari 2015), and in particular why and how these groups speak back to power in the way that they do (hooks 1989, 2015; Raissiguier 2010).

I borrow three key concepts from existing scholarship in critical race and postcolonial studies.

The first is racism. This is a key principle for social organization in Western democracies, and it is maintained and reproduced by laws and policies as well as racist ideology (Kendi 2019; Omi and Winant 2015). Here, I follow Kendi's definition of racism:

Racism is a marriage of racist policies and racist ideas that produces and normalizes racial inequities. . . Racial inequity is when two or more racial groups are not standing on approximately equal footing .... A racist policy is any measure that produces or sustains racial inequity between racial groups. By policy, I mean written and unwritten laws, rules, procedures, processes, regulations, and guidelines that govern people. There is no such thing as a nonracist or race neutral policy. Every policy in every institution in every community in every nation is producing or sustaining either racial inequity or equity between racial groups.

(Kendi 2019, 18-19)

Kendi's definition is relevant for this book, because it allows defining as "racist" not only open policies, regulations, and ideologies hostile to immigrants, but also those policies, ideologies, and practices, that have undermined immigrants' equal treatment and inclusion in society and have, as a result, contributed to reproducing exclusion and inequality of particular groups, namely, citizens and non-citizens of migrant background. As this book will show, most pro-immigrant actors in Italy, through their discourses and practices, and despite their different political views on immigration issues, have wittingly or unwittingly, and for various reasons, failed to actively make efforts to remove obstacles for immigrant exclusion in their organizations and in society. Moreover, in some cases, despite their claims of inclusiveness, they have developed mechanisms that have actively produced unequal treatment of immigrants.

The second key sociological concept of this study is racialization, the process of attributing social meaning to human bodies (Fanon 1967; Omi and Winant 2015). Here, I follow two American critical race theorists, Omi and Winant. Racial inequality is not only based on constructed differences of ethnicity, appearance, origin, culture, and language but is also attached to classifications of people on the basis of their skin color and who are considered different and inferior because of their phenotypical characteristics ("people of color"). These perceived differences are historically rooted in colonialism and white supremacy and are constantly reactivated over time across geographical contexts (Omi and Winant 2015). This makes it easier to justify and support unequal and differential treatment and abuses toward historically inferiorized groups. ${ }^{3}$ In this view, it can be 
argued, that mass migration in recent years has served to re-activate and expose pre-existing forms of racism, rather than producing new instances. ${ }^{4}$

In this book, I use the term racialization rather than race, because I want to put more emphasis on the processual nature of meaning construction. However, as Omi and Winant (2015) also explain, the concept of race is not to be understood as fixed either. It does not make sense as a biological category, it is still relevant as a social category as race is socially and politically constructed across time and space. As these authors point out, race continues to signify and symbolize social conflicts and interests. Thus, concepts referring to race, such as "white", "nonwhite" and "people of color" are relevant within so-called "post-racial," "colorblind" societies, because it continues to play a fundamental role in structuring and representing the social world (Omi and Winant 2015). Racialization is a relation of power and indicates how discourses and practices are structured across "racial" lines allocating power and resources.

The third key concept, closely connected to racialization, is othering: a vital concept in understanding power dynamics and processes of meaning construction, especially that of inferiorizing immigrant groups. Othering is a process of constructing some immigrant groups as "not deserving" and producing unequal treatment and marginalization on the basis of this construction. El-Tayeb (2011) explains that the othering of immigrants and immigrant communities is reflected in complex processes of marginalization of immigrants in receiving societies. "To be in the margin," to quote bell hooks, "is to be part of the whole but outside the main body" (hooks 2015, xvii). By connecting this reflection with racialization, here I understand othering as a process that constructs racialized groups (or "people of colors"), and especially non-EU immigrants, as inferior, and that puts them in a position not of complete exclusion, but of marginality in society, as part of the whole, but outside the main body.

This study echoes the important work of post-colonial scholars, who have shown why and how Western civilization produces its Other. Saïd $(1978,12)$ writes: "ideas, cultures, and histories cannot seriously be understood or studied without their force, or more precisely their configurations of power also been studied." Said explains that the Other, under the colonizer's gaze, became the representation of the "West" in its own terms. Spivak (2010) further argues that the result of the "West" representing and defining the "Non-West" on its own terms was "to constitute the colonial subject as Other" and thus as someone that could be colonized. Thus, the process of othering, by which the West is defined as the norm and non-West cultures/peoples as deviations from the norm, implies the dehumanization and inferiorization of other cultures/peoples (Said 1978; Spivak 2010), including non-Western immigrants residing in European countries.

Applying critical social theories to the fields of citizenship, migration, and social movement studies, this book pushes the boundaries of existing research on migrant mobilizations and racialization in Europe. The critical lens allows me to show that anti-immigrant policies and ideologies are not the only factors in producing racialization of immigrants in society: pro-immigrant groups from across the whole political spectrum can also contribute, overtly and covertly, to othering 
immigrant activists and marginalize migrant populations and their descendants in receiving societies. Moreover, through this lens, it is possible also to better explain that why and how immigrant activists mobilize to make right claims in society is also largely affected by their attempt to resist processes of othering and racialization by pro-immigrant groups claiming to support their cause.

\section{An actor-oriented approach}

Migration scholars in the fields of political science, sociology, and anthropology have long argued that the city is where the inclusion and exclusion of people of migrant background is de facto negotiated (Caponio et al. 2018; Caponio and Borkert 2010; Glick Schiller and Çağlar 2011; Good 2009). Existing studies have analyzed existing variations in forms of civic and political participation of immigrant activists at the local level, across states, and within states (Penninx et al. 2004; Jones-Correas 2001). Immigrant mobilizations, moreover, are characterized by a great variety of responses that differ depending on specific local political opportunities (Koopmans 2004; Garbaye 2005; Caponio 2006; Morales and Giugni 2011). Much of this scholarship typically focuses on the role of institutional actors and top-down dynamics and understates the role of plural actors and their interactions in shaping immigrant activism (Cappiali 2016). However, sociological and anthropological literature has crucially redefined our understanding of how cities allow immigrants to experience "citizenship in practice" or "active citizenship" through their involvement in the civic and political life of the city (Penninx et al. 2004; Reed-Danahay and Brettell 2008).

Following this insight, in the 2000s, migration scholars in Europe promoted a "local turn" in the study of migration (Caponio and Borkert 2010). The book Citizenship in European Cities (2004), edited by Penninx et al., offers empirical and theoretical insights into the role of local contexts in shaping civic and political participation of people of migrant background in European cities. It examines the relationship between local government policies and the participation of immigrants and minorities from a comparative perspective. It also attempts to move beyond an overly narrow conceptualization of actors in cities. The authors explain that a focus on local contexts helps us to move beyond the mainstream political system (barred to most non-nationals) and consider the "practices of citizenship." Because "many immigrants or ethnic groups in European cities do not enjoy the legal status of national citizenship and are thus excluded from the formal political system," they suggest that we look at local governments, which "may have granted alternative opportunities to influence the politics and policies that affect them" (Penninx et al. 2004, 7). The authors add that "the concept of local-level citizenship" allows us to examine "formal, informal, and parallel channels" of participation (Penninx et al. 2004, 7), and to see how mobilization by people of migrant background occurs in practice (Ibid., 8).

Civic and political participation, the literature suggests, results from the interaction between local contextual factors and immigrants' initiatives - a conceptualization that emphasizes the agency of a plethora of actors (Penninx et al. 2004; 
see in particular the chapter by Marques and Santos 2004 for cities in Southern Europe). Moreover, while social movement scholars emphasize the role of cities as "relational incubators" (Nicholls and Uitermark 2016, 25), and argue that cities create the proximity needed to build trust among immigrants and their supporters to develop immigrant mobilizations (Chimienti 2011; Monforte and Dufour 2011), critical social theories, and especially critical race and post-colonial studies, allow us to zoom in power dynamics between "native-born" (or "white" supporters) and immigrant activists, and to identify processes of racialization by pro-immigrant groups, and resistance to these processes by immigrant activists.

As mentioned previously, I adopt an actor-oriented approach to build my theoretical model of local dynamics. This approach focuses on the role of agency and interactions among pro-immigrant and immigrant actors and seeks to account for how conflicts and alliances impact the participatory outcomes of immigrant activists. I re-conceptualize the "context" in which immigrant activists mobilize and look into how alliances and conflicts between pro-immigrant and immigrant actors affect participation outcomes. This approach allows me to develop a more fine-grained sociological analysis of the opportunities and constraints immigrant activists face when they formulate demands to promote their rights (see also Però 2008). I enlarge the local political arena to include the whole spectrum of pro-immigrant actors involved in processes of inclusion in cities - namely local authorities, the Catholic Church, trade unions, church-based organizations, political parties, and non-institutional actors, such as informal lay organizations, grassroots trade unions, and social movements of the radical left - and the variety of individual immigrant activists and immigrant organizations active in each city.

\section{Two key concepts to build the model: local realm of immigration and approaches to inclusion}

As I anticipated earlier, I have elaborated two key concepts to analyze local dynamics. The first key concept is the "local realm of immigration." I developed this concept through my reading of the social movement literature and Mantovan's (2007) study on three Italian cities (see also Cappiali 2016). ${ }^{5}$ The concept of "realm" refers to a structured space of relations created by the involvement of local actors on issues of immigration and immigrant inclusion. It postulates that local dynamics on these matters are the result of interaction between these actors. This concept moves us beyond the idea that the context is a given to identify both which actors matter and how they promote inclusion in different local arenas by way of their interactions (Cappiali 2018). Through this concept, the focus is not on the configurations of power and local actors in general but on which actors matter in specific local contexts and how they mobilize to promote immigrants' inclusion. Beyond simply identifying actors, it offers a particular way of thinking about their roles in framing and structuring opportunities and constraints for immigrant participation through their discourses and practices. Moreover, the concept allows one to grasp variations across cities, precisely because it does not determine in advance what actors matter when it comes to immigration/inclusion issues. Instead, it leaves 
such questions open to the empirical investigation: what actors matter, how, and to what extent- these are the result of complex interactions.

In the case of the cities studied here, this conceptualization enabled me to not only map the actors that mattered but also explain why and how they mattered (on the analysis of cities using a case-by-case approach, see, e.g., Pastore and Ponzo 2016). Furthermore, it also helped me to consider immigrant activists as part of the same interaction, and as potentially relevant players. Overall, this concept is compatible with my commitment to overcoming the political opportunities approach in migration studies and moving beyond the structure/agency dichotomy by considering the role of context from a dynamic, actor-oriented perspective.

The second key concept of the model is approaches to inclusion. This concept is linked to the first and puts an emphasis not only on what local actors do to encourage immigrants' greater inclusion in society but also on how and why they do so (see Cappiali 2018). It refers to how local actors understand and frame migration and the inclusion of people of migrant background, based on ideological and strategic considerations, and how this understanding affects their discourses and practices. It is not just concerned with what actors do to promote inclusion (e.g., what type of local policies or services have been created), but how they do this. In this respect, the concept speaks to how immigrants are constructed as a "subject of inclusion" through discourses and practices by pro-immigrant groups. Through this construction, we can grasp why and how local actors frame and promote a certain approach to include immigrants and what type of inclusion they facilitate or hinder. ${ }^{6}$

Examining approaches to inclusion reveals how power is involved to legitimize the work of pro-immigrant groups in the local realm of immigration and why and how immigrant voices are encouraged, channeled, or marginalized in specific ways. The approaches they adopt, in turn, affect (directly or indirectly) the civic and political participation of immigrants, as well as their rights claims, and which groups of immigrants and rights claims are more likely to be made visible. At the same time, these dynamics affect immigrants' engagement in the city, and how they interact with pro-immigrant actors. Here, trust emerges as a key aspect of the analysis and determines whether pro-immigrant actors will be considered allies or not by immigrant activists.

As will become clearer in the empirical chapters (Chapters 3 to 7) and the Conclusion, the use of this conceptual apparatus has several advantages. First, focusing on an actor-oriented analysis, the concept of the local realm of immigration makes it possible to study actors and actions and to go beyond the structure/agency dichotomy implied by most literature in the field. In particular, it affords an understanding of cities as dynamic contexts shaped by actors' interaction. From this perspective, it allows us to grasp mechanisms and processes at work and thus to examine interactions in a dynamic rather than a static way. Second, it allows an understanding of the role of pro-immigrant groups and immigrant activists in context. The reasons pro-immigrant actors adopt one "approach to inclusion" rather than another is affected by ideological and practical considerations. While church-based organizations, for instance, tend to depict migrants as poor and in need of specific services, left-wing actors, such as trade unions and anti-racist movements, tend to promote empowerment and self-determination in addition to delivering services 
(Campomori 2008; see also Mantovan 2007, 147). These actors promote different approaches to inclusion depending on their ideological affiliations. Therefore, it is likely to find similar approaches in the cities where these actors are present.

Yet, the conceptual apparatus allows us to look into complex power dynamics and to explain why these approaches vary across cities as the local realm of immigration is the result of interactions of actors. Third, the new conceptual apparatus helps us to study the actions of immigrant activists within their interaction with pro-immigrant actors and to break with the idea that they are external to existing dynamics of power. Finally, the inductive strategy is coherent with my postulate that the role of local actors in shaping participation is an open question that must be assessed empirically, case by case. In addition to identifying actors, I offer an account of how their framing of migration and inclusion issues, and their interactions with immigrant activists, structure opportunities for participation. Furthermore, I grasp analytically how immigrant communities take part in the local interaction as potentially relevant players, by challenging, among others, pro-immigrant groups who tend to silence their voices.

\section{Three approaches to inclusion and implications for participation}

Using an inductive approach in the four cities analyzed, I have identified three main approaches to inclusion, or ideal types - namely assistance, intercultural, and political rights promotion - and I have laid out the implications of each approach for participation. As will become clear, in large part these approaches are linked to the ideology of the actors who promote them and they have, either directly or indirectly, an impact on the participation of immigrant activists (see Table 2.1).

Table 2.1 Three approaches to inclusion and their implications for participation

\begin{tabular}{|c|c|c|c|}
\hline Approaches & Characteristics & Ideology of actors & $\begin{array}{l}\text { Implications for opening } \\
\text { channels for participation }\end{array}$ \\
\hline Assistance & $\begin{array}{l}\text { Immigrants are } \\
\text { in need }\end{array}$ & $\begin{array}{l}\text { Catholic Church and } \\
\text { Christian -democrat } \\
\text { trade unions }\end{array}$ & Obstacles to participation \\
\hline Intercultural & $\begin{array}{l}\text { Immigrants are } \\
\text { would-be } \\
\text { citizens and } \\
\text { "inclusion" is } \\
\text { reciprocal }\end{array}$ & $\begin{array}{l}\text { Left-wing } \\
\text { administrations } \\
\text { and lay } \\
\text { organizations }\end{array}$ & $\begin{array}{l}\text { Promotion of civic } \\
\text { channels }\end{array}$ \\
\hline $\begin{array}{l}\text { Promotion of } \\
\text { political rights }\end{array}$ & $\begin{array}{l}\text { Immigrants } \\
\text { are entitled } \\
\text { to political } \\
\text { rights, } \\
\text { independent } \\
\text { of their } \\
\text { formal status }\end{array}$ & $\begin{array}{l}\text { Moderate and } \\
\text { radical left } \\
\text { (Political parties and } \\
\text { radical groups/ } \\
\text { movements) }\end{array}$ & $\begin{array}{l}\text { Promotion of } \\
\text { conventional channels } \\
\text { by moderate actors } \\
\text { Promotion of non- } \\
\text { conventional channels } \\
\text { by more radical actors }\end{array}$ \\
\hline
\end{tabular}


However, as will be explored further, once they are observed in the context of the local realm of immigration, their combination and interaction exhibit a complex role in shaping participation across cities. The conclusion of this chapter and the empirical analysis of the four cities will establish the relevance of these three approaches in shaping local dynamics. It is important to highlight that, although the approaches identify here are drawn from an in-depth study of four cities, my research suggests that in other Italian cities, where similar actors are in place, one can expect to find the same ideal types. At the same time, other approaches may exist in other cities in Italy and beyond. Yet, by making explicit the criteria and steps I use to identify the ideal types and to build the theoretical model make the model applicable to other contexts. The concluding chapter of this book will suggest how the model can be integrated into future research on immigrant participation beyond the case of Italy.

\section{The assistant approach}

The assistant approach is based on the idea that immigrants are "in need" and it refers to intervention by state and non-state actors to promote "social protection," through the delivery of services and advocacy on behalf of immigrants in vulnerable conditions. A clear example of the predominance of this approach is the direct association of inclusion policies with social services. The assistance approach is the dominant approach to inclusion in Italy, as it goes hand in hand with the country's continued treatment of migration as a temporary phenomenon and its focus on welfare delivery (Campomori 2008, 32). Given the lack of substantial state intervention in support of immigrants' needs since the beginning of the 2000s, non-state organizations have developed this approach to respond to the vulnerable conditions of immigrants in the country. This approach, moreover, has been predominantly promoted by the Catholic Church and church-based organizations, but lay organizations and traditional trade unions have also supported it. All these actors have a tradition of working closely with poor and vulnerable groups to offer support to immigrants since their first arrival in the 1980s. In addition, in the last decade, the growing vulnerability of migrants, caused by restrictive migration laws and the financial crisis that started in 2008, has resulted in a renewed focus on this issue, even by actors who had previously attempted to surpass this approach, using one of the two other approaches listed here.

The assistance approach has significant implications for participation by people of migrant background, and in most cases represents an obstacle to political participation. This is because it constructs immigrants as passive subjects in both discourses and practices, and tends to speak on behalf of immigrants and racialized communities. For this reason, actors who adopt this approach tend to act on behalf of immigrants rather than offering them the space to speak for themselves. It also fails to promote the opening of channels of civic participation (e.g., intercultural centers and the creation of immigrant associations) and political participation (e.g., the creation of conventional and non-conventional channels to allow immigrants to grow politically and/or organize collectively). By contrast, in most 
cases, the approach becomes an obstacle to both civic and political participation because it treats immigrants as passive subjects. Here, practices of tokenism, subordination, and marginalization of immigrant voices are widespread. Moreover, this approach tends to victimize those to whom services are delivered (Cobbe and Grappi 2011) and produce subordination rather than equal partnership (Torrese 2010; Eliassi 2015). This results from an inability to "see," "acknowledge," and/ or "encourage" immigrants' agency. As such, this approach can be defined as a powerful process of othering, as immigrants are seen not for who they are, but for what they "represent" to the organizations that promote their inclusion. As I will explain later, local actors who promote the other approaches in Italy often do so by explicitly contrasting this approach to the other two approaches, which seek to overcome the negative effects of victimizing immigrants and treating them as passive subjects.

\section{The intercultural approach}

The intercultural approach is founded on the idea that immigrants are would-be citizens. It is usually promoted by left-wing institutional actors (such as local administrations and political parties). This approach encourages participation through cultural exchanges and interactions among immigrants and the receiving society, mainly through the support of civil society organizations. As such, the intercultural approach results mostly in opening up opportunities for civic participation at the individual and collective levels. However, this strategy can tend to put most emphasis on immigrants' "ethnic" associations and their role in promoting immigrants' culture as immigrant associations are constructed as separate entities. Moreover, as I will show in the empirical chapters, processes of de-politicization of immigrant activism can occur as focusing on "ethnicity" and cultural aspects of inclusion limits these associations' demands for greater equality and rights, based on equal treatment and substantial inclusion.

The intercultural approach is based on the idea that diversity must be valorized as a resource in a growing and multi-cultural and multi-ethnic society, thus encouraging exchanges between the population of the receiving society (often defined as the "natives," so to speak) and immigrant communities (including new citizens of migrant origin), as well as through the support of civil society organizations. As Bouchard $(2011,438)$ puts it, interculturalism refers to an understanding of inclusion "based on the principle of reciprocity" by newcomers and the receiving society, and also on the idea that "collective inclusion is a global process affecting all the citizens and constituents of a society, not only immigrants." This approach constructs immigrants as would-be citizens of a future multi-ethnic society and inclusion is considered reciprocal. An alternative word used in the Italian context is "interaction," emphasizing that inclusion is a two-way process. In practice, this approach translates into initiatives that encourage cultural exchanges and interactions between the receiving society and newcomers, and it favors cohabitation, especially through the involvement of civil society organizations and immigrant associations in the processes of inclusion. Here, intercultural policies are used as 
a strategy of governance to promote greater inclusion (see Zapata-Barrero 2015; Zapata-Barrero and Cantle 2018).

In Italy, the intercultural approach has been promoted by several actors, through top-down and/or bottom-up initiatives. The ideological affiliations of these actors resulted in different ways of understanding and acting to promote this approach. On the one hand, the Christian Democratic trade unions (e.g., the CISL) and some church-based organizations have framed interculturalism as a way to promote cohabitation between different cultures. Activities linked to this approach usually include the promotion of immigrant associations or cultural activities. In this view, the intercultural approach does not challenge the assistance approach, but it is in some cases an extension of it (see Chapters 5 and 6 for the cases of Brescia and Bergamo). This approach has been criticized for encouraging folklore and ethnicization of the immigrant associations, by constructing them as separate entities and de-politicizing their demands (Torrese 2010). On the other hand, moderate left-wing actors, such as local authorities, political parties, and lay organizations (Caponio 2006; Però 2007), have encouraged interculturalism as a strategy of governance of diversity and as a way of looking to the future of a multi-ethnic society. In the past decade, the intercultural approach has been widely promoted by many cities across Europe, including Italy, with the support of the European institutions' incentives and especially the Council of Europe (Wood 2010; see Chapters 3 and 4). While this approach has many advantages, it has also been criticized for its tendency to valorize exclusively "diversity management" and "culture," and to avoid conflicts and "hot" political issues, including immigrant workers' rights and the criminalization of some immigrant groups (e.g., undocumented immigrants) (on this point, see especially the case of Reggio Emilia in Chapter 3).

This approach results mostly in the opening of opportunities for civic participation for immigrant communities at the individual and collective levels. This can be done by opening civic channels in at least two directions: (1) by promoting the participation of individual immigrants in the voluntary sector, often by taking into account their specific needs and (2) by encouraging the creation and development of immigrant associations in a pluralistic environment. To this end, local actors, and especially local administrations, may create intercultural centers (usually seen as "neutral spaces") where immigrant associations can meet and develop their own activities (Bonora and Giardini 2004; Caponio 2006).

\section{The political rights promotion approach}

The political rights promotion approach holds that immigrants are entitled to political rights, independent of their formal status. It points to the necessity of encouraging conventional and non-conventional participation. It is usually promoted by left-wing actors of a large political spectrum through the opening up of alternative channels of political participation for immigrants who do not have voting rights or who encounter other obstacles when seeking to fully exercise their political rights (Kosic and Traindafyllidou 2005). Actors who promote this 
approach see political rights as fundamental for guaranteeing immigrants' full inclusion in society. Instead of depicting them as passive subjects, they believe they should be included in the receiving society with full rights. Moreover, they challenge the assumptions of the assistance approach, according to which immigrants are people in need. Instead of speaking on behalf of immigrants, they promote immigrants' self-determination and the idea that they must be able to speak for themselves.

The literature suggests that left-wing local actors have been pivotal in promoting this approach (Kosic and Traindafyllidou 2005; Penninx et al. 2004) by opening channels of participation, including parallel channels to allow immigrants to have representatives (such as consultative bodies), platforms in existing organizations (e.g., forums or coordination organizations in political parties and trade unions), and non-conventional or informal channels (such as protests and mobilizations). Through the creation of these platforms, these organizations aim to empower immigrants and offer them a space to grow politically. It also accounts for which immigrant groups will be encouraged more to participate and become visible. While, for instance, trade unions aim to empower "legal" immigrant workers, the radical left actors tend to be more concerned with the undocumented. Some research also shows that the more radicalized left-wing actors are the more incentives they favor so as to promote immigrants' political participation (see, e.g., Marino 2010 on the case of more radicalized trade unions). Thus, one can infer that the more numerous left-wing actors are in a city, the more likely it is to find political channels available to immigrants. This means that one can expect more incentives to participate in traditionally Communist cities, where left-wing organizations are stronger (e.g., Reggio Emilia and Bologna). Nonetheless, while this description indicates what kind of channels actors tend to promote, it does not help us to predict how pro-immigrant actors promote them. Moreover, it tells us very little about the variations across cities with the same political culture, unless we apply the theoretical model developed in this study to explain these variations.

The empirical analysis of the four cities demonstrates the relevance of this approach in offering incentives to political participation and in effecting alliances between pro-immigrant actors and immigrant activists. Despite explicit claims of inclusiveness, left-wing pro-immigrant actors exhibit a tendency to marginalize immigrant communities in the struggles that concern them (see, in particular, Chapter 7). My findings suggest these actors use the issue of migration to legitimize their presence in the local arena and thus adopt complex processes of tokenism and co-optation. Nevertheless, it is also undeniable they are the actors who have contributed the most to offering resources and opening up channels of political participation (see also Mantovan 2007 for similar results).

\section{Theoretical model of local dynamics}

Building on the conceptual apparatus described earlier, I have developed the theoretical model as described in Figure 2.1. The model summarizes local dynamics. It exhibits how agency is involved within a given institutional context. Overall, this 


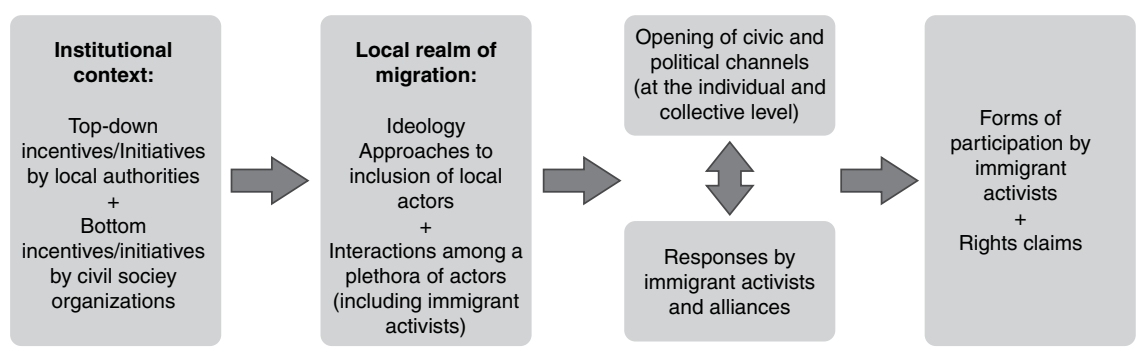

Figure 2.1 Overview of the theoretical model of local dynamics

model accounts for why and how immigrants do or do not become civically and politically active in cities and why and how they form alliances with some proimmigrant groups rather than others. Here, variations of participatory outcomes and rights claims (dependent variable) are explained by four interacting factors identified in the model.

Figure 2.1 illustrates the following four factors that explain the participatory outcome of immigrant activists in cities:

Institutional context: This defines the main institutional framework in which local actors interact and accounts for potential interactions between topdown and bottom-up incentives (or lack thereof) for the inclusion of immigrants. The literature on Italian cities shows that the political sub-culture (Communist vs. Christian Democratic) (Campomori 2008) and the political orientation of local administrations (left-wing vs. right-wing) matter (Caponio 2006). The political sub-culture is relevant for two reasons: It predicts, at least in part, whether the local administration would be proactive or not in promoting inclusive policy from above. As Campomori explains (2008), in the Communist sub-culture, local administrations have tended to promote immigrants' inclusion with top-down initiatives (policies and actions) and in collaboration with the third sector. Here the third sector is defined as the part of society that comprises the non-governmental and nonprofit-making organizations or associations, including charities, voluntary and community groups, cooperatives. Conversely, in Christian Democratic sub-culture, local administrations have devolved initiatives concerning immigrant inclusion to the third sector and in particular the Catholic Church, which plays an important role in promoting bottom-up initiatives (Campomori 2008) (cf. also Appendix A). The sub-culture also defines the prevalence and political strength of left-wing actors (e.g., lay NGOs and the main left-wing trade union, the CGIL) in the Communist cities and the prevalence and political strength of Catholic actors (e.g., the Caritas and the CISL). The political orientation of the local administrations is also important, as in recent years one can observe variations in approaches to inclusion 
in many European cities depending on the political leaning of the administration (Caponio 2006; Garbaye 2005). While progressive or left-wing cities tend to be more inclusive and proactive in trying to develop initiatives to include immigrants, the conservative, right-wing cities tend to be less open. However, the presence of anti-immigrant parties and the politicization of migration issues may reduce these differences, as the rise of anti-immigrant parties in more recent elections raises the "electoral costs" associated with positively addressing migration issues (Caponio 2006, 104). This is why in recent years we have seen left-wing administrations even in left-wing regions adopting xenophobic and securitarian discourses (Bellinvia 2013; Caponio 2006; Castelli Gattinara 2016).

The local realm of immigration and interactions of approaches to inclusion: As explained earlier, the two concepts of "local realm of immigration" and "approaches to inclusion" allow to grasp how a plurality of pro-immigrant actors with different ideologies have the power and/or the will to engage on issues around immigration and the inclusion of immigrants. The local realm of immigration emphasizes in particular local interactions between actors who promote different approaches to inclusion. Depending on the approaches to inclusion adopted by each local actor, we can expect the opening or closing of civic and political channels of participation for immigrants. The opening of these channels shapes alliances between actors. Moreover, immigrant activists may or may not contribute to shaping the local realm of immigration by promoting or challenging themselves the approaches promoted by other actors. The local realm of migration, therefore, is able to grasp what actors do and how they interact with each other in a given institutional context. It accounts for variations in local dynamics in cities with similar institutional arrangements. Here, the presence of one or more dominant actors with very different ideologies may create important conflicts between actors with different approaches to inclusion (see, e.g., Chapter 6 on Brescia).

Civic and political channels of participation: Local dynamics provide the "context" to ascertain whether and how local actors will promote civic and political channels for immigrant participation. The approaches to inclusion adopted by local actors and their interactions have implications for the kind of channels promoted. They also affect which immigrants are encouraged to participate and become visible and which are (wittingly or unwittingly) discouraged from doing so. Thus, the result will be not only the opening of certain channels rather than others but also the promotion of civic and/or political activism of some categories of immigrants. In turn, this will have an impact on which immigrants are active in the city, in what ways, and with which pro-immigrant organizations they will likely form alliances. The more incentives there are, the greater the opportunities for immigrant activists to make a difference in the city and to choose the channels that better correspond to their own political views and needs.

Engagement of immigrant activists and alliances: The model puts immigrant activists at the center of local dynamics and postulates that they play a key 
role by interacting with others and in shaping participatory outcomes. Specific legal frameworks affect partly why and how immigrant activists seize and act upon opportunities and constraints. For instance, legal frameworks allow some immigrants with "regular" status to be part of parties, unions, associations, or to engage in contentious politics by taking part in political organizations or demonstrating in the streets. In addition, individuals who have permanent status or have become new citizens can engage in the processes of integration within specific organizations. They can also be elected to positions of responsibility or run for office. Whatever opportunities they seize, they can in turn promote their recognition by contributing to opening new opportunities of participation (including by creating new channels) and by pressuring other actors to recognize their political voice. In most cases, immigrant activists use their personal trajectory to advance the cause of immigrant communities in the receiving society and thus open up and promote new opportunities and pathways of interaction. They can do so by lobbying and changing these organizations from within or by using their positions in these organizations as a platform to lobby for greater attention to the cause of foreigners in general. Thus, by becoming civically and politically active and by creating alliances with some pro-immigrant actors and avoiding others, and by choosing their political strategies to improve their rights and enlarge their range of options available to them and their communities, they largely contribute to shaping mobilization and rights claims of immigrants in cities. Here, alliances between pro-immigrant supporters and immigrant activists are key. Immigrant activists are not external to local dynamics, but they actively engage with other actors in order to make their voices heard. Moreover, as detailed in Chapter 7, these alliances can be negatively affected by processes of marginalization, co-optation, and tokenism - and by political opportunism of some pro-immigrant groups. Immigrant activists may criticize and challenge practices of marginalization through their civic and political activism and by refusing to ally with organizations that have deceived them and lost their trust.

In the empirical chapters that follow (Chapters 3 to 6), I offer a detailed demonstration of the relevance of the theoretical model of local dynamics. Strong empirical evidence shows how local pro-immigrant actors shape participation in each city by structuring the local realm of immigration through the adoption (or not) of three approaches to inclusion described earlier. These approaches vary not only with respect to the local political culture and political orientation of the main actors but also as a result of power dynamics and interactions. In Chapter 7, I further explain how beyond ideological differences and local variations, all the pro-immigrant supporters have posed some obstacles to participation in immigrant groups by producing the political racialization of immigrants. By looking at immigrant activists' perceptions and responses to challenges posed by proimmigrant groups, I show how they expose and challenge the discourses/practices of pro-immigrant supporters through their counter-narratives and actions and by creating strategic alliances with some actors/organizations rather than others. 


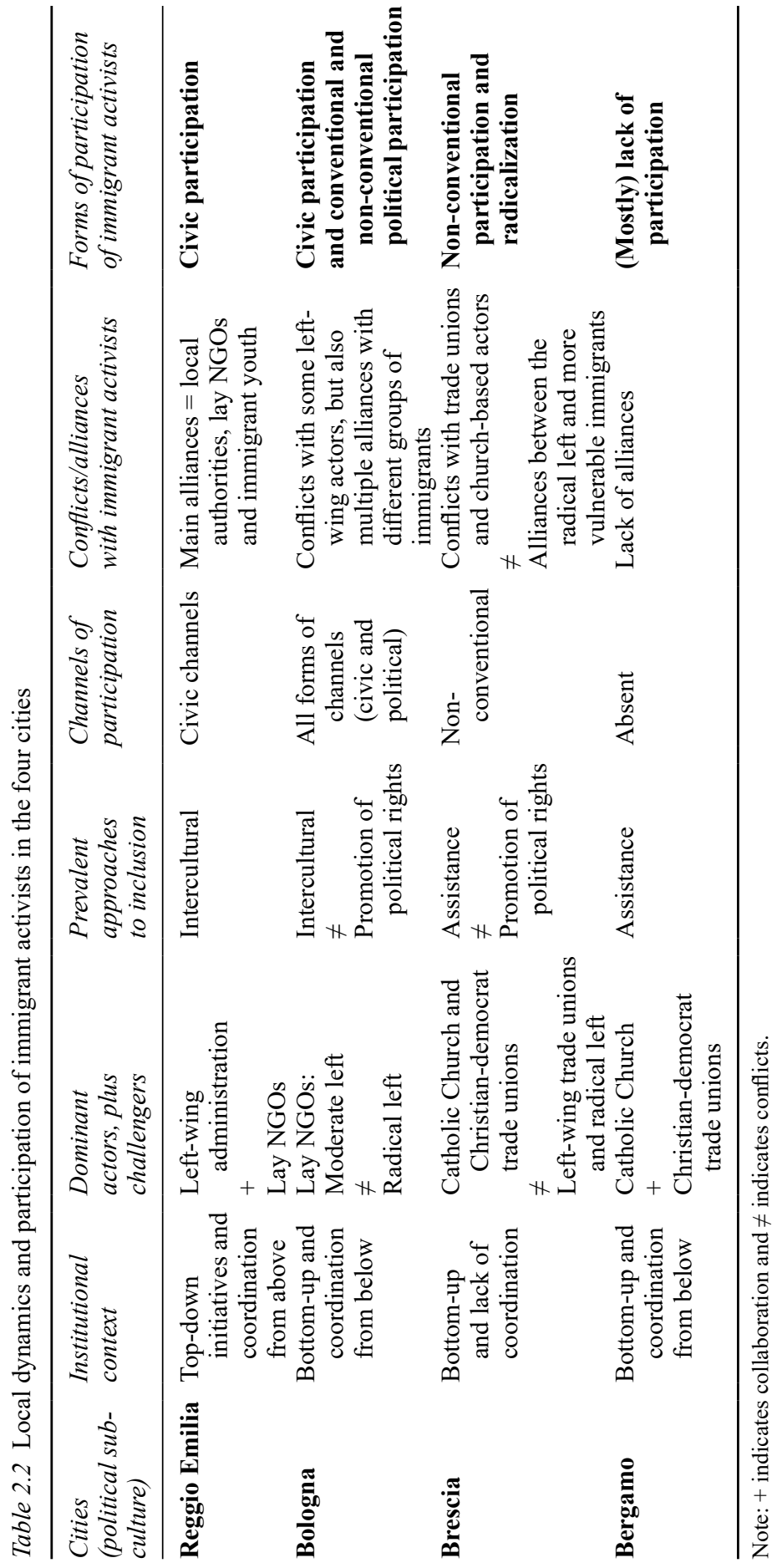




\section{Explaining civic and political participation in the four cities}

Looking at the four cities, the model of local dynamics shows that interactions among a plurality of actors explain variations in forms of participation and rights claims. Table 2.2 summarizes the main results of this study. Each city will be described in more detail in the empirical chapters that follow.

Table 2.2 shows striking variations in the four cities, even between cities with similar institutional contexts. It illustrates that interactions between key actors with different ideologies account for four different patterns of participation in the four cities. As predicted by the literature (Caponio 2006; Garbaye 2005; Mantovan 2007), in the traditionally Communist (or more progressive) cities, participation of immigrant activists is more important than in the traditionally Christian Democrat (or conservative) cities. The strong presence of left-wing actors in Reggio Emilia and Bologna helps explain a higher level of participation. However, depending on their different ideology, left-wing actors favor one type of participation rather than another (civic or political, conventional or non-conventional). Actors encourage the participation and visibility of some groups of migrants rather than others, such as second-generation immigrants in Reggio Emilia and undocumented immigrants in Brescia. The variations in participation and rights claims of immigrants sketched out in Table 2.2 offers evidence of the need to develop a theoretical model that can help us grasp the complexity of local dynamics and interactions among various actors in cities and, as a result, immigrant participation and rights claims. The following empirical chapters will illustrate how the theoretical model of local dynamics works and how it allows explaining these important local variations.

\section{Notes}

1 The political opportunity approach in the migration field should not be confused with the one used in social movement studies. Ireland (1994) borrowed the term from the latter field, but since then, a large part of migration studies has used it to analyze both civic and political participation of immigrants (including, e.g., the fundamental work of Bloemraad 2006). This literature is not concerned with immigrant social movements as such, but on formal channels for immigrants' civic and political engagement.

2 Focusing on social movements of undocumented immigrants, Nicholls and Uitermark $(2016,25)$ explain that specific geographical locations can function as "relational incubators" for mobilizations and creation of coalitions between a variety of actors. They suggest there is a link between configurations of actors and the different types of proimmigrant and immigrant groups involved. These scholars, moreover, highlight the crucial role of pro-immigrant groups in providing resources for political participation and rights claims of extremely vulnerable immigrant groups, especially in hostile contexts.

3 On the reactivation of "symbolic repertoires," see Marx 2001.

4 For an analysis on the case Italy, see Giuliani 2018.

5 My definition echoes Mantovan's (2007) work. This author adopts a sociological approach to study multiple local actors in Italian cities. She elaborates the concept of "local field of immigration" referring to the French sociologist Pierre Bourdieu's concept of "field" (1992). She defines the local field of immigration as follows:

a transversal domain that includes subjects belonging to different spheres . . . that is, people (Italian and migrants) who, with different roles and interests, are invested 
in the area of immigration . . . and who thus have an interest in influencing what is happening in that domain.

(Mantovan 2007, 145; my translation)

6 As I have noted elsewhere (Cappiali 2018), this concept echoes that of "frames" used by Scholten (2011) to study how immigration/inclusion issues are understood and implemented in local-level policy-making. Both concepts emphasize the processual and dynamic aspects that affect practices by local actors. However, while Scholten's focus is on top-down dynamics, that is, institutional actors (such as local administrations), my analysis is more comprehensive, as it focuses both on top-down and bottom-up dynamics.

\section{References}

Bellinvia, Tindaro. 2013. Xenofobia, sicurezza, resistenza. L'ordine pubblico in una città "rossa." Il caso di Pisa. Milano: Mimesis edizioni.

Benford, Robert D. 1993. "Frame Disputes within the Nuclear Disarmament Movement." Social Forces 71 (3): 677-701.

Benford, Robert D., and David A. Snow. 2000. "Framing Processes and Social Movements: An Overview and Assessment." Annual Review of Sociology 26 (1): 611-639.

Bilge, Silma, and Patricia Hill Collins. 2018. Intersectionality (Key Concepts). Cambridge: Polity Press.

Bloemraad, Irene. 2006. Becoming Citizens: Incorporating Immigrants and Refugee in the United States and Canada. Berkeley and Los Angeles: University of California Press.

Bonora, Paola, and Angelo Giardini. 2004. I centri interculturali in Emilia-Romagna. Un progetto di ricerca-azione per una territorialità attiva. Bologna: Industrie Grafiche Labanti e Nanni.

Bouchard, Gérard. 2011. "What is Interculturalism?” McGill Law Journal 56 (2): 435-468.

Bourdieu, Pierre. 1992. "Rites as Acts of Institutions." In Honor and Grace in Anthropology, edited by John G. Peristiani and Juloan Pitt-Rivers, 79-89. Cambridge: Cambridge University Press.

Campomori, Francesca. 2008. Immigrazione e cittadinza locale. La governance dell'integrazione in Italia. Roma: Carocci.

Caponio, Tiziana. 2006. Città italiane e immigrazione. Discorso pubblico e politiche a Milano, Bologna e Napoli. Bologna: Il Mulino.

Caponio, Tiziana, and Maren Borkert, eds. 2010. The Local Dimension of Migration Policymaking. Amsterdam: Amsterdam University Press.

Caponio, Tiziana, Ricard Zapata-Barrero, and Peter Scholten, eds. 2018. The Routledge Handbook on the Governance of Migration and Diversity in Cities. New York: Routledge.

Cappiali, Teresa M. 2016. "Beyond the Political Opportunity Structure Approach: Studying Agency Through the 'Local Realm of Immigration'." In Spaces of Difference: Conflicts and Cohabitation, edited by Ursula Lehmkuhl, Hans-Jürgen Lüsebrink, and Laurence McFalls, 125-151. Münster: Waxmann.

Cappiali, Teresa M. 2017. “'Whoever Decides for You without You, He is Against You!' Immigrant Activism and the Role of the Left in Political Racialization." Ethnic and Racial Studies 40 (6): 969-987.

Cappiali, Teresa M. 2018. "How do Local Actors Promote Civic Participation of Immigrants and Ethnic Minorities? Approaches to Integration and Local Dynamics." In The Routledge Handbook on the Governance of Migration and Diversity in Cities, edited by Tiziana Caponio, Ricard Zapata-Barrero, and Peter Scholten, 136-149. New York: Routledge. 
Cappiali, Teresa M. 2019. "Ideological Affiliations, Conflicts, and Competing Mobilization Frames: The Role of Pro-Immigrant Allies in Shaping Immigrant Struggles for Greater Rights." International Migration Review 53 (3): 869-899.

Castelli Gattinara, Pietro. 2016. The Politics of Migration in Italy: Perspectives on Local Debates and Party Competition. London: Routledge.

Chimienti, Milena. 2011. "Mobilization of Irregular Migrants in Europe: A Comparative Analysis." Ethnic and Racial Studies 43 (8): 1338-1356.

Cobbe, Luca, and Giorgio Grappi. 2011. "Primo marzo, percorsi di uno sciopero inatteso." In La normale eccezione. Lotte migranti in Italia, edited by Felice Mometti and Maurizio Ricciardi, 55-90. Rome: Edizioni Alegre.

d'Appollonia, Ariane Chebel. 2015. Migrant Mobilization and Securitization in the US and Europe. How Does it Feel to Be a Threat? London: Palgrave Macmillan.

de Graauw, Els. 2016. Making Immigrant Rights Real: Nonprofits and the Politics of Integration in San Francisco. Ithaca: Cornell University Press.

della Porta, Donatella, ed. 2018. Solidarity Mobilizations in the "Refugee Crisis": Contentious Moves. London: Palgrave Macmillan.

della Porta, Donatella, and Mario Diani. 2011. Social Movements: An Introduction. Oxford: Blackwell.

Diani, Mario. 1997. "Social Movements and Social Capital: A Network Perspective on Movement Outcomes." Mobilization 2: 129-147.

Diani, Mario, and Doug McAdam, eds. 2004. Social Movements and Networks: Relational Approaches to Collective Action. Oxford: Oxford University Press.

Eliassi, Barzoo. 2015. "Constructing Cultural Otherness with the Swedish Welfare State: The Cases of Social Workers in Sweden." Qualitative Social Work 14 (4): 554-571.

El-Tayeb, Fatima. 2011. European Others: Queering Ethnicity in Post-National Europe. Minneapolis: University of Minnesota Press.

Evans, Elizabeth, and Éléonore Lépinard, eds. 2020. Intersectionality in Feminist and Queer Movements. Confronting Privileges. New York: Routledge.

Fanon, Frantz. 1967. The Wretched of the Earth. New York: Grove Press.

Garbaye, Romain. 2005. Getting into Local Power: The Politics of Ethnic Minorities in British and French Cities. Oxford: Blackwell.

Giugni, Marco, and Florence Passy. 2004. "Migrant Mobilization between Political Institutions and Citizenship Regimes: A Comparison of France and Switzerland." European Journal of Political Research 43: 51-82.

Giuliani, Gaia. 2018. Race, Nation and Gender in Modern Italy: Intersectional Representations in Visual Culture. Basingstoke: Palgrave Macmillan.

Glick Schiller, Nina, and Ayşe Çağlar, eds. 2011. Locating Migration: Rescaling Cities and Migrants. Itacha: Cornell University Press.

Good, Kristin. 2009. Municipalities and Multiculturalism: The Politics of Immigration in Toronto and Vancouver. Toronto: Toronto University Press.

Hochschild, Jennifer L., Jacqueline Chattopadhyay, Claudine Gay, and Michael JonesCorrea, eds. 2013. Outsiders No More? Models of Immigrant Political Incorporation. Oxford: Oxford University Press.

hooks, bell. 1989. "Choosing the Margin as a Space of Radical Openness." Framework: The Journal of Cinema and Media 36: 15-23.

hooks, bell. 2015. Feminist Theory: From Margin to Center (3rd ed.). New York: Routledge. Ireland, Patrick. 1994. The Policy Challenge of Ethnic Diversity: Immigrant Politics in France and Switzerland. Cambridge, MA: Harvard University Press.

Jones-Correa, Michael, ed. 2001. Governing American Cities: Inter-ethnic Coalitions, Competition, and Conflict. New York: Russell Sage Foundation. 
Kendi, Ibrahim X. 2019. How to be an Antiracist. London: Penguin.

Koopmans, Ruud. 2004. "Migrant Mobilisation and Political Opportunities: Variation among German Cities and a Comparison with the United Kingdom and the Netherlands." Journal of Ethnic and Migration Studies 30 (3): 449-470.

Koopmans, Ruud, and Paul Statham, eds. 2000. Challenging Immigration and Ethnic Relation Politics: Comparative European Perspective. Oxford: Oxford University Press.

Kosic, Ankica, and Anna Triandafyllidou. 2005. Active Civic Participation of Immigrants in Italy. Country Report prepared for the European Research Project POLITIS. Oldenburg. www.politis-europe.uni-oldenburg.de/download/Italy.pdf

Lépinard, Éléonore. 2020. Feminist Trouble. Intersectional Politics in PostSecular Times. New York, London: Oxford University Press.

Mantovan, Claudia. 2007. Immigrazione e Cittadinanza. Auto-organizzazione e Partecipazione dei Migranti in Italia. Milan: FrancoAngeli.

Marino, Stefania. 2010. "Le strutture specifiche per la rappresentanza dei lavoratori migranti: un confronto tra Italia e Olanda." In Immigrazione e Sindacato. Lavoro, cittadinanza e territori. VI Rapporto, edited by Francesco Carchedi, Francesca Carrera, and Giovanni Mottura, 337-352. Roma: Ediesse.

Marques, M. Margarida, and Rui Santos. 2004. "Top-Down and Bottom-Up Reconsidered: The Dynamics of Immigrant Participation in Local Civil Society." In Citizenship in European Cities: Immigrants, Local Politics and Integration Policies, edited by Rinus Penninx, Karen Kraal, Marco Martiniello, and Steven Vertovec, 107-125. Aldershot: Ashgate.

Martiniello, Marco. 2005. "Political Participation, Mobilization and Representation of Immigrants and their Offspring in Europe." Willy Brandt Series of Working Papers in "International Migration and Ethnic Relations." Malmö: Malmö University.

Martiniello, Marco. 2009. "Immigrants and their Offspring in Europe as Political Subjects." In Bringing Outsiders In: Transatlantic Perspectives on Immigrant Political Incorporation, edited by Jennifer L., Hochschild and John H. Mollenkopf, 33-47. Ithaca: Cornell University Press.

Marx, Anthony. 2001. Making Race and Nation: A Comparison of South Africa, the United States, and Brazil. Cambridge: Cambridge University Press.

Monforte, Pierre, and Pascale Dufour. 2011. "Mobilizing in Borderline Citizenship Regimes: A Comparative Analysis of Undocumented Migrants' Collective Action." Politics \& Society 39 (2): 203-232.

Morales, Laura, and Marco Giugni. 2011. Social Capital, Political Participation and Migration in Europe: Making Multicultural Democracy Work? London: Palgrave Macmillan.

Mulinari, Paulina. 2015. "Exploring the Experiences of Women and Migrant Medical Professionals in Swedish Hospitals: Visible and Hidden Forms of Resistance." Equality, Diversity and Inclusion: An International Journal 8 (34): 666-677.

Nicholls, Walter J. 2013. "Making Undocumented Immigrants into a Legitimate Political Subject: Theoretical Observations from the United States and France." Theory, Culture \& Society 30 (3): 82-107.

Nicholls, Walter J. 2014. "From Political Opportunities to Niche-Openings: The Dilemmas of Mobilizing for Migrant Rights in Inhospitable Environments." Theory \& Society 43 (1): 23-49.

Nicholls, Walter J., and Justus Uitermark. 2016. Cities and Social Movements: Immigrant Rights Activism in the US, France, and the Netherlands, 1970-2015. London: Wiley-Blackwell.

Nyers, Peter, and Kim Rygiel, eds. 2012. Citizenship, Migrant Activism, and the Politics of Movement. London: Routledge. 
Oliveri, Federico. 2012. "Migrants as Activist Citizens in Italy: Understanding the New Cycle of Struggles." Citizenship Studies 16 (5-6): 793-806.

Oliveri, Federico. 2018. "Racialization and Counter-Racialization in Times of Crisis: Taking Migrant Struggles in Italy as a Critical Standpoint on Race." Ethnic and Racial Studies 41 (10): 1855-1873.

Omi, Michael, and Howard Winant. 2015. Racial Formation in the United States: From the 1960 s to the 1990s. New York: Routledge.

Pastore, Ferruccio, and Irene Ponzo. 2016. "Introduction.” In Inter-group Relations and Migrant Integration in European Cities, edited by Ferruccio Pastore and Irene Ponzo, 1-18. Heidelberg: IMISCOE Research Series-Springer.

Penninx, Rinus, Karen Kraal, Marco Martiniello, and Steven Vertovec, eds. 2004. Citizenship in European Cities: Immigrants, Local Politics and Integration Policies. Aldershot: Ashgate.

Però, Davide. 2007. Inclusionary Rhetoric/Exclusionary Practices: Left-Wing Politics and Migrants in Italy. Oxford: Berghahn.

Però, Davide. 2008. "Migrants' Mobilization and Anthropology: Reflection from the Experience of Latin Americans in the United Kingdom." In Citizenship, Political Engagement, and Belonging: Immigrants in Europe and the United States, edited by Deborah ReedDanahay and Caroline Brettell, 103-123. New Brunswick: Rutgers University Press.

Pilati, Katia. 2010. La partecipazione politica degli immigrati: Il caso di Milano. Rome: UNAR. Raissiguier, Catherine. 2010. Reinventing the Republic: Gender, Migration, and Citizenship in France. Stanford: Stanford University Press.

Reed-Danahay, Deborah, and Caroline Brettell, eds. 2008. Citizenship, Political Engagement, and Belonging: Immigrants in Europe and the United States. New Brunswick: Rutgers University Press.

Sager, Maja. 2011. Everyday Clandestinity: Experiences on the Margins of Citizenship and Migration Policies. Lund: Lund University.

Saïd, Edward W. 1978. Orientalism. London: Vintage Books.

Scholten, Peter. 2011. Framing Immigrant Integration: Dutch Research-Policy Dialogues in Comparative Perspective. Amsterdam: Amsterdam University Press.

Siméant, Johanna. 1998. La cause des sans-papiers. Paris: Presses de Sciences po.

Soysal, Yasemin Nuhoglu. 1994. Limits of Citizenship: Migrants and Post-National Membership in Europe. Chicago: University of Chicago Press.

Spivak, Gayatri Chakravorty. 2010 [1988]. Can the Subaltern Speak? Reflections on the History of an Idea. New York: Colombia University Press.

Steinhilper, Elias. 2021. Migrant Protest. Interactive Dynamics in Precarious Mobilizations. Amsterdam: Amsterdam University Press.

Tarrow, Sidney. 2011. Power in Movement: Social Movements and Contentious Politics (3rd ed.). Cambridge: Cambridge University Press.

Tilly, Charles, and Sidney Tarrow. 2015. Contentious Politics. Oxford: Oxford University Press.

Torrese, Eugenio. 2010. Oltre il binomio welfare-immigrazione. Un'esperienza locale: l'Agenzia per l'Integrazione. Milano: Franco Angeli.

Voss, Kim, and Irene Bloemraad, eds. 2011. Rallying for Immigrant Rights: The Fight for Inclusion in 21st Century America. Berkeley: University of California Press.

Wood, Phil. 2010. Intercultural Cities: Towards a Model for Intercultural Integration. Strasbourg: Council of Europe.

Zamponi, Lorenzo, and Castelli Gattinara, Pietro (2020) "Uneven Ground: The Asymmetric Competition between Anti-Refugee and Solidarity Movements in Italy." Politiche Sociali 2: 267-290. 
Zapata-Barrero, Ricard, ed. 2015. Interculturalism in Cities: Concept, Policy and Implementation. Cheltenham: Edward Elgar Publishing.

Zapata-Barrero, Ricard, and Ted Cantle. 2018. "City Governance of Migration and Diversity: Interculturalism as a City Policy Paradigm." In The Routledge Handbook on the Governance of Migration and Diversity in Cities, edited by Tiziana Caponio, Ricard Zapata-Barrero, and Peter Scholten, 193-203. New York: Routledge.

Zepeda-Millán, Chris. 2017. Latino Mass Mobilization: Immigration, Racialization and Activism. Cambridge: Cambridge University Press. 


\section{Civic participation in a city of intercultural dialogue}

In the 2000s, the increasing power of the Northern League at the national, regional, and local levels discouraged most local left-wing authorities' involvement in the sphere of immigration. As the Northern League gained even more power in the elections of 2008 and the politicization of the discourse around immigration raised the "electoral cost" (Caponio 2006, 92), both moderate right-wing and leftwing politicians were less likely to speak out in favor of immigrants' inclusion. In some cases, they even adopted the security discourse of the Northern League (Castelli Gattinara 2016). In cities where right-wing coalitions won the elections with a strong presence of the Northern League (e.g., as in Brescia between 2008 and 2013; see Chapters 5), local administrations shifted their attention to security measures rather than inclusion. For left-wing administrations, there was a great fear of talking about the subject of immigration, and in some cases, local administrations turned to issues of public order for fear of the electorate (Bellinvia 2013). Even in the Italian stronghold of the left, the Emilia-Romagna region, several local left-wing actors withdrew, though less visibly than elsewhere (as in the case of the left-wing administrations in Bologna between 2004 and 2014; see Chapter 4).

In response to these events, already in 2004, the Emilia-Romagna region introduced (among other things) a law on integration in 2004 (Campomori and Caponio 2013), which adopted a culture-friendly model. The law was clearly designed to counter the anti-immigrant legislation, the so-called Bossi-Fini Law, and the increased hostility toward immigrants at the national level. Many leftwing regions soon followed its example (Rossi et al. 2013). Moreover, a few local authorities raised their voices and stood up against the rising xenophobia and exclusion. This was, for instance, the case of the city of Reggio Emilia, considered among the best local models of inclusion in Italy since the first inflow of migration in the country (Turco 2005). ${ }^{1}$

Based on the theoretical model introduced in Chapter 2, this chapter looks closely into the approaches to inclusion adopted in this "virtuous" city to understand their implications for immigrants' activism and rights claims. How did local actors in Reggio Emilia promote inclusion through an intercultural approach? What actors were promoting this approach? How and why? How did immigrants engage with other actors in the city? And how did they perceive the role of proimmigrant actors in promoting immigrants' rights and inclusion in the city? What 
was the impact of these local dynamics on immigrants' mobilizations and right claims? In order to answer these questions, this chapter will analyze the main actors in the city and their interactions with immigrant activists. It begins with a description of the campaign "Italy is me, too! For the rights of citizenship" that was launched in 2010 by the left-wing administration in cooperation with lay and church-based civil society organizations, as well as migrant communities. Using this example and asking why this campaign was launched in Reggio Emilia, I identify the actors involved in the mobilization, their characteristics, as well as the forms of participation and demands that were made by these pro-immigrant actors and immigrant groups. I analyze the role of ideological and strategic positioning and the interactions of these actors in affecting approaches to inclusion, and the types of alliances they developed with immigrant groups and the type of activism they encourage. I explain how specific local dynamics affect the ways in which immigrant groups mobilize and make claims in the city, as well as the role of some immigrant activists in appropriating the intercultural approach adopted, and the role of some others in challenging the lack of political rights promotion.

I will show how local actors in the city of Reggio Emilia have promoted interculturalism from above.

Reggio Emilia is, accordingly, the city of intercultural dialogue, as key local actors - the institutional left-wing authorities, trade unions, lay organizations of the left — tend to promote an advanced approach to interculturalism. Because the local administration and the political parties strongly encourage their participation, the most visible immigrant activists in the city are new Italian citizens and immigrant youth. The empirical chapter will explain further why and how immigrant activists, and especially second-generation immigrants, participate mainly in formal civic channels, and why they create alliances with institutional actors rather than other actors. The chapters will also explain how some forms of activism are encouraged over others, why there are few channels for political participation in the city, and how this has an impact on which immigrant activists are made "visible," as well as the ways in which some immigrant activists mobilize and strategically make specific rights claims rather than others.

\section{The "Italy is me, too! For the rights of citizenship" campaign"}

On September 9, 2011, the city of Reggio Emilia, in Northern Italy, launched the national campaign "Italy is me, too! For the rights of citizenship" (L'Italia sono anch 'io! Per i diritti alla cittadinanza). From Reggio Emilia, the campaign spread in many cities across Italy. The campaign's goal was to collect enough signatures to present two popular legislative propositions to Parliament. The first called for a change in the citizenship law based on jus sanguinis, which would instead apply the jus soli principle to children of immigrant parents born in Italy. ${ }^{3}$ The citizenship law in Italy is particularly restrictive (see Chapter 1). Based on jus sanguinis (or "right of blood"), the law excludes children of non-EU immigrant parents from citizenship status. The change would instead apply a "moderate" jus soli ("right of soil") principle, allowing many second-generation immigrants born or 
raised in the country and excluded from naturalization criteria to become Italians with full rights. The second proposition focused on granting non-EU citizens, who had been residents in Italy for several years, the right to vote in local elections. ${ }^{4}$ The second proposition promoted in the campaign focused on granting non-EU citizens the right to vote in local elections. ${ }^{5}$ The national campaign was supported by several lay and church-based civil society organizations, traditional trade unions (including the CGIL and the CISL), and immigrant organizations, especially "second-generation" immigrant organizations, such as Network G2Second Generation (Rete G2-Seconde Generazioni).

In addition to its main goals, the campaign was also created in response to the growing climate of intolerance that followed the financial crisis, and which was reflected in the legislation and in the dominant criminalizing discourses on immigration. For this reason, it was as much a cultural battle to reshape the debate on immigration, which had become almost completely monopolized by the main anti-immigrant party, the Northern League. Moreover, many left-wing mayors across the country participated in the initiative with the support of civil society organizations. Even though the campaign did not succeed in pressuring the parliament to change the citizenship law and to promote local voting rights, the committee achieved its goal of collecting enough signatures to send the propositions to the Italian Parliament and to prompt a new debate on the level of discrimination in the legislation.

Graziano Delrio, the mayor of Reggio Emilia, was the president of the national committee of the "Italy is me, too!" campaign. He incentivized the involvement of the local administration and the main left-wing party, and the Democratic Party (through the Provincial Forum of Immigration). These actors were proactive during the entire campaign and promoted various initiatives to sensitize public opinion and to encourage public debate on the campaign's central themes. ${ }^{6}$ The campaign's main pro-immigrant actors promoting immigrant rights were the Mondinsieme Intercultural Center (Centro Interculturale Mondinsieme, hereafter the Mondinsieme Center), the church-based organizations (including Caritas and Abram's Home-Dimora d'Abramo), and the two main trade unions (CISL and CGIL). ${ }^{7}$ Among the promoters were immigrant associations, in particular two established second-generation immigrant organizations: Young Muslims of Italy (Giovani Musulmani d'Italia) and Network TogethER (Rete TogethER), a network of associations of young people of Italian and migrant background in the Emilia-Romagna region. Thanks to the support of the Mondinsieme Center and these two immigrant associations, it was possible to encourage greater participation among young people of foreign origin, the so-called "second-generations," who helped to organize events and create videos and documents to sensitize the Italian and immigrant population to the themes of the campaign. ${ }^{8}$

The organizers drew an explicit link between respecting the universality of rights (as established in the third article of the Italian Constitution) and a vision of Italy as a multi-ethnic society, which would respect the rights of immigrants, including the right to vote at the local level. According to the third article of the Constitution: "All citizens have equal social status and are equal before the law, without regard to their sex, race, language, religion, political opinions, and 
personal or social conditions." By making a link to the third article, the organizers promoted the view that people of migrant background who live in Italy are entitled to fundamental rights independent of their status. On the official site of the campaign, it states: "Immigrants must enjoy the same rights as nationals and as citizens of the countries of residence in all fundamental spheres of economic, political, cultural, social and educational life."'9

The campaign's themes aligned with the general approach adopted by the two left-wing administrations led by Mayor Delrio from 2004 to 2008 and from 2008 to 2014. The administration had distinguished itself in the Italian landscape (and in Europe) for its promotion of an innovative intercultural approach to inclusion, the intercultural dialogue, which encouraged the idea of Italy as a multi-ethnic society and argued that diversity is a positive and valuable resource. At the heart of the local administration's approach was the idea that second-generation immigrants are the future of the Italian multi-ethnic society. For the administration of Reggio Emilia, the campaign was an occasion to move beyond the local context and open a completely new national debate about political rights and the country's multi-ethnic future.

In many parts of the country, the campaign was well received and exceeded its main goal of collecting 50,000 signatures (the minimum threshold) for each proposition at the national level. At the end of the campaign, the committee had collected 109,268 signatures for the change in citizenship law and 106,329 signatures for the right to vote. The city of Reggio Emilia obtained the highest number of signatures, more than 5,400 signatures for each proposition, in the region of Emilia-Romagna. On March 6, 2012, the organizing committee deposited the two propositions at the Chamber of Deputies. ${ }^{10}$

While the campaign did not succeed in convincing the parliament to transform the propositions into laws, ${ }^{11}$ the leaders of the initiative in Reggio Emilia believed that the campaign had been successful in raising public awareness of the issue of immigrants' rights in Italy. When presenting the results of the campaign to the press, Delrio declared himself greatly satisfied:

Today we celebrate a great result, which we have believed in since the beginning, when there were only few people who believed in it. The duty of politics is exactly this: to say things that are uncomfortable and that do not build consent. Politics must say the truth in difficult moments. With this campaign we have been able to stimulate cultural debate on the issues of citizenship and rights. And this is probably the biggest result .... The delivery of the signatures represents only the first step of a long and demanding path. ${ }^{12}$

I interviewed Rinaldo D., a longtime worker at the Mondinsieme Center of Reggio Emilia. He was an Italian male in his thirties. He told me:

More than a political battle it was a "cultural battle." We knew that most likely things would not evolve very quickly in parliament. Our extraordinary result has been to impose a debate at the cultural level. The campaign has succeeded in drawing attention to these themes. Before, there was zero interest in the subject! 
Persuaded of the importance of this "cultural battle," the administration of Reggio Emilia continued its communication campaign after the deposition of the signatures. They undertook various initiatives, with the support of, among others, the Mondinsieme Center, the Democratic Party's Provincial Forum of Immigration, and the association Network TogethER. ${ }^{13}$ Moreover, as it will be shown in this chapter, the civil society in Reggio Emilia, composed of a dense web of lay organizations, including autonomous cooperatives, also plays an important role and has an impact on how migration issues are dealt with by local actors in the city.

\section{Political continuity and the role of the left-wing administrations in promoting inclusion}

The city of Reggio Emilia has long been characterized by an "open" institutional context for immigrants since the 1990s (Turco 2005), and its historical trajectory and responses to immigration have had specific consequences for the approaches adopted by local actors at the time of my field research in 2013 and 2014. The city is known not only as a stronghold of the Communist Party in Italy until its dissolution in the 1990s but also as a symbol of the Italian resistance against fascism. ${ }^{14}$ This legacy is particularly relevant. Thus, its identity has been greatly shaped by its left-leaning, or Communist, political sub-culture, and by its pride in supporting progressive policies and fights against discrimination and injustice around the world (RE/N13, RE/N17, and RE/N18). Moreover, since the end of the Second World War, Reggio Emilia has been governed without interruption by relatively progressive left-wing administrations. As many interviewees explained, this political sub-culture proved to be a fertile ground for promoting inclusive policies for immigrants by local actors in the city and was linked to its strong commitment to universal human rights. Consequently, left-wing administrations have been particularly welcoming to new immigrants since their first arrival in the 1980s and 1990s (RE/N17). As a result, by the end of the 1990s, the city had been experimenting with its first innovative inclusive interventions (RE/N17) and soon became one of the best models in Emilia-Romagna and an exemplar for other cities in Italy and Europe alike (Turco 2005). All the key informants in the city confirmed that long before the rest of Italy made its first steps toward inclusion, Reggio Emilia was already experimenting with several innovative initiatives.

In keeping with the prevailing Communist political sub-culture and quite progressive left-wing political orientation (Caponio 2006), the left-wing administrations of Reggio Emilia guided by Antonella Spaggiari (1994-1999 and 19992004) were particularly proactive. These administrations made significant efforts to promote initiatives from above and to coordinate civil society organizations to promote cooperation with other actors in the area of immigration (see Campomori 2008). This coordination allowed the administration to develop initiatives both in the direction of assistance - in order to help immigrants in need - and interculturalism - in order to acknowledge and accommodate immigrants' cultural diversity (RE/N17). The local administration's investment in assistance was supported by the strong welfare system present in the Emilia-Romagna region (RE/N17: Mario 
G., Italian (M), Director of Caritas). As most of my interviewees acknowledged, the public services and dense network of third-sector organizations covered most of the needs of immigrants (e.g., RE/N7 and RE/N17). Reggio Emilia was also among the first cities (together with Modena, another city in Emilia-Romagna) to offer a comprehensive set of services for "undocumented" immigrants (RE/N11: Clara A., Italian (F), In charge of the Office for Migrants of the CGIL (2001-2010)).

At the end of the 1990s, the Spaggiari administration created a Municipal Office to help immigrants orient themselves in the city (in 1997) and sought to accommodate cultural and religious diversity, developing one of the first intercultural approaches to services in Italy (RE/N17). This included the production of pamphlets in different languages to introduce people of foreign origin to the use of local services and of several intercultural mediators in hospitals, schools, etc. (RE/N11). There was also an emphasis on training intercultural mediators and creating workshops on interculturalism in schools (RE/N3 and RE/N4). Over the years, the administration - in collaboration with other local actors, in particular the CGIL - created innovative courses to talk about the importance of encouraging inclusion by respecting diversity in the workplace and other spheres of life (RE/N2: Teresa E., Italian (F), cultural mediator working for municipality of RE). Moreover, these organizations worked toward creating pamphlets in different languages to help immigrants understand basic notions linked to the workplace and above all workplace safety (RE/N11). ${ }^{15}$ Furthermore, Cesare F, an Italian man in his fifties, and the Assessor of Security and Social Cohesion of the local leftwing administration since 2003, told me: "because the administration at the time wanted to avoid an exclusively assistance-based approach to inclusion, it encouraged participation in civic life through the support of immigrant associations" (RE/N1). To this end, it created the Mondinsieme Center in 2001 to offer a space where immigrant associations could meet and engage in cultural exchanges (for more details on the Center, see later). Finally, during our interview, Francesca F., an Italian female in her 50s, and a member of the Democratic Party who was very active in politics during Spaggiari's administration, explained that the debate on immigrants' political rights was a central issue at that time and that attempts were made to promote the participation of immigrants in mainstream politics through the political party. In contrast with other local administrations in Italy (Caritas Italiana 2005), the administration refused to create Consultative Bodies or other parallel channels of participation. Francesca F. added, "The administration at the time did not believe in this 'surrogate' of participation, so it did not support the creation of parallel channels of participation" (RE/N17). ${ }^{16}$

Reggio Emilia is peculiar for the continuity of its administrations' political orientation. When the campaign "Italy is me, too!" was organized in 2011, the left-wing administration led by Mayor Delrio had been in power since 2004 and was in its second term. Before Delrio's administration, another mayor governed the city for two terms (1994-1999 and 1999-2004) with a left-wing coalition. Bolstered by its progressive local and regional context, the administration of Reggio Emilia led by Delrio opted for a new strategy to challenge the hostile political developments around the country (RE/N1). Moreover, as Cesare F., the Assessor 
of Security and Social Cohesion explained, the political continuity allowed local authorities to develop a different approach from any other city in Italy and "to take some risks" (RE/N1). The administration was also helped by its strong economic performance. For many years, Reggio Emilia had one of the highest levels of immigrant population $(15.7 \%$, or 25,687 of 163,928$)$ (Istat 2013). This density reflected the strong economic pull of the territory with Reggio Emilia being one of the richest cities in Italy. The 10 most relevant groups were from China $(3,437)$, Albania (3,149), Morocco $(2,626)$, Ghana $(1,984)$, Ukraine $(1,795)$, Romania (1,531), Moldova (1,512), Nigeria (1,108), Egypt (927), and Sri Lanka (801). Moreover, before the financial crisis, in the years 2006-2008, Reggio Emilia was among the cities with the highest economic performance in the country, giving it the capacity to include immigrants socioeconomically. The latter point was also confirmed by the fact that the city and its surrounding areas had the highest employment rate of immigrant workers in the country, as well as the highest indexes of "integration" (CNEL 2009).

\section{The local realm of immigration and the prevalence of the intercultural approach}

\section{A new strategy to foster cohabitation? Promoting the intercultural dialogue from above}

At the time of my fieldwork in 2013, the local realm of immigration was largely characterized by the strength of the main left-wing actors, typically strong in the Communist political sub-culture (Campomori 2008). As noted earlier, the specific institutional context within the city created the conditions for giving the left-wing local governments led by Graziano Delrio a great deal of power in the domain of migration. Thus, in this context, the local realm of immigration was largely shaped by the left-wing administrations in the city, which also promoted the inclusion of immigrants in the city in close collaboration with the civil society organizations of both Italians and immigrants. A key actor linked to the administration was also the intercultural center of Mondinsieme Center. The leftist NGOs, the main left-wing trade union (the CGIL), and the main left-wing party (the Democratic Party), moreover, were also powerful actors. A radical left organization, the Migrant City (Città Migrante), was also present, but it was marginal compared to other left-wing actors. Finally, the main Christian Democratic actors, Caritas and CISL, though weaker than left-wing actors, invested a great deal in the local area of immigration and made a difference in the city. In particular, their approach was influenced by the powerful left-wing actors, and this resulted in a strong investment in the direction of interculturalism.

The proactive role of the administration of Reggio Emilia is an example of how local actors can capitalize on the resources they have to promote an innovative twist. By building on the work of the previous administration, during Delrio's second term (2008-2013), the administration gradually moved toward a new approach and a more coherent strategy of inclusion-intercultural dialogue. ${ }^{17}$ 
According to most local actors I interviewed in Reggio Emilia and in the other cities, the approach in Reggio Emilia was unique in the Italian landscape and represented a model to get inspiration from.

According to the promoters and several other pro-immigrant actors in the city, the intercultural dialogue represented "a qualitative leap," also compared to the city's previous approaches to inclusion (RE/N1). As Delrio proclaimed in his promotion of the "Italy is me, too!" campaign, local authorities in Reggio Emilia believed that "the duty of politics" is to say truthful things, even if they "are uncomfortable" and "do not build consent." In other words, the administration decided to take a stand on issues of immigration and to take some risks that may have an electoral cost, but that would allow to promote a vision of the left that was aligned with its values. On this topic, I interviewed Reda B., an Italian citizen, in his early thirties, who moved from Tunisia with his family when he was 6 . He was the person in charge of the Provincial Forum of Immigration of the Democratic Party at the time of the interview. He explained:

Since 2006, there has been an important change in the local policies: Reggio Emilia has opened a dialogue that did not exist before . . . a dialogue that scared previous administrations. Before 2006, the dialogue already existed, of course, but it was overshadowed. There was no emphasis on the theme of migration, because there was a fear of political repercussions. It is a very delicate issue also in Reggio Emilia. Whoever works on immigration issues in Italy today has no political advantage, because immigrants do not vote. In Reggio Emilia some administrators made the difference!

(RE/N18)

On the official website of the municipality, one can find an explanation of the intercultural approach that is unique to Reggio Emilia. ${ }^{18}$ It is not a mere "valorization of diversity," but a pragmatic approach, a "strategy of governance" aiming to address major challenges linked to the inclusion of immigrants and diversity management (see also Zapata-Barrero and Cantle 2018). As described in the website, the first step toward intercultural dialogue is the recognition that immigration is a structural phenomenon and that Italy has become de facto a multi-ethnic society. In response to the massive change in the structure of Italian society, the document states:

the intercultural dialogue carries out a crucial role in constructing together new identities and a sense of citizenship, precisely because it explores the benefits of our rich cultural heritage and the opportunities to learn from different cultural traditions .... The intercultural dialogue is indispensable for the construction of a new social and cultural model, because it offers the possibility to adopt an approach of governance that makes possible the involvement of all of the sectors (the public administration and the economic, social and cultural actors of the city) and the valorization of the different cultures present in the context based on respect of the rules. 
Thus, recognizing the positive role of diversity, through an intercultural approach, is seen by the administration as a strategy of governance that allows to capitalize on and valorize the diversity in the city. In order to succeed, moreover, this approach needs to bring together different sectors of society. Cesare F., the Assessor of Cohesion and Security since 2003 and the main promoter of the intercultural dialogue during Delrio's two administrations, helped me to reconstruct how this approach evolved over time and how made Reggio Emilia, most likely, the most advanced model of inclusion in the national landscape (RE/N1). The Assessor explained that the distinct approach of Reggio Emilia developed at the beginning of the 2000s, underwent "a qualitative leap" in 2006 and continued to develop progressively until 2013, at the time of the interview. While the promotion of inclusion through assistance was never questioned by the local administrations since 2006 ("precisely because it is assumed as the basis for all other forms of integration"), local authorities decided to clearly distinguish between the dimension of assistance and that of interculturalism. Thus, policies of immigration integration were no longer limited exclusively to social policies (as in the rest of Italy), Cesare F. explained, but were extended to other fields, including education. Cesare F. also emphasized that intercultural dialogue implies a change of perspective as to how the administration conceives of inclusion. This marked a substantial move by the administration not only to go beyond the assistance approach but also to promote "active citizenship" and self-determination of the city's migrant population. Cesare F. proudly explained why the city of Reggio Emilia decided to move in this direction. It is significant that compared the political sub-culture of the city with the Catholic sub-culture to explain how the ideological dimension also plays a role in shaping how local actors understand inclusion of immigrants.

While the Catholic sub-culture tends to focus on social enterprise, the Communist sub-culture is more concerned with cultural enterprise. For us, this means giving dignity back to immigrants. Here in Reggio-Emilia we want to propose a "qualitative leap" in the approach to inclusion: We want all our citizens to participate and feel responsible for the history of this city! The major change was the mentality of governance. The key to the change has been the adoption of an integrated approach. The embryos were there, but the alliances were missing. Until 2004, the approach was mainly “Oh, poor immigrant!” People from Reggio Emilia did not appreciate this kind of approach, precisely because there were also "Italians" who needed assistance and they did not like the distinctions between them and the immigrant population. From 2004 to today, considerable efforts have been made to go beyond this approach. We have decided to detach the "issue of integration" from the dimension of "social exclusion."

(RE/N1; emphasis mine $)^{19}$

Following this reasoning, he explained that the promotion of intercultural dialogue starts from the hospitals, schools, and neighborhoods. The idea is to open up spaces for dialogue in primary meeting places. A particular role is attributed to the intercultural mediators, that is, professional figures whose role is to "mediate" 
and create the conditions for genuine dialogue between Italians and immigrants This approach tries to go beyond a dichotomy between "us" and "them" and to use language more appropriate for the city of today, which has been transformed by the interaction between the "old" and "new" Reggians (e.g., RE/N2 and RE/ N3). For this reason, several actors in the city told me that the goal of the administration was to create local alliances to encourage participation of all citizens and make them feel responsible for the history of this city.

This last point is crucial since it has implications for the forms of participation developed in the city. The intercultural dialogue encourages a form of active citizenship by investing in new alliances through the voluntary sector. This approach is rooted in the specific context of the city and emerges from the idea that, above all, institutions should "intercept needs and resources" and "redistribute their richness" throughout the territory. Cesare F. suggested that being a citizen of "the multi-ethnic city" means taking part in the initiatives that concern the residents of the city and promoting respect for diversity and inclusion. In this view, people of migrant background willing to collaborate with the administration were likely to be included in its projects. In order to achieve its goals, the administration supported civic participation in two directions. The first concerned individual participation, by including, for instance, intercultural mediators of migrant background in its innovative projects. The second aimed to involve migrant groups in volunteer activities and to encourage them to promote intercultural dialogue.

Despite their successes, local authorities in Reggio Emilia were also facing some major challenges, and local authorities were also exposed to some criticism from immigrant and pro-immigrant groups active in the city. First, notwithstanding their great efforts to create cooperation among local actors, the Delrio administrations struggled to bring together every institution in the city, particularly the prefecture and the police headquarters $(\mathrm{RE} / \mathrm{N} 10)$. In this respect, several actors recognized that there were limits to the administration's ability to do more in the direction of inclusion, due to the barriers also posed by some local actors (and especially the policy and the prefecture). Second, the intercultural approach encouraged highly conventional or formal participation by immigrant associations at the expense of non-conventional or informal participation. Several interviewees explained that all the organizations in the city, including immigrant associations, have to formalize in order to have a voice, and this fact undermines the vitality of other political expressions in the city that do not fit into the main approach adopted in the city. This aspect emphasizes the fact that there was a tension between the governance of diversity promoted in the city and the attempt to avoid conflicts around migration issues in the city, which resulted in the overshadowing of some relevant issues linked, for instance, to worker rights and the protection of undocumented immigrants. Strong criticism came from members of leftist organizations and immigrant activists working at the forefront of rights of most vulnerable groups in Italy who were exposed to labor exploitation and state repression, because of their precarious status (RE/N11). The emphasis on civic participation and formalized immigrant organizations, moreover, resulted in the depoliticization of the migration issues in the city. Third, Reggio Emilia was strongly criticized for not having one single 
person of foreign origin within the administration. Most of the selected interviewees, who had the question of immigrants' inclusion in the city at heart, were acutely aware of the contradiction of the administration: Despite the fact that Reggio Emilia is one of the most advanced models in Italy, when it came to representation, the city was falling behind (RE/N17). ${ }^{20}$

Despite the challenges described earlier, the city administration showed what local actors can do and how to develop an inclusive approach to immigration based on the material and resources of one's territory. ${ }^{21}$ The link between the "Italy is me, too!" campaign was an example that testified to local administration enduring commitment to promoting greater awareness of the issue of inclusion and encouraging an intercultural approach, including alliances with other local actors and immigrant groups in the city. The Assessor of Cohesion and Security was one key figure in promoting inclusion, but he was able to build on the fertile ground that had been left to him. Thus, according to him and many other actors, the campaign was not a superficial or isolated initiative, but an example of the long-lasting and serious commitment by the Reggio Emilia's administrations to develop new strategies for greater inclusion..$^{22}$ This is remarkable if one considers that most left-wing administrations in Italy, including in the virtuous region of Emilia-Romagna, withdrew almost, if not, entirely from the issue of immigration in the face of growing influence of the securitarian and anti-immigrant discourses, as the example of Bologna illustrates (Chapter 4).

\section{Left-wing cooperatives and the intercultural approach from below}

To understand how the left-wing administrations of Reggio Emilia shaped the local response to immigration in the direction of intercultural dialogue, one needs to look at the specific characteristics of the third-sector organizations and their relationship with the local authorities. In accordance with the Communist, political sub-culture (Campomori 2008), the third sector in Reggio Emilia is composed of a dense web of lay organizations, in particular autonomous cooperatives that provide assistance and promote activities to better welcome newcomers to the city. Some of these organizations are also directly involved in promoting intercultural dialogue. On the official site of the local administration, one can find a list of the main organizations and cooperatives in the city that offer assistance or promote intercultural dialogue. Together with these organizations, the public authorities attempt to construct a system of co-planning, which promotes the entrepreneurial skills of these organizations and their ability to improve the approach over time (RE/N5).

Rinaldo D., a young Italian man in his thirties, and a worker at the Mondinsieme Center, told me how the local administration had encouraged cooperation with the third sector. He saw this approach as a smart strategy and particularly appealing:

The local administration believes in the relevance of networks because it realizes that it cannot be everywhere. Thus, the administration has no other choice but to fill this vacuum through collaboration. If there is a model of inclusion in Reggio Emilia, I would call it an interaction-cooperation model. 
It is linked to the history of Reggio, which has always had a high awareness of community relations. Here there is a great presence of the cooperatives, which means proximity and solidarity and which appeals to the third sector.

(RE/N5)

These points show how other actors in the city approved of the work done by the administration in the direction of the intercultural dialogue, and many well willing to collaborate with local authorities to contribute to promoting inclusion by embracing the same approach.

Under the heading "immigration," one can find all the cooperatives and voluntary organizations that are linked with the social policies of the local administration and address issues of assistance. ${ }^{23}$ Together with the lay cooperatives, the site lists the main branches of the Catholic Church (in particular Caritas and the parishes) and church-based organizations (such as Abram's Home) as part of the city's network. ${ }^{24}$ Thanks in large part to the incentives of the administrations, these organizations cooperate with each other in the provision of basic services for more vulnerable groups and promote Italian language courses (RE/ N7, N8, and N9). Some associations, such as Passa-Parola and Migrant City (Città Migrante) (the radical left organization in the city), offer Italian language courses to undocumented immigrants (RE/N21). Influenced by the administration's emphasis on interculturalism, Caritas promotes intercultural dialogue in the city through intercultural workshops in schools and the involvement of immigrant youth in initiatives that address themes related to understanding cultural diversity (RE/N7). Caritas encouraged the individual participation of a few people of migrant background in its organization by adhering to an initiative of the EmiliaRomagna region that allowed immigrant youth to do social service (which is usually open only to citizens) (RE/N8 and RE/N9).

These organizations focus mainly on assistance approaches to the process of inclusion with an intercultural twist, but one can find a link on the local administration's site to an intercultural center in the city, the Mondinsieme Center, and a list of the immigrant associations in the city, all under the heading "Intercultural dialogue." 25 The administration sees the Center as the symbol of intercultural dialogue in the city. As Assessor Cesare F. explained, "Today the Mondinsieme Center fulfills the crucial role of diffusing the intercultural approach within the territory of Reggio Emilia and beyond." The Center was created in 2001 by the Spaggiari administration to promote intercultural policies and the participation of immigrant associations in the city. Over the years, together with the development of the intercultural approach to inclusion by the Delrio administration, the Mondinsieme Center has expanded its work and activities. The Center's official site stakes out its mission in the following terms:

The Mondinsieme Center focuses on the life experiences of the individual, experiences that, when shared and re-elaborated together, become a common value. In this perspective, those who emigrate or immigrate are not people who need assistance, but have something to offer to society. For this reason 
[the Center] deals with integration as a bidirectional process in a cross-cultural perspective. ${ }^{26}$

I spoke with Mohamed A., a first-generation immigrant who had arrived in Italy from Morocco in the 1990s. At the time of the interview, he was in his fifties and had been the director of the Mondinsieme Center for about 12 years. He explained how important it was for him to promote "a change of viewpoint, that is, we say that integration concerns everyone." He added:

We are more advanced intercultural center in Italy, including in EmiliaRomagna. We created a Center to support active participation. We want to make the youth aware. The Mondinsieme Center is an evolution in the world of immigrant associations. When the Mondinsieme Center refers to the world of associations, it is talking about a very important change. It is a cultural enterprise! We create networks with other cities and among other groups in the city. I am happy to do the things I do in collaboration with the administration.

(RE/N4)

Thus, the Director of Mondinsieme Center showed an important alignment with the views of the local administration. He emphasized a change in perspective and a qualitative leap with respect to the evolution of the intercultural dialogue in the city. Together with the administration, Mondinsieme Center was committed to promoting the intercultural approach to foster a better public understanding of the social processes of inclusion, as well as the social and psychological mechanisms of prejudice formation and the risks of xenophobic attitudes. ${ }^{27}$

In order to promote inclusion, Mondinsieme Center promotes civic participation in several ways. Like many other Intercultural Centers in Emilia-Romagna (Bonora and Giardini 2004), the Center offers a space for immigrant associations to meet and organize their activities. In 2013, there were around 40 immigrant associations that collaborated with the Center or simply held their activities in the Center. ${ }^{28}$ These organizations were of different sizes and included both firstand second-generation groups. They promoted a large number of activities, from providing assistance to their compatriots or the general immigrant community, also in collaboration with the Mondinsieme Center or the administration (see also Mottura et al. 2012, on the associations in Reggio Emilia). ${ }^{29}$

The strong collaboration with second-generation associations is particularly remarkable and testifies to the work done by Mondinsieme Center to promote the participation of the immigrant youth and their involvement in intercultural dialogue (RE/N6). ${ }^{30}$ With its work with second-generation immigrants, the Mondinsieme Center attempts to empower youth and to promote the emergence of a new immigrant leadership in the city. Assessor Cesare F. explained, "The Mondinsieme Center is very precious for us, because it encourages the emergence of a young elite of foreign origin" (RE/N1).

One remarkable example of this was the election of Khalid Cauchi (a young man originally from Morocco) as a member of the House of Deputies in 2013 in Italy. 
He started his political trajectory in Reggio Emilia with the Young Muslims of Italy (Giovani Musulmani d'Italia), which he founded along with other second-generation immigrants (Frisina 2005). The association had strong relationships with the Mondinsieme Center and was very active during the "Italy is me, too!" campaign.

It is also for this reason that, along with the region of Emilia-Romagna, the Center has been encouraging the project Youth in the Net: Protagonism, countering racism and discrimination (Giovani in Rete: Protagonismo, contrasto al razzismo e alle discriminazioni) in order to promote the emergence of mixed youth organizations, such as Network TogethER, while fighting against racism and discrimination. ${ }^{31}$

Network TogethER is a regional intercultural network of associations of young people of Italian and migrant backgrounds of the Emilia-Romagna region, composed of six autonomous associations. It was created in 2008 and has been trying to consolidate its trajectories in the region, with the aim of promoting intercultural dialogue, empowering youth, and fighting against racism in Italy. ${ }^{32}$ During our interview, Sahid A., an Italian citizen and a second-generation Moroccan (M) in his early thirties, who was the President of Network TogethER, explained that this network was an autonomous organization that did not depend on the Emilia-Romagna region or the Mondinsieme Center. He added, however, that it relied on the guidance of the Mondinsieme Center, because the Center had more experience. The Mondinsieme Center was particularly helpful in organizing intercultural workshops in schools. However, while the Mondinsieme Center concentrated on the province of Reggio Emilia, Network TogethER organized the workshops in the rest of the region, including the "Week against Racism" (Settimana contro il razzismo) (RE/N15). The emphasis placed by Sahid A. on the autonomy of Network TogethER is relevant because it signals his desire to show that the network was not an instrument of local authorities, but an independent actor in the local realm of immigration, willing to promote its agenda in collaboration with other actors.

Overall, as illustrated earlier by the examples of second-generation immigrants and the organization Network TogethER, the approach of the Mondinsieme Center has major implications for the participation of people of migrant background in the city. Together with the administration, it promotes a form of participation that coheres with the idea of active citizenship historically rooted in the city. Rinaldo D., in charge of the Communications Office of the Mondinsieme Center, put this point well:

The Mondinsieme Center is the child of the cultural, economic, and social habitus of the social tissue of Reggio Emilia. It is about active citizenship by citizens in terms of volunteer work and other aspects of civic participation, which, in turn, can also be applied to the question of integration. At the local level, there are no other similar experiments in Italy. Immigration is seen either through the lens of needs - the delivery of services, health care, and housing - and thus strictly linked to welfare (and in this case, people of foreign origin are seen exclusively as in need of welfare) or from the point of view of the militants [where] the emphasis is on the rights of asylum seekers and undocumented immigrants (the "clandestini"). But if you can look through the lens of diversity advantage, you will realize that integration crosses all spheres 


\section{Civic participation}

of society and that it affects the sphere of economic performance, for instance, as well as the urban dimension. Thus, attending to rights is important, but the question of the cultural process is also crucial. This is also a gamble, right?! One day someone will grasp the meaning of the work we are doing.

(RE/N5)

This view also explains why the Mondinsieme Center has moved away from the classical understanding of participation by immigrant associations (often conceived as separate entities - see, e.g., Chapter 6, on the case of Bergamo). On the contrary, just like the administration, it encourages the participation of people of migrant background in existing or new organizations that support the idea of Reggio Emilia as a multi-ethnic society. This explains also why the Mondinsieme Center places its major investment in the associations that promote this vision of Italian society, an attitude that moves beyond the ethnicization of the immigrant community (RE/N1, RE/N3, RE/N4, RE/N5, and RE/N6) to promote cohabitation between "old" and "new" Italians.

\section{De-politicization of immigrant rights claims by leftist trade unions and political parties}

\section{The communist trade union and the end of alliances with immigrant workers}

Favored for its leftist political orientation, the CGIL is the most important union in Reggio Emilia. In 2012, around 117,600 people were enrolled in the CGIL of the province, compared with around 37,000 workers in the CISL. Of the total number of people enrolled in the CGIL, 49,190 were active workers and 11,100 were immigrants. ${ }^{33}$ Since the 1980 s and 1990s, the union has played a crucial role in the area of immigration by promoting two main approaches to inclusion: assistance and promoting political rights. It has been recognized as particularly invested in promoting greater participation of its workers-Italians and people of foreign origin alike. The Reggio Emilia branch of the CGIL, along with the CGIL of Brescia, is considered one of the most radical local branches in Italy.

Here, the ideological position of the CGIL has implications for the approach to inclusion adopted by the organization and its capacity to open channels of participation (RE/N11). A more radical approach by the CGIL goes hand in hand with more investment in immigration and a greater focus on political participation, including specific platforms for immigrants' organizing (e.g., the Migrants Coordination Organization; Marino 2015). According to one of my key informants, the CGIL started to invest in immigration in Reggio Emilia before any other organization. In 1989, the trade union pushed the local administration to open an Office for Foreigners to help the first immigrants arriving in the city. Around the same time, the CGIL opened its own Office for Foreigners to offer services to immigrant workers. With the support of the Office for Foreigners, the CGIL created a Migrants Coordination Organization in 1995 to give a voice to immigrants within 
its own organization and throughout the territory of Reggio Emilia (Marino 2012; Rinaldini and Marino 2012). My interviewees agreed that in the past the organization was a relevant feature in the city and was able to promote immigrants' political participation (RE/N11 and N12). Farooq M., an immigrant man from Pakistan who was working for the Office for Foreigners of the CGIL, explained that the Office for Foreigners served as a pilot scheme:

At one point, immigrant delegates got together and created the Migrants Coordination Organization. It was a very important space to talk and discuss our issues. At the time the CGIL was very visible, was present during the negotiations with institutions and during the organization of mobilizations of immigrant workers.

(RE/N12)

However, since the second half of the 2000s, the CGIL had been doing very little in the direction of political rights promotion, and the situation worsened during the financial crisis. As Farooq M. explained: "The CGIL focuses only on service delivery now and has stopped doing politics!" Many other members of the CGIL that I interviewed complained about this fact, because they believed the CGIL had "lost its vocation" (RE/N13). Moreover, this was particularly frustrating for many of them, as they had allied with these trade unions because of its commitment to workers' rights. In this respect, many were critical mostly of the political change in the CGIL as it was for Sarah K., an Italian woman originally from Algeria, who was openly communist and a Functionary of the CGIL-FIOM. She believed that the CGIL had lost its vocation of fighting for workers' rights.

Clara A. was an Italian woman in the fifties and the person in charge of the Office for Foreigners, succeeding Mohamed A (at the time the Director of Mondinsieme). She was a key promoter of the activities of the Migrant Coordination Organization during her tenure and a very critical person of her own organization. During our interview, she explained it was not easy to promote the participation of immigrant workers because the Secretary of the CGIL at the time "did not want to expose himself on the issue of immigration and often discouraged the political initiatives of the Office." Clara A. complained that the Migrant Coordination Organization was no longer working, and this was a serious problem "because immigrants are not coming to the CGIL anymore." This lack of attention to political issues around migration reflected the de-politization of issues about immigrant workers' rights in the city and the low level of representation of people of migrant background in the organization. This mechanism resulted in the exclusion or marginalization of many immigrant activists in the organization.

What is more, opportunism and mistrust (when not outright racism) toward immigrants discouraged major figures within the organization from treating immigrant members as equal. For these reasons, according to Farooq M., most Migrant Coordination Organizations across the country had disappeared from the CGIL. "The immigrant is considered in relation to bureaucratic procedures and no one really cares anymore about their real situation!" According to Farooq M., this was a big problem for immigrants' participation in the city. The Migrant Coordination 
Organization had been able to mobilize a large number of migrant workers, and because of the crucial role of the organization in the past, "no other actor in the city was able to mobilize immigrants the way we did!" For this reason, the loss of the Organization "has left a hole in the city at the level of immigrant workers' political activism and mobilizations" (RE/N12).

The CGIL faced two major interrelated challenges. Reda B. was a member of the Democratic Party and an Italian citizen of Tunisian origin in his early thirties. $\mathrm{He}$ explained that one major problem was that traditional trade unions had grown too old and were now unable to offer adequate responses to a changing society (RE/N18).

The second problem was the financial crisis, which was having an enormous impact on immigrants' working and juridical conditions and was affecting the unions' ability to offer adequate responses. Carmela R. of the CGIL told me: "The crisis is hitting immigrants a great deal because they work in the mechanical and construction sectors. Many of the firms in this sector have failed" (RE/N10). Sahid A. added:

Today it is very hard to be a unionist, because all the instruments we used to have before do not work anymore. Industrial relations are changing very quickly. However, this does not mean that the union does not have to be there. The union is necessary to protect people and mediate in the workplace.

(RE/N15)

In this respect, many strongly criticized the trade union for its lack of attention for some vulnerable labor sectors that were lacking protection.

The Democratic Party, unequal treatment, and weak incentives for the political rights promotion approach

The main political party in Reggio Emilia, the Democratic Party, is a very strong actor. In collaboration with the administration, it was one of the main local actors promoting the "Italy is me, too!" campaign, through the Provincial Forum of Immigration. I interviewed Reda B. when he was still the local councilor in Quattro Castella (in the province of Reggio Emilia), and had been in charge of the Provincial Forum since 2010 (RE/N18). He explained that the Provincial Forum was developing quickly because it benefitted from the work done by the regional and local branches of the party. At the regional level, the Democratic Party of the Emilia-Romagna region had created a Regional Forum, which was coordinated by Cecile Kyenge since 2010, until she became Minister of Integration in 2013. The Forum in Emilia-Romagna was the only one in Italy, and it "allowed the creation of an adequate space to coordinate the work of the Provincial Forums and share the 'good practices'" (RE/N18).

Reda B. helped me to reconstruct the activities of the Forum in the territory in order to offer a sense of its areas of intervention. At the national level, the Provincial Forum focuses on issues related to immigration policies (such as resident permits, family reunifications) and on the universal values expressed in the Italian Constitution. Furthermore, the Provincial Forum discusses the line of the Democratic Party 
on a whole range of immigration issues, including the right to vote and the jus soli, the situation of detention centers and refugees, and immigration policies.

I asked Reda B. about the roles of the Provincial Forum in Reggio Emilia and the Democratic Party in supporting political participation by immigrants in the city. $\mathrm{He}$ explained that the party sought to move toward the new generations. This point was acknowledged by many actors in the city. However, he also explained that there were major problems in promoting a political leadership of the youth within the party.

We try to encourage participation among the "new citizens." On these occasions we go beyond immigration issues and we address themes of interest for the Democratic Party as a whole. Many new Italians recognize the Forum, but they struggle to recognize the Democratic Party. They come to the meetings organized by the Forum, but not to those organized by the Party.

This quote refers to the fact that the people who joined for Forum were not interested in party's events, and this was mostly because they did not trust the organization, also because it made very little effort to include immigrants in its organization. Francesca F., a member of the Democratic Party, expressed a similar point. During the interview, she showed frustration concerning the barriers at the level of representation of immigrants in the political party:

In a city like Reggio Emilia, so progressive and inclusive, it is unacceptable that there has yet to be a councilor [of immigrant origin] in the city. Reggio Emilia, the city of intercultural dialogue and the city of the people! Now, we need to let them go where decisions are made. Let them represent who they are, their ideas and their points of view. It is of paramount importance to make a qualitative leap in this direction.

(RE/N17)

Thus, as most interviewees in Reggio Emilia show, there was great resistance in the Democratic Party to properly investing in promoting immigrants' inclusion and pushing for substantial immigrant participation in the party. The reasons for this resistance will be further explored in Chapter 7, where I will explain how the Democratic Party imposes systematic barriers to immigrant activists trying to develop

a political career in their organizations, thereby producing political racialization of immigrant activists. This issue was not unique to Reggio Emilia, but part of a larger problem of left-wing political parties and trade unions in the country.

\section{The intercultural dialogue and implications for participation in civic channels}

The role of Italian organizations and their approach to inclusion need to be combined with a consideration of the role of immigrant activists in the city. Depending on the channels opened up and the alliances they were able to form with leftwing actors, immigrant activists could play their role in shaping the local realm of 
immigration in the city and establish channels of participation. Immigrant activists who created strong alliances with the left-wing administration were able to shape their own trajectory of participation and resisted dynamics of co-optation, clientelism, and unequal treatment vis-à-vis left-wing actors in the city. What is more, by appropriating the discourses and practices of intercultural dialogue promoted by the local administration and the third sector, they contributed to shaping the local realm of immigration in the direction of interculturalism and encourage participation by other people of migrant background (including Italians). Overall, these examples show that successful alliances with moderate local actors represent a combination of ideological affiliations and pragmatic considerations by immigrant activists, closely associated with local actors' capacity to open up channels of participation for these individuals. Finally, the analysis has demonstrated the diminished capacity for people of migrant background active in the CGIL to interact with the organization in a meaningful way. This situation changed when the right-wing government got in power in 2006. While during the first half of the 2000s, the CGIL had encouraged more participation and mobilization by immigrants, by the second half of the 2000s it was focused more on service than on politics. These developments severely restricted the ability of immigrant activists to participate in the organization and to open up channels of political participation for themselves and others.

\section{Immigrant leadership and alliances with institutional actors}

The immigrant activists who had been most empowered in Reggio Emilia were those working in close collaboration with the local administration or in other organizations largely promoting the intercultural approach in collaboration with the administration. At the individual level, some key alliances can be observed between the local administration and people with older trajectories of migration, and second-generation activists. As a way of example, two successful trajectories of inclusion will be mentioned here, which give a sense of the work done by key local actors in the city. The first example is that of Mohamed A., the Director of the Mondinsieme Center (2001-2014), who was originally from Morocco. He arrived in Reggio Emilia in 1985, in his 20s, to study at university. At the time of the interview, he had been the Director of the Mondinsieme for more than 12 years. He explained that, in Morocco, he was a leftist political activist when he was a university student. In the 1970 s, there was a great desire to be emancipated in the developing world and many young activists left to study abroad. He was drawn to Bologna by the figure of Antonio Gramsci, his understanding of class struggle, and the role of the Communist Party in Emilia-Romagna. The second example is Sahid A., who was an Italian citizen and second-generation immigrant from Morocco. He was the President of Network TogethER since 2008 and functionary of the CISL since 2010. Born in Morocco in 1985, he moved to Reggio Emilia with his parents at the age of six. He married an Italian woman, with whom he had a child. In 2008, he founded the association Network TogethER and he has been its coordinator since then. He was also a functionary of the CISL and in charge of the CISLANOLF since 2010. At the CISL, in addition to offering assistance to immigrants 
and carrying out unionist work in the surrounding territory of Reggio Emilia, he was also in charge of political-administrative decisions on matters of immigration - a role that very few immigrants working in trade unions have held in Italy.

Both Mohamed A. and Sahid A. spent many years in Reggio Emilia and were both very proud to be active in the city. They felt lucky to be living in a territory that they considered to be open to immigrants and which they could thrive. Sahid A. explained that Reggio Emilia was a "happy island" in the Italian context:

When we move from one region to another, the other people tell us that they can't put in practice what we do. And this is not only with respect to interculturalism. This year, Emilia-Romagna has produced three ministers, including Cécile Kyenge, the Minister for Integration. This region is a point of reference for all the other regions of Italy. With respect to the other regions, we are faring pretty well ... and Reggio Emilia represents a model in many respects.

(RE/N15)

Mohamed A. expressed a similar point:

Reggio Emilia is the city of the people. For me it exists as a model. Here, everyone participates and takes part in the activities of the city. People think about the social. This context affects you in positive way. This can be observed among immigrant leaders too.

(RE/N4)

They both acknowledged that it was partly for this reason that they had been able to develop their skills of leadership over the years, thanks to the multiple channels of participation opened up in the territory by local actors. Thanks to the idea of "active citizenship" promoted in the city, they were able to share their individual capital and put it at the service of the community. As director of the Mondinsieme Center, through his hard work and experience, Mohamed A. was able to strengthen the Center and transform it into an important think tank in EmiliaRomagna. Thanks to his work, the Center became more visible in the city and was able to support a "qualitative leap" toward the intercultural dialogue proposed by the administration. Among other things, his role was crucial in encouraging youth participation (of both Italians and immigrants) in the direction of intercultural dialogue. Similarly, Sahid A. was a key figure in promoting the intercultural approach. He described Reggio Emilia as a multi-ethnic society in which each individual could contribute actively to improve interaction. Through collaborations between Network TogethER and the Mondinsieme Center, with his network, he promoted anti-racist campaigns and intercultural workshops in the schools of the territory of Reggio Emilia and advanced the idea that Italy was changing so fast that new strategies were necessary to understand society.

We are in a society that is starting to close . . people fear others. We want to be a group of young people and of associations that deal with the issues that will concern the society of tomorrow. Italy will have to deal with a world that 
is more and more plural. We are not living in homogenous societies anymore. We must start imagining this society ... because a state can formulate the laws, but if those laws are not supported by a culture, then that law has no foundation. We want to help people have the tools to face the challenges of a plural society.

(RE/N15)

During our second interview, Sahid A. added:

The process of inclusion must be supported. . . . We need to build the basis of cohabitation beyond ideological conflicts. Integration concerns neighborhoods, work, schools, and social life. It is of paramount importance to create harmony with the local society. . . . If you want a person to give the best of him- or herself, you have to support pathways of openness among people who live in the territory. Also, we need to use lots of pragmatism and start from the concrete realities of a territory and build from that.

(RE/N15)

This quote shows how Sahid A. shared the same vision of other actors in the city promoting the intercultural dialogue. The main point was to work in the direction of accompany the processes of transformation linked to immigration and to promote inclusion for both old and new Italians. It was emphasized the need to move beyond the distinction "Us" versus "Them" and start talking about society as a whole: "For me it is crucial to move beyond a distinction between Italians and immigrants. We need to work with everyone!"

The two examples presented here show that when it comes to including immigrants through the promotion of an intercultural approach, the city of Reggio Emilia was able to foster immigrant leadership in ways that no other city has been able to do in the national context. Thus, the specific power configuration in the city - and the development of intercultural dialogue as the dominant approach to inclusion-favored mainly civic and formalized channels of participation, resulting in the creation of alliances with some groups of immigrants with institutional actors. However, as the following analysis will show, other groups of immigrants felt alienated in this local context, namely undocumented immigrants and immigrant workers, and several barriers imposed by other local actors impeded several immigrant activists to have a voice in the city.

\section{Weak political participation and the end of alliances with main left-wing actors}

Immigrant activists who had allied with the CGIL and the left-wing political party experienced significant difficulties in becoming agents of change in the city. One of the main immigrant activists in the CGIL for many years, Farooq M., exemplifies this point. Farooq M. was a first-generation immigrant. He was born in Pakistan in 1975 and moved to Reggio Emilia at the age of 21 in 1996. He had earned a university degree in Mathematics in Pakistan. In Italy, he married a woman from Pakistan. He moved to Italy because it was a gateway into Europe, but he would have preferred 
to go where his degree could have been valued more. He arrived without documents and was regularized thanks to an amnesty launched in 1996. In 2013, he was very active in the world of associations and he had been president of the Pakistani association at the provincial level for seven years. He was also active in the voluntary sector and participated in events that promoted cohabitation between Italians and migrants. Farooq M. believed in civic activism as a means to create the conditions for dialogue between the Italian and the immigrant communities. Between 1996 and 1999, he worked as a metalworker, and between 1999 and 2006 he worked in a factory that did injection molding. He was very active in the workplace and was a delegate of the CGIL. Since 2002, he volunteered for the CGIL's Office for Foreigners. In 2006, the CGIL asked him to become a functionary of the Office.

In describing his participation in the CGIL, Farooq M. explained that in the past, he had been proud to be an immigrant activist in the Migration Coordination Organization of the CGIL, because it was extremely active and visible. He said that the CGIL was able to make immigrant workers aware of the meaning of representation in the workplace and was a key actor in helping them understand political participation.

We were able to mobilize immigrant workers and to exert pressure to change things in the city. The strength of the Migration Coordination Organization was that it was managed by immigrants and was able to give them the space they needed to frame their rights claims.

(RE/N12)

However, everything had changed in the second half of the 2000s, when the CGIL stopped encouraging participation and political activities of immigrants. He explained: "In my opinion there was a will to fly low when it concerned immigrants' rights! Migrant Coordination Organizations have disappeared from the territorial branches of the CGIL. This means that this was something intentional."

According to Farooq M., the end of the Migration Coordination Organization also marked the end of true political participation of immigrant workers in Reggio Emilia, and he was not sure how things would evolve in the future. As far as his personal trajectory was concerned, he planned to leave the country and join his family in England. A year later, when he moved to Great Britain, he wrote me an email saying: "Unfortunately, the anti-immigrant politics of the Office for Foreigners of the CGIL forced me to leave a role that had become only bureaucratic and non-political." Farooq M.'s experience speaks to the impossibility for people of migrant background active in the CGIL to interact with the organization in a meaningful way. His testimony demonstrates how the organization willingly blocked the participation of immigrant workers in the city. This signaled the end of the alliance between this key pro-immigrant organization and several immigrants in the city, who like Farooq M. felt the strong sense of exclusion produced by the CGIL.

Another actor criticized in the city was the Democratic Party. Criticism was less strong than the one against the CGIL, but relevant nonetheless. There was a recognition that the Party in Reggio Emilia encouraged participation through 
the Provincial Forum of Immigration, a platform dedicated to fostering debate on immigration within the party. It attracted some people of migrant background.

Like many interviewees in the city, a member of the Democratic Party, Reda B., was grateful to live in Reggio Emilia. Yet, he was extremely critical of the Party as he believed there was "no equal treatment" of immigrants. Reda B. was a secondgeneration immigrant, born in Tunisia in 1985. He moved to Reggio Emilia at the age of 13 , in 2000 , thanks to a family reunification. His parents had been living in Italy since the 1980s. After gaining his degree in a technical school, he worked as a metalworker. Reda B. has been married to a woman from Tunisia since 2011, is a Muslim, and has had Italian citizenship since 2006. He told me that three months after receiving his Italian citizenship, he decided to run for elections with the Democratic Party, and in 2006 he became a councilor in Quatro Castella (province of Reggio Emilia). He adhered to the political orientation of the Democratic Party and its political position on immigration. This is why he decided to become more involved over the years at the national level as well. In 2010, he became the promoter of the Provincial Forum of Immigration of the Democratic Party of Reggio Emilia, and since then he has been the person in charge. Reda B. explained that, before the Forum, there were other attempts to create strong networks, but it was often hard to create a platform for participation. He promoted the idea of the Provincial Forum in Reggio Emilia because he wanted "to open up a space, hoping that the confrontation would allow the development of discussions on immigration issues," which was still lacking according to him.

Other interviews with immigrant activists close to the Democratic Party confirmed that this important pro-immigrant organization deceived immigrant communities, even in the generally more supportive context of Reggio Emilia. For this reason, despite its recent efforts to create a Forum to discuss migration issues, the political party was unable to construct strong alliances with the migrant population as mistrust among immigrant activists was particularly strong. As I will further explain in Chapter 7, immigrant activists identified some fundamental problems in the political party such as co-optation, prejudice, instrumental use of migrant causes, marginalization of their voices, and lack of interest in the development of their career in the organization. These aspects will be further explored in Chapter 7, where the book will explain why this is the case, by looking at the mechanisms that produce political racialization.

\section{Lessons from Reggio Emilia}

The analysis of the local dynamics at work in Reggio Emilia has offered an important opportunity to answer the questions of why and how the campaign "Italy is me, too!" was organized in this city and not in other Italian cities, and why and how it involved certain pro-immigrant and immigrant groups and not others. In particular, I have demonstrated why and how local actors can provide opportunities for immigrants' participation in urban settings, why immigrant activists form alliances with some pro-immigrant actors rather than others, and why and how they develop certain forms of participation and rights claims over others. 
The organization of the "Italy is me, too!" campaign manifested the vital role of the local left-wing administration in the area of immigration and its ability to encourage the involvement of other local actors through top-down initiatives. As suggested by the promotion of the "Italy is me, too!" campaign by the left-wing administration, Reggio Emilia stood out in the national context for its capacity to engage with the area of immigration in a unique way. It developed an innovative approach to promote inclusion involving all sectors of society in the direction of the intercultural dialogue. It also created networks at the Italian and European levels to promote the exchange of good practices and stimulate a broader debate. This testifies of the important engagement of the local administration in the promotion of the inclusion of immigrants in the city. The important role of the administration in the city was recognized by the vast majority of interviewees.

The overall picture described in this chapter has also highlighted the strong level of cooperation between local actors involved in immigration, including immigrant organizations, particularly second-generation groups and more established immigrant groups. The dense and cooperative network of third-sector organizations was shown to be crucial in shaping the local engagement with immigration in the direction of assistance and interculturalism. The aforementioned analysis also establishes that the specific nature of the third sector enabled the "qualitative leap" promoted by the administration, because it worked toward not only protecting people in vulnerable conditions (assistance approach) but also investing in exchanges between the receiving society and people of migrant background (intercultural approach). In particular, the Mondinsieme Center's intercultural approach moved beyond a simplistic valorization of diversity towards a more comprehensive approach to the construction of a multi-ethnic society. Its work with youth and second-generation immigrants in particular helped to promote a better understanding of the processes involved in including immigrants in a society significantly transformed my global processes, including mass migration.

In line with the theoretical model presented in Chapter 2, what was remarkable about the approach to inclusion adopted by the main actors in the city was not simply what they were doing, but also how they were doing it. The intercultural approach did not just seek to valorize diversity and pluralism but rather ventured to help build the plural society of the future. Central to the discourses and practices of these actors in the city were several strategies that helped to generate the "qualitative leap" and go beyond the "us" versus "them" distinction. Its most innovative aspect was that of talking with citizens- "old" Italians, new Italians, and the immigrant population at large. In addition, the specific approach developed in Reggio Emilia by the dominant actors tended to encourage primarily civic participation on the part of immigrant groups. Several individuals and immigrant groups were included in the intercultural initiatives promoted in the city and were given space and resources to further develop this approach. This specific urban setting explained why several immigrant activists - particularly secondgeneration immigrants and immigrants with longer trajectories of immigrationforged alliances with the local administration and other organizations in the city who were opening up civic channels. In particular, it was precisely because these 
activists appropriated the dominant intercultural approach that they were able to shape their own trajectory in the city and contribute to the intercultural approach in collaboration with others. At the same time, other immigrant activists-for example, undocumented immigrants and immigrant workers - who sought other means to make their voice heard, were silenced and marginalized in the city. Not only other local organizations did not offer substantial support for their claims, but they also produced what I call political racialization, via mechanisms of silencing their voices and inequal treatment, as I will further show in Chapter 7.

Beyond the case of Reggio Emilia, this chapter offers an important insight into how an intercultural approach to inclusion from above can foster participation and rights claims on the part of immigrant activists. Today, interculturalism "is considered to be the most pragmatic answer to concrete concerns in cities and their plans for the future" (Zapata-Barrero 2015, viii). This is why we have assisted what Zapata-Barrero (2015) calls the intercultural turn by many progressive administrations in Europe. In the migration literature in Europe, "intercultural" is presented as both a theoretical concept and a practical strategy deployed by policy-makers to manage diversity in cities (Zapata-Barrero 2015; Caponio and Ricucci 2015). Further developments of this approach have been strongly encouraged in order to improve policy so as to better respond to the challenges of increasing diversity (Cantle 2012). However, there is still a pressing need to understand not only when and how interculturalism works in practice, in governmental policy or local implementation (Zapata-Barrero 2015), but also how it can promote or hinder immigrants' civic and political engagement in receiving society. Beyond the debate on intercultural policy, the analysis presented here is relevant because, unlike most research that focuses on the impact of interculturalism on social inclusion (Caponio and Ricucci 2015), this chapter draws a clear link between the intercultural approach and civic and political rights, setting out exactly how it may encourage or hinder both civic and political participation of people of migrant background in cities.

An acknowledgment of the merits of the intercultural approach in the city of Reggio Emilia needs to be combined with a closer look at other aspects of inclusion that are missing in the city. The findings presented here suggest that the intercultural approach, if not combined with other approaches to inclusion, can also encounter some important limitations. The presence of strong left-wing institutional actors and their dominant intercultural approach have had an impact on the forms of participation of people of migrant background: their presence has encouraged conventional forms of civic participation (individual and collective) over political participation. While civic participation (mainly in formal channels) was strongly encouraged, in terms of political participation the local actors invested in a limited way in respect of the political rights promotion approach. A de-politization of immigrant rights claims by most organizations in the city could be also observed. This de-politization speaks of an attempt to avoid complex, conflicting issues around immigrant workers' and undocumented immigrants' rights, and to silence immigrant activists who have political demands on these matters. The lack of a strong presence of radical left actors in the city resulted in a lack of support 
for these issues in the city. The radical left organization, Migrant City, was a very weak actor in the local context. They launched many initiatives to encourage local institutions to do more to improve immigrants' conditions in the city and were very active on refugee issues. However, these actors were not able to open up relevant channels of political participation, for more vulnerable groups, and rights claims by these groups found very little space to be expressed in the city.

In the next chapter, I turn to the other traditionally Communist city of Bologna. I will show that here local actors investing in the realm of immigration and interactions among actors were very different from Reggio Emilia. The specific local dynamics in this city resulted in the promotion of some key alliances with radical left organizations, for instance, as well as the promotion of various forms of immigrant participation and rights claims. These outcomes were unique if compared to the other cases examined in this book.

\section{Notes}

1 As Campomori and Caponio $(2013,172)$ show in their study of Italian regions, there has been an attempt to create a qualitative leap in the direction of inclusion, especially in the left-wing regions in Italy. This can be seen in the evolution of regional policies toward a "would-be citizens frame," that is, an approach that "looks at immigrants as permanent settlers and would-be citizens" rather than as temporary workers. The main region in Italy to promote this approach has been Emilia-Romagna (with the introduction of a regional law on integration in 2004, which stresses the intercultural approach as a viable governance strategy to address challenges and conflicts concerning immigrants' inclusion). At the local level, the city of Reggio Emilia is one of the main promoters of this approach in Italy. In this view, the intercultural approach openly challenges the assistance approach, and it is presented as an attempt to promote a "qualitative leap" in how actors in society address the issues of migration and inclusion. More specifically, this approach strives to create a more welcoming context to improve cohabitation and, at the same time, encourages the involvement of immigrants in the world of associations. Cf. also Region Emilia-Romagna (2004) Regional Law 24 March 2004, n. 5 "Norme per l'integrazione sociale dei cittadini stranieri immigrati." $\mathrm{http}: / /$ demetra.regione.emilia-romagna.it/al/monitor.php?urn=er:assemblealegislativa: legge:2004;5 (Accessed May 20, 2020).

2 A briefer analysis on Reggio Emilia has been published previously in Cappiali (2018). For a complete list of the interviews in the city of Reggio Emilia, see Appendix B.

3 Jus sanguinis (or, "right of blood") refers to the legal principle of acquisition of citizenship based on the nationality or ethnicity of one or both parents. Children at birth may be citizens of a particular state if either or both of their parents have citizenship of that state. The principle of Jus soli (or, "right of soil"), instead, is the right of citizenship based on the fact that a person is born in a specific territory, or state, independently from the nationality or ethnicity of the parents. Many states combine both principles. Italy still applies prevalently the jus sanguinis principle. The procedures to acquire citizenship for children born from foreign parents is complicate and not easy to obtain.

4 In opposition to EU citizens, virtually all non-EU citizens have no local voting rights in Italy (Groenendijk 2008). In order to guarantee the promotion of some basic civic and political rights, in 1992, the Council of Europe adopted the Convention on the Participation of Foreigners in Public Life at the Local Level (Council of Europe 1992) with the aim of encouraging the active participation of foreign residents in the life of the local community and the development of its prosperity by enhancing their opportunities to 
participate in local public affairs. As the official document states, "The Convention aims to improve integration of foreign residents into the life of the community. It applies to all persons who are not nationals of the Party and who are lawfully resident on its territory" (Council of Europe 1992). The Convention is made up of three fundamental parts. First, foreign residents should be granted the right of "freedom of expression, assembly and association," including the right to form trade unions (Chapter A). Second, the Convention opens the possibility for the creation of Consultative Bodies at the local level (Article 5), elected by the foreign residents in the local authority area or appointed by individual associations of foreign residents (Chapter B). Third, Article 6 invites national authorities to grant foreign residents the right to vote in local elections and stand for election in local authority elections after five years of lawful and habitual residence in the host country. However, this latter article is optional and countries that ratify the Convention can choose to drop it. As can be read in Article 7, it is at the discretion of the Member States to grant (or not) "the right to vote." Currently, out of 44 Members of the Council of Europe, only 11 Member-States have signed up and eight have ratified this Convention. Italy ratified the Convention in 1998 with the Turco-Napolitano Law (Parlamento Italiano 1998). Moreover, the state is also encouraged to inform foreign residents about their rights and obligations in relation to local public life.

5 See official site: www.litaliasonoanchio.it and the campaign's channel on YouTube: www.youtube.com/user/litaliasonoanchio (Accessed June 20, 2015).

6 See the official site of the municipality: www.municipio.re.it/retecivica/urp/retecivi. nsf/0/5326756FDCFCA76EC1257919003CE7A8?opendocument\&FROM=Ltlsn nch2 (Accessed June 20, 2015). At the national level, the campaign was promoted by 22 civil society organizations. For a list of the main organizations involved in the campaign, see the page "Who we are" (Chi siamo) on the official site: www.litaliasonoanchio.it/index.php?id=521 (Accessed June 10, 2015).

7 "Mondinsieme" is a combination of two words: "world" and "together."

8 For a complete list of the members of the committee, as well as some of the initiatives promoted by the administration of Reggio Emilia and the other local organizations, see www.municipio.re.it/retecivica/urp/retecivi.nsf/PESIdDoc/0D761E7B331DC137C12 57C2B002E167B/\$file/Comunicato\%20stampa.pdf (Accessed June 10, 2015).

9 See the official site of the campaign: www.litaliasonoanchio.it/index.php?id=584 (Accessed June 20, 2015).

10 The numbers in Reggio Emilia were exactly 5,423 signatures for the citizenship law and 5,634 signatures for the right to vote. The campaign collected more than 18,000 signatures for each proposition in Lombardy, more than 15,000 in Emilia-Romagna, more than 11,000 in Piedmont, around 6,000 in Lazio, and 1,700 in Campania. See the official site of the municipality of Reggio Emilia: www.municipio.re.it/retecivica/urp/ retecivi.nsf/0/5326756FDCFCA76EC1257919003CE7A8?opendocument\&FROM=L tlsnnch2 (Accessed June 20, 2015). See also V. Polchi. “'L'Italia sono anch'io': 110 mila firme. Consegnati alla camera due ddl popolari." Repubblica.it. March 6, 2012. www.repubblica.it/solidarieta/immigrazione/2012/03/06/news/italia_sono_anch_io_ firme-31025368/ (Accessed June 20, 2015).

11 Nine years after the campaign, the Italian parliament has failed to change the citizenship law and to grant the right to vote to non-EU immigrants. Heated debates have taken place since 2011, especially on the introduction of the Jus soli principle. These debates are mostly ideological and political leaders fail to use existing scientific research to support their arguments. They reveal the anti-immigrant climate promoted by anti-immigrant parties in the past decade in Italy and the fear of other political leaders to support a change in the current legislation.

12 See the official site of the municipality of Reggio Emilia: www.municipio.re.it/retecivica/ urp/retecivi.nsf/0/5326756FDCFCA76EC1257919003CE7A8?opendocument\&FRO $\mathrm{M}=$ Ltlsnnch2 (Accessed June 10, 2015). 
13 See in particular the project with second-generation immigrants, "Inside Out." www. spaziogerra.it/2012/09/08/inside-out-litalia-sono-anchio/ (Accessed June 20, 2015).

14 www.anpireggioemilia.it/la-resistenza-reggiana/ (Accessed June 20, 2015).

15 See the pamphlet Vivere a Reggio Emilia. Vademecum per $i$ cittadini immigrati. www. provincia.re.it/page.asp?IDCategoria $=701 \&$ IDSezione $=4245 \& I D=92947 \quad$ (Accessed June 20, 2015).

16 For more details on the various experiences of Consultative bodies in Europe, see, for instance, Gsir and Martiniello (2004).

17 In 2004, the Council of Europe launched a project to create networks and exchanges between cities that were experimenting with "good practices" of inclusion. Its official website dedicated to the program of the Intercultural Cities is: www.coe.int $/ \mathrm{t} / \mathrm{dg} 4 /$ cultureheritage/culture/Cities/origin_en.asp (Accessed June 20, 2015).

18 See document of the Municipality of Reggio Emilia, "Reggio Città del Dialogo Interculturale: Le politiche del commune." www.municipio.re.it/retecivica/urp/retecivi.nsf/ PESDocumentID/4B91F3CC51106CADC12578BD0034B0D6?opendocument\&FRO $\mathrm{M}=$ Pltchmblt2 (Accessed June 20, 2015).

19 Cesare F. went on explaining how the city moved away from an assistance approach:

Before, we were more protected, because "the social" [welfare] has been always very powerful in Reggio Emilia and it has many functionaries who work in the field. However, if we had remained in that domain, we would have been locked into that framework without a way out, and without the possibility to stretch our influence in other fields and thus to create new possibilities of action toward inclusion. So, in 2004, we said: "Enough!" Thus, between 2004 and 2007, the intercultural approach received a theoretical infusion by breaking with the approaches of the past. It was possible to put at the center of the debate the importance of individual self-determination. I think that the most important change can be seen in the way we seek to frame the theme of immigration. It is no longer something that concerns just migrants and receiving institutions, but all citizens and thus the entire society as a whole. Hence, in these last years, the debate has reawakened and regained vitality. The initiative of 'the cities of the dialogue' is important because it re-launches the debate on integration in Italy. In Reggio Emilia, we understood we had to talk with all the citizens and to move away from the viewpoint that we had to talk only with immigrants. Hence, when we talk about "intercultural dialogue," we have to understand that it is, indeed, a strategy, a political project. It is a strategy that aims to create an alliance between all the Reggian citizens and the local authority.

(RE/N1)

20 Moreover, many interviewees also expressed the fear that the model of Reggio Emilia would soon crash as an effect of the financial crisis and economic restructuring. They observed that, in a time of crisis, it became increasingly difficult to manage social conflicts and guarantee social cohesion. As Teresa E., a young Italian woman in her thirties and cultural mediator employed by the administration explained:

Today we don't have the social system we used to have. There is no money anymore. We are missing the resources to create the professional figures able to promote the structures that can answer to the needs of a changing society.

(RE/N2)

21 It is also remarkable that, in May 2010, Reggio Emilia became the promoter (in collaboration with the Council of Europe) of "The Italian Network of Intercultural Cities" to encourage intercultural dialogue across the country. Composed of 23 cities, the network aims to create collaborations on the themes of integration and governance, and to share "good practices" of inclusion. See the official site: "The Italian Network of Intercultural Cities.” www.coe.int/t/dg4/cultureheritage/culture/Cities/Italy_en.asp 
(Accessed June 10, 2015). Before, in 2004, the Delrio administration decided to participate in a project launched by the Council of Europe, a creation of the "Network of European Cities" designed to promote the exchange of intercultural practices of integration. Thanks to its experimental approach to inclusion, Reggio Emilia was selected in 2008 by the Council of Europe to take part in a project called "Intercultural cities: Governance and policies for diverse communities" (see Wood 2010). By 2014, 12 cities of the EU had participated in the program. The Assessor Cesare F. further explained what it meant to be an intercultural city according to the Council of Europe, and how this was perfectly in line with the approach already developed in Reggio Emilia:

The Council of Europe indicates the general approach to follow. The idea is an integrated approach to governance by the municipality. Governance is to be brought forth from the collaboration between local authorities and the third-sector organizations, the trade unions, and the non-profit organizations. In 2008, the Council of Europe distributed the "white book" and encouraged local governments to create the conditions for a "true dialogue" in their cities. The book promotes the idea that diversity, if valorized, can bring many advantages to the community. On page 9 of the book, you can find the main philosophy. You can see that in the last column they talk about the intercultural strategy. It is called "community building." ... We are proud to be the only Italian city taking part in this project. The project with the Council of Europe allows us to exchange good practices with other cities all across Europe and to encourage the intercultural dialogue in other Italian cities. We know, of course, that it is an ambitious project, which is still far from being realized.

(RE/N1)

The page of the Council of Europe is "Intercultural cities: Examples of good practices." www.coe.int/t/dg4/cultureheritage/culture/cities/guidance_en.asp (Accessed June 20, 2015).

22 It is important to note here that, with the exception of a few initiatives organized by more radical political organizations (such as Città Migrante, the Association GA3 and the Network Security Package-Network Pacchetto Sicurezza), there are very few organizations in the city that focus on political claims and conflicting aspects of inclusion.

23 For a list of these organizations, see the official site of the municipality under the main item, "if you are a foreigner" ("se sei straniero"). www.municipio.re.it/retecivica/urp/ pes.nsf/web/dlscnt8?opendocument (Accessed June 25, 2015). See also the official site "Migrare: Dialogo interculturale a Reggio Emilia." www.migrare.it (Accessed June 10, 2015).

24 For a list of the services offered by Caritas, see the official site: www.caritasreggiana. it/index.php?prec=34 (Accessed June 20, 2015). The Cooperative Dimora d'Abramo is a church-based organization. It was created in 1988 and was the first cooperative in Italy to invest in the area of immigration. See the official page: www.consorzioromero. org/dimora_abramo.html (Accessed June 20, 2015).

25 Official site: www.mondinsieme.org/en/ (Accessed June 25, 2015).

26 www.mondinsieme.org/en/who-we-are/mission-e-metodo (Accessed June 20, 2015). As noted earlier, from 2001 to 2003, on behalf of the Spaggiari administration, the Mondinsieme Center organized different initiatives, such as "il mondo tra i fornelli" [The world in the cooker], "Donne d'altrove" [Women of elsewhere], "Spazio donne" [Women's space]. Then, from 2004 to 2005, it organized the initiative "Mondinsieme in Piazza" [Mondinsieme in the square]. According to Cesare F., "these initiatives were the first embryos of the intercultural dialogue" (RE/N1).

27 See the official site of the Mondinsieme Center: www.mondinsieme.org/servizi/laboratoriedu (Accessed June 20, 2015).

28 See the page www.mondinsieme.org/chi-siamo/associazioni (Accessed June 20, 2015).

29 See document "L'associazionismo degli immigrati a Reggio Emilia. Caratteristiche e sviluppi," produced in 2012 by the administration through the collaboration of three 
researchers: Mottura et al. 2012. http://migrare.it/wp-content/uploads/2012/03/ricercacompleta1.pdf (Accessed June 20, 2015).

30 On the Center's official site, it states:

The Mondinsieme Center is engaged in searching for and experimenting with innovative strategies toward the real involvement of second-generation immigrants in social and preventive activities, aiming to overcome the dangerous "banlieue effects" [sub-urbanization effect] that all too easily attract those who feel themselves excluded. Our approach is constructive and aims to value youths' belonging in two cultures. Mondinsieme offers an open opportunity to second-generation youths, a place to develop projects and activities focused on supporting youths' cultural métissage.

See the heading "Second Generations" on the official site of the Mondinsieme Center: www.mondinsieme.org/en/services/second-generations (Accessed June 20, 2015).

31 See the page www.mondinsieme.org/2012/progetti/giovani-in-rete (Accessed June 20, 2015).

32 See also the official site of Network TogethER: www.retetogether.it (Accessed June 20, 2015). The network was one of the promoters of the "Italy is me, too!" campaign in 2011. See the official site of the association: www.retetogether.it/blog/comunicatostampa-litalia-sono-anchio/ (Accessed June 20, 2015).

33 I collected these data during the regional conference of the CGIL, titled "Lavoro, diritti and rappresentanza: gli impegni della CGIL Emilia-Romagna nella conferenza regionale sull'immigrazione" ["Work, rights and representation: The proposals of the CGIL Emilia-Romagna in the Regional Conference on Immigration"], organized in Bologna on June 10, 2013.

\section{References}

Bellinvia, Tindaro. 2013. Xenofobia, sicurezza, resistenza. L'ordine pubblico in una città "rossa." Il caso di Pisa. Milano: Mimesis edizioni.

Bonora, Paola, and Angelo Giardini. 2004. I centri interculturali in Emilia-Romagna. Un progetto di ricerca-azione per una territorialità attiva. Bologna: Industrie Grafiche Labanti e Nanni.

Campomori, Francesca. 2008. Immigrazione e cittadinza locale. La governance dell'integrazione in Italia. Roma: Carocci.

Campomori, Francesca, and Tiziana Caponio. 2013. "Competing Frames in Immigrant Integration in the EU: Geographies of Social Inclusion in Italian Regions." Policies Studies 34: 163-179.

Cantle, Ted. 2012. Interculturalism: The New Era of Cohesion and Diversity. Basingstoke: Palgrave Macmillan.

Caponio, Tiziana. 2006. Città italiane e immigrazione. Discorso pubblico e politiche a Milano, Bologna e Napoli. Bologna: Il Mulino.

Caponio, Tiziana, and Roberta Ricucci. 2015. "Interculturalism: A Policy Instrument Supporting Social Inclusion?” In Interculturalism in Cities: Concept, Policy and Implementation, edited by Ricard Zapata-Barrero, 20-34. Cheltenham: Edward Elgar Publishing.

Cappiali, Teresa M. 2018. "Local Actors and Approaches to Integration: What is their Impact on Immigrants' Political Participation?" In The Routledge Handbook on the Governance of Migration and Diversity in Cities, edited by Tiziana Caponio, Ricard Zapata-Barrero, and Peter Scholten, 136-149. New York: Routledge.

Caritas Italiana. 2005. Immigrati e Partecipazione. Dalle Consulte e dai Consiglieri al Diritto di Voto. Rome: Edizioni Idos. 
Castelli Gattinara, Pietro. 2016. The Politics of Migration in Italy: Perspectives on Local Debates and Party Competition. London: Routledge.

CNEL (Consiglio Nazionale dell'Economia e del Lavoro). 2009. VII Rapporto. Indici di integrazione degli immmigrati in Italia. www.cnel.it/18?tag_area_tematica $=35$ (Accessed June 30, 2015).

Council of Europe. 1992. Convention on the Participation of Foreigners in Public Life at Local Level. http://conventions.coe.int/Treaty/Commun/QueVoulezVous. asp?CL $=$ ENG\&NT $=144$ (Accessed June 20, 2015).

Frisina, Annalisa. 2005. "Giovani musulmani di Italia. Trasformazioni socioculturali e domande di cittadinanza." In Giovani musulmani in Europa, edited by Andrea Pacini and Jocelyne Cesari, 139-160. Turin: Centro E. Agnelli.

Groenendijk, Kees. 2008. Local Voting Rights for Non-Nationals in Europe: What We Know and What We Need to Learn. Washington, DC: Migration Policy Institute.

Gsir, Sonia, and Marco Martiniello. 2004. Local Consultative Bodies for Foreign Residents. Strasbourg: Council of Europe Publishing.

Istat. 2013. Gli stranieri al $15^{\circ}$ Censimento della Popolazione. www.istat.it/it/files/2013/12/ Notadiffusione stranieri20122013.pdf

Marino, Stefania. 2012. "Trade Union Inclusion of Migrant and Ethnic Minority Workers: Comparing Italy and the Netherlands." European Journal of Industrial Relations 18 (1): 5-20.

Marino, Stefania. 2015. "Trade Unions, Special Structures and the Inclusion of Migrant Workers: On the Role of Union Democracy.” Work, Employment, and Society 29 (5): 826-842.

Mottura, Giovanni, Matteo Rinaldini, and Andrea Pintus. 2012. L'associazionismo degli immigrati a Reggio Emilia. Caratteristiche e sviluppi. http://migrare.it/wp-content/ uploads/2012/03/ricerca-completa1.pdf

Parlamento Italiano. 1998. "Disciplina dell'Immigrazione e Norme sulla Condizione dello Straniero.” Gazzetta Ufficiale n. 59. Suppl. ord. n. 40, March 12.

Rinaldini, Matteo, and Stefania Marino. 2012. "Trade Unions and Migrant Workers in Italy: Between Labour and Social Rights." In Trade Unions and Migrant Workers, edited by Stefania Marino, Judith Roosblad, and Rinus Penninx, 266-286. Cheltenham: Edward Elgar Publishing.

Rossi, Emanuele, Francesca Biondi dal Monte, and Massimiliano Vrenna, eds. 2013. La governance dell'immigrazione. Diritti, politiche e competenze. Bologna: Il Mulino.

Turco, Livia. 2005. I nuovi Italiani. L'immigrazione, i pregiudizi, la convivenza. Milano: Mondadori.

Wood, Phil. 2010. Intercultural Cities: Towards a Model for Intercultural Integration. Strasbourg: Council of Europe Publishing.

Zapata-Barrero, Ricard, ed. 2015. Interculturalism in Cities: Concept, Policy and Implementation. Cheltenham: Edward Elgar Publishing.

Zapata-Barrero, Ricard, and Ted Cantle. 2018. "City Governance of Migration and Diversity: Interculturalism as a City Policy Paradigm." In The Routledge Handbook on the Governance of Migration and Diversity in Cities, edited by Tiziana Caponio, Ricard Zapata-Barrero, and Peter Scholten, 193-203. New York: Routledge. 


\section{Multiple forms of participation in a stronghold of the left}

\section{"A day without us: the strike of migrants": a demonstration and strike for and with immigrant workers}

On March 1, 2010, a national strike of immigrants, called "A day without us: The strike of migrants," was organized by an anti-racist movement-composed of coalitions of church-based, left-wing civil society organizations, and radical left organizations - and many immigrant workers and associations who formed the Committee of the First of March (Comitato Primo Marzo). The event saw thousands of people take to the streets for organized sit-ins, demonstrations, and strikes (Oliveri 2012; Cappiali 2019). This was the first strike of immigrant workers in the country at the national level, and the organizers managed to coordinate its actions in several large and mid-sized cities from the South to the NorthBologna, Genoa, Trieste Brescia, Mantua and Basso Mantovano, Milan, Padua, Rome, Turin, Naples, Bari, and Palermo. The action brought 300,000 people to demonstrate in the streets and prompted many workers to strike (Cappiali 2019; Cobbe and Grappi 2011). National in scope, the event exposed important geographical variations among the pro-immigrant and immigrant groups - and the alliances and conflicts between groups with different ideological affiliationsacross the country (Cappiali 2019). As a result of these differences, immigrants' participatory outcomes and levels of visibility were also different across contexts.

The organization of "A day without us" started on November 29, 2009, when a post on Facebook was published, asking: "What would happen if the four and a half million immigrant workers who live in Italy decided to cross their arms for one day?" The organizers were inspired by the movement that launched "The day without immigrants: 24 hours without us" ("La journée sans immigrés: 24 h sans nous") in France. In Italy, the event was put together by various pro-immigrant groups of civil society and immigrant organizations of different political orientations. These groups were united by the will to protest against institutional racism, codified into law by the right-wing government in 2002 - the Bossi-Fini Law, which criminalizes immigrants and makes their status in Italy more precarious (Triandafyllidou and Ambrosini 2011). This dispensation was intensified by two new measures in 2008 and 2009 - the so-called Security Package. Reinforcing the idea that immigration is a security threat, these measures promoted greater labor 


\section{Multiple forms of participation}

vulnerability of immigrants. As Cannella explains, these measures "increased the probability that immigrants will accept the worst working conditions, low paid jobs, work in very bad conditions and in impossible hours, and in places where there is lack of security" (2010, 45; cf. also Triandafyllidou and Ambrosini 2011). Focusing on the importance of organizing a strike of immigrants, the organizers sought to emphasize the importance of immigrant workers for the country's economy and expose the fact that the existing laws, by criminalizing immigrants and making their status precarious, were de facto racist and produced immigrants' "illegality" (Cobbe and Grappi 2011).

Despite the unity of intention, two main conflicts emerged during the event's organization, which threatened successful turnout. Traditional trade unions refused to take part in the strike, arguing that a strike of immigrants could become a divisive element in Italian society and that it would alienate Italian workers and have the opposite effect of sensitizing the Italian population to the conditions of immigrants. In particular, conflicts emerged between the main organizersthe National Committee of the First of March 2010 (Comitato Nazionale Primo Marzo 2010) — and the CGIL. The latter labeled the strike of immigrants an "ethnic strike" undermining the unity of all workers. The second main conflict was linked to the first. Given the lack of support from the trade unions, the organizers were divided on whether to risk organizing a strike instead of a demonstration. A demonstration was considered safer in terms of success, while a strike was less likely to succeed without the participation of the major trade unions. Since the trade unions were the actors best placed to reach workers in their workplace, their absence made the strike's success significantly less likely (Cobbe and Grappi 2011). The strike versus demonstration dilemma created conflicts between the members of the National Committee of the First of March 2010 and exposed ideological divergences between members of the anti-racist movement in Italy, particularly between moderate and more radical left-wing actors (see also Cappiali 2019, for more details).

Bologna was one of the few cities in Italy to organize a strike of immigrants entirely from below and without trade union support. ${ }^{1}$ The Committee of the First of March based in Bologna was composed of three main actors: a group from the civil society guided by a member of the Democratic Party, Cécile Kyenge (acting on her own behalf without the involvement of the Party), and main radical leftwing organizations of the city, including a key organization, the MCO (Migrant Coordination Organization of the Province and the City of Bologna-Coordinamento Migranti della Provincia e della Città di Bologna), linked to the social center MX24. During my fieldwork in 2013, several members of the MCO explained that while the other members of the Committee of the First of March focused on advertising the event, the MCO concentrated on mobilizing workers for the strike, with the partial support of delegates of the most radical branches of the left-wing trade union, the CGIL-FIOM (Cappiali 2019, 886-887). They also explained how the organization of the strike was helped by the "double militancy of immigrant activists," who were both members of the MCO and delegates of trade unions, mainly but not exclusively of the CGIL-FIOM. Thus, according to this informant, the first 
remarkable aspect of the event was the fact that in Bologna, the strike was entirely organized from below with immigrants, without the official support of the trade unions as in other cities, where the union took up the call and mobilized their own workers. While the MCO was able to replace the union by supporting the strike via their networks, the double affiliation of many immigrants with both the MCO and the trade unions made the strike possible. In some cases, immigrants were not covered by trade unions and went on strike against their own organization (Interviews BO/N9, BO/N11, BO/N12, and BO/N13; see Cappiali 2019; Galeotti 2009-2011). Given the major involvement of a plethora of immigrant activists and organizations with different orientations and viewpoints, the organization of the event had a significant impact in Bologna with immigrant activists being uniquely visible and involved in its organizations.

The city of Bologna is the city of multiple forms of participation. In this chapter, I will show how, in the absence of institutional intervention from left-wing administrations in more recent years, left-wing actors have encouraged two approaches - interculturalism and political rights promotion - from below. Several channels have been opened by local actors over the years and this has created the conditions for immigrant activists to grow in the city. Immigrants have created their own channels of participation and have formed alliances with several institutional and non-institutional left-wing actors, including trade unions, grassroots organizations, and radical left actors. Immigrant activists participate in various ways and, in many cases, their activities overlap. Moreover, they have more choice in allying with several pro-immigrant groups, depending on their immigrant status and working conditions. In the empirical chapters, I explain how conflicts between moderate and radical left-wing actors are also problematic as they prevent many immigrant activists from shaping local dynamics. Despite their discourses on the need to include immigrants, left-wing actors in Bologna have often marginalized immigrants' voices, often in more subtle ways but sometimes overtly too. Yet, as the interviews with immigrant activists will show, in some cases, the obstacles imposed by pro-immigrant organizations of the left have presented important opportunities to create alternative ways to participate and to make rights claims.

\section{The withdraw of the institutional left}

The city of Bologna is known for having been the unquestioned stronghold of the Communist Party (the PCI) in Italy (until its dissolution in the 1990s). It is also known as being a city in which left-wing actors (including trade unions and radical left organizations) are predominant (Però 2007; Caponio 2006). Following the first arrival of immigrants in the city in the 1980s and 1990s, left-wing local actors became involved in promoting inclusion and presented themselves as the vanguard of progressiveness in the country (Però 2007, 35). Since the 1980s, the city's left-wing heritage and its openness (in addition to its rich economy) has encouraged the arrival of many immigrants seeking out a better future, including asylum seekers and refugees, students from developing countries and many 


\section{Multiple forms of participation}

immigrants of communist and socialist political orientation who left their countries for political reasons (Però 2007; Caponio 2006). Since the 1990s, the leftwing administrations in power presented new immigrants not only as people in need of aid and protection (assistance approach) but also as people capable of enriching the city because of their cultural heritage (intercultural approach) and as subjects entitled to basic political rights (political rights promotion approach) (Però 2007; Caponio 2006). Because of this comprehensive approach, by the end of the 1990s, Bologna was considered to be one of the most inclusive cities in Italy (Però 2007; Caponio 2006). In line with its inclusive discourse of interculturalism and political rights promotion, the left-wing administration of Bologna launched an experimental initiative in 1996 in order to foster the participation of people of foreign origin: the ISI, or the Institute of Services for Immigrants (Istituto Servizi Immigrazione). The ISI was launched at the provincial level but very soon it became an instrument operating at the municipal level. It was an autonomous body, with its own administrative council, composed of a number of immigration experts and appointed by the mayor. The administration assigned responsibility forsocialservices to immigrants to ISI. The ISI offered someservicesfor example, a helpdesk, legal counseling, healthcare, help to find jobs, and courses in literacy - as well as projects to help with access to housing.

During our interview in 2014, Marco G., an Italian man in his seventies and the former director of ISI from 1996 to 1999, explained that the explicit goal of the center was to move beyond a service-delivery approach and promote a political rights promotion approach "to create the conditions for a full social, economic, and cultural integration that would allow the effective participation of people of foreign origin in the democratic life of the local community" (BO/N3: Director of ISI between 1996 and 1999, and one of the main experts in Italy on the responses of trade unions to immigration). The ISI was pivotal in the organization of the network of services in the city. It was within this network of services that it was possible to promote the participation of people of foreign origin in public life. In October 1997, through the ISI, the administration created a second organization in the city, the Metropolitan Forum of the Associations of Citizens of Non-EU Countries in Bologna and its Province (Forum Metropolitano delle associazioni dei cittadini non comunitari a Bologna e Provincia, from now on the Metropolitan Forum), to offer immigrant associations a voice in the city (Caponio 2006, 195; see more details in the following). This Forum represented an important opportunity to develop a political trajectory for many immigrant leaders in the city, although, by most immigrant activists and other people in the city, it was considered by most actor a façade (analysis of the interviews will show in the reminder of this chapter). ${ }^{2}$

By the beginning of the 2000s, the local administrations gradually withdrew from active policy promoting inclusion in the city. In contrast to its neighboring city of Reggio Emilia, Bologna lacked political continuity at the level of local administrations. The city's administration was a left-wing majority one between 1994 and 1999, and a right-wing majority one between 1999 and 2004. This change in the political orientation came as something of a surprise in one 
of the major strongholds of the Italian left (Barbagli 1999). Among the reasons often given by researchers and actors to explain this change, it appears that, while in 1999, left-wing parties were not able to move beyond their internal conflicts and organize a coherent electoral campaign, the right-wing coalition was able to appeal to the fears of citizens, who were mainly concerned about issues of immigration constructed as a security problem at both the national and local level (Caponio 2006, 154-155). During the electoral campaign of 1999, members of the right-wing parties emphasized the themes of security and the degradation of the city (Barbagli 1999; Caponio 2006, 155). Additionally, they "defined immigration essentially as a question of public security" and they increased the level of hostility toward immigrants (Caponio 2006, 15). ${ }^{3}$

In 2004, the left returned to power under the guidance of Mayor Sergio Cofferati, the national secretary of the main left-wing trade union, the CGIL, from 1994 to 2002. Despite the change, as Caponio $(2006,92)$ explains, the rise of the Northern League at the national and regional level and the left's fear of "electoral costs" resulted in a shift of attention from integration policies to security measures by the Cofferati administration. As a matter of fact, following this period, the left-wing administrations that governed the city between 2004 and 2011 were increasingly uninterested in the subject. Francesca L., an Italian woman in her forties, and an employee of the administration (working in the Office of Cooperation and Human Rights), who worked for the administrations of Bologna since the Cofferati administration (2004-2009), corroborated this point. She explained: "After five years of the right-wing government, the new administration had to start from scratch. Nonetheless, what was lacking the most was a real interest in promoting interventions towards greater inclusion of immigrants" (BO/N2). From the start of its mandate, the Cofferati administration expressed concerns over the potential electoral cost of addressing the issue of immigration in an open way, which resulted in the adoption of security discourses favored by right-wing parties (Castelli Gattinara 2016). This quote suggests that there were both external and internal factors affecting the left-wing administration. While the right-wing administrations demolished the work done by previous left-wing administrations, the new left-wing administration willingly continued to follow the line of its rightwing predecessors.

Subsequently, the city was governed by two different left-wing majorities from 2004 to 2014, with a political vacuum opening between 2009 and 2010 in the wake of a corruption scandal. Therefore, after a first attempt by the left-wing administration that governed the city between 1994 and 1999 to promote inclusion, things did not continue in this direction. On the contrary, throughout the right-wing administration (1999-2004), a security-focused left-wing administration (2004-2009), and the aforementioned two-year political void (2010-2011), there were very few initiatives promoted by the local administration in the area of immigration in general and in the area of civic and political participation in particular. Moreover, by appropriating the discourses of the right-wing parties and by emphasizing security rather than inclusion, the left-wing administration of 20042009 stopped investing in the subject of immigration and left an institutional gap. ${ }^{4}$ 
This was an emerging phenomenon in Italy among left-wing cities, where at the beginning of the 2000s a greater emphasis was put on the need for security over "integration" (Bellinvia 2013; Caponio 2006; Castelli Gattinara 2016).

Civil society and grassroots movements in Bologna reacted to the security turn of the left-wing administration. ${ }^{5}$ The phenomenon was so remarkable that a journalist of La Repubblica pointed out that Bologna's left-wing administration was becoming a model for other left-wing cities, calling it the "Cofferati Effect." For instance, one journalist noted that, following the example of Cofferati, many other left-wing mayors in Italy were becoming "more sheriff-like."

In 2013, I interviewed an expert on immigration, Francesca L., who had worked for the administration when Cofferati was in power. She recounted that "the administration was very closed and self-referential in many respects, and they showed a great disinterest in the issues of immigration" (BO/N2). As far as assistance was concerned, the Cofferati administration devolved most tasks to the third sector. In terms of intercultural dialogue, the administration took charge of the Zonarelli Center, which had been created in 1999. However, little planning was done to encourage intercultural dialogue in the city, particularly in key institutions such as schools. Finally, at the level of participation and political rights promotion, the Cofferati administration was silent $(\mathrm{BO} / \mathrm{N} 2$ and $\mathrm{BO} / \mathrm{N} 3)$.

It is also important to note that the left-wing government at the provincial level, led by Vittorio Prodi, in power between 2004 and 2009, took over some initiatives, introducing a help desk and filling some of the gaps created by the right-wing administration. In collaboration with the Emilia-Romagna region, it also created an Observatory against Discrimination. Francesca L. told me that in order to bypass the stalemate of the left-wing municipal administration, the provincial government of Bologna, guided by Vittorio Prodi, created the Council of Foreign Citizens and Stateless People in the Province of Bologna (Consiglio dei cittadini stranieri e apolidi della Provincia di Bologna) in 2007. ${ }^{7}$ The Council was a consultative body composed of 30 councilors, elected by immigrants' residents in the city. It was believed that this consultative body would be more representative and more democratic. The idea was that every five years, at each provincial election, immigrants would vote for the representatives of their Council. At the time of the first elections in 2007, out of about 43,000 non-EU immigrants officially resident in the province who could vote, only 9,200 (about $21 \%$ ) went to the polls. In the electoral competition, there were 32 lists and 275 candidates. According to the official statute, the Council "can express points of view and give advice on all the subjects of competence of the provincial council. The propositions are obligatory on issues linked to the balance sheet and all the expenses concerning policies for foreigners." However, most of my interviewees active in the Council and other key actors explained that the problem was that the role of the Provincial Council was rather superficial and had little in the way of genuine power (BO/N22). This and other initiatives from the provincial administration, however, were not sufficient to fill the gaps left by the local administration (BO/N3).

Several interviewees in the city of Bologna acknowledged that the Council was one of the most advanced and democratic of Italy's consultative bodies. From this 
point of view, it was seen as an opportunity for immigrant residents in the city to be represented at the provincial council. It also offered an opportunity for those who were elected to gain visibility and promote the interests of the immigrant communities they were supposed to represent. Irene A., a Filipino woman, elected member of the Provincial Council of Foreign Citizens and Stateless People in the Province of Bologna and President of the Federation of Filipino Associations of Bologna, explained that, for her, it was also an opportunity to gain experience on how to be civically engaged in the city $(\mathrm{BO} / \mathrm{N} 8)$. However, most interviewees - both Italians and immigrants alike - were very critical of this body. They explained that one problem was that the Council encouraged mere affiliation to "ethnic" groups $(\mathrm{BO} /$ N19). Instead of being an organization that represented immigrants in the city as a whole, some of my interviewees considered it as a body in which one voted for one's own compatriots in order to obtain privileges (BO/N8) ${ }^{8}$

Alessandro F., an Italian man in his sixties, and the Director of the intercultural center, the Zanorelli Center, was strongly critical of the Council, emphasizing its role in social control:

The Consultative Bodies clearly take on a role of social control [of the immigrant community]. As you might know, they are based on communities and associations. It is the paradigmatic example of a form of social control applied by the local administration of Bologna. The idea of the Council of Foreign Citizens of the Province of Bologna was to compensate for a right that does not exist. Participation through voting is precluded to immigrants. The representatives of the Council were elected, which made it more representative than those bodies in which the representatives are appointed by the local authorities. However, the elections themselves were full of contradictions. People were grouped by ethnic origin or politico-geographic areas. This distinction does not work because it does not correspond to social dynamics. If we want to offer representation-whatever that means! - we should keep in mind the reality of things.

$(\mathrm{BO} / \mathrm{N} 7)^{9}$

In other words, Alessandro F. and other actors in the city criticized the lack of understanding by the local administration of what was required to promote the political voice of immigrants in the city. In particular, the Consultative Bodies were based on a distorted interpretation of social processes and immigrant groups' characteristics and needs. In this respect, the aforementioned channels promoted by the left in the city tended to create parallel spaces for immigrants. In addition, they reproduced a false representation of immigrants in the city. These latter were divided on the basis of their "ethnicity" and national belonging rather than their political views and perspectives which would cut across national belonging.

For several immigrant activists, there was more at stake, as various consultative bodies created by the left were seen mostly as a façade, and immigrants' voice was de facto marginalized in the city. Donald R. was an Italian man in his fifties, who was originally from Cameroon. He was in charge of the Provincial Forum on 
Immigration of the PD and Assessor of Integration of San Lazzaro (Province of Bologna) pushed this criticism further. His political trajectory could be considered a success. Several actors in the city considered him one of the best examples of immigrant leadership in Bologna. He explained that the left-wing actors in the city courted immigrant activists to have their own representative of foreign origin. This had also happened to him at different stages of his career. He also had, however, complex interactions with all these actors who produced political racialization of immigrants in the city, as this will appear clearer in Chapter 7. According to Donald R., this was done by silencing immigrants' own demands and claims and by disempowering the immigrant activists who showed more independence and a resistance to be co-opted.

The path of the Provincial Council for foreign people was not an easy one. Every Italian organization (the administration, the CGIL, the CISL) wanted to place its own representative of foreign origin. There was little space for freedom of expression and for immigrants' autonomy and self-determination. The Council has remained the kind of body the administration wanted it to be. The administration wanted a steered council, rather than an autonomous one. Today the Council is a ghost of itself. The administration keeps it as a symbol. The budget is derisory. If one does not work to fulfill the aims of the administration, then no one really cares.

$(\mathrm{BO} / \mathrm{N} 22)$

The left-wing administration led by Mayor Virginio Merola between 2011 and 2013 had shown more interest in the subject of migration. Even though this administration did not get involved directly, it supported the bottom-up initiatives promoted by the third-sector organizations. However, the absence of previous structured interventions and the cutting back of resources left many actors skeptical about the administration's ability to address the major challenges of integration ahead (see, e.g., BO/N3, BO/N5, BO/N6, and BO/N7). In addition to the legacy of more than ten years of the left's political lack of interest, the new administration in Bologna was unprepared to tackle the new challenges posed by the financial crisis of 2008. This prolonged event affected the most vulnerable parts of the population (both Italians and immigrants alike), with rising unemployment, the weakening of workers' rights, and the increase in labor exploitation, not to mention the housing crisis.

\section{The local realm of immigration and approaches to inclusion from below}

In line with the city's Communist political sub-culture (Campomori 2008), the third sector in Bologna is mainly represented by a dense network of lay organizations of the left. Despite the lack of coordination on the part of the local administration, as it was in the case of Reggio Emilia, the work of civil society organizations in Bologna was favored by their well-established networks and the strength of the 
city's economy. The traditional left-wing trade union, the CGIL, and many radical left organizations and trade unions are also particularly strong. The church-based organizations, on the other hand, do not play a strong role and the majority of initiatives are confined to the parishes or small groups of volunteers, as a member of the Caritas also admitted (BO/N4; see also Caponio 2006, 133-137). There are also a few church-based associations and parishes active in the territory. Moreover, the Christian Democratic trade union, the CISL, and the political party are little involved. Together, all these organizations have created the conditions for the creation of networks to assist immigrants, but they have also promoted both intercultural and political rights promotion approaches from below. As it will be shown in this chapter, the presence of a variety of actors investing in the realm of immigration in Bologna, created the space for the development of several civic and political forms of participation. This resulted also in the incentive given to active citizenship by local actors, considered key for securing inclusion at the local level.

Moreover, Bologna has had one of the highest levels of immigrant population $(13.6 \%$, or 51,771 of 380,635$)$ (Istat 2013). ${ }^{10}$ Bologna is one of the richest regions in Italy with one of the strongest economies (see also Chapter 2 and Appendix A). In the years 2006-2008, prior to the financial crisis, Bologna was among the cities with the best economic performance in the country, which allowed it to include immigrants socioeconomically. The city and its surrounding areas, for instance, had the highest employment rate of immigrant workers in Italy, as well as the highest indexes of "integration" (CNEL 2009). To achieve these high rates of integration, lay organizations in Bologna develop itineraries of participation from below by Italians and immigrants active in the local realm of immigration, particularly through well-developed immigrant associations. The network of associations builds on existing formal and informal networks through collaboration on a range of projects and initiatives.

\section{Lay organizations and the intercultural approach from below}

Surveying the municipal websites of Bologna focusing on the voluntary sector, one finds a wide array of pages dedicated to immigration. The official site of the municipality of Bologna, World of Associations in the Realm of Themes Linked to Immigration (Associazionismo nell'ambito delle tematiche legate all'immigrazione), reads:

There are many organizations of the third sector that work in the sphere of immigration: many of these organizations are directly promoted by immigrants and others are organizations already active in the city in other domains. The realms in which these organizations intervene are: defence of rights, interculturalism, activities of socio-sanitary assistance, etc.

Additionally, the site refers to two types of associations: the associations of immigrants - that is, associations composed of immigrants; and associations for immigrants - that is, Italian associations which work on immigration. ${ }^{11}$ However, 
as I observed during my fieldwork, this distinction is not always so obvious, as many people of migrant background who have been living in the city for many years are also key actors in some key Italian organizations. Moreover, unlike any other city I was studying, Bologna allowed the creation of both formal and informal types of collaboration between organizations, with important overlaps between the people participating in these organizations. It is remarkable that the nature of the third sector in the city allowed for the creation of mixed associations, which makes it harder to distinguish clearly between Italian and immigrant associations. This is an aspect that was clearly missing in the other three cities studied herein.

\section{The Zanorelli Center}

The first key actor of the third sector that warrants attention is the intercultural center, the Massimo Zonarelli Center (hereafter Zonarelli Center), which is a central entity for promoting programs of civic participation via an intercultural approach. The Center was created in 1998 by the left-wing administration in power at the time. On the official site of the municipality of Bologna, the Zonarelli Center is presented as a key organization for the promotion of participation in Bologna. It provides associations with spaces to meet and to develop activities and mutual exchange. ${ }^{12}$ In 2013, the Center hosted around 120 immigrant associations. On its official site, one can read that the Zonarelli Center promotes "itineraries of exchange and valorization of diversity through various activities, including training and workshops in languages of different countries, celebrations of festivities, public demonstrations and debates, and institutional activities." 13

During our interview, I asked the Director of the Zonarelli Center, Alessandro F. (BO /N7), to further explain how the Center understood the intercultural approach and its support of participation from below:

We [in the Center] consider "citizenship" as a social process. We believe that we need to invest in cultural resources. . . It is about a change of perception: we want to show that immigration is not a problem but a resource. We should convey this idea adequately and give information in an honest way. ${ }^{14}$

$(\mathrm{BO} / \mathrm{N} 7)$

He was very critical of politicians' reliance over the years on a false idea of immigrant associations as representative of the immigrant communities. He explained that politics was disconnected from reality and that the local authorities of Bologna, by creating parallel bodies for immigrants (e.g., Provincial Council), had created "representation without a mandate and thus without legitimation from below."

It is very hard to work today for immigrants, precisely because for twenty years politics has done everything but favor processes of integration. There is a discrepancy between the practices of citizenship and politics. This is a huge problem because this situation does not make it possible to deal with the processes of inclusion in the right way. 
Aligned with the intercultural approach of the Center aiming to promote active citizenship, Alessandro F. invested in the realization of two documentaries in collaboration with the Emilia-Romagna region and other partners: Citizenship in 2009 and Beyond Islam's Door (Oltre le Porte dell'Islam) in 2013. While the first film aimed to stimulate reflection on the notion of active citizenship and the meaning of belonging for people of migrant background in Bologna, the second film tried to encourage an understanding of the plural reality of Muslims living in Bologna. ${ }^{15}$

I asked several immigrants who were active in the world of associations how they viewed the role of the Zonarelli Center in the city. All of the immigrant activists I interviewed told me that they had close relations with the Center and that they considered it a great opportunity to promote the activities of their associations. Most importantly, all of them saw the Center as a place to meet with other organizations, enlarge their networks, and create initiatives together. The Center also offered the opportunity to reach out to other people (Italians and immigrants alike) and engage other immigrants who otherwise would not be involved.

A notable example of the Center's positive role in the city was relayed to me by Yana L., a woman from Ukraine in her thirties, in 2010, she created an association called Association Italy-Ukraine Bologna (Associazione Italia-Ucraina Bologna), to help women caregivers from her country of origin. She acknowledged that the Association Italy-Ukraine Bologna helped the women to open up socially, and in only three years the group's membership grew from 20 to 300, of which 120 women were very active. She added that the organization planned activities to invite women from Ukraine to "come out from the houses in which they are too often isolated and become depressed." A year after the creation of the Association Italy-Ukraine Bologna, young Italian people joined the association to learn about Ukrainian culture and to take classes in cooking, singing, and Russian. Yana L. explained:

Without the Zonarelli Center, my association could not have evolved the way it did. The Center offered a "neutral" space in which cultural exchanges were possible and diversity was celebrated. Here one is encouraged to go towards others and to establish new friendships. We organize events in which we include other associations. There is no hate or fear of other peoples. . . The Center also encourages the participation of people who otherwise would not have gotten involved.

$(\mathrm{BO} / \mathrm{N} 23)$

This quote is one example of how immigrant activists in the city believed in the importance of having a neutral space for associations to meet and develop their activities without the interference of other actors. These kinds of spaces can help immigrant activists to develop activities that are in line with their needs and preferences.

\section{Amitié}

In addition to the Zanorelli Center, there are other significant examples of the unique role of third-sector organizations in Bologna. Amitié (meaning Friendship in French) 
was launched by the employees of the municipality of Bologna during the political vacuum between 2009 and 2011. Amitié represents an example of good practices from below, in the absence of consistent intervention by the local administration. Since 2011, the new left-wing administration in power, led by Mayor Merola, took charge of the project. According to Amitié's official site, the project strives to raise "[a]wareness on migration, development and human rights through local partnerships." The project was carried out in collaboration with other European cities and relied on EU funding. ${ }^{16}$ One can also read that Amitie "wants to create new spaces of communication, encounter, and exchange about migration, development, and human rights through research, educational programs, communication, and local participation." ${ }^{17}$ During our interview, Francesca L. (Italian (F), an employee of the local administration and one of the main promoters of the project) explained that Amitie was an opportunity to fill a political void by creating coordination from below:

Amitié is a European project of cooperation and development. It was launched in March 2011 and ended in May 2013 with the involvement of Italians and citizens of migrant background, including immigrant associations. The goal was to better communicate what we used to do in the domain of immigration and cooperation. We thought that coordination was necessary: because work in this direction was never done at the political level, we decided to do it at the technical level.

$(\mathrm{BO} / \mathrm{N} 2)$

Thus, Amitié succeeded in involving a great number of people of migrant background and immigrant associations active in the city, including the Association Universe (see section below) and groups of young people associated with the radical left-wing organization of $\mathrm{MCO}$ (Migrant Coordination Organization), or On the Move. Amitié involved On the Move in the workshops they organized in Bologna's schools to sensitize students and professors about racism and human rights $(\mathrm{BO} /$ N14: Farid M., second-generation Moroccan (M), founder and a key member of the youth group of the radical left, On the Move; for more details see the section on the radical left in this chapter). On the group's official site, it states that, alongside other associations, Amitié organized campaigns of sensitization and various activities to raise awareness, including movie screenings and a human rights festival. ${ }^{18}$

\section{AMISS and Association Universe}

In addition to Amitié, two major "immigrant" associations are examples of the work carried out by the third sector in the area of immigration: AMISS, Association of Intercultural Mediators for Social and Health Services (Associazione Mediatrici Interculturali Sociali e Sanitari), and the Association Universe (Associazione Universo). AMISS was founded in 1999 by women intercultural mediators of different immigrant origins in Bologna. At the time of our interview, Adelina Y., a woman in her thirties from Albania, was the President of AMISS. She explained that she founded the organization to respond to the need for well-prepared intercultural mediations for women in hospitals (BO/N19). ${ }^{19}$ Later on, AMISS developed its 
activities in other spheres, such as schools and prisons, and founded a cooperative of 18 associates to distinguish workers from volunteers. At the time of my fieldwork, the association was composed of 160 women and a few men. It was mainly self-financed and participated in European projects, when possible, to support its work. In 2013, because of the shrinking of funding at the municipal level, most of its efforts were dedicated to finding money to support the cooperative. Adelina Y. explained the ways in which AMISS understood and encouraged the intercultural approach in the city: "For us mediation does not mean translation, but cultural mediation." In addition to cultural mediation, the association gets involved in other projects throughout the city, including preventive healthcare for women, cooking courses, and care for elderly people and children. AMISS also promotes political activities by working to fight against institutional discrimination at the local level in collaboration with other actors. Adelina Y. recalled how AMISS "collaborates with everyone: the institutions (region, province, municipality), the third sector, including immigrant associations of the city." She also explained that most of the initiatives with other immigrant associations were informal in character: "We contact immigrant associations directly, without the help of institutions." This was the case, for instance, with the Multiethnic Feast of the Peoples, a feast that AMISS had been organizing with other organizations every year since 2010 in Bologna.

It is not about an exchange of different cultures, but an occasion for people of migrant background to come out and become visible. In the past two years [June 2013 and June 2014], more than 3,000 people were present. There were more than 32 associations of people of foreign origin and 15 Italian associations.

(BO/N19)

This quote shows how AMISS, together with other immigrant associations, tries to move beyond the promotion of interculturalism understood as an exchange of different cultures. By promoting the active participation of immigrant associations and by making their work visible, AMISS aims to empower the immigrants in the city and make them feel part of the receiving society.

Association Universe was founded in 1998 by Lionel F., an immigrant man in his forties originally from Cameroon. ${ }^{20}$ Lionel F. was the President of the organization at the time of the interview. He stated that at first the idea was to support immigrants' inclusion in the local community, by helping them to find houses and jobs and teaching them Italian (BO/N24). The association helps both Italians and immigrants who are in need. The association was self-financed, to begin with. Then, from 2000, it won funding from the municipality for specific projects. In more recent years, it has been largely financed by private organizations. The organization had 40 volunteers and more than 100 people enrolled. In addition to offering assistance, Universe wanted to promote intercultural exchanges as well as "active citizenship" and participation via various activities. As Lionel F. noted:

At the moment, we are working on restoring a park that was abandoned. This is also an occasion for us to present the person of foreign origin as someone who collaborates in the growth of the city. We collaborate with the 
administration to do that. We decide the place and the municipality approves the place and the project.

$(\mathrm{BO} / \mathrm{N} 24)$

Lionel F. added that the organization promotes "political participation, through cultural activities, participation in the demonstrations, and solicitation of the local authorities." In general, the association, he explained, is open to all initiatives that can encourage the "promotion of human rights" and that the association participates in the demonstrations organized by the radical left (in particular the MCO) and other associations at the local level. Association Universe was widely recognized by other associations in the city and that it was active within many channels (including the Metropolitan Forum when Donald R. was its president between 2002 and 2007). The extensive networks of associations is an example of how many immigrant associations in Bologna developed collective participatory trajectories for both immigrants and Italians.

Overall, AMISS and Association Universe are two useful examples that convey the crucial role of third-sector organizations in shaping the local realm of immigration toward assistance and intercultural approaches. Together with other organizations in the city, the investment of these organizations in the direction of interculturalism results in the opening of civic channels of participation for immigrants. It is also remarkable that in this context civic participation has some pertinent political implications. The examples of the participatory trajectories of Adelina Y. and Lionel F. speak to how many immigrant activists in Bologna were able to practice "active citizenship" and to promote the inclusion of immigrant communities by making them visible and by fostering their sense of belonging via the creation of participatory channels for them.

\section{The ambivalence of the main left-wing trade union}

Given its leftist orientation and historical context of Bologna, the CGIL is the most powerful trade union in the city and has great influence. ${ }^{21}$ In 2013 , the total number of people enrolled in the CGIL of the province of Bologna was around 172,000, of which 75,377 were active workers and 11,551 were immigrants $(15.3 \%$ of all active workers). ${ }^{22}$ At the time, the number of workers enrolled in the second main union, the CISL, was around 43,000. ${ }^{23}$ In the 1980s and 1990s, the CGIL carried out important work welcoming immigrants, playing a major role in the processes of inclusion in Bologna. In order to respond to the needs of immigrant workers, in 1989, the CGIL opened the Center for Foreign Workers (Centro Lavoratori Stranieri) to provide information and assistance to immigrant workers (Cozzi and Mottura 2010). One can observe the clear political position of the CGIL and its open challenge to the Bossi-Fini Law and the Security Package on its official website:

The Center for Foreign Workers is the place in the CGIL where foreigners can go to exercise their civil, social, and labor rights. The Center lobbies the government in favor of better integration policies and asks for equal rights and equal dignity for all, starting with the abolition of the Bossi-Fini Law and the Security Package. ${ }^{24}$ 
This official statement of the CGIL suggests an expansive framework when it comes to addressing migration and integration issues. This is remarkable because these views are closer to the ones of the radical left according to which there is no distinction between groups of immigrants, as all should be treated equally, including undocumented immigrants.

In order to carry out its activities, the CGIL creates networks with other organizations in the city both at the level of services and at the level of advocacy and political rights promotion. The person in charge of the Center for Foreign Workers of the CGIL since 2010, Roberta A., was an Italian woman in her fifties. She explained that "as far as delivery of services is concerned, the CGIL works closely with other organizations in the city, including the Caritas, to make sure that no one is left behind." 25 Moreover, she added, the CGIL offers legal services and is involved in the struggle against the detention center, the Center of Identification and Expulsion or CIE (Centro d'Identificazione and Espulsione). ${ }^{26}$ For this purpose, it collaborates with the radical left organizations (e.g., the Social Center TPO and the association Ya Basta! Bologna) (BO/N6). I asked Roberta A. about the level of representation of immigrants in the organization. She made a list of the immigrants working in the organization. She admitted also that there were very few people in positions of responsibility and that there was more representation before.

We have eight people [of immigrant background] working for the organization. In the office there are two people. The FILLEA [construction sector] has two functionaries, one from Albania and one from Morocco; the FIOM [metalworkers] has one functionary from Morocco; the FILCAMS [service sector] does not have functionaries anymore, but it has many delegates. In the Center for Foreign Workers, there are three volunteers: a Moroccan person, another from Albania [Patronage Inca], and another from Pakistan.

(BO/N6)

The immigrant workers' representation in the organization was better than in many other territories of Italy, but Roberta A. admitted that it was "still too low." In her view,

the CGIL is not able to give enough space to immigrants' voices. In some sectors of the CGIL, the immigrant enrolment is between 20 and $35 \%$. If you look at the level of representation you will see that it is extremely low. They have to have voice and space! It is an unbearable gap that the CGIL EmiliaRomagna ... intends to deal with, by making adequate choices at the political level, by investing in new policies and assuming the multi-ethnic character of its own organization.

(BO/N6)

At this point, while comparing the approaches of the CGIL and the main radical left organization in the city, the MCO, Roberta A. admitted that the MCO was right in criticizing the CGIL on at least two points. First, the CGIL considered "the theme of immigration as a marginal one," outsourcing the issue to the Center for Foreign Workers. Corrado G. of the MCO expressed similar concerns: "At the assemblies 
that the trade unions organize today concerning the theme of immigration, they say the same things they used to say ten years ago. Ten years ago, actually, they used to be more critical than today" (BO/N9). Second, Roberta A. acknowledged that the CGIL failed to protect some sectors of workers, in particular the logistics sector:

There is a lack of attention by the organization to the question of representation. The branch of the metalworkers, the FIOM, has the most solid structure. Certainly, they pay great attention to the domain of migration and participation of immigrants. By contrast, the situation at the FILT, the category of transports and logistics, got out of hand. There are many immigrants in the sector and the CGIL has underestimated the situation. The work has not diminished in this sector, but it has diminished in prestige. They are very lowpaid jobs. The grassroots unions have started working in this sector. They have done what every union should do. If I don't have the minimum of rights, as a unionist I am not doing my job. In that sector, grassroots unions have intervened and have improved the conditions of those workers.

(BO/N6)

On this point, Roberta A. recognized that the metalworkers' branch (CGIL-FIOM) had been more attentive to these issues because it had understood the challenges at stake and had created the conditions for greater participation. For this reason, it expanded its work by creating and empowering political channels of participation for immigrants, through the creation of the Migrant Coordination Organization of the CGIL-FIOM. ${ }^{27}$ In many ways, the CGIL-FIOM represented an exception. Many people of migrant background active in the left recognized the role of this category in the city. Corrado G. (BO/N9) expressed a viewpoint that was shared among most immigrant activists I interviewed:

The FIOM-CGIL fought many important battles in these last years . . . many political and union battles against the anti-labor laws. Their struggles are very close to those of immigrants. Among the trade unions, this category is the only one that understands the centrality of immigrant labor. For trade unions, laborers are all the same. The CGIL-FIOM, like the MCO, says that the condition of immigrants is different because of the different political and working conditions.

(BO/N9)

The aforementioned analysis clearly shows that the CGIL did an important work in the realm of immigration in the city, but that this situation had changed more recently. Some working sectors were not covered by the CGIL (such as the logistic sector) and the level of representation of immigrants in the organization was very low. This was in line with criticism addressed in all the other cities part of this study and was in line with internal and external criticism of the CGIL at the national level.

\section{The role of the $\mathrm{MCO}$ and the political rights promotion approach}

The main radical left organization in Bologna, the MCO, has a significant political weight in the city of Bologna and is able to attract many immigrants to its 
organization. The decline of trust toward more moderate left-wing organizations (including the CGIL) over the 2000s has helped to open the way for the greater intervention and increased influence of this organization (Cappiali 2017a) ${ }^{28}$ The MCO (which prefers to describe itself as a collective rather than an organization) was created in 2004 and has never been formalized. It is linked to the social center XM24, which was formed in 2002, following the occupation of an abandoned market in the center of the city. ${ }^{29}$ One of the main members of the organization, Corrado G., an Italian man in his early thirties and a researcher in Political Science at the University of Bologna, said:

The MCO was born in the post-Genoa Period [after 2001] from the thematic tables of the Social Forum. On that occasion, a Migrant Table [of the Social Forum] was created. It was a group of radical left activists, who were fighting for the rights of migrants. At one point, we thought that it was possible to get out of the logic of the Social Forum [that used to talk for migrants] and do something with migrants. It was at that point that there was a break with various mediations by other actors.

$(\mathrm{BO} / \mathrm{N} 9)^{30}$

Corrado G. explained: "The problem of most moderate and radical left movements in Italy is that they represent immigrants as the weakest link among the workers and thus they depict them as substantially unable to strike" (Interview by Galeotti 2009-2011, 152). For this reason, he lamented that, apart from the MCO, there were very few organizations able to recognize the role of immigration law in producing institutional racism through the control of immigrant labor. Also, few were ready to acknowledge "the strategic position" of immigrants in the workforce and "to bet on the self-determination of migrants" (ibid.). ${ }^{31}$ According to G., the MCO had done all these things, but most radical left actors in Italy were stuck with an inadequate understanding of the processes at work and thus were not able to recognize the self-determination of immigrants, which he argued came into full light during the organization of "A day without us." ${ }^{2}$

Composed of both Italians and immigrants, the MCO mobilized immigrants around issues linked to institutional racism and workers' exploitation. ${ }^{33}$ At the national level, the organization also created collaborations with new radical leftwing trade unions that gained ground around immigration issues during the financial crisis that started in 2008 and mobilized immigrant workers - in particular the grassroots unions SiCobas and USB. ${ }^{34}$ At the international level, the MCO is affiliated with the groups of the NoBorder Network, though it is important to note that the ideologies of these two organizations do not completely align. ${ }^{35}$ At the national level, the MCO is not attached to any other organizations and it proclaims its autonomy and uniqueness in the Italian landscape. Over the years, the collective has attempted to forge alliances with other actors, but, as Sorana E., a Moldovan young woman in her late twenties, and an active member of the MCO, told me, "always from the viewpoint of creating satellite organizations with groups that are willing to adhere to the key points of the MCO" (BO/N17). Like most members of the $\mathrm{MCO}$, this interview wanted to make the point that the MCO 
was not willing to compromise with other actors, but was seeking to recruit other organizations willing to support their views.

Several members of the MCO explained that there was something unique about their organization, as the organization was the only one in Italy to avoid using immigrants and victimizing them. Corrado G. further explained:

The specificity of our collective is that it combines political action and immigration. There is nothing like that in the rest of Italy. It is a very specific reality of Bologna. First, because there is no other reality that has worked with such a continuity, for more than ten years. Second, no one took the gamble that we did: to believe that migrants are a strategic part of the labor force and that they can act to transform things.

(BO/N9)

These last two aspects - immigrants' strategic position in the labor force and their self-determination - sparked conflicts between the anti-racist movement in the organizing of "A day without us," which brought about the creation of the Coordination for the Strike of Migrant Labor in Italy (Cappiali 2019). By looking at the history of the creation of the MCO, it is possible to understand the distinctive ideology of the MCO in the city and across the Italian landscape.

During our interview, Corrado G. explained that at the beginning of the 2000s, a few mobilizations by immigrant workers made activists aware of a new perspective: "migrants' self-determination and the necessity for the movement to work with migrants, rather than on their behalf." This aspect emerged more clearly later on during the organization of "A day without us." At the time, protests by migrants across Italy had encouraged activists and intellectuals of the movement to further develop their thinking on migrant self-determination. As Corrado G. highlighted - and as "A day without us" demonstrated - the link between immigration laws and exploitation became visible among civil society. MCO immigrants exposed how exploitation in the labor market is guaranteed by immigration laws - placing the concept of "institutional racism" at the center of the movement.

Claudia E., a young Italian woman in her thirties, and another key member of the MCO, confirmed the importance of the concept of migrant labor: "The most important difference between us and most of radical left organizations, such as the No Borders movement. is that we concentrate on migrant labor" (BO/N16:). Corrado G. further clarified this point:

We argue that "migrant labor" is a mechanism to control the labor market within the state. Trade unions and social movements have two different and mirror-image visions. Trade unions are caught in the national horizon. Social movements are couched in the universalistic dimension of human rights and the idea that we are all the same. They talk about the global proletariat. This means denying the important differences that exist between migrants and nonmigrants. In the past, people used to talk about equality for all and then they forgot that women and slaves were excluded from a more general struggle 
for equality. The truth is that trade unions and social movements do not talk about migrants. Trade unions talk only about workers and social movements only about migrants. Thus no one makes the political investment we do.

(BO/N9)

Abou B., an immigrant activist of Senegalese origin in his fifties, and a key member of the organization who contributed to its creation in 2004, helped reconstruct the development of the MCO. He explained how the collective was founded and emphasized the presence of some intellectuals mentioned earlier:

The collective was created around nine years ago [2004]. I had met with young Italian people who were studying Political Science at the University of Bologna. At that point, we decided to create a group. It was a group composed of both Italians and migrants. There were four or five founders. Those five people who founded the organization are still there. Today the nucleus of the collective is composed of 15 people, and it is linked to many other networks in the city and beyond, mainly migrant networks of Senegalese, Pakistanis, Bengalese, Tunisians, Moroccans, Peruvians, and Albanians.

$(\mathrm{BO} / \mathrm{N} 10)$

Abou B. explained that the MCO was not a hierarchical organization and did not have a president like the immigrant associations in the city. They decided to call themselves a collective to emphasize this difference. As Abou B. illustrated to me:

The structure of the MCO has a strategic value as well as a political one. As far as the strategic dimension is concerned, if someone denounces us for our political claims, no one can find us because "we do not exist" [formally]. There is no representation. This is our strategy to exist and to continue to exist. In this way they cannot attack us. This facilitates our political struggle because we can say what we want without being attacked. The political value is that I believe that we are free to discuss anything. For us, it is important to listen to what one has to say, as long as this is reasonable. There are no hierarchies.

$(\mathrm{BO} / \mathrm{N} 10)$

The MCO has been extremely active in the territory of Bologna and its province since its creation in 2004. It meets once a week, and on some occasions, it organizes activities in other places in Italy. Over the years it has been able to organize demonstrations with up to a few thousand people of migrant background. At the local level, it works to put pressure on institutions to improve the life conditions of migrants in the city, particularly protesting against the police headquarters and the prefecture for slowness in releasing the permit of stay and other documents. ${ }^{36}$

To counter political clandestinity, the organization makes explicit its goal to support claims and self-determination of migrants wherever they arise. For this reason, in 2013, they mobilized to support the workers of the transport and logistics sector (along with the grassroots union, the SiCobas), who had been 
left without the protection of traditional trade unions. To give a clear signal to all the organizations in the city that promote a service-delivery approach, the MCO makes clear its will to avoid any form of welfarism.

On this point, one of the members of the organization made clear that "We decided not to create a helpdesk, because we are against any form of assistance" (BO/N17). She added: "the difference between the MCO and all the other organizations in the city is that we don't wait for migrants to come to us, but we go toward them."

The MCO has built the trust of migrants over years. We go towards migrants. Personally, I have gone to Umbria and the Abruzzi to talk with migrants who are paid 2.5 euros per hour. At first, they hesitate, they are fearful and they feel vulnerable. Over time we have built a relationship of trust.

$(\mathrm{BO} / \mathrm{N} 17)$

I asked the members of the MCO about their relationships with the other organizations in the city. All of them confirmed that they had agreed as members to avoid any collaboration with local institutions. Among the reasons was that the collective wanted to guarantee its autonomy with respect to institutions in order to remain "independent, critical and free," as Sonora E. emphasized. Abou B. said: "The organization is not looking for any institutional recognition, because it doesn't want to compromise" (BO/N17).

The MCO's major conflict in the city was with one of the most powerful organizations: the CGIL. ${ }^{37}$ One interviewee explained: "According to us, trade unions have failed to protect migrants" (BO/N17). Another interviewee told me:

We have the interests of workers at heart (women and men). The trade unions have failed to give voice to migrants. At our meetings there are often 300 migrants, who talk and intervene freely. They can express their point of view.

$(\mathrm{BO} / \mathrm{N} 16)$

Corrado G. also made the following point:

At the beginning we used to do things together with the CGIL and there was never a direct clash. Unfortunately, the goal of all trade unions is to make their organization work. With the Bossi-Fini Law, when trade unions compromised with the right-wing government when they agreed to be in charge of the bureaucratic practices [in 2006], the relationship has stiffened a great deal. This was the time of the first direct clash. The trade unions criticized the Bossi-Fini Law, but when it was time to react, they did not do anything concrete. They should have mobilized.

$(\mathrm{BO} / \mathrm{N} 9)^{38}$

Corrado G. went on to say that the "new perspective" opened by the MCO bothers the existing trade unions and social movements because it "questions traditional consolidated ways of political action" (BO/N9). Abou B. expressed a similar point of view when he stated that trade unions and social movements were victims of 
"political opportunism." "They all talk about the Bossi-Fini Law. However, the one that really contacted migrants was the MCO. The existing organizations have not changed their approach or their conception of participation of migrants" (BO/ N10). Abou B. went on to explain:

We want to detach ourselves from all the groups that use migrants for their purposes. For instance, during "A day without us," we asked trade unions to strike with us. They refused with the excuse that it was an "ethnic" strike. For us, this was just an excuse for the traditional trade unions, the CGIL and CISL. They didn't take a position because they wouldn't gain from it.

$(\mathrm{BO} / \mathrm{N} 10)$

I asked Nnkeme N., the president of the Nigerian Association, about the MCO. I met him thanks to my contact with the Director of the Zanorelli Center. However, I saw him several times in meetings held by the MCO. He explained the reason why he appreciated the MCO, even if he was not a member of the collective. He considered it more as a crucial alignment on the issue of immigrants' rights in the city. He explained:

In my view, the greatest strength of the $\mathrm{MCO}$ is raising the political consciousness of migrants. Their goal is to allow migrants to achieve a certain level of political awareness so that they can become active subjects of this territory.

(BO/N21)

This view was shared by many key activists in the city, including Lionel F., the president of the Association Universe.

Several local actors I interviewed in Bologna expressed some concerns regarding the MCO's strategies. I asked Roberta A. from the Center for Foreign Workers of the CGIL of Bologna about the relationship between the CGIL and the radical Left in the city. She answered that the MCO was not willing to collaborate with them. She tried several times since she arrived in the office in 2009, but it did not work (Roberta A.). In turn, I asked Roberta A. about one of the main points made by the $\mathrm{MCO}$, the importance of promoting migrants' self-determination. She answered:

The MCO is right on this. It is about time to stop talking for them: It is necessary to give voice to them. The CGIL has many people [of migrant origin] enrolled in the organization. The number of people enrolled in the CGIL Emilia-Romagna increases because migrants increase.

(BO/N6)

Thus, members of the CGIL were willing to admit that the strong criticism by MCO was in part justified, especially with respect to immigrants' empowerment in the organization. The need to give immigrants voice was considered even more relevant as immigrants' high rate of membership in the union contributed to strengthening the union. 


\section{The resistance of the Democratic Party}

In 2013, the main left-wing political party in Bologna was the Democratic Party. For many years, the party had been riven by powerful internal conflicts. The Party had been little involved in the sphere of immigration and only gradually became a marginal actor with respect to participation and the promotion of migrants' political rights (BO/N22). Between 2009 and 2010, the Democratic Party advanced two main initiatives to promote the participation of people of migrant background in Bologna. The first was to support candidates of foreign origin in the province of Bologna during the municipal elections of 2009. In order to be elected, people of migrant background needed the support of the political party. The election of candidates of migrant background is, in part, the result of the party's attempts to promote greater inclusion. ${ }^{39}$

The second initiative was the creation of the Provincial Forum of Immigration (full name: Provincial Forum of Rights, Cultures and Immigration of Bologna of the Democratic Party-Forum Provinciale Diritti, Culture, Immigration del Partito Democratico) in 2010. The Provincial Forum was created in 2010 to support the discussion of immigration in the territory. Donald R. had been the person in charge of the Provincial Forum since 2012. During our interview, he stressed that the Forum was meant to enhance trajectories of participation from below:

It is a space where Italians and people of foreign origin (new citizens and migrants) discuss subjects linked to immigration and create documents linked to immigration. The Forum is open to everyone, even to citizens who are not members of the Party. It also opens important itineraries of participation and political militancy within the Democratic Party. What is also important from the point of view of political participation is that these platforms must be coordinated not by the Democratic Party, but by ordinary citizens.

$(\mathrm{BO} / \mathrm{N} 22)$

Donald R. explained that it was notable that the person in charge of the Provincial Forum of Immigration was himself, a person of foreign origin. This fact is important because, as Donald R. explained, "it gives a sense of the work done in Bologna and in the Emilia-Romagna region in terms of political participation of people of migrant background" (BO/N22). ${ }^{40}$

Most of the immigrants I interviewed in Bologna recognized that the two initiatives described earlier were important, but noted that they were far from making a significant difference in the city, because the political party had been silent on these issues for too long. As the decisions taken at the municipal level in the 2000s demonstrate, the Democratic Party long ago lost any real interest in the issue of immigration, and when it was in power it was a marginal actor in opening the channels of political participation. Many interviewees highlighted that there was a real resistance in the party to accept change, to give a voice to migrants, to initiate a genuine debate in the city capable of moving beyond a distinction between "us" and "them," and to offer places where migrants' claims could be voiced. It is not 
surprising that the party was completely absent during the organization of "A day without us," which, according to many interviewees, was a visible sign of the party's disengagement on key issues that concerned the worsening of immigrants' working and living conditions. ${ }^{41}$

\section{Multiple channels, overlapping alliances, and conflicts}

Unlike any other city I was studying, Bologna stood out for the high level of immigrants' participation within numerous channels. Their activities often overlapped and many of them were affiliated with more than one organization. Despite the weak incentives offered by the mainstream left (local administrations, the CGIL, and political parties) in more recent years, the city had a uniquely high number of civic and political channels, mostly established from below by civil society organizations of the left. Interviews with several people of migrant background active in the world of associations revealed why and how they were contributing to opening up the channels of civic and political participation in Bologna. Most of the immigrant interviewees admitted that, some years earlier, Bologna was a model of inclusion, a legacy still present in the city. They also pointed out that, notwithstanding the great reticence on the part of some local actors to truly empower immigrants, it was undeniable that, in the Italian landscape, Bologna was still a uniquely open city.

Many interviewees of migrant background made reference to Bologna's distinctive character in this regard. Donald R., for instance, told me:

Like Reggio Emilia, Bologna is in the Emilia-Romagna region. This is a marvellous territory for immigration. It is not by chance that the current Member of the Parliament, Khalid Chaouchi, the Minister of Integration, Cécile Kyenge and myself, an Assessor of Integration, emerged in these territories [Emilia-Romagna]. . . . As far as I know, few places in Italy have done what Bologna and Reggio Emilia did.

$(\mathrm{BO} / \mathrm{N} 22)^{42}$

This virtuous context not only offered a variety of opportunities for immigrants to become active but also allowed them to promote the participation of other immigrants and Italian citizens alike, as the examples of the AMISS and Associations Universe described earlier show.

Immigrant activists in Bologna could be grouped into those who were interested in promoting civic participation from below through the world of associations, and those who preferred to get involved in political channels promoted by different organizations, such as political parties and trade unions and grassroots movements. This second group was composed of people who were convinced that direct political action was crucial to improving immigrants' rights. It is also worth noting that most immigrants active in political channels were or had been part of at least one immigrant or mixed association. This fact revealed the porous borders between civic and political participation and the importance attributed 


\section{Multiple forms of participation}

to active citizenship by local actors, as a means of securing greater inclusion. It is also important to note that immigrant activists engaged in politics, strictly defined, were active in different channels opened up by the Democratic Party (the Provincial Forum of Immigration), the CGIL, and the MCO. All these left-wing organizations promoted different forms of political participation, and individuals decided to mobilize with them for different reasons, as will be explained later. The fact that immigrants seized upon the opportunities to participate promoted by the aforementioned actors did not mean that they trusted them and considered them as allies. On the contrary, most interviewees offered some critical comments regarding the strong discrepancy between the discourses and practices (see also Però 2007) of left-wing actors in the city and, in some cases, even entered into open conflict with them.

Given the considerable number of immigrant activists involved in the city, by way of example, in the next section, I focus on a few immigrant activists who were considered by other actors in the city to be among the most active actors and also a vital part of Bologna's history.

\section{Civic participation and political claims}

One first remarkable aspect of Bologna was the strong link between civic and political channels. Most of the immigrant activists involved in the world of associations had a political understanding of civic participation and believed that participating in the world of associations was the best way to promote greater inclusion of the immigrant communities. Through their activism, they have been able to engage in the city and to create opportunities for the participation of other people of both Italian and migrant backgrounds. Most of the interviewees, moreover, had been disappointed by mainstream left-wing actors (mainly the Democratic Party and the CGIL) and, for this reason, they found it more useful to be active in civic channels to pursue their political goals.

For instance, Lionel F., President of the Association Universe, began our interview by saying: "I am interested in politics out of formal political channels." Lionel F. was born in Cameroon in 1970 and arrived in Bologna in 1994. At the time of the interview, he was waiting for his Italian citizenship. He left his country in part for political reasons. He was active in Cameroon while at university, where he promoted democracy in his country. He moved to Italy to study and he always had his documents. He did many jobs in Italy and he also worked for ten years as a bouncer in the four social centers in Bologna, including the TPO. He clarified that his political orientation was very close to that of the radical left and that if he could vote, he would vote for them.

For this reason, he explained that he was very active in the world of associations, because it allowed him to make a link between active citizenship and political engagement without being active directly in politics. ${ }^{43}$

Politics is not abstract. On the contrary, we do it. I understood that the system works because you are in it and the system is in you. One individual 
can change things from within. When I first arrived in 1994, I was lost. I was welcomed by the associations and the social centers in the city and that made all the difference. Now I want to take part in it myself. I am not the one who does things. I am the one who allows others to do things. For me the most important things are people. For me it is crucial to be a unifying element.

(BO/N24; emphasis mine)

This idea of being a bridge was a recurring one among most of the interviewees. Irene A., President of the Federation of Filipino Associations, shared similar ideas. She was born in the Philippines in 1978 and moved to Bologna in 1989 at the age of 11 to join her mother. She married a Filipino man and had two children. At the time of the interview, she was very active in the world of associations. She was President of the federation of the Filipino associations in the city and she was very active in a Protestant church run by Filipinos. She had also been a councilor of the Provincial Council for non-EU immigrants since its creation in 2007.

Irene A. was a central point of reference for the Filipino community and was highly invested in improving their rights in the city. I asked her why she was so active, and she explained that it was because of her faith: "A Christian should fight for the rights of other people. As a Christian it is my duty." She added that often people asked her: "Why do you do it?" To this she always answers: "I do it because I believe in it and because I hope that my kids will have a better future in this country."

Irene A. was very critical of local institutions, trade unions, and political parties. She also expressed a clear sense of disappointment. She emphasized that these actors were guided by economic interests, and though they said many thingsincluding that they wanted to encourage inclusion - in the last instance they were not really willing to include people of migrant background in the political arena. When talking about the Provincial Council, she said that she was disappointed, because there were very few results: "The administration created the Council, but then it did not encourage its empowerment." Irene A. added that she somehow had expected this outcome because, as far as she could tell, the organizations in the city did not genuinely want to change things. In her view, left-wing political parties and trade unions were mostly worried about internal conflicts, rather than dealing directly with the issues concerning immigrants' rights.

I asked Irene A. if she thought that the Italian associations in Bologna were more visible and stronger than the immigrant associations, and if this had consequences for immigrant associations in the city. She answered:

To me, there are immigrant associations that are able to carry on the responsibilities that are given to the Italian associations. Many migrants like me believe that the immigrant associations can do a lot, in some cases better than the Italian associations. I am convinced that this is the case. Immigrant associations are not always as weak as they are seen to be. The real problem is that the Italian associations and main trade unions have important interests 
to defend. It is mainly about economic interests. Some of them believe in what they do, but then they lose themselves because of their interests. Often what they want is visibility. The emergence of immigrant associations creates problems for them.

(BO/N8)

She admitted that the city was not completely closed to migrants' participation, in particular when channeled through associations and that when it was possible, everyone would give a little support. At this point, I asked why she had decided to participate in the Provincial Council, since she was so skeptical from the outset, to which she replied:

In 2007, it was the first time that migrants were voting for their representative in Bologna. At that time the Filipino community was the biggest in the city. It was the first time that Filipinos voted. They were all there. We took that opportunity to create a federation of Filipino associations. We already had 11 associations: religious associations (Catholic and not), associations of women and of workers, associations based on regional areas. I worked with them to write the deed of incorporation. Our objective was to have an honorary consulate in Bologna, but we never achieved that goal.

(BO/N8)

She also added that, notwithstanding its limitations, from her own personal point of view, the Provincial Council was a very positive opportunity for participation: "The Council was crucial from the point of view of formative experience, to discuss and debate. For me it has been useful from the point of view of active citizenship."

Irene A. concluded by noting that processes of inclusion were possible through active citizenship and that her contribution to the city and the Bolognese community was made possible by her activism. "Active citizenship" for her meant to "care for [others]" and she was doing so by actively contributing to improving the city and for the good of others.

The trajectories of Lionel F. and Irene A. show the key role of immigrant activists in opening up the channels of civic and political participation for themselves and for members of the immigrant communities. Through their mobilization, they have been able to create opportunities for the participation of other people of both Italian and migrant backgrounds (in the case of Lionel F.) or for their communities (in the case of Irene A.). They were also promoting a discourse of active citizenship linked to the world of associations of Bologna, which lends a political meaning to the notion of civic participation. The interviewees also expressed their concerns about major obstacles to participation posed by Italian organizations. Nonetheless, my analysis of the interviews shows that the city not only offered these individuals opportunities for participation but also allowed them to shape the realm of immigration by creating new spaces for participation, through the promotion of alternative visions of their role in the city. These points were confirmed by many other interviewees I met in Bologna during my fieldwork, who were also active within other channels. 


\section{Political participation in conventional channels}

Makham M. was involved in the activities of the Provincial Forum of Immigration of the Democratic Party since 2010 and, like Irene A., he was elected to the Provincial Council in 2007. Makham M. was born in Senegal in 1965. He decided to migrate in order to improve his economic situation. He arrived in Bologna in 1998 at the age of 33 and married an Italian woman. He was awaiting his Italian citizenship at the time of the interview. Makham M. was very active in various channels. He became active in Bologna almost immediately upon his arrival. He explained that in his country he used to be involved in political activities because his uncle was the mayor of his city with a left-wing party. In Italy, Makham M. became active in the schools by organizing musical workshops. He soon started teaching music to disabled children. He did so from 1998 to 2006, and from 2008 to 2013 he kept himself busy with music through collaborations with other associations.

I asked him what prompted him to participate in the world of associations, the Provincial Council, and the Provincial Forum of Immigration. He answered straightforwardly: "because each field is a good opportunity to become representatives, ambassadors, of ourselves."

To solve problems, we need to start from those who are experiencing them. The Forum, the Council, associations ... each body has its own function, which is very useful for bringing them together and producing results. With the Provincial Forum we worked with Cécile Kyenge, who was the person in charge of the Forum of Immigration at the regional level. Now she is a minister of the Republic. This is a great result. The regional context also matters and the uniqueness of this region in the national landscape is visible. There have been some results at the national, regional, and local level, but they are not enough. We need to work hard to change things. The first three things we need to fight for are: the abolition of the Bossi-Fini Law; the right to vote at the administrative level for migrants; and the jus soli. These three things would change everything.

$(\mathrm{BO} / \mathrm{N} 20)$

Makham M. believed that Italians and people of migrant background needed to work together to bring about results. Neither Italians nor migrants alone could change things. Makham M. also added that participation meant "to speak for oneself," "to be active in changing and improving things," something that, he believed, was strongly opposed by powerful left-wing actors in the city. Despite this, Makham M. was convinced that, though slow to arrive, there had been results, and he was ready to make all the necessary efforts to get involved and create the conditions for greater inclusion of migrants in Italy.

As mentioned previously, Donald R. was also a key immigrant activist in the city. He was a first-generation migrant, originally from Cameroon, and an Italian citizen. Born in Cameroon in the 1970s, he arrived in Bologna in 1996. Donald R. married an Italian woman in 2001. At the time of the interview, he was working for the Emilia-Romagna region. Moreover, he had been the Assessor of Integration of San Lazzaro (Province of Bologna) since 2009 and was in charge of the 
Provincial Forum of the Party in Bologna since 2011. Before, he had been very active in the multiple channels opened in the city in the world of associations, among others, and had several roles with responsibilities. He arrived with a student permit and worked many different jobs to pay for his studies. He graduated from the University of Bologna in 2001 in communication science. He explained that these communicative skills were very useful for both his work and political engagement. At the time of the interview, he was also doing a $\mathrm{PhD}$ in Montreal in Communication Studies. However, Donald R. was interested in politics in a strict sense, and since 2007 had been active with the main left-wing political party, the Democratic Party. When studying at the University of Bologna, Donald R. decided to get involved in politics. In 2000, he met with the Metropolitan Forum and started volunteering by helping associations with bureaucratic issues and writing their statutes. In 2002, he enrolled with an association and in 2005 became President of the Forum. Then, in 2006, he became very active with the DS, and in 2007 with the new left-wing party, the Democratic Party. In 2008, he stood as a candidate for the Italian Parliament, but he was not elected.

Although Donald R. acknowledged the role of associations, he believed that change could only happen in the world of politics. His long trajectory of civic and political participation is crucial for understanding the emergence of migrant leaders in the city, which could not have been possible in a more closed context. It illustrates two interlinked factors within the local dynamics in Bologna: the possibility of people of migrant origin emerging as independent actors, on the one hand, and the conflict-filled relationships that emerged between main left-wing actors and immigrants active in the city, on the other. Recalling the experience of the consultative body, the Metropolitan Forum, Donald R. told me that at the time of his presidency between 2005 and 2007, the Forum was forging relationships with the general population in the city and with institutions. The Forum also organized political struggles by denouncing, for instance, the conditions of immigrants' children in schools and the increased prevalence of racism on the part of Italian parents who did not want foreign people in the same class as their own children. ${ }^{44}$

Donald R. commented:

This proactive role, of course, bothered some organizations in the city and in particular [the] trade unions . . . They want to have the exclusive discourse on migration issues and when they found some other protagonists who talked about things that concerned them, this situation floored the powerful leftwing actors in the city.

$(\mathrm{BO} / \mathrm{N} 22)$

He added that, at the time, the CGIL, the Communist Refounding Party, and the Democrats of the Left (DS) did not get along well, and since he "had been starting to do political activities with the Democrats of the Left, the CGIL was not very happy."

The CGIL saw me and said: "Who is he? All immigrants have to come to do the documents in our offices, but we haven't seen him before!" They didn't see me because I used to do my documents alone, and since they are used to 
thinking that immigrants are people who are not able to do anything, they were sorrowful.

$(\mathrm{BO} / \mathrm{N} 22)$

$(\mathrm{BO} / \mathrm{N} 20)$

The examples of Makham M. and Donald R. demonstrate that immigrant activists choose to seize upon the conventional channels opened up by left-wing actors, despite their awareness of the lack of will on the part of local organizations to promote their empowerment. They also suggest that while left-wing actors in Bologna opened up some channels of participation, including consultative bodies, they preferred to keep them as largely superficial rather than offering a genuine kind of empowerment. When such empowerment did arise, there was strong resistance from Italian organizations. This point will be analyzed further in Chapter 7 where I will examine the role of the Italian left in producing processes of othering and in using immigrants' demands for greater participation for their own political interests.

\section{Political participation in non-conventional channels}

In Bologna, many immigrant activists were particularly active in the radical left organization, the Migrant Coordination Organization (MCO). Despite the controversial nature of this actor, it is undeniable that among the political left-wing organizations in the city, the MCO was the only one to gain the trust of several immigrant activists. For many immigrants, their engagement with the MCO was a response to the failure of the main political parties and the trade unions to adequately respond and give a voice to the interests of immigrants (see, e.g., BO/N10, $\mathrm{BO} / \mathrm{N} 11, \mathrm{BO} / \mathrm{N} 12$, and $\mathrm{BO} / \mathrm{N} 13$ ).

People of migrant background active in the radical left organizations were key in promoting immigrants' mobilizations around issues of institutional racism and worker exploitation. The MCO, composed of Italian and immigrant activists, offered an important platform for mobilization thanks to the links that the members established with the migrant communities. Within the MCO, migrants promote a discourse of inclusion in Italian society by transforming the relationship of power that confines them to a very small space and leaves few opportunities to express themselves. Through the MCO, immigrants believed they could make a difference, by giving voice to their claims without compromising with the political interests of other powerful left-wing actors in the city.

Tariq I. was a first-generation immigrant and a leading member of the MCO and President of the Pakistan association since 2004. He was born in Pakistan in the 1970s. He arrived in Bologna in 1998. He graduated in Political Science in his country of origin and left to find more security abroad. When he arrived in Italy, he did all kinds of non-skilled jobs before he bought a boutique and started working for himself. He was a very active member of the immigrant community, a main representative of the Pakistani community, and a key member of the MCO. Before the interview, I met with Tariq I. during several meetings and assemblies of the MCO. He was one of the people who would 
intervene the most during the meetings. We also had several informal conversations. I asked him why he was so active in the city. He answered:

It is something natural for me to help others. I help fellow Pakistanis and other immigrants. I want to express the voice of immigrants through my activities! Since the beginning, I always told myself that an immigrant is not someone who arrives in a place and that is it. In reality, the immigrant brings his whole self and he needs to express himself. My question is then: How can a migrant express his project of life? How can he give voice to his needs? We need to go toward Italians and tell them who we are and what we do.

$(\mathrm{BO} / \mathrm{N} 12)$

At this point, I asked Tariq I. why he decided to become a key member of the $\mathrm{MCO}$ and what distinguished this organization from other organizations and channels of participation:

The MCO is the voice of immigrants, for immigrants. It starts from the real problems of migrants. It is unique in the landscape of Bologna. In other places, such as the Provincial Council, people of migrant background can talk and listen, but they cannot take decisions. Since my arrival I have tried to find a way to get involved and give voice to the needs of people. Most of the places I went, migrants were supposed to listen and stay quiet. In 2004, with the creation of the $\mathrm{MCO}$, we decided to create the conditions for migrants to express their voices starting from their problems and conditions in complete autonomy. The trade unions have political affiliations and do not act in our interests.

(emphasis mine)

This response was in accordance with what he had said during an assembly, which I attended with the MCO in May 2013 in a social center in Milan. Addressing the assembly, Tariq I. stated that the MCO was my life. For many years he had one main thought: "that of being the voice of migrants." He explained why the MCO was the only political platform he decided to join and contribute to.

In Italy I have found many tables, many trade unions. I have understood that trade unions ... only want to use migrants. The MCO has offered all the possibilities. It has shown that migrants in Italy are very important. I have seen many groups. They organize assemblies and meetings and they are all linked to the political parties. They never act in our interest, the interest of migrants, but in their own interest. Five or six years ago they called me and asked me: "Are you coming to our event? How many are you?" I asked them: "What projects do you have for migrants? What projects for workers?" and they made me understand that they had not thought about it . . . then I told them: "Then, why should I come to you? I am not coming! This is a very important day for migrants, for workers and you don't do anything for them?!" They said: "We can discuss it later," but I answered: "No! Before, not after! You 
had to think about immigrants long before. Now migrants have woken up!" With this point I want to say: The MCO is you. Each one of you is responsible! Each worker! Each one is responsible because we can go ahead together, shoulder to shoulder. We have always been used. The message I want to send to everyone is that: the MCO goes ahead with us. You are the MCO and thanks to you the MCO goes ahead.

(fieldnotes, Assembly MCO in Milan, May 19, 2013)

A singer in a hip-hop group, Farid M. was a second-generation immigrant, originally from Morocco. He arrived in Italy with his family when he was very young. Both his parents were from Morocco. At the time of the interview, he was only 17 years old, and for this reason he did not have the Italian citizenship, which can be asked only at the age of 18 , by children of immigrants, according to the citizenship law. Farid M. was a main member of On The Move, the youth organization linked to the MCO since 2011. He was one of the main artists in a hip-hop group connected to the organization. At the time of the interview, he was present at all the events organized by the MCO in which I participated, and, on most occasions, he intervened as a spokesman for On the Move. His commitment to the cause of improving the conditions of migrants in Italy was very clear in all the meetings in which I participated. I asked him: "Have you ever thought about leaving the country?" He answered: "To leave would mean to go and look for a better place, but this doesn't work because if you think of leaving you assume that you can't change the place where you are!" (BO/N14). For Farid M., political action was necessary to change things and his way of doing so was through the interpretative lens offered by the MCO. I asked him: "Why did you decide to be active with the MCO?" He replied: "Because I share its goals: the MCO fights for the creation of a global and complete struggle against the Bossi-Fini Law and tells migrants that they have to raise their heads."

In their own words, immigrant activists made major contributions to the fight to improve immigrants' rights by mobilizing with the radical left organization, the MCO. Almost all the people of migrant background that I interviewed acknowledged that the MCO was the most relevant actor in the realm of immigration. It gave immigrants a way to speak for themselves, and some who were active in the world of associations mobilized with this organization for political reasons. As will be shown in Chapter 7, according to immigrant activists, the MCO's approach to inclusion is not unproblematic. However, as many Italian and immigrant interviewees told me, in Bologna, they represent the main ally of immigrant communities (see also BO/N3, BO/N6, BO/N21, BO/N24).

\section{Lessons from Bologna}

The "A day without us" action in Italy identified specific dynamics in Bologna. The organization of the event sparked some conflicts between different organizations, including civil society associations, traditional trade unions, and radical left-wing actors. Two main disputes emerged: (1) the lack of support from 
traditional trade unions, including the main left-wing organization in the city, the CGIL; and (2) the conflict between moderate and radical left actors over whether to organize a demonstration or a strike. In most local contexts, where the trade unions did not support the strike, the organizers opted for a demonstration. In Bologna, however, the lack of support from the CGIL did not prevent radical left organizations in the city from organizing a strike from below. Both the demonstration and the strike, moreover, saw a great involvement of people of migrant background with different political orientations and views. The mobilization points to the existence of a dense network of pro-immigrant and immigrant groups of the left, especially within civil society, with a variety of conflicts and convergences shaping their alliances or lack thereof. It illustrates, in particular, a strong presence of several left-wing actors and important conflicts over the issue of immigration among mainstream left-wing actors (in particular the CGIL), other moderate leftwing actors, and the radical left. It also indicates a strong presence of immigrant activists and the creation of alliances between many immigrants politically active in the city and one major radical left-wing actor, namely the MCO.

Despite the conflicts that emerged, "A day without us" also showed that the participatory outcomes in Bologna were particularly successful according to the organizers, including both Italian and immigrant activists alike (Cappiali 2019). In this respect, one can say that the dense networks of left-wing actors, including immigrant activists, who mobilized in favor of immigrant rights comprise an important "relational incubator" (Nicholls and Uitermark 2016) and preferred mobilizations organized both in solidarity with or on behalf of vulnerable immigrants and with many immigrants who can actively participate to this end. Finally, the mobilization illustrated the silence of other key left actors, such as the main political party of the left, the Democratic Party, and Christian Democratic organizations, the Church and CISL. Despite this, one can observe a plethora of alliances - often overlapping — as well as an important role of immigrant activists with different statuses and political orientations. In the national context, immigrants' participation across multiple channels in Bologna speaks to the city's uniqueness in this regard.

Since the end of the 1990s, Bologna became a model of inclusion in Italy. Demonstrated by the local dynamics of the organization of "A day without us," Bologna is unique, especially with respect to how it promotes immigrants' civic and political engagement within the national landscape. The reconstruction of the institutional context reveals the key role of left-wing actors in promoting immigrant activists' participation. The local administrations undertook a comprehensive approach, seeking to empower immigrants through the opening of several channels of participation (see also Caponio 2006; Però 2007). In recent years, in the absence of interventions from above, both moderate and radical left-wing actors within civil society, including immigrant organizations, have filled the institutional vacuum. They have promoted immigrants' inclusion by adopting both an intercultural approach and a political rights promotion approach from below. Through them, civil society organizations could build on the previous work done in the city by local administrations and other key left-wing organizations, including the CGIL. 
Bologna's unique way of addressing immigrants' inclusion in the city led to the emancipation of several immigrant activists and the creation of multiple alliances between pro-immigrant actors and immigrant activists. The result was the development of a wide range of forms of civic and political participation, both formal and informal, with immigrant activists engaging with and taking on responsibilities within different organizations. The most relevant aspect was leadership within the immigrant community, whereby people of migrant background engaged in the city to open up channels of civic and political participation in Bologna. Multiple channels of participation enabled considerable flexibility for migrants to participate and, in turn, to open up channels of participation for other immigrants, and to challenge pro-immigrant actors by using several strategies to empower themselves. Their engagement shaped the local realm of immigration through their support of the intercultural and political rights promotion approaches and to bring forth new understandings about immigrant participation and inclusion.

Comparing Bologna and Reggio Emilia allows us also to draw some conclusions regarding the variations of local dynamics in traditionally Communist cities. Despite having the same political sub-culture, the local realm of immigration in Bologna was different from that of Reggio Emilia. In Reggio Emilia, the strong presence and investment of moderate left-wing actors in the realm of immigration, through an intercultural approach, combined with the weak investment by other left-wing actors of the political rights promotion approach, resulted almost exclusively in the opening of civic channels. In Bologna, there was a lack of involvement by the local administration in the realm of immigration, and the lack of coordination from above made it more complicated to cover the main issues around immigration and inclusion. Nonetheless, the third sector and the radical left-wing organizations encouraged both civic and political forms of participation from below. This resulted in a wider range of participatory channels for immigrant activists and the creation of relevant channels to allow many immigrant activists to grow in the city as relevant political actors Thus, in Bologna, the presence of multiple channels, mostly promoted from below, favored immigrant activism in a unique way. It enabled flexible forms of participation on the part of immigrant activists and encouraged an overlapping of their activities.

While immigrants appropriated the main language used in Bologna of "active citizenship," they also actively promoted their own channels and views. In the case of the third sector, immigrant activists promoted both the intercultural approach (by presenting themselves as bridges between the Italian and the immigrant communities) and the political rights promotion approach (by mobilizing for the abolition of the Bossi-Fini Law and greater recognition of immigrants' rights). Alliances with radical left actors, in particular the $\mathrm{MCO}$ (composed of Italians and immigrants alike), were vital. By allying with this actor, many immigrant activists defied traditional left-wing organizations (especially the Democratic Party and the CGIL) and helped to open up non-conventional channels of political participation. Given the trust gained among immigrant activists, many immigrant organizations became involved in the initiatives promoted by the MCO, as was the case during "A day without us." 
Overall, Bologna had multiple channels of participation opened by left-wing actors and lay organizations, which allowed intense participation by immigrant activists. It also allowed them to take on roles as active political subjects and contribute by encouraging participation by other migrants. This context was quite different from Reggio Emilia, for instance, where participation could be mostly seen in civic channels. While the latter were important, and should not be underestimated, in the absence of other channels in the city, they offered limited opportunities for immigrants to pursue new trajectories beyond those defined by the local administrations and other civil society organizations. All things considered, even though there were many conflicts between Italian pro-immigrant organizations, and between the latter and immigrant organizations, in Bologna, the plethora of channels available offered several relevant opportunities for immigrants to grow in the city as key political players. Even though they sometimes faced major barriers and power dynamics $v i s-\grave{a}$-vis Italian organizations, immigrant activists were able to defy these organizations on their own terms, by creating their own organizations or by creating alliances with less institutionalized actors (such as the MCO). Beyond these opportunities, however, the analysis also showed conflicts between pro-immigrant organizations and between pro-immigrant organizations and immigrant activists. The ambivalent of the left and the powerful barriers imposed on immigrant activists will be further explored in Chapter 7, where I will delve deeper into the process of political racialization produced by the left and the reasons for it.

\section{Notes}

1 A briefer analysis on Bologna has been published previously in Cappiali $(2018,2019)$. For a complete list of the interviews in Bologna, see Appendix C.

2 For a detailed analysis of the period preceding 1998, see the excellent work by two Italian scholars: Però (2007) and Caponio (2006).

3 See also interview with Marco G. (BO/N3).

4 To be more precise, throughout this period, the political continuity of the left-wing parties at the provincial level represented an important factor in the promotion of some initiatives of inclusion and political participation in the city of Bologna. In 2007, the province of Bologna did create the Provincial Council to promote the political participation of immigrants. However, as many interviewees explained, there was no motivation or material support to empower the Council, which until 2013 was a façade rather than a body capable of advancing immigrants' interests and needs in the city $(\mathrm{BO} /$ N8: Irene A., Filipino (F), Councilor; and BO/N22: Donald R., Cameroonian (M), in charge of the Provincial Forum on Immigration of the PD and Assessor of integration of San Lazzaro (Province Bologna)).

5 See, for instance, the mobilization by the three main organizations of the radical left in the city: Ya Basta! Bologna, the Social Center TPO, and Passpartout. "Immigrazione e casa: La ricotta di Cofferati. Comunicato stampa e foto di Ya Basta! TPO and Passpartout." Meltingpot.org. March 21, 2005. www.meltingpot.org/Immigrazione-e-casa-laricetta-di-Cofferati.html\#.VM-uCcY5D0p (Accessed June 15, 2015).

6 At the beginning of the 2000s, the term "sheriff" (sceriffi) became popular in Italy. It was used to talk about the local administrators of the Northern League who were particularly tough toward immigrants and other vulnerable groups such as the Roma (as anticipated in the Introduction). E. Bonerandi. "Effetto Cofferati, sindaci di sinistra più 'sceriffi'.” Bologna Repubblica.it. July 9, 2007. http://bologna.repubblica.it/dettaglio/ effetto-cofferati-sindaci-di-sinistra-piu-sceriffi/1337067 (Accessed June 15, 2015). 
7 See the official document: "Delibera di Consiglio Provinciale di Bologna n. 39/2007 di approvazione del Regolamento del Consiglio degli stranieri." www.cittametropolitana.bo.it/storia/Engine/RAServePG.php/P/258411410405/T/Consiglio-dei-cittadinistranieri-e-apolidi-della-Provincia-di-Bologna (Accessed June 15, 2015).

8 Most interviewees said that the Council faced the same major problems as the Metropolitan Forum: it was never empowered and the immigrant community was never given a voice. Irene A., for instance, stated that she had never believed that the Council would make any difference in the city. As proof of its uselessness, she said that many had left the Council (BO/N8: Filipino (F), Councilor). I asked her if she was also disappointed, and she answered: "Yes, because we have not achieved any result: the province created the Council and left us on our own" (Irene A., Interview in Bologna, July 2, 2013). Irene A. continued:

Immigrants were supposed to vote every five years, together with the administrative elections. In reality, at the end of the mandate in 2012, the elections were not done again. The administration wants to keep it alive because it does not want to admit that it has been a failure. The truth is that the Council is useless.

(Irene A., Interview in Bologna, July 2, 2013)

During our interview, Marco G. explained:

On paper, it is an outstanding body. It is one of the most advanced consultative bodies made by the local authorities in Italy. It was also based on past experiences. It was done by trying to avoid the errors of the past. However, what was lacking was the people able to make it work. The real problem is that it was never conceived as a political organization as an instrument of negotiation between (1) the different national components through their associations and (2) the executives of the consultative body and the executive of the province.

$(\mathrm{BO} / \mathrm{N} 3)$

9 The Council was the last initiative by local authorities in the direction of political rights promotion and the promotion of participation through consultative bodies. During my fieldwork in 2013, the Council was still in place, but its future was unclear (BO/N8: Irene A.).

10 The 10 most numerous groups were from Romania (6,856), Philippines $(5,133)$, Bangladesh (4,935), Moldova (4,558), Morocco $(3,792)$, Ukraine $(3,163)$, China $(3,032)$, Pakistan $(2,803)$, Albania $(2,509)$, and Sri Lanka $(1,355)$ (Istat 2013).

11 On its official site, there are 112 associations of immigrants present on the list, 75 in the city of Bologna and the rest in the province. Among the 42 associations for immigrants, 33 are in the city and the others are in the province. For a list of the associations working at the provincial level, see: www.cittametropolitana.bo.it/sanitasociale/Engine/ RAServePG.php/P/256611180706/T/Le-associazioni (Accessed June 15, 2015). For a list of the associations working at the municipal level, see the page "Associations" on the official site of the Zonarelli Center: http://zonagidue.it/index.php?option=com_con tent $\&$ view $=$ article $\& i d=144 \& I t e m i d=61$ (Accessed June 15, 2015). See also: http:// informa.comune.bologna.it/iperbole/sportellosociale/servizi/2709/2689 (Accessed June 15, 2015). For more details, see the official report by the province of Bologna, 2011. "L'associazionimo degli immigrati a Bologna: tra identità e integrazione?" www.cittametropolitana.bo.it/sanitasociale/Engine/RAServeFile.php/f/Documenti/ Report_ricerca_associazioni3.pdf (Accessed June 15, 2015). On the associations that promote cooperation and development and that are concerned with immigration, social marginalization, and education, see the page of the voluntary sector of the municipality of Bologna: www.flashgiovani.it/volontariato/associazioni/pagina/331 (Accessed June 15, 2015). It includes 23 associations.

12 See the official site of the municipality: http://comune.bologna.it/sportellosociale/ servizi/2709/45973/ (Accessed June 15, 2015). Created in 1998 by the left-wing provincial administration, in 2007 the Zonarelli Center was managed by the municipality 
of Bologna's Division of Social Services, but it was de facto almost independent from the administration.

13 According to the official site of the municipality, the Center:

is the historical place where Italians and immigrants can meet. Its actions aim to support, promote and multiply the opportunities of encounter, reciprocal knowledge, exchange and intercultural dialogue.... The Center is a space to express, act, and build the mosaic of individual and collective identities.

The associations that belong to the Center are divided as follows: (1) associations created in the second half of the 1990s (49\%); (2) associations interested in promoting relationships between the homeland and Italy, usually older than the first ones (15\%); (3) associations interested in promoting intercultural dialogue (15\%); and (4) new associations interested in the cultural or artistic promotion of intercultural dialogue (21\%) www.comune.bologna.it/sportellosociale/servizi/2709/45973/ (Accessed June 15, 2015). See also the official site of the Center Zonarelli (http:// zonagidue.it/)

14 In the section titled "values," one can read that the Zonarelli Center follows the definition of "the Universal Declaration of the UNESCO on the Cultural Diversity." The Center acknowledges that "cultural diversity is a patrimony of the collectivity, a democratic value and a factor of social, civil, and cultural development." http://zonagidue.it/index.php?option=com_content\&view $=$ article \&id=181\&Itemid=74 (Accessed June 15, 2015).

15 MunicipalityofBologna.2009.Citizenship.www.youtube.com/watch?v=MvOtp7dNV_Q (Accessed June 15, 2015); and LaDamaSognatrice. 2013. "Beyond Islam's Doors." http://beyondislamsdoors.wordpress.com (Accessed June 30, 2015).

16 See the link of the Municipality of Bologna. www.comune.bologna.it/amitie/ (Accessed June 15, 2015) and the official European site: http://amitie-community.eu/ (Accessed June 15, 2015).

17 See the official site: www.comune.bologna.it/amitie/ (Accessed June 15, 2015).

18 It also created visual material in collaboration with other cities involved in the project, including a documentary titled "This is my story," which tells the stories of many immigrants residing in European cities and the challenges they encounter. This was one examples of ways in which civil society organizations in Bologna foster intercultural ideas, by sensitizing the population in Bologna and in Italy about the lived-experience of immigrants.

19 See the official site of the organization: http://amissbologna.org/ (Accessed June 15, 2015) and also the site of the Emilia-Romagna region: www.informafamiglie.it/emiliaromagna/ bologna/famiglia-e-associazioni/associazioni-per-famiglie-straniere/amiss-associazionemediatrici-interculturali-sociali-e-sanitarie/user_view (Accessed June 15, 2015).

20 The official website of the association is: www.universointerculturale.it (Accessed June 15, 2015).

21 It is also important to note that the CGIL has strong political links in the city. One example is that the left-wing administration that governed Bologna between 2004 and 2009 was led by Mayor Cofferati, the National Secretary of the CGIL from 1994 to 2002. This fact suggests that the trade union is not independent from the political sphere.

22 See documents of the conference "Lavoro, diritti and rappresentanza: gli impegni della CGIL Emilia-Romagna nella conferenza regionale sull'immigrazione," organized in Bologna on June 10, 2013. The data on representation are found in the documents of the conference and in particular the CGIL (2013).

23 It was not possible to find the number of immigrants enrolled in the CISL in any official site or document. Several interviewees claimed that these data do not exist. In contrast to the CGIL, the Christian Democratic trade union, the CISL, is a relatively weak actor in the city of Bologna. All my interviewees agreed that the CISL has less weight than the CGIL, and it is very rare that these two trade unions organize things 
together. As one of the persons in charge of the CISL-ANOLF, Pietro M., told me, the CISL in Bologna "has to compete with the CGIL at all levels. In any case, it is a healthy rivalry. We do alliances with the CGIL when we cannot do otherwise" (BO/N5: Pietro M., Italian (M), service desk of the CISL-ANOLF). In line with the main approach adopted by the national organization, the CISL of Bologna concentrates mainly on assistance and the promotion of interculturalism through the CISLANOLF. As stated on its official site, the trade union's goal through the CISL-ANOLF is "to create a society open to diversity in a world more and more multi-ethnic and multi-cultural, through the respect and valorization of ethnic, cultural, and religious specificities." The organization also wants to fight against racism and xenophobia by creating programs of reciprocal acquaintance among "different social groups." I asked Pietro M. with whom the CISL created alliances and collaborations in the city. He answered:

The CISL is particularly isolated in the city with respect to all left-wing actors. It has never created alliances with other organizations, except with the CGIL on some sporadic occasions. The other organizations never let the CISL in and the CISL never wanted to be involved anyhow.

Pietro M. explained that he wished his organization would collaborate more with other organizations in the city, including the MCO, but according to him, this was unlikely, because of ideological reasons. As far as representation in the organization is concerned, the interviewee told me that the CISL had some delegates of foreign origin, but "no functionaries in the organization, let alone in the direction, where decisions are taken." See also the CISL's official site: www.cislmetropolitana.bo.it/associazioni/ anolf.html (Accessed June 15, 2015).

24 See the official page of the Center: www.cgilbo.it/centro-lavoratori-stranieri (Accessed June 15, 2015).

25 Roberta A. highlighted that, "unfortunately, because of the financial crisis, Bologna has been regressing in terms of welcoming immigrants. The problem is that we would need three times more resources." She added:

In Bologna it is very hard to see people under international protection on the streets. There are many associations that work for a minimum of dignity. On the issue of welcoming, Bologna has taken many backward steps. If you consider that the needs are growing and that the resources are diminishing, you understand that the problem is enormous and that no one is thinking about integration anymore.

(BO/N6)

26 "Il Cie Bologna deve chiudere: Comunicato stampa CGIL e FP." www.cgilbo.it/flex/ $\mathrm{cm} /$ pages/ServeBLOB.php/L/IT/IDPagina/268 (Accessed June 15, 2015).

27 The lack of space in the organization to give voice to immigrants was a particularly sensitive issue at the time of my fieldwork in 2013. The territorial CGIL in the EmiliaRomagna region had just released a study on the low levels of representation of immigrants in the organization and was arranging meetings to discuss ways to overcome this problem. The data on representation are found in CGIL (2013).

28 Historically, in Bologna there have been several radical left organizations and they have always been particularly active in the context of migration. At the time of my fieldwork, there were two main organizations: the TPO and the MCO. Of these organizations, the MCO was particularly successful in gaining legitimacy among migrants in the city and the province, and was well known for its ability to open up channels of political participation and provide platforms for the mobilization of a great number of migrants. The organization of "A day without us" exemplified the MCO's ability to substantially support participation from below.

29 The Center is affiliated with the "autonomist" movement of the radical left, for whom the leftist intellectuals Antonio Negri and Sandro Mezzadra (Professor at the 
University of Bologna) are key reference points. The official site of the Social Center XM24 is www.ecn.org/xm24/ (Accessed June 15, 2015). For a complete list of the collectives linked to the Center, see www.ecn.org/xm24/progetticollettivi/ (Accessed June 15, 2015). For an overview of the different political tendencies of the radical left, see Cosseron 2007.

30 The break with the anti-racist movement in the beginning of the 2000s was theorized by Fabio Raimondi (Professor of Political Philosophy at the University of Salerno) and Maurizio Ricciardi (Professor of Political Science at the University of Bologna) in the Introduction to the co-edited book Lavoro Migrante. Esperiences and prospettiva, published in 2004. These authors introduced the key concept of immigrant labor and presented a theoretical interpretation of the role of immigrants in the Italian labor force that would be crucial for the development of the positions of the MCO of Bologna in the realm of migration.

31 The conflict between the two main radical left-wing organizations in Bologna-the $\mathrm{TPO}$ and the MCO - over the potential of immigrants to mobilize emerged in the declarations expressed in the aftermath of "A day without us" on the MCO's blog. The MCO made the same criticism of the anti-racist groups that they made in the case of the Coordination for the Strike of Migrant Labor.

32 On the home page of the official site of the MCO, one can find a list of its activities. On the home page, the collective presents itself as a "Movement of migrants against racism and exploitation." On the top of the page, one can read: "Abolition of the BossiFini Law, enough pay to stay, citizenship immediately for the new generation, close the CIE (Detention Centers)." In particular, the MCO fights against the strict link between the permit of work and permit of stay-established in Italian legislation since the Turco-Napolitano Law and reinforced with the Bossi-Fini Law-which is at the heart of what they believe to be "institutional racism" that creates the conditions for differentiated treatment between Italian and immigrant workers. See the link: http://comibo. altervista.org/nuovo-sito-del-coordinamento-migranti/ (Accessed June15, 2015).

33 In more recent years, the MCO has enlarged its structure in order to be more inclusive towards women and second-generation migrants. On the home page one can find links to two organizations: Project On the Move-New Generations in Movement (Laboratorio On the Move-Nuove generazioni in movimento) and Migranda. The sites are respectively: https://labonthemove.wordpress.com (Accessed June 15, 2015) and http://migranda.org (Accessed June15, 2015).

34 During my fieldwork, thanks to interviews with key members of the MCO, informal conversations, participant observation in meetings and events in Bologna, Brescia and Milan, as well as active examination of the activities published on the MCO's website, I was able to assess the uniqueness of the organization in the city and in the Italian political landscape by observing its structure, its discourses and its actions.

35 See the official site of the NoBorder Network: www.noborder.org (Accessed June 15, 2015).

36 The organization has kept archives since its creation in 2004. For the historical archive of the MCO between 2004 and 2011, see the official site: http://comibo.altervista. org/nuovo-sito-del-coordinamento-migranti/ (Accessed June 15, 2015). For the more recent archive (from 2011 to 2015), see the new official site: http://coordinamentomigranti.org (Accessed June 15, 2015).

37 Corrado G. also explained that there were no relationships with the CISL because of major ideological differences. Abou B. confirmed this point when he said that, "the CISL is in favor of the Detention Centers. For us it is unacceptable" (BO/N10, see also BO/N13).

38 Here, the interviewee is referring to when the CGIL assisted the state in the renewal of immigrants' permits of stay and more in general with bureaucratic practices related to their residence of immigrants in Italy. This was considered by many immigrant workers as a betrayal by the CGIL. 
39 This was the case in other municipalities in Emilia-Romagna, where two people of migrant background were elected in the province of Reggio Emilia - in Quattro Castella (the Municipal Councilor Reda B.) and in Novellara (the Municipal Assessor of Social Policies Yossef Salmi) - and one in the province of Modena (Provincial Councilor Cécile Kyenge, who became the first Minister of Integration of Italy in March 2013).

40 It is important to recall that the Democratic Party of Emilia-Romagna was the only one that was able to create a network of Provincial Forums with a high level of coordination at the regional level. Many of my interviewees in Reggio Emilia and Bologna recognized the role of Kyenge in creating a solid network in the region. In 2013, two people of migrant background were in charge of the Provincial Forum of Immigration of Reggio Emilia and the Regional Forum of Emilia-Romagna.

41 Almost all the immigrants I interviewed in the city exposed this problem. Some of these interviewees who spoke more openly about this issue were $\mathrm{BO} / \mathrm{N} 8, \mathrm{BO} / \mathrm{N} 13$, $\mathrm{BO} / \mathrm{N} 15, \mathrm{BO} / \mathrm{N} 19, \mathrm{BO} / \mathrm{N} 20, \mathrm{BO} / \mathrm{N} 22, \mathrm{BO} / \mathrm{N} 23, \mathrm{BO} / \mathrm{N} 24$.

42 In the past few years, the Democratic Party in Emilia-Romagna made a some effort to promote the elections of some leaders of migrant origin (cf. also Cappiali 2017b). As a result of this strategy, in addition to the elections of some councilors and members of the executive at the local level, two people of migrant background were elected during the national elections of February 2013: Khalid Chaouchi, from Reggio Emilia, and a person of Moroccan origin, and Cécile Kyenge, a person of Congolese origin from Modena. While Chaouchi became a Member of the Parliament, and Kyenge became the first Minister of Integration of the Italian Republic.

43 Lionel F. told me that half of his life was devoted to work and half to volunteer work. He said that he had been volunteering in prisons for more than 12 years. Every Friday he would go into the prisons to do mediation and read about moral philosophy with detainees, following the teachings of the German philosopher Albert Schweitzer who won the Nobel Prize in 1952. He explained that in the first two years of his arrival (between 1994 and 1996), he had participated in training on cultural mediation funded by the municipality of Bologna, hoping to find a job. The attempt proved unsuccessful and in 1996 he decided to create an association Di Mondi:

During the course [for cultural mediators] they taught us the theater of the oppressed, and they made it clear to us what the conditions of immigrants were and how to intervene to help those who needed it. So, after the course we created the association Di Mondi.

The association Di Mondi was composed of Italians and migrants and sought to facilitate the integration of migrants and present the beauty of other cultures. In 1997, Lionel F. left the association. In the following years, he founded and was the president of two other associations: Universe, created in 1998 and formalized in 2000; and Harambe in 2004. As noted, the association Universe is composed of 100 members and plays a very active role in the city, promoting active citizenship and the "idea that immigrants contribute to the growth of the city." The association Harambe is composed of 50 members and organizes projects for the camps of Roma and collaborates with students from the University of Bologna. During an interview released in 2010, Lionel F. said:

Each year I go to the University to talk with first- and second-year students. I give them a class on "the translation of theory into practice," because to be able to change the world one needs to look around and try to do something in the world around him.

44 Donald R. added that the Metropolitan Forum created in the 1990s by the left-wing administration, with all its limitations, was politically and socially strategic and allowed the development of an immigrant leadership in the city. 


\section{References}

Barbagli. Marzio, ed. 1999. Egregio signor sindaco: lettere dei cittadini e risposta dell'istituzione sui problemi della sicurezza. Bologna: Il Mulino.

Bellinvia, Tindaro. 2013. Xenofobia, sicurezza, resistenza. L'ordine pubblico in una città "rossa." Il caso di Pisa. Milano: Mimesis edizioni.

Campomori, Francesca. 2008. Immigrazione e cittadinza locale. La governance dell'integrazione in Italia. Roma: Carocci.

Cannella, Giovanni. 2010. "La Condizione Giuridica dei Lavoratori dopo il 'Pacchetto Sicurezza'." In Immigrazione e Sindacato. Lavoro, Cittadinanza e Territoti. VI Rapporto, edited by Francesco Carchedi, Francesca Carrera, and Giovanni Mottura, 41-56. Roma: Ediesse.

Caponio, Tiziana. 2006. Città italiane e immigrazione. Discorso pubblico e politiche a Milano, Bologna e Napoli. Bologna: Il Mulino.

Cappiali, Teresa M. 2017a. “'Whoever Decides for You without You, He is Against You!' Immigrant Activism and the Role of the Left in Political Racialization." Ethnic and Racial Studies 40 (6): 969-987.

Cappiali, Teresa M. 2017b. "An Italian 'Integration Crisis': The Role of the State and Political Actors in Excluding Immigrants and Ethnic Minorities." In Italy from Crisis to Crisis: Political Economy, Security, and Society in the 21st Century, edited by Matthew Antony Evangelista, 168-198. New York: Routledge.

Cappiali, Teresa M. 2018. "Local Actors and Approaches to Integration: What is their Impact on Immigrants' Political Participation?" In The Routledge Handbook on the Governance of Migration and Diversity in Cities, edited by Tiziana Caponio, Ricard Zapata-Barrero, and Peter Scholten, 136-149. New York: Routledge.

Cappiali, Teresa M. 2019. "Ideological Affiliations, Conflicts, and Competing Mobilization Frames: The Role of Pro-Immigrant Allies in Shaping Immigrant Struggles for Greater Rights." International Migration Review 53 (3): 869-899.

Castelli Gattinara, Pietro. 2016. The Politics of Migration in Italy: Perspectives on Local Debates and Party Competition. London: Routledge.

CGIL (Confederazione Generale Italiana del Lavoro). 2013. “Conferenza Regionale CGIL Emilia-Romagna sull'immigrazione. Rappresentanza e migrant.” Bologna, June 10.

CNEL (Consiglio Nazionale dell'Economia e del Lavoro). 2009. VII Rapporto. Indici di integrazione degli immmigrati in Italia. www.cnel.it/18?tag_area_tematica $=35$ (Accessed June 30, 2015).

Cobbe, Luca, and Giorgio Grappi. 2011. "Primo marzo, percorsi di uno sciopero inatteso." In La normale eccezione. Lotte migranti in Italia, edited by Felice Mometti and Maurizio Ricciardi, 55-90. Rome: Edizioni Alegre.

Cosseron, Serge. 2007. Dictionnaire de l'extrême gauche. Paris: Larousse.

Cozzi, Silvia, and Giovanni Mottura. 2010. "A metà strada. CGIL e questione migratoria nel territorio Bolognese." In Uscire da Babele. Percorsi e problemi del rapporto tra sindacato e lavoratori immigrati, edited by Giovanni Mottura, Silvia Cozzi, and Matteo Rinaldini. Rome: Ires.

Galeotti, Francesca. 2009-2011. Discorsi e Pratiche di una mobilitazione migrante: lo sciopero del Primo Marzo. PhD diss., unpublished.

Istat. Gli stranieri al $15^{\circ}$ Censimento della Popolazione. www.istat.it/it/files/2013/12/ Notadiffusione_stranieri20122013.pdf

Nicholls, Walter J., and Justus Uitermark. 2016. Cities and Social Movements: Immigrant Rights Activism in the US, France, and the Netherlands, 1970-2015. London: Wiley-Blackwell. 
Oliveri, Federico. 2012. "Migrants as Activist Citizens in Italy: Understanding the New Cycle of Struggles." Citizenship Studies, 16: 5-6, 793-806. DOI: 10.1080/13621025. 2012.698509.

Però, Davide. 2007. Inclusionary Rhetoric/Exclusionary Practices: Left-Wing Politics and Migrants in Italy. Oxford: Berghahn.

Triandafyllidou, Anna, and Maurizio Ambrosini. 2011. "Irregular Immigration Control in Italy and Greece: Strong Fencing and Weak Gate-Keeping Serving the Labor Market." European Journal of Migration and Law 13 (3): 251-273. 


\section{Political contention amid the rise of the Northern League}

The Christian Democratic cities of Brescia and Bergamo present a different institutional context than the traditionally Communist cities, as described in Chapter 2. Here local authorities tend to devolve to the third sector, and especially to the Catholic Church, most social issues, not least interventions in the realm of immigration. This institutional context, moreover, varies little with the change of the color of the local administrations (left-wing vs. right-wing), except when the anti-immigrant party, the Northern League, has significant power and influence. This was the case of Brescia. When the financial crisis started, it was led by leaders of the Northern League party who had "declared a war" against immigrants since their electoral campaign in 2008. In this peculiar context, a unique mobilization took place in the city. Known later as the "Struggle of the crane" (Lotta della gru), this mobilization became famous among anti-racist organizations across the country because of its intensity and endurance. This was one of the most contentious protests that took place in Italy after the financial crisis. The protest was organized by undocumented immigrants who were exploited in the underground economy and who had only recently arrived in Italy. Throughout the year national and local authorities responded negatively to the thousands of undocumented immigrants employed in the underground economy who had applied for mass regularization of their status. So, inspired by the occupation of the crane by Italian workers, nine undocumented immigrants climbed onto a crane in Brescia in Northern Italy in November 2010 (Cappiali 2016). Some immigrants occupied a crane for several weeks. Part of a larger mobilization of hundreds of immigrants, supported especially by the city's radical left, the protesters wanted to expose the state's failure to regularize most of the immigrant workers who had applied, holding Brescia's right-wing administration accountable for raising the requirements and slowing down the regularization process. Immigrants and their supporters called this the "swindle amnesty," because they felt that the state used this mass regulation to steal money from immigrant workers, but with no actual intent to regularize their employment status. For several months, they organized demonstrations and occupied a public space in front of the Prefecture, the governmental office that issues permits to immigrants and where their applications were processed (Cappiali 2016).

This protest was described by the anti-racist movement in Italy as a symbolic protest, not only of the struggle against exploitation and unjust treatment of 
undocumented immigrants, but also of immigrants' self-determination, courage, and ability to resist institutional racism (Cappiali 2016; Mometti and Ricciardi 2011). Because of its disruptive character, moreover, this dramatic event represented the peak of the protests in 2010 . It marked a very contentious and polarized moment, attracting the attention of national and international media. What is more, it triggered a national debate on the deplorable living and working conditions of many immigrant workers across the country-not least in the rich cities of the North. Immigrants found support from radical left organizations, but major conflicts emerged between immigrant groups and traditional pro-immigrant supporters, particularly between the left-wing trade union, the Italian General Confederation of Labor (CGIL, Confederazione Generale Italiana del Lavoro), and the radical left organizations.

In this chapter, I will ask: What was the specific configuration of actors in Brescia that led to the "Struggle of the crane" and its particular dynamics? What actors mattered in the city and how do they promote the inclusion of immigrants? How do they compete around the issue of inclusion and how can we explain their conflicts around the protest? And how do their interactions affect immigrants' participation, right claims, and alliances in the city? In Brescia, in addition to the Catholic Church, which promotes a dominant assistance approach to inclusion, there is an important challenger, the radical left and the more radicalized branch of the left-wing trade union-the GCIL-FIOM, which encourages a political rights promotion approach in non-conventional channels. In the absence of other channels to participation, this particular configuration of actors has contributed to the creation of a migrant social movement in the city, and the development of alliances between radical left actors and immigrant activists. This empirical chapter on Brescia further demonstrates why and how the "visible" immigrant activists are mostly made up of vulnerable and precarious immigrant workers, enrolled in radical trade unions of the metalworkers, the CGIL-FIOM, and non-unionized undocumented migrants, and why they are so active in the city.

\section{The "Struggle of the crane": an extreme form of protest by undocumented immigrants against the 2009 amnesty}

From September 28 to November 16, 2010, the city of Brescia was at the center of a movement that showed the despair of undocumented immigrants and their will to fight against discriminatory treatment by the state and the right-wing local administration. ${ }^{1}$ In September 2009, a policy initiative, which sought to grant amnesty "for housemaids and caregivers," was launched (Law 102/2009) by the right-wing Berlusconi government. After a year had passed, they had not received an answer (Oliveri 2012). ${ }^{2}$ Protests were organized in support of the many undocumented immigrants in the city who had applied to regularize their status. The action, known among activists as the "Struggle of the crane" (Lotta della gru), started on the early morning of September 28 in the center of the city, with a protest of around two hundred people of migrant background (many undocumented male Egyptians) and some Italian supporters of the radical left and 


\section{4}

people of migration background with a more stable status, that is, new citizens and documented immigrants (Piancentini 2011).

There were several reasons behind the protests. After waiting a full year, most of those who had submitted an amnesty application had not received an answer because of the slowness of the Italian bureaucracy. Since the amnesty aimed at regularizing exclusively housemaids and caregivers, it was considered discriminatory, given that many undocumented immigrants working in the underground economy in Italy were also industrial workers, masons, farmers, etc. In order to regularize, many workers had no choice but to declare that they were working as housemaids and caregivers even if they were not. This was the only option many of them felt they had in order to regularize their existing work relation and leave the underground economy.

The permit application depended on the employer will to go through the process. So many immigrants found themselves in the situation of paying additional money to their employers in order to have their applications submitted. This exposed immigrants to opportunism by those who wanted to take advantage of their vulnerable situation and make money out of the amnesty. Protesters, therefore, stigmatized the mass regularization as a "swindle amnesty" organized by a right-wing government to take money from immigrant workers and to expose them to abuse of the employers. They also found it was designed to identify irregular immigrants on Italian soil through the amnesty in order to expel them (see Cappiali 2016). ${ }^{3}$

In addition to the hostile national context, protesters were exposing the unjust treatment and the promotion of "institutional racism" of the local right-wing administration in Brescia since 2008, with a strong presence of the anti-immigrant party, the Northern League. To add to the tensions, in 2010, following a circular launched by the right-wing government in March 2010 (the so-called Circolare Manganelli, because it was signed by the Chief of Police Manganelli), the Prefecture of Brescia had agreed to retroactively exclude from the amnesty all those who had received a paper of expulsion before the submission, even if they had a job and had paid for a regular application. ${ }^{4}$ The circular was in accord with the Security Package (Law 94/2009), which was launched by Minister Roberto Maroni (the then principal voice of the Northern League) in July 2009, which introduced the controversial "crime of illegal immigration" (clandestinity). In September 2010, faced with the choice of whether or not to accept the circular, Brescia's right-wing administration endorsed it and thus denied the permit of stay to all undocumented immigrants found with, in their words, "criminal records"meaning with a paper of expulsion.

The first day of protest, September 28, was marked by an occupation, which was violently attacked by the police the following morning. In response, a second demonstration the next day attracted around three hundred people of migrant background of different origins and immigration status. By the end of the second day, protesters decided to establish a permanent occupation in front of the Prefecture (which would last one month) to demand a table of negotiation with public authorities. The organizers asked for the support of the Italian radical left association Rights for All (Diritti per tutti). This organization was well known 
among immigrants for their long-standing support for immigrants' struggles in the face of governmental opposition at both the national and local level since the 1990s (Giancola 2008/2009). Additionally, the left-wing trade union CGIL backed protesters' demands by giving them two large shelters to sleep in throughout the occupation. Members of the Indian, Pakistani, Senegalese, and Moroccan communities - mostly men - also joined the first group of Egyptians (BR/N14). Throughout the occupation, the other major local actors in the city, including the Catholic Church, the CISL (the second main trade union in the city after the CGIL), did not support the protests.

Over the months, the situation escalated as right-wing local authorities adopted a hard line by refusing to negotiate with the immigrants and responding with police violence and anti-immigrant rhetoric. This was consistent with the approach they had taken toward immigrants over the course of the previous two years and their characterization of immigration as a "problem of public order" and undocumented immigrants as "people with no rights." Nevertheless, the protesters maintained the occupation and organized several initiatives at the national and local levels for almost one month. Then, on October 30, the protest was marked by a turning point, as a group of nine undocumented immigrants (from different nationalities) climbed a crane to protest for several weeks in the cold (BR/N14; see Cappiali 2016, 5). As Yusuf A., a young undocumented immigrant man from Pakistan, in his twenties, and one of the leaders of the protest, explained to me:

the policemen showed their batons, to indicate that they were ready to beat us ... At that point, some of us left the demonstration. We took the banner on which there was written "AMNESTY!" . . we wanted to be visible . . we decided to go to the highest point of the city ... we climbed up on a crane within the construction site at the center of the city.

$(\mathrm{BR} / \mathrm{N} 13)$

The men who climbed onto the crane were undocumented immigrants who had applied for amnesty and were between 24 and 35 years old. They were all from different countries of origin and had spent between three and seven years in Italy. ${ }^{6}$ Hanging on a crane at a height of 35 meters, they demanded five things: (1) to talk with the Minister of the Interior, the leader of the Northern League, Roberto Maroni; (2) a negotiation with local institutions (the local administration and the prefecture); (3) authorization for a permanent occupation in a visible place in the city; (4) the amnesty for all who had applied for it; and (5) guarantees that they would not face charges after the protest. ${ }^{7}$ Facing the complete stonewalling and repression by local authorities, the immigrants who were protesting on the crane-and their supporters under the crane-sustained their protest for 17 days, until a decision to climb down was taken after long negotiations with the involvement of the Catholic Church and the local trade unions CGIL and CISL. The undocumented immigrants decided to climb down even though they had not received any answer from the authorities. But they did so on one condition: that they would be defended by the lawyers of Rights for All, a key organization of 
the radical left, and in their words, the only ones they "really trusted" and who remained close to the crane during the long days of resistance.

The "Struggle of the crane" marked a very contentious and polarized moment in Brescia, with open conflicts with local authorities, repression, and violence. It marked a unique case in the context of Italy in terms of immigrant visibility as well as its duration and intensity. It did not bring about the results protesters were hoping for. They did not succeed in meeting with the Minister of the Interior, Roberto Maroni. They did not secure a chance to negotiate with the local authorities and the prefecture or receive authorization for a permanent occupation in the city. Also, several immigrants who were protesting under the crane were deported. What is more, they did not obtain a "permit for all" for the undocumented immigrants who applied for the amnesty in Italy. Finally, they experienced repression and increased violence on the part of local authorities. However, according to the people involved in the protest, it was not a complete failure. The action did achieve a number of things: (1) it drew the attention of the national and international media and public discourse to the issues faced by undocumented immigrants in the country; (2) it demonstrated immigrants' capacity to fight injustice and endure very difficult conditions; and (3) it built greater solidarity between the mobilized immigrants and their allies, the radical left organizations. According to Ibrahim M., an undocumented immigrant man in his thirties, from Senegal and a member of the migrant social movement, told me: "The local government tried to intimidate those people who were very active in the movement. But they did not succeed. The more they tried to repress us, the stronger we would become" (BR/N16).

The "Struggle of the crane" represents a key window through which to examine the role of multiple local actors in the city of Brescia, and in particular to understand how pro-immigrant groups' approaches to inclusion shaped how the protest developed. In the face of a highly hostile institutional context, the protest clearly caused major divisions in the city among pro-immigrant organizations involved in the realm of immigration. The first visible conflict emerged between the right-wing administration and the immigrants themselves; the second between the two powerful Christian Democratic actors (the Church and the CISL) and two powerful actors of the left (the CGIL and the radical left-wing organizations); and the last between the CGIL and the immigrant activists allied with the radical left). Additionally, the struggle illustrates the silence of other left actors in some cities involved in migration issues (e.g., the main political party of the left, the Democratic Party). Finally, the protest suggests the reinforcement of the migrant social movement in the city and of a strong alliance between people of migrant background active in the city and one main radical left-wing actor, the association Rights for All.

In this chapter, I use the example of the "Struggle of the crane" to ask why immigrant mobilization in Brescia was so unique. I identify and analyze the actors involved in the mobilization, their characteristics, and the reasons behind the strong presence of non-conventional participatory forms used by immigrant activists to make their rights claims in the city. The analysis offers the opportunity to examine the impact of the approaches to inclusion developed by the Catholic actors - based predominantly on assistance — and the CGIL and the radical left—-based chiefly on 
political rights promotion - on immigrants' political activism. I start by reconstructing the institutional context, explaining how local authorities moved from a situation of lack of intervention in the realm of immigration to a securitarian approach. I continue by describing the local realm of immigration and the approaches to inclusion developed by main local actors. In particular, I explain why and how the specific configuration of actors in Brescia and their interactions resulted in the exclusive promotion of non-conventional political channels, and why and how this resulted in a lack of alliances between more traditional actors and immigrant organizations. The chapter continues by analyzing the discourses and practices of selected immigrant activists and offers an insight into their decision to ally with the radical left instead of other prominent actors in the city. Overall, it will become clear why and how the "Struggle of the crane" took place in Brescia in the years following the financial crisis of 2008 and the rise in power of the Northern League, and why and how immigrant mobilizations radicalized in response to the securitarian turn of the right-wing administration in the city and strengthened their alliances with the radical left at the expense of other pro-immigrant actors.

\section{Devolution to the Church and the securitarian turn}

\section{The weak investment of the left-wing administrations}

Between 1998 and 2008, Brescia was governed by two left-wing administrations led by Mayor Paolo Corsini for two terms (1998-2003 and 2003-2008). At the time the city was characterized by a high degree of economic inclusion of immigrants in the city and the surrounding areas. For many years, the city of Brescia had the highest percentage among Italian cities of immigrants $(16.9 \%$, or 31,888 , in 2013) compared to the local population of 188,520 (Istat 2013). The high number was due to the strong economic attractiveness of the territory. Before the financial crisis, in the years 2006-2008, Brescia was among the cities with the highest economic performance in the country, resulting in a high capacity to include immigrants at the socioeconomic level. This latter was also confirmed by the fact that Brescia had the highest employment rate of immigrant workers in the country (CNEL 2009, 30). Despite this, like many other cities in the North, the city was also characterized by a high number of undocumented immigrants working in the underground economy.

Traditionally associated with the Christian Democratic political sub-culture, closely linked with the Christian Democratic Party (until its fall at the beginning of the 1990s), the city of Brescia is characterized by processes of devolution to the Catholic Church (Campomori 2008). Over the years, public authorities have tended to devolve most social policies to the third sector and in particular to the Catholic Church and other Christian Democratic actors (e.g., the trade union CISL) (Caponio 2006; Campomori 2008). This also meant a lack of planning and coordination of the third sector by the local administration in favor of the third sector.

Taking advantage of the situation, the left-wing Corsini administrations attempted to avoid devolving inclusion policies to the third sector. However, unlike the left-wing governments of the two cities of Reggio Emilia and Bologna, 
the administration failed to promote policies to the inclusion of immigrants in the city. In practice, the result was the development of an assistance approach with little planning and coordination, combined with a lack of substantial incentives to promote intercultural and political rights promotion approaches.

As far as assistance is concerned, the administration developed a Municipal Office for Foreigners (Ufficio Municipale per Stranieri), a centralized office already in existence since 1989, but empowered in 1998 with the aim of promoting inclusive policies for immigrant workers. It sought to support new immigrants and enable them to orient themselves and easily access services. I interviewed Vittorio F., an Italian man in his early sixties and the Director of the Municipal Office for Foreigners of the local administration, during the entire period in which the Corsini administration was in power (1998-2008). He explained that the administration had intended to work with the idea that the public has to be actively involved in political decision-making. Housing and employment were considered foundational, because "they are the basis for the stabilization of formal democratic structures in the territory" (BR/N2). ${ }^{8}$ The concrete measures to promote the inclusion of people of migrant background in Brescia were as follows: (1) strengthening the office with the goal of reducing the problems in renewing residency documents; (2) diminishing conflicts in the city by helping individuals to enter into the area's economy (mainly in the three sectors of agriculture, service, and factories); (3) supporting the process of inclusion through social work in neighborhoods with a high concentration of people of migrant background; and (4) monitoring the phenomenon of migration, through the creation of an observatory within the municipality of Brescia, focused on the labor market and housing (BR/N2; cf. Fondazione ISMU 2010). The Director of the diocese's Migrants Center Association (Associazione Centro Migranti) expressed the point of view of many interviewees in the city, when he recounted that "in the 1990s, Brescia was an experimental city" (BR/N3). Furthermore, among the local institutions, the police headquarters and prefecture were relatively open in this period, which aided the work of the administration (BR/N2).

Despite its attempts to move towards a greater involvement in the processes of inclusion of immigrants, however, the administration de facto devolved many programs related to service delivery and socialization to the third sector and in particular to the Church, thereby disempowering the public in favor of the private sector and failing to coordinate the third sector (BR/N3). Most of my interviewees in Brescia acknowledged that the Corsini administration failed to govern the process. Carlo L., an Italian man in his forties, and a social worker in the center Carmine Street, was a very active person on immigration issue in the city. He told me:

The municipality of Brescia spent a large amount of money over ten years for social services, summer camps, etc. Yet, the real problem was the lack of an organic planning of the phenomenon as a whole. In the long run, instead of governing the processes, the left watched them happen. Behind this attitude there was the assumption typical of the center-left of Catholic background: The motto is "one must welcome." The current precariousness of many structures created to welcome people of migrant background in the city is the 
direct result of the lack of planning and vision by left-wing administrations. Today, these structures are facing the holes created by the short-sighted policies of the left-wing administration.

$(\mathrm{BR} / \mathrm{N} 5)$

Benedetto G., an Italian man in his sixties and the Director of the Migrants Center Association of the diocese, confirmed this point:

The left lacked the courage to develop enduring projects. The Municipal Office for Foreigners never dealt with all it could. Some initiatives could have developed more, but instead they have been slowed down by indecision and cautiousness by the left. All they built was grounded on precariousness.

$(\mathrm{BR} / \mathrm{N} 3)$

Thus, a lack of planning also meant the creation of precarious public structures to support inclusion. Benedetto G. suggested an explanation of why the left-wing authorities adopted their particular approach to inclusion:

The vision of politics is to work to give answers to people. But if the responses one gives do not contemplate a vision of the whole, then it becomes very complicated. Politics does not exist to satisfy a particular need, but for the interests of all. The fear felt by politicians today is due to a political culture that is not linked to the general interest.

$(\mathrm{BR} / \mathrm{N} 3)$

Additionally, despite the initiative described earlier, my field research showed that the Corsini administrations did not promote significant interventions in the direction of interculturalism and political rights promotion. This inaction prevented the opening of viable civic and political channels of participation for the migrant population from above. The lack of intervention and movement toward an intercultural approach was visible in the absence of intercultural centers for immigrant associations and programs in schools, where the number of students with immigrant parents was growing. As for the Intercultural Centers, one member of the Provincial Forum on Immigration of the Democratic Party told me: "there was a lack of public space for immigrant associations. This was a problem because it prevented us [immigrants] from gaining more visibility and developing our own trajectories of participation in the city" (Field notes during a local meeting of the Provincial Forum on Immigration PD Brescia, September 10, 2013). Moreover, interest in participation and greater involvement of immigrants in the receiving society emerged very late in the administration's term (only in 2006) and was not combined with other initiatives, such as the promotion of participation in local and immigrant associations or projects addressing the issue of immigrant participation in schools and public services. Indeed, there was an almost total lack of attention to interculturalism.

In addition, the administration attempted to develop other forms of political inclusion, but with little success. As several interviewees explained, in 2006, 
in the last years of the Corsini administration, there were attempts to promote a project intended to increase the political participation of people of migrant background. They also added that the administration wanted to avoid the "naive approach" supported by other left-wing administrations in Italy (between the end of the 1990s and the 2000s), which created "parallel channels of participation like the Consultative Bodies" and promoted an alternative channel of participation through the project Civic Network: Brescia Open and Supportive (Rete civica: Brescia aperta e solidale) (BR/N2). The goal of the project was "to promote active citizenship." "Thus, every neighborhood would have its own representative council. One main goal was to allow immigrants to participate by encouraging the election of two immigrants and two Italians, who would also be two women and two men. These representatives would speak for the neighborhood at the central level (of the municipal council), where they would deliberate about issues that concerned the city and in particular their own communities. However, the project was still in its infancy when the right-wing administration came to power in 2008 and canceled the program entirely.

\section{The rise of the Northern League and the "war against immigrants"}

In 2008, the right-wing political orientation of the new elected administration drastically changed the direction of local authorities concerning immigrants' inclusion. The political climate before the elections was revealing. Before they won the local elections in April 2008, the right-wing coalition led by Mayor Adriano Paroli (People of Freedom) and Fabio Rolfi (Northern League) launched a ferocious electoral campaign centered almost exclusively on the fight against "illegal immigration" and on the need for "more severe security" in the city. ${ }^{10}$ Rolfi, the future deputy major, gave several openly racist speeches promising to reduce the number of immigrants, to eliminate the presence of irregular immigrants, and to increase safety in the city during his term in office. Among other things, he promised to close the Municipal Office for Migrants created by the left-wing administration in order to deter immigrants who intended to move to Brescia. As promised, the day after it won the elections, "the right-wing coalition closed the office with a phone call and dismantled it the same day" (BR/N5). ${ }^{11}$ In addition to the closure of the Municipal Office for Foreigners, there was an explicit shift to security policies. While policies of inclusion (focusing on economic and social issues) were abandoned, more funds were spent on reinforcing surveillance and Rolfi acquired more control over the security force. ${ }^{12}$

In addition, "a war against immigrants was launched" and manifestations of symbolic and material exclusion became increasingly widespread in the city (BR/N6). As far as symbolic exclusion is concerned, the leader of the Northern League, Rolfi, issued several openly racist statements and, for this reason, he was denounced on several occasions by the left-wing trade union, the CGIL, and several lay and church-based organizations. ${ }^{13}$ Yet, even more striking were the forms of discrimination and "differential treatment" towards immigrants in hospitals, schools, and public spaces (Guariso 2013; Ambrosini 2013a). In his article, “" 'We 
are Against a Multi-ethnic Society!' Policies of Exclusion at the Urban Level in Italy," Ambrosini presents an overview of the "discriminatory measures" directly or indirectly targeting the immigrant population in the Lombardy region and the province of Brescia between 2008 and 2010 (Ambrosini 2013a, 138). His research shows that in Brescia some of the most blatant discriminatory ordinances concerned: (1) cultural exclusion, such as the prohibition on playing cricket in the parks or using public spaces; (2) social exclusion, for example, limiting migrants' access to specific services; and (3) security exclusion, by reinforcing surveillance and by banning gatherings in public spaces. ${ }^{14}$

Furthermore, influenced by the local political context, supposedly "neutral" local institutions like the police headquarters and the prefecture became increasingly hostile and adopted several discriminatory practices toward the immigrant population in general (documented and undocumented). Carmine E., an Italian man, in his fifties, and in charge of the Office Against Discrimination of the CGIL, told me:

[S]ince 2008 there was lots of physical and psychological violence towards immigrants. Since immigrants were considered a "threat" to public security [by the right-wing administration], they were observed more and more and thus they experienced continuous violence and control by the police. The hostility of the local administration had an impact on other local institutions, who started discriminating more openly towards the immigrant population, documented and undocumented alike.

$(\mathrm{BR} / \mathrm{N} 10)$

As far as the "Struggle of the crane" is concerned, the hostile and discriminatory attitude adopted by the right-wing administration was at the heart of immigrants' frustrations. By institutionally discriminating against immigrants for more than two years, the administration contributed to their anger and perceptions of injustice. What is more, the attitude of the right-wing administration indicates, in large part, why the protest erupted in the first place, and why it was so conflicting, intense, long-lasting, and occurred mainly through non-conventional means. First of all, by adopting the Circular Manganelli during the amnesty, local authorities triggered the protest that started in September 2010 and enhanced the perception on the part of immigrants that they had been swindled by the state. Second of all, the administration's extremely hostile response of repression and violence over dialogue and negotiation contributed to the protest's prolongation and radicalization. Mayor Paroli defined the requests by undocumented immigrants as "unacceptable blackmail," while the deputy mayor, Rolfi, declared: "They can stay on the crane forever. They will never have the permit of stay, because they have no right to have it according to the current legislation." 15

A few days after the event, the spokesman on the crane, declared that the repression by the police had only reinforced their determination:

After the police charge on Saturday [30 October] during the demonstration, impeding us from demonstrating for our rights when they evacuated our 
occupation ...., they did not know [it] but they made us stronger. It was like saying to us that we have nothing to lose. ${ }^{16}$

The evolution of the institutional context described earlier had a great impact on the other actors involved in the local realm of immigration. In the absence of substantial institutional intervention in the realm of immigration by local administrations of the left over the years, gaps have been mostly filled by two main networks of actors with opposing political ideologies, namely those linked to the Catholic Church and those linked to the CGIL and the radical left organizations. As a result, these actors were the main players when the right-wing administration gained power. By plugging major institutional gaps, they have largely shaped the approaches to inclusion through initiatives from below. In the direction of assistance, the Church and the CISL have created several initiatives to promote the inclusion of the most vulnerable groups. With regard to political rights promotion, the CGIL, the radical left, and the immigrant social movement have also created several initiatives and platforms in their organizations to promote immigrants' empowerment and to give them political voice. Both went in the direction of creating platforms for immigrant workers and, on several occasions, passed through non-conventional channels. Unsurprisingly, this plethora of actors were key players during the "Struggle of the crane."

\section{The local realm of immigration and two conflicting approaches to inclusion from below}

In the city of Brescia, the Catholic Church and the trade union, the CISL, are two powerful actors and have played a major role in promoting an assistance approach to inclusion in the city. The local realm of immigration is shaped by two other actors: the CGIL (which in Brescia is among the most radicalized local branches in the country and has a significant degree of influence in the realm of immigration) and the radical left-wing organizations, mostly linked to the older organization Rights for All. These actors have been central in encouraging political channels for immigrants' participation in the city, especially workers in the case of the CGIL and undocumented immigrants in the case of the radical left. ${ }^{17}$

\section{The Catholic Church and the Christian-Democrat trade union in promoting the assistance approach}

In line with its Christian Democratic political sub-culture, in Brescia the diocese and parishes are very wealthy and almost entirely dominate the third sector, at the expense of lay organizations and cooperatives which are very weak and have little weight. ${ }^{18}$ Several key informants explained that, in Brescia, the Church is very powerful, it owns lots of properties, and its role in the realm of immigration is crucial (e.g., BR/N5). This role is widely recognized by local authorities and other local actors. It is inevitable to collaborate and ally with the Church, or to compete with it. 
As early as the 1980s, the diocese in Brescia played a crucial role in shaping the local realm of immigration in the city by promoting an assistance approach. The diocese foresaw the changes that immigration would bring about in Italian society and, already in 1981, it created the Migrants Center Association, an office dedicated to assisting immigrants. ${ }^{19}$ Benedetto G., Director of the Center, explained that its goal was in line with the Church's universalist view of rights and aimed to conduct human rights promotion and help immigrants and their families integrate into the social fabric of Brescia. On the Center's official site, one can read about its main goal of helping immigrants to regularize their status through bureaucratic itineraries and knowledge of the Italian language. Furthermore, the Center operates alongside other associations, including public authorities and religious institutions, in order to assist immigrants - especially those "in need." It also offers legal counseling for "complicated cases" (such as expulsions, violence against women, and unaccompanied minors), and it interacts with local institutions such as the police and the prefecture $(\mathrm{BR} / \mathrm{N} 3)$.

The strong presence of the diocese and church-based organizations and their dominant assistance approach leads to certain limitations with respect to opening the channels of civic and political participation. These organizations did not promote intercultural and political rights promotion approaches. In addition, according to many of the interviewees, these organizations' strong presence prevents other organizations, such as immigrant associations and Italian lay associations, from developing their own trajectories in the city. In Reggio Emilia and Bologna, lay organizations were key actors in opening and enlarging civic and political participatory channels from below by promoting an intercultural approach (as in Reggio Emilia) or both an intercultural and political rights promotion approach (as in Bologna). In Brescia, however, in addition to a lack of initiative from above, the weak development of these organizations was a major cause of the lack of civic and political channels available for immigrants in the city.

The control church-based organizations exercises over the issue of immigrants' inclusion in the city was a problem. As several informants explained, places dedicated to social activities are mostly managed with a religious approach. Carlo L. (social worker at Carmine Street) explained: "The implications of the presence of the Church in these activities are subtle and not simple. A lay approach to immigration issues would avoid the imposition of a religious view and would promote a more pluralistic approach to inclusion" (BR/N5). The same informant went on to point out three major problems with this situation: The first problem is the lack of acknowledgment of difference and pluralism: "Unfortunately, very often it is not possible to go beyond a religious logic." The second problem was the "selection of the educators, which is also univocal." He explained: "the selection of educators can depend on their belonging to a specific religious area rather than on their specific expertise or their commitment to the promotion of pluralism and diversity." Thus, the strong presence of the Church makes it difficult to guarantee a neutral approach in the city and makes it harder to promote an intercultural approach that emphasizes the relevance of other cultural and religious views and the ability of immigrant groups to gain public space in the city. 
Aside from the Church, the city's sub-culture also favored the strength of the CISL, the main Christian Democratic trade union in Italy. At the beginning of the 1990s, the CISL created the association CISL-ANOLF to offer services to immigrant workers as well as to encourage an intercultural approach by favoring cultural exchanges between immigrants and Italians. The CISL-ANOLF promotes an approach to inclusion that supports "a culture of integration, of tolerance and respect" (CISL Brescia). ${ }^{20}$ In line with this general approach, the CISL in Brescia responded to the climate of closure created by the rise of the Northern League that started already at the end of the 1990s (BR/N6). Marta G., an Italian woman in her early fifties, and the president of the CISL-ANOLF, explained:

the reason why the CISL-ANOLF of Brescia focuses mainly on culture and education is to fight against the widespread ignorance of the local population promoted by the Northern League over the past ten years. The Northern League switched from the war against immigrants to the war against foreigners! They generated enormous problems for coexistence, including with immigrants who have been living and working regularly for many years. The reason is ignorance. Thus, the CISL-ANOLF has opted to support the cultural and intellectual potential of the territory.

(BR/N6)

The same interviewee added: "Our approach reflects the logic of cohabitation. We look at the culture and intellectual potential. Only in this way can we hope to construct the basis of coexistence." For this reason, she clarified, the CGIL was promoting initiatives in the schools to sensitize teachers and students to the importance of respect and cohabitation. Through the CISL-ANOLF, the CISL of Brescia has contributed to shaping the local realm of immigration by promoting both a service delivery (assistance) approach and a weak intercultural approach, understood here mostly as "favoring dialogue and cohabitation," rather than immigrants' civic participation in the city. However, the CISL has also been criticized for not having done more to protect immigrant workers against discrimination and at the level of political rights promotion. During our interview, Benedetto G. (Director of the Migrants Center Association of the diocese) told me:

Until 1994 I was secretary of the CISL, and in 2000 I arrived in the Center of the diocese. I have to admit that the most relevant incentives arrived from the CGIL rather than the CISL. This is paradoxical when you think that when I was at the CISL, the CGIL was our daily enemy. The CGIL has undoubtedly been more present and it has paid much more attention to its work in the field of migration.

$(\mathrm{BR} / \mathrm{N} 3)^{21}$

This quote emphasizes the limited role of the CISL in the realm of immigration, despite its influence in the territory of Brescia, and the more relevant action of the CGIL, including in negotiating with other Christian-Democrat organizations in the city. 


\section{The role of the Communist trade union, the fight against racism, and the political rights promotion approach}

The CGIL is a very strong actor in the city of Brescia with more than 114,000 people enrolled in 2012. These are relevant numbers if one considers that in the same year the number of people enrolled in the CISL was around 100,000 (BR/N9). The CGIL is particularly radicalized with a strong influence of the branch of metalworkers (the CGIL-FIOM). This ideological position has an impact on the greater involvement of the trade union in the realm of immigration and especially in the direction of political rights promotion (Marino 2010). This characteristic of the organization is historically rooted in the city. However, since the end of the 1990s, the GGIL reinforced its proactive role in the realm of migration when it got more involved in the fight against increasing institutional discrimination in Italy as well as political rights promotion in its organizations. During our interview, the Secretary of the CGIL of Brescia, Giulio D., clarified that, in the area of immigration, the CGIL of Brescia had always been "in the forefront" in the areas of assistance and political rights promotion (BR/N9: Italian (M), Secretary of the local branch of the CGIL). First, with the initial arrival of immigrants in the 1980s, the CGIL created the Office for Foreigners (Ufficio Stranieri) to assist immigrants, by supplying immigrants and their families with information and bureaucratic assistance. Second, it encouraged greater participation of immigrants in the workplace, through the creation of a Migrant Coordination Organization attached to the Office (see Marino 2010). Khalid D., an immigrant man of Moroccan origin, and in charge of the Office for Migrants of the CGIL since the 2000s, as well as a leading member of the migrant social movement pointed out that the CGIL's role was remarkable in promoting immigrants' participation:

the CGIL of Brescia promoted political channels in the workplace, by creating and supporting a Migrant Coordination Organization to allow immigrants to stake their political claims within the organization and in the territory of Brescia. The goal of the organization is to support immigrant workers' selforganizing in the union and to provide a space where they can get together and bring forth their claims.

$(\mathrm{BR} / \mathrm{N} 17)$

The official site of the Office states that, through the Migration Coordination Organization, the CGIL "proposes to organize, participate and support anti-racist mobilizations against any form of institutional discrimination." ${ }^{22}$ Unlike the other Migrant Coordination Organizations in Reggio Emilia and Bologna, the Organization in Brescia has been coordinated by people of migrant background - an immigrant from Senegal in the 2000s and then Khalid D. from Morocco from 2010 until the year of my fieldwork, 2013 - and exhibited a greater degree of inclusiveness. The fact that the CGIL gave this responsibility to these persons speaks to the commitment of the organization to be more representative of the immigrant population and to give them more visibility and more influential roles in the organization. ${ }^{23}$ As Khalid D. highlighted, the organization had supported immigrants' mobilizations and demands for better living and working conditions 
since the first waves of immigration in the 1980s, and it had been consistent in its approach since at least the first half of the 2000s (BR/N17; see also Giancola $2008 / 2009$, 94). As the case of the "Struggle of the crane" has shown, however, this is no longer the case (BR/N17). ${ }^{24}$

In addition to the initiatives aimed at empowering immigrants in Brescia, the CGIL has reacted to the growing presence of the Northern League in the territory of Brescia since the beginning of the 1990s, which has strongly influenced its more recent "radical" approach to inclusion and its work in the territory. Rosa S., an Italian woman in her fifties and in charge of immigration policies of the CGIL, had no doubts about the role of the CGIL in Brescia:

The CGIL is very strong and radical not only with respect to those in Lombardy, but also to those in Emilia-Romagna. The CGIL of Brescia has been working for years to improve the difficult situations of immigrants that have been created by the strong presence of the Northern League in this territory.

(BR/N11)

Giulio D., an Italian man in his fifties, and the Secretary of the local branch of the CGIL in Brescia, recounted, the CGIL has done five "relevant things" since the end of the 2000s: (1) it reinforced the Office for Foreigners; (2) it pursued lawsuits against institutional discrimination; (3) it created an Observatory Against Institutional Discrimination (Osservatorio contro la discriminazione istituzionale); (4) it established a legal office; and (5) it invested in the workplace and promoted the participation of people of migrant background through the support of workshops and other formative activities (BR/N9).

In this general context, the union has been particularly attentive to the protection of immigrants against institutional discrimination. Institutional discrimination explains why the CGIL in Brescia has expanded its activities in the city and in the province of Brescia in order to compensate for the institutional void reinforced by the presence of the Northern League.

Giulio D. highlighted:

In contrast with Emilia-Romagna, the most important characteristic of this region [Lombardy] and other regions of the North, such as Veneto and Friuli Venice Giulia, is the strong presence of the Northern League, both at the regional and local level. Our office is among the most advanced in Italy. In Emilia-Romagna, the regions have created a document that establishes guidelines in order to deter municipalities from having discriminatory attitudes, behaviors, and ordinances. In Tuscany, two weeks ago [end of June 2013], they put an end to the distinction between foreigners and Italians when it comes to employment in the public sector. This is undoubtedly an example of a positive step towards the conquest of equality. In Brescia, there has been a battle to gain equal access to the health system and parity with the labor system. We wanted to affirm that Italians and foreigners should have the same treatment.

(BR/N9; emphasis mine) 
He explained that,

with respect with the Office for Foreigners, in the last five years [2008-2013], when the Office of the municipality was closed by the right-wing administration, the Office of the CGIL reinforced its work for the residents of other municipalities in the province of Brescia in order to offer basic orientation and services.

As far as lawsuits are concerned, between 2009 and 2013, the CGIL pursued 36 cases to fight against the practices of the Northern League in the province of Brescia (Guariso 2013). This was unique in the national context. The lawyer Alberto Guariso, an executive member of the ASGI, or Association for the Juridical Studies on Immigration (Associazione per gli Studi Giuridici sull'Immigrazione), and President of the Association of Pro-Bono Lawyers (Avvocati per Niente), is a national expert on workers' rights and civil rights in general. He worked in collaboration with the CGIL of Brescia and pursued the most difficult cases of discrimination towards immigrants in the territory of Brescia, some of which were covered by the national media (Ambrosini 2013b, 319). While the Observatory Against Institutional Discrimination was officially established by the CGIL in 2009, the person in charge of the Observatory, Carmine E., the person in charge of the Office Against Discrimination of the CGIL, told me that "many activities had been around already for almost twenty years" (BR/N10). He continued:

De facto, the Observatory has existed since 1986. At that time, there was the first major amnesty in the history of Italy and we were already very active on anti-discrimination issues. Moreover, in 1998 and 1999, there was the crisis in the Balkans and the CGIL got involved in anti-discrimination actions, on the topic of social policies and prisons.

The CGIL has also sponsored a decentralized legal office to follow the cases of discrimination in the province. Giulio D., the Secretary of the local branch of the CGIL in Brescia, observed: "The province of Brescia is the biggest province of Italy. More than thirty offices have been created in this vast province in order to deal with the extreme situation of institutional discrimination that undermines basic rights" (BR/N9).

Taking everything into account, the CGIL has been a key actor since the 1990s in the city of Brescia and has been crucial in shaping the local realm of immigration by promoting assistance and advocacy and by empowering people of migrant background in the city. The trade union clearly expanded its work against discrimination during the years in which the right-wing government was in power, between 2008 and 2013, but it also diminished its efforts to support undocumented immigrant workers' rights in the city, as well as their inclusion in the organizations. For this reason, radical left actors and people of migrant background active in the migrant social movement have critiqued the CGIL for not being as supportive as it used to be. 


\section{The radical left and the politization of the rights of vulnerable immigrants}

The radical left organization and the migrant social movement occupy a significant place in the city of Brescia and are key in shaping the local realm of immigration in the direction of political rights promotion. In particular, they promote participation and the empowerment of the most vulnerable immigrants in the city (especially undocumented workers and immigrants exposed to the threat of eviction). When necessary, they are willing to open non-conventional channels, including protests and occupations of public spaces and abandoned buildings, and to challenge other key actors in the city. During our interview, Vinicio M., an Italian man in his fifties and a lawyer with Rights for All, the main organization of the radical left in the city, said: "It is obvious what the radical left does in the city. Local institutions as well as social and political forces have no other choice but to recognize this fact" (BR/N12). He made clear that "political participation by people of migrant background in the city of Brescia almost always passes through two actors: the radical left organizations and the CGIL." ${ }^{25}$ Vinicio M. clarified that in the city there are four main actors linked to the radical left: the well-established association Rights for All; the social center Warehouse 47 (Magazzino 47); the Radio Collision Wave (Radio onda d'urto); and Cross-point, a more recent organization established in 2010 after the "Struggle of the crane" which was trying "to construct its own itinerary of participation in the city." As he explained:

Rights for All is the oldest organization and keeps all the other organizations of the radical left together. It is open to all the groups that belong to the radical left in a broad sense and its convergences and assemblies are organized at the Warehouse 47. Like Rights for All, the Radio Collision Wave and the social center Warehouse 47 have existed since the 1990s and have always been active in the radical left. Probably because of the size of the city-not too big, not too small - people of different political orientations converge in one of these groups. The radio is very important, because in addition to information, it supports politics in the area by following and transmitting news about the struggles while they are happening.

$(\mathrm{BR} / \mathrm{N} 12)$

Since the 1990s, together with the CGIL, the radical left organizations have contributed to putting the issue of political rights promotion at the center of local attention, supported mobilizations organized by people of migrant background, and offered them platforms and material resources (including space) to organize. The history of Rights for All and the emergence of a migrant social movement are closely interrelated: Rights for All was key in supporting spontaneous mobilizations by people of migrant background in the 1990s and 2000s, and at the same time these mobilizations allowed the strengthening of the radical left and its legitimation in the local realm of immigration in Brescia. The migrant social movement endured and developed due to this alliance with the radical left (and previously 
also with the CGIL). ${ }^{26}$ The history of these mobilizations can be divided into three key moments, each separated by about one decade: (1) the mobilization of 1991, when the first mobilization by immigrants took place around the problem of housing; (2) the struggle of 2000 against the failures of the amnesty program launched by the left-wing government in 1998; and (3) the "Struggle of the crane" in 2010, against the amnesty program launched by the right-wing government in 2009 (for a reconstruction of these phases, see also Cappiali 2016).

Several activists of the radical left (Italians and people of migrant backgrounds who had been active in the movement for many years) helped me to reconstruct the history of these alliances. Lawyer Vinicio M. explained that his organization was born in the first years of the 1990s, as a further development of the radical left movement. "From the beginning, their mandate expressed a commitment to the recognition of immigrants as subjects with rights independent of their [legal] status." He made clear that the radical left in Brescia intervened on the issue of immigration because "it is committed to the universalization of human rights, against the exploitation of individuals, independent of their status" (BR/N12).

At the beginning of the 1990s, there were some welcoming centers, mainly offered by the Church, but there was a lack of intervention by local authorities (CNEL 1991, 60). For this reason, there was a severe lack of housing for immigrants, which led immigrants to stage several occupations of empty buildings (see Giancola 2008/2009, 65-70). The most clamorous occurred in 1991, when around four hundred immigrants occupied the Motel Agip (CNEL 1991, 60; see also Giancola 2008/2009, 70-75). Vinicio M. commented:

It was a multiethnic group. There were people from North Africa, Pakistan and India. Many were from Senegal. The involvement by the radical left started in those years. These were years when it was particularly hard to talk about the participation and self-determination of immigrants. We got involved in a situation in which institutions had not responded promptly and adequately to the problem of immigrant workers' housing. Immigrants were the first to organize the occupations and the radical left simply decided to support them. Back then, around one hundred families had been deported and we attempted a very quick operation to avoid other deportations. We occupied a school. There was a negotiation with the prefecture and we managed to find a place for them both in the city and in the province.

$(\mathrm{BR} / \mathrm{N} 12)^{27}$

In addition to the radical left, other organizations got involved to support the immigrants: the Church, which was the first to respond in the 1980s and at the beginning of the 1990s, and the CGIL, which "soon got involved and created the Office for Foreigners." On the other hand, "the CISL, the moderate left and the Communist Refoundation Party did very little" (BR/N12).

The second major phase of the development of Rights for All and the migrant movement took place in 2000. At that time, the movement focused on the new policy on mass regularizations of undocumented immigrants, which was launched 
with the Turco-Napolitano Law by the left-wing government in 1998 (see Giancola $2008 / 2009,86$ ). In 2000 , two years after the mass regularization, many people still had not received an answer. Vinicio M. said:

At that time people used to go to the prefecture. There were endless lines. There had been a huge demonstration with an incredible number of immigrants. It was the first public demonstration in the city. Then, things escalated. There were other occupations and then demonstrations in Piazza Loggia, in front of the city hall..$^{28}$

According to several interviewees, this moment of great tension was crucial for the formation and consolidation of the migrant social movement and its alliances with the radical left in Brescia (BR/N12; fieldnotes of an informal conversation with one of my gatekeepers in Brescia, Sonia M., a member of the radical left). As Giancola $(2008 / 2009,85)$ documents, this event led to a 50-day protest movement "that had as participants a few hundred immigrants and lasted in its entirety a few months, with a continuous occupation of the squares of the city, bringing them to directly negotiate with the national government and a political victory." The protest at that time was very important because it forced the left-wing government to respond to the immigrants' request for permits for all those who were excluded from the amnesty (Giancola 2008/2009, 123-124). As such, those years saw the first major split between the moderate and the radical left on the issue of immigration in Italy (Cappiali 2017). The conflict that emerged in Brescia reflected the national situation. As Vinicio M. explained, the Turco-Napolitano Law, introduced by a moderate left-wing majority, created the "link between the permit of stay and the work permit." He elaborated that the law positioned an immigrant not "as a subject with rights, but as an economic subject, as a simple labor force." For this reason, the radical left opposed the Turco-Napolitano Law and worked on redefining the concept of citizenship:

Challenging the concept means questioning the system and the state, and the place of immigrants within it. Since then, the struggle of the radical left against the link between the permit of stay and the work permit has been a struggle for equal access to rights independent of one's legal status. That is why the association is called Rights for All — to emphasize the idea that rights are attached to individuals and not to citizens of a specific country.

$(\mathrm{BR} / \mathrm{N} 12)$

Thus, the development of the migrant social movement in Brescia went hand in hand with the developments that followed the protests to oppose the G8 Summit organized in Genoa (Italy) in 2001. The Genoa 2001 protests were accompanied by a string state repression and it represented a turning point for left-wing social movements opposing capitalist globalization around the world. ${ }^{29}$ Several platforms were created, including a Table of Migrants to foster knowledge exchange and mobilizations around immigration issue and immigrants' rights. Following these developments, at the beginning of the 2000s, the radical left of Brescia created 
Warehouse 47, a space to meet with the Table of Migrants in the city. Since then, the place "served as a support of immigrants' mobilizations and offered them a platform from which to organize" (BR/N12).

The third significant phase of the development of Rights for All and the migrant social movement was in 2010, during the "Struggle of the crane." The association offered material and logistical support to the struggle until the very end of the protest and even afterward. Several activists in the city noted that the mobilization, like previous ones, started from immigrants and that the radical left offered support when they were asked for it. Vinicio M. explained that during the long months of the protest, the close contact between Italian and immigrant protesters created new bonds among people active in the radical left of Brescia and that this had a long-lasting impact (BR/N12). This point of view was shared by most immigrants active in the migrant social movement (e.g., BR/N13, BR/N14, BR/ $\mathrm{N} 15$, and BR/N16). The support the radical left gave to immigrant activists in 2010 during the "Struggle of the crane" was crucial, and the memory of that support remained very strong even in 2013.

Hence, the radical left-wing actors and the immigrant social movement significantly affected the local realm of immigration in the city of Brescia and contributed greatly to opening channels for political participation available since the 1990s. Some of the main advantages of the strong presence of the radical left in the city identified by local actors were: (1) filling the gaps left by the institutions by offering assistance beyond the usual delivery of services, space for meetings, and radio for the immigrant communities; (2) preventing other more institutionalized organizations from occupying all the space in the city and thus challenging the status quo and their traditional positions with respect to immigrants' rights; (3) forcing more moderate organizations (the Church, CISL, and left-wing political parties) to take the issue of immigrants' inclusion and political participation more seriously (e.g., during the evictions in 1991 and 2010 (BR/N20)); and finally (4) putting social and political conflict at the center of the political debate (BR/N5) ${ }^{30}$

However, my interviewees also identified some drawbacks. First, as Vinicio M. clarified: "the organization hinders the creation of other organizations. Among other things, it impeded immigrant associations in the city from acquiring political relevance" (BR/N12). This suggests, therefore, a crowding-out effect at the expense of immigrant organizations (Caponio 2006). The radical left was also widely criticized by more moderate local actors in the city. Most of my interviewees agreed that the radical left in the city privileges political self-determination over protection. This can be a problem because it exposes people in very vulnerable conditions to state repression (BR/N3). Benedetto G., the Director of the Migrants Center Association of the diocese, for instance, commented that given the extremely vulnerable conditions of people of migrant background in Brescia (in particular undocumented immigrants), they can be more easily manipulated by local actors.

It is pretty easy to use immigrants. Even the Northern League knows how to use them. They have one who they tell to say: "stop with niggers!" Groups like Rights for All attract those who are desperate, and because these latter see someone with open arms, they fling themselves at them. If they want to 
find their way through, immigrants have to grow, know, and understand the reality in which they live. On our end, we have the duty to help them because they can't make it alone.

$(\mathrm{BR} / \mathrm{N} 3)$

Additionally, the President of CISL-ANOLF told me that the radical left privileges a megaphone culture and makes instrumental use of immigrants to gain power in the political arena (BR/N6). ${ }^{31}$ This criticism came not only from Italian actors but also from people of immigrant background. For instance, during our interview, Mammadu F., an Italian citizen of Senegalese origin in his forties, and a functionary of the CISL in the category of the FIM (metalworkers), told me:

I do not agree with extremism. It is time that the law is equal for everybody. In Italy they treat immigrants as they want. Things change with the administrations. I am against the idea of bringing immigrants into the streets [to protest]. I want immigrants and Italians together. Here in Brescia, there is a tendency to mobilize only immigrants. If we are divided it is not good. We must go together. Some bring the people to the squares to have visibility. These people tell immigrants: "We go together, six and seven immigrants, with no Italians!" They tell them, "Do this and you will have your documents!" The "Struggle of the crane" was a big error. What have we gained?! The result was that the city was divided in two! We can defend our rights without being extremists!

(BR/N7)

Finally, by framing migrant claims in a very specific way and focusing primarily on the residency permit and work permit, the radical left leaves aside other crucial considerations linked to the processes of inclusion as I was told by Bujar A., an Italian man, originally from Albanian, who was also a member of the Provincial Forum on Immigration of the Democratic Party (PD) (BR/N20).

\section{Alliances, conflicts, and political radicalization}

\section{Alliances between the radical left and the immigrant social movement}

In the sections before, I have described some key factors in the city that help us explain why immigrants were so active in Brescia and why were they able to build a collective identity strong enough to support a migrant social movement in the city. In this section, I explore how they were able to identify with the radical left's discourse and practices, and eventually emerge and endure as a collective actor.

During my fieldwork, I set out to answer these questions and determine why the political activity in Brescia was so intense in 2013. Migrants were mobilizing in two main areas: the struggle against the failed amnesty policy of 2012 and the struggle against evictions. While the first type of mobilization aligned with previous struggles in the cities (the struggle in 2000 and the "Struggle of the crane" in 
2010), the struggle against evictions was relatively new. In the struggle against eviction, many people started mobilizing as a direct result of the threat of their own eviction between 2010 and 2013. The evictions were a direct consequence of the economic crisis. Between 2010 and 2013, in the province of Brescia alone, there was an average of 20 evictions per month, and the first to be hit by the crisis were people of migrant background (Caritas/Migrantes 2014). The radical left was active in supporting mobilizations to prevent evictions, by organizing people (mainly but not only immigrants) for the pickets and by organizing occupations of empty houses to provide shelter for families who had already been evicted.

Those immigrants who had been in Italy for longer periods of time (since the end of the 1980s or during the 1990s) and those who had participated in the mobilizations that took place in Brescia in the first half of the 2000s were still active in 2013. Immigrants had distinguished themselves by resisting injustice and institutional discrimination over this period, and on many occasions, people drew explicit links between ongoing struggles and previous mobilizations dating back to 2000 , when the migrant social movement of Brescia was first established. Some who had recently immigrated had known the radical left for a few years, participating in some events before becoming more politicized and politically aware during the "Struggle of the crane," while others only started to engage with the radical left during the struggle. Many of the immigrants active in the migrant social movement in Brescia in 2013, whether old activists or new, had played an important role during the "Struggle of the crane." In this general context, the "Struggle of the crane" was an exemplary event that epitomized the uniqueness, courage, and selfdetermination of immigrant activism in the city of Brescia since 2000.

While the legacy of the struggles of the 2000s shaped the collective identity of the social movement, the "Struggle of the crane" reactivated it. During our interview, Khalid D., one of the activists who was part of the migrant social movement, and who was also in charge of the Office for Migrants of the CGIL since 2000, told me: "Since 2000, the fight in Brescia has never stopped!" (BR/N17). Thus, one element that helped trigger the "Struggle of the crane" in the first place, making a focused collective action possible, was precisely the collective identity of migrant social movements in the city, which could be traced back to the struggles of the 2000s.

This idea was shared even by immigrants who were not there in 2000. Yusuf A., one of the undocumented immigrants who climbed on the crane in 2010, had not even arrived in Italy when the struggle of 2000 took place in Brescia. Yet, he made the link between 2000 and 2010 several times during our interview, as well as during the meeting in preparation for the demonstration that took place on September 28, 2013 (BR/N13).

Some activists I interviewed had arrived only recently (Abou D., Ibrahim M., and Yusuf A.), but others had been living in Brescia for a while and had a much less precarious status (Mohamed A. and Khalid D.). Yusuf A., Abou D., and Ibrahim M. started mobilizing during the tenure of the local right-wing administration (between 2008 and 2013). They were all undocumented at the time of the "Struggle of the crane" in 2010 and had applied for the amnesty of 2009, and two of them received their documents as a result of the amnesty. I asked all 
these interviewees why they mobilized in the way they did. They unanimously answered that the extreme situations of injustice in Italy in general, and in Brescia in particular, required radical claims and radical responses. At the national level, they saw injustice suffered by immigrants as a result of "the institutional racism perpetuated by unjust laws" (BR/13). In Brescia, immigrants faced injustice due to institutional discrimination since right-wing forces had come to power in 2008.

Abou D. was born in Senegal in 1979 and arrived in Italy in 2006. He arrived without documents. He told me that he took "the boat of death" after he crossed the desert of Mali and Algeria, and lived in Libya for two years. Like Yusuf A., he worked underground doing different jobs, mainly in the agricultural sector (in the South) and in the construction and transport sector (in the North). Like Yusuf A., he applied for the 2009 amnesty but could not regularize. He was not linked to any immigrant group in the city in particular, but he was strongly linked with the association Cross-point.

It was a very bad moment for immigrants. The leader of the Northern League said: "Brescia is a garage and I am going to transform it into a drawing room." He was referring to ethnic cleansing, of course! At that time, there were inspections everywhere: in the streets, in the stores, in the call centers. I heard there was a reward for the number of operations carried out to harass immigrants. The Northern League was omnipresent. They used to say horrible things. Not long ago, during the electoral campaign [in 2013], they took pictures of black people in the center of the city and said: "If the Democratic Party wins, this is what the old town center of Brescia will look like." In another flyer with similar pictures, they wrote: "If the Democratic Party wins, they will command the city."

$(\mathrm{BR} / \mathrm{N} 15)$

Ibrahim M. was born in Senegal in 1976 and arrived in Brescia in 2005. He was without documents upon arrival and was able to regularize thanks to the 2009 amnesty. He also worked all manner of jobs in the underground economy. He was strongly linked to the Senegalese community and collaborated with his compatriots when it was time to mobilize for immigrants' rights. He met with Rights for All for the first time at the end of 2008, because he was denounced by the police as undocumented after visiting the hospital for an illness, and he was hiring because of fear of expulsion. Rights for All became involved right away in his case and defended him before the local institutions. Ibrahim M. explained

The right-wing administration was looking for clear historical victories against immigrants. Rolfi talked to the newspapers and said of me: "He is still here, but we will find him." One day they took me, and then the judge let me go, because he claimed that what was happening was against Article 32 of the Italian Constitution. Even after this, Rolfi declared war against me and kept chasing after me in the city. Since then, I have become very active in all the struggles that take place in Brescia. I am very busy with my Italian 
language courses now, but I try to participate in all the assemblies and I am always up-to-date. I keep in contact with everyone thanks to the radio and email and I never stop my involvement in the mobilizations.

$(\mathrm{BR} / \mathrm{N} 1)$

Yusuf A. was born in Pakistan in 1984 and arrived in Italy in 2006, without documents. He was linked to the Muslim community in Brescia aligned with the main mosque in the city. He became involved in the Brescian social movement in 2010. He was one of the protagonists of the "Struggle of the crane" and the spokesman for the young undocumented immigrants on the crane. From 2010 to 2013, together with another protagonist of the crane, Ramzi J., he was one of the most visible immigrant activists in the city. He was originally from Egypt and he was in his late twenties at the time of the interview. n 2013, Yusuf A. was mostly active with the association Rights for All and was still undocumented because he could not regularize after the 2009 amnesty. I asked my interviewees to define the political meaning of the "Struggle of the crane." Yusuf A. explained:

it was a great opportunity for us [migrants] to raise our voice! People started to talk with each other sporadically. In those days people kept abreast of events. Moreover, every evening there were assemblies to get more information about what was going on ... There were lawyers with us ... It was a time of ferment, of great mobilization.

$(\mathrm{BR} / \mathrm{N} 13)$

Several interviewees explained how during the first month of the protest, before the occupation of the crane, members of the radical left maintained the occupation with them day and night. They all agreed that the "Struggle of the crane" started from immigrants (undocumented, but also documented), who asked for the support of Rights for All, and they also believed that protest was a crucial moment in the reinforcement of the social movement in Brescia and the alliances with the radical left.

During an informal conversation, one immigrant activist who started the "Struggle of the crane" told me: "Our friends from the radical left organized meetings, trainings, and sit-ins with us. They slept alongside us in the tents to protect us from the police. The Radio covered the protest continuously, which allowed for the spread of information and increased local support" (fieldnotes, informal conversation with Ramzi J. during a demonstration in Brescia in 2013). Yusuf A.-a key member of the migrant social movement and Rights for All, and one of the young men who climbed on the crane-confirmed this point during our interview:

The radical left organizations have always been with us! They have always supported us! They have confronted the police for us! During the occupation of the crane, they sent mattresses, blankets, and food to the protesters. They kept in radio contact with those who were occupying the crane and joined with the immigrant communities in organizing an occupation below. 
Ibrahim M., an Italian citizen of Senegalese origin in his fifties and a member of the migrant social movement, added:

The radical left was with us throughout. In the months after the crane, they created events in support of the immigrants' cause and promoted the symbolic relevance of our initiative. They offered legal help to the undocumented immigrants who had been on the crane and succeeded in bringing back the nine undocumented immigrants who had been deported during the protest.

(BR/N16)

Abou D. made a similar statement: "I believe that the only organizations who are really on our side are the radical left organizations. It is about material, logistical, political, and moral support!" (BR/N15). Overall, most of my immigrant interviewees recognized the key role of the radical left organizations in supporting them in their cause.

Thus, the "Struggle of the Crane" resulted in the reinforcement of the migrant social movement and of trust towards the allies of the radical left with and other immigrant activists who had been living in the country and who were politically active in the city for a longer period. These allies offered the material and symbolic support that allowed for a cycle of activities around the country in the following months and years, as I could testify during my fieldwork in 2014.

From more moderate actors, major criticism, including in my interviews, emerged in response to the "Struggle of the crane." They particularly criticized the "illegality" of occupying the crane. Detractors argued that the "Struggle of the crane" had been detrimental to the inclusion process already at work in the city. The Church, the CISL, and the Democratic Party all claimed that the struggle had alienated the Brescian population from the immigrant population, undermining the basis of cohabitation and wiping out years of work. ${ }^{32}$ Many local actors, including the Church and the CISL, criticized the radical left for taking advantage of vulnerable immigrants for ideological purposes and for encouraging them to continue using "illegal means" to fight for their recognition. As noted earlier, Father Toffari declared: "They [the protesters on the crane] are very determined. I have the impression they are manipulated by people under the crane. ${ }^{" 33}$ According to one member of the Forum of the Democratic Party, "the 'Struggle of the crane' has detached Italians from immigrants" (BR/N20). According to Marta G., the President of CISL-ANOLF, "The event was exploited instrumentally both by the radical left and the Northern League. Today we are fighting to reconstruct the bonds in the city" (BR/N6). Therefore, there are reasons to believe that the radical left may have pushed for a more extremist response by immigrants on the crane.

Other activists mobilizing in the few channels opened by moderate left-wing actors, for example, the Provincial Forum of Immigration of the Democratic Party, were also critical of the radical left (Bujar A. and Fatima N.). They acknowledged the role of the radical left and the migrant social movement in opening the channels of political participation in the city. They lamented, however, that the exclusive focus on promoting political rights - without the support of other 
trajectories, such as the intercultural approach—risked preventing greater inclusion of the immigrant community in Brescian society in the long run. These individuals instead chose to mobilize through more moderate channels to force local actors to invest in other directions than those promoted by the radical left.

As mentioned previously, there were also several immigrants with a more permanent migration status active in the migrant social movement in Brescia. One example was Mohamed A. He was born in Morocco in 1965 and arrived in Italy in 1998. He moved to Brescia in 2003. He had a long-stay permit and, like the others, worked in a wide range of jobs, including in the underground economy. Once in Brescia, he got involved right away. In 2013, he would not miss a local or national event (e.g., demonstrations, meetings, and other initiatives). He was particularly active in the struggles against evictions, supported by Rights for All, and he tried to be helpful in the Moroccan community, helping people who were losing their homes. He believed that the situation needed to be addressed by the active mobilization of those losing their homes, and he supported the idea of creating a network of solidarity to organize pickets against evictions (BR/N19). Another example of activism in the social movement was Khalid D. He was also born in Morocco in the 1960s and arrived in Italy in the 1990s. At the time of the interview, he was an Italian citizen and the person in charge of the Office of Foreigners of the CGIL of Brescia. He had been working for the CGIL since the beginning of the 2000s. Even though he recognized as positive the fact that he was working for the CGIL, he also made the point that he was happy to do so because the CGIL did not try to stop him from mobilizing in the migrant social movement and making radical claims for the improvement of immigrant conditions in Brescia (BR/N17).

\section{Conflicts, mistrust, and lack of alliances with the Catholic Church and the main trade unions}

Especially during the "Struggle of the crane," conflict arose between the certain pro-immigrant actors in the city and mobilized immigrants. The Catholic Church and the CISL played a crucial role as mediators between these groups until the very end of the protest. They followed the same line: they were present at all the negotiations with local authorities and pushed for a quick end to the protests by privileging compromise over conflict. Moreover, they were particularly critical of "any extremism" in the city, both by the administration and by the protesters. Then-director of the Migrants Center Association, Father Mario Toffari, entered into a heated conflict with the radical left and with protesting immigrants who felt the diocese was going against their interests and right claims.$^{34} \mathrm{He}$ was extremely critical toward this type of protest, saying that it was "at the limit of legality and there is no place for outlaws." On several occasions, Father Toffari put himself on the line in an attempt to find a compromise between the opponents, to avoid extremism, and to protect the lives of immigrants on the crane. In trying to prevent the situation from degenerating, Father Toffari climbed up on the crane to try to talk with the immigrants and encourage them to climb down on two occasions (November 2 and 9). ${ }^{35}$ On a number of different occasions, he expressed his belief 
that the radical left was manipulating the undocumented immigrants on the crane and accused them of exploiting the vulnerability of immigrants on the crane for political purposes. ${ }^{36}$ These statements created tensions not only with the radical left but also with the immigrants who were protesting on the crane, who believed that the Church in Brescia was not doing enough to help them and that Father Toffari should have supported their protest instead of criticizing them openly.

The CISL condemned both the attitude of local authorities and the "illegal" forms of protest adopted by those involved in the "Struggle of the crane." The secretary of the CISL, Renato Zaltieri, was the spokesman of the organization and was present throughout the struggle. Zaltieri highlighted the centrality of immigrants' rights, but also denounced those "who decided to organize an unauthorized demonstration." He emphasized that the protest was reinforcing "the fracture between immigrants and citizens. The latter need to be reached with information to make them understand what kind of injustices are inflicted on people who come into the country." He criticized the radical left, too, "who use immigrants as an expedient for political conflict, thereby forgetting that there are people up there." He added: "They must climb down! They are damaging the rights of other workers.... the right of someone to finish where others start!" He concluded by saying that the protest on the crane was "against the city!" ${ }^{37}$ Thus, as in the case of the Church, the "Struggle of the crane" reinforced the conflict between the CISL and the migrant social movement supported by the radical left. For their part, immigrants who were protesting felt abandoned by the trade union, which, according to them, was not working on their behalf as a defender of universal human rights.

From the perspective of immigrant activists, the Church and the CSIL not only failed to offer support for their cause, but they also sought to delegitimize the reasons for their protest. Ramzi J., an Egyptian man in his twenties and a member of the migrant social movement and the radical left, summarized the view of many of my interviewees:

We are angry with these organizations because before the occupation of the crane, when we were demonstrating in front of the prefecture for more than a month, they never showed up. Then when we occupied the crane, they kept saying we should have stopped the protest. We wanted them to understand how desperate we were, we wanted them at our side to support our claims, but they didn't.

(BR/N14)

Immigrant activists I interviewed recognized that, unlike the Church and the CISL, the CGIL responded strongly to the growth of discrimination in the city. Nonetheless, these responses were considered insufficient by immigrant activists who believed that the CGIL had not done enough to fight against the existing legislation that made them very vulnerable. Abou D. summarized a point of many of my interviewees:

The actions against institutional discrimination by the CGIL are important. But we consider it to be a marginal issue compared to things that matter for 
us. We want to see the CGIL express an authentic solidarity, not one of façade. Most immigrants in the city have reasoned as follows: "They do not represent us! They have detached themselves from our struggles and our claims." We want to see the CGIL fight against the underground economy and in favor of our dignity. Before the "Struggle of the crane," in 2009, when the "fraudulent amnesty" was launched, they could have struck a few hours to show their support, but they didn't. We could have had better and quicker results.

(BR/N15; emphasis mine)

Referring to the "Struggle of the crane," Khalid D, a key member of the CGIL, originally from Morocco, described how the CGIL changed with respect to past mobilizations organized by immigrant workers in the past:

The CGIL used to have a really positive political role. It gave immigrant activists the possibility to work autonomously and it created platforms to support our mobilizations . . . It was a very important time for immigrants' participation! There were platforms at the time in which even undocumented immigrants could participate ... During our protests in 2000, the CGIL gave its support to the [immigrant] movement 24 hours a day. During the "Struggle of the crane," the CGIL betrayed us.

$(\mathrm{BR} / \mathrm{N} 17)$

Most of my interviewees explained that the CGIL did not help to organize the occupation and it did not fully understand and support them.

Nevertheless, at the beginning of the protest, the CGIL backed protesters' demands by giving them two large shelters in which to sleep during the occupation. It was very critical of the local administration and it was more supportive than the other traditional actors, such as the Church and the CISL. In contrast to the Church and the CISL, the CGIL did not openly criticize protesters, because it did not want to enter into an open conflict with the mobilized immigrants. When the protesters climbed the crane, the trade union attended negotiations but did not fully support the protest, because unlike in the past, the CGIL did not support immigrants' demands. According to some immigrant activists (including people who were members of the trade union), the CGIL was nevertheless present during the long occupation in front of the prefecture. However, the CGIL's unwillingness to come out fully in support of the protesters created major fractures in that organization, with some of the more active immigrant members choosing to disengage from union activity.

Ibrahim M. told me:

At one point, the trade union drew back. It was ambivalent . . . We wanted to go ahead and they hesitated. Later on, when the "Struggle of the crane" ended, the CGIL understood that they had made a mistake and they came to apologize. 
Overall, the "Struggle of the crane" brought to the surface existing tensions between immigrant activists and the CGIL. These tensions had been nourished by the perception among protesters that this organization had not done all that they could have to show solidarity towards immigrant workers. As my interviews with activists in Brescia in 2013 show, the lack of support of the CGIL created major conflicts with the immigrants protesting on the crane and the immigrants active in the migrant social movement, including three key members of migrant origin (one from Morocco and two from Senegal). One of them, who was in charge of the Office for Foreigners, left his role of responsibility after the "Struggle of the crane."

\section{Exploring alternative paths in more conventional channels}

In Brescia, a small number of people of migrant background were involved with the Democratic Party since the creation of the Provincial Forum of Immigration in 2010. I interviewed two people of migrant background linked to the Forum and very active in the city: Bujar A. and Fatima N. Their trajectories of inclusion looked particularly successful from the economic and social point of view. I wanted to understand their perception of the other local actors and the migrant social movement and why their participation was so different in form than the radicalized activists associated with the radical left.

At the time of our interview, Bujar A. was in his early thirties. He had just received his Italian citizenship and he was from Albania. He arrived in Italy in 2001 (twelve years before our interview) at the age of 24 . At the time of the interview, he had applied for citizenship, and he was hoping to be able to enter politics in the near future. At his arrival in 2001, he did not have documents and lived as a clandestino for 3 years, until he regularized with the amnesty of the Bossi-Fini Law in 2002. He received his documents in 2003, and since then his status has been regular. In Italy, he worked many different jobs and, once he received his permit, enrolled at the University in the Law Department. At the time of the interview, he was working as a freelance professional and offered expert advice on immigration. He recalled that he started being politically active in 2003 , when he was a student at the University of Brescia. In 2009, he became a member of the Democratic Party.

I asked Bujar A. to tell me why he was active and why he opted for the Democratic Party. When the Provincial Forum of Immigration of the party was created in 2010, he became the person in charge of its institutional relations. He explained that the main reason he participated in politics was "to deal with daily discrimination (permits, restrictions on movement, delays in the release of documents.)" (BR/N20). He chose the Democratic Party because it represented most closely his political orientation and he thought that mainstream politics was the best way to bring about change. He explained that mainstream politics could have made it possible for immigrants to become stronger and "force politics to listen."

When I interviewed her in October 2013, Fatima N. was in her early forties. She was an Italian cultural mediator, originally from Morocco. She arrived in Italy in 1985 and lived as a clandestino for five years in the South (Sardinia) before 
moving to Brescia in 1990. She is married to an Italian and has a daughter and is now an Italian citizen. At the time of the interview, she was studying for a diploma in the school of education. Fatima N. was a very active person in the city. She had started being active for the first time when she volunteered in a cooperative in Brescia nine years before, in 2004. Then in 2011, she founded an association called "Association Together," to help women from Morocco in Italy. In 2013, she participated in the local elections with a minor left-wing party. The party obtained only a few votes and she was not elected. Like Bujar A., Fatima N. was also active in the Provincial Forum of Immigration of the Democratic Party.

Fatima N. also explained that she became active because she did not want to wait another generation before immigrants' conditions improved in Italy (BR/ N21). She decided to go to the Forum because she believed that the city of Brescia needed to make a "qualitative leap" to promote inclusion, by going beyond political partisanship. She continued: "I relate with others regardless of their political flag. The Northern League is the product of ignorance and if they don't talk about immigrants they do not get votes."

I go where people work for immigrants. We are all working for the same thing and I want to help to promote the "qualitative leap." We are all one! We need to work for what unites us. If we don't move in this direction, many years will go by without us seeing any major social change. I have always thought that coming out of oneself means moving away from the idea that we are immigrants and starting to take care of our city. We need to make the necessary steps ahead. The Brescians understand you and you start thinking like them. This for me means imposing our problems on the administration. But it also means talking about the city and its real problems. We [the immigrants] have two cultures. This can be a great advantage. However, we fall behind if we are not able to make the qualitative leap: Once we overcome the label of immigrants, we must act as people who talk about the city. ${ }^{38}$

$(\mathrm{BR} / \mathrm{N} 21)$

Both Bujar A. and Fatima N. expressed concern about the low level of participation among people of migrant background in institutional channels. Bujar A. told me: "Many people of migrant background feel they are blackmailed for this reason. We [immigrants] distance ourselves from politics day after day. Just like many Italians, we believe that politicians have been corrupted" (BR/N20). These two interviewees also identified major barriers to participation. They talked about the lack of unity and communication among immigrants, and also emphasized the fact that immigrants are exposed to blackmail because of the restrictiveness of the Bossi-Fini Law, the exploitation of the issue of immigration by politicians (in both left-wing and right-wing parties) and the fear among immigrants themselves of being controlled by the police. Bujar A. explained: "We are continuously exposed to the vigilant eye of the police. We have heard about cases of people who did not receive their permit because they had participated in political rallies and thus were considered "dangerous individuals"” (BR/N20). 
The interviews with Bujar A. and Fatima N. revealed their points of view on whether moderate left actors were responsible for the limited channels for participation in the city. Bujar A. said:

The problem is that we do not have the power to negotiate politically, because we do not have the numbers. Someone wants us divided. Not those who refuse us, but those who exploit us. The left fears the right to vote.

$(\mathrm{BR} / \mathrm{N} 20)$

He continued: "The new mayor, Emilio del Bono, thinks that immigrants are like everybody else. He is a balanced person and he tries to accommodate everyone. However, during the electoral campaign he never used the word 'immigrant." The Forum, for Bujar A., was an opportunity to create the conditions to "force politics" to deal with immigration and inclusion in a better way. He explained:

In the city, the extreme left has the allegiance of the immigrants who are active. We [the moderates] believe that there is more than just the streets. We also want to build a trajectory that allows us to negotiate politically. We are trying to make Italians understand other aspects of immigration, beyond the exclusive focus on the permit of stay. We also live the crisis, even in a deeper way.

$(\mathrm{BR} / \mathrm{N} 20)$

Bujar A. and Fatima N. believe that the right to vote is a necessary step for greater inclusion. They believe in the validity of the principle "no taxation without representation." Fatima N. tells me: "The administration sends me a request for the taxes every year. If you don't give me the right to vote, why do you ask this duty of me?" Bujar A. also agreed on this point. For him, "[t]he left fears the right to vote! And this is the case for both the radical left and the moderate left. In this sense, the left is guilty of duplicity."

The interviews with these two immigrant activists mobilized in more conventional channels show that, despite the opportunities of political participation offered by the radicalized actors in the city, not everyone adheres to its political views. Bujar A. and Fatima N.'s activism is rooted in a refusal to accept Italy's institutional racism and unjust laws and in the fundamental idea that the BossiFini Law must be abolished. However, when it comes to their perceptions and reactions to the opportunities of participation opened in the city, they explain that even though the radical left is an undeniable ally of immigrant activists, it should not have a monopoly on the discourse about migration and participation. Both Bujar A. and Fatima N. have mobilized in more conventional channels because they believe that it is important to address other questions that concern immigrants and Italian society as a whole. This is in line with the intercultural approach promoted by more moderate actors in Italy, from above (see the examples of Reggio Emilia) or from below (as in the case of Bolgona) to promote cohabitation. It is relevant that both expressed mistrust towards the radical left, which in their opinion never talks about the right to vote for fear that it might make immigrants become more autonomous and less radicalized. 


\section{Lessons from Brescia}

Since the 1990s, the local administrations in Brescia devolved most of the work on supporting immigrant inclusion to the third sector. This situation has created an opportunity for the radical left to encourage and support a migrant social movement in the city at the expense of more moderate forms of participation. When the first inflow of immigration arrived in Italy, the Church, the CISL, and the CGIL in Brescia provided assistance and protection to the immigrant population through specific offices. Their support for immigrants has its roots in their commitment to universal solidarity. As Ambrosini (2013b, 315) explains, "although they start from very different ideological and political assumptions," these non-state organizations "agree on the moral principle that immigrants should be welcomed with no distinction based on race, nationality, religious belief, or status." Nonetheless, the different ideological positions of these organizations determine their responses to immigrant mobilizations in the city (cf. the theoretical model in Chapter 2). While the Church and the CISL in Brescia tend to favor compromise over conflict and to avoid promoting mobilizations, the CGIL, a left-wing trade union with communist roots and a particularly radical branch in Brescia, was more prone to engage in mobilizations and to support contentious politics to make claims. In the past, they mobilized on several occasions to support immigrants' claims and this helped to develop an alliance with the migrant social movement. However, by the end of the 2000s, as hostility towards immigrants in the city grew, things changed in a significant way. Immigrant activists became increasingly distrustful of the CGIL, also because of its withdrawal on key issues concerning immigrant workers' rights. In this peculiar context, the strong presence of radicalized leftwing actors and an approach that promoted political rights has resulted in the emergence of radicalized forms of political participation over the years, including protests and occupations.

It is significant that a migrant social movement developed in Brescia and not elsewhere. This movement shifted the city's approach toward the promotion of political rights and rights claims of immigrants in vulnerable conditions. Immigrant activists through radicalized channels could emerge as a collective actor and encourage the participation of other immigrants by appropriating the discourses and practices of their main allies, the radical left actors. Though willing to promote interculturalism and political rights, the weak strategy of moderate left-wing actors resulted in a complete absence of alternative channels of civic participation and limited opportunities to participate in conventional political channels. This situation created an opportunity for the radical left to fuel the development of a migrant social movement in the city at the expense of more moderate forms of participation, which are usually promoted by more moderate actors of the left.

The foregoing analysis sheds light on two key aspects concerning the nature of conflicts and alliances in hostile environments.

First, conflicting discourses around immigrant rights and "deservingness" influence the kind of alliances immigrant activists establish with potential supporters. In Brescia, the right-wing administration depicted undocumented immigrants as 
people with "no rights" and restated the right of the citizens of Brescia to live in peace from immigrants. This represented a securitarian turn of the local administration with heavy consequences on the immigrant population living and working in the city. The Church and the CISL opposed this situation by speaking about human dignity and universal human rights, but they also opposed the "illegal" occupation and contrasted the rights of immigrant protesters with the rights of other citizens to work and live in peace. The CGIL was a little more cautious in this respect, but this merely created conflicts with the immigrants who expected more from this traditional ally. The radical left and the mobilized immigrants, on the other hand, utilized a discourse of deservingness and human dignity that challenged the discourses put forward by all other actors. Since undocumented immigrants perceived their situation of exclusion and repression by state and local institutions as unjust, they found the more moderate position of other non-state actors unacceptable. They believed that their radicalization was not something to condemn, but rather something that had to be understood within the context of extreme social and political exclusion. That immigrant protesters were often targeted as extremists was a strategy meant to disqualify their claims. From this point of view, we can interpret the alliance between immigrant activists and the radical left organizations as resulting from their shared understanding of immigrant rights and deservingness.

Second, state repression and hostility do not necessarily result in political radicalization, just as immigrants' rights claims do not necessarily result in contentious politics. As Nicholls $(2013,99)$ points out, in most cases, activists stress "the moral and cultural attributes" that make a specific group "particularly deserving of the legal rights to stay in the country," and more radical claims are often left aside. In hostile environments, this approach can be an even stronger incentive for undocumented immigrants to stress their deservingness and belonging in the receiving society. Nicholls (2014) adds that participation is possible because "even the most hostile contexts produce countless cracks and fissures that can serve as narrow niche-openings" (26) for "stigmatized groups" (25) (see also Zepeda-Millán 2017). He explains that the presence of allies, and in particular their material and symbolic support, can be crucial to transforming political grievances into political action, and can allow immigrants to become "visible" and represent themselves as legitimate political subjects (Nicholls 2013, 84). Thus, under some conditions hostile environments can trigger shared radical action. The case of Brescia shows that the presence and legacy of a longstanding migrant social movement and the alliances between radical actors and mobilized immigrants brought about radicalization. By offering material and symbolic support, radical left allies encouraged immigrant activists to make more radical claims, while also contributing to the polarization of local politics. Still, Nicholls notes the complexity of the relationships between undocumented migrants and their allies, arguing that these alliances are "prone to divisions and splits, opening possibilities for alternative visions and discourses of citizenship" $(2013,86)$. Moreover, as Steinhilper and Ataç $(2019,346)$ point out, "[s]uch alliances of actors in highly different power positions ... have proven to be highly precarious and prone to conflicts 
concerning paternalism." Nonetheless, they add, "shared experiences of 'eventful protest' . . . can contribute to collective identities and alliances, which are built and negotiated during contentious actions."

Two interrelated factors determine why undocumented immigrants created partnerships with radical left organizations: while conflicting relationships between immigrant activists and pro-immigrant supporters, such as the Church and the trade unions, stemmed in large part from these latter organizations' unwillingness to provide significant material and symbolic support to the protesters, the historical alliances with the radical left were further strengthened during the "Struggle of the crane." The case of Brescia, thus, suggests that the decisiveness of alliances at a specific moment in time relies on previously established alliances (see Nicholls and Uitermark 2016). They also depend on the effect of changing legislations as well as national and local contexts. The CGIL, which was an important ally in the past, withdrew its support for immigrants' political claims over the years. This aspect was shared by the national organization more generally (see also Chapters 3 and 4, on the cases of Reggio Emilia and Bologna, and Chapter 7, on the mechanisms that produce political racialization of immigrants). The obvious ideological conflicts between the Church and CISL (and their assistant approach to inclusion), and the radical left (and its political right promotion approach to inclusion) are important, but they do not fully explain the local dynamics in Brescia, especially when it comes to explaining why the mobilization took place in this city specifically and in the specific form that it did. In order to understand, as illustrated in Chapter 2 when presenting the theoretical model of local dynamics, in addition to ideology, we need to take into account the interactions between multiple actors (including immigrant activists' role at both the individual and the group level) in opening and/or obstructing spaces for immigrant participation. While the role of the radical left in promoting some forms of rights claims and the visibility of some immigrants in the city is undeniable, two other aspects need to be considered: its competition with other actors and its political views tend to encourage specific forms of participation and some immigrants and to leave other issues out of its reach. Moreover, there are concerns regarding its instrumental use of the immigrant cause. A lack of other relevant civic and political channels and of substantial support by other actors leaves a void in the city when it comes to promoting, other approaches to inclusion, namely the intercultural approach by more moderate immigrant activists.

\section{Notes}

1 Some analyses of the "Struggle of the crane" protest and of local actors in Brescia have been published previously in Cappiali (2016). For a complete list of the interviews conducted in the city, see Appendix D.

2 As Fasani $(2009,13)$ explains: "More than half of the documented migrants currently residing in Italy have obtained legal status through one of the[se] mass regularizations." In total, around 1,760,200 migrants have been regularized, making Italy the country in Europe with the highest number of people regularized through this method (ibid.). 
3 These critiques were supported by numerous testimonies of the unlawful procedures that took place around the country and by academic research done on this particular amnesty (Colombo 2009).

4 The Prefecture in Italy is a territorial office linked to the Minister of the Interior which represents the government and has responsibilities concerning the release of documents to immigrants.

5 G. Spatola. "Sgomberati gli immigrati in sciopero." Corriere della Sera. September 30, 2010.

6 In the first few days, one of the undocumented immigrants on the crane climbed down. The six undocumented immigrants who remained on the crane were: R. (35, from Morocco, four years in Italy), A. (24, from Pakistan, four years), J. (25, from Egypt, five years), S. (27, from Pakistan, three years), S. (26, from India, five years), and P. (24, from Senegal, seven years). Information found on a flyer distributed during the occupation under the crane, which was titled "Who are our brothers on the crane?" Brescia, October 6, 2010.

7 S. Galieni. "Se non ci danno risposte positive noi da qui non scendiamo." Liberazione. November 3, 2010.

8 On the role of the administration on these issues, see document Fondazione ISMU (2010).

9 www.comune.brescia.it/servizi/servizisociali/servizistranieri/Pagine/bresciaAperta ESolidale.aspx; see also Paolo Attanasio, "Progetto 'Rete civica: Brescia aperta e solidale." Rete dei diritti di integrazione. June 3, 2009. http://retedeidirittiedintegrazionedocument.blogspot.it/2009/06/progetto-rete-civica-brescia-aperta-e.html (Accessed June 20, 2015).

10 The right-wing coalition came to power in April 2008. The People of Freedom received $28.31 \%$ of the vote (14 out of 40 seats) and the Northern League $15.83 \%$ ( 8 seats). The coalition won a total of 61,061 votes or $51.4 \%$ ( 24 seats). The left-wing coalition gained 42,483 votes or $35.76 \%$ (13 seats), of which $27.92 \%$ (11 seats) were for the Democratic Party. http://tg24.sky.it/tg24/speciale_elezioni/comunali/2008/lombardia/ risultati_brescia.html (Accessed June 20, 2015).

11 On the closure of the office, see C. Del Frate. "Brescia chiude l'ufficio migranti." Corriere della Sera. October 9, 2008. http://archiviostorico.corriere.it/2008/ottobre/09/ Brescia_chiude_ufficio_immigrati_co_7_081009018.shtml (Accessed June 20, 2015).

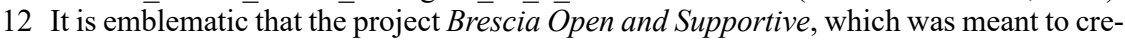
ate "spaces of cohabitation between Italians and immigrants," was replaced by a new project called Brescia Città Sicura (Brescia Safe City). See in particular the document: Minister of the Interior, 2008. "Patto per Brescia Sicura" (translation: Pact for Brescia Secure). www.interno.gov.it/mininterno/export/sites/default/it/assets/files/15/0419 Patto per_Brescia Sicura.pdf

13 I. Brontesi. “"Razzista': la CGIL denuncia Rolfi.” Corriere della Sera. June 13, 2012. http://brescia.corriere.it/brescia/notizie/cronaca/12_giugno_13/20120613BRE02_16201582224807.shtml (Accessed June 20, 2015).

14 Ambrosini (2013a, 142) notes

how measures of local policies take form in various ways to combat the settlement, inclusion or expression of specific requirements on the part of immigrants. This resulted in 788 by-laws, issued between the summer of 2008 and that of 2009 by the 445 municipalities involved, mostly concentrated in Lombardy, Veneto and Friuli, but also with examples in a region ruled by a center-left party such as Emilia-Romagna.

The most famous event was that of the Baby Bonus (Bonus Bebé) (Guariso 2013). In Lombardy, in 2010, an economic bonus was given to help families with newborn babies. The Northern League said that if the baby did not have at least one Italian parent, the family could not have the bonus. The CGIL of Brescia challenged the Northern 
League on this point and the cause was won on the ground that this would imply "differential treatment" and as such went against the third article of the Italian Constitution (see also Guariso 2013; Ambrosini 2013a, 319). Another significant episode happened in the municipality of Adro, in the province of Brescia. The lawsuit was brought forth at the European level. As Giulio D., the Secretary of the local branch of the CGIL in Brescia, explained,

[a]t Adro, in a public school, the Northern League put the symbol of its political party in all classes, desks, and lockers of the school. The legal cause was conducted by calling to the fact that these practices challenged professors' beliefs. It was the first case in Europe of this kind.

Like all lawsuits settled by the CGIL, the two cases cited earlier were won (BR/N9; see also Guariso 2013).

15 See M. Varone. "La Lega chiude: 'Sanatoria? Mai." Bresciaoggi. November 6, 2010; A. della Moretta. "Il sindaco Adriano Paroli: "un ricatto inaccettabile."' Giornale di Brescia. November 8, 2010. Rolfi also added: "It is they who are denying the Brescians the right to work, to study, to free movement and to exercise their economic activities in the area where they are protesting." M. Lanzini. "Paroli: offesa la città. Ora nuovo patto sociale." Giornale di Brescia. November 6, 2010. See I. Panighetti. "Resistono, nonostante la febbre." Bresciaoggi. November 3, 2010; F. Mantovani. "Rabbia e stanchezza, ma non molliamo." Liberazione. November 5, 2010.

16 S. Galieni. "Se non ci danno risposte positive noi da qui non scendiamo." Liberazione. November 3, 2010.

17 At the time of my fieldwork, the left-wing administration led by Emilio de Bono had been in power since 2013, replacing the right-wing administration led by Mayor Paroli. The main left-wing political party in the city is the Democratic Party. It has done little to encourage the participation of people of migrant background in their organizations. The party has not promoted candidates of migrant background or created platforms for participation. Many interviewees in Brescia emphasized that "the Democratic Party in the city has not gotten directly involved in the realm of immigration for many years, and in so doing it has left a huge gap that other organizations, such as the radical left, have filled" (BR/N20: Bujar A., Albanian (M), Democratic Party (PD), Member, Provincial Forum on Immigration). What is more, in recent years, the party has continued to adopt an "ambiguous" approach and have been seen as "using immigrants rather than encouraging their participation" (BR/N20).

18 On the official sites of the municipality and the province of Brescia, the only page dedicated to "Foreigner" (Stanieri) is the page of the social services. It is significant that unlike the traditional Communist cities of Reggio Emilia and Bologna, there is no reference to associations for immigrants or associations of immigrants. For the page of the services offered to the immigrant population, see www.comune.brescia.it/servizi/ servizisociali/servizistranieri/Pagine/default.aspx (Accessed June 20, 2015).

19 For a complete list of the activities promoted by the Migrants Center Association, see their official site: www.diocesi.brescia.it/diocesi/uffici_servizi_di_curia/u_migranti/ migranti.php?codice $=88 \&$ (Accessed June 20, 2015).

20 Official site: www.cislbrescia.it/servizi/anolf (Accessed June 20, 2015).

21 Nonetheless, there was an attempt by the CISL to push for a greater representation of immigrant workers in its organization and give them some visibility. In 2013, there were few individuals of migrant background with roles of responsibility: Mammadu F., a unionist from Senegal and a functionary of the metalworkers' sector (the FIM), and Anna E., a unionist from Moldavia and a volunteer in the office of the CISL-ANOLF, who were both very proud of being active members of this organization (BR/N7 and $\mathrm{BR} / \mathrm{N} 8$ ).

22 Official page of the "Migration Coordination Organization." http://194.244.4.156/ cgil_bs/sito_sportelloimmigrati/?page_id=89 (Accessed June 20, 2015). 
23 In the province of Brescia, around $30 \%$ of people of migrant background are enrolled in the CGIL. In some sectors, such as construction and agriculture, more than $40 \%$ are of migrant background (BR/N17: Khalid D., Moroccan (M), migrant social movement, CGIL, main member, in charge of the Office for Migrants). Giulio D. added:

By now, there are eight people who have important responsibilities in our union in Brescia. There are two functionaries at the FIOM (metalworkers sector), two at the FILLEA (construction sector), two at the FLAI (agricultural sector), and two people in charge of the Office for Foreigners.

(BR/N9)

24 Giancola (2008/2009) explains that, back in the 2000s, the CGIL offered unconditional support for the radical claims of immigrants during one major mobilization.

25 He added that, in some cases, the mosques had also played a role in the city, but they were marginal compared to these two actors.

26 For a detailed reconstruction of the first phase of mobilizations between the 1990s and the 2000s, see Giancola 2008/2009. It is important to highlight that the CGIL's support was vital during these years.

27 The official document of the CNEL highlights that, following prolonged protests of both immigrants and social forces, the administration left the building to the occupants and legalized their occupation (CNEL 1991, 60).

28 See also Giancola 2008/2009, 85-148.

29 In 2000, movements, political parties and civil society organizations around the world created a strong coalition. This coalition was created one year before the 27th G8 Summit and it was strengthened in the years following the submit with the creation of Social Forums of specific thematic areas. For more information, see Chapter 1.

30 During the "Struggle of the crane," the radical left played a key role in supporting the immigrants' protest. However, the radical left organizations also experienced deep tensions and came out of the struggle with irreconcilable internal divisions. A new organization, Cross-point, was born during the struggle, thanks to the initiatives of some women who were active in the struggle as well as in earlier struggles of the 2000s. Their concern was to reflect on and challenge the traditional approach adopted by the radical left-wing organizations in relation to immigration and human rights. They challenged the approach of Rights for All, claiming that what needed to be privileged was the "encounter" of difference based on gender and also on cultural background (see the official site: http://cross-point.gnumerica.org/en/; Accessed June 20, 2015). As the key members of Cross-point told me during the organization's weekly meetings and informal meetings, the members of the new group - mainly Italian women - wanted to distance themselves from the rhetoric of the traditional association Rights for All. They saw the latter as opposed to alternative approaches to the mobilization of immigrants. They believed that it was necessary to move towards a more inclusive approach within the Brescian social movement by considering the role of diversity and pluralism. Vinicio M. added: "I think that the discourse is linked to the need to be recognized by the women in the movement. It is about a divergence that translates into practices. This is why they talk about 'crossing' and 'recognition'" (BR/N12). During one of the weekly meetings of the organization, one of the members told me:

We come from the experience of the radical left and of the social centers. However, we believe that we need to change the approach to our claims. The "Struggle of the crane" has shown that the movement has been transformed by immigration and by the participation of people who come from many different places and have different visions of the world. We privilege the idea of encounters and hybridization. The "Struggle of the crane" has had a role in this process of hybridization and we believe that this fact needs to be encouraged because this is the way to go.

(fieldnotes Brescia, September 9, 2013)

Despite these internal conflicts, however, the support of the radical left for immigrants' rights and their political participation in the city did not diminish after the "Struggle of 
the crane." Instead, it resulted in the division of labor (as I observed in 2013 and 2014 during my fieldwork). On the one hand, Rights for All concentrated on mobilizations against evictions, resulting from the financial crisis. The organization helped Italians and immigrants alike in their struggle for housing. The organizations supported the struggle against evictions by organizing weekly meetings, supporting the pickets and the mobilizations at the national and local level, and by organizing the occupation of empty buildings. Vinicio M. explained: "The struggle is now against evictions. Here you can see the real self-determination of people of migrant background in the territory of Brescia at work. They are very active in the picket lines to impede eviction of their peers" (BR/N12). Cross-point, on the other hand, concentrated mostly on protesting against the slowness of the mass regularization that was launched in 2012. During my fieldwork, it organized weekly meetings in front of the prefectures to protest against the government's delays, and a major demonstration took place in the city on September 28, 2013. At that time, the organization was still very weak and had to seek support from Rights for All. However, it was working to develop its own trajectory in the city, one that would be independent of Rights for All.

31 This kind of criticism was also developed by people who were active in the organization Cross-point. This was one of the main reasons at the origin of the split between Rights for All and Cross-point after the "Struggle of the crane."

32 M. Lanzini. "Paroli: offesa la città. Ora nuovo patto sociale." Giornale di Brescia. November 6, 2010. For example, the then-secretary of the CISL, Renato Zaltieri, declared that the protest was "against all the city of Brescia" and also that it "damages the rights of all workers." G. Spatola. "Extracomunitari sulla gru. Denuncia dell'Ansaldo." Corriere della sera. November 3, 2010.

33 M. Tedeschi. "Bruciati tutti i margini per chi vuole mediare." Bresciaoggi. November 10, 2010.

34 Father Toffari was involved in the entire event, acting on behalf of the diocese and of the bishop, Luciano Monari. When the occupation of the crane began on October 30, Father Toffari made explicit the political stance of the diocese. On November 2, after the heavy use of violence by police against those under the crane, he condemned the police actions and criticized the right-wing administration for its "attempts to collect votes on the skin of immigrants, people who hold human rights as people." R. Manieri. "L'ultimatum di Paroli: 'Decidere subito o la parola al questore."” Giornale di Brescia. November 2, 2010. M. Tedeschi. "Bruciati tutti i margini per chi vuole mediare." Bresciaoggi. November 10, 2010.

35 See W. Pentenzi. "La proposta: presidio e tavolo. Ancora una notte di tensione." Bresciaoggi. November 3, 2013. One day, after he had climbed up on the crane for the second time, he declared: "I found them very determined, sure of themselves. I had the impression they were manipulated." M. Tedeschi. "Bruciati tutti I margini per chi vuole mediare." Bresciaoggi. November 10, 2010.

36 Manieri. "L'ultimatum di Paroli."

37 A. Dessì. "La CISL: 'Manifestare si, ma nel rispetto delle regole.'” Bresciaoggi. November 3, 2010. The CISL's public line was also shared by many of the immigrants who worked in the organization.

38 Fatima N. added:

I have always thought that coming out of oneself means moving away from the idea that we are immigrants and starting to take care of our city. We need to make the necessary steps ahead. The Italians understand you and you start thinking like them. For me this means imposing our problems on the administration. But it also means talking about the city and its real problems. We [immigrants] have two cultures. This can be a great advantage. We need to move away from the idea that we are "immigrants," and start taking care of our city and its real problems. However, we [immigrants] will fall behind if we are not able to make this qualitative leap: Once we overcome the "immigrant" label, we must act as people who talk about the city and who are part of this society. 


\section{References}

Ambrosini, Maurizio. 2013a. “ “We Are Against a Multi-Ethnic Society': Policies of Exclusion at the Urban Level." Ethnic and Racial Studies 36 (1): 136-155.

Ambrosini, Maurizio. 2013b. "Fighting Discrimination and Exclusion: Civil Society and Immigration Policies in Italy." Migration Letter 10 (3): 313-323.

Campomori, Francesca. 2008. Immigrazione e cittadinza locale. La governance dell'integrazione in Italia. Roma: Carocci.

Caponio, Tiziana. 2006. Città italiane e immigrazione. Discorso pubblico e politiche a Milano, Bologna e Napoli. Bologna: Il Mulino.

Cappiali, Teresa M. 2016. "Activism of Immigrants in Vulnerable Conditions and RadicalLeft Allies: A Case Study of Italy's Struggle of the Crane." Journal of Ethnic and Migration Studies 42 (15): 2508-2527.

Cappiali, Teresa M. 2017. “An Italian 'Integration Crisis': The Role of the State and Political Actors in Excluding Immigrants and Ethnic Minorities." In Italy from Crisis to Crisis: Political Economy, Security, and Society in the 21st Century, edited by Matthew Evangelista, 168-198. New York: Routledge.

Caritas/Migrantes. 2014. Dossier Statistico Immigrazione 2014. Rome: Anterem.

CNEL (Consiglio Nazionale dell'Economia e del Lavoro). 1991. Società e Istituzioni di fronte al processo migratorio. www.cnel.it/53?shadow_documenti=16714 (Accessed June 30, 2015).

CNEL (Consiglio Nazionale dell'Economia e del Lavoro). 2009. VII Rapporto. Indici di integrazione degli immmigrati in Italia. www.cnel.it/18?tag_area_tematica $=35$ (Accessed June 30, 2015).

Colombo, Asher. 2009. "La sanatoria delle badanti e colf del 2009: fallimento o esaurimento di un modello?" Fieri. www.fieri.it (Accessed June 25, 2015).

Fasani, Francesco. 2009. Country Report Italy. Country report prepared under the research project CLANDESTINO Undocumented Migration. Counting the Uncountable. Data and Trends across Europe, funded by the 6th Framework Programme for Research and Technological development under Priority 7, "Citizens and Governance in a Knowledge-Based Society." Research DG, European Commission. http://irregular-migration. net/typo3_upload/groups/31/4.Background_Information/4.4.Country_Reports/Ita ly_ CountryReport_Clandestino_Nov09_2.pdf

Fondazione ISMU. 2010. Dieci Anni di Immigrazione in Lombardia. Milan: FrancoAngeli. Giancola, Simona. 2008/2009. Tra cittadinanza e lavoro: Le lotte degli immigrati in Italia. Il caso studio Brescia. PhD diss., unpublished.

Guariso, Alberto, ed. 2013. Senza distinzioni: quattro anni di contrasto alle discriminazioni istitutionali nel Nord Italia. Milan: ASGI, UNAR e Avvocati per niente.

Istat. 2013. Gli stranieri al $15^{\circ}$ Censimento della Popolazione. www.istat.it/it/files/2013/12/ Notadiffusione_stranieri20122013.pdf (Accessed June 30, 2015).

Marino, Stefania. 2010. "Le strutture specifiche per la rappresentanza dei lavoratori migranti: un confronto tra Italia e Olanda." In Immigrazione e Sindacato. Lavoro, cittadinanza e territori. VI Rapporto, edited by Francesco Carchedi, Francesca Carrera, and Giovanni Mottura, 337-352. Roma: Ediesse.

Mometti, Felice, and Maurizio Ricciardi, eds. 2011. La normale eccezione. Lotte migranti in Italia. Rome: Edizioni Allegre.

Nicholls, Walter J. 2013. "Making Undocumented Immigrants into a Legitimate Political Subject: Theoretical Observations from the United States and France." Theory, Culture \& Society 30 (3): 82-107. 
Nicholls, Walter J. 2014. "From Political Opportunities to Niche-Openings: The Dilemmas of Mobilizing for Migrant Rights in Inhospitable Environments." Theory \& Society 43 (1): 23-49.

Nicholls, Walter J., and Justus Uitermark. 2016. Cities and Social Movements: Immigrant Rights Activism in the US, France, and the Netherlands, 1970-2015. London: Wiley-Blackwell.

Oliveri, Federico. 2012. "Migrants as Activist Citizens in Italy: Understanding the New Cycle of Struggles." Citizenship Studies 16 (5-6): 793-806.

Piancentini, Daniele. 2011. "I migranti là in alto: Sulla gru di Brescia." In La normale eccezione. Lotte migranti in Italia, edited by Felice Momentti and Maurizio Ricciardi, 21-54. Rome: Edizione Alegre.

Steinhilper, Elias, and Ilker Ataç. 2019. "Contentious Subjects: Spatial and Relational Perspectives on Refugee Mobilizations in Europe.” In Handbook on Critical Geographies of Migration, edited by Katharyne Mitchell, Reece Jones, and Jennifer L. Fluri, 345357. Cheltenham: Edward Elgar Publishing.

Zepeda-Millán, Chris. 2017. Latino Mass Mobilization: Immigration, Racialization and Activism. Cambridge: Cambridge University Press. 


\section{Obstructing participation in a stronghold of the Catholic Church}

The Catholic Church can be a very powerful actor in the realm of immigration and affect other actors in the city, as the analysis of Brescia showed. The case of Bergamo offers an opportunity to delve deeper into the role of this key actor. In Bergamo, the absence of relevant left-wing actors and the dominant presence of the Catholic Church help us examine why, in contrast to all the other cities, participation here is almost non-existent. This chapter examines the strong impact of the approach to inclusion developed by the Catholic Church and its alliespredominantly based on assistance - and especially on the implications for the political silencing of other competing organizations, not least immigrant groups. Zooming in the specific local dynamics, it shows why and how the dominant role of the Catholic Church and the lack of strong challenges of the left result in the exclusive promotion of the assistance approach to inclusion, the lack of alliances between local actors and immigrant organizations and weak participatory channels available for immigrant activists. The chapter also analyzes the discourses and practices of selected immigrant activists to offer an insider perspective on the main obstacles they face.

As a way of example, I will start my analysis by examining the configuration of actors what organized the 2010 mobilization "A day without us: The strike of migrants," which occurred also in the city of Bologna (Chapter 4). The event saw two separate demonstrations with a low level of participation by immigrant communities. Using this example, I analyze the actors involved in the mobilization and identify their key characteristics and the reasons behind the lack of participatory forms taken up by immigrant activists. Based on the theoretical model of local dynamics presented in Chapter 2, I will reconstruct the institutional context, which over the years has led to the complete disengagement of the local administration and a devolving of power to the Church on matters of migration. I continue with a description of the local realm of immigration and the approaches to inclusion developed by main local actors. In particular, I explain why and how the specific configuration of actors in Bergamo and their interactions resulted in the exclusive promotion of the assistance approach. I also explain why and how this has resulted in a lack of alliances between local actors and immigrant organizations, as well as setting up major obstacles to any form of civic and political participation on the part of immigrant activists. The chapter continues by analyzing 
the discourses and practices of selected immigrant activists and offers an insight into some of the main challenges they face. It will show that political opportunism and processes of co-optation are more pronounced and obstruct participation more so here than in the other cities studied. The chapter concludes by reflecting on the lessons we can draw from the case of Bergamo.

I will show that the most powerful actor, the Catholic Church, followed by other key actors in the city - trade unions and church-based organizations, including those of the left — promote an almost exclusive assistance approach. Here there are some more radical left actors, but they are very weak. As such, there are no major challengers to the dominant approach in the city. This in turns results in an almost complete lack of civic and political incentives on the part of local actors. In addition, when these incentives arise from immigrant activists themselves, they are almost completely obstructed. The empirical chapter will further identify the mechanisms by which there is such a limited participation by immigrant activists in the city, in striking contrast to the other three cities studied. Among other factors, processes of racialization and co-optation of immigrant activists are particularly pronounced and clearly show how the Catholic Church and other organizations in the city blocked immigrants' participation here more than elsewhere.

\section{"A day without us! The strike of migrants": a mobilization for, but without immigrants}

On March 1, 2010, in Bergamo various civil society organizations and trade unions took to the streets to protest against institutional racism during a national mobilization called "A day without us: The strike of migrants" (see Chapter 4 on the city of Bologna). ${ }^{1}$ In the previous two months, a committee was created by the main pro-immigrant organizations in the city to prepare the mobilization. However, a few days before the demonstration, the organizers split into two factions with different political orientations. The first, called the March 28 Network (Rete 28 Marzo), was composed of the main trade unions (the CISL and the CGIL) and a number of organizations linked to the Catholic Church. ${ }^{2}$ The second, called the Committee of the First of March (Comitato Primo Marzo), was formed, instead, by the anti-racist organizations close to the Communist Refoundation Party as well as the more radicalized branch of the CGIL, the CGIL-FIOM and other grassroots unions of radical left orientation, such as CUB (Unitary Base Confederation (Confederazione Unitaria di Base)) and USB (Base United Unions (Unione Sindacale di Base)).

Despite attempts to organize the events together, these two main groups came up against traditional ideological disagreements. On February 5, 2010, tensions erupted into open conflict. The March 28 Network wanted to distance itself from "any instrumental use of the protest" for political purposes by the anti-racist movement led by the Communist Refoundation Party in Bergamo, so they wanted to avoid bringing the flags of the political parties and trade unions to the demonstration. ${ }^{3}$ They opposed a strike of immigrants because, they argued, it would represent an "ethnic" protest that could widen the distance between immigrant 
workers and the Italian population (workers in particular). ${ }^{4}$ These organizations did support a demonstration without a strike. ${ }^{5}$ The Committee of the First of March pushed for a politicization of the demonstration and sought immigrants' support for the strike, but given its marginal influence, it could not successfully pull off a strike - because it did not have the support of the traditional trade unions. Due to the conflicts between local actors, there were two demonstrations and no strike. The level of participation by immigrant activists was very limited in at least in two ways. First, individual immigrants and immigrant organizations did not take part in organizing the event in the months preceding it. Therefore, their voice was marginalized and made invisible in the negotiations among pro-immigrant actors. Second, during the demonstration, the immigrants who did participate in the event were small in number and were members, in one way or the other, of the main Italian actors, organizing the event on their behalf (for a more detailed reconstruction of the conflicts around the event, see Cappiali 2019).

Examining the organization and participatory outcome of a "A day without us" reveals the local dynamics in Bergamo and the interactions between the many actors involved in promoting immigrant inclusion. Powerful actors allied with the Catholic Church - including key traditional trade unions and church-based NGOs-and a smaller group of organizations, close to the Communist Refoundation Party and the radical left, were ideologically opposed to each other. In this local struggle among Italian organization, immigrant activist voices ended up being marginalized. Why did the local dynamics in Bergamo result in the silencing of immigrant activists? To answer this, I identify and analyze the actors involved in the mobilization, their characteristics, and the reasons behind the lack of participatory forms used by immigrant activists. The analysis examines the impact of the approach to inclusion developed by the Catholic Church and its allies - predominantly based on assistance - and the implications of the political silencing of other competing organizations - not least immigrant groups in the city.

\section{Devolution and the rise in power of the Catholic Church as the dominant actor}

Like Brescia, the city of Bergamo is traditionally associated with the Christian Democrat political sub-culture. The local administrations devolved most policies to the third-sector actors, particularly the Catholic Church (Campomori 2008). But even more than Brescia, Bergamo represents a city almost completely without intervention by both left-wing and right-wing administrations of the city. This institutional arrangement increased the power of the Catholic Church in the realm of immigration and other actors linked to its networks (see also Cappiali 2018).

These processes of devolution are historically rooted and cannot be explained from the economic point of view. Just like other three cities analyzed in this study, before the financial crisis, Bergamo was one of the richest cities in Italy. Moreover, just before the financial crisis, the city was characterized by a high degree of economic inclusion of immigrants in the city and the surrounding areas (CNEL 2009). For many years, moreover, the city had the highest percentage 
among Italian cities of immigrants $(13.8 \%$, or 15,833 , in 2013$)$ compared to the local population of 163,928 (Istat 2013). The high number was due to the strong economic attractiveness of the territory. Before the financial crisis, in the years 2006-2008, Brescia was among the cities with the highest economic performance in the country, resulting in a high capacity to include immigrants at the socioeconomic level. This latter was also confirmed by the fact that Brescia had the second-highest employment rate of immigrant workers in the country after Brescia (CNEL 2009, 30). Despite this, like many other cities in the North, the city was also characterized by a high number of undocumented immigrants working in the underground economy.

Raimondo D., an Italian man in his fifties and the Director of the patronage ACLI (Christian Association of Italian Workers [Associazioni Cristiane Lavoratori Italiani]), and one of the main social services agencies of Catholic orientation in the city, told me:

Over the years, politicians in Bergamo have preferred not to govern the phenomenon of immigration. They have observed it rather than governed it. There is a lack of coordination of the management of integration. The Right has always closed down any possible initiatives and projects. The left has always preferred not to expose itself. The left has known that it is in a territory where people vote right, so it did not want to be penalized. Thus, it remained silent. What is more, in any case, there was always the idea that the Catholic Church would have taken care of everything by dampening down the problems due to lack of governance. As a result, politicians have failed to govern the process. What is missing is a culture of integration!

(BG/N5)

Strong criticism of the blatant lack of intervention and coordination from above was shared unanimously by all the actors I interviewed in the city, irrespective of their political orientation. Some admitted that the administration of the left had been slightly more open than those of the right. Yet, the difference was seen as marginal by most interviews active in the realm of immigration in the city.

In the years following the financial crisis of 2008 and the rise of the Northern League, Bergamo was governed by a right-wing administration (2009-2014). Accordingly, in addition to a lack of relevant policies to promote the inclusion of immigrants, a significant security-focused approach emerged. The incumbent Mayor Franco Tentorio expressed this turn very clearly in his electoral program in the section titled "A Safer Bergamo." He argued that it was necessary to reinforce police interventions to ensure a safer city. ${ }^{6}$ This stance was restated in the official document of the administration once he took power. ${ }^{7}$

The strong presence of the Northern League in the administration contributed significantly to politicizing the issue of migration for electoral purposes and to shaping the attitude of more moderate politicians by raising the "electoral cost" of supporting pro-immigrant views (Caponio 2006, 104) for both left-wing and right-wing actors. On the one hand, the center-right parties adopted discourses 
more centered on security measures; on the other, the left-wing parties became even more detached from the issue of immigrant inclusion than in the past, for fear of losing votes by addressing the issue openly and courageously. In 2013, the administration refused to authorize the creation of a mosque, and the "threat" of Islam became a feature of the political debate (BG/N16). ${ }^{8}$

This political context also had implications for the work of other actors in the city. Zaccaria M., an Italian man in his fifties and the Head of the Department of Social Policy of Caritas, expressed several concerns about this shift:

With this last right-wing administration in power, politicians have now almost entirely submitted to the discourse of security. Their focus is on security, not integration. For this reason, the third sector has taken on the task of heavy substitution. This last administration has not done anything, except to use the subject for electoral purposes. Politics in Bergamo is not able to provide answers. Now, with the financial crisis, we are going backwards by twenty years.

(BG/N3)

Several interviewees were extremely worried about the financial crisis, which added a new burden to an already difficult situation, as there was a lack of funding. In addition, unemployment was affecting the situation of immigrants in the city.

Despite these difficulties, unlike the right-wing administration of Brescia (2008-2013), the Tentorio administration adopted a softer approach: it did not build its consensus exclusively around this issue and it did not explicitly target the immigrant community as a security problem (BG/N1 and BG/N5). Moreover, it never adopted openly xenophobic attitudes toward immigrants. In its official program, the administration also emphasized the importance of supporting projects of solidarity, including solidarity with the immigrant communities legally residing in the city (BG/N7).

Many interviewees suggested the presence of the Catholic Church represented a powerful deterrent for the local administration. The Church is de facto the provider of welfare services in Bergamo, so anti-immigrant discourse and attempts to impede immigrants from accessing services are often powerfully opposed. The strong presence of the Church even deters manifestations of political extremism. When it comes to basic social policies, the right-wing administrations dare not oppose the work of the Catholic Church, which dampens social and political conflicts. This was, for instance, the opinion of Giorgio B., the Director of Ruah Cooperative, one of the most important organizations of the Catholic Church offering services to vulnerable immigrants in Bergamo (BG/N4). Simultaneously, as Alessio O. explained to me: "The Church plays a crucial role in the processes of integration and against the spread of racism!" (BG/N7). When the Minister of Integration Cécile Kyenge went to Bergamo on July 11, 2013, "the local authority did not show up. However, out in front of the meeting there was the Archbishop of the Bergamo diocese to shake hands with the Minister.",

In the next section, I analyze the contradiction between the Catholic Church role in dampening social and political conflict and in promoting religious and 
cultural tolerance, and how this is combined with political opportunism and processes of othering of the immigrant communities, including silencing their voices in the political sphere.

\section{The local realm of immigration and the prevalence of the assistant approach}

\section{The uncontested power of the Catholic Church and the promotion of passive cohabitation}

As a result of the specific institutional context described earlier, over the years, the Catholic Church has become the dominant actor in the realm of immigration, in collaboration with other church-based organizations. The Church is very powerful and has developed robust infrastructures. Since the first arrival of immigrants in the 1980s, the diocese understood the significance that immigration would assume in the city and created bodies that could address the issues involved in welcoming new arrivals. Caritas created the Pastoral Migrant Office (Ufficio Pastorale dei Migranti) in 1993, while the Patronage San Vincenzo gave birth to the Cooperative Ruah in 1991, a non-profit organization devoted to delivering services to refugees and immigrants in vulnerable conditions. ${ }^{10}$ The main tasks performed by the Pastoral Migrant Office of Caritas are assistance and pastoral care for the Catholic communities, sensitizing the local population, and developing relations with the public and civil institutions. ${ }^{11}$ The Office had also established privileged relationships with some groups of Catholic immigrants. Those particularly close to the Church were the Bolivians, the Ukrainians, the Filipinos, the Francophone Africans, and some other Catholic communities (BG/N2).

At the time of my fieldwork, the Catholic Church was a central point of reference within the third sector, with its main operative bodies being Caritas and the Patronage San Vincenzo. As Zaccaria M., the Head of the Department of Social Policy of Caritas, explained: "The peculiarity of the Church in the city is that it assumes the role of coordinating the parishes and other church-based organizations. Outside the church-based organizations, there is little space for lay cooperatives and organizations" (BG/N3). As a matter of fact, the lay organizations are very few in number and have very little weight in the city and a crowding effect can be observed. ${ }^{12}$

This configuration of actors determines, in part, how immigrants are perceived and integrated in the city. What prevails is a dominant assistance approach to inclusion with almost no countervailing movement in the direction of other approaches. Zaccaria M., the Head of the Department of Social Policy of Caritas, for instance, critically reflected on the role of the Church:

The Church is attentive to the issue of poverty in general. On the issue of immigration, the diocese and the parishes have invested a great deal in the sectors of service and insertion into society. They focus on the delivery of low-threshold services and managing the social services that are devolved 
by the public sector. The powerful role of the Church in Bergamo is almost unique in the Italian context.

(BG/N3)

In addition to the main organizations listed earlier, various parishes across the province of Bergamo collaborate with Caritas in a large network to deliver services. Finally, there is also the voluntary sector that contributes to this network, and though not directly linked to the Church, it is also Catholic in its orientation. ${ }^{13}$ In line with the diocese, church-based organizations involved in the realm of immigration concentrate chiefly on the delivery of services.

As highlighted by most interviewees, the Church treats immigrants as "poor" and in need of assistance, which influences other actors and prompts them to adopt the same perspective. Salvatore E., the Director of the Agency for Integration, told me: "The Church must stop treating immigrants as the losers of the earth!" (BG/ N1). Similar criticisms emerged during my interviews with leading members of church-based organizations. Don Mariano M., an Italian priest working for the Caritas, stated: "Immigrants are always seen as people who need assistance, as if they were always in need" (BG/N2). Several interviewees explained that, as long as the Church limits the available modes of engagement, "it is impossible to promote a pluralistic and more inclusive view of society as well as autonomous participation by immigrants" (BG/N8).

The Church's construction of immigrants in need has inevitable practical consequences on the type of inclusion developed in the city. Don Mariano M. explained:

an approach of "giving and receiving" has been developed rather than a more balanced insertion into society. The process of integration is made easier by having an open attitude toward those who are in need. But the problem is that we have promoted passive cohabitation instead of a true relationship and integration of these people within the host society. The parishes should have developed a true openness toward the poor and thus towards immigrants. It is all about charity, assistance, but that has not entered into the social fabric. There is no dialogue that helps to value difference. If you are the mayor of your city, you look at the wellbeing of your city. If you have an association, you look at the interests of your association. There is not a real network. Here we are starting to create a network, but out of necessity and not because of a spontaneous initiative or spirit of collaboration.

(BG/N2)

Carlo F., an Italian man in his forties, and one of the main members of the PRC (Communist Refoundation Party) in charge of the immigration sector) explained that this approach erects barriers to immigrants' empowerment:

At the beginning of the processes of immigration, the Church was crucial in offering first aid, and they have created a net of reception co-financed by the administrations and the Lombardy region. However, one very negative 
aspect is that there is an immense problem of subsidiarity. The public procurements are privatized in favor of the Church and there is no space for lay organizations. We have many conflicts with the Church, simply because they do not think of immigrants' self-organization and political claims. They see immigrants as passive subjects. . . . What is more, they do not put their approach into question. They do not conceive that there is a subaltern process of integration [with respect to social and working rights].

(BG/N9)

The Church's approach has a major effect also on the civic and political participation of immigrants in the city. Piero P., an Italian man in his thirties and an activist of the radical left, noted:

This context has great implications for participation. The Church is a very specific container. There are few chances to develop any kind of participation whatsoever, whether by Italians or immigrants. If you want to do it, you do it at their rhythm, within their boundaries and rules.

(BG/N8)

Raimondo D., Director of the ACLI, explained that "the overwhelming presence of the Church prevents the growth of political self-awareness of individuals in the city." He used the example of Reggio Emilia to clarify how hard it was in Bergamo to move away from a service-oriented approach to inclusion and promote participation:

In comparison with Reggio Emilia, in Bergamo we are still in the Stone Age. Here there is assistance, but not true integration. The Church does a huge amount of work at the level of reception and welcoming. But assistance is a funnel. There is no way out. Precisely because there is a lack of other models of reference, the Church perpetuates a model of passive dependency of immigrants on welfare (modello assistentialista).

$(\mathrm{BG} / \mathrm{N} 5)^{14}$

Many interviewees, moreover, highlighted that behind the "humanistic reasons" of the Church-which promotes religious and cultural tolerance as well as an approach focused on taking care of the "poor"- this powerful actor has its own interests to defend: it gains enormous power and money from the issue of inclusion and has little incentive to act otherwise, since no one has the power to challenge its approach. For this reason, one of my interviewees, Damiano D., an Italian man in his twenties, and an independent activist of the radical left, stated: "the interest of the Church in the phenomenon of integration is also very instrumental" and "immigrants' integration serves the purpose of the Church in reinforcing and retaining its power in the city" (BG/N11). Many interviewees also expressed the view that, by occupying a great space in the political arena, the Church blocks other local actors (Italian and immigrant organizations alike) from developing and affirming themselves in the local arena. As will be seen in the 
following sections, the Church's assistance-based approach affects the approaches adopted by other local actors, including left-wing organizations such as the CGIL, which are strongly influenced both ideologically and logistically by the presence of the Church. Damaniano D., for instance, expressed frustration for the fact that the prevailing approach of the Church and other actors in Bergamo was "political opportunism" and self-conservation.

There is no incentive whatsoever to encourage participation and political rights promotion. ... When this participation from below arises, it is channeled elsewhere unless it is harmless or it brings personal advantages. In general, the approach is conservative, that is, linked to self-conservation. During the organization of the demonstration on March 1, 2010, the CISL said: "No flags!" Nonetheless, they would pull the strings of the entire organization of the event. The CISL was the one that coordinated the committee to further its own political interests, while it criticized the other organizations for doing so at the same time.

$(\mathrm{BG} / \mathrm{N} 11)$

This quote highlights the presence of powerful barriers to immigrants' activism. According to this and many other interviews, it is difficult in Bergamo to promote approaches to inclusion beyond assistance. In particular, the dominant presence of the Church and the Catholic organizations gave rise central dynamics within the realm of immigration, affecting the strategies and approaches of all the other actors. Finally, these dynamics resulted in the depoliticization of demands for immigrant rights coming from both immigrant activists themselves and from their supporters from the left.

\section{Traditional trade unions promoting the assistance approach}

Along with the Catholic Church, the two main trade unions, the CISL and CGIL, have been pivotal in shaping the local realm of immigration in the direction of service delivery. As Salvatore E., Director of the Agency for Integration, told me: "Traditional trade unions are places of protection, attentive allies of the Church for all that has to do with immigration. It is a particularity of the organizations, and in Bergamo they make a real difference" (BG/N1). Given its Catholic background, the CISL is the most important union in Bergamo. It has the greatest number of workers enrolled in the province-around 127,000 in 2012 compared with around 96,500 of the CGIL — and is among the most powerful territorial branches of the CISL in Italy. ${ }^{15}$ In 1989, the CISL opened the CISL-ANOLF, and since then it has provided service delivery. ${ }^{16}$ As in the rest of Italy, the CISL of Bergamo, through the CISL-ANOLF, promotes cultural projects and international cooperation. On the homepage of its official site, one can read that the CISL-ANOLF "works to create a society open to diversity, in a country ever more multiethnic and multicultural." The Association "fights against racism by promoting mutual knowledge and it works for equality among people, emphasizing rights, duties and mutual respect in a society founded on peaceful cohabitation, as outlined 
by the Italian Constitution" (CISL-ANOLF Bergamo). In terms of participation, the CISL-ANOLF works alongside the immigrant associations, offering space for their meetings, co-organizing cultural activities and events, and assisting them through training courses and technical support.

Notwithstanding its official declarations, however, the CISL has worked mainly on delivering services, rather than promoting other activities. As Angelo A., an Italian man in his forties, and Head of the office of CISL-ANOLF, admitted during our interview: "In the last ten years, the office diverted its attention to the helpdesk instead of doing social activities. They use the space we offer for personal purposes and opportunism" (BG/N6). My interview with Angelo A. confirmed what interviewees identified as problems with the trade union: the organization tends to assume that the role of an immigrant association is to offer mutual aid to compatriots, adding that the CISL adopted a paternalistic approach towards immigrant associations Angelo A. claims, "We work very well only with the immigrant associations with whom we have been working for decades" (BG/N6), but the associations he was talking about were precisely mono-national associations, which since the 1990s had been offering service delivery and help to the people of their "ethnic" community. Justified by paternalism, the CISL, in fact, interferes in the work of immigrant associations and leaves little space for associations to develop autonomously.

Interviewees outside the trade union identified other problems linked to the CISL. The first problem was an overwhelmingly assistance-based approach, which left very little space for immigrant workers linked to the CISL to develop trajectories of participation within the organization. At the time of my fieldwork, there was only one Senegalese union employee (who worked for the Office of the CISL-ANOLF) and one person of second-generation migrant background (the vice-president of the CISL-ANOLF). Additionally, with the exception of one person of Moroccan origin who left the organization in 2012, there were no people of foreign origin in positions of responsibility in the CISL. ${ }^{17}$

The left-wing trade union, the CGIL, is also very influential in the city, and many workers are members of its organization. ${ }^{18}$ Like other local branches in Italy, the CGIL in Bergamo offers its members protection in the workplace, mediation with institutions (e.g., police headquarters and the prefecture), and delivery of services through the Migrant Office to migrants in the city. In order to compete with the CISL in the unionization of immigrants, it expanded its range of services to include courses on acquiring citizenship, civic education, and support for centers that offer Italian language courses. ${ }^{19}$ The CGIL has also mobilized to fight against discrimination in the territory, and at the time of my fieldwork, it was attempting to expand its activities in this direction (like the CGIL of Brescia) (BG/N7).

Similar to the CISL, the CGIL of Bergamo had cultivated relationships with immigrant associations by helping them to formally organize, find space to meet, and pursue their activities. However, these attempts had little success and were eventually abandoned. Finally, at the time of my fieldwork, the CGIL was investing very little in the political rights promotion of immigrants, and it had little leverage in the mobilization of immigrants. According to Alessio O., an Italian man in his 
fifties, and the Head of the CGIL's migration policy, there were two main barriers to immigrants' participation in the city: institutional discrimination and racism. $\mathrm{He}$ clarified: "There are many barriers to participation in Bergamo .... the climate is very difficult . . . the greatest challenge is not work but the territory." He added:

Babacar S., one of the functionaries of the CGIL's FIOM, of Senegalese origin, was many times kept out of the factories because Italian workers did not let him in. The territory is intimidating for immigrants and prevents them from exposing themselves and making claims in the workplace. Thus, it is more difficult than elsewhere to find immigrants willing to invest time and energy in union activities.

(BG/N7)

There have been training courses for representatives in the workplace (delegates) and for leaders of different sectors of workers (functionaries). One important initiative is the More Colors (Più colori) course, which was promoted in 2007. "It was a course addressed to immigrants. The goal was to illustrate what is the union, what are rights and duties, and what is participation in Italy. The goal was to make them grow in the union" (BG/N7). Twelve delegates of different sectors participated in the training. After the course, three of them were selected to leave the factory and assume roles of responsibility: one man of Senegalese origin was in the sector of metalworkers (FIOM), and two other men (one of Moroccan and the other of Norwegian origin) were functionaries in the construction sector (FILLEA) (BG/N7). According to Alessio O., the CGIL's initiatives are important to counteract hostility and promote participation in the difficult context of Bergamo. Yet, he added that, "notwithstanding the attempts to promote participation by the CGIL, so far the results have been very limited" (BG/N7).

Other interviewees, including immigrants active in the union, explained that some of the problems faced by the CGIL were due to barriers to participation that were internal to the union. A deeper analysis of the practices put in place by the CGIL shows that the union acted very similarly to the Church and the CISL. Its approach to inclusion was strongly influenced by these powerful actors - hence the union did not consistently pursue an approach based on promoting political rights but instead focused on assisting immigrants (BG/N15). The CGIL thus had to be cautious in supporting immigrant claims, since, at the end of the day, it had to be accountable to its Italian members as well.

Thus, the CGIL was inclined to tone down its more political claims, adopting an assistance approach similar to the CISL and the Church. One of my key informants, Damiano D. highlighted:

Notwithstanding the CGIL's usual tendency to lay claims and politicize workers, it gave up its conflict with the CISL and toned down its claims in order to bring immigrants into its organization, in line with the general apolitical approach of other local actors in the city of Bergamo, and because of the challenging context 
beset by discrimination. This has resulted in the absence of substantial initiatives to promote the participation of people of foreign origin in the territory and a great investment instead in the delivery of services and assistance.

$(\mathrm{BG} / \mathrm{N} 11)$

The local context and its own internal divisions served to constrain the ability of the CGIL to invest consistently in the political rights promotion approach. At the individual level, immigrants who work in the union and have roles of responsibility (the functionaries) have few opportunities to really express their point of view in the union. Indeed, many interviewees expressed their concerns about significant levels of co-optation and tokenism. They believed that immigrants who had roles with responsibilities were being used by the union to bring other immigrants into the organization. Karim M., who had been part of the CGIL-FIOM for many years, brought up the example of Babacar S., one of the few functionaries of the CGIL of migrant background, to illustrate this point. Babacar C. was a man in his fifties, originally from Senegal, and the Functionary of the FIOM-CGIL and President of the Senegalese Association. According to Karim M.,

At the CGIL there are very few functionaries and they are not visible. Their role is often limited to the assistance of immigrants. At the FIOM they have a Senegalese, Babacar S. We have waged a war as immigrant workers to push for his election. Babacar S. should go along with the secretary, discuss the union and its political decisions, and take part in the decision process. Instead they use him to attract immigrants and to deliver services. The image is used to attract more people to enroll in the union.

$(\mathrm{BG} / \mathrm{N} 16)$

It is notable that, at the collective level, the CGIL of Bergamo never created a Migrant Coordination Organization - that is, an organization providing a platform for delegates of foreign origin to voice and make specific claims within the organization and the territory.

To add to these problems, Damiano D., the young activist of the radical left, explained that the CGIL dealt with immigrants in a paternalistic and instrumental way:

The CGIL responded to the aggressiveness of the CISL, which was aiming to take all the immigrants. The migrant coordination of the FIOM has been an answer to the aggressiveness of the CISL. It is about a dynamic of personal favors. The dynamic works this way: "I welcome you and help you, and you bring my flag." Political participation and activism are the opposite of this dynamic. In general, none of these organizations like having autonomous individuals in their organizations, because these people are believed to create problems. Here, assistance and paternalism are prevalent. For this reason, the dynamic of the personal relationship dominates.

(BG/N11) 
I asked my interviewees about the relationship between the CGIL and other local actors. They clarified that, for both ideological and practical reasons, the CGIL was more inclined to create alliances with the CISL and the church-based organizations than with left-wing or immigrant organizations. The CGIL in Bergamo was more moderate than the national organization and other territorial CGILs in Italy, which further bolstered its relationship with the CISL and the Church (BG/ N7). The other left-wing organizations in the city are very weak and do not play a significant role in the local political arena. For this reason, it was easier for the CGIL to build alliances or collaborations with the CISL and the Church, even if this meant moderating its claims and reducing its efforts in the direction of the political rights promotion approach.

\section{The weak role of left-wing organizations and the absence of political rights promotion}

With the exception of the CGIL, all left-wing actors in Bergamo have little political weight. Salvatore E., an Italian man in his fifties and the Director of the Agency for Integration, told me: "The more moderate left is completely absent. The Democratic Party does not get involved." During the local electoral campaign in 2009, the Democratic Party and minor left-wing parties supported the election of a few candidates of migrant background. However, these candidates did not succeed in the elections. ${ }^{20}$ The radical left is also very weak. As one of my key informants recounted: "both the radical left and the social center are marginal actors" (BG/ N1). Sergio S., and Italian man in his twenties and a member of the Asia-USB (Associazione inquilini e abitanti), the branch of the radical left trade union fighting for the right to housing), said: "There is a hole in the city. In Bergamo there is no radical organization able to fill the gaps left by local institutional actors" (BG/ N10). Most interviewees agreed that the Communist Refoundation Party was more important than any other left-wing organization, yet its role was marginal (BG/ N10; BG/N9; and BG/N16). Carlo F., the key reference in the city for the Communist Refoundation Party, who has worked with migrant communities for many years, explained that the weakness of the radical left and the Communist Refoundation Party at the national level reflected the situation in Bergamo as well:

Until very recently, the anti-racist movement still had a role in Italy. However, with the fall of the Prodi government in 2008, the movement in Bergamo melted away. Since then, there has not been an organization on the left able to stand up in the territory to give voice to immigrants. The big problem concerns the type of struggles we have been able to organize at the local level. Unfortunately, as an anti-racist movement we haven't been able to take root in the city. This means that we haven't been able to become a relevant mediator, capable of imposing ourselves as a relevant political subject and thus opening negotiations and challenging institutions.

(BG/N9) 
Hence, both moderate left-wing actors (the Democratic Party) and traditional radical left organizations (such as the Communist Refoundation Party and the social centers) were very weak in Bergamo and did not constitute a challenge to the dominant actors in the city (as was the case in Brescia, for instance; see Chapter 5). During the financial crisis, in 2009, the Communist Refoundation Party tried to organize around the issue of evictions by creating the Union for Tenants (Unione Inquilini). New radical left actors, such as the USB, have also organized around the problem of evictions since 2011, with its branch Asia-USB. However, members of these organizations admit that their ability to impose themselves as relevant actors and to mobilize immigrants in the city was extremely limited.

The local realm of immigration in Bergamo has been shaped largely by the predominance of an assistance approach to inclusion and a lack of relevant initiatives focusing on intercultural and political rights promotion approaches. Between the overwhelming power of the Church and its allies and the difficulties experienced by other local actors - lay NGOs and more radical left-wing political actors - it is difficult to institutionally intervene and challenge the predominant assistance approach. But how did this predominant approach result in a lack of alliances between pro-immigrant and immigrant organizations, creating barriers to participation for the city's immigrants? I argue that paternalism, processes of tokenism, and political opportunism prevented immigrant activists from developing meaningful participatory trajectories in the city and having a political voice.

\section{Lack of alliances, and high barriers to participation}

During my fieldwork in Bergamo, I contacted the main organizations in the city working on immigration. When I announced my intention to investigate the forms of immigrants' participation in the city, the response of most of my interviewees was unanimous. One of my key contacts in the city, when I asked him about immigrant activism in the city replied, with a sarcastic tone: "Political participation?! In Bergamo, political participation is equal to zero!” (BG/N6). Likewise, according to Angelo A., the person in charge of the CGIL-ANOLF, "to talk about political participation in Bergamo is like putting a roof on a house without a foundation." The findings presented in the previous chapters reveal, however, that political participation in different forms, although often stifled, was present in all the other cities studied. Thus, one can ask: what was the experience of immigrant activists mobilizing in the city? How did they perceive and act upon the lack of opportunities to participate in the city?

To search for answers for this striking lack of participation, through a snowball method and the use of explorative and ad hoc interviews, I contacted as many immigrants as possible who were or had been active in the world of associations, trade unions, and the radical left over the years. This search also confirmed that not only were there very few opportunities for immigrants to participate politically but those forms of engagement initiated by immigrants themselves at different points in time were discouraged or blocked. While the analysis of interviews 
with Italian local actors was particularly insightful to shed light on key local dynamics producing marginalization of immigrant activists in the city, the interviews with immigrant active in the city allowed to offer a better grasp of how they experienced this marginalization in their interactions with Italian actors.

\section{The de-politization of immigrant associations}

The few channels of participation in the city were civic channels, especially through immigrant associations. As one of my interviewees put it, "unless they create an association, immigrants in the city are practically invisible" (BG/N2). Through my research, I found out, however, that there were some political channels opened up by more radicalized left-wing actors, the FIOM-CGIL, the PRC, and newest left-wing actor, the USB. The latter had started gaining ground during the financial crisis around issues of housing rights, but it was still very weak.

What matters is not only the number of activities in which immigrants are involved but also how they are involved. While the Church admittedly offers space for immigrant associations to meet, the Church generally obstructs intercultural exchanges, and church-based organizations have mostly adopted a paternalistic approach vis-à-vis immigrant associations, instead of allowing them to grow and exchange freely with one another. As Giorgio B. (Director of Cooperative Ruah) told me: "Unfortunately, what the Church wants in Bergamo is folklore rather than real inclusion" (BG/N4), and, as Don Mariano M. explained, "for this reason, there has never been a qualitative leap here for immigrant associations" (BG/N2). He added that the Church's approach is always "organizing Feasts of the People and intercultural events, but there is no intention to promote any kind of claim beyond 'cultural' recognition of the presence of immigrants in the city" (BG/N2). Overall, its approach towards immigrant associations led the Church to not treat them as equal partners in the city and dissuaded them from contributing to the activities of the third sector. It is difficult for these associations to even develop an assistance approach, let alone a more activist profile.

Initiatives to encourage civic participation by immigrants through their associations have been supported by local actors since the end of the 1990s. In particular, the Agency for Integration, an entity created by a local administration at the provincial level, was created to encourage intercultural exchanges and the growth of immigrant associations (Cappiali 2018). Additionally, the diocese, church-based organizations, and traditional trade unions made efforts to give space to immigrant associations and to collaborate with them. Despite these efforts, however, my interviews with Italian local actors and immigrants active in the world of associations report that it was still very difficult to develop trajectories of participation in the city through immigrant associations. According to the Regional Observatory for Integration and Multi-ethnicity (Osservatorio Regionale per l'Integrazione e la Multietnicità), in 2013 there were around 45 formal immigrant associations in the province of Bergamo, of which only 17 were based in the city of Bergamo. This number was very small compared with other cities of the same size in Lombardy. ${ }^{21}$ In addition to the small number, these associations were mainly mono-cultural 
or mono-"ethnic." ${ }^{22}$ Finally, these associations had very little weight and limited influence in the city. Salvatore (Director of the Agency for Integration) told me: "Even if thinking about the world of associations can be positive, one needs to pose some questions. You have to ask yourself, 'what weight do they have?'" (BG/N1).

Among the barriers to participation were the following: (1) the absence of a space to meet (i.e., intercultural centers); (2) the interference of major local actors in the activities of the associations; and (3) the failure of immigrant associations to find common ground.

My interviewees observed that there were no opportunities at all to meet. There was no neutral space where immigrants could interact and associate (BG/N10). As observed in the case of Bologna, for instance, intercultural centers can represent neutral spaces where immigrant associations can develop their own organizations and meaningful trajectories of participation, both at the civic level and at the political level. As it will appear clearly in what follows, in Bergamo, these intercultural centers were lacking and the only spaces available for immigrant associations were managed by the Church, or in some cases the trade unions.

A second problem was that the associations were constructed as separate entities and were not able to build connections with one another. In the last ten years, different attempts were made by the Agency for Integration and the church-based organizations to promote participation with the associations, but the results were very poor. This created difficulties in creating exchanges and collaborations between the immigrant associations. Don Mariano confirmed this point: "The associations are very closed. They think of their own interests and it is almost impossible to create a network" (BG/N2). Salvatore E. told me: "In 2004, we organized a 'multicultural party' and there was not even a minimum of socialization among immigrants of different associations" (BG/N1). ${ }^{23}$ Priest Don Mariano's response was straightforward: "The truth is that these associations reflect the general context of Bergamo. We have attempted to encourage their networking for more than ten years. But it was a failure" (BG/N2). He added that this problem was closely related to the lack of a common, neutral space for immigrants to meet. A deeper look at the configuration of actors in the city reveals that notwithstanding the great efforts made by local actors to encourage immigrant associations and the interactions between immigrant associations, how local actors addressed the issue of participation diminished positive results.

A third issue, my interviewees explained, was that the main organizations in the city had tried to create at least two immigrant committees or events with immigrant associations without the active involvement of the associations themselves. "The creation of these organizations was decided by Caritas, the traditional trade unions and the radical left. Everyone was involved!" (BG/N11). According to this interviewee, it was problematic and "shameful" that these organizations interfered in the activities of immigrant organizations instead of letting them grow as autonomous entities (see also BG/N16).

During my fieldwork in Bergamo, I interviewed several members of immigrant associations and trade unions. All interviewees expressed frustrations concerning the limited opportunities for participation in the city and that it was very hard for immigrants to build meaningful trajectories. Interviews revolved mostly around 
the barriers they faced rather than the opportunities available to them. They spoke about, among others, the weakness of the immigrant associations, and how barriers to participation in the city substantially constrained their ability to shape the local realm of immigration and make rights claims.

Donkor A., an immigrant man from Ghana in his forties was the founder and former president of the Ghanaian Association. Born in Ghana in 1963, he arrived in Italy in 1982. At the time of the interview, he held a long permit of stay (Carta di Soggiorno). He created the association to provide help to his compatriots. $\mathrm{He}$ explained that while the association was very active in the 1990s when the Ghanaian community needed help, its existence was more formal than substantial. Since there was less need for them to help the community, the role of the association was less significant. He continued to run the association in case people of his community needed help. Donkor A. recognized that there were major barriers to participation in the city. The first major problem, he said, was the lack of a "neutral space" where associations could meet. He observed:

If associations want to get together, they have to pay for a place. The administration never gave it and some groups relied on the spaces offered by the trade unions. They were free, but people wouldn't want to come to the union to meet.

(BG/N14)

Another problem was the complete absence of funding for the associations. $\mathrm{He}$ also clarified that for immigrants, it was very hard to become visible in the city. When I asked him whether he and his compatriots participated in "A day without us," he told me that, as far as he knew, "it had not taken place" (BG/N14).

Sarah F., an Italian Moroccan woman, was the main representative of the Moroccan association Toubakal, created in 2005. Born in Morocco in 1977, she arrived in Italy with her family when she was eight years old. She had Italian citizenship, was married to an Italian citizen, and had two children. The main activities of her associations were teaching Arabic to the children of immigrants and volunteering for projects in the city, with the support of other organizations. With the CISL and the Cooperative Ruah, the association organized meetings about citizenship and access to rights for immigrants. ${ }^{24}$ She explained that, in Italy, people of foreign origin were not valued and that in this way the state and politicians were "ruining the new generations." She also added that immigrants' right to vote needed to be recognized since immigrants paid taxes. She added: "In this country, they stifle you, they don't allow you the possibility of doing anything. A young person in this country is like a flower that dries out." At the local level, she commented that the administrations in Bergamo "had just taken things away from us [the immigrants] and given nothing back. When we opened our school of Arabic in 2005, they promised things and they have done nothing." Sarah F. explained that she became active in the association Toubakal three years prior to our interview, in 2010. She spoke of her difficulties and the role of the Association in her life:

For me, working for the association is a breath of fresh air. You meet marvelous people. It is helping me at the emotional level. I had an accident seven 
years ago and now I am disabled. In Italy if you can't work, it means you don't exist. Italy abandons you. Being part of an association allows me to get more information. Otherwise, I would succumb.

(BG/N13)

Sarah F. expressed frustrations and deep concerns about the barriers to participation for immigrant associations in Bergamo. She observed that the lack of a "neutral space" where associations could meet was a major problem. She told me: "We are trying to get an autonomous space. We go to the Patronage of the diocese now, but to go there we pay. We need to have a space to do our activities."

The fact that there is not a center to meet discourages participation of immigrant associations and also more general exchanges between people of different origins. Immigrant associations have too little visibility. It is extremely hard work for us. Our association teaches Arabic, and this is why we are looked at with mistrust. They say that Italy is a free country, but before they give you anything, they take a lot. Our association stands alone. No one helps us or gives us funding.

(BG/N13)

I asked Sarah F. why teaching Arabic to their children was important for her community. She answered: "It is important for us to transmit our culture and language to our kids. There is nothing wrong with it!"

Daniela D. was the President of the association House of the Bolivians created in 1997. Born in Bolivia in 1980, she arrived in Brescia in 2004 without documents. She was regularized in 2005. In 2013, she became president of the sociocultural association House of the Bolivians (Casa dei Boliviani). ${ }^{25}$ Like Sarah F., Daniela D. was very critical of the national context. Even though they did not have her trust, she felt left-wing parties were closer to immigrants than right-wing parties, but that they did not have the courage to act. She admitted that "The left has used the theme of immigration in an instrumental way for many years. Now, they fear the right to vote. They know that not all immigrants vote left. For this reason, they fear it." Regarding the local context, Daniela D. recognized that Bergamo was a "closed city." She pointed out that "public institutions are very closed and do not stimulate participation by immigrants. Sometimes you find someone who helps you, but this is very rare." She told me that she decided to get involved because she has always been a very active person and she believed in the benefits of volunteering. She also clarified that she did not like to participate through demonstrations in the streets and thus she did not get involved in the activities organized by the Communist Refoundation Party. She highlighted:

It is already difficult to be accepted by people from Bergamo. The Bolivian community doesn't want to become visible that way. We prefer to make ourselves known differently. Through our cultural activities in the city, we want to become visible in a calm way. 
As far as participation in the immigrant associations was concerned, Daniela D. reported that the main obstacles to participation in the city, as for Donkor A. and Sarah F., was the lack of meeting space:

In Bergamo, there are no places where immigrants can meet. The authorities do not pay attention to this problem. We have asked them several times to create a center, but we never received a positive answer. For this reason, many immigrant associations resort to the spaces offered by the parishes. However, the problem here is that these places are for general use. One cannot rely on them. There are many associations that go there and often there is not enough space for everyone. Moreover, they have their own priorities and you have to adapt your schedules to theirs.

$(\mathrm{BG} / \mathrm{N} 12)$

I asked Daniela D. whether she thought this fact had implications for the forms of participation developed by immigrant associations. She answered:

It is difficult to mix with each other because we don't have the space. While there is no space to meet, everyone is on their own. Also, a center would be crucial to encourage participation by those who do not participate. The fact that we don't have a center discourages participation. What is more, since the places are very small, our activities are very limited. Also, there is no space to organize events with other groups. Thus, as you can understand, the lack of space is a huge problem because this fact does not allow us to develop meaningful trajectories in the city.

$(\mathrm{BG} / \mathrm{N} 12)$

According to Daniela D., it is also for this reason that most immigrant associations have not been able to move from their "small gardens" - that is, to go beyond their national affiliations and start to think of the city as a place to which immigrants themselves could contribute. She also noted that the Bolivian community in the city is in some ways an exception. The community is the most visible in the city and the Bolivian association is very active and able to develop activities in the city. Daniela observed that this community was more successful at promoting participation for several reasons: (1) they were greater in number than any other community; (2) they had the tendency to get involved in their country of origin; (3) they were supported by the Church of Bergamo because of their Catholic background; and finally (4) they were less stigmatized than other groups and thus able to build more significant trajectories of inclusion in the city. She suggested that, because of these advantages, the organization of Bolivians was able to make some additional steps to leave their "small gardens" and become more engaged in the city through civic activism. ${ }^{26}$

The three selected interviews presented earlier clearly show that, to a certain extent, civic participation of immigrant associations in Bergamo is possible but very difficult. Despite very different migratory trajectories, immigrant activists encountered 
very similar barriers to participation. As far as participation in the world of associations was concerned, the three interviewees noted that institutions did not offer incentives and that, in general, participation was not encouraged but obstructed. In particular, they said that the lack of neutral spaces to meet and develop autonomous trajectories of participation, as well as the lack of funding, were stifling. The greater visibility of the Bolivian association in comparison to others represents an exception that proves the rule. Precisely because of its strong link with the Church in the city and its Catholic background, the Bolivian association was able to "come out" and enhance its visibility. Finally, the interviewees expressed major concerns about the possibility of immigrant associations building significant trajectories of participation in the city. Even though they took action, it was very hard to move beyond the activities organized by the most powerful actors in the city.

\section{Obstructing political participation}

Political participation in Bergamo was even more complicated. Very few individuals participated in the few political channels opened in the city by left-wing actors. I interviewed three people who were considered by many actors in the city to be particularly active and who held roles (or had previously held roles) of responsibility in major organizations: Babacar S. (Senegal), a functionary of the FIOM-CGIL; Mohamed (Morocco), an active member of the CGIL-FIOM and of the Communist Refoundation Party; and Ayoub A. (Morocco), a member and representative of the USB, the new grassroots movement in the city. The fact that these people could be active in these organizations demonstrated that a minimal opening was present in the city and there were still opportunities, albeit limited ones, to get involved. However, the analysis of the interviews showed that their ability to act upon the opportunities open to them and to act as agents of change in the city was extremely limited.

Babacar S. was born in Senegal in 1967 and arrived in Italy in 1989. Between 1989 and 1991, he lived and worked in the South of Italy, and in 1991 he moved to Bergamo. At the time of the interview, he had just received his Italian citizenship. In 2007, he became a functionary of the FIOM-CGIL after being a delegate in the factory for more than ten years. He was very active in the world of immigrant associations and was the president of the Senegalese association. Many political forces, including the migrants active in the Communist Refoundation Party's migrant committee, pushed for his appointment to a position within the CGIL-FIOM.

Babacar S. admitted that the context of Bergamo was extremely closed and that this made it very difficult to participate. He told me that he considered himself one of the few "lucky immigrants": "I experienced distrust and closeness, but I have overcome them. Many people don't make it." He also told me that, compared to Reggio Emilia and Bologna, in terms of the integration and inclusion of immigrants:

Bergamo is more than 30 years behind. The responsibility is reciprocal: immigrants are responsible because they don't get involved, and politicians are responsible because there is a total absence of incentives. The context is 
very closed. Immigration in Lombardy in general and in Bergamo in particular is a taboo, because politicians think they will lose votes. They don't say it, but they think it. What is more, the Bossi-Fini Law is the worst law in Italy: its main goal is to squeeze immigrants until it is possible to throw them away.

(BG/N15)

Babacar S. expressed his fear about the changing attitudes of the left-wing party and trade unions in the Lombardy Region:

I fear that even the other politicians are adjusting to the Bossi-Fini Law. They say that it is not too bad after all. I say, instead, that it must be abolished. At the regional level in Lombardy, the Northern League is governing now. This means that everyone has to bow to them and to the Bossi-Fini Law. What is more, left-wing trade unions in Bergamo are affected by this, because many people who are enrolled in the CGIL vote for the Northern League. The union cannot avoid considering the point of view of its members.

$(\mathrm{BG} / \mathrm{N} 15)$

Karim M. was born in Morocco in 1959. He arrived in Italy in 1986 after many years of living in other countries. Like Babacar S., he was enrolled in the CGIL for many years and he was part of the CGIL-FIOM. In Morocco, he had been active in the communist movement when he was young, and he explained that, for him, it was obvious to get involved in left-wing organizations in the country of arrival. I asked him the second key immigrant activist in the city, about the reasons for his participation and why he chose to be active in the CGIL-FIOM and the PRC. Karim M. answered:

This country has given me a lot. I want to give back something in return. For this reason, if there is a chance to fight for the defense of rights, I get cracking. Politics has lost its credibility and this holds true for the Communist Refoundation Party too. The left has not understood that yet. I am not sure how it will be possible to win the trust of the people again. I chose the CGILFIOM and the PRC because I had a communist background, but also because my comrades encouraged me. . . . At that time there were strong relationships of friendship and a real involvement. I was at ease with them. I was a candidate with them several times, but, unfortunately, I was never elected. I have always been an activist within the CGIL-FIOM, but I have never been co-opted. I did not want to have a career inside the union. I wanted to be free. I have always had a good relationship with those who think like me.

$(\mathrm{BG} / \mathrm{N} 16)$

I asked Karim M. what comprised the main barriers to participation. He talked about the cultural barriers:

We are far behind in Italy in terms of participation. They still see you as a poor devil. Even our comrades [in the Communist Refoundation Party] have this 
attitude towards us, apart from those who have gone abroad, and thus understand a little bit more and change their attitude. Then they are different from the people who come from the valleys. In Northern Italy, there is lot of closure. There is no opening toward diversity, and this is a great problem.

I asked Karim M. to tell me about his allies, the PRC.

Teresa $C .:$ Does the Communist Refoundation Party act differently?

Karim M.: It is always the same thing . . I have talked about it to my comrades. We are very far from giving immigrants space in the Party. All these organizations use immigrants and they treat them as subordinated.

Teresa $C$.: What about the grassroots unions? Are they also using immigrants?

Karim M.: Grassroots unions have gained power by giving light to immigrants and making them very visible in their organization. However, in reality they adopt the process of co-optation like anybody else. They use the image of immigrants in their organization. In this way immigrants are swindled. It is the same for the case of Brescia, you know. Some people were active with the Communist Refoundation Party, then they became unionists. At that point they have been calmed down.

$(\mathrm{BG} / \mathrm{N} 16)$

Ayoub A. was born in Morocco in 1985 and arrived in Bergamo in 2004 to study at university. He was only 19 when he moved to Italy and his migration trajectory was more recent compared to that of Babacar S. and Karim M. During the time of the interview, Ayoub A. was active in the USB, the grassroots union of Bergamo, which had become more prominent during the financial crisis. He had several responsibilities in the trade union. He was in the national council, the regional coordination organization, and was in charge of the immigration sector in Bergamo. Ayoub A. observed that in 2004, right after his arrival in Italy, he became very active in a student association of Moroccans at the university. In 2009, he left the association to work with the USB. He met with the USB at the beginning of 2008 . He wanted to get involved in working with immigrants and dealing with problems linked to migration. In 2008, Ayoub A. participated in training to work with the union and since then he has been active on a voluntary basis.

Ayoub A. explained that the reason why he was active in the USB and not in the traditional trade unions was that "traditional unions fight for the cards [enrolment] rather than for the true things." He continued:

In the USB I feel at home. The USB is the only union that still makes claims and does not compromise! The other unions stipulate accords without representation. As an activist, I have never seen a traditional trade union in Italy that has raised its voice for the rights of immigrants. This should be the role of the unions: to represent workers and to fight for their rights! The USB has decided to adopt the following path: that the immigrant is first a worker and a person and then an immigrant. This choice of the USB shows that it is a real union.

(BG/N17) 


\section{Obstructing participation}

Ayoub A. added that, in addition to the experience with the union, he participated in the Migrant Committee created by the Communist Refoundation Party in 2005 to offer a platform for immigrants to have a voice in the city. He told me that "even though it lasted only a short time, it was fundamental for my formation."

All things considered, these three interviewees' perceptions of the city's participatory channels were that the barriers to political participation in Bergamo are greater than the opportunities. Additionally, the limited channels of participation restrict the possibility for them to affect local dynamics in significant ways. The interviewees acknowledged that a few channels had been opened in the city in the past, such as the Communist Refoundation Party's Migrant Committee. They explained that despite being very weak and short-lived, these platforms had been useful to acquire new skills and experience. However, they highlighted the predominant inability to build on the resources and skills of immigrants active in the city. The interviewees lamented the fact that these organizations used migrants just like other organizations in the city, adopted processes of co-optation, and overall did not promote the autonomy of people of migrant background within their organizations. These were important barriers impeding immigrant activists from contributing in a meaningful way to opening up channels of participation. These difficulties were present in all four cities examined in this study. However, in Bergamo, the limited channels of participation prevented activists of migrant background from using the channels available to them to construct their own trajectories in the city, and from challenging other actors' practices by making alliances with left-wing actors in the city. Finally, the experience of Ayoub A. from the USB suggests that the emergence of new left-wing actors might serve to open up new channels of participation in the city, thus potentially creating new possibilities for people of migrant background to build alliances and challenge the practices of other actors. However, in 2013, this new left-wing actor was still very weak and was far from representing a challenge to the dominant local actors. In this respect, the role of immigrants active in the organization was still far from representing a significant opening of the channels of participation in the city.

\section{Lessons from Bergamo}

At the beginning of this chapter, I described the involvement of local actors in Bergamo in the national mobilization of "A day without us," organized in 2010 in many cities across Italy. I observed that there was great difficulty in organizing the event for two reasons: (1) the conflicts between the main Christian Democratic organizations linked to the Catholic Church and main trade unions, and the antiracist movement of the more radicalized left; and (2) the limited involvement of immigrant communities. I used this example as an entry point to explain why and how local dynamics tend to obstruct immigrant activism. Drawing on the theoretical model presented in Chapter 2, I showed that, in the absence of institutional intervention in the local realm of immigration by local administrations, over the years local dynamics have been shaped by significant devolution to the Catholic Church. As a result, this actor gained greater power, becoming one of the most 
powerful local branches of the organization in Italy. In this unique context, the Catholic Church has no relevant challengers in the city and promotes a dominant assistance approach, by creating relevant structures to deliver services to vulnerable immigrants. Influenced by its approach, the most relevant trade union-the CISL-also focuses predominantly on service delivery to immigrants, neglecting almost entirely other approaches to inclusion. The other actors of the left are either too weak (as in the case of the Democratic Party and the radical left-wing organizations, including the Communist Refoundation Party) or unwilling to enter into conflict with the Church and the CISL (as in the case of the CGIL, which was defined by many actors in the city as a Christian Democratic actor, meaning conservative). Moreover, the newest left-wing actor in the city, the USB, though it gained ground during the financial crisis around issues of housing rights, is still a very weak actor. This specific configuration of local actors results in the development of a dominant assistance approach in the city, which prevents the creation of significant channels of participation for immigrants. In turn, the limited channels of participation have prevented most immigrant activists from developing meaningful participatory trajectories themselves. This situation is further complicated by the fact that immigrant associations are mostly constructed as separate entities, and processes of co-optation, tokenism, and ethnicization of these associations and of individual immigrants are particularly pronounced.

In Chapter 2, I explained that the assistance approach discourages active participation by people of migrant background, because it constructs immigrants as needy and passive subjects. The in-depth analysis of power dynamics in Bergamo informs why and how this approach results in powerful processes of othering of the immigrant population. It is undeniable that the Catholic Church has promoted more open views and tolerance in a city governed by the right-wing administration (2009-2014). However, a closer look at the role of this actor in shaping local dynamics reveals its ambivalent role. The analysis demonstrates that, by victimizing and constructing immigrants as people in need, the Catholic Church legitimizes its own work on immigration. In doing so, the organization seeks to justify its powerful structures to deliver services and, as a consequence, to reinforce and retain its undisputed power as the main political actor in the city. This is where, we can say, the Church's promotion of the assistance approach and resistance to other approaches represents an important strategic and discursive battle vis-àvis other competitors - Italian and immigrant groups alike- - who would like to emerge as alternative voices. Thus, the strong mechanisms of marginalization and the silencing of immigrants' voices can be interpreted not only as a means for the organization to justify the work it does on behalf of immigrants but also as a way of blocking immigrants' participatory claims, since the latter would express precisely the opposite of what the Church wants to convey - namely immigrants' passivity.

By way of conclusion, the analysis presented in this chapter sheds light on the potential role of the Catholic Church in preventing immigrants' social inclusion, beyond the case of Bergamo. Given the complex geographical variations of local actors among the cities studied here, the Catholic Church acts differently depending on its power and the actors it competes with in each context. In the case of 


\section{Obstructing participation}

Reggio Emilia, for instance, the Catholic Church helped the other local actors to promote the intercultural approach. However, it is undeniable that this organization tends to promote a specific view of immigrants in society, despite this geographical diversity. Humanistic reasons motivate the Church to take care of the "poor," inclining it to focus on assisting vulnerable immigrants - rather than including them. However, based on my comparative research on the four cities, and in light of the findings of other scholars (see, e.g., Campomori 2008; Mantovan 2007), I would suggest that the city of Bergamo should be considered more as a revealing window through which we might explore the role of the Church and its approach to inclusion, rather than an exception. What we need is more research into why and how the Catholic Church, in order to defend its political interests, may prevent immigrants' wider participation and inclusion in receiving societies. While the Church is often studied when it succeeds in promoting immigrant rights (see, e.g., its role in the movement for the mass regularization of sans-papiers in France and the United States: Nicholls and Uitermark 2016; Nicholls 2013; Siméant 1998; Heredia 2011; Marquardt et al. 2013), my analysis shows that more research is needed to uncover the Church's political interests when it comes to engaging with the issue of migration.

\section{Notes}

1 Some analyses of Bergamo have been published previously in Cappiali $(2018,2019)$. For a complete list of the interviews in Bergamo, see Appendix E.

2 For a complete list of the groups who participated in the Rete 28 Marzo, see the article by K. Manenti. "CGIL al Primo marzo: 'Regolarizzare tutti gli immigrati che lavorano." Eco di Bergamo. February 25, 2013. http://ecodibergamo.it/stories/Cronaca/119457_cgil/?attach_m\&object_id_from=119662\&content_type_from_id=11 (Accessed June 25, 2015).

3 "Rete 28 Marzo: No a strumentalizzazioni." Bergamonews.it. February 27, 2010. www. bergamonews.it/politica/rete-28-marzo-no-strumentalizzazioni (Accessed June 25, 2015).

4 "Bergamo. Manifestazione anti-razzista." March 1, 2010. www.alternainsieme.net/?p= 9346 (Accessed June 25, 2015).

5 R. Clemente. "Il primo marzo un presidio della CISL per i diritti degli immigrati." Eco di Bergamo. February 25, 2010. www.ecodibergamo.it/stories/Cronaca/119368_integrazione_il_1_marzo_presidio_per_le_vie_di_bergamo/(Accessed June 25, 2015).

6 See the document "Programma Elettorale" (Electoral Program). www.claudiasartirani. it/pdf/PROGRAMMA-ELETTORALE-LUNGO.pdf (Accessed June 15, 2015).

7 See the document "Comune di Bergamo. Linee programmatiche: Mandato 20092014," in particular pages $1-5$ in which the new administration presents its program by emphasizing its commitment to "solidarity and security." www.comune.bergamo.it/upload/bergamo_ecm8/notizie/Linee\%20programmatiche_12927_5327.pdf (Accessed June 15, 2015). The right-wing coalition entered into power on June 9, 2009, winning with a majority of $51,4 \%$. The People of Freedom got $26.2 \%$ of the vote (13 seats out of 38 ) and the Northern League $14.9 \%$ (7 seats). The coalition won a total of 35,160 votes or $51.4 \%$ (24 seats). The left-wing coalition gained 28,940 votes or $42.3 \%$ (14 seats), of which $21.5 \%$ (8 seats) were for the Democratic Party. www.repubblica.it/ speciale/2009/elezioni/comunali/bergamo.html (Accessed June 20, 2015).

8 On the refusal by the local administration of Bergamo to allow the opening of a mosque in Rongo (province of Bergamo) and the responses of the Islamic community 
which brought the case to court, see R. Clemente. "Moschea, il Comune in tribunale. La comunità islamica ricorre al Tar." L'Eco di Bergamo. April 16, 2013. www.ecodibergamo.it/stories/Cronaca/368291_moschea_il_comune_in_tribunale_la_comunit islamica_ricorre_al_tar/ (Accessed June 25, 2015).

9 On the event, see F. Paravisi. "Il ministro Kyenge: 'Il ghiaccio del razzismo a Bergamo si è sciolto'." Corriere delle sera, Bergamo. July 12, 2013. http://bergamo.corriere. it/bergamo/notizie/cronaca/13_luglio_12/razzismo-kyenge-ghiaccio-sciolto-ministrobergamo-2222115811650.shtml (Accessed June 25, 2015). R. Clemente. "Il ministro Kyenge a Bergamo. Provocazione leghista dal cielo.” Eco di Bergamo. July 11, 2013. www.ecodibergamo.it/stories/Cronaca/385859_copia_di_il_ministro_kyenge_in arrivo_a_precederla_tante_polemiche/ (Accessed June 25, 2015).

10 For the official site, see: www.cooperativaruah.it/ (Accessed June 25, 2015).

11 For a complete list of the activities promoted by the diocese, see the official site: www.diocesibg.it/home_page/curia/00000142_Segretariato_Migranti.html (Accessed June 25, 2015).

12 On the official site of the Province of Bergamo, on the page "World of associations and voluntary sector," under the heading "Immigration," one can read about the help desks present in the city and also find a list of conferences and training programs organized in the city on the subject of immigration. However, there is no information on the associations for and of immigrants that offer services or promote other activities. Also, among the conferences organized in the city, there is no allusion to activities that go beyond assisting immigrants to renew their permit of stay or similar issues linked to the renewal of documents. See page: www.provincia.bergamo.it/ProvBgSettori/provBgSettoriHomePageProcess.jsp?folderID=603 (Accessed June 25, 2015).

13 For a list of the numerous lay organizations of Catholic orientation, see: www.webdiocesi.chiesacattolica.it/pls/cci_dioc_new/v3_s2ew_consultazione.mostra_pagina?id_ pagina $=11739$ (Accessed June 25, 2015).

14 The complete quote deserves attention. It reads as follows:

In this respect, in comparison with Reggio Emilia, in Bergamo we are still in the Stone Age. Here there is assistance, but not true integration. In addition to the strong presence of the Northern League, the overwhelming presence of the Catholic Church represents a further impediment to the processes of political inclusion in Bergamo. Don't get me wrong! The Church has made a great effort to welcome people of foreign origin and has played a crucial role as a social dampener. Yet, the Church is not able to support socio-political subjectivity. There is no political subjectivity for the social operators that work within it. They have no clue of what political subjectivity is. There is widespread illiteracy when it comes to other cultures. The advantage of Reggio Emilia is that for many years there has been an alternative power to that of the Catholic Church. To talk about political subjectivity in the territories around Bergamo and in the city is extremely hard. In Reggio Emilia, there is more social cohesion and they have recognized diversity. Here in Bergamo, cohabitation will inevitably happen, but it will be the result of deep lacerations and conflicts. The Church does a huge amount of work at the level of reception and welcoming. But assistance is a funnel. There is no way out. Precisely because there is a lack of other models of reference, the Church perpetuates a model of passive dependency on welfare (modello assistentialista).

(BG/N5)

15 For the number of people enrolled, see: www.bergamo.cisl.it (Accessed June 25, 2015).

16 For a list of its activities, see the official site: www.cisl-bergamo.it/sistema-servizi/ anolf-associazione-nazionale-oltre-le-frontiere (Accessed June 25, 2015).

17 It is important to note that because of the lack of research on the topic, little is known about the number of representatives of people of foreign origin in the workplace. 


\section{Obstructing participation}

18 In 2013, the total number of people enrolled in the CGIL (retirees and active workers) was 96,168 and among them 48,421 were active workers and 10,074 immigrant workers. www.cgil.bergamo.it/images/documenti/DATI_TESSERAMENTO_2013.pdf (Accessed June 25, 2015).

19 On the services offered by the CGIL, see: www.cgil.bergamo.it/index.php/migranti (Accessed June 25, 2015). Note that there is very little information on the official site; I owe most of my information to my interviewees.

20 See R. Clemente. "I volti 'stranieri' candidati alle elezioni." L'Eco di Bergamo. May 21, 2009. www.ecodibergamo.it/stories/Cronaca/73038_i_volti_stranieri_candidati_alle_elezioni/ (Accessed June 25, 2015). Clemente notes that in 2009 there were six candidates of migrant background supported by left-wing parties for the local administration and one for the Province.

21 See the official site of the ORIM: www.orimregionelombardia.it/AM-risultatiRicerca. php?operatore $=$ AND \& chiaveRicerca $=\&$ provincia $=15 \&$ nazionalita $=0 \&$ obiettivi[ $]$ $=0$ \&obiettivi []$=0$ \&obiettivi []$=0$ \&obiettivi []$=0$ \&action=ricerca (Accessed June 25, 2015) and of the province of Bergamo: www.provincia.bergamo.it/cd_01/Istituzioni/ associazioni.htm (Accessed June 25, 2015).

22 This point was confirmed by Caselli and Grandi (2010). They explain that immigrant associations in Bergamo are weak and lack structure. What is more, these organizations do not mix with each other or with Italian organizations, and never participate in institutional negotiations or receive funding from institutions.

23 For the complete list of immigrant associations in the city, see: www.agenziaintegrazione.it/images/Documenti/ASSOCIAZIONIIMMIGRATIDICEMBRE2013.pdf

24 For a list of the activities of the association, see the official document: www.cooperativaruah.it/wp-content/uploads/2013/01/PROGRAMMA-SCUOLA-CITTADINANZA-2013.pdf (Accessed June 25, 2015).

25 See the official site: www.casadeiboliviani.altervista.org (Accessed June 25, 2015).

26 For the activity organized by the Bolivian association, see the official site: www. santalessandro.org/2014/05/italiani-boliviani-insieme-per-bergamo-tutti/ (Accessed June 25, 2015). See page of the diocese: www.santalessandro.org/2014/05/italianiboliviani-insieme-per-bergamo-tutti/ (Accessed June 25, 2015).

\section{References}

Campomori, Francesca. 2008. Immigrazione e cittadinza locale. La governance dell'integrazione in Italia. Rome: Carocci.

Caponio, Tiziana. 2006. Città italiane e immigrazione. Discorso pubblico e politiche a Milano, Bologna e Napoli. Bologna: Il Mulino.

Cappiali, Teresa M. 2018. "Local Actors and Approaches to Integration: What is their Impact on Immigrants' Political Participation?" In The Routledge Handbook on the Governance of Migration and Diversity in Cities, edited by Tiziana Caponio, Ricard Zapata-Barrero, and Peter Scholten, 136-149. New York: Routledge.

Cappiali, Teresa M. 2019. "Ideological Affiliations, Conflicts, and Competing Mobilization Frames: The Role of Pro-Immigrant Allies in Shaping Immigrant Struggles for Greater Rights." International Migration Review 53 (3): 869-899.

Caselli, Marco, and Francesco Grandi. 2010. "L'Associazionismo di Immigrati in Lombardia." In Dieci Anni di Immigrazione in Lombardia, edited by ISMU, 395-413. Milan: Fondazione ISMU.

CNEL(Consiglio Nazionale dell'Economia e del Lavoro). 2009. VII Rapporto. Indici di integrazione degli immmigrati in Italia. www.cnel.it/18?tag_area_tematica=35 (Accessed June 30, 2015). 
Heredia, Luisa L. 2011. "From Prayer to Protest: The Immigrant Rights Movement and the Catholic Church." In Rallying for Immigrant Rights: The Fight for Inclusion in 21st Century America, edited by Irene Bloemraad and Kim Voss, 101-122. Berkeley: University of California Press.

Istat. 2013. Gli stranieri al $15^{\circ}$ Censimento della Popolazione. www.istat.it/it/files/2013/12/ Notadiffusione_stranieri20122013.pdf

Mantovan, Claudia. 2007. Immigrazione e cittadinanza: Auto-organizzazione e partecipazione dei migranti in Italia. Milan: FrancoAngeli.

Marquardt, Marie-Friedmann, Susanna J. Snyder, and Manuel A. Vásquez. 2013. "Challenging Laws." In Constructing Immigrant "Illegality": Critiques, Experiences, and Responses, edited by Daniel Kanstroom and Cecilia Menjívar, 272-297. Cambridge: Cambridge University Press.

Nicholls, Walter J. 2013. "Making Undocumented Immigrants into a Legitimate Political Subject: Theoretical Observations from the United States and France." Theory, Culture \& Society 30 (3): 82-107.

Nicholls, Walter J., and Justus Uitermark. 2016. Cities and Social Movements: Immigrant Rights Activism in the US, France, and the Netherlands, 1970-2015. London: Wiley-Blackwell.

Siméant, Johanna. 1998. La cause des sans-papiers. Paris: Presses de Sciences po. 


\section{Political racialization and resistance}

To be in the margin is to be part of the whole but outside the main body.

... We could enter that world but we could not be there.

We had always to return to the margin, to cross the tracks

to shacks and abandoned houses on the edge of town.

(hooks 2015, xvii)

This chapter centers on immigrants' perceptions of, and responses to, opportunities and obstacles to participation imposed by pro-immigrant actors. The analysis critically deploys selected interviews with immigrant activists to investigate why and how pro-immigrant groups have produced immigrants' otherness through their discourses and practices - and how immigrant activists have resisted them. It demonstrates the range of perspectives among immigrant activists with respect to the meaning of inclusion and participation in the receiving society and their different strategies of resisting processes of racialization by pro-immigrant actors.

As I have shown in the previous empirical chapters, Italian left-wing organizations have offered several opportunities for participation to immigrants, through the creation of various civic and political channels, including platforms for discussion on issues of immigration (see also Kosic and Triandafyllidou 2005; Mantovan 2007). Organizations have mobilized together with immigrant activists to promote the improvement of immigrants' working and living conditions. Nevertheless, the previous empirical chapters also suggested that the mainstream left organizations - in particular, the Democratic Party and the main Italian trade union, the CGIL - have been vigorously criticized for failing to fully support the participation and equal inclusion of immigrants and migrant workers in all four cities. These actors were once considered immigrants' main allies. Yet, in more recent years, they have been accused of failing to support the claims of the most vulnerable immigrants (e.g., the undocumented) and to offer concrete responses to the rights of immigrants with "legal" status, working and living in Italy for many years (see also Cobbe and Grappi 2011; Cappiali 2016, 2017a; Mottura et al. 2010). Therefore, despite their efforts to create platforms for immigrants' participation, they had lost immigrants' trust, even in the cities of Reggio Emilia 
and Bologna where immigrant activists were more proactive and engaged than elsewhere.

This situation has led to a political vacuum, which the more radical left-wing groups have increasingly sought to fill (see also Cappiali 2016). In particular, the radical left organizations and grassroots trade unions (such as the USB and Cobas) have mobilized on issues of material justice, and have become especially active in spheres in which other left-wing actors have been absent, such as housing rights, the rights of refugees, and the working rights of undocumented immigrants (see also Oliveri 2015). Especially after the beginning of the financial crisis of 2008, these actors have gained the trust of many immigrants. Nonetheless, as I show in this chapter, some of the critiques addressed to mainstream political actors are also addressed to these radical left-wing organizations (see also Cappiali 2017a). ${ }^{1}$

This chapter will show that, despite their ideological differences and different approaches to inclusion, as identified in the previous chapters, most pro-immigrant actors in Italy have failed to acknowledge immigrant groups as equal partners. In so doing, they have reproduced what I have called political racialization (Cappiali 2017a, 971). This concept refers to a process whereby pro-immigrant actors, in order to legitimize their work on immigration, have partially included immigrants in the political sphere (e.g., by creating channels of participation and promoting their representation), but in a relationship of "ethnic" or "racial" subordination. The concept of political racialization highlights the mechanisms of "differential inclusion," or "subaltern inclusion" specifically in the political sphere (ibid.). In this chapter, I expand this insight by showing why and how political racialization is at work in the four selected cities, whatever important differences obtain between them. The comparative studies of the four cities, and the findings presented, reflect more deeply on the issue of power relations between immigrant activists and Italian pro-immigrant groups beyond specific local dynamics. To be in the margin, to repeat bell hooks, "is to be part of the whole but outside the main body" (hooks 2015, xvii). In the following, I will show that Italian actors activate disciplinary mechanisms of power in order to maintain the relationship of subordination of immigrant activists.

It is also important to highlight that, even though immigrant activists are often a minority within migrant communities (Martiniello 1993), they are not isolated individuals. Processes of othering and resistance link immigrant activists with the collective experiences of larger immigrant communities that they work with and for; this is epistemically important. Not only do they share experiences with their families and immigrant communities in the sending and receiving countries, as most immigrants do, but through their engagement, they devote countless time and energy to immigrant communities, listening to their suffering and needs, helping them to find solutions to their problems, and sensitizing them to their rights and duties. Thus, their experiences give them critical insights not only into their own situation, but into those of many immigrants they have encountered and helped during their journey and who are part of their networks and lives, and who have shaped their own understanding of structural injustice. 


\section{Seeing silencing and political racialization from immigrant activists' perspectives}

During one of our interviews, a main leftist activist of migrant origin in Italy told me:

For many years, left-wing organizations from the whole political spectrum have prevented us [immigrants] from having a say in the decisions taken on our behalf. As Gandhi said: "S/he who decides for you without you is against you!" You want to support immigrants' struggles for recognition? We have to construct the political itinerary together, because if we do not, we construct itineraries that represent a true regression with respect to immigrants' political participation and self-determination.

- Aboubakar Soumahoro man, Turin, Head coordinator of farm workers for the trade union USB

I interviewed Aboubakar Soumahoro twice, once in Reggio Emilia and once in Turin, both in 2013. He is an Italian citizen, first-generation immigrant, originally from Cote d'Ivoire. He is the head coordinator of farmworkers for USB, an independent trade union founded in 2010. He is also the author of Humanity in Revolt: Our Struggle for Work and the Right to Happiness (Soumahoro 2019; my translation). Today, he is one of the main figures of Italy's left-wing movements. ${ }^{2}$ I have explained elsewhere that Gandhi's expression was used by Aboubakar Soumahoro and many immigrant activists in Italy to criticize the tendency of their leftwing allies to talk on their behalf and prevent their self-determination, thereby creating obstacles to their ability to develop their own claims and strategies for greater recognition (Cappiali 2017a, 2019).

The problem identified by this immigrant interviewee eloquently summarizes the views of many other immigrant activists I met in the four cities studied here and elsewhere (Rome, Milan, and Turin). These views were expressed by individuals who had different identities based on, among other things, their gender, migration trajectory, and political affiliation. All immigrants I interviewed expressed the following view:

In Italy, we feel that there is no real platform where we can compete in the political arena as equals and make our own legitimate claims as individuals and as collective political forces. They always talk about us, but never truly with us!

- Babacar S. (M), Bergamo, Functionary of FIOM-CGIL and President of the Senegalese Association

The strong criticism directed toward pro-immigrant supporters by the immigrant activists I interviewed echoes analyses on the othering and silencing of racialized groups in other parts of the world. In the book Freedom is a Constant Struggle, while discussing agency and struggles, Angela Davis notes that:

Whenever you conceptualize social justice struggles, you will always defeat your own purpose if you cannot imagine the people around whom you are 
struggling as equal partners. Therefore, and this is one of the problems with all the reform movements, if you think of [them] simply as objects of charity of others, you defeat the purpose. ... You are constructing them as an inferior in the process of trying to defend their rights ... without their participation and without acknowledging them as equals, we are bound to fail.

(Davis 2016, 26; emphasis mine)

Likewise, in the article "Choosing the Margin as a Space of Radical Openness," bell hooks denounces the power dynamics and appropriation of the struggle of vulnerable groups by those who are in a stronger position:

No need to hear your voice when I can talk about you better than you can speak about yourself. No need to hear your voice. Only tell me about your pain. I want to know your story. And then I will tell it back to you in a new way. Tell it back to you in such a way that it has become mine, my own. Rewriting you, I write myself anew. I am still author, authority. I am still [the] colonizer, the speaking subject, and you are now at the center of my talk.

(hooks 1989, 22)

Davis's reflections on unequal treatment undertaken by political actors who mobilize in solidarity with vulnerable groups, and hooks' point on the re-appropriation ("re-writing") of the story of the Others, both speak to and expose the dynamics of silencing between two groups who are in an asymmetrical power relation.

I have not met a single immigrant activist who did not express some degree of resentment and frustration about their pro-immigrant supporters' unequal treatment. In particular, they conveyed a strong desire to expose and challenge the systematic marginalization and re-appropriation of their own suffering and political claims on the part of Italian actors who mobilized in support of their struggles for greater rights. These voices recounted the will to speak back to power and to reframe the debate about their suffering on their own terms.

Another remarkable aspect is that the same awareness about processes of othering was not found among the "white" pro-immigrant actors I interviewed. In some cases, Italian activists who were closer to immigrants and particularly interested in improving their rights had a better awareness of this problem. As I also showed in the previous empirical chapters, many offered a range of critiques of the paternalism and unequal treatment of their own organizations (e.g., political parties, trade unions, grassroots organizations) in the four cities analyzed.

Giovanni Mottura, an Italian expert on the role of trade unions in including immigrant workers, could see the power dynamics within the left. During our interview pointed to the left's failure to treat immigrants as equals:

The truth is that even though the left was more open, in the end they did not understand much. While those of the Communist Refoundation Party and the radical left organizations befriended the immigrants and treated them as equal partners, as normal people, the other left-wing political parties (the PCI and the PD, for instance) were not treating them equally. 


\section{4}

This interviewee pointed out that the radical left parties and grassroots organizations tended to have a more inclusive approach to immigrants and to treat them as equal partners than more established left-wing parties. Yet, beyond these exceptions, he added, all left-wing actors shared "a big problem":

In substance . . It was never about trying to build something new together. It was about an instrumental use of the people of migrant background. It was not always conscious. They used immigrants to bring forth their own ideas, their own political claims... This is what it has been missing until today: The awareness that these interactions and exchanges should change everything.

(Interview in Bologna, June 26, 2014) (previously quoted in Cappiali 2017b)

This quote highlights that Italian organizations resisted change. According to this interviewee, while their claims were about promoting immigrants' rights, they used immigrants' cause instrumentally and made very little effort to "listen to" and "act on" the political demands and perspectives of immigrant activists.

During my research, the deeper criticism of the left-wing actors always came from immigrant activists, who were directly affected by power dynamics and processes of othering. From an epistemic point of view, this comes as no surprise. Narayan (1989), an influential non-Western feminist scholar, calls this phenomenon "epistemic advantage." She argues that, while it is possible for non-members of marginalized groups to understand systems of oppression/domination, it is both "easier and more likely for the oppressed to have critical insights into the conditions of their own oppression than it is for those who live outside these structures" $(1989,264$; emphasis mine). In the same spirit, hooks (1989) calls this approach "epistemology of marginality." She argues that marginality can be seen as the central location for the production of a counter-hegemonic discourse. This is not just found in words but is embedded in individuals and communities, shaping the ways in which they live and experience the world.

Together with Narayan and hooks, critical social theorists (e.g., race, feminist, intersectional, and post-colonial scholars) offer a unique lens through which to understand processes of othering and the resistance of immigrants and racialized groups via their own perspectives and lived experiences (see, e.g., Bilge and Collins 2018; Sager 2011; Mulinari 2015). According to this research, bringing in the point of view of oppressed groups (whose voices have often been sidelined or silenced) improves knowledge production in social science. In turn, this helps to represent the views and experiences of previously marginalized and silenced voices thereby resulting in "stronger objectivity" to such research (Harding 1992).

Immigrants' points of view are of crucial importance because the migration literature often victimizes immigrants and considers them as objects of policy and interventions (Però and Solomos 2010) thereby reproducing misleading assumptions about their passive role in society (Cappiali 2017a). Bringing in immigrants' own perspectives is also necessary since, as the most advanced research on racism shows, exclusion and systemic racism are most visible to those who experience such phenomena, while the latter are often made invisible to groups (e.g., whites) who benefit from the status quo (Lamont et al. 2017; Essed 1991; Lépinard 2020). 
This epistemology not only helps us understand immigrants' perspectives and lived experiences but also improves our knowledge of the specific function of discrimination and racism on the part of the left, a topic often understudied in the literature of migration and racism. As will become clear in this chapter, immigrant activists' perspectives are insightful and valuable because they enable us to theorize power from below - to understand and theorize the resistance and agency of marginalized groups (Bilge and Collins 2018; Sager 2011; Mulinari 2015), in particular why and how these groups speak back to power (hooks 1989). Following Bilge and Collins (2018, 22), I define power in Foucauldian terms, namely as a disciplinary power that constitutes subjects' lives rendering some social and political pathways available while precluding others. In this respect, responses and strategies by immigrant activists are embedded in complex networks of interactions with other groups in society, including pro-immigrant groups, who tend to appropriate their struggles (see also Cappiali 2017a). As Foucault put it, "Where there is power, there is always resistance, and yet, or rather consequently, this resistance is never in a position of exteriority in relation to power" $(1978,95$, quoted in Nicholls and Uitermark 2016, 559).

Using selected interviews with immigrant activists, I analyze the experience of immigrants and how they expose and challenge the mechanisms and dynamics of power between them and their pro-immigrant supporters. Such dynamics are often overlooked by many academics and European anti-racist movements alike (Lentin 2004; Evans and Lépinard 2020). Through the epistemic approach of the critical theories outlined here, I illustrate why and how immigrant activists expose processes of othering and unequal treatment. I also explicate why these processes are at work, and, in turn, why immigrant activists decide to resist them in the way that they do.

\section{Exposing political racialization in Italy: The "consumer paradigm"}

\section{Resisting local voting rights}

The first remarkable criticism was that the left lacked political courage. A member of the Democratic Party in Reggio Emilia and the city councilor of Quattro Castella (Province of RE), elaborated on this point:

To take up the theme of immigrants' inclusion, in the specific case of Italy, means first of all to be accused of defending the thieves, the clandestini, the colf and badanti ... Moreover, why should one try to eradicate a cultural inheritance if there is no gain in doing so?! Immigrants do not vote. To eradicate cultural prejudice takes an enormous amount of time and energy, but politics does not have time. Moreover, the work doesn't pay you back. Unfortunately, if we continue in this direction, the cultural prejudices will never be overcome.

- Reda B., man, Reggio Emilia, City councilor of Quattro Castella (Province of RE) and in charge of the Forum of the Democratic Party 
As such, this lack of courage was seen by this interviewee as an unwillingness to truly fight for immigrants' rights and the improvement of their conditions, as this proved too costly for left-wing actors. More specifically, immigrant activists felt "used" and "exploited." It was repeatedly emphasized that the left endeavored to keep immigrants' voices marginal, not least by resisting the demand to grant local voting rights. Most of the immigrant activists I interviewed considered this to be a key problem, as it represented the most obvious example of how the Democratic Party and other left organizations obstructed immigrants' political voice.

The lack of voting rights hindered the conditions for immigrants to have any effective power in the political arena. Resistance to local voting rights prevented immigrants from having a viable channel through which to convey their demands, to speak for themselves, and to become autonomous. According to several immigrant activists, the left knew that voting rights would shift the power relations and prevent immigrants from being merely used for political ends. For this reason, resistance to local voting rights was seen as exposing the left's instrumental use of the immigrants' cause more generally. Two members of the Forum of Immigration of the Democratic Party, respectively, from Brescia and Bologna, expressed similar criticism.

In the last twenty years in Italy, there is a political side that defends immigrants [the left] and a side that is against them [the right]. In spite of their differences, both sides impede immigrants from speaking for themselves ... [T] here is no representation! Immigrants are used by politics: the right refuses them and the left exploits them. The problem is that we do not have the power to negotiate politically, because we do not have the numbers. Someone wants us divided. Not those who refuse us, but those who exploit us. The left fears the right to vote, because that will allow us to become autonomous.

- Bujar A., man, Brescia, Member of the Forum of the Democratic Party

The truth is that there is a real fear that people [immigrants] will become autonomous. In this context, it is obvious that immigrants do not participate and do not trust anybody. The Democratic Party in particular pretends that it is doing something, but it is not doing anything at all. The principle is divide et impera [divide and rule]. The left-wing party knows that the right to vote can change everything, but since the fall of left-wing Government led by Romani Prodi in 2008 there is no majority in Italy that acts in favor of immigrants.

—Makham M., man, Bologna, Member of the Forum of the Democratic Party

It is remarkable that such criticism was addressed to radical left organizations as well, who also seemed reluctant to support the right to vote. A third immigrant activist from Brescia, also active in the Forum of the Democratic Party, told me:

Why do the radical left-wing organizations never talk about the right to vote? This is called duplicity, pure propaganda. They are just like the Northern 
League. The latter attacks us, but the radical left is like a traitor friend. With the Northern League you can at least fight back. The radical left preaches, but they don't help you succeed. Why don't they talk of the right to vote? And the Democratic Party, why don't they talk about the Bossi-Fini Law? The left knows that not all immigrants are adherents of the left. Many immigrants are confused about their political orientation ... The left knows that if immigrants could vote, many would not vote for them.

-Fatima N., woman, Brescia, Member of the Forum of the Democratic Party

These three quotes show a consistent criticism of the left. The three cases presented here are only some examples of similar criticism I could observe during most of my interviews with immigrant activists. These were also persistent across cities.

Most of my interviewees pointed out that the left's reluctance to introduce local voting rights and the instrumental use of immigration issues fostered a degree of political apathy among the migrant population, with a subsequent sense of alienation and social and cultural marginalization. Other factors were also mentioned, of course, as in Italy, political parties are not even trusted by the Italian population more generally. Bujar A. told me: "Many people of migrant background feel they are blackmailed. We [immigrants] distance ourselves from politics day after day. Just like many Italians, we believe that politicians are corrupt."

We have lost many years and now the political apathy of immigrants is a consolidated practice. .. . The left should have promoted local voting rights to encourage a sense of belonging at the local level. Because this has not been done, the result is a complete disinterest in politics and more in general the withdrawal of many migrant communities from the broader Italian society.

- Adelina Y., woman, Bologna, President of AMISS, Association of Cultural Mediators

This reflection is relevant, as it points out to a major problem, also identified in the literature on immigrants' political participation in society: immigrants' lack of interest in political participation. This interviewee is suggesting another recurrent theme found in the research: the mistrust towards potential allies can represent a crucial factor in explaining why immigrants' withdraw from mainstream politics.

\section{Disempowering platforms, fora, and immigrant organizations}

Resistance to local voting rights was considered to be one of many strategies used by the mainstream left (and especially political parties) to silence immigrants' voices. In the same vein, the platforms and fora created by the left to give immigrants opportunities to self-organize were seen more as a façade than any genuine opportunity for them to discuss, on an equal footing, the matters that concerned them. Moreover, it was argued that, when immigrants took autonomous initiatives and put forth their demands, they were systematically disempowered. Many 
examples were offered to illustrate this point. For instance, recalling the experience of the Metropolitan Forum of Bologna (see Chapter 4), the Assessor of San Lazzaro (Province of BO) and in charge of the Forum of the Democratic Party, told me that at the time of his presidency between 2005 and 2007, the Forum was constructing its itinerary in the city by building relationships with the general population and also with institutions. The Forum organized political struggles, by denouncing, for instance, the conditions of migrant children in the schools and the increase in racism on the part of Italian parents who did not want foreign people in the same class as their own children. Donald R. commented:

This of course bothered some organizations in the city and in particular [the] trade unions ... They want to have the exclusive discourse on migration issues and when they found some other protagonists who talked about things that concerned them, this situation floored the powerful left-wing actors in the city.

Though he acknowledged the role of internal conflicts between immigrant associations in contributing to the failure of the Metropolitan Forum, he also noted the critical role of left-wing actors, especially the political parties and trade unions, in putting pressures that led to the failure of the Metropolitan Forum. It is remarkable that all these actors of the left — moderate and radical alike — were also objects of his criticism.

The Forum died because of the people [members of immigrant associations] of the Forum, who were fighting all the time. But it died also because of the trade unions that worked in the territory. They could not put up with the fact that people who were the objects of their discourses were becoming political subjects, able to carry out their own aspirations and requests. This obviously created some problems for them: they could not tolerate the requests of immigrants who could alone present their own problems. They thought it was better for them to represent us... The hardest shots that I received in the world of politics did not come from migrants or from the xenophobic right, but from the extreme left and the labor unions which, by definition (and also by their own definition), are said to be close to immigrants. Each one of our public appearances had to be organized by them, in support of greater visibility for their work on immigration, as this was their exclusive subject (emphasis of the interviewee).

-Donald R., man, Bologna, Assessor of San Lazzaro (Province of BO) and in charge of the Forum of the Democratic Party

Donald R.'s criticism reveals some ways in which the left actors in Bologna blocked immigrants' initiatives in the city. He was not bothered by political conflict per se. He recognized that "politics is a combative field" and conflicts were part of the game. What bothered him, instead, was the reappropriation of the left of the immigrants' cause to advance their agenda. 
Donald R. highlighted that internal struggles within the left also played a role. In turn, this affected immigrant activists as well. At the time, the CGIL, the Communist Refounding Party, and the Democrats of the Left (Democratici di Sinistra) did not get along well, and since he "had been starting to be politically active with the Democrats of the Left, the CGIL was not very happy."

The CGIL saw me and said: "Who is he? All immigrants have to come to do the documents in our offices, but we haven't seen him before!" They didn't see me because I used to do my documents alone, and since they are used to thinking that immigrants are people who are not able to do anything, they were sorrowful.

-Donald R., man, Bologna, Assessor of San Lazzaro,

Democratic Party

During my fieldwork, the Metropolitan Forum was still in place, but I was informed by many actors in the city that it was "a ghost of itself," as Makham M., a Member of the Forum of the Democratic Party told me (BO/N20). Commenting on this point, Irene A., the President of the Federation of Filipino Associations of Bologna, told me: "The Forum had become what the administrations of Bologna wanted it to be-disempowered"

The interview with Donald R. highlights an important aspect, which was shared by other activists as well: the criticism reflected strong resentment for obstacles posed not only to greater representation of the immigrant communities but also to their own personal trajectory of upward mobility with left-wing organizations. Like Donald R., several immigrant interviewees shared experiences of obstacles they encounter in their attempt to create a political career in Italy with the leftwing organizations.

It is also remarkable the criticism of the Provincial Forum of Immigration created by the Democratic Party since 2011 across the country. The Forum was created by a current within the Party that was more open to immigration issues. It aimed to promote a dialogue within the political party. ${ }^{3}$ Despite the effort, however, the Forum was also criticized for having a role of façade:

The Forum, like other things [promoted by pro-immigrant actors], has a role of a façade. The person in charge of the Forum has little power and cannot make the voice of the Forum heard. The power is extremely limited and we can take very few decisions. Some of the Italians involved are interested in the issue of immigration. However, many are put there when they [the Party] do not know where to send them.

-Fatima N., woman, Brescia, Member of the Forum of the Democratic Party

The fact that the leadership of the local Fora is given to people who have a marginal position in the party is significant. It suggests a lack of interest in the party to open up a space to address immigration issues in a substantial way. 
In another interview from Bologna, Irene A, the President of the Federation of Filipino Associations and elected member of the Council of Foreign Citizens and Stateless People in the Province of Bologna, believed that the mechanism of disempowerment was particularly visible in how immigrant organizations were marginalized by the left.

Teresa $C$. .: Research on immigrant associations in Italy suggests that there is a crowding-out effect. According to this hypothesis, immigrant associations are less visible in Italy, because they have to compete with stronger Italian organizations, who already do important work on immigration. ${ }^{4}$ Based on your extensive experience working in the world of associations in Bologna, what is your understanding of this matter?

Irene A.: Immigrant associations are not always as weak as they are described. To me, there are immigrant associations that are able to carry out the responsibilities that are given to the Italian associations. Many migrants like me believe that the immigrant associations can do a lot, in some cases better than the Italian associations. I am convinced that this is the case. The real problem is that the Italian associations, political parties, and main trade unions have important interests to defend. It is mainly about economic interests. Some of them believe in what they do, but then they lose themselves because of their interests. Often what they want is visibility. The emergence and empowerment of immigrant associations creates problems for them.

-Irene A., woman, Bologna, President of the Federation of Filipino Associations of Bologna and elected member of the Council of Foreign Citizens and Stateless People in the Province of Bologna

In this and other interviews, it appeared clear that the immigrant associations were often constructed as weak, even when they could show that they were able to bring forth their instances. The quote with Irene A. is particularly important, because she was the representative of one of the most important associations in the city. The Filipino community is particularly strong in Bologna and over the years it has built important networks and associations. It is striking to observe how this immigrant activist talks about how the visibility of immigrant associations is not welcomed, and it is disciplined as this would make the Italian associations working in the realm of immigration less relevant.

The radical left was not spared from similar criticism. In 2001, a group of immigrant activists created a national organization, the Immigrant Committee of Italy (Comitato Immigrati d'Italia), in opposition to the Table of Migrants of the Social Forum created by the radical left the same year (cf. Chapter 1). I interviewed the two immigrant activists (one based in Milan and the other in Turin) who created the organization. They told me that the silencing of their voices by the radical left was the main reason why they created the Immigrant Committee. It was about an organization that reunited many immigrant grassroots activists and unionists who were tired of being silenced by the radical left organizations. They also believed 
that what bothered these organizations was the attempts for immigrants to express their voices. Immigrant self-determination, according to these interviewees, was threatening for the radical left, as its power relied on taking decisions on behalf of immigrants. It is remarkable, that just like the Metropolitan Forum in Bologna, in addition to internal divisions between immigrant groups, they explained, the pressure of the Italian organizations - radical left organizations and trade unionshastened the organization's demise just two years after its creation.

The processes described so far reveal the powerful mechanisms that silence immigrant activists and demands. The left's re-appropriation of immigrants' cause is about a struggle for legitimacy over the discourses around "who are the immigrants" and "what are their needs" and, consequently, who is legitimized to speak for and represent them. In this respect, several interviewees emphasized the existence of a "consumer paradigm" or a "paradigm of dependence and subordination" of immigrants, which the left helps to reproduce, alongside other actors, such as the Catholic Church (see also Cappiali 2017a). Moreover, another crucial aspect is that, the different approaches to inclusion these actors adopt, are not only based on different ideological stands; they are also an integral part of the struggle for legitimacy of these actors. As mentioned in previous chapters, the left actors have promoted two types of approaches - intercultural and political rights promotion. The first is mostly encouraged by the institutional left and moderate lay organizations; The second by political parties, trade unions, and the radical left. The first focuses on various aspects of the inclusion of immigrants, considered as would-be citizens. The second centers on the rights of immigrants to promote their claims via different political channels. Both approaches challenge the assistant approach, which tends to victimize immigrants and subordinate them to the paradigm of giver-receiver.

While this mechanism of subordination is more obvious among actors who promote the assistant approach such as the Catholic Church (as explained in Chapters 5 and 6 for the cases of Brescia and Bergamo) in this chapter it appears more obvious how marginalization and subordination is also produced by actors who adopt the intercultural approach and the political rights promotion approach. The analysis of this chapter allows to take a closer look at how the two approaches to inclusion promoted by the left - intercultural and political rights promotion - can serve a similar purpose than the assistant approach, which they claim to challenge. This purpose is to gain and maintain "visibility" regarding the work they do in the realm of immigration. This is significant because left-wing organizations compete with other powerful actors, such as the Church, and among each other, around who has the legitimacy to talk about immigration topics and who gets the resources (including finances) to do so. This competition reflects their relationships with immigrants, and their interest in promoting the visibility of the immigrant activists who fit in their narrative, rather than those who may challenge it.

Although the analysis of this chapter focuses primarily on left-wing actors, it is important to note that the case of Bergamo presented in Chapter 6 revealed already that processes of othering are heavily produced by the Catholic Church as well. The findings revealed that the different expressions of political racialization-for example, unequal treatment, co-optation, the silencing of immigrants' voices, 
depoliticization of immigrant organizations - were even more blatant in the stronghold of the Catholic Church than in any other cities covered in this study.

Donald R. explain this point by revealing how the "immigrants" in Italy are constructed by all the Italian organizations, and despite their different ideologies, as a "consumers," as people "to be served":

This is the country of mediation: do you have a problem?! It is the Italian organizations [such as the Catholic Church, trade unions, NGOs] that must deal with your problem. And you remain a "third" party, as if the thing did not concern you. When immigrants enter Italy, they are wedged in at the interior of an enormous paradigm of which the left is also an important actor. In this paradigm the immigrant is represented as a consumer, as someone who has to be served, and as a passive subject. The discourse of the left contributes to reproducing and reinforcing this discourse. You are part of their discourse, because this legitimates those who talk on your behalf. The left doesn't want immigrants to become autonomous, because they want you to go to them and have them do things for you (emphasis mine).

-Donald R., man, Bologna, Assessor of San Lazzaro, Democratic Party

This quote, coupled with previous comments on the disempowerment of immigrants' platforms and fora, speaks to how the left appropriates and instrumentalizes the cause of immigrants for political ends. It echoes bell hooks' remark about appropriation and re-writing:

No need to hear your voice when I can talk about you better than you can speak about yourself . . . Re-writing you, I write myself anew. I am still author, authority. I am still [the] colonizer, the speaking subject, and you are now at the center of my talk.

(hooks 1989, 22)

In this way, the left legitimizes its own work on immigration and yet silences immigrants and constructs them as objects of its discourse. This appropriation (or "re-writing"), therefore, goes hand-in-hand with the left's inferiorization and subordination of immigrants. As Donald R. aptly recalled: "There is a saying, 'The hand that gives is always above the one that receives'." In the context of migration in Italy, this process of appropriation by the left produces immigrants' racialization via the perpetuation of the consumer paradigm. Here I understand racialization, as bell hooks puts it, as being "in the margin," as being "part of the whole but outside the main body" (hooks 2015, xvii).

\section{Lack of meaningful representation and unequal treatment}

The "consumer paradigm" allows us to understand why opportunities for democratic representation are particularly restrained within left-wing organizations. Immigrant activists spoke of powerful structural barriers. They noted that these 
barriers worked to include immigrants in a racialized position, as immigrant representatives were placed in a situation of differential inclusion within left-wing organizations. This relation of power persists precisely because immigrant activists are constructed as "outsiders" or inferior Others, in a binary narrative that (re-)produces a distinction between "us" and "them."

One point that was often raised was that the left prevented immigrants from having a say on matters that affected them. The silencing of immigrants' voices within left-wing organizations was a frequent strategy to this end. In response to such practices, I was told by Sahid A., the person in charge of CISL-ANOLF and President of Network TogethER, in Reggio Emilia:

For me participation doesn't mean going to immigrants with a paper already written and saying: "This is the program!" Rather it means going to them with a draft and allowing them to contribute to it. It must be a work in progress. For a trade union to "give voice" would mean listening to what people have to say and representing them according to their demands and needs.

-Sahid A. (M), Reggio Emilia, in charge of CISL-ANOLF and President of Network TogethER

I discussed with many immigrant activists the three main indicators of democratic representation-descriptive, symbolic, and substantive - as described by Bird et al. (2011). The first indicator of democratic political inclusion is "descriptive representation." This term refers to the number of people of immigrant background who have roles of responsibility in political organizations. Bird et al. $(2011,5)$ observe that "systematic exclusion of a group from elected office tends to signal [that] group's exclusion from full membership in the political community."

Additionally, enhancing group representation is crucial to the progress of democratic and pluralistic inclusion. Representation can make available "less intimidating channels" through which marginalized groups can convey their own preferences outside of elections. It also introduces "new perspectives and [a] broader range of reasons to [engage in] democratic debate" (ibid.). Most of my interviewees were very critical of the role of left-wing organizations in preventing greater "descriptive representation." They all agreed that the low level of descriptive representation was the result of a lack of will on the part of the left to open up to diversity and pluralism and to assume the implications of being truly inclusive.

I have shown elsewhere that barriers to representation are widespread in Italy (Cappiali 2017a). Several studies report a very low level of representation of the migrant population in Italian political parties and the main left-wing trade union, the CGIL, at both the national and the local levels (CGIL 2013). Also, during my fieldwork, I found that no one with an immigrant background was elected at the regional level in the CGIL. As for the CGIL, recent research conducted by the organization shows a very low level of migrant representation within this organization. While immigrant workers make up about $15 \%$ of the total union membership, only $3 \%$ of the union's leadership is of immigrant background. What is more, their representation is generally at the level of delegates, that is, as representatives of workers (Italian 


\section{4}

and migrant) in the workplace. Delegates are usually elected on a democratic basis by their co-workers. However, there is little representation of immigrants as functionaries, where members have roles of responsibility in the union at the level of their sector, or at the executive level, where members take decisions on behalf of the organization as a whole (Mottura et al. 2010). In 2014, there was only one immigrant activist, who was a member of the national executive of a trade union, the USB.

My interviewees also condemned how the left used "symbolic representation." Bird et al. $(2011,5)$ explain the importance of the "symbolic value of representation." A party or union leadership that accurately reflects the diversity of its membership sends a message about the importance of giving a greater voice to marginalized groups in society. Over the years, Italian left-wing organizations have promoted this approach in many ways, by making more "visible" activists who had an immigrant background. However, when I asked my interviewees about this matter, they argued that the left adopted this practice instrumentally, to gain legitimacy in the political arena, rather than working in favor of substantial inclusion for the migrant population. Here, practices of co-optation and tokenism were widespread. These practices were seen as a way of attracting immigrants to one's organization, while nonetheless ensuring that they would not be able to exercise any actual power. On this point, I could observe that left-wing groups selected immigrants for certain positions based on their "ethnic" background (country of origin), in an attempt to attract particular "ethnic" groups (communities of the same country of origin) into their organizations. ${ }^{5}$ Immigrant activists described this process as "ethnicization."

Before becoming the Director of Mondinsieme, Mohamed A. had long been an active member of the CGIL in Reggio Emilia. He described his personal trajectory and the problems he faced in his interactions with this organization.

My idea was always that of creating a pedagogy of discontinuity. I tried to do it by coming to Italy and interacting with the left-wing organizations. It is a matter of breaking with the idea that immigrants represent immigrants. Today many immigrants who have a role of responsibility do this thing: they play the game the left wants them to play, that is, they talk as immigrants for other immigrants. I tried to break with this mechanism when I was working with the CGIL. For me, it was crucial to break with what I call the process of ethnicization imposed on people of migrant background by Italians. The problem with left-wing trade unions and political parties is that they do not create the conditions to make immigrants grow and become leaders (emphasis mine).

- Mohamed A. man, Reggio Emilia, the Director of the Mondisieme Center

Similarly, a long-time activist of the GCIL in Bergamo, who was very well connected with the immigrant communities in the city, told me:

[Trade unions] haven't done anything! It suffices to look at the level of representation. Compare the number of their members and the percentage of the 
representatives. They let you say very few things. Many of the delegates and functionaries are there because they tell them what they want. What is more, the Italian unionists are not prepared on the questions of immigration. Many fear the foreigners. They fear the other. They always fear that the foreigner will steal their jobs. In the past they asked me to be part of the CGIL. It was 15 years ago. I refused. I was one of the first to be targeted by the CGIL. . . The CGIL was the first to play on the image of immigrants and they continue to do so today. There are people of migrant background in the CISL and CGIL that have been working there for 25 years and haven't advanced in the organization.

-Karim M., man, Bergamo, Member of the CGIL-FIOM and the Communist Refoundation Party

Immigrant activists like Karim M. highlighted the presence of different forms of exclusion of the immigrants in leadership positions, including prejudice on the basis of race and religion, and fear of the Other. They all agreed that these mechanisms were systematically racializing migrant activists within the organizations of which they were members. Talking about the CGIL, a long-time member of the union told me: "If there is little or no representation, it means that there is racism! In the CGIL there is a widespread idea that Italians are more trustworthy than immigrants" (Farooq M., Reggio Emilia, Member of the CGIL).

It is also remarkable that "symbolic representation," instead of promoting more inclusion, can contribute to producing immigrant racialization in left-wing organizations. The use of symbolic representation, via tokenism and the instrumental use of immigrants' image, was strongly felt to be major obstacles to achieving the most important form of political inclusion: "substantive representation." According to Bird et al. $(2011,6)$, substantive representation tells us "what a representative does, and who he or she speaks for." I use this term to analyze the level of substantial inclusion of those immigrant activists who hold roles of responsibility in left-wing organizations. Substantive inclusion can be captured by looking at two aspects: (1) the extent to which immigrant activists in roles of responsibility are able to speak out and negotiate their interaction with other members of the organization on an equal footing; and (2) the extent to which immigrant activists are recognized for their individual skills and characteristics.

Unequal treatment was deemed to be a significant hindrance to substantive representation. I asked the city councilor of Quattro Castella, who was also the person in charge of the Provincial Forum of the Democratic Party of Reggio Emilia, about his experience in the Democratic Party:

Teresa C.: Can you describe the Party's treatment of people of foreign origin? Would you say that it is an equal treatment?

Reda B.: I am afraid there is no equal treatment! The reason is that the party puts meritocracy into the background. What matters for the party are your contacts and networks. When you think of it, it is obvious that a person of Italian origin has more networks and an immigrant is disadvantaged. 
Teresa C.: When you think about Cécile Kyenge [the Minister of Integration], how would you define the Party's treatment of her? Equal treatment?

Reda B.: I call the treatment by the Democratic Party "Democratic racism"! They recognize you have difficulty adapting in the country and they want to lend a hand. However, their mistrust and their culture of prejudice remain. No one in the Democratic Party dares to counter and openly challenge the general mistrust of the population and hostility towards immigrants by the populists, because they also think the same way.

Teresa $C .:$ In practice, what does this mean?

Reda B.: Within the Democratic Party, there are people who think: "I support you for the battle, I encourage you during the campaign, but, in the end, it is always the Moroccan people who steal."

Teresa $C .:$ Is it only about national origin, or does class play a role as well?

Reda B.: Italy struggles to imagine a person of foreign origin in a responsible position or as a director of a hospital, for instance. So yes, it is about both class and national origin.

-Reda B., man, Reggio Emilia, City councilor of Quattro Castella (Province of RE) and in charge of the Forum of the Democratic Party

During my research I tried, but I could not interview the newly elected Cécile Kyenge (who had been the Ministry of Integration since February 2013). However, I participated in many events in the region Emilia-Romagna, organized by left-wing organizations, including trade unions, to which she was invited. I observed her political trajectory and explore the meaning of her election and the role of the left. In many of the informal conversations and interviews, immigrant and non-immigrant interviewees mentioned the role of façade of her elections and the processes of co-optation she faced. Her case was often used as an emblematic example to explain the role of the left in taming immigrant activists or choosing the most compliant activists.

It is notable in this respect, how Donald R. clearly linked the lack of substantive representation to the "consumer paradigm" described previously in one of his quotes:

The concrete fact to which I refer here is that the role occupied by immigrants in any political organization in Italy is mainly based on compliance. If one of us is a Minister of Integration, like Cécile Kyenge, or Assessor of Integration - as in my case - regrettably, we are not doing anything but answering to the consumer paradigm of immigrants. We are still consumers. Because the mayor, when he appointed me, thought he was doing a favor to the cause, instead of thinking that I am actually competent. This is why, instead of working on communication, which is my specialty, I am given the role of Assessor of Integration, which reminds me that this is supposed to be my role: an immigrant working for and representing other immigrants.

-Donald R., man, Bologna, Assessor of San Lazzaro and in charge of the Forum of the Democratic Party 
Most of my interviewees explained that being elected or appointed as a representative in the political party or trade union was the first step toward greater autonomy and self-determination, but that this was not enough. They observed that left-wing organizations stood in the way of those who had been elected, and instead of valorizing their individual competencies and merits, they promoted their compliance and subordination through, among other things, tokenism, ethnicization, unequal treatment, lack of meritocracy, and paternalism. These were seen as some of the other disciplining mechanisms that served to silence and marginalize immigrants' voices, once activists had secured some role of responsibility within the organization.

\section{Radical left organizations as ambivalent allies}

As mentioned in the previous empirical chapters, the lack of trust shown towards mainstream left-wing organizations explained why many immigrant activists allied with the radical left. The alliances with the left were particularly obvious in Bologna and Brescia, where the left was particularly visible: As I explained in Chapters 4 and 5, the substantial support offered by the radical left to immigrant workers, including the undocumented ones, in these two cities over the years, created the conditions for this actor to become a key reference for the immigrant communities.

In these two cities, several immigrant activists confirmed the role of the radical left in supporting their struggles. Addressing the assembly during a meeting in May 2013 in a social center in Milan organized by the radical left organization from Bologna, the Migrant Coordination Organization (MCO), Tariq I. tried to convince immigrant workers to join his organization. He was had been an active member of the MCO for many years. He was also particularly active in the Pakistan community in Bologna. He founded an association to help his community. During the assembly, he addressed the immigrant workers in the room and explained how the MCO had his full trust.

I want to say something: the MCO is my life. For many years we had one main thought: that of being the voice of migrants. In Italy I have found many tables, many trade unions. I have understood that trade unions . . . only want to use migrants. The MCO has offered all the possibilities. It has shown that migrants in Italy are very important. I have seen many groups. They organize assemblies and meetings and they are all linked to the political parties. They never act in our interest, the interest of migrants, but in their own interest. . . . With this point I want to say: The MCO is you. Each one of you is responsible! Each worker! Each one is responsible because we can go ahead together, shoulder to shoulder. We have always been used. The message I want to send to everyone is that: the MCO goes ahead with us. You are the MCO and thanks to you all the MCO goes ahead (Fieldnotes, Assembly MCO in Milan 19 May 2013).

—Tariq I., man, Bologna, radical left organization MCO 
During our interview, I asked Tariq I. to further explain what was his take on the left organizations in Italy. He expressed his deep frustration about the left. The MCO was, according to him, the only organization that could be trusted as it allowed immigrants to have a voice in the city and to self-organize around their needs. He added:

The MCO is the voice of immigrants, for immigrants. It starts from the real problems of migrants. It is unique in the landscape of Bologna. In other places, such as the Provincial Council, people of migrant background can talk and listen, but cannot make decisions. Since my arrival in Italy, I have tried to find a way to get involved and give voice to the needs of people. Most of the places where I went, migrants were supposed to listen and stay quiet. In 2004, with the creation of the MCO, we decided to create the conditions for migrants to express their voices starting from their problems and conditions with complete autonomy. The trade unions have political affiliations and do not act in our interests.

- Tariq I., man, Bologna, radical left organization MCO

Alliances with the radical left were, nonetheless, complicated. I asked immigrant activists in the four cities about the role of radical left organizations in promoting inclusion and whether they were considered as an alternative to traditional leftwing organizations. The analysis of the interviews showed mixed perceptions. Immigrant activists in these radical left organizations acknowledged that, while mainstream left-wing organizations had failed to promote inclusion and neglected to address some key issues that concerned them, the radical left was more inclined to support their struggles for greater recognition and to treat them as equals. Some immigrant activists in more vulnerable conditions - such as undocumented immigrants of recent arrival - stated that radical left organizations let them "take the floor" and allowed them to put forth their claims. Other immigrant activists in the radical left with a longer stay acknowledged the ability of radical left actors to advocate for, and mobilize with, immigrants in vulnerable conditions. The financial crisis was believed to encourage these alliances, and they argued that it was better to have these organizations than to be faced with a completely empty space.

However, immigrant activists addressed also severe criticism. Several interviewees explained that, even though they shared the struggles supported by the radical left, these organizations were "using immigrants like anybody else," and in many ways, they were not as different from other left-wing organizations as they claimed to be. One strong criticism came from Adelina Y., a woman from Albania and the President of the Association of Cultural Mediators AMISS in Bologna (see also Chapter 4). She expressed some frustration as she believed that "The radical left does not know how to identify with immigrants." She pinpointed a problem that was shared by most radical left organizations in the country-that of exposing immigrants to state repression. "If someone goes to their demonstration, he/she risks being deported." This made her concluded that the radical left has "a political agenda that silences vulnerable immigrants' voices and needs. Many immigrants don't trust them." 
Many activists like Adelina Y. felt that radical left organizations had their own goals and were not willing to challenge their own traditional political strategies to include those of immigrants. Above all, they criticized the radical left for exposing vulnerable immigrants to state violence, for instance by confronting the openly police during their demonstrations. In doing so, they exhibited some resistance to the idea of opening up to pluralism and change. This was visible, for instance, in their lack of attention for safer strategies, when organizing demonstrations and protests to promote immigrants' rights claims. For this reason, some immigrant activists who did not ally with the radical left organizations believed that the latter were not capable of promoting real inclusion or offering viable political solutions.

Karim M., a long-time activist of the radical left in Bergamo observed that the Communist Refoundation Party and the radical left would also tend to co-opt and use immigrants and treat them as inferiors:

Teresa $C .:$ Does the Communist Refoundation Party act differently?

Karim M.: It is always the same thing . . I I have talked about it to my comrades. We are very far from giving immigrants space in the Party. All these organizations use immigrants and they treat them as subordinated.

Teresa C.: What about the grassroots unions of the radical left? Are they also using immigrants?

Karim M.: In recent years, grassroots unions have gained power by giving light to immigrants and making them very visible in their organization. However, in reality, they adopt the process of co-optation like anybody else. They use the image of immigrants in their organization. In this way, immigrants are swindled. Some people were active with the Communist Refoundation Party, then they became unionists. At that point they have been placated.

-Karim M., male, Bergamo, Member of the CGIL-FIOM and the Communist Refoundation Party

Moreover, interviewees explained that the radical left's focus was on a limited number of issues, rather than on the multiplicity of problems associated with inclusion. These organizations addressed issues such as undocumented immigrants' rights and exploitation. They also concentrated on housing and bureaucracy. However, they neglected major issues linked to cultural inclusion, while also ignoring the challenges faced by the more stable migrant population, including pluralism, religious accommodation. Many interviewees addressed this ambivalence or contradiction of the radical left's strategies. While recognizing its merits, they expressed a strong desire to address all the domains of interventions necessary to promote the inclusion of the immigrant population in the different spheres of Italian society.

Bujar A., a Member of the Forum of the Democratic Party in Brescia, took a clear position with respect to the role of the radical left in the city.

We wouldn't like the radical left to have a monopoly on the discourse on immigration. It is a question of parallel trajectories. One trajectory does not 
exclude the other. Above everything, we want to avoid going beyond the limits of legality. ... The radical left prioritizes conflicts with authorities rather than integration. . . . We need to build a basis of cohabitation beyond ideological conflict. Integration concerns neighborhoods, work, schools, and social life. The radical left is blind to most of these issues.

- Bujar A. man, Brescia, Member of the Forum of the Democratic Party

Sahid A., who was in charge of CISL-ANOLF and President of Network TogethER, was very critical of the ideological divisions between left organizations, and especially of the positions of the radical left. According to him, the radical left pushed for the escalations of conflicts, and this was not always necessary or justified. Above all, he was critical of the tendency of these organizations to only mobilize vulnerable immigrants and to reinforce conflicts with the state.

We need ask ourselves what our battles are. If our goal is the well-being of people, of all people, then we should not nourish ideological conflicts. The economic crisis now has become a socio-cultural crisis as well. People are getting stuck. We need to figure out new approaches that allow us to understand the processes at work and transform them for the good of the community. . . . For me it is important to move beyond a distinction between immigrants and Italians. We need to work with everyone, not only with immigrants. This is my philosophy. Today everyone needs everyone. The radical left needs $u s$ and we need them.

- Sahid A. man, Reggio Emilia, in charge of CISL-ANOLF and President of Network TogethER

Bujar A. and Sahid A. expressed a view on one aspect that characterized the radical left: the focus on only some issues concerning immigration and inclusion in society, instead of the whole spectrum of challenges a society faces as a result of deep transformations triggered by immigration flows. Moreover, the strategies used by the radical left are considered by these interviewees as problematic, as they prioritize conflicts with the state. This according to them can hinder the processes of inclusion, as less focus is given on how to promote co-habitation by overcoming distinctions between "us" and "them"- an aspect conveyed by the intercultural approach promoted by more moderate actors.

\section{Speaking for oneself and reframing resistance from below}

The political trajectories that immigrant activists have developed in Italy show that, in their struggles for greater recognition, they prioritize strategies to challenge the political racialization produced by the Italian left. Their trajectories are multiple and rich in activity. They vary depending on their political views, interests, and understanding of their conditions and immigrants generally in Italy. Yet, it is striking that their views reflect a converging understanding of how to transform the mechanisms that marginalize their voices. First of all, immigrant 
activists all openly expressed the need to break with the left's tendency to appropriate their suffering and struggles and to speak on behalf of immigrants. They shared the idea that it was about time they started taking the floor without asking. Despite their different political strategies, immigrant activists conveyed the same idea: " 'Participation' is synonymous with self-determination. It means to 'speak for oneself'."

I asked all my immigrant interviewees to tell me why they were active and why they did in specific political channels. Bujar A., for instance, explained why he opted for the Democratic Party. He explained that the main motivation behind his political participation was "to deal with institutional discrimination (permits, restrictions on movement, delays in the release of documents)" in the city of Brescia. He chose the Democratic Party because it aligned most closely with his own political orientation and he thought that mainstream politics was the best way to bring about change. He explained that mainstream politics had the potential to enable immigrants to become stronger and to "force politics to listen":

The real problem is that we [immigrants] are weak. Instead of asking, we need to force politicians to listen to us. To talk of immigrants makes them lose votes. So, we need to change politics and stop asking for charity. Immigrants should represent immigrants, and bring forth their claims with the support of the [existing] associations. Immigrants have different mentalities, different cultures. Yet, they should unite and go beyond their differences. Many people [left-wing organizations] are impeding this transition (emphasis mine).

- Bujar A., male, Brescia, Member of the Forum of the Democratic Party

I questioned Makham M. about his reasons for participating in many political channels promoted by the left in Bologna, namely the world of associations, in the Provincial Council and the Forum of Immigration of the Democratic Party. He answered straightforwardly: "because each field is a good opportunity to become representatives, ambassadors, of ourselves." For him, participation meant "to speak for oneself," "to be active in changing and improving things." He believed that Italians and people of migrant background needed to work together to bring about the necessary outcomes. Neither Italians nor migrants alone could change things. This could be possible for him, by breaking with the distinction between "us" and "them."

Similarly, Fatima N., a Member of the Forum of the Democratic Party in Brescia, explained that she became active because she did not want to wait another generation before immigrants' conditions improved in Italy. She decided to go to the Forum because she believed that Brescia needed to make a "qualitative leap" to promote integration, by going beyond political partisanship.

I relate with others regardless of their political flag. The Northern League is the product of ignorance and if they don't talk about immigrants, they do not get votes. I go where people work for immigrants. We are all working for the same thing and I want to help to promote the "qualitative leap." We are all 
one! We need to work for what unites us. If we don't move in this direction, many years will go by without us seeing any major social change.

-Fatima N., woman, Brescia,

Member of the Forum of the Democratic Party

For some interviewees, the best way to promote change was through mainstream politics, by reversing the consumer paradigm and by becoming political leaders and breaking with the idea that immigrants are "receivers" of services:

Our true political participation will consist in saying that we are "those who serve," that is, the citizens legitimized to occupy with full rights the roles of those who administrate and take decisions and not only of "those who receive." There is a saying, "The hand that gives is always above the one that receives." We want to affirm that today participation for us means being on the side of the hand that gives and not always on the side of the hand that takes. . . In my view, to assume even a minimal role within the political party is the beginning of a proactive participation. This is the threshold! . . to move beyond the world of associations. Immigrants who come to Italy are represented as users, as those who are served. And the political discourse of the right and of the left reinforces this approach. I believe that true participation of immigrants in Italy will be possible by affirming the opposite of this representation. And this must be done not only in words, but with concrete deeds.

-Donald R., man, Bologna, Assessor of San Lazzaro and in charge of the Forum of the Democratic Party

Similarly, immigrant activists who were members of the radical left organizations expressed the same need to speak for themselves. Farid M., a young immigrant activist living in Bologna, told me:

"Participation" means to speak for oneself. No one can talk about something if he doesn't live it. Participation is synonymous with self-determination. It is you that knows your situation and can bring a change to that situation. "Integration" is a weird word for us, the young people, because we are already integrated with each other. Our only constraint is institutional discrimination. The legislation is far behind with respect to the development of society. This is what we want to affirm.

-Farid M., man, Bologna, On the Move -Generation on Movement (radical left)

Tariq I., an activist of the MCO and the President of the main Pakistani association in Bologna, explained that it is natural for him to help others and that this leads him to invest his entire life to activism.

I help fellow Pakistanis and other immigrants. I want to express the voice of immigrants through my activities! Since the beginning, I always told myself that an immigrant is not someone who arrives in a place and that is it. In reality, the 
immigrant brings his whole self and he needs to express himself. My question is then: How can a migrant express his project of life? How can he give voice to his needs? We need to go toward Italians and tell them who we are and what we do.

Thus, despite their different political views and different civic and political activities, immigrant activists chose activism as a way of contributing to change Italian society in their own terms. They were firmly convinced that it was necessary to become active and speak out to bring their own perspectives to the political debate, including their own vision of inclusion, a better understanding on the part of Italians, and their role in the country's future. Immigrant activists noted the need to go beyond the "us"/"them" dichotomy conveyed by the left, by refraining from reproducing this narrative themselves. They saw themselves not only as people who could speak from their experiences and those of other immigrants as marginalized or oppressed groups, but also, thanks to their perspectives, they had several advantages that could help Italy find solutions and grow in the future.

I believe we [immigrants] can overcome our difficulties with our added value! We are people who have lived in different countries and this allows us to see things differently, with a more detached eye. This added value is the fact that we live things first-hand, including racism and negative things. As an immigrant, I have come to realize that Italian people know very little about the phenomenon of immigration, even politicians. There is lots of ignorance that needs to be overcome through our contribution.

- Reda B., man, Reggio Emilia, City councilor of Quattro Castella (Province of RE) and in charge of the Forum of the Democratic Party

Similarly, one immigrant who was very active during the "Struggle of the crane" in Brescia explained how his political claims, which sought to improve the rights of immigrants in extremely vulnerable conditions, was actually a fight for greater rights for all in Italy.

When the "Struggle of the crane" ended, we left Brescia and we went everywhere. We went to talk with people around the country. We talked about the Bossi-Fini Law, about how unfair and racist it is. We emphasized the importance of human value. And we talked about the enormous sufferings that immigrants have to go through. We told them about our comrades who were deported. We told them that they wanted to come back with a regular temporary permit of stay. We explained that we came to work and to improve our lives and not to steal jobs. We explained that the law didn't give us any alternative. We tried to make them understand that the fight has to continue .. . that the fight is necessary not only for immigrants, but for Italians too. It is a fight, as our organizations made clear, for the rights of all, that is, for Italian workers as well. . . . It is a struggle for the Italian society as whole.

_-Yusuf A., man, Brescia, radical left organization Rights for All 
Although having two different migration trajectories and different political perspectives and views about immigrant rights and inclusion in society, the interviews with Reda B. and Yusuf A. speak about the desire of many immigrants to promote democracy in Italy, by sensitizing the Italian population about immigration issues and about how important it is to understand immigrant situations for everyone. This idea was shared by many immigrant activists and Italian organizations supporting them. As several Italians particularly closed to the immigrant cause told me: "less rights for some, means less democracy, and thus less rights for all!" (RE/ N10). These were also, at least on paper, the main moto of the CGIL at the time of my fieldwork. As Sarah K., an Algerian trade unionist living in the province of Reggio Emilia told me: "If some workers in the factory lose their labor rights, everyone does. This is why we need to tell Italian workers, that protecting immigrant rights in the workplace is a way to protect their rights as well" (RE/N13).

\section{Conclusion}

The findings presented in this chapter represent one of the main contributions of this book to the literature on migration and immigrants' social inclusion. By analyzing the experiences of immigrant activists, this chapter reveals powerful mechanisms that contribute to silencing immigrant voices in political life and, as a consequence, in Italian society at large. In particular, the findings demonstrate why and how political racialization works within the Italian left as a way to include immigrants, but in a position of subordination.

The marginalization and silencing of immigrant voices go hand-in-hand with the re-appropriation of immigrants' suffering and struggles on the part of Italian organizations. The mechanisms that produce political racialization-differential treatment, co-optation, paternalism, disempowerment of immigrant organizations, etc. - are not just the result of everyday racism and prejudice; they perform a specific disciplinary function. They are devices of power that systemically subordinate immigrants in Italian politics, while allowing the Italian organizations to gain and maintain power via the appropriation of immigrant struggles. Taking up Donald R.'s words, I have dubbed this system the "consumer paradigm" or "paradigm of dependence and subordination." By appropriating and "re-writing" the cause of immigrants, the Italian left legitimizes its discursive monopoly on immigration issues. As bell hooks notes, "No need to hear your voice when I can talk about you better than you can speak about yourself. No need to hear your voice. Only tell me about your pain." And again, she adds: "Re-writing you, I write myself anew. I am still author, authority. I am still [the] colonizer, the speaking subject, and you are now at the center of my talk" (hooks 1989, 22).

Thus, this power struggle is, first and foremost, a discursive practice in the Foucauldian sense (Foucault 1978) - as it represents types of behaviors that define what is acceptable and desirable from immigrants if they want to be included in the Italian left. This means that the Italian left organizations, in order to legitimize their work on immigration, construct immigrants as objects of inclusion in their own terms and act accordingly. These actions reinforce the organizations' own 
narratives about immigrants and their role in society and impose on immigrants to comply with these narratives in order to be accepted in Italian society. This mechanism can be effective, however, only if immigrant activists are assumed to be passive subjects. As this chapter has suggested, despite the different approaches to inclusion promoted by actors with different ideological affiliations and analyzed in the previous empirical chapters - namely, the assistant, the intercultural and political rights promotion - processes of marginalization and silencing are, at different degrees, applied by all pro-immigrant actors, examined in this study.

As hooks writes:

We are re-written. We are "Other." We are the margin. Who is speaking and to whom? Where do we locate ourselves and comrades? Silenced. We fear those who speak about us, who do not speak to us and with us. We know what it is like to be silenced. We know that the forces that silence us, because they never want us to speak, differ from the forces that say speak, tell me your story. Only do not speak in a voice of resistance. Only speak from that space in the margin that is a sign of deprivation, a wound, an unfulfilled longing. Only speak your pain.

(hooks 1989, 23)

Based on the analysis of this chapter, one can hypothesize that, in times of deep ideological crisis, the Italian left uses the issue of the most vulnerable, the immigrants, as an opportunity to re-write itself, at the expenses of immigrants' desire to speak for themselves and take part in the leftist movement in Italy.

Thus, it comes as no surprise, then, that the left makes use of powerful mechanisms to prevent immigrants from becoming autonomous at the individual and collective level and to speak for themselves. Such empowerment would result in a significant power shift, obliging the left to step back and give up the discursive terrain in order for immigrant activists to be able to bring forth their own claims and needs. From this perspective, it is little wonder that the left resists immigrants' self-empowerment in its multiple forms and mostly promotes, through co-optation, the visibility of immigrants who "play the game the left wants them to play," namely to "talk as immigrants for other immigrants," as Mohamed A., the Director of the Mondisieme Center in Reggio Emilia, put it.

Immigrant activists have endeavored to bring about greater recognition in receiving society, by challenging exclusionary views that construct them as outsiders and force them into narrowly defined roles. Bringing in the point of view of immigrants with a variety of political affiliations and immigration trajectories, the chapter highlights the complexity and diversity of immigrants' views and trajectories. It also shows how immigrants' participatory paths are embedded in specific power dynamics, and especially complex networks of interactions. Moreover, to a certain extent, the disciplinary power of the left directs immigrants' trajectories in ways that make some options viable to them while precluding others (see also Bilge and Collins 2018, 22). This is also why immigrants' discourses and attempts to empower themselves can be seen as challenging their racialization, that is, as a 
response to being treated as "part of the whole but outside the main body" (hooks $2015, x v i i)$. In this respect, the observation offers an opportunity to question some biases in research focusing on the "political incorporation" of immigrants and racialized communities of migrant origin, which tend to dichotomize receiving societies and immigrants in ways that assume them to be separate entities. This kind of discourse also involves power and is essentializing as it reduces immigrants to fictitious homogenous groups (El-Tayeb 2011).

While challenging Italian pro-immigrant organizations, immigrants and activists are fully inscribed in extant power dynamics. As Donald R. puts it: "When immigrants enter Italy, they are wedged into the interior of an enormous paradigm of which the left is also an important actor." Being part of the whole but outside the main body is a performative act, rather than a fixed reality. Yet, despite the important challenges they face and the weaker power they have vis-à-vis other political actors, immigrant activists are key players in Italian politics. Rather than being a mere passive subject to power dynamics, or external to them, they strategically engage in multiple pathways of activism, even amid the most hostile contexts, to promote their rights. As such, they have a significant role to play in shaping these dynamics by speaking back to power in their own terms.

Finally, the chapter illustrates the value of the plurality of immigrant activists' viewpoints and the range of definitions and meanings they attach to active citizenship, political participation, and inclusion. In particular, my findings show how immigrants connect these issues. Participation is seen as the way to greater inclusion. But it is also more than that. Through their discourses, immigrants are redefining participation and inclusion on their own terms. They are presenting their struggles for their rights as a struggle to transform Italy into a more thriving democracy, where political pluralism is valued and human rights of all lives are protected.

The content of this chapter has emerged out of a systematic analysis of 63 explorative and ad hoc interviews conducted with immigrant activists in Italy. These data were combined with material collected during extensive field research. The analysis allows me to say with confidence that the results presented here, even though counter-intuitive, are robust and reliable. I am also confident that if another researcher were to adopt a similar theoretical approach and research design in Italy — even if studying different cities - they would end up with similar results. Indeed, it would be invaluable to have the aforementioned findings corroborated by further research in this area in Italy and other countries.

\section{Notes}

1 In his study of Bologna, Però (2007) finds that there is a blatant discrepancy between the left's inclusive rhetoric and its exclusionary practices. On the one hand, the left promotes an inclusive discourse about immigrants' empowerment and self-determination, and in line with this rhetoric, it creates platforms that promote their civic and political participation. Yet, on the other hand, as this study substantiates, in practice many of these channels are largely a façade and they are opposed when immigrants attempt to make their own voices heard. For Però (2007), there appears a contradiction. By using a critical lens to study existing power dynamics and forms of resistance, my analysis 
shows that this contradiction is apparent. The analysis of this chapter will show the role played by the systematic silencing of immigrants' voices across the entire political spectrum of Italian politics.

2 See A. Poletti. "Aboubakar Soumahoro, the Ivorian trade unionist shaking up Italy." The African Report. May 26, 2020. www.theafricareport.com/28771/aboubakarsoumahoro-the-ivorian-trade-unionist-shaking-up-italy/

3 In the Emilia-Romagna region, these Provincial Fora were led by two new citizens of immigrant background (Reda B. and Donald R.). They were, moreover, coordinated by Cécile Kyenge at the regional level (from 2010 to 2013), until she was appointed Minister of Integration in 2013. The Regional Forum in Emilia-Romagna was the only one in Italy, and it "allowed the creation of an adequate space to coordinate the work of the Provincial Forums and share the "good practices"” (Reda B.). In Brescia and Bergamo, on the other hand, the Fora were led by "white" Italians and they were much less active and relevant in the cities.

4 The hypothesis of the crowding-out effect in Italy was first introduced by Caponio (2006).

5 The CGIL, for instance, uses this strategy extensively with the aim of unionizing immigrant workers so as to avoid the union's decline in the face of decreasing numbers of "white" Italian workers. The case of Bergamo also showed that other trade unions, including the CISL, adopt the same approach.

\section{References}

Bilge, Silma, and Patricia Hill Collins. 2018. Intersectionality (Key Concepts). Cambridge: Polity Press.

Bird, Karen, Thomas Saalfeld, and Andreas M. Wüst, eds. 2011. Political Representation of Immigrants and Minorities: Voters, Parties and Parliaments in Liberal Democracies. London: Routledge.

Caponio, Tiziana. 2006. Città italiane e immigrazione. Discorso pubblico e politiche a Milano, Bologna e Napoli. Bologna: Il Mulino.

Cappiali, Teresa M. 2016. "Activism of Immigrants in Vulnerable Conditions and RadicalLeft Allies: A Case Study of Italy's Struggle of the Crane." Journal of Ethnic and Migration Studies 42 (15): 2508-2527.

Cappiali, Teresa M. 2017a. “'Whoever Decides for You without You, He is Against You!' Immigrant Activism and the Role of the Left in Political Racialization." Ethnic and Racial Studies 40 (6): 969-987.

Cappiali, Teresa M. 2017b. "An Italian 'Integration Crisis': The Role of the State and Political Actors in Excluding Immigrants and Ethnic Minorities." In Italy from Crisis to Crisis: Political Economy, Security, and Society in the 21st Century, edited by Matthew Evangelista, 168-198. New York: Routledge.

Cappiali, Teresa M. 2019. "Ideological Affiliations, Conflicts, and Competing Mobilization Frames: The Role of Pro-Immigrant Allies in Shaping Immigrant Struggles for Greater Rights.” International Migration Review 53 (3): 869-899.

CGIL. 2013. "Conferenza Regionale CGIL Emilia-Romagna sull'immigrazione.” Bologna, June 10.

Cobbe, Luca, and Giorgio Grappi. 2011. "Primo marzo, percorsi di uno sciopero inatteso." In La normale eccezione. Lotte migranti in Italia, edited by Felice Mometti and Maurizio Ricciardi, 55-90. Rome: Edizioni Alegre.

Davis, Angela. 2016. Freedom is a Constant Struggle: Ferguson, Palestine, and the Foundations of a Movement. Chicago: Haymarket Books. 
El-Tayeb, Fatima. 2011. European Others: Queering Ethnicity in Post-National Europe. Minneapolis: University of Minnesota Press.

Essed, Philomena. 1991. Understanding Everyday Racism: An Interdisciplinary Theory. Newbury Park: Sage.

Evans, Elizabeth, and Éléonore Lépinard, eds. 2020. Intersectionality in Feminist and Queer Movements. Confronting Privileges. New York: Routledge.

Foucault, Michel. 1978. The History of Sexuality I: The Will to Knowledge. London: Penguin.

Harding, Sandra. 1992. "Rethinking Standpoint Epistemology: What is 'Strong Objectivity'?" The Centennial Review 36 (3): 437-470.

hooks, bell. 1989. "Choosing the Margin as a Space of Radical Openness." Framework: The Journal of Cinema and Media 36: 15-23.

hooks, bell. 2015. Feminist Theory: From Margin to Center (3rd ed.). New York: Routledge.

Kosic, Ankica, and Anna Triandafyllidou. 2005. Active Civic Participation of Immigrants in Italy. Country Report prepared for the European Research Project POLITIS. Oldenburg. www.ubi-oldenbrug.de/politis-europe

Lamont, Michèle, Graziella Moraes Silva, Jessica S. Wellburn, Joshua Guetzkow, Nissim Mizrachi, Hanna Herzog, and Elisa Reis. 2017. Getting Respect: Responding to Stigma and Discrimination in the United States, Brazil, and Israel. Princeton: Princeton University Press.

Lentin, Alana. 2004. Racism and Anti-Racism in Europe. London: Pluto Press.

Mantovan, Claudia. 2007. Immigrazione e Cittadinanza: Auto-Organizzazione e Partecipazione Dei Migranti in Italia. Milan: FrancoAngeli.

Martiniello, Marco. 1993. "Ethnic Leadership, Ethnic Communities' Political Powerlessness and the State in Belgium." Ethnic and Racial Studies 16 (3): 236-255.

Mottura, Giovanni, Silvia Cozzi, and Matteo Rinaldini. 2010. Uscire da Babele. Percorsi e problemi del rapporto tra sindacato e lavoratori immigrati. Rome: Ires.

Mulinari, Paulina. 2015. "Exploring the Experiences of Women and Migrant Medical Professionals in Swedish Hospitals: Visible and Hidden Forms of Resistance." Equality, Diversity and Inclusion: An International Journal 8 (34): 666-677.

Narayan, Uma. 1989. "The Project of Feminist Epistemology: Perspectives from a Nonwestern Feminist." In Gender/Body/Knowledge: Feminist Reconstructions of Being and Knowing, edited by Alison M. Jaggar and Susan R. Bordo, 256-272. New Brunswick: Rutgers University Press.

Nicholls, Walter J., and Justus Uitermark. 2016. Cities and Social Movements: Immigrant Rights Activism in the US, France, and the Netherlands, 1970-2015. London: Wiley-Blackwell.

Però, Davide. 2007. Inclusionary Rhetoric/Exclusionary Practices: Left-Wing Politics and Migrants in Italy. Oxford: Berghahn.

Però, Davide, and John Solomos. 2010. "Introduction: Migrant Politics and Mobilization. Exclusion, Engagement, Mobilization.” Ethnic and Racial Studies 33 (1): 1-18.

Sager, Maja. 2011. Everyday Clandestinity: Experiences on the Margins of Citizenship and Migration Policies. Lund: Lund University.

Soumahoro, Aboubakar. 2019. Umanità in rivolta: La nostra lotta per il lavoro e il diritto alla felicità. Milan: Feltrinelli. 


\section{Conclusion}

\section{Reframing resistance today}

This book's main aim has been to expand our understanding of why and how immigrants become civically and politically active in receiving society, especially under very hostile contexts. Today, Italy, like many countries in Europe, is home to systemic and everyday racism towards racialized, non-EU immigrants and communities of immigrant background. This was the case throughout the 2000s and it has intensified since the financial crisis that started in 2008. Anti-immigrant parties have garnered greater electoral support, while securitarian approaches to immigration have been endorsed by both right-wing and left-wing governments. In response, political voices that speak up in defense of immigrant rights in mainstream politics are few in number, lacking in courage, and often marginalized. In this context, as the book shows, immigrant and racialized communities of migrant background have raised their voiced and mobilized to promote their rights, although in many cases with very little tangible success.

One of the main contributions of the book is to show how the issue of immigration and immigrants' inclusion in society, including their activism, is strictly connected with racism and racialization in Europe. While the connection between immigration and racialization is still undertheorized and under-researched (Bulmer and Solomos 2019), it is nonetheless a phenomenon particularly obvious for immigrant and racialized communities trying to advance their rights in Europe. Even more significant is the little research on the role of pro-immigrant actors more generally, and anti-racist movements in particular, in contributing to immigrant racialization. With this book, I have aimed to start filling this gap.

This study is based on a field research conducted between 2013 and 2014, when Cécile Kyenge became the first Black Minister in Italian history, leading the newly created Ministry of Integration. ${ }^{1}$ Today, she is one of the key Black human rights leaders in Europe, at the front line on the issues of inclusion and discrimination of vulnerable communities. In an article published in The Guardian in 2018, Kyenge wrote:

Racial discrimination is now "commonplace" across 12 European countries, and one in three people of African descent has experienced harassment in the past five years. ... This doesn't surprise me. Since my election to the Italian 
Chamber of Deputies in 2013, I have constantly faced racist abuse. When I became Italy's Minister for Integration, as the country's first black minister, it got worse. A fellow Italian MEP, Mario Borghezio, called my appointment "a shitty choice" by a "bongo-bongo" government, adding that I had "the face of a housewife." A former vice-president of the Italian Senate, Roberto Calderoli, said in a public meeting: "When I see pictures of Kyenge I can't help but think of the features of an orangutan." Other extreme-right politicians have called me "Zulu" and "Congolese monkey." I have faced death threats and now live under police protection. ... The increase in hate speech we are witnessing across Europe threatens our shared democratic values by dehumanising minorities. ... I worry about the times that we are living in. We need to work harder to build societies where we can all live in equality, regardless of our race, ethnicity, religion or belief, gender, sexual orientation or disability. ${ }^{2}$

This quote is relevant because it summarizes how Kyenge's experience of racism in Italy is connected to a broader problem of racism in Europe. The racist attacks directed toward her represent just a small sample of the countless instances of racist abuse that has characterized Italy's social and political life over the course of the past two decades. These attacks, moreover, are not surprising but represent a more general trend. In European countries, non-EU immigrants and racialized communities of migrant background are constructed as inferior Others by laws, policies, and political discourses, and this construction has long served to keep such immigrants in a position of racial inequality (Calavita 2005; El-Tayeb 2011). Research shows that the lives of non-EU immigrants and racialized groups are characterized by a high level of discrimination when interacting with institutions and in their everyday life, based on their skin color and/or their religious signs for Muslims, including veiled women (FRA 2019; ENAR 2018). Consistent evidence shows the existence of important structural barriers that keep these groups at the margin of society (economically, culturally, and politically). Looking at these data, one can infer that exclusion based on racism are only in part affected by the different "models of integration" adopted by European countries - such as multicultural, universalist, assimilationist - as experiences of racialization by "non-white" groups of migrant origin are in many ways similar across countries (cf. El-Tayeb 2011).

In this general context, the experience of Kyenge and of many other immigrant activists described in this book needs to be better connected to their experience of racialization in the country where they reside. Someone like Kyenge, who claims a political space to promote her rights and those of excluded immigrants represent what Puwar (2004) would call "space invaders." As women and racialized groups enter into politics, they do not step into "neutral" fields, but rather "spaces" that are assigned to white men. White male bodies are seen to be "naturally" entitled to spaces of power, whereas women and immigrant bodies are precluded from them and punished when they transgress the boundaries created to keep them out. Thus, when racialized women like Kyenge defy these boundaries, the racist reactions can be violent and threatening, as these reactions function as disciplinary mechanisms to remind them what their "natural" role in society is supposed to be. 
Activists like Kyenge perturbate the political realm because they dare to expose rooted racism and discrimination in society, not least in those political spaces occupied by leftist organizations - where one would not expect them to be. It is remarkable that the reactions to Kyenge's elections found resistance not only among the most hostile and racist parties and movements in Italy but also from pro-immigrant parties from the left. The barriers imposed by the left have represented a main topic of this book. Pro-immigrant actors in Italy have plaid an ambivalent role in the face of the attempts by a great number of immigrants and new citizens of migrant background to have a political voice in the country. Interviews with immigrant activists have emphasized the powerful barriers imposed by pro-immigrant groups, concerning both the greater political representations of immigrant communities and the greater inclusion of immigrant activists seeking to develop a political career in Italy. During my fieldwork, the role of Kyenge within the left was a recurring theme among many interviewees. As mentioned in Chapter 7, according to one activist who knew Kyenge well, as they were both active in the regional Forum of Immigration of the Democratic Party of EmiliaRomagna, the party did not treat Kyenge equally — on the contrary, it applied what they called "Democratic racism!" He described this as a general "mistrust and prejudice," which brings the left to turn its back on immigrant activists. So instead of challenging the populism and anti-immigrant discourses, these left-wing organizations contribute to perpetuating immigrants' racialization in Italian society.

The book is an important contribution to research on immigration, as it shows how immigrant activists expose exclusion and resist to it, via their activism and political demands, despite the significant challenges they face. Kyenge's successful trajectory is one among many examples that demonstrates the strength and resilience of women and men of immigrant background who have resisted exclusion and empowered themselves through their activism. Many experiences and trajectories of immigrant activists I have met during my research were not always as positive and successful. Yes, their desire and willingness to improve their rights in Italian society were not undermined, despite their challenges in the realm of politics and in their lives.

Inclusion of immigrants in society, as endorsed in this book, means full access to rights and equal treatment as well as freedom from discrimination and mistreatment. The findings of this book show that inclusion in Italy is undermined not only by politicians of the anti-immigrant parties, laws, media, and the local population but also by a plethora of pro-immigrant actors - left-wing and Catholic organizations alikewho claim to act in support of immigrants. The obstacles to inclusion imposed by these actors are subtle but powerful nonetheless. They not only represent a backward step in terms of the possibility of immigrants fully participating in society as political agents, but they also serve to construct immigrants as inferior Others.

As such, this book constitutes my modest contribution to the wider effort to highlight the barriers that prevent potential allies from fully supporting immigrants in their struggles for greater rights, and to open up a new debate about the possibilities to create more inclusive spaces of interaction, beyond historical problems rooted in centuries of European racism. 


\section{Conclusion}

In the recently published book titled Decolonizing anti-racism (De-colonizzare l'anti-razzismo) Palmi (2020) highlights the importance of promoting an antiracist movement free of racism in Italy and in Europe. This would be possible, according to the author, by creating a political space in which racialized subjects are freed of constructions and representations of passivity and vulnerability. She highlights what my book also exposes: the humanitarian discourses, promoted also by the left, place immigrants in a condition of marginality. He explains:

The humanitarian (framework) has effectively become an industry, within which the racial device works tirelessly in its work of enhancing and hierarchizing differences. ... By alternating a tragic and victimizing register with a paternalist one, the migrant subject is metabolized to respond positively to the criteria of management and governance of international migration. What passes off as integration is nothing other than the precise location of migrants within a more complex chain of exploitation and value extraction.

(Palmi 2020, 8-9; my translation)

While the crucial role of racial exploitation in the Italian labor market was not the direct focus of my analysis, the analysis shows how discourses and practices by pro-immigrant actors work as disciplinary mechanisms of marginalization of immigrant groups within Italian society. I have called these disciplinary mechanisms political racialization. This is an encompassing concept that pinpoints to the multiple discursive devises and actions that contributes to place immigrants in a position of marginality within the Italian leftist and "humanitarian" organizations, such as the Catholic Church. The rich empirical data and the in-depth analysis of these mechanisms represent a step ahead in the direction of understanding the complicated role of anti-racist organizations in the process of racialization in one crucial country at the border of Europe and of exploring a possible way out to address racialization processes within anti-racist movements (Palmi 2020; Mellino 2020; The Black Mediterranean Collective 2021).

The influential anti-racist American scholar, Kendi (2019) tells how to move forward in the direction of dismantling racism. He writes: "The only way to undo racism is to consistently identify it and describe it—and then dismantle it" (p. 9). A few pages later, he adds: "We know how to be racist. We know how to pretend to be not racist. Now let's know how to be antiracist!" (Kendi 2019, 11). Thus, research aiming to identify and explain the work of racism in society is the first step to bring change in the direction of ending what racism produces: racial inequality. Additionally, Kendi pinpoints that anti-racism is something that needs to be acquired through hard work. Historically, we have all learned in schools and our society about white superiority and the Others' inferiority. It will take us an important amount of work to unlearn racism and to identify and dismantle it. Yet, today we have enough resources to educate ourselves and learn how to become anti-racist $(i b ., 11)$.

The research conducted with immigrant activists fighting for their rights in Italy taught me that, by listening with humility and integrating into our research the 
practices and perspectives of those who have been for too long the object of our investigations and discourses, we can expand our understanding of the social world and the processes involved in the movement of people who are victims to multiple forms of exclusion. In addition, self-criticism creates new spaces of resistance and new possibilities to develop emancipatory struggles for immigrants in receiving societies. Treating immigrants as passive subjects, silencing their voices in the struggles that concern them, is a form of racism, even if a subtle one. As Kendi points out, discourses and practices are either racist or anti-racist, and anti-racist discourses and practices are only those who actively engaged in ending racial inequalities.

Silencing by pro-immigrant actors in Italy is striking because immigrants' activism and rights claims clearly demonstrate not only that they understand their situation better than most Italian actors, but also that they are pointing the way to the future, as their struggle is the struggle for democracy. In a recent interview, while talking about the Black Lives Matter movement in the USA, Angela Davis conveyed this point well:

What is important, when we look at the black movement, the movements against racism, for justice ...., these movements are really at the heart of the struggle for democracy. When we say Black Lives Matter, the meaning of this phrase is: when the lives of blacks count all over the world, then at that time, all human lives will count . . . . It is a radical demand for democracy against racism, against sexism, against homophobia, transphobia, economic discrimination, and, for many of us, against capitalism. And especially for the health of the planet.

$(\text { my translation })^{3}$

In this respect, the demands that immigrant activists promote in Italy are part of a larger struggle of marginalized groups around the world. Their demands are not only an act of despair but a vocal response for greater justice. As one of the activists based in Brescia told me during our interview:

When you know that the government does not give answers, when it leaves you with despair ... in these extreme conditions ... you must react. This situation makes you go out and shout. It makes you protest. People cry out: 'No to the violation of rights! No one is illegal! Immigration is not a crime!' I ask politicians: 'What is your role?' They are killing people. When I participate, I do not do it for myself. People here fight not for themselves, but for their kids. No one wants this future for their kids. ${ }^{4}$

Historically, progressive social movements and struggles from below have helped to democratize societies by extending rights to groups who were previously excluded from them. While many of these struggles focused on securing citizenship rights and voting rights to disenfranchised groups (e.g., the working class, women, and Black people in the United States), they were mostly about demands for substantial inclusion to achieve parity and equality of opportunity. As this 


\section{Conclusion}

book has shown, immigrant activists, for many years, have been making these same demands to improve their situation in Italy; hopefully, one day our democracies will reap the fruits of their sacrifices, by opening up to new debates and by developing solutions for sustainable pluralistic societies.

\section{Theoretical contribution to current research}

When seen from the point of view of the political variety in mobilizations and claims, and the complexity of actors involved, academic accounts of why and how immigrants in vulnerable conditions mobilize in highly hostile environments remain still insufficient. The findings of this book complicate existing explanations in the scholarship on migration (focusing on national and local integration regimes) and social movements (focusing on both institutional and non-institutional factors) by exploring the ambivalent role of a plethora of pro-immigrant actors in favoring or hindering immigrants' activism and inclusion in the receiving society. This book has sought to shift attention from the state to pro-immigrant and immigrant actors, adopting an actor-oriented approach and expanding the scholarship on the mobilizations of immigrants and their allies (Cappiali 2016, 2019; Nicholls 2013; Nicholls and Uitermark 2016; Zepeda-Millán 2017). In particular, my work reveals the complex role of interactions between pro-immigrant and immigrant groups, and especially asymmetrical power dynamics and racialization, in shaping civic and political participation of immigrant activists in receiving societies.

This study contributes to establishing a basis for a new research agenda. This new agenda strives to bridge migration literature with social movement studies and critical race and postcolonial theories in order to better understand the factors that shape the opportunities and constraints for the promotion of immigrant rights. With implications for citizenship and migration studies more generally, this kind of research sheds light on the role of a variety of pro-immigrant supporters and immigrant activists in reshaping debates on immigrant rights and inclusion from below. While some scholars have repeatedly highlighted the important role of proimmigrant groups (Cappiali 2016, 2019; della Porta 2018; Hansen 2019; Nicholls 2013; Siméant 1998; Zepeda-Millán 2017), our knowledge on the topic needs further theorization. As Menjívar $(2010,18)$ notes, the relationship between social movements and immigration "has remained underdeveloped and thus could stand to benefit from a more active dialog." This study argues that, to explain this relationship, we need to incorporate research from the field of critical theory as well to further analyze power dynamics and especially processes of othering by proimmigrant groups and forms of resistance by immigrant activists.

In Europe, these mechanisms have been partly uncovered by feminist researchers working with intersectionality, and addressing privilege and whiteness in the feminist movements (Evans and Lépinard 2020; Lépinard 2014, 2020). This research looks closely into power dynamics in the feminist movement and emphasizes how white privilege plays a key role in marginalizing or excluding women of color. While many white feminist movements, faithful to their core principle of gender equality, continue to promote solidarity for women, simultaneously they oppose resistance 
to political demands for more inclusion from feminists of color (Lépinard 2020). There are several examples of how women of color are prevented to be part of the movement as subjects with their own legitimate claims, political views, and demands. By treating these women as objects of charities, their political demands are silenced and delegitimized by many white feminist organizations and movements (Lépinard 2020). As my book shows, just like racialized feminists, many immigrant and racialized communities have exposed and resisted what feminist scholars call "exclusionary solidarity" (Ferree and Roth 1998, 629), by organizing both within and outside the leftist organizations to promote their rights.

Building on this insight, this book contributes to theorizing immigrant participation and rights claims from the bottom up, improving our knowledge about the complexity of urban settings and the role of grassroots organizations in supporting, containing, or undermining immigrant rights claims and political participation. The main argument of the book is that conflicts and alliances among Italian pro-immigrant groups and immigrant activists, as well as processes of othering by pro-immigrant actors, affect patterns of civic and political participation and grassroots mobilizations of immigrants and racialized communities. They do so by encouraging some forms of participation (e.g., conventional vs. non-conventional) while discouraging others. Additionally, particular approaches to inclusion-how local actors understand and frame immigration and inclusion-affect the channels of participation promoted by local actors and the alliances created between pro-immigrant and immigrant actors. Finally, immigrant activists are key players and have a significant impact on local dynamics, both directly and indirectly, by interacting with pro-immigrant actors.

\section{A theoretical model to explain conflicts and alliances in context}

The first main theoretical contribution of my research lay in its re-conceptualization of local context. The literature on the local turn has already established the key role of localities in favoring or hindering participation (Caponio 2006; Garbaye 2005; Penninx et al. 2004; Triviño-Salazar 2018). However, only recently has more attention been paid to the role of local spaces as "relational incubators" and with a particular focus on interactions and agential factors among a plurality of actors (Nicholls and Uitermark 2016; Cappiali 2019).

In Chapter 2 I introduced a new theoretical model of local dynamics to account for local variations in forms of participation of immigrant activists and the alliances created between immigrant activists and pro-immigrant groups. I explained that, in order to grasp local dynamics and immigrants' agency, we need to go beyond a rigid conceptualization of "context." Following Però's $(2008,122)$ observation, context should be conceived as a "flexible" concept rather than a deterministic one, and scholars should rethink the framework "in more comprehensive, loose, actors-oriented and interactive terms so as to avoid monocausal institutional determinism." In line with Però's criticism, I endeavored to redefine the opportunities and constraints available to immigrant activists by enlarging the local arena and by looking to a wide range of pro-immigrant and immigrant actors 
and their interactions. To this end, I developed a theoretical model of local dynamics based on the study of the four cities.

This model, I argued, helps us to "see" the factors and mechanisms that shape local dynamics and variations of participation outcomes in cities. In particular, it shows that, while institutional settings affect local configurations and the types of actors that may matter the most in a given setting, they do not allow us to fully unpack how actors get involved in the local arena and how their complex interactions affect the inclusion of immigrants and racialized communities. The model, therefore, demonstrates that, within given institutional settings, ideological affiliations, strategic considerations, conflicts, and alliances between a plethora of pro-immigrant and immigrant groups explain why and how immigrant activists mobilize or not across cities (both at the individual and group levels) and when they do, why they decide to do it in certain ways.

Chapters 3-6 illustrated how the model can help us to explain significant variations in forms of participation by immigrant activists and to grasp complex local interactions among a plurality of actors. In Chapter 7, I showed that immigrants' discourses and practices were, for the most part, not aimed at challenging the exclusionary practices of the state and anti-immigrant parties. Rather, they revealed strong criticism and, in some cases, irreconcilable conflicts with proimmigrant supporters who had failed to treat them as equal partners and often preferred to use immigration issues to advance their own interests rather than promoting immigrants' rights. The analysis offered in these five empirical chapters shows evidence of the relevance of the model. It showed that bottom-up dynamics and agential factors matter more than what the literature on migration and cities has tended to concede so far. In short, we need to reframe our conceptualization of the opportunities and constraints available to immigrant activists in cities and refine research on immigrant participation and cities, because the latter has tended to focus mainly on institutional incentives (e.g., Caponio 2006; Garbaye 2005; Ireland 1994; Koopmans 2004; Morales and Giugni 2011; Triviño-Salazar 2018). Over and above institutional incentives, we should emphasize, instead, incentives promoted from below by pro-immigrant and immigrant actors. In cities like Bologna and Brescia, for instance, these channels have been crucial in offering immigrant activists' opportunities to develop some key civic and or political trajectories of participation, especially when local institutional opportunities are weak (e.g., Bologna) or inexistent (e.g., Brescia).

\section{Theorizing immigrant activism in context}

The second main theoretical contribution of this study was conceptualizing immigrant activism via a critical lens, zooming in on the power dynamics and processes of othering by pro-immigrant groups, as well as the responses by immigrant activists. I argued that responses and strategies by immigrant activists are embedded in local dynamics and especially complex networks of interactions with pro-immigrant groups. As Foucault put it, "Where there is power there is always resistance, and yet, or rather consequently, this resistance is never in a position of exteriority in relation to power" (Foucault 1978, 95, quoted in Nicholls and Uitermark 2016, 
559). The local dynamics and complex interactions described in this book show that power relations tend to include immigrants in a position of subordination. At the same time, they offer opportunities for immigrants to resist pro-immigrant actors' tendency to appropriate their cause and marginalize them. To a certain extents, moreover, immigrant activists' resistance does not take place in a vacuum but it is embedded in the specific discursive regime of power in each city.

Paradoxically, much recent research on immigrant activism, and especially in the field of critical citizenship and borders studies (e.g., Nyers and Rygiel 2012; Oliveri 2015), while emphasizes immigrants' agency and self-determination; it also tends to erase power dynamics between pro-immigrant actors and immigrants. Thus, the conditions that make immigrants' self-determination possible are rarely adequately addressed empirically. If we want to understand immigrants ' agency and resistance to exclusion, we need to better acknowledge why and how their discourses and practices are ineluctably inscribed in the contexts in which they operate and are embedded in complex networks of relational-and often competing - discourses and practices conveyed by a multiplicity of pro-immigrant actors.

Acknowledging the complex role of power dynamics in affecting immigrant activism does not diminish the crucial role of immigrants agency. Instead, it helps to put immigrant activism into perspective. Immigrant activists do not enter empty spaces, but complex systems of interactions and power relations that can be both detrimental and favorable to their activism and rights claims. Some options might be precluded to people of migrant background in certain phases of their trajectories and become available only in the phases of stabilization. Other options might be available and yet considered not viable for ideological or strategic reasons. All these choices are strongly affected by the power dynamics in which immigrants find themselves, but they remain choices nonetheless.

\section{Empirical contribution to current research}

The empirical research was comprised of an in-depth analysis of four cities in the North of Italy. Building on the large migration literature on localities, I selected two traditionally Communist (or progressive) cities (Reggio Emilia and Bologna) and two traditionally Christian Democrat (or conservative) cities (Brescia and Bergamo), in order to control for institutional variations and configurations of actors in both similar and different political sub-cultures (see Chapter 1 and Appendix A). Studying the discourses and practices of multiple local pro-immigrant and immigrant organizations through extensive ethnographic work, and documenting how their approaches to inclusion shaped their range of actions, I identified the main factors and mechanisms that explain variations in alliances and participation and rights claims of immigrant activists in the four cities. I briefly summarize the main findings here.

\section{Ideology and approaches to inclusion}

How actors construct "who is an immigrant" and, consequently, "who is to be integrated/included" matter. How pro-immigrant actors construct immigrants as 
objects of inclusion is largely affected by their ideology. Previous research has shown that ideology affects the way in which local actors, and especially policymakers, promote inclusion (Caponio 2006; Mantovan 2007; Penninx et al. 2004). Church-based organizations tend to mobilize in favor of immigrants' protection, by resorting to legal devices to fight discrimination and by offering assistance to the most vulnerable (Ambrosini 2013). Moderate left-wing actors often prefer to mobilize in favor of the greater inclusion of all immigrants and racialized communities by promoting a vision of the receiving society as multi-ethnic, focusing on the value of sharing ethnic and cultural differences, defining immigrants as would-be citizens and a resource (Campomori and Caponio 2014). More radical left-wing organizations (political parties, trade unions, and grassroots movements) tend to mobilize in favor of immigrants' rights claims and self-determination, supporting political forms of participation, and focusing more overtly on capitalism and class issues (Adler et al. 2014; Cosseron 2007). Finally, the extra-parliamentary or radical left and grassroots unions of Marxist, socialist, or anarchist orientations - such as the No One Is Illegal! or No Border movements - tend to support mobilization in non-conventional politics of immigrants in vulnerable conditions (e.g., sans-papiers, refugee-status claimants, and workers employed in the underground economy) (Cosseron 2007; Hansen 2019; Siméant 1998). These non-institutional actors, in particular, have been vital in challenging the legitimacy of the state's role in ruling on citizenship and legal status and in denouncing its role in producing immigrants' precarious status. This precariousness, it has been argued, produces immigrant illegality and guarantees their exploitation in the labor market (see Anderson 2010; Calavita 2005; De Genova 2010). Finally, radical left organizations have been the main challengers to other pro-immigrant groups, by criticizing the role of the Catholic Church in treating immigrants as people in need of assistance on the one hand, and the more moderate left-wing actors for neglecting issues of class and marginalization on the other (Cosseron 2007, 158-259; see, e.g., Siméant 1998 on the sans-papiers movement in France).

How the interactions between this variety of pro-immigrant actors with different ideologies shape immigrants' civic and political engagement across local contexts is, however, less explored. To fill this lacuna, I introduced the concept of "approaches to inclusion" to analyze not only what actors do, but why and how they do so. This allowed me to scrutinize the discourses and practices of local actors and to identify three main approaches - assistance, intercultural, and political rights promotion. These approaches largely depend on how immigrants are constructed as, respectively, people in need, would-be citizens, or people with full political rights. These constructions and their associated approaches connect to the creation (or not) of incentives for immigrants' participation (see Table 7.1).

These approaches speak to how immigrants are constructed as "subjects of inclusion" through discourses and practices and, consequently, why and how their political voices are encouraged or channeled in specific ways. These findings have implications that extend beyond the specific case of Italy. I will set out some of these implications at the end of this concluding chapter. Although we can expect different approaches to inclusion in other cities, the analytical framework and methods used here remain both relevant and valuable as examples on which to build. 
Table 7.1 Ideology and approaches to inclusion

\begin{tabular}{|c|c|c|c|}
\hline Ideology of actors & $\begin{array}{l}\text { Construction of } \\
\text { immigrants }\end{array}$ & Approaches & $\begin{array}{l}\text { Implications for } \\
\text { participation }\end{array}$ \\
\hline $\begin{array}{l}\text { Catholic Church and } \\
\text { Christian- } \\
\text { democrat trade } \\
\text { unions }\end{array}$ & $\begin{array}{l}\text { Immigrants are in } \\
\text { need }\end{array}$ & Assistance & Obstacles to participation \\
\hline $\begin{array}{l}\text { Moderate left-wing } \\
\text { administrations } \\
\text { and lay } \\
\text { organizations }\end{array}$ & $\begin{array}{l}\text { Immigrants are } \\
\text { would-be citizens } \\
\text { and "inclusion" is } \\
\text { reciprocal }\end{array}$ & Intercultural & $\begin{array}{l}\text { Promotion of civic } \\
\text { channels }\end{array}$ \\
\hline $\begin{array}{l}\text { Moderate and } \\
\text { radical left } \\
\text { (Political } \\
\text { parties and } \\
\text { radical groups/ } \\
\text { movements) }\end{array}$ & $\begin{array}{l}\text { Immigrants are } \\
\text { entitled to political } \\
\text { rights, independent } \\
\text { of their formal } \\
\text { status }\end{array}$ & $\begin{array}{l}\text { Promotion } \\
\text { of political } \\
\text { rights }\end{array}$ & $\begin{array}{l}\text { Promotion of conventional } \\
\text { channels by moderate } \\
\text { actors } \\
\text { Promotion of non- } \\
\text { conventional channels } \\
\text { by more radical actors }\end{array}$ \\
\hline
\end{tabular}

\section{Local dynamics and political competition among a plethora of actors}

While previous research has pointed to the importance of local dynamics in shaping mobilizations (Monforte and Dufour 2011; Nicholls and Uitermark 2016), it has not fully unpacked the question of intramural conflicts and ideological schisms between pro-immigrant actors in explaining differences across local contexts. As Nicholls and Uitermark $(2016,719)$ point out, while cities are considered key "relational incubators," not all cities are conducive to immigrant mobilizations. Actors compete with each other over their approaches to inclusion, which has an impact on how they promote or block participation across cities. In particular, the ways in which local actors frame migration issues vary, not only with respect to their political orientation but also as a result of their interactions with each other in different settings. Here, their struggle to gain legitimacy in the work they do in the field of migration is particularly important.

My research revealed two main findings in terms of political competition among pro-immigrant actors. First, it explained why and how some mobilizations are characterized by high turnout and significant participation of immigrant groups (e.g., Reggio Emilia, Bologna, and Brescia), while others have a low turnout with a "weak" presence of immigrant activists (e.g., Bergamo). I showed that the presence and strength of dominant actors with different political affiliations was pivotal in defining the mobilizations' strategies and outcomes in each city. Dominant actors usually play a key role and may direct how migration issues are addressed by other actors who compete with them in the political arena, affecting how their challengers become involved. The presence or absence of challengers can change primarily local dynamics. The absence of challengers gives a great deal of power to dominant actors, as they encounter no relevant obstacles (such as for the Catholic Church in Bergamo). In contrast, the presence of challengers 
can create conflict and competition between actors. In some cases, challengers can prompt dominant actors to reconsider their framing of inclusion issues and push other actors to promote a more nuanced approach. Moreover, different understandings and framings of immigration and inclusion issues can often diverge so much as to give rise to open conflict (such as between the radical left and the Catholic Church and trade unions in Brescia).

Second, my analysis of the different actors involved in the mobilizations in the four cities illustrated that interactions between pro-immigrant actors and immigrant activists may affect which forms of participation as well as which immigrants will be more engaged and visible in each city (e.g., second-generation immigrants in Reggio Emilia or undocumented immigrants in Brescia), as summarized in Table 7.2. Based on my analysis of Bologna and Bergamo, for instance, important local variations in mobilization strategies and outcomes during the organization of "A day without us" in 2010 may be explained by looking more closely at the role of civil society groups. In Bologna, left-wing actors promoted the idea that mobilizations should be organized with immigrants. This specific approach was not new in Bologna, as the promotion of immigrants' empowerment has been a central feature of grassroots pro-immigrant actors. Here, the dominant actors - the left-wing pro-immigrant actors - have adopted both the intercultural and the political rights promotion approaches, which favor immigrants' empowerment through the opening of civic and political channels. In the organization of "A day without us," these particular approaches were reflected in the relevant presence of immigrants in the organization of the mobilization, in the months preceding it as well as the day it took place the first of March (cf. also Cappiali 2019). In contrast with Bologna, the case of Bergamo revealed that the interactions of actors can sometimes block, rather than merely limit, immigrants' voices. The main dominant actors in the city- the

Table 7.2 Alliances and participatory variations in the four cities

\begin{tabular}{lll}
\hline $\begin{array}{l}\text { Cities } \\
\text { (political sub- }\end{array}$ & $\begin{array}{l}\text { Conflicts/alliances } \\
\text { with immigrant activists }\end{array}$ & $\begin{array}{l}\text { Forms of participation of immigrant } \\
\text { activists }\end{array}$ \\
\end{tabular}

\begin{tabular}{|c|c|c|}
\hline Reggio Emilia & $\begin{array}{l}\text { Main alliances }=\text { local } \\
\text { authorities, lay NGOs and } \\
\text { immigrant youth }\end{array}$ & $\begin{array}{l}\text { Civic participation of new citizens, } \\
\text { mostly youth }\end{array}$ \\
\hline Bologna & $\begin{array}{l}\text { Conflicts with some left-wing } \\
\text { actors, but also multiple } \\
\text { alliances with different } \\
\text { groups of immigrants }\end{array}$ & $\begin{array}{l}\text { Civic participation } \\
\text { and conventional and non- } \\
\text { conventional political participation } \\
\text { of different groups of immigrants }\end{array}$ \\
\hline Brescia & $\begin{array}{l}\text { Conflicts with trade unions } \\
\text { and church-based actors } \\
\neq \\
\text { Alliances between the radical } \\
\text { left and more vulnerable } \\
\text { immigrants }\end{array}$ & $\begin{array}{l}\text { Non-conventional participation and } \\
\text { radicalization of undocumented } \\
\text { immigrants }\end{array}$ \\
\hline Bergamo & Lack of alliances & (Mostly) lack of participation \\
\hline
\end{tabular}


Catholic Church and their allies - promoted an assistant approach to inclusion, which tends to victimize and silence immigrants. This approach resulted in the tendency to obstruct immigrant civic and political involvement completely.

Similarly, the cases of Reggio Emilia and Brescia showed contrasting examples too. In Reggio Emilia, the main actor promoting immigrants' inclusion in the city was the left-wing administration. Here one can observe the promotion of an intercultural approach from above, in collaboration with the lay organizations. This approach resulted in the creation of alliances between the local administration and second-generation immigrants and in the promotion of second-generation leadership. This situation, however, resulted also in the depoliticization of key immigrant issues (such as lack of housing and immigrants' criminalization) and the marginalization of the voices of those groups that did not fit with the local actors' promotion of interculturalism (e.g., undocumented immigrants). Conversely, in Brescia, the main local actor promoting immigrants' inclusion were the Catholic Church and the main trade unions, on the hand, and the radical left and a more radicalized branch of the leftist trade union, on the other. While the Catholic Church and the CISL (the Cristian Democrat trade union) promoted mostly an assistant approach from below, the CGIL and the radical left focused on empowerment and the promotion of political rights of immigrants, including vulnerable and undocumented workers, victims of institutional racism and exploitation in the labor market. These particular configurations of actors and approaches to inclusion resulted in the development of non-formal and non-conventional forms of political actions and the creation of alliances mostly between the radical left and undocumented immigrants. Moreover, ideological clashes between these actors were particularly visible.

\section{Power dynamics and political racialization}

Alliances and participation of immigrant activists are affected not only by competition among pro-immigrant actors but also by power relations and processes of othering by pro-immigrant groups. These factors contribute to the marginalizing and silencing of immigrants' voices in the struggles that concern them. Confirming results reported in studies of immigrant movements in other countries (Nicholls 2013; Nicholls and Uitermark 2016), immigrant supporters in Italy tend to overshadow immigrants' struggle for greater rights by appropriating their causes. Marginalization of immigrant voices is often a side effect of framing processes where actors attempt to construct counternarratives of immigrant "deservingness" (Nicholls 2013; Yukich 2013). However, using a critical lens to unveil power dynamics, my analysis showed that ideology and struggles for legitimacy among pro-immigrant actors play a key role in marginalizing immigrant voices. In particular, pro-immigrant actors in Italy tend to produce what I have called political racialization. This means that political actors, in order to legitimize their work on immigration, promote the participation of some immigrant groups that fit with their views, and include immigrants in the political sphere, but in a relationship of "ethnic" or "racial" subordination (see also Cappiali 2016). From this 


\section{Conclusion}

perspective, the role pro-immigrant actors play in racializing immigrant activists, via mechanisms of exclusion and marginalization, reduce the scope of their mobilizations and rights claims. Pro-immigrant actors often promote claims and views that support their overall goals, forming alliances with immigrants who reinforce their power. As such, while immigrant supporters may open up some opportunities for mobilization across ideological lines and close down others, depending on their different approaches to inclusion (e.g., intercultural vs. political rights promotion), more commonly they leave little space for constructing mobilizations grounded in immigrant claims that challenge or come into conflict with their own.

Several pro-immigrant groups have failed to address deep internal barriers that prevent immigrants' self-determination. Paternalism and opportunism function as instruments of power, giving visibility to those who work for immigrants (Cappiali 2017). For this mechanism to work, immigrants' rights claims have to be channeled in certain directions - as in the case of more disruptive politics by the radical left, for instance - or silenced, as is often the case with the Catholic Church. These mechanisms vary in the four cities on account of the local dynamics at play and the different approaches of inclusion adopted by these actors. Caponio (2006) notes that Italian actors within civil society are particularly powerful in comparison to immigrant associations, and thus create a crowding-out effect. However, if the issue is looked at through a critical lens (Cappiali 2017), specific power dynamics are revealed that reproduce unequal treatment and exclusion of immigrant association through de-politization mechanisms. Among the various mechanisms identified were also victimization, political opportunism, co-optation, dis-empowerment of immigrant platforms, and the silencing of immigrant voices. It is no surprise that many immigrants have sought alternative channels through which to participate and make their voices heard, beyond those offered by traditional left-wing actors, and especially by mainstream political parties and traditional trade unions. In some cases, immigrant activists have turned to political disengagement as a form of protest.

\section{Immigrant activists as key political players}

Immigrant activists are, to differing degrees, relevant political players, promoting their inclusion through civic and political activism and rights claims. Deplorable living and working conditions in Italy encourage and shape immigrants' activism. Existing literature argues that when mobilizations take place, alliances and rights claims are made particularly complicated when hostile environments restrict the possibilities available for expansive claims (Nicholls 2013) and successful mobilizations (Voss and Bloemraad 2011). Moreover, immigrant activists have less individual and collective strength when trying to navigate complex power relations and overcome obstacles imposed by pro-immigrant groups to make their voices heard (della Porta 2018). Against this, my research found that activism occurs not so much despite, but rather because of the highly hostile environment in which they operate.

Whatever challenges they face, immigrant activists strategically evaluate their options and create alliances with some pro-immigrant actors rather than others. 
These decisions can be based on, among others, the trust they have in these actors, as well as their own beliefs, political affiliations, and economic and juridical status. Since it is not always possible for them to transform local dynamics directly, immigrant activists often promote their political rights and claims by allying with some pro-immigrant supporters rather than others. In most cases, they appropriate the approaches to inclusion adopted by their allies in the city where they live, reinforcing them or challenging them through their discourses and practices, giving or denying them legitimacy in the local arena. In other cases, they can be crucial players in promoting alternative visions of migration and inclusion beyond those promoted by their supporters, or they can appropriate and reinterpret the approaches to inclusion adopted by these actors through their activism.

As I anticipated in the Introduction to this book, much research in the field of migration tends to dichotomize receiving societies and immigrants in ways that assume that immigrants are separate entities. In this book, I have sought to illustrate that, through their mobilizations at the individual and collective levels, immigrant activists are fully embedded in local dynamics and significantly affect these dynamics both directly and indirectly. They do so by interacting with their allies and by interpreting and challenging their views and framings of immigration and integration issues. They shape alliances by challenging other actors, and they engage in multiple forms of civic and political participation, making their voices and claims heard. Considering migrant activists as relevant political players, my research has demonstrated that they are not external to local dynamics, but rather play a vital role in transforming local dynamics. I have established that immigrant activists influence and shape their local context in a range of ways, including developing powerful counter-narratives from below about what it means to be included with full rights in receiving societies. These narratives, moreover, are only in part shaped by their conditions of being constructed as "immigrants" in the society, via also powerful processes of othering; their views are largely shaped by their ideological affiliations and life experience.

\section{Recommendations for future research}

By focusing on the conditions of immigrant activism in four Italian cities in the North, this study has only scratched the surface of several issues that have a bearing on the relationship between pro-immigrant supporters and immigrant activists in receiving society, as well as the role of immigrant activists in transforming receiving societies from below. By way of conclusion, I will highlight some potentially fruitful avenues for future research.

First, more studies on the role of pro-immigrant groups are needed in order to understand how, in different countries, they have responded to immigrants and racialized communities striving for greater inclusion. This book suggests that proimmigrant groups have been only partially able to fulfill their promise of greater equality and inclusion and that they have often been slow in understanding what is at stake in the promotion of greater inclusion of the migrant population beyond self-preservation. In more recent years, in response to the rise of anti-immigrant 
sentiments, many traditional pro-immigrant supporters - and especially political parties and trade unions - have become more reluctant to stand up for immigrants' rights. Hence, we need to deepen our knowledge about why and how this is the case, and, possibly, propose solutions to improve this situation (Kendi 2019).

Second, there is a growing body of research today addressing the implications for immigrants' exclusion in light of the rise of the right in Europe. At the same time, there is very little systematic research on the role of the left in excluding or racializing immigrants (Cappiali 2017, 2019; Però 2007). My research has revealed the presence of forms of more subtle racism. This is not surprising. As Van Dijk (1993), one of the main experts on elite racism in Europe, has observed, European democracies have maintained racialized groups in unequal positions in society through what he calls subtle or less overt rather than more blatant forms of racism (see also Wodak and Van Dijk 2000). Indeed, in this regard, with the exception of anti-immigrant and far-right parties, contemporary analyses of the role of political elites across the entire political spectrum are lacking.

This book has shown that the instrumental use of immigrants by the left is a major problem in Italy. The failure on the part of left-wing parties and other proimmigrant key actors to treat immigrants as equal is not unique to Italy. Indeed, it is quite common in many countries across Europe. It has strained alliances and caused conflicts with immigrant organizations (Raissiguier 2010; Siméant 1998). Yet, many human rights defenders and academics still struggle to acknowledge and tackle less blatant practices as expressions of racism, even though those practices represent visible barriers for the inclusion of immigrants and racialized communities in receiving societies (El-Tayeb 2011; Palmi 2020; Curcio 2020; Lentin 2004).

Third, one actor that calls for greater attention is the Catholic Church. In the context of migration, the Church is an influential political force in many countries around the world (Gaspari 2017). In the European context, in recent years, it has sometimes replaced the state in delivering services to immigrants (Itçaina 2006; Mantovan 2007). There are several examples of the crucial role of the Catholic Church in promoting a positive vision of immigrants and advocating for immigrants' human rights in increasingly hostile environments (Kanstroom and Menjívar 2013). These include mobilizing in coalition with other pro-immigrant actors and immigrants' groups (see, e.g., their role in the movement for the mass regularization of sans-papiers in France and the United States: Nicholls 2013; Siméant 1998; Heredia 2011). In the United States, moreover, it has been argued that the Catholic Church "has been among the clearest voices defending the dignity and rights of undocumented immigrants" (Marquardt et al. 2013, 278). It has been a crucial actor in the movement of sanctuary cities, defying national laws that criminalize immigrants without documents. In recent years, the leadership of Pope Francis has taken an especially liberal view on migration and refugees (Kasper 2015; Scanone 2016), challenging the climate of intolerance promoted by anti-immigrant politicians around the world.

In Italy, the Catholic Church was involved early in the realm of immigrationincluding the opening of local desk centers around the country since the $1980 \mathrm{~s}$ - and by its continued effort to respond to the needs of the most vulnerable immigrants, 
including after the financial crisis of 2008. Adopting a universalistic view of human rights and advocating for religious and non-religious tolerance, the Catholic Church remains a key actor in the realm of migration in Italy (see also Mantovan 2007). However, more research is needed to assess why and how the Catholic Church may prevent immigrants' greater inclusion in receiving society. My research suggests a rather ambivalent role when it comes to defending its political interests. The case of Bergamo, for instance, showed that while the Catholic Church has promoted, a climate of tolerance, at least at the level of discourse, also by opening challenging the anti-immigrant party, the Northern League, it has also de facto posed powerful obstacles to religious and non-religious pluralism and has prevented immigrants' empowerment and civic and political participation in the city.

Fourth, people of migrant background have long played a crucial role in the processes of inclusion and recognition, engaging in multiple forms of civic and political participation at the individual and collective levels (Però and Solomos $2010,7)$. There is ample research in the field of citizenship and migration on how societies respond to immigration and diversity. Research based, however, on the perspectives of immigrants themselves is still underdeveloped. In this respect, what would be welcome in Europe, and especially in the Southern European context, is a broader research agenda that examines how the processes of othering of immigrants in receiving societies works along ethnic, racial, religious, gender, and class lines. Feminist and diaspora studies have shown the importance of examining interlocking systems of oppression (Crenshaw 1989; El-Tayeb 2011) and how they affect oppressed people's subjectivity (Lépinard 2014). By looking at how immigrants and racialized communities resist these processes and make their voices heard (see, e.g., Pojmann 2006; El-Tayeb 2011; Kassir and Reitz 2016), we can better understand the meaning of their activism and rights claims (Cissé 1999; Raissiguier 2010). This intersectional perspective remains undertheorized in most studies of migrant activism, especially in the field of migration studies, social movements, and critical and borders studies.

\section{Reframing resistance, reimagining a European anti-racist movement for the future}

This study has implications both for academics working in the field of migration and for practitioners and human rights defenders. In European academic circles and political context, immigrants and racialized communities of immigrant background are often victimized objects of policies and study. This approach assumes immigrants are passive subjects, especially those in vulnerable conditions, and their voices are seldom represented in scholarship. As a consequence, scholars tend to underestimate the key role of immigrants and racialized communities in actively promoting social and political inclusion. The quest for mobility is in itself a political act, and many immigrants around the world have been politically active, sometimes simultaneously, in both their host and sending countries. To better account for immigrant voices and views, this study has aimed to place immigrant activists at the center of political dynamics and brings 
in their multiple perspectives in order to better understand their role in European societies. In doing so, the study has uncovered not only their lived experiences of racism and exclusion as seen through their own eyes, but it also shows how their activism and political claims - despite being stifled, disciplined, and repressed at every turn - mark important, if not vital, steps toward achieving a more thriving and inclusive democracy.

It is worth noting that the findings presented here have also practical implications. Today, immigrants' goal of achieving greater rights in Italy is undermined by anti-immigrant politics. Their struggles are stifled by anti-immigrant policy and discourses. Nonetheless, immigrants' voices are of vital importance, especially in tracing a new path for a more inclusive political system, wherein more open structures and opportunities for them will emerge, allowing them to have a greater influence on Italian laws and discourses. As Angela Davis explains, this goal will be better achieved when potential allies start to treat immigrants as equal partners and find ways to prevent their inferiorization in the struggles that concern them $(2016,26)$. As this book has shown, rather than being passive onlookers, immigrants are very much active protagonists.

Thus, reflections presented in this book are relevant beyond academia, for they call on all anti-racists - individuals and groups alike - to do better at improving immigrants' access to human rights. As Gilroy notes in Postcolonial Melancholia (2005, xvii):

I suppose I should say that the movement aimed at extending and consolidating human rights would be stronger and far more plausible if it could show that racism was something it had thought about as a historical problem and as a corrosive feature of contemporary democracy.

On the basis of my research, European practitioners and human rights defenders should reconsider some of their current approaches to better expose and dismantle power dynamics in their organizations, which contribute to reinforcing immigrants' unequal treatment and exclusion in society. Such a change can be initiated by listening more attentively to immigrants' voices and by offering the spaces they are calling for to express their views. This effort would allow us to make anti-racism movement stronger and to bring about much-needed transformations in Europe, especially by human rights organizations seeking to create more just societies. Thus, the findings of this book call on pro-immigrant groups to engage with Europe's deep-seated racism and to develop a self-critique of their dominant strategies. This self-criticism could create new spaces of resistance and new possibilities through which to develop emancipatory struggles for immigrants. In turn, by developing more expansive frames of action, such struggles could be broadened and connected to other movements against other important forms of discrimination on the part of other groups (including women, LGBTQ+ communities, and people with disabilities) in Italy and beyond.

The research described in this book left me with an increased awareness of the similarity of experiences of marginalization of immigrant activists and racialized groups in 
Italy and other racialized groups around the world. After spending many years trying to make sense of the material I had collected, I am left with some troubling thoughts about the role of immigrants and racialized groups in Italy and the future of Italian democracy. These thoughts are well summarized by the influential American writer and intellectual James Baldwin, who expressed deep concerns, where not despair, about the situation of Black people in the United States. These concerns echo those of the many immigrant activists I met during my research. Baldwin said:

There are days when you wonder, what is our role in this country and what our future is in it. I can't be a pessimist because I am alive . . The question you have to ask yourself - the white population in this country, has to ask itself - why it was necessary to have the Negro in the first place. Because I am not a Negro, I am a man. But if you think I am a Negro, it means you need me. And you have to find out why. And the future of the country depends on that. ${ }^{5}$

I hope this book will open new avenues of research in the European context, as more scholars will endeavor to challenge academic silence on racism and racialization and resistance to see, talk and study racial relations from a critical race study perspective. In this view, this book is my modest attempt to contribute unmasking and deconstructing the myth of universalism and the erasure of whiteness as a privilege sight through which power over non-white and racialize groups is exercised by pro-immigrant groups in Europe.

This study has taught me that encounters with other human beings are always encounters with ourselves. The intense debates around the Others within Europe can be considered as a unique opportunity to understand ourselves, the "West," and how our history is embedded in myths of eurocentrism and white superiority. By dismantling orientalist and racist "representations" of the Others, built over centuries of exploitation and colonialism, it will be possible to transform Western views about itself, renew its democratic vision, and promote a new political project based on human responsibility, fundamental rights, and justice. Time is ripe to recognize that "racism is not only corrosive feature of contemporary democracy," as Gilroy explains, but a problem that we have the means, as well as and the moral responsibility, to expose and resolve. The time has come for the organizations in Europe, who claim to be closer to the most marginalized groups-from leftwing organizations to humanitarian and Church-based organizations - to listen to the call for change, understand why and how our society creates its Others, and decolonize their discourses and actions accordingly.

\section{Notes}

1 She was Minister of Integration between April 28, 2013 and February 22, 2014, during the short-lived left-wing government led by Enrico Letta.

2 C. Kyenge. "As Italy's first black minister, I suffered vile racist abuse. But this poison damages us all." The Guardian. November 29, 2018. www.theguardian.com/commen tisfree/2018/nov/29/italys-first-black-minister-racist-abuse-discrimination (Accessed June 28, 2020). 
3 A. M. Lecomte. "L'abolition du racisme systémique passe par une solidarité mondiale, dit Angela Davis." Radio-Canada. June 25, 2020. https://ici.radio-canada.ca/ nouvelle/1714889/angela-davis-entrevue-telejournal-azeb-wolde-giorghis-racismesystemique-floyd (Accessed June 28, 2020).

4 BR/N13: Yusuf A., Pakistanis (Male), a main member of the migrant social movement and Cross-point in Brescia.

5 Quoted in the documentary "I am not your Negro!" (Peck 2016).

\section{References}

Adler, Lee H., Maite Tapia, and Lowell Turner, eds. 2014. Mobilizing Against Inequality: Unions, Immigrant Workers, and the Crisis of Capitalism. Ithaca: Cornell University Press/ILR Press.

Ambrosini, Maurizio. 2013. "Fighting Discrimination and Exclusion: Civil Society and Immigration Policies in Italy." Migration Letters 10 (3): 313-323.

Anderson, Bridget. 2010. "Migration, Immigration Controls and the Fashioning of Precarious Workers Work.” Work, Employment and Society 24 (2): 300-317.

The Black Mediterranean Collective, ed. 2021. The Black Mediterranean: Bodies, Borders and Citizenship. Cham, Switzerland: Palgrave Macmillan.

Bulmer, Martin, and John Solomos, eds. 2019. Migration and Race in Europe. New York: Routledge.

Calavita, Kitty. 2005. Immigrants at the Margins: Law, Race, and Exclusion in Southern Europe. Cambridge: Cambridge University Press.

Campomori, Francesca, and Tiziana Caponio. 2014. "Migrant Reception Policies in a Multi-Level System: Framing and Implementation Structures in the Italian Regions." In Politics of Immigration in Multi-Level States: Governance and Political Parties, edited by Eve Hepburn and Ricard Zapata-Barrero, 130-149. London: Palgrave Macmillan.

Caponio, Tiziana. 2006. Cittá italiane e immigrazione: Discorso pubblico e politiche a Milano, Bologna e Napoli. Bologna: Il Mulino.

Cappiali, Teresa M. 2016. "Activism of Immigrants in Vulnerable Conditions and RadicalLeft Allies: A Case Study of Italy's Struggle of the Crane." Journal of Ethnic and Migration Studies 42 (15): 2508-2527.

Cappiali, Teresa M. 2017. “'Whoever Decides for You Without You, He Is Against You!' Immigrant Activism and the Role of the Left in Political Racialization." Ethnic and Racial Studies 40 (6): 969-987.

Cappiali, Teresa M. 2019. "Ideological Affiliations, Conflicts, and Competing Mobilization Frames: The Role of Pro-Immigrant Allies in Shaping Immigrant Struggles for Greater Rights." International Migration Review 53 (3): 869-899.

Cissé, Madjigène. 1999. Parole de sans-papiers. Paris: La Dispute.

Cosseron, Serge. 2007. Dictionnaire de l'extrême gauche. Paris: Larousse.

Crenshaw, Kimberlé. 1989. "Demarginalizing the Intersection of Race and Sex: A Black Feminist Critique of Antidiscrimination Doctrine, Feminist Theory and Antiracist Politics." University of Chicago Legal Forum 1 (8): 139-167.

Curcio, Anna. 2020. "Razza e capitale: La doppia traccia del razzismo." In De-colonizzare l'anti-razzismo: Per una critica della cattiva coscienza bianca, edited by Tommaso Palmi, 34-52. Milan: Deriveapprodi.

Davis, Angela. 2016. Freedom Is a Constant Struggle: Ferguson, Palestine, and the Foundations of a Movement. Chicago: Haymarket Books.

De Genova, Nicholas. 2010. "The Deportation Regime: Sovereignty, Space, and the Freedom of Movement." In The Deportation Regime: Sovereignty, Space, and the Freedom 
of Movement, edited by Nicholas De Genova and Nathalie Peutz, 33-65. Durham, NC: Duke University Press.

della Porta, Donatella, ed. 2018. Solidarity Mobilizations in the "Refugee Crisis": Contentious Moves. London: Palgrave Macmillan.

El-Tayeb, Fatima. 2011. European Others: Queering Ethnicity in Post-National Europe. Minneapolis: University of Minnesota Press.

European Network against Racism (ENAR). 2018. "Forgotten Women: The Impact of Islamophobia on Muslim Women." https://www.enar-eu.org/IMG/pdf/forgottenwomenpublication_lr_final_with_latest_corrections.pdf.

European Union Agency for Fundamental Rights (FRA). 2019. "Being Black in the EUSecond European Union Minorities and Discrimination Survey - Summary." https://fra. europa.eu/sites/default/files/fra_uploads/fra-2019-being-black-in-the-eu-summary_en.pdf.

Evans, Elizabeth, and Éléonore Lépinard, eds. 2020. Intersectionality in Feminist and Queer Movements: Confronting Privileges. New York: Routledge.

Ferree, Myra Marx, and Silke Roth. 1998. "Gender, Class, and the Interaction Between Social Movements: A Strike of West Berlin Day Care Workers." Gender \& Society 12 (6): 626-648.

Foucault, Michel. 1978. The History of Sexuality I: The Will to Knowledge. London: Penguin. Garbaye, Romain. 2005. Getting into Local Power: The Politics of Ethnic Minorities in British and French Cities. Oxford: Blackwell.

Gaspari, Oscar. 2017. "L'impegno storico della Chiesa cattolica sulle migrazioni." Libertácivili.it. http://www.libertacivili.it/wp-content/uploads/2017/05/L-impegno-storicodella-Chiesa-cattolica.pdf.

Gilroy, Paul. 2005. Postcolonial Melancholia. New York: Columbia University Press.

Hansen, Christina. 2019. "Solidarity in Diversity: Activism as a Pathway of Migrant Emplacement in Malmö.” PhD diss., Malmö University, Malmö.

Heredia, Luisa L. 2011. "From Prayer to Protest: The Immigrant Rights Movement and the Catholic Church." In Rallying for Immigrant Rights: The Fight for Inclusion in 21st Century America, edited by Irene Bloemraad and Kim Voss, 101-122. Berkeley: University of California Press.

Ireland, Patrick. 1994. The Policy Challenge of Ethnic Diversity: Immigrant Politics in France and Switzerland. Cambridge, MA: Harvard University Press.

Itçaina, Xabier. 2006. "The Roman Catholic Church and the Immigration Issue: The Relative Secularization of Political Life in Spain." American Behavioral Scientist 49 (11): 1471-1488.

Kanstroom, Daniel, and Cecilia Menjívar, eds. 2013. Constructing Immigrant "Illegality": Critiques, Experiences, and Responses. Cambridge: Cambridge University Press.

Kasper, Walter. 2015. Pope Francis'Revolution of Tenderness and Love. New York: Paulist Press.

Kassir, Alexandra, and Jeffrey G. Reitz. 2016. "Protesting Headscarf Ban: A Path to Becoming More French? A Case Study of 'Mamans Toutes égales' and 'Sorties scolaires avec nous'." Racial and Ethnic Studies 39 (15): 2683-2700.

Kendi, Ibrahim X. 2019. How to Be an Antiracist. London: Penguin.

Koopmans, Ruud. 2004. "Migrant Mobilisation and Political Opportunities: Variation Among German Cities and a Comparison with the United Kingdom and the Netherlands." Journal of Ethnic and Migration Studies 30 (3): 449-470.

Lentin, Alana. 2004. Racism and Anti-Racism in Europe. London: Pluto Press.

Lépinard, Éléonore. 2014. "Doing Intersectionality Repertoires of Feminist Practices in France and Canada." Gender \& Society 28 (6): 877-903.

Lépinard, Éléonore. 2020. Feminist Trouble: Intersectional Politics in PostSecular Times. New York and London: Oxford University Press. 
Mantovan, Claudia. 2007. Immigrazione e cittadinanza: Auto-organizzazione e partecipazione dei migranti in Italia. Milan: FrancoAngeli.

Marquardt, Marie-Friedmann, Susanna J. Snyder, and Manuel A. Vásquez. 2013. "Challenging Laws." In Constructing Immigrant "Illegality”: Critiques, Experiences, and Responses, edited by Daniel Kanstroom and Cecilia Menjívar, 272-297. Cambridge: Cambridge University Press.

Mellino, Miguel. 2020. "Per una critica dell'anti-razzismo europeo." In De-colonizzare l'anti-razzismo: Per una critica della cattiva coscienza bianca, edited by Tommaso Palmi, 16-33. Milan: Deriveapprodi.

Menjivar, Cecilia. 2010. "Immigrants, Immigration, and Sociology: Reflecting on the State of the Discipline." Sociological Inquiry 80 (1): 3-27.

Monforte, Pierre, and Pascale Dufour. 2011. "Mobilizing in Borderline Citizenship Regimes: A Comparative Analysis of Undocumented Migrants' Collective Action." Politics \& Society 39 (2): 203-232.

Morales, Laura, and Marco Giugni. 2011. Social Capital, Political Participation and Migration in Europe: Making Multicultural Democracy Work? London: Palgrave Macmillan.

Nicholls, Walter J. 2013. "Making Undocumented Immigrants into a Legitimate Political Subject: Theoretical Observations from the United States and France." Theory, Culture \& Society 30 (3): 82-107.

Nicholls, Walter J., and Justus Uitermark. 2016. Cities and Social Movements: Immigrant Rights Activism in the US, France, and the Netherlands, 1970-2015. London: Wiley-Blackwell.

Nyers, Peter, and Kim Rygiel, eds. 2012. Citizenship, Migrant Activism, and the Politics of Movement. London: Routledge.

Oliveri, Federico. 2015. "Subverting Neoliberal Citizenship: Migrant Struggles for the Right to Stay in Contemporary Italy." ACME: An International E-Journal for Critical Geographies 14 (2): 492-503.

Palmi, Tommaso, ed. 2020. De-colonizzare l'anti-razzismo: Per una critica della cattiva coscienza bianca. Milan: Deriveapprodi.

Peck, Raoul. 2016. "I am Not Your Negro!” Documentary.

Penninx, Rinus, Karen Kraal, Marco Martiniello, and Steven Vertovec, eds. 2004. Citizenship in European Cities: Immigrants, Local Politics and Integration Policies. Aldershot: Ashgate.

Però, Davide. 2008. "Migrants' Mobilization and Anthropology: Reflection from the Experience of Latin Americans in the United Kingdom.” In Citizenship, Political Engagement, and Belonging: Immigrants in Europe and the United States, edited by Deborah ReedDanahay and Caroline Brettell, 103-123. New Brunswick: Rutgers University Press.

Però, Davide, and John Solomos. 2010. "Introduction: Migrant Politics and Mobilization. Exclusion, Engagement, Mobilization.” Ethnic and Racial Studies 33 (1): 1-18.

Pojmann, Wendy. 2006. Immigrant Women and Feminism in Italy. Aldershot: Ashgate.

Puwar, Nirmal. 2004. Space Invaders: Race, Gender and Bodies Out of Place. Oxford: Berg.

Raissiguier, Catherine. 2010. Reinventing the Republic: Gender, Migration, and Citizenship in France. Stanford: Stanford University Press.

Scanone, Juan Carlos. 2016. "Pope Francis and the Theology of the People." Theological Studies 77 (1): 118-135.

Siméant, Johanna. 1998. La cause des sans-papiers. Paris: Presses de Sciences po.

Steinhilper, Elias. 2018. "Mobilizing in Transnational Contentious Spaces: Linking Relations, Emotions and Space in Migrant Activism." Social Movement Studies 17 (5): 574-591. 
Steinhilper, Elias, and Ilker Ataç. 2019. "Contentious Subjects: Spatial and Relational Perspectives on Refugee Mobilizations in Europe.” In Handbook on Critical Geographies of Migration, edited by Katharyne Mitchell, Reece Jones, and Jennifer L. Fluri, 345-357. Cheltenham: Edward Elgar Publishing.

Triviño-Salazar, Juan-Carlos. 2018. "The Politics of Immigration Locally: Alliances Between Political Parties and Immigrant Organizations." Ethnic and Racial Studies 41 (9): 1728-1746.

Van Dijk, Teun. 1993. Elite Discourse and Racism. London: Sage Publications.

Voss, Kim, and Irene Bloemraad, eds. 2011. Rallying for Immigrant Rights: The Fight for Inclusion in 21st Century America. Berkeley: University of California Press.

Wodak, Ruth, and Teun Van Dijk. 2000. Racism at the Top: Parliamentary Discourses on Ethnic Issues in Six European States. Klagenfurt: Drava Verlag.

Yukich, Grace. 2013. "Constructing the Model Immigrant: Movement Strategy and Immigrant Deservingness in the New Sanctuary Movement." Social Problems 60 (3): 302-320.

Zepeda-Millán, Chris. 2017. Latino Mass Mobilization: Immigration, Racialization and Activism. Cambridge: Cambridge University Press. 


\section{Appendix A}

\section{Research design and methodology}

\section{Case selection}

In my research strategy, I have prioritized a small-N over a large- $\mathrm{N}$ comparison for two main reasons. First, the literature shows that small-N comparisons have the advantage of exposing the interplay between official local policy priorities and the role played by various actors involved in the realm of immigration (Caponio and Borkert 2010, 28). Thus, a small-N comparison appeared to be the best approach to grasp the phenomena I am seeking to explain, that is, the interplay between local actors, including immigrants, in the local political arena. A few authors have used small-N analyses to compare European cities. For instance, Alexander (2004) made one of the first attempts to construct a typology of European cities while giving priority to the local-level migrant policy models. Small-N comparisons are used to assess the role played by characteristics attached to immigrants, such as their background, migratory trajectories, cultural factors, and so on. Scholars thus select a few groups on the basis of ethnicity and compare them in a given context. On the other hand, most studies today aim to explain how structural constraints and opportunities shape immigrants' inclusion in their new society. Scholars of this perspective usually select one or a few ethnic groups across different contexts. This approach is called divergent comparison. It assesses variations with respect to context, within a country or across countries (see, e.g., Caponio 2006; Fauser 2012 for cross-local analysis, and Koopmans 2004; Moore 2004; Garbaye 2005 for a combination of cross-local and cross-national analysis).

The case selection is constructed through a "most similar cases" procedure, taking into account Italian civic traditions (Putnam 1993) and political sub-cultures (Campomori 2008; Messina 2001). It is based on the selection of the independent variable (contextual factors) rather than the dependent variable (outcomes) in order to control for contextual variations (Geddes 1990). Moreover, the choice of regions and cities is designed to allow both cross-regional and intraregional comparisons between cities, enabling the control of the effects of the political sub-culture and the political orientation. As noted, studies that seek to explain how constraints and opportunities shape immigrants' inclusion in receiving societies usually select one or a few immigrant groups across different contexts. My research design utilizes the same methodology but makes sure to avoid selecting 
immigrants on the basis of their assumed ethnic belonging. ${ }^{1}$ Second, given the little knowledge we have about the role of multiple local actors in shaping participation, small-N comparisons offer an opportunity to make advances via in-depth analysis and theory-building. As Glaser and Strauss (1967) underscore, a close knowledge of the empirical reality allows one to develop testable, relevant, and valid theory. The comparison of a relatively small number of cities, therefore, allows me to establish a deep knowledge of each case (within-case research) and at the same time explore similar and diverging patterns of inclusion among the four cases and advance new suggestions for further research (see George and Bennett 2005, 149). ${ }^{2}$

\section{Selecting the regions}

In order to control for local variations and assess how local actors shape local dynamics and why and how they open channels of participation for immigrants, this research uses a comparison of four cities in two regions of Northern Italy with two different political sub-cultures: Reggio Emilia and Bologna in the Communist region of Emilia-Romagna, and the cities of Brescia and Bergamo in the "white" or Christian-Democrat region of Lombardy.

My selection of these regions was based on the assumption that different political sub-cultures at the regional level will affect different local power configurations and thus different attitudes by local actors towards the inclusion of people of foreign origin (Campomori 2008; Caponio 2006). I chose the regions EmiliaRomagna and Lombardy because, while differing in terms of their respective political sub-cultures, they represent the "most similar cases" in Italy.

To begin with, Emilia-Romagna and Lombardy are very similar because they have the highest GDP (and thus strong and stable economies) (Istat 2013), they are among the best performing economies in the country, they have substantial welfare systems (the highest in the country), they have the highest level of employment, at least before the 2008 financial crisis (CNEL 2009). In terms of regional economic performance, the two regions are among the richest in Italy. In 2008 (prior to the crisis), Emilia-Romagna and Lombardy had the second and third highest regional GDP per capita in Italy, respectively, after the small region of South Tyrol, with an average of 31,900 and 33,500 euros per capita, respectively. By comparison, the national average in 2008 was 27,000 euros per capita (Eurostat 2011).

Moreover, with reference to the economic inclusion of immigrants, the two regions were very similar in their high levels of employment (again, prior to the crisis) (CNEL 2009) and the types of occupation undertaken by the immigrant population. During the second half of the 2000s, the annual reports by the CNEL (National Council for the Economy and Labor-Consiglio Nazionale Economia e Lavoro), the national organization for the coordination of the policies of social inclusion for immigrants, indicated that the regions of Emilia-Romagna and Lombardy had the highest capacity for "integration." This means that they were capable of absorbing immigrants into the economy and assuring social inclusion, thanks to 


\section{Appendix $A$}

the strength and efficiency of the welfare system (CNEL 2009, 28). The two regions offer similar job opportunities to immigrants. In 2012, immigrants were primarily occupied in the service sector (mostly hotels, restaurants, and households) $-51 \%$ in Emilia-Romagna and 60\% in Lombardy - and in industry (mostly construction and metalwork) $-37.1 \%$ in Emilia-Romagna and 34.1\% in Lombardy. The remaining immigrant population worked in the agricultural sector-9.9\% in Emilia-Romagna and 3\% in Lombardy — or were unemployed - 2\% in Emilia-Romagna and 2.4\% in Lombardy (Caritas/Migrantes 2012, 313 and 362).

Furthermore, with respect to immigration characteristics, in 2013, EmiliaRomagna and Lombardy were the regions with the highest number of immigrants in relation to the local population. They were also among the regions that experienced the highest rate of increase in the immigrant population during the 2000s. In 2012, Emilia-Romagna and Lombardy had the largest immigrant population (nonEU citizens) in absolute numbers in Italy (488,489 and 1,028,633, respectively), the highest percentage of non-Eu and EU immigrants in comparison to the total population (11.2\% and $10.5 \%$, respectively, while the national average was $8.2 \%$ ) (Caritas/Migrantes 2013). The regions are also home to some of the strongest traditions of civil society engagement with solid, well-established networks in place (Putnam 1993). These networks have played a particularly crucial role since the early arrival of migrants in the 1980s and 1990s, offering first aid and other vital forms of assistance (Campomori 2008; Caponio 2006; Mantovan 2007). ${ }^{3}$

Despite their overall similarities, the regions of Emilia-Romagna and Lombardy represent two opposing political sub-cultures (Campomori and Caponio 2013). While the region of Emilia-Romagna has been the unchallenged stronghold of the Communist Party from 1945 until its decline at the beginning of the 1990s, and of the Social Democrats from the 1990s until 2013, Lombardy has been governed

Table 1 The largest immigrant communities in each region by country of origin (2012)

\begin{tabular}{ll}
\hline Emilia-Romagna & Lombardy \\
\hline Romania 67,360 & Romania 136,233 \\
Morocco 66,360 & Morocco 103,115 \\
Albania 59,393 & Albania 98,318 \\
Moldavia 30,281 & Egypt 54,443 \\
Ukraine 26,728 & China 50,653 \\
China 24,615 & Philippines 49,338 \\
Pakistan 18,498 & India 48,383 \\
Tunisia 17,490 & Peru 43,128 \\
India 16,762 & Ukraine 42,352 \\
Philippines 13,024 & Ecuador 37,232 \\
Ghana 11,444 & Pakistan 34,237 \\
Poland 10,988 & Senegal 30,848 \\
Senegal 9,566 & Sri Lanka 24,902 \\
Nigeria 9,304 & Moldova 22,004 \\
Macedonia 9,253 & Tunisia 18,185 \\
\hline
\end{tabular}

Source: Istat 2013 (January 1, 2013) 
without interruption by the Christian Democrats until the 1990s (when the political party was dissolved) and by the center-right from the beginning of the 1990s until $2013 .{ }^{4}$ What is more, the Northern League became an increasingly powerful presence in Lombardy in the 2000s, with the leader of the party, Roberto Maroni, becoming the region's president in 2013.

Table 2 shows the main differences between the two regions in terms of political sub-culture, their more recent political orientations, and their responses to immigration. It indicates that the two regions have been developing two different approaches to inclusion. Thanks to the continuity of the left-wing parties in Emilia-Romagna in the 2000s, the region had developed an intercultural approach to inclusion in addition to an assistance approach and was moving toward what Campomori and Caponio $(2013,174)$ call a "culture-friendly approach." On the other hand, Lombardy had adopted mainly an assistance approach, and in the 2000s, because of the rise of the Northern League, moved progressively from assistance toward securitization and policies of exclusion (Ambrosini 2013). What is more, there has been a visible attempt to reduce interventions that encourage immigrant inclusion. To this end, in 2013, the regional government dismantled some of the structures that had been created to monitor the phenomenon of immigration and develop adequate interventions. ${ }^{6}$ The political sub-culture and orientation also affect the government's relationship with the third sector (Campomori 2008).

Table 2 Comparison of two regions (1998-2013)

\begin{tabular}{|c|c|c|}
\hline & Emilia-Romagna & Lombardy \\
\hline $\begin{array}{l}\text { Political culture since } \\
1945\end{array}$ & Communist & Christian Democrat \\
\hline $\begin{array}{l}\text { Political orientation } \\
\text { from } 1998 \text { to } 2012\end{array}$ & Center-left & Center-right (PDL) \\
\hline $\begin{array}{l}\text { Main Party in Power } \\
\text { in } 2013\end{array}$ & Democratic Party & Northern League \\
\hline Administrative style & Top-down initiatives & Devolution ot the third sector \\
\hline $\begin{array}{l}\text { Main third-sector } \\
\text { organizations }\end{array}$ & $\begin{array}{l}\text { Lay non-profit } \\
\text { organizations }\end{array}$ & Church-based organizations \\
\hline $\begin{array}{l}\text { Main traditional } \\
\text { trade unions }\end{array}$ & CGIL and CISL & CGIL and CISL \\
\hline $\begin{array}{l}\text { Regional law on } \\
\text { integration }\end{array}$ & Since 2004 & No \\
\hline $\begin{array}{l}\text { Approach to inclusion } \\
\text { in the } 2000 \mathrm{~s}\end{array}$ & $\begin{array}{l}\text { Assistance approach } \\
\text { Intercultural approach }\end{array}$ & Assistance approach \\
\hline $\begin{array}{l}\text { Areas of interventions } \\
\text { in the 2000s }\end{array}$ & $\begin{array}{l}\text { Social } \\
\text { Economic } \\
\text { Cultural } \\
\text { Political }\end{array}$ & $\begin{array}{l}\text { Social } \\
\text { Economic }\end{array}$ \\
\hline $\begin{array}{l}\text { Approach to inclusion } \\
\text { in the } 2010 \mathrm{~s}\end{array}$ & $\begin{array}{l}\text { Toward a culture-friendly } \\
\text { approach }\end{array}$ & $\begin{array}{l}\text { Toward securitization and } \\
\text { policies of exclusion }\end{array}$ \\
\hline
\end{tabular}

Source: Caritas/Migrantes 2012; www.comuni-itaiani.it; www.regione.emilia-romagna.it; www. regione.lombardia.it; www.comunediblogna.it ${ }^{5}$ 
While in Emilia-Romagna, the regional authorities have enlarged the public sector, bestowed a large amount of funding, and developed a welfare system in collaboration with lay cooperatives, in Lombardy, the strong presence of the Catholic Church has impeded this process. By contrast, in Lombardy, the Catholic Church and church-based organizations manage $99 \%$ of public services. This has resulted in a process of devolution without collaboration between the public and private sectors. These different political sub-cultures and orientations have resulted in the two regions adopting very different approaches to inclusion. Henceforth, the regions' opposing and long-established political orientations allow me to control for different approaches to inclusion adopted by the regional governments and regional actors (Campomori and Caponio 2013). ${ }^{7}$

\section{Selecting the cities}

My comparison of four cities aims to grasp not only the differences between cities with distinct political sub-cultures and orientations but also the differences between cities with similar political sub-cultures and orientations. What is more, such a comparative analysis highlights how local actors' approaches to inclusion are affected by ideology (left vs. right) and pragmatic considerations that are linked to the interaction between local actors in each context. The four cities I have selected can be seen as particular cases of the regional context. With the exception of their political sub-culture (which varies by region), they are all very similar in terms of: (1) local economic performance; (2) "integration" capacity; and (3) immigration characteristics. In the years preceding the financial crisis (that is, 2006-2008), the four cities had the best economic performance and the largest capacity to include immigrants socioeconomically (CNEL 2009, 23). In 2013, the four cities had among the highest percentages of immigrant population in relation to the total population in Italy, with Brescia the highest in the country (see Table 1.2, Chapter 1). ${ }^{8}$

The literature on cities predict the pro-migrant attitudes from left-wing authorities and anti-migrant attitudes from the right-wing ones (Caponio 2006; Garbaye 2005). Based on the literature on Italian cities in particular (Caponio 2006; Mantovan 2007), one would expect greater institutional interventions in traditionally Communist cities, as well as greater political participation of immigrants and racialized minorities, because left-wing actors are stronger there. At the same time, one would expect an absence of institutional intervention, as well as less participation, in the traditionally Christian-Democrat cities, where the strong presence of the Catholic Church is a dominant factor (Campomori 2008). Using two cities for each sub-culture, therefore, allows me to control for variations of institutional or top-down dynamics, as well as for power configurations among local actors in both similar and different political sub-cultures. As such, I was also able to assess the extent to which institutional dimensions mattered in shaping immigrant participation and rights claims in the four cities. While one can expect a more open institutional environment in left-wing cities than right-wing cities, including more support for civic and political participation (Caponio 2006; 
Mantovan 2007), recent scholarship shows that despite their different political discourses, left-wing and right-wing political actors may adopt convergent practices of inclusion (Campomori 2008) or similar practices of exclusion (Bellinvia 2013). Caponio $(2006,91)$ observes that migration issues tend to divide political actors by creating "cross-cutting cleavages" within the same political spectrum. In this context, a major role is played by the increasing power of the anti-immigrant party, the Northern League, which has highly politicized the discourse on migration (Caponio 2006, 247). This has been accompanied by growing anxieties over "the electoral cost" of pro-immigrant policies for parties on both sides of the political divide $(2006,104)$.

\section{Fieldwork and data triangulation}

My empirical research centered on extensive fieldwork for approximately two months in each city under observation, for a total of 14 months between FebruaryNovember 2013 and May-August 2014. ${ }^{9}$ This was enough time to interview the main regional and local actors and immigrants who were engaged in politics, to conduct participant observation of the main events linked to the inclusion of immigrant activists (such as meetings, assemblies, demonstrations), and to gather important archival sources (e.g., local newspapers, pamphlets, reports, documents, visual material published on the internet) produced by local authorities, the Catholic Church (and in particular Caritas), lay and church-based organizations, trade unions, and grassroots organizations. ${ }^{10}$ I also traveled to other key cities - Rome, Turin, and Milan - to meet with key actors (Italian and immigrant activists and experts, who provided me with additional relevant information) and to participate in key events (e.g., national, regional, and local meetings, demonstrations, and protests). The triangulation of secondary and primary data was essential to develop my methodology and to obtain robust results. I used different sources to cross-check my data. I also discussed my results with gatekeepers and key informants, after completing the fieldwork.

During my fieldwork, I used an ethnographic approach (Aiello 2010; Bray 2008; Lichterman 2002; O'Reilly 2008). The literature on social movements has shown the importance of ethnography and the combination of different qualitative methods to study actors and their actions (Smith 1995; Della Porta 2014; see also Bray 2008). In this study, I combined various qualitative research methods and accorded central importance to semi-structured interviews, since these are considered the most useful way to grasp individuals' perspectives on their actions and how they relate with material and symbolic resources offered by other actors (Blee and Taylor 2002). ${ }^{11}$ In addition to the interviews, other methods used in ethnographic research are particularly useful because they are highly inductive and privilege an actor-oriented analysis. Critics of the political opportunities approach in the migration literature, such as Fauser $(2012,181)$, have underscored that "[i]nstitutional approaches generally start with a strong and rigid concept of institutional structure and this consequently affects the conceptualization of immigrants' agency." For this reason, Fauser suggests that one's theory and concepts 


\section{Appendix A}

should rely on a framework that is flexible and procedural in nature and which makes it possible to go back and forth from deductive research design to empirical findings (Glaser and Strauss 1967, quoted in Fauser 2012). As Fauser explains, this approach is particularly useful for the study of immigrant actions in recent migration cities "where little research has been done so far" (Fauser 2012, 181). All things considered, my methodological approach and the explorative nature of this study were apt to address my main research questions. In particular, I was able to work through the conceptual apparatus I developed in Chapter One and to reach important results I would not have been able to find otherwise. The research I conducted in Italy sought to understand the actors' motivations and their intended scope of action. My immersion in the field allowed me to assess the effective role played by multiple actors, including immigrants active in the city (see also Bayard de Volo 2009 for the importance of "participant observation").

The interviews with local actors were the main primary sources used in this research. In total, I conducted 118 interviews (including 63 immigrant activists) (see Table 3). While most interviewees were contacted through snowball sampling, several interviewees were also selected for ad hoc interviews. The interviews lasted from 90 minutes to two hours and were conducted mostly in Italian. ${ }^{12}$

Table 3 Summary of the fieldwork

\begin{tabular}{|c|c|c|}
\hline $\begin{array}{l}\text { Category of } \\
\text { interviews }^{13}\end{array}$ & Quantity & Type of organization \\
\hline $\begin{array}{l}\text { Interviews with } \\
\text { Italian national- } \\
\text { level stakeholders }\end{array}$ & 4 & $\begin{array}{l}\text { Parliament (Democratic Party); } \\
\text { Members Unions' Directive (CGIL) }\end{array}$ \\
\hline $\begin{array}{l}\text { Interviews with } \\
\text { Italian regional- } \\
\text { level stakeholders }\end{array}$ & $\begin{array}{l}9 \text { (4 in Lombardy; } 5 \\
\text { in Emilia-Romagna) }\end{array}$ & $\begin{array}{l}\text { Left-wing administrators; right-wing } \\
\text { administrators (Northern League); } \\
\text { Members Unions' Directive (CGIL) }\end{array}$ \\
\hline $\begin{array}{l}\text { Interviews with } \\
\text { members of Italian } \\
\text { organizations }\end{array}$ & $\begin{array}{l}\text { Between } 9 \text { and } 12 \text { in } \\
\text { each city }\end{array}$ & $\begin{array}{l}\text { Local administrators; union members; } \\
\text { Caritas; representatives of the } \\
\text { intercultural center; cultural } \\
\text { mediators; anti-racist associations; } \\
\text { the radical left (militants), etc. }\end{array}$ \\
\hline Immigrant activists & $\begin{array}{l}\text { National level } 4 \\
\text { Regional level } 2 \\
\text { Reggio Emilia } 14 \\
\text { Bologna } 18 \\
\text { Brescia } 16 \\
\text { Bergamo } 9\end{array}$ & $\begin{array}{l}\text { Democratic Party (Forum); } \\
\text { administrators (Council and } \\
\text { executive); CGIL; CGIL-FIOM; } \\
\text { CISL; social movements; and USB }\end{array}$ \\
\hline $\begin{array}{l}\text { Events organized by } \\
\text { Italian national, } \\
\text { regional, and local } \\
\text { organizations }\end{array}$ & 20 main events & $\begin{array}{l}\text { Regional and local events organized } \\
\text { by administrations and unions }\end{array}$ \\
\hline $\begin{array}{l}\text { Events organized by } \\
\text { immigrants at the } \\
\text { national, regional, } \\
\text { and local levels }\end{array}$ & 40 main events & $\begin{array}{l}\text { Assemblies; demonstrations; strikes; } \\
\text { protests; weekly meetings of some } \\
\text { key organizations }\end{array}$ \\
\hline
\end{tabular}


The interviews with immigrant activists were conducted at their workplace, in cafes, or other informal places, including private houses. All the interviews were recorded and fully transcribed. They were guided by a questionnaire of wideranging open questions. Some key actors were interviewed more than once; some others had gatekeeping roles and I kept in contact with them throughout the entire period of the fieldwork and thereafter. I also participated in more than 60 formal and informal meetings organized by a variety of actors. These meetings provided occasions to observe the role of the main actors in each city and to locate the activities of these actors (including immigrants active in the cities). These meetings represented an opportunity to assess what role each actor occupied in the local context and how these actors interacted with one another. These methods were also combined with intense exchanges with actors in the cities, through informal conversations. These conversations were often more revealing than the interviews themselves. Sometimes they took place a few minutes before or after the formal interviews; at other times they took place during follow-up phone calls, during random meetings in public spaces or during formal events in which I participated.

I first interviewed key Italian actors in the city, such as regional and local administrators, members of the Catholic Church, lay and church-based organizations, traditional trade unions (CGIL and CISL), political parties, militant groups, and members of emerging grassroots unions (such as USB). Thanks to my first contacts with these organizations, I was also able to reach immigrants active in civic and political channels in each city. The relatively small size of the cities (with the exception of Bologna) allowed me to identify and interview a large proportion of those immigrants "visible" in the city who had been and/or still were active. While the interviews with "native-born" Italians were useful to identify which actors were involved in the local dynamics, and in what ways, the interviews with immigrants were useful to examine their perceptions of and reactions to the opportunities opened to them by other local actors, as well as their will and ability to shape local dynamics and open up participatory channels by getting involved and interacting with local actors. During the interviews, I tried to gather as much biographical information as possible in order to identify who my interviewees were, so as to better explain how their social and economic background, education, personal immigration experience, and ideological commitments could have shaped their trajectories of civic and political participation. ${ }^{14}$

Most of the immigrants active in civic and political channels whom I was able to identify and/or interview were male, first-generation immigrants in their thirties, forties, or fifties, and most were from North Africa (Morocco, Tunisia, and Egypt), the Sub-Saharan region (Nigeria, Cameroon, and especially Senegal), and Central Asia (in particular from the Indian Subcontinent: India, Pakistan, and Bangladesh). I also met with many individuals (women and men) who were particularly active in immigrant associations. I contacted and interviewed some of these people to ask them why they did not participate in political channels. Unfortunately, it was difficult to find interviewees from the larger communities of immigrants from EU countries, such as Romanians, and from non-EU countries, such as Albanians, Chinese, and Ukrainians, because these groups were less active. In addition, it was 
Table 4 Summary of interviews with immigrant activists ${ }^{15}$

\begin{tabular}{|c|c|}
\hline Category & Distribution \\
\hline $\begin{array}{c}\text { Country of } \\
\text { origin }\end{array}$ & $\begin{array}{l}\text { Total number of interviewees: } 49^{16} \\
\text { Morocco } 13 \\
\text { Senegal } 9 \\
\text { Pakistan } 4 \\
\text { Ghana } 3 \\
\text { Moldova } 2 \\
\text { Albania } 2 \\
\text { Cameroon } 2 \\
\text { Algeria } 1 \\
\text { Bangladesh } 1 \\
\text { Bolivia } 1 \\
\text { China } 1 \\
\text { Congo } 1 \\
\text { Cote d'Ivoire } 1 \\
\text { Egypt } 1 \\
\text { Nigeria } 1 \\
\text { Peru } 1 \\
\text { Philippines } 1 \\
\text { Somalia } 1 \\
\text { Togo } 1 \\
\text { Tunisia } 1, \\
\text { Ukraine } 1\end{array}$ \\
\hline $\begin{array}{r}\text { Geographical } \\
\text { distribution }\end{array}$ & $\begin{array}{l}\text { National level: number of interviews (4) } \\
\text { Number of interviewees (3): Peru 1, Congo 1, Cote d'Ivoire } 1^{17} \\
\text { Regional level: number of interviews (2) } \\
\text { Number of interviewees (2): Somalia 1, Pakistan } 1^{18} \\
\text { Reggio Emilia: number of interviews (14) } \\
\text { Number of interviewees (11): Morocco 4, Ghana 2, Senegal 1, Tunisia 1, } \\
\text { Algeria 1, Togo 1, Pakistan 1 } \\
\text { Bologna: number of interviews (18) } \\
\text { Number of interviewees (15): Senegal 4, Morocco 2, Cameroon 2, Pakistan 1, } \\
\text { Moldova 1, Nigeria 1, Philippines 1, China 1, Ukraine 1, Albania 1 } \\
\text { Brescia: number of interviews (16) } \\
\text { Number of interviewees (12): Morocco 4, Senegal 3, Pakistan 1, } \\
\text { Moldova 1, Egypt 1, Bangladesh 1, Albania 1 } \\
\text { Bergamo: number of interviews (9) Number of interviewees (6): } \\
\text { Morocco 3, Ghana 1, Senegal 1, Bolivia 1 }\end{array}$ \\
\hline $\begin{array}{l}\text { Gender } \\
\quad \text { distribution }\end{array}$ & $\begin{array}{l}\text { Total number of interviewees in the cities (44): Females (F) } 12 \text { /Males } \\
\text { (M) } 32 \\
\text { Reggio Emilia: F2/M9 Females: Algeria1, Ghana 1 } \\
\text { Bologna: F5/M10 Females: Albania 1, Senegal 1, Philippines 1, } \\
\text { Ukraine 1, Moldova 1 } \\
\text { Brescia: F3/M9 Females: Morocco 1, Moldova 1, Bangladesh } 1 \\
\text { Bergamo: F2/M4 Females: Bolivia 1, Morocco 1 }\end{array}$ \\
\hline Generation & $\begin{array}{l}\text { Total number of interviewees in the cities (44): Second-generation 10/ } \\
\text { First-generation } 34 \\
\text { Reggio Emilia: Second-generation (5): Ghana 2, Tunisia 1, Morocco 1, } \\
\text { Togo 1 } \\
\text { Bologna: Second-generation (3): China 1, Morocco } 1 \\
\text { Brescia: Second-generation (1): Bangladesh 1 } \\
\text { Bergamo: Second-generation (2): Morocco } 2\end{array}$ \\
\hline
\end{tabular}


Table 4 (Continued)

\begin{tabular}{|c|c|}
\hline Category & Distribution \\
\hline $\begin{array}{l}\text { Citizenship } \\
\text { status }\end{array}$ & $\begin{array}{l}\text { Italian citizenship (13): Reggio Emilia 4, Bologna 4, Brescia 4, } \\
\text { Bergamo 1 } \\
\text { Resident permit (14): Reggio Emilia 2, Bologna 6, Brescia 3, Bergamo } 3 \\
\text { Work and study permit (14): Reggio Emilia 4, Bologna 4, Brescia 4, } \\
\begin{array}{l}\text { Bergamo } 2 \\
\text { Undocumented (3): Reggio Emilia 1, Bologna 1, Brescia 1, Bergamo } 0\end{array}\end{array}$ \\
\hline $\begin{array}{l}\text { Immigrant } \\
\text { activists } \\
\text { per type of } \\
\text { organization }^{19}\end{array}$ & $\begin{array}{l}\text { Democratic Party (6): }:^{20} \text { Reggio Emilia 2, Bologna 2, Brescia 2, } \\
\text { Bergamo } 0 \\
\text { Links with the local administration (3): Reggio Emilia 3, Bologna } 0 \text {, } \\
\text { Brescia 0, Bergamo } 0 \\
\text { Trade unions (7): Reggio Emilia 2, Bologna 0, Brescia 3, Bergamo } 2 \\
\text { Actives in Italian and/or immigrant associations (15): Reggio Emilia 4, } \\
\text { Bologna 7, Brescia 1, Bergamo } 3 \\
\text { Radical left NGOs and trade unions, such as USB (13): Reggio } \\
\text { Emilia 0, Bologna } 6, \text { Brescia } 7, \text { Bergamo } 1\end{array}$ \\
\hline
\end{tabular}

particularly hard to find second-generation individuals, women of all origins, and men and women from Central and Eastern Europe or from South America who were active. Among these people, it was surprising to discover that EU citizens, who had the right to vote and to stand at local elections, were only minimally involved in either civic or political channels in the four cities. My research revealed that the main local actors who were concerned with promoting immigrants' civic and political participation focused most of their attention on non-EU citizens, and largely neglected to encourage the participation of EU citizens.

Some interviewees and people I contacted informally during the fieldwork offered explanations of weak or no participation by people belonging to certain nationalities. According to my informants, people from certain countries were less likely to be involved in politics for a variety of reasons. Certain communities were less likely to get involved in politics because of the lack of democratic culture in their countries of origin. These communities included some of the largest immigrant groups, such as Albanians, Chinese, and Romanians. Yet, as the migration literature suggests, this factor needs to be combined with others, such as status in the country of arrival (Bloemraad 2006) and the immigrants' political orientations (Siméant 1998). An additional factor must be considered in the specific case of Italy: some people were less likely to get involved in politics because most of the channels available were controlled by left-wing organizations, and certain groups did not identify with the values of the left for personal inclinations or because of their experience with the left in their home country, as was the case for immigrants coming from ex-communist countries, such as Albanians, Ukrainians, and Romanians. Additionally, some interviewees explained that many immigrants would have been interested in participating in mainstream politics in more conservative parties for ideological reasons, but declined to do so because the right-wing party had been hostile towards people of foreign origin and had not created viable channels for them to participate.

Finally, as I explain in more detail in the empirical chapters, additional reasons for the limited presence of immigrant activists in conventional channels are to be 
found in the Italian context. There is a general mistrust toward politics in general, and people of foreign origin who have acquired formal citizenship and can vote do not trust mainstream politics any more so than "native-born" Italians, especially mainstream parties and traditional trade unions of the left (see also Cappiali 2017). Also, the vulnerability of women and foreign people who have arrived more recently and who face precarious working and living conditions makes them reticent toward any kind of public exposure or political engagement. Above all, the restrictive immigration laws, the exponential growth of racism in the public discourse, and discrimination in the workplace and public spaces are strong deterrents to immigrants' participation in the receiving society (Carchedi et al. 2010). ${ }^{21}$ This study will show, moreover, that increasing mistrust towards main left-wing actors - the Democratic Party and the CGIL — has negatively affected immigrants' interest in getting politically engaged (cf. Chapter 6; see also Cappiali 2017).

In addition to the interviews and participant observation of main events, I made substantial use of archival research to reconstruct the trajectories of local actors in the city. Many documents (written, auditory, and visual) were personal archives of key actors. They were given to me during the interviews, while many others were accessible on the official sites and blogs of the organizations. During my visit to each city, I also collected pamphlets and took pictures of the places I visited: these included posters and flyers on the walls of the different organizations. I also consulted local newspapers to reconstruct major events in the city. Finally, I combined the data collected earlier with daily fieldnotes, which allowed me to reflect on what was happening during the fieldwork and to develop new questions based on my observations. Following the suggestions of Bernard, I collected descriptive, methodological, and analytical notes (Bernard 2006, 387; see also White 2007; Emerson et al. 1995), which became invaluable sources while analyzing the data upon completing the fieldwork.

\section{Data analysis}

In line with my ethnographic approach, I conducted part of my main analysis in the field. The fieldwork was explorative in nature and relied heavily on an inductive approach. I analyzed the data during the exploration of the field, by using the findings to generate new research questions and to identify new themes to explore. This analysis was highly interpretative and based on the analysis of contextualized practices and discourses (Eliasoph 2001; Geertz 1973) by local actors and individuals of migrant background interacting with those actors.

At the end of the fieldwork, I undertook a selective analysis of the significant amount of material gathered. I used the qualitative data analysis software NVivo to upload and analyze the data. The software allowed me to gather in the same program all the visual, auditory, and textual documents (including the interviews and fieldnotes) collected during the fieldwork, as well as official documents, websites, newspapers, and other relevant electronic documents. The use of NVivo was particularly helpful in: (1) organizing and exploring the material; (2) reconstructing each case under observation (within-case analysis); (3) performing systematic 
comparisons of different cases; (4) cross-checking the results; and (5) comparing the final results of the research (see Eisenhardt 1989, 533).

During the analysis, I followed four steps. First, I focused on the within-case studies. For each city, mainly through the help of local newspapers and interviews, I analyzed campaigns or protests that took place in the cities between 2010 and 2011 and identified the main local actors, including immigrant activists, involved in the mobilization. Second, with the support of official documents, interviews, and surveys of local organizations' official sites, I reconstructed the local dynamics in 2013 and explained the role of local actors by looking at their historical trajectory in the city since 1998 . When possible, I combined primary and secondary sources. I focused on why and how local actors contributed to shaping local dynamics in the way that they did, and whether they were opening up channels of participation for immigrants. Third, I concentrated on the discourses and practices of immigrants active in the city and assessed their role in the local context to evaluate whether and how they were shaping local dynamics through their civic and political activities. Finally, once I analyzed each context, I drew general conclusions by comparing the four cities.

\section{Notes}

1 See Bousetta 2000; Però 2008 on the problem of ethnicization present in most migration literature.

2 To my knowledge, this is the first study to conduct this kind of systematic comparison in the field of immigrants' inclusion in Italian cities.

3 Despite this, it is also important to note that many immigrant workers are employed in the underground economy and are victims of exploitation even in these highly performing regions.

4 For a reconstruction of the left-wing and right-wing divide until the 1990s, see Pelmutter 1995.

5 I have relied on the work of Campomori and Caponio 2014; Ambrosini 2013, as well as primary sources collected during my data collection, to develop this table.

6 I owe this insight to one of the interviewees, who worked for the regional administration of Lombardy from 1998 to 2013. This interviewee explained:

The political orientation of the region matters. Until 2010, the ORIM, the Regional Observatory for the Integration and Multi-ethnicity (Osservatorio Regionale per l'Integrazione e la Multiethnicità) was able to entertain a relationship with the region of Lombardy through a convention that could be renewed every five years. Today, there is lot of confusion. There is a visible political will to destroy what exists already. This new political management reduces the tasks and impact of the ORIM.

(Interview in Milan, June 9, 2014)

See the official site of the ORIM www.orimregionelombardia.it (Accessed June 30, 2015).

7 In their study, Campomori and Caponio (2013) analyze the multi-level governance of immigrant reception policies in Italy by considering the regions not only as administrative bodies, but also as political institutions. In their study, the authors ask how the regions' different political orientations combine with vertical and horizontal governance relations with respect to the different framings of inclusion, and they show that the political orientations of regional governments make a great difference to the kind of approaches to inclusion being pursued, especially in a context of limited financial 
resources. As a result, while center-right regions would contrast recognition of basic rights of immigrants by limiting their access to services, center-left governments would tend to be more open toward migrants and thus pursue more favorable policies.

8 It is important here to explain why I have not selected a region from the South or from the Center of Italy for my comparison. Unlike Caponio (2006), Campomori (2008), Campomori and Caponio $(2013,2014)$, who tried to represent the "main three areas of Italy" by selecting three cities on the basis of their geographic position, for the sake of a systematic comparison, I chose to select my cases on the basis of general similarities and also on the stability of the regions' political orientation. This selection allows me to isolate factors which could not be controlled in the Center and South of Italy, where more unstable economies, little industrialization, low levels of unionization, and an immense number of irregular workers (to name a few aspects) would have affected the reliability of my comparison.

9 I was in Reggio Emilia between February and April, in Bologna between April and June, in Brescia between June and September, and in Bergamo between September and November 2013. Due to health reasons, I spent less time in Bergamo, the last city I visited, compared to the other cities (a little less than two months) and interviewed fewer people there than in any other city. Between May and August 2014, I traveled to the four cities and others to collect additional data to complete my research.

10 For a similar empirical approach, see Mantovan (2007, 151-153).

11 Blee and Taylor $(2002,92-93)$ explain, for instance, that:

Semi-structured interviews are particularly useful for understanding [social movements'] mobilizations from the perspective of [movement] actors or audiences. They provide greater breadth and depth of information, the opportunity to discover the respondent's experience and interpretation of reality, and access to people's ideas, thoughts, and memories in their own words rather than in the words of the researcher.

The same authors also add that semi-structured interviews are useful to: (1) gain access to the motivations and perspectives of a broader and more diverse group of social movement participants than would be represented in most documentary sources; (2) generate new categories and themes of analysis; (3) "scrutinize the semantic context of statements by [social movement] participants and leaders" $(2002,94) ;(4)$ assess the context of motivations, beliefs, and attitudes; (5) "allow scrutiny of meaning, both how activists regard their participation and how social movement participants make sense of and justify their actions" $(2002,94)$; (6) "access [to such] nuanced understandings of social movement outcomes as the construction of collective and individual identities" (2002, 95); (7) "bring human agency to the center of movement analysis;" and finally (8) scrutinize the ways in which social movements' messages are received by members, targeted recruits, intended audiences, and others. In my research, I followed Blee and Taylor's suggestions and relied on semi-structured interviews to study civic and political participation of immigrants and the role of pro-immigrant groups at the local level.

12 The interviews with immigrant activists were mostly conducted in Italian and French.

13 The table summarizes the 118 interviews and events in which I participated in the four cities and elsewhere in Italy (February-November 2013 and May-August 2014). The total amount of interviews includes also those conducted twice with some of the interviewees.

14 In order to protect the identity of my interviewees, I have used pseudonyms (a full first name followed by a last name initial) for both Italian and immigrant interviewees. Each interviewee quoted in this book read and signed a document in which they consented to the use of the information shared during the interview. Most of them also agreed to be identified. However, in order to avoid revealing their identities, I have chosen not to use their real names. 
15 The table offers an overview of the number of interviews with immigrant activists by country of origin, geographical distribution, gender distribution, generation, citizenship status, and main organizational affiliation.

16 In total, the interviewees were 49 ( 44 with immigrant activists working in the four cities and 5 with immigrant activists based in other places). However, 14 of them were interviewed twice. Thus, the total number of interviews conducted with immigrant activists is 63 .

17 I interviewed the first two activists respectively in Milan and Rome. I interviewed the third one twice: once in Turin and once in Reggio Emilia in 2013.

18 I interviewed the first person in Milan and the second in Bologna in 2013.

19 When the activist has more than one affiliation, I indicate the most important one according to the person. This is particularly the case for activists in Bologna, where immigrants happen to have multiple affiliations.

20 Some where members of the Provincial Forum of Immigration and others were elected members of local administrations.

21 I attempted to avoid the limitations of an overly restricted sample by trying to enlarge as much as possible the national origin of my interviewees and to have at least a few interviews with second-generation youth. However, this was not always possible. As such, the reader should acknowledge that if some nationalities are under-represented or not represented at all, it is mainly because they are not represented in the civic and political channels in the cities selected for this study.

\section{References}

Aiello, Leslie C. 2010. "Engaged Anthropology. Diversity and Dilemmas: Wenner-Gren Symposium Supplement 2.” Current Anthropology 51 (S2): S203-S226.

Alexander, Michael. 2004. "Comparing Local Policies toward Migrants: An Analytical Framework, a Typology and Preliminary Survey Results." In Citizenship in European Cities: Immigrants, Local Politics and Integration Policies, edited by Rinus Penninx, Karen Kraal, Marco Martiniello, and Steven Vertovec, 57-84. Aldershot: Ashgate.

Ambrosini, Maurizio. 2013. “'We are Against a Multi-Ethnic Society': Policies of Exclusion at the Urban Level." Ethnic and Racial Studies 36 (1): 136-155.

Bayard de Volo, Lorraine. 2009. "Participant Observation, Politics, and Power Relations: Nicaraguan Mothers and US Casino Waitresses." In Political Ethnography, edited by Edward Schatz, 217-236. Chicago: The University of Chicago Press.

Bellinvia, Tindaro. 2013. Xenofobia, sicurezza, resistenza. L'ordine pubblico in una città "rossa." Il caso di Pisa. Milano: Mimesis edizioni.

Bernard, H. Russell. 2006. Research Methods in Anthropology: Qualitative and Quantitative Approaches. London: Altamira.

Blee, Kathleen, and Verta Taylor. 2002. "Semi-Structured Interviewing in Social Movement Research." In Methods of Social Movement Research, edited by Bert Klandermans and Suzanne Staggenborg, 92-117. Minneapolis: University of Minnesota Press.

Bloemraad, Irene. 2006. Becoming a Citizen: Incorporating Immigrants and Refugees in the United States and Canada. Berkeley and Los Angeles: University of California Press.

Bousetta, Hassan. 2000. "Institutional Theories of Immigrant Ethnic Mobilization: Relevance and Limitations." Journal of Ethnic and Migration Studies 26 (2): 229-245.

Bray, Zoe. 2008. "Ethnographic Approaches." In Approaches and Methodologies in Social Sciences: A Pluralist Perspective, edited by Donatella della Porta and Michael Keating, 296-315. Cambridge: Cambridge University Press.

Campomori, Francesca. 2008. Immigrazione e cittadinza locale. La governance dell'integrazione in Italia. Roma: Carocci. 
Campomori, Francesca, and Tiziana Caponio. 2013. "Competing Frames in Immigrant Integration in the EU: Geographies of Social Inclusion in Italian Regions." Policies Studies 34: 163-179.

Campomori, Francesca, and Tiziana Caponio. 2014. "Migrant Reception Policies in a Multilevel System: Framing and Implementation Structures in the Italian Regions." In Politics of Immigration in Multi-Level States: Governance and Political Parties, edited by Eve Hepburn and Ricard Zapata-Barrero, 130-149. London: Palgrave Macmillan.

Caponio, Tiziana. 2006. Città italiane e immigrazione. Discorso pubblico e politiche a Milano, Bologna e Napoli. Bologna: Il Mulino.

Caponio, Tiziana, and Maren Borkert, eds. 2010. The Local Dimension of Migration Policymaking. Amsterdam: Amsterdam University Press.

Cappiali, Teresa M. 2017. “'Whoever Decides for You without You, He is Against You!' Immigrant Activism and the Role of the Left in Political Racialization." Ethnic and Racial Studies 40 (6): 969-987.

Carchedi, Francesco, Francesca Carrera, and Giovanni Mottura, eds. 2010. Immigrazione e sindacato. Lavoro, cittadinanza e territory. VI Rapporto. Rome: Ediesse.

Caritas/Migrantes. 2012. Immigrazione Dossier Statistico 2012. Rome: Anterem.

Caritas/Migrantes. 2013. Immigrazione Dossier Statistico 2013. Rome: Anterem.

CNEL (Consiglio Nazionale dell'Economia e del Lavoro). 2009. VII Rapporto. Indici di integrazione degli immmigrati in Italia. www.cnel.it/18?tag_area_tematica $=35$ (Accessed June 30, 2015).

Della Porta, Donatella, ed. 2014. Methodological Practices in Social Movement Research. Oxford: Oxford University Press.

Eisenhardt, Kathleen M. 1989. "Building Theories from Case Study Research.” Academy of Management Review 14 (4): 532-550.

Eliasoph, Nina. 2001. Avoiding Politics: How Americans Produce Apathy in Everyday life. Cambridge: Cambridge University Press.

Emerson, Robert M., Rachel I. Fretz, and Linda L. Shaw. 1995. Writing Ethnographic Fieldnotes. Chicago: Chicago University Press

Eurostat (European Statistics). 2011. Regional GDP per Inhabitant in 2008. February 24, 2011. http://europa.eu/rapid/press-release_STAT-11-28_en.htm (Accessed June 15, 2015).

Fauser, Margit. 2012. Migrants and Cities: The Accommodation of Migrant Organizations in Europe. Aldershot: Ashgate.

Garbaye, Romain. 2005. Getting into Local Power: The Politics of Ethnic Minorities in British and French Cities. Oxford: Blackwell.

Geddes, Barbara. 1990. "How the Cases You Choose Affect the Answers You Get: Selection Bias in Comparative Politics." Political Analysis 2: 131-150.

Geertz, Clifford. 1973. The Interpretation of Cultures. New York: Basic Books.

George, Alexander L., and Andrew Bennett. 2005. Case Studies and Theory Development in the Social Sciences. Cambridge, MA: Harvard University Press.

Glaser, Barney G., and Anselm L. Strauss. 1967. The Discovery of Grounded Theory: Strategies for Qualitative Research. Chicago: Aldine Publishing Company.

Istat. 2013. Gli stranieri al $15^{\circ}$ Censimento della Popolazione. www.istat.it/it/files/2013/12/ Notadiffusione_stranieri20122013.pdf (Accessed June 30, 2015).

Koopmans, Ruud. 2004. "Migrant Mobilisation and Political Opportunities: Variation among German Cities and a Comparison with the United Kingdom and the Netherlands." Journal of Ethnic and Migration Studies 30 (3): 449-470.

Lichterman, Paul. 2002. "Seeing Structure Happen: Theory-Driven Participant Observation." In Methods in Social Movement Research, edited by Bert Klandermans and Suzanne Staggenborg, 188-145. Minneapolis: University of Minnesota Press. 
Mantovan, Claudia. 2007. Immigrazione e Cittadinanza. Auto-organizzazione e Partecipazione dei Migranti in Italia. Milan: FrancoAngeli.

Messina, Patrizia. 2001. Regolazione politica dello sviluppo locale. Torino: Utet.

Moore, Damian. 2004. "Migrants as Mediators in a Comparative Perspective." In Citizenship in European Cities: Immigrants, Local Politics and Integration Policies, edited by Rinus Penninx, Karen Kraal, Marco Martiniello, and Steven Vertovec, 127-138. Aldershot: Ashgate.

O'Reilly, Karen. 2008. Key Concepts in Ethnography. London: Sage.

Pelmutter, Ted. 1995. "Italian Immigration Politics in the 1990s: The Decline of Parties and the Rise of Interest Groups." American Political Science Association Meetings (Chicago August 31-September 3).

Però, Davide. 2008. "Migrants' Mobilization and Anthropology: Reflection from the Experience of Latin Americans in the United Kingdom." In Citizenship, Political Engagement, and Belonging: Immigrants in Europe and the United States, edited by Deborah ReedDanahay and Caroline Brettell, 103-123. New Brunswick: Rutgers University Press.

Putnam, Robert D. 1993. Making Democracy Work: Civic Traditions in Modern Italy. Princeton: Princeton University Press.

Siméant, Johanna. 1998. La cause des sans-papiers. Paris: Presses de Sciences po.

Smith, Jonathan A. 1995. "Semi-structured Interviewing and Qualitative Analysis." In Rethinking Methods in Psychology, edited by Jonathan A. Smith, Rom Harré, and Luk Van Langenhove, 9-26. London: Sage.

White, Robert W. 2007. “' I am not Sure What I Told You the Last Time': Methodological Notes on Accounts from the High-risk Activists in the Irish Republican Movement." Mobilization 12 (3): 287-305. 


\section{Appendix B}

\section{List of interviews conducted in Reggio Emilia}

\begin{tabular}{|c|c|c|c|c|c|}
\hline Code & Name & $\begin{array}{l}\text { Country of } \\
\text { origin and } \\
\text { sex }\end{array}$ & Organization & Role & $\begin{array}{l}\text { Date of } \\
\text { interview }\end{array}$ \\
\hline RE/N1 & Cesare F. & Italy (M) & $\begin{array}{l}\text { Left-wing } \\
\text { administration }\end{array}$ & $\begin{array}{l}\text { Assessor of } \\
\text { Security } \\
\text { and Social } \\
\text { Cohesion } \\
\text { since } 2003\end{array}$ & $\begin{array}{l}\text { Mar 3, } 2013 \\
\& \\
\text { May 10, } \\
2013\end{array}$ \\
\hline RE/N2 & Teresa E. & Italy (F) & $\begin{array}{l}\text { Municipality of } \\
\text { RE }\end{array}$ & $\begin{array}{l}\text { Cultural } \\
\text { mediator }\end{array}$ & Oct 29,2013 \\
\hline $\mathrm{RE} / \mathrm{N3}$ & Adil M. & $\begin{array}{l}\text { Morocco } \\
\text { (M) }\end{array}$ & $\begin{array}{l}\text { Municipality of } \\
\text { RE }\end{array}$ & $\begin{array}{l}\text { Cultural } \\
\text { mediator }\end{array}$ & $\begin{array}{l}\text { May 11, } \\
2013\end{array}$ \\
\hline RE/N4 & $\begin{array}{l}\text { Mohamed } \\
\text { A.* }\end{array}$ & $\begin{array}{l}\text { Morocco } \\
\text { (M) }\end{array}$ & $\begin{array}{l}\text { Mondinsieme } \\
\text { Center }\end{array}$ & Director & $\begin{array}{l}\text { Mar 4, } 2013 \\
\text { \& June 11, } \\
2013\end{array}$ \\
\hline RE/N5 & Rinaldo D. & Italy (M) & $\begin{array}{l}\text { Mondinsieme } \\
\text { Center }\end{array}$ & $\begin{array}{l}\text { Communication } \\
\text { Officer }\end{array}$ & May 3, 2013 \\
\hline RE/N6 & Morgan M. & $\begin{array}{l}\text { Second- } \\
\text { generation } \\
\text { Ghanaian } \\
\text { (F) }\end{array}$ & $\begin{array}{l}\text { Mondinsieme } \\
\text { Center }\end{array}$ & $\begin{array}{l}\text { Logistics and } \\
\text { Organization } \\
\text { Officer }\end{array}$ & May 3, 2013 \\
\hline $\mathbf{R E} / \mathbf{N} 7$ & Mario G. & Italy (M) & Caritas & Director & Feb 19, 2013 \\
\hline RE/N8 & Roberto I. & Italy (M) & Caritas & $\begin{array}{l}\text { Youth, volunteer, } \\
\text { civil service } \\
\text { sectors }\end{array}$ & May 9, 2013 \\
\hline RE/N9 & Emanuel S. & $\begin{array}{l}\text { Second- } \\
\text { generation } \\
\text { Togolese } \\
\text { (M) }\end{array}$ & Caritas & Volunteer & $\begin{array}{l}\text { May 12, } \\
2013\end{array}$ \\
\hline RE/N10 & Carmela R. & Italy (F) & CGIL & $\begin{array}{l}\text { In charge of } \\
\text { immigration } \\
\text { policies since } \\
2012\end{array}$ & Oct 20,2013 \\
\hline RE/N11 & Clara A. & Italy (F) & CGIL & $\begin{array}{l}\text { In charge of } \\
\text { the Office } \\
\text { for Migrants } \\
(2001-2010)\end{array}$ & May 7, 2013 \\
\hline
\end{tabular}




\begin{tabular}{|c|c|c|c|c|c|}
\hline Code & Name & $\begin{array}{l}\text { Country of } \\
\text { origin and } \\
\text { sex }\end{array}$ & Organization & Role & $\begin{array}{l}\text { Date of } \\
\text { interview }\end{array}$ \\
\hline RE/N12 & Farooq M. & $\begin{array}{l}\text { Pakistan } \\
\text { (M) }\end{array}$ & CGIL & $\begin{array}{c}\text { Functionary } \\
\text { Office for } \\
\text { Migrants }\end{array}$ & Oct 8,2013 \\
\hline RE/N13 & Sarah K. ${ }^{1}$ & Algeria $(\mathrm{F})$ & CGIL-FIOM & Functionary & Oct 28,2013 \\
\hline RE/N14 & Sandra M. & Italy (F) & CISL & $\begin{array}{l}\text { Secretary of the } \\
\text { local branch } \\
\text { (Reggio } \\
\text { Emilia) }\end{array}$ & $\begin{array}{c}\text { June 18, } \\
2013\end{array}$ \\
\hline RE/N15 & Sahid A. ${ }^{*}$ & $\begin{array}{l}\text { Second- } \\
\text { generation } \\
\text { Moroccan } \\
\text { (M) }\end{array}$ & $\begin{array}{l}\text { Network } \\
\text { TogethER \& } \\
\text { CISL- } \\
\text { ANOLF }\end{array}$ & $\begin{array}{l}\text { In charge of } \\
\text { the CISL- } \\
\text { ANOLF and } \\
\text { President } \\
\text { Network } \\
\text { TogethER }\end{array}$ & $\begin{array}{l}\text { May 3, } 2013 \\
\quad \& \\
\text { Nov 26, } \\
2013\end{array}$ \\
\hline RE/N16 & Pamela F. & Italy (F) & GA3 & Member & May 5, 2013 \\
\hline RE/N17 & $\begin{array}{l}\text { Francesca } \\
\text { F. }\end{array}$ & Italy (F) & $\begin{array}{l}\text { Democratic } \\
\text { Party }\end{array}$ & Main member & Oct 30,2013 \\
\hline RE/N18 & Reda B. ${ }^{*}$ & $\begin{array}{l}\text { Second- } \\
\quad \text { generation } \\
\text { Tunisian } \\
\text { (M) }\end{array}$ & $\begin{array}{l}\text { Democratic } \\
\text { Party }\end{array}$ & $\begin{array}{l}\text { City Councilor } \\
\text { of Quattro } \\
\text { Castella } \\
\text { (Province of } \\
\text { RE) \& } \\
\text { In charge of the } \\
\text { Provincial } \\
\text { Forum of } \\
\text { Immigration } \\
\text { of the Party }\end{array}$ & $\begin{array}{l}\text { Feb 20, } \\
2013 \& \\
\text { Nov 27, } \\
2013\end{array}$ \\
\hline RE/N19 & $\begin{array}{l}\text { Dhakirah } \\
\text { S. }\end{array}$ & $\begin{array}{l}\text { Second- } \\
\text { generation } \\
\text { Ghanaian } \\
\text { (M) }\end{array}$ & $\begin{array}{l}\text { Democratic } \\
\text { Party }\end{array}$ & $\begin{array}{l}\text { Member of the } \\
\text { Provincial } \\
\text { Forum of } \\
\text { Immigration }\end{array}$ & $\begin{array}{c}\text { Nov 24, } \\
2013\end{array}$ \\
\hline RE/N20 & Patrik P. & Senegal (M) & $\begin{array}{l}\text { NGO: Passa- } \\
\text { parola }\end{array}$ & Musician & $\begin{array}{c}\text { Nov } 27, \\
2013\end{array}$ \\
\hline RE/N21 & Salim S. & $\begin{array}{l}\text { Morocco } \\
\text { (M) }\end{array}$ & $\begin{array}{l}\text { NGO: Passa- } \\
\text { parola }\end{array}$ & Volunteer & $\begin{array}{c}\text { June 11, } \\
2013\end{array}$ \\
\hline
\end{tabular}

Note: The symbol ${ }^{*}$ indicates that people were interviewed twice.

\section{Note}

1 Interview conducted in Guastalla (Province of Reggio Emilia). 


\section{Appendix C}

\section{List of interviews conducted in Bologna}

\begin{tabular}{|c|c|c|c|c|c|}
\hline Code & Name & $\begin{array}{l}\text { Country of } \\
\text { origin and } \\
\text { sex }\end{array}$ & Organization & Role & $\begin{array}{l}\text { Date of } \\
\text { interview }\end{array}$ \\
\hline BO/N1 & Monica $\mathrm{T}$. & Italy (F) & $\begin{array}{l}\text { Emilia- } \\
\text { Romagna } \\
\text { Region } \\
\text { (left-wing } \\
\text { government) }\end{array}$ & $\begin{array}{l}\text { Assessor of Social } \\
\text { Policies since } \\
2003\end{array}$ & Nov 25, 2013 \\
\hline $\mathrm{BO} / \mathbf{N 2}$ & $\begin{array}{l}\text { Francesca } \\
\text { L. }\end{array}$ & Italy (F) & $\begin{array}{l}\text { Municipality of } \\
\text { Bologna }\end{array}$ & $\begin{array}{l}\text { Employee of the } \\
\text { administration } \\
\text { (Office of } \\
\text { Cooperation } \\
\text { and Human } \\
\text { Rights) }\end{array}$ & June 26, 2014 \\
\hline BO/N3 & Marco G. & Italy (M) & $\begin{array}{l}\text { Municipality of } \\
\text { Bologna }\end{array}$ & $\begin{array}{l}\text { Director of the } \\
\text { office ISI } \\
\text { (Istituto Servizi } \\
\text { Immigrazione) } \\
\text { (1996-1999) } \\
\text { and expert on } \\
\text { trade unions' } \\
\text { responses to } \\
\text { immigration }\end{array}$ & June 26, 2014 \\
\hline BO/N4 & Veronica P. & Italy (F) & Caritas & $\begin{array}{l}\text { In charge of } \\
\text { the Center } \\
\text { of Listening } \\
\text { (Centro } \\
\text { d'Ascolto) }\end{array}$ & June 4, 2013 \\
\hline BO/N5 & Pietro M. & Italy (M) & CISL-ANOLF & Service desk & June 19, 2014 \\
\hline $\mathrm{BO} / \mathrm{N} 6$ & Roberta A. & Italy (F) & CGIL & $\begin{array}{l}\text { In charge of } \\
\text { the Office for } \\
\text { Foreign Workers } \\
\text { since } 2010\end{array}$ & Oct 30, 2013 \\
\hline BO/N7 & $\begin{array}{l}\text { Alessandro } \\
\text { F.* }^{*}\end{array}$ & Italy (M) & $\begin{array}{l}\text { Intercultural } \\
\text { Center } \\
\text { Massimo } \\
\text { Zonarelli }\end{array}$ & Director & $\begin{array}{l}\text { May 5, } 2013 \\
\quad \& \\
\text { May 30, } 2013\end{array}$ \\
\hline
\end{tabular}




\begin{tabular}{|c|c|c|c|c|c|}
\hline Code & Name & $\begin{array}{l}\text { Country of } \\
\text { origin and } \\
\text { sex }\end{array}$ & Organization & Role & $\begin{array}{l}\text { Date of } \\
\text { interview }\end{array}$ \\
\hline BO/N8 & Irene A. & $\begin{array}{l}\text { Philippines } \\
\text { (F) }\end{array}$ & $\begin{array}{l}\text { Federation } \\
\text { of Filipino } \\
\text { Associations } \\
\text { of Bologna \& } \\
\text { Member of } \\
\text { the Council } \\
\text { of Foreign } \\
\text { Citizens and } \\
\text { Stateless } \\
\text { People in the } \\
\text { Province of } \\
\text { Bologna }\end{array}$ & $\begin{array}{l}\text { President of the } \\
\text { Federation, and } \\
\text { elected member } \\
\text { of the Council }\end{array}$ & July 2, 2013 \\
\hline BO/N9 & Corrado G. & Italy (M) & $\begin{array}{c}\text { MCO (Migrant } \\
\text { Coordination } \\
\text { Organization) }\end{array}$ & Main member & July 19, 2013 \\
\hline BO/N10 & Abou B.* & Senegal (M) & $\begin{array}{l}\text { MCO \& } \\
\text { Association of } \\
\text { the Senegalese } \\
\text { community in } \\
\text { Bologna }\end{array}$ & $\begin{array}{l}\text { Main member of } \\
\text { the MCO and } \\
\text { President of the } \\
\text { Association }\end{array}$ & $\begin{array}{l}\text { May } 17,2013 \\
\quad \& \\
\text { Oct } 28,2013\end{array}$ \\
\hline BO/N11 & Ben S. ${ }^{*}$ & Senegal (M) & $\mathrm{MCO}$ & $\begin{array}{l}\text { Main member of } \\
\text { the MCO \& } \\
\text { delegate of the } \\
\text { CGIL }\end{array}$ & $\begin{array}{l}\text { May } 15,2013 \\
\& \\
\text { Oct } 29,2013\end{array}$ \\
\hline BO/N12 & Tariq I. & $\begin{array}{l}\text { Pakistan } \\
\text { (M) }\end{array}$ & $\begin{array}{l}\text { MCO \& } \\
\text { Association of } \\
\text { Pakistanis in } \\
\text { Italy }\end{array}$ & $\begin{array}{l}\text { Main member } \\
\text { of both } \\
\text { organizations }\end{array}$ & June 3, 2013 \\
\hline BO/N13 & $\begin{array}{l}\text { Mohamed } \\
\text { A. }\end{array}$ & $\begin{array}{l}\text { Morocco } \\
\text { (M) }\end{array}$ & $\begin{array}{l}\text { MCO \& } \\
\text { Association } \\
\text { of Moroccan } \\
\text { Workers }\end{array}$ & $\begin{array}{l}\text { Main member } \\
\text { of both } \\
\text { organizations }\end{array}$ & June 13, 2013 \\
\hline BO/N14 & Farid M. & $\begin{array}{l}\text { Second- } \\
\text { generation } \\
\text { Moroccan } \\
\text { (M) }\end{array}$ & $\begin{array}{l}\text { MCO \& On } \\
\text { the Move- } \\
\text { Generation in } \\
\text { movement }\end{array}$ & $\begin{array}{l}\text { Founder and key } \\
\text { member of } O n \\
\text { the Move }\end{array}$ & June 19, 2013 \\
\hline BO/N15 & Sonia F. & Senegal (F) & $\begin{array}{l}\text { Association of } \\
\text { Senegalese } \\
\text { Women \& } \\
\text { Member of the } \\
\text { MCO }\end{array}$ & $\begin{array}{l}\text { Member of } \\
\text { the MCO, } \\
\text { President of } \\
\text { the Association } \\
\text { of Senegalese } \\
\text { Women }\end{array}$ & June 3, 2013 \\
\hline BO/N16 & Claudia E. & Italy (F) & $\mathrm{MCO}$ & Main member & May 8, 2013 \\
\hline BO/N17 & Sorana E. & Moldova (F) & $\mathrm{MCO}$ & Main Member & July 2, 2013 \\
\hline BO/N18 & Yon W. & $\begin{array}{l}\text { Second- } \\
\text { generation } \\
\text { Chinese } \\
\text { (M) }\end{array}$ & $\begin{array}{l}\text { Asso-Cina in } \\
\text { the Network } \\
\text { Rete } \\
\text { TogethER }\end{array}$ & Main member & June 4, 2013 \\
\hline
\end{tabular}


(Continued)

\begin{tabular}{|c|c|c|c|c|c|}
\hline Code & Name & $\begin{array}{l}\text { Country of } \\
\text { origin and } \\
\text { sex }\end{array}$ & Organization & Role & $\begin{array}{l}\text { Date of } \\
\text { interview }\end{array}$ \\
\hline BO/N19 & Adelina Y. & Albania (F) & $\begin{array}{l}\text { AMISS } \\
\text { (Association } \\
\text { of Cultural } \\
\text { Mediators) }\end{array}$ & $\begin{array}{c}\text { Founder and } \\
\text { President }\end{array}$ & June 19, 2014 \\
\hline BO/N20 & $\begin{array}{l}\text { Makham } \\
\text { M. }\end{array}$ & Senegal (M) & $\begin{array}{l}\text { Democratic } \\
\text { Party \& } \\
\text { Council } \\
\text { of Foreign } \\
\text { Citizens and } \\
\text { Stateless } \\
\text { People in the } \\
\text { Province of } \\
\text { Bologna }\end{array}$ & Councilor & Oct 30,2013 \\
\hline BO/N21 & Nnkeme N. & Nigeria (M) & $\begin{array}{l}\text { Nigerian } \\
\text { Association }\end{array}$ & $\begin{array}{l}\text { Founder and } \\
\text { President }\end{array}$ & July 2, 2013 \\
\hline BO/N22 & Donald R." ${ }^{* 1}$ & $\begin{array}{l}\text { Cameroon } \\
\text { (M) }\end{array}$ & $\begin{array}{l}\text { Democratic } \\
\text { Party }\end{array}$ & $\begin{array}{l}\text { Assessor of } \\
\text { integration of } \\
\text { San Lazzaro } \\
\text { (Province } \\
\text { of BO) \& In } \\
\text { charge of the } \\
\text { Provincial } \\
\text { Forum on } \\
\text { Immigration of } \\
\text { the Party }\end{array}$ & $\begin{array}{l}\text { June 5, } 2013 \\
\& \\
\text { Oct } 29,2013\end{array}$ \\
\hline $\mathrm{BO} / \mathrm{N} 23$ & Yana L. & Ukraine (F) & $\begin{array}{l}\text { Ukrainian } \\
\text { Association }\end{array}$ & $\begin{array}{c}\text { Founder and } \\
\text { President }\end{array}$ & Apr 3,2013 \\
\hline BO/N24 & Lionel F. & $\begin{array}{l}\text { Cameroon } \\
\text { (M) }\end{array}$ & $\begin{array}{l}\text { Association } \\
\text { Universe }\end{array}$ & $\begin{array}{c}\text { Founder and } \\
\text { President }\end{array}$ & June 19, 2014 \\
\hline
\end{tabular}

Note: The symbol ${ }^{*}$ indicates that people were interviewed twice.

\section{Note}

1 Interview conducted in San Lazzaro (Province of Bologna). 


\section{Appendix D}

\section{List of interviews conducted in Brescia}

\begin{tabular}{|c|c|c|c|c|c|}
\hline Code & Name & $\begin{array}{l}\text { Country of } \\
\text { origin and sex }\end{array}$ & Organization & Role & $\begin{array}{l}\text { Date of } \\
\text { interview }\end{array}$ \\
\hline BR/N1 & $\begin{array}{c}\text { Emilio Del } \\
\text { Bono }^{1}\end{array}$ & Italy (M) & $\begin{array}{l}\text { Local left-wing } \\
\text { administration }\end{array}$ & $\begin{array}{l}\text { Mayor of since } \\
2013\end{array}$ & Sept 19, 2013 \\
\hline BR/N2 & Vittorio F. & Italy (M) & $\begin{array}{l}\text { Local } \\
\text { administration } \\
\quad(1998-2008)\end{array}$ & $\begin{array}{l}\text { In charge of the } \\
\text { Municipal } \\
\text { Office for } \\
\text { Foreigners }\end{array}$ & July 12, 2013 \\
\hline BR/N3 & $\begin{array}{l}\text { Benedetto } \\
\text { G. }\end{array}$ & Italy (M) & $\begin{array}{l}\text { Migrants Center } \\
\text { Association of } \\
\text { the diocese }\end{array}$ & Director & Nov 11, 2013 \\
\hline BR/N4 & Luciano F. & Italy (M) & Carmine Street & Director-Priest & July 11, 2013 \\
\hline BR/N5 & Carlo L. & Italy (M) & Carmine Street & Social worker & Oct 11,2013 \\
\hline BR/N6 & Marta G. & Italy (F) & CISL-ANOLF & President & May 17,2013 \\
\hline BR/N7 & $\begin{array}{l}\text { Mammadu } \\
\text { F. }\end{array}$ & Senegal (M) & CISL & $\begin{array}{l}\text { Functionary of } \\
\text { CISL-FIM } \\
\text { (metalworkers) }\end{array}$ & May 25,2013 \\
\hline BR/N8 & Anna E. & Moldova (F) & CISL-A & Volunteer & May 25, 2013 \\
\hline BR/N9 & Giulio D. & Italy (M) & CGIL & $\begin{array}{l}\text { Secretary of the } \\
\text { local branch }\end{array}$ & July 11,2013 \\
\hline BR/N10 & $\begin{array}{l}\text { Carmine } \\
\text { E. }\end{array}$ & Italy (M) & CGIL & $\begin{array}{l}\text { In charge of the } \\
\text { Office Against } \\
\text { Discrimination }\end{array}$ & July 12, 2013 \\
\hline BR/N11 & Rosa S. & Italy $(\mathrm{F})$ & CGIL & $\begin{array}{l}\text { In charge of } \\
\text { immigration } \\
\text { policies }\end{array}$ & July 12,2013 \\
\hline BR/N12 & Vinicio M. & Italy & Rights & Lawyer & Sept 6, 2013 \\
\hline BR/N13 & Yusuf A. & Pakistan $(\mathrm{M})^{*}$ & $\begin{array}{l}\text { Migrant social } \\
\text { movement \& } \\
\text { Rights for All }\end{array}$ & Main member & $\begin{array}{l}\text { July } 18 \text {, } \\
2013 \& \\
\text { Sept 6, } 2013\end{array}$ \\
\hline BR/N14 & Ramzi J. & Egypt $(\mathrm{M})^{*}$ & $\begin{array}{l}\text { Migrant social } \\
\text { movement \& } \\
\text { Cross-point }\end{array}$ & Main member & $\begin{array}{l}\text { July } 18,2013 \\
\quad \& \\
\text { Sept 7, } 2013\end{array}$ \\
\hline BR/N15 & Abou D. & Senegal (M) & $\begin{array}{l}\text { Migrant social } \\
\text { movement \& } \\
\text { Cross-point }\end{array}$ & Main member & July 15,2013 \\
\hline
\end{tabular}


294 Appendix D

(Continued)

\begin{tabular}{|c|c|c|c|c|c|}
\hline Code & Name & $\begin{array}{l}\text { Country of } \\
\text { origin and sex }\end{array}$ & Organization & Role & $\begin{array}{l}\text { Date of } \\
\text { interview }\end{array}$ \\
\hline BR/N16 & $\begin{array}{l}\text { Ibrahim } \\
\text { M. }\end{array}$ & Senegal (M) & $\begin{array}{c}\text { Migrant social } \\
\text { movement \& } \\
\text { Senegalese } \\
\text { Association }\end{array}$ & Main member & Sept 8, 2013 \\
\hline BR/N17 & Khalid D. & Morocco (M) & $\begin{array}{l}\text { CGIL \& } \\
\text { Migrant social } \\
\text { movement }\end{array}$ & $\begin{array}{l}\text { Main member, } \\
\text { in charge of } \\
\text { the Office for } \\
\text { Migrants }\end{array}$ & July 15, 2013 \\
\hline BR/N18 & $\begin{array}{l}\text { Mustafa } \\
\text { M. }\end{array}$ & Morocco (M) & $\begin{array}{l}\text { Communist } \\
\text { Refoundation } \\
\text { Party (PRC) }\end{array}$ & Main member & Sept 6, 2013 \\
\hline BR/N19 & $\begin{array}{l}\text { Mohamed } \\
\text { A. }\end{array}$ & $\operatorname{Morocco}(\mathrm{M})^{*}$ & Rights for All & Main Member & $\begin{array}{l}\text { Sept } 7 \text {, } \\
2013 \& \\
\text { Oct } 21,2013\end{array}$ \\
\hline BR/N20 & Bujar A. & Albania (M) & $\begin{array}{l}\text { Democratic } \\
\text { Party (PD) }\end{array}$ & $\begin{array}{l}\text { Member, } \\
\text { Provincial } \\
\text { Forum on } \\
\text { Immigration }\end{array}$ & Oct 11, 2013 \\
\hline BR/N21 & Fatima N. ${ }^{*}$ & $\operatorname{Morocco}(\mathrm{F})$ & $\begin{array}{l}\text { Democratic } \\
\text { Party (PD) }\end{array}$ & $\begin{array}{l}\text { Member, } \\
\text { Provincial } \\
\text { Forum on } \\
\text { Immigration }\end{array}$ & $\begin{array}{l}\text { July } 14 \text {, } \\
2013 \text { \& Oct } \\
\quad 8,2013\end{array}$ \\
\hline BR/N22 & Sanshia S. & $\begin{array}{l}\text { Second- } \\
\text { generation } \\
\text { Bangladeshi } \\
\text { (F) }\end{array}$ & $\begin{array}{l}\text { Association } \\
\text { of Second- } \\
\text { generation } \\
\text { Bangladeshi } \\
\text { Women }\end{array}$ & President & Sept 13, 2013 \\
\hline
\end{tabular}

Note: The symbol ${ }^{*}$ indicates that people were interviewed twice.

\section{Note}

1 This is the real name. 


\section{Appendix E}

\section{List of interviews conducted in Bergamo}

\begin{tabular}{|c|c|c|c|c|c|}
\hline Code & Name & $\begin{array}{l}\text { Country of } \\
\text { origin and } \\
\text { sex }\end{array}$ & Organization & Role & $\begin{array}{l}\text { Date of } \\
\text { interview }\end{array}$ \\
\hline BG/N1 & $\begin{array}{l}\text { Salvatore } \\
\text { E. }\end{array}$ & Italy (M) & $\begin{array}{l}\text { Agency for } \\
\text { Integration }\end{array}$ & Director & Sept 5, 2013 \\
\hline BG/N2 & $\begin{array}{l}\text { Don } \\
\text { Mariano } \\
\text { M. }\end{array}$ & Italy (M) & Caritas & Priest, member & Nov 12, 2013 \\
\hline BG/N3 & $\begin{array}{l}\text { Zaccaria } \\
\text { M. }\end{array}$ & Italy (M) & Caritas & $\begin{array}{l}\text { Head of the } \\
\text { Department of } \\
\text { Social Policy }\end{array}$ & Nov 30, 2013 \\
\hline BG/N4 & Giorgio B. & Italy (M) & $\begin{array}{l}\text { Ruah } \\
\text { Cooperative }\end{array}$ & Director & Nov 14, 2013 \\
\hline BG/N5 & $\begin{array}{l}\text { Raimondo } \\
\text { D.* }\end{array}$ & Italy (M) & $\begin{array}{l}\text { Patronage } \\
\text { ACLI }\end{array}$ & Director & $\begin{array}{l}\text { Nov } 15,2013 \\
\quad \& \\
\text { Nov } 20,2013\end{array}$ \\
\hline BG/N6 & Angelo A. & Italy (M) & CISL & $\begin{array}{l}\text { Head of the office } \\
\text { CISL-ANOLF }\end{array}$ & Nov 13, 2013 \\
\hline BG/N7 & Alessio O. & Italy (M) & CGIL & $\begin{array}{l}\text { Head of the } \\
\text { Department } \\
\text { of Migration } \\
\text { Policy }\end{array}$ & Nov 14, 2013 \\
\hline BG/N8 & Piero P. & Italy (M) & Radical left & $\begin{array}{l}\text { Independent } \\
\text { activist of the } \\
\text { radical left }\end{array}$ & Nov 15, 2013 \\
\hline BG/N9 & Carlo F. & Italy (M) & $\begin{array}{l}\text { Communist } \\
\text { Refoundation } \\
\text { Party (PRC) }\end{array}$ & $\begin{array}{l}\text { Main member, in } \\
\text { charge of the } \\
\text { immigration } \\
\text { sector }\end{array}$ & Nov 12, 2013 \\
\hline BG/N10 & Sergio S. & Italy (M) & Asia-USB & $\begin{array}{l}\text { Main member } \\
\text { and activist of } \\
\text { the radical left }\end{array}$ & Nov 15, 2013 \\
\hline BG/N11 & $\begin{array}{l}\text { Damiano } \\
\text { D. }\end{array}$ & Italy (M) & Radical left & $\begin{array}{l}\text { Independent } \\
\text { activist of the } \\
\text { radical left }\end{array}$ & Nov 15, 2013 \\
\hline BG/N12 & Daniela D. & Bolivia (F) & $\begin{array}{l}\text { Bolivian } \\
\text { Association }\end{array}$ & President & Nov 29, 2013 \\
\hline
\end{tabular}


(Continued)

\begin{tabular}{|c|c|c|c|c|c|}
\hline Code & Name & $\begin{array}{l}\text { Country of } \\
\text { origin and } \\
\text { sex }\end{array}$ & Organization & Role & $\begin{array}{l}\text { Date of } \\
\text { interview }\end{array}$ \\
\hline BG/N13 & Sarah F.* & $\begin{array}{l}\text { Second- } \\
\text { generation } \\
\text { Moroccan } \\
\text { (F) }\end{array}$ & $\begin{array}{l}\text { Moroccan } \\
\text { Association }\end{array}$ & Main member & $\begin{array}{l}\text { Nov } 13,2013 \\
\quad \& \\
\text { Nov } 29,2013\end{array}$ \\
\hline BG/N14 & Donkor A. & Ghana (M) & $\begin{array}{l}\text { Ghanaian } \\
\text { Association }\end{array}$ & President & Nov 29, 2013 \\
\hline BG/N15 & Babacar S. & Senegal (M) & $\begin{array}{l}\text { FIOM-CGIL \& } \\
\text { Senegalese } \\
\text { Association }\end{array}$ & $\begin{array}{l}\text { Functionary \& } \\
\text { President }\end{array}$ & $\begin{array}{l}\text { Nov 13, } 2013 \\
\quad \& \\
\text { Nov 28, } 2013\end{array}$ \\
\hline BG/N16 & $\begin{array}{l}\text { Karim } \\
\text { M. }^{*}\end{array}$ & $\begin{array}{l}\text { Morocco } \\
\text { (M) }\end{array}$ & $\begin{array}{c}\text { FIOM-CGIL \& } \\
\text { Communist } \\
\text { Refoundation } \\
\text { Party (PRC) }\end{array}$ & Main member & $\begin{array}{l}\text { Nov 14, } \\
2013 \text { \& } \\
\text { Nov 28, } \\
2013\end{array}$ \\
\hline BG/N17 & Ayoub A. ${ }^{*}$ & $\begin{array}{l}\text { Second- } \\
\text { generation } \\
\text { Moroccan } \\
\text { (M) }\end{array}$ & USB & $\begin{array}{l}\text { Volunteer, } \\
\text { role with } \\
\text { responsibilities } \\
\text { for immigration } \\
\text { policies }\end{array}$ & Nov 7, 2013 \\
\hline
\end{tabular}

Note: The symbol ${ }^{*}$ indicates that people were interviewed twice. 


\section{Index}

Note: Page numbers in italics indicate a figure and page numbers in bold indicate a table on the corresponding page.

\section{ACLI (Christian Association of Italian \\ Workers, Associazioni Cristiane \\ Lavoratori Italiani) 43, 195, 199}

active citizenship 62, 93, 121-124, 136

actor-oriented approach 9-12, 55, 57, 63,254

advocacy $58,66,125,167,264-265$

alliances and/or allies 71-72, 172-182,

255-256, 260; and the Communist trade union 94-96; explaining alliances 55-62; and immigrant leadership 98-100; and local dynamics 63-64, 70-73; overlapping 133-141; and the political rights promotion approach 69; and weak political participation 100-102; see also lack of alliances alternative paths $180-182$ ambivalence 124-126

ambivalent allies 237-240

AMISS (Association of Intercultural Mediators for Social and Health Services, Associazione Mediatrici Interculturali Sociali e Sanitari) 122-124

Amitié 121-122

amnesties 31, 40, 153-157, 169-170,

$172-175,179,180$

anti-immigrant hostilities 2-3, 183-184

anti-immigrant parties 22, 36, 71,

249-251, 256; see also Northern

League

anti-racism and anti-racist movements

$3-4,40-41,111-112,204,252-253$;

reimagining for the future $265-267$

anti-racist organizations $4,152,193,252$ approaches to inclusion 10-12, 20-21, $63-65,70-73,80-81,231,275-276$; and ideology 257-259, 259; and implications for participation $\mathbf{6 5}$; see also approaches to inclusion from below approaches to inclusion from below: and the ambivalence of the main left-wing trade union 124-126; the Catholic Church and the Christian-Democrat trade union in promoting the assistance approach 162-164; lay organizations and the intercultural approach from below 119-124; and the local realm of immigration 118-133, 162-172; the radical left and the politicization of the rights of vulnerable immigrants 168-172; the role of the Communist trade union, the fight against racism, and the political rights promotion approach 165-167; the role of the MCO and the political rights promotion approach 126-131; and the weak role of the Democratic Party 132-133

assistance approach 21-22, 43-44, 66-69, 192-193, 205, 215, 275; the Catholic Church and the ChristianDemocrat trade union in promoting 162-164; traditional trade unions promoting 200-204

assistant approach 66-67, 197-205, 231, 261

Association Universe (Associazione Universo) 122-124

asymmetrical relations of power 16,59 , 223,254 
barriers to participation 205-214

Base United Unions (USB, Unione Sindacale di Base) 47, 127, 193, 213-215, 222

Bergamo 21-22, 44-47, 192-196, 259-260, 295-296; the de-politicization of immigrant associations 206-211; lessons from 214-216; obstructing political participation 211-213; political racialization and resistance 231 , 234-235, 239; traditional trade unions promoting the assistance approach 200-204; the uncontested power of the Catholic Church and the promotion of passive cohabitation 198-200; the weak role of left-wing organizations and the absence of political rights promotion 204-205

Bologna 18-21, 40-42, 44-47, 227-232, 236-238, 241-243, 260; "A day without us: the strike of migrants" 111-113; lessons from 141-144; list of interviews conducted in 290-292; the local realm of immigration and approaches to inclusion from below 118-133; multiple channels, overlapping alliances, and conflicts 133-141; the withdraw of the institutional left 113-118

bottom-up dynamics (from below) 8, 11-12, 57, 90-94, 119-124, 256; see also approaches to inclusion from below

Brescia 3-4, 20-21, 45-47, 152-153, 195-196, 261, 293-294; alliances, conflicts, and political radicalization 172-182; devolution to the Church and the securitarian turn 157-162; lessons from 183-185; the local realm of immigration and conflicting approaches to inclusion from below 162-172; political racialization and resistance 226-227, 239-243; "Struggle of the crane" $153-157$

bringing in the point of view of oppressed groups 224

\section{case selection $272-277$}

Catholic Church 192-193; conflicts, mistrust, and lack of alliances with 177-180, 205-214; devolution to 157-162; as the dominant actor 194-197; and high barriers to participation 205-214; lessons from
Bergamo 214-216; and mobilization 193-194; in promoting the assistance approach 162-164; and traditional trade unions promoting the assistance approach 200-204; uncontested power of 197-200; and the weak role of leftwing organizations 204-205

CGIL (Italian General Confederation of Labor, Confederazione Generale Italiana del Lavoro) 37-38, 42-43, 47, 70, 261, 279, 282; civic participation in a city of intercultural dialogue 82 , 85-86, 94-96, 98, 100-101; multiple forms of participation in a stronghold of the left 112, 115, 118-119, 124-127, 130-131, 133-134, 138-139, 142-143; obstructing participation in a stronghold of the Catholic Church 193, 200-205, 212, 215; political contention amid the rise of the Northern League 153, 155-156, 160-162, 164-169, 173, 177-180, 183-185; political racialization and resistance 220, 229, 233-235, 244

CGIL-FIOM (Metalworker's Federation, Federati Impiegati Operai Metallurgici della CGIL) 21, 38, 47, 112, 126, 153; obstructing participation in a stronghold of the Catholic Church 193, 202-203, 206, 211-212; political racialization and resistance 222, 235, 239

channels of participation, conventional and non-conventional $71,85,98-100$, 139-144, 159-160, 214-215

charity 70, 198, 223, 241, 255

Christian Democrats (DC, Democrazia Cristiana) 43-45, 86, 257, 273, 275-276; alliances and conflicts in context 68-70, 74; multiple forms of participation 119, 142; obstructing participation 194, 214-215; political contention 152, 156-157

Christian-Democrat trade union 162-164 CISL (Italian Confederation of Workers'

Trade Unions, Confederazione Italiana Sindacati Lavoratori) 37, 47, 68, 70, 261, 279; civic participation 82,86 , 94, 98; multiple forms of participation 118-119, 124, 131, 142, 146-147n23; obstructing participation 193, 200-204, 208, 215; political contention 155-157, $162,164-165,169,171-172,176-179$, 183-185; political racialization and resistance $233,235,240$ 
citizenship (and lack of citizenship) 2-5, 10, 13, 16, 19, 34; alliances and conflicts in context 61-62; civic participation 81-83, 87-88, 93, 102; multiple forms of participation 119-121, 123-124, 134-136; obstructing participation 208; political contention 180

civic participation $71,74,80-81,97-102$, 134-136; intercultural dialogue and implications for 97-102; "Italy is me, too! For the rights of citizenship" campaign 81-84; lessons from Reggio Emilia 102-105; the local realm of immigration and the prevalence of the intercultural approach 86-97; political continuity and the role of the left-wing administrations in promoting inclusion 84-86

civil society organizations 19-20, 43-45, 57,67

clandestini $93,180-181,225$

clandestinity 129, 154

clientelism 98

CNEL (National Council for Economics and Labor, Consiglio Nazionale dell'Economia e del Lavoro) 273

coalitions 3-6, 12-13, 39-41, 47, 57-59, 160

COBAS (Confederation of Basic

Committees, Confederazione dei

Comitati di Base) 47, 221

cohabitation between different cultures 68 , 86-90, 197-200

Communist Refoundation Party (PRC, Partito di Rifondazione Comunista) 40-41, 169; obstructing participation 193-194, 198, 204-206, 209, 211-215; political racialization and resistance 223 , 235, 239

Communists 45, 69, 74, 84, 90, 105, 113-114, 152, 257, 273-276; see also CGIL; CGIL-FIOM; Communist Refoundation Party

Communist trade union see CGIL; CGIL-FIOM

Confederation of Basic Committees (COBAS, Confederazione dei Comitati di Base) 47, 221

cohabitation between different cultures 68 , 86-90, 197-200

conflicts 133-134, 177-179; in hostile environments 57-59; theoretical model $55,61,63,68,71,73,255-256$ construct immigrants as objects of inclusion (in their own terms) 244

consultative bodies $9-10,40,69,85$, $116-117,139,160$

"consumer paradigm" ("paradigm of dependence and subordination" of immigrants) 242, 244; disempowering platforms, fora, and immigrant organizations 227-232; lack of meaningful representation and unequal treatment 232-237; resisting local voting rights $225-227$

contratto di soggiorno 32

conventional channels: alternative paths in 180-182; political participation in 137-139

co-optation 193, 213-215, 234-236, 244-245

country of origin 121, 139, 210, 234, 274

criminalization of immigrants $2-3,32,56$, 68, 261

critical ethnic and race (or racial) studies 59-60, 63, 254, 267

critical lens 59, 61, 256, 261-262

CUB (Unitary Base Confederation, Confederazione Unitaria di Base) 47, 193

data analysis $282-283$

data triangulation 277-282

"day without us: The strike of migrants, A" 193-194

DC see Christian Democrats

democracy 244, 253, 266-267

Democratic Party (PD, Partito

Democratico) 35, 38-39, 225-229, 235-236, 239-243; civic participation 96-97, 101-102; multiple forms of participation 137-138, 142-143; obstructing participation 204-205; political contention 156-159, 174-176, 180-181; weak role of $132-133$

Democratic racism 236, 251

democratic representation 233

Democrats of the Left (DS, Democratici de Sinistra) 38, 138, 229

demonstrations 2-4, 239; "A day without us: the strike of migrants" 111-113; multiple forms of participation 124, 142; obstructing participation 192-194; political contention 152-155, 170, 173-178; see also protests de-politicization 94-97; of immigrant associations 206-211 
descriptive representation 233

devolution 157-162, 194-197

differential or subaltern inclusion 16 , 221,233

differential treatment 160, 244

disciplining mechanisms 237

disempowered groups 227-229

disempowerment (of platforms, fora, and immigrant organizations) 227-232

dismantle power dynamics 252,267

distinction between "us" and "them" 9 , $15,132,233$; civic participation 89 , 100, 103; political racialization and resistance 240-241, 243

dominant actor, Catholic Church as 194-197

DS (Democrats of the Left, Democratici de Sinistra) 38, 138, 229

economic burden 58

El-Tayeb, Fatima 2, 9, 14-16, 61, 246, 250, 264-265

Emilia-Romagna region 39-40, 45, 166, 273-276; civic participation $80,83-85$, 90-93, 96-99; multiple forms of participation 131-133

empirical contribution 12-13, 257-263

engagement $71-72$

epistemological postures 59

equal partnership 67

essentializing (immigrant groups) 246

"ethnic" background 234

ethnicity $105 \mathrm{n} 3,117,272$

ethnicization 9, 94, 215, 234, 283

ethnic minorities 14

ethnographic approach 7

exclusion 1-2, 14-16, 233, 250-253, 262-266; alliances and conflicts in context 59-62; political contention $160-161,184$

exclusionary discourses and practices 16 , $22,34-36,42$

exploitation in the labor markets 16,32 , $127-128,252,261$

extra-comunitari 14,36 ; see also non-EU immigrants

fieldwork 277-282

financial crisis (2008) $1-5$

foreign-born immigrants 7,282

framing $6,58-59,260-261$

future research, recommendations for 263-265 grassroots organizations 40, 48, 255

grassroots unions 126-129, 213, 239, 279

hierarchical power relations 59

high barriers to participation 205-214

hooks, bell 60-61, 220-221, 223-225, 232, 244-246

hostile environments 29-34, 56-59, 262

ideological conflicts 41, 100, 240

ideology 57-60, 257-258, 259

illegality $3,20,31,112,176,258$

immigrant activism $1-3,8-9,12-13$, $55-62,256-257$

immigrant activists $71-72,73,222-225$, 280-281, 262-263

immigrant associations 66-68, 91-94, 119-124, 135-136, 201; de-politicization of 206-211

Immigrant Committee of Italy (Comitato Immigrati d'Italia) 230

immigrant communities 30, 65-69, 196-197, 274

immigrant groups $1-6,12-19,56-58$, $68-69,102-103,254-256$

immigrant leadership 98-100

immigrant mobilizations $1-5$; see also mobilizations

(immigrant) rights claims 11-12, 19-21, 70-74, 80-81, 101-105, 183-185,

253-258; de-politicization of 94-97

immigrants, vulnerable 168-172

immigrant social movement $172-177$

immigrant status 20, 113, 263

immigrant struggles see also resistance 244

immigrant workers 94-96, 111-113

"impossible subjects" 2, 16

inclusion 37-44, 63-69, 65, 84-86; and ideology 257-258, 259; see also approaches to inclusion

inferiorization of immigrants 61, 232, 266

institutional actors 56, 98-100

institutional context $70-71$

institutional left 113-118

institutional racism 29-34

integration $14-17,92-93,99-100$, $114-120,124-125,195-200,239-242$

interactions of actors in cities 7

intercultural approach $67-68,80-81$, 86-90, 94-100, 103-104, 142-143, $163-164$

intercultural approach from below 90-94, $119-124$ 
intercultural cities $107-108 \mathrm{n} 21$

intercultural dialogue $19,44,81,83$, 90-93, 103, 116; implications for participation in civic channels 97-102; promoting from above $86-90$

interculturalism 19-20, 67-68, 85-88, $103-104,123-124$

intramural conflicts and ideological schisms 259

Italian Confederation of Workers' Trade Unions (CISL, Confederazione Italiana Sindacati Lavoratori) 37, 47, 68, 70, 261, 279; civic participation 82,86 , 94, 98; multiple forms of participation $118-119,124,131,142,146-147 \mathrm{n} 23$; obstructing participation 193, 200-204, 208, 215; political contention 155-157, $162,164-165,169,171-172,176-179$, 183-185; political racialization and resistance 233, 235, 240

Italian General Confederation of Labor (CGIL, Confederazione Generale Italiana del Lavoro) 37-38, 42-43, 47, $70,261,279,282$; civic participation in a city of intercultural dialogue 82 , 85-86, 94-96, 98, 100-101; multiple forms of participation in a stronghold of the left 112, 115, 118-119, 124-127, 130-131, 133-134, 138-139, 142-143; obstructing participation in a stronghold of the Catholic Church 193, 200-205, 212, 215; political contention amid the rise of the Northern League 153, 155-156, 160-162, 164-169, 173, 177-180, 183-185; political racialization and resistance 220, 229, 233-235, 244

Italian migration laws: Bossi-Fini Law 32-33, 38-40, 130-131, 180-182; Security Package (Pacchetto Sicurezza) 3, 32-33, 111, 124, 154; Turco-

Napolitano Law 33, 38, 41-42, 148, 170

"Italy is me, too! For the rights of citizenship" (L'Italia sono anch 'io! Per $i$ diritti alla cittadinanza) 81-84

jus sanguinis $4,34,81,105 \mathrm{n} 3$ jus soli 4, 19, 34, 81-82, 97, 137

key concepts $13-18,63-65$

key political players $262-263$

labor force $3,32-33,128,170$ lack of alliances $177-180,205-214$ lack of meaningful representation 232-237

lack of meritocracy 237

lay organizations 119-124

leftist civil society actors 19-20

leftist movement 245

leftist organizations $86,89,204-205$, 251-252, 255

leftist political parties $1,37-40$

leftist trade unions 37-40, 94-97, 124, 261; see also specific trade unions

left-wing actors $100-102$

left-wing cities/administrations 19-20, $80-86,113-122,157-160,276$

left-wing cooperatives 90-94

left-wing organizations, weak role of 204-205

left-wing trade unions 124-126

lived experiences of marginalization 266-267

local dynamics $7-13,18-22,70$, 73, 142-143, 214-215, 255-257; approaches to inclusion and implications for participation 65-69; explaining alliances and immigrant activism 55-62; explaining civic and political participation 74; and political competition 259-261; theoretical model of $62-65,69-72$

local level 38-41, 45-46, 123-124

local realm of immigration $63-65,71$, 86-97, 118-133, 162-172, 197-205, 259-261

local voting rights $225-227$

Lombardy region 45, 161, 166, 198, 206, 212, 273-276

"low-skilled" jobs 14, 29

main approaches to inclusion $11,65,94$, 258; see also specific approaches

marginalization 6-7, 59-61, 244-245, 261-262

marginalization of immigrant voices 67, 261

Martiniello, Marco 9-10

Massimo Zonarelli Center see Zonarelli Center

(mass) regularization 4, 7, 31, 152-154, 169-170, 216, 264

MCO (Migrant Coordination Organization of the Province and the City of Bologna, Coordinamento Migranti della Provincia e della Città di Bologna) 112-113, 124-131, 139-144, 237-238 
meaningful representation, lack of 232-237

Metalworkers' Federation of the CGIL (CGIL-FIOM, Federati Impiegati Operai Metallurgici della CGIL) 21, $38,47,112,126,153$; obstructing participation in a stronghold of the Catholic Church 193, 202-203, 206, 211-212; political racialization and resistance 222, 235, 239

migration (key concepts) 13-18

mistrust $177-180$

mobilizations 8-9, 18-19, 142, 254-255, 259-263; alliances and conflicts in context 55-58, 61-63; civic participation 95-98; "A day without us! The strike of migrants" 193-194; political contention 156-157, 168-175, 183-185; and racialization 1-5; studying in context 5-7

monopoly on the discourse on immigration $182,239-240$

most similar cases $44,272-273$

multiple channels 133-141

"native-born" Italians 3, 13, 18, 32, 63, 279,282

networks 43-44, 57-58, 256-257; civic participation 90-93, 102-103; multiple forms of participation 113-114, $118-121,124-129$

new citizens 1, 12-14, 56, 97, 251

"niche openings" 58

non-conventional channels, political participation in 139-141

non-EU immigrants 4, 14, 36, 81, 249-250

Northern League (Lega Nord) 34-36, 39-43, 80-82, 152-153, 195, 212; alliances, conflicts, and political radicalization 172-182; devolution to the Church and the securitarian turn 157-162; lessons of Brescia 183-185; the local realm of immigration and conflicting approaches to inclusion 162-172; "Struggle of the crane" 153-157

obstructing participation 193, 206, 211-214

on behalf $66,142,215,231,234,241$

Other 245

Othering 13-14, 59-62, 221-225, $254-256$

overlapping alliances 133-141 participation 111-117, 119-124, 126, 131-132, 133, 142-144; and approaches to inclusion 65-69; civic participation and political claims 134-136; civic and political channels of 71, 97-102; high barriers to 205-214; political participation in conventional channels 137-139; political participation in non-conventional channels 139-141; see also obstructing participation

participation of immigrants $11,37,56,85$, $165,242,276$

participatory outcomes $4,8,19,63,70-72$, 111,142

participatory variations $\mathbf{2 6 0}$

passive cohabitation 197-200

passive subjects $13-15,66-69,199,215$, $245,253,265$

paternalism 6, 42, 185, 201-205, 252, 262

PCI (Italian Communist Party, Partito Comunista Italiano) 38, 113, 223

PD (Democratic Party, Partito

Democratico) 35, 38-39, 225-229, 235-236, 239-243; civic participation 96-97, 101-102; multiple forms of participation 137-138, 142-143; obstructing participation 204-205; political contention 156-159, 174-176, 180-181; weak role of $132-133$

people of color 1, 14, 60

people with full political rights 258

people with no rights $2,33,155$

permanent occupation 154-156

political channels of participation 71

political claims 134-136

political competition 259-261

political continuity $84-86$

political opportunity approach $8,55-57$, $74 \mathrm{n} 1$

political orientations, different $3,8,22,47$, 142, 168, 193

political participation 5-13, 16-20, 37-38, 44-45, 254-255; alliances and conflicts in context 55-56, 62-69; civic participation 97-99, 104-105; in conventional channels 137-139; explaining 74; multiple forms of participation 132-136; in non-conventional channels 139-141; obstructing 211-214; political racialization and resistance 241-242; weak 100-102 
political parties 94-97

political players $262-263$

political racialization $8-9,22,220-221$, 240, 244-246, 261-262; "consumer paradigm" 225-237; immigrant activists' perspectives $222-225$

political radicalization $172-182$

political rights promotion approach 68-69, 96-97, 114, 126-131, 142-143, 163-167, 203-205

political sub-culture 45-46, 84-90, 275-276

political vacuum 115, 122, 221

politicization of migration 71

politicization of the rights of vulnerable immigrants $168-172$

power dynamics $261-262$

power of the Catholic Church 194-200

power relations $59,221,226,257$, 261-262

precarious status $89,173,258$

PRC (Communist Refoundation Party, Partito di Rifondazione Comunista) 40-41, 169; obstructing participation 193-194, 198, 204-206, 209, 211-215; political racialization and resistance 223 , 235,239

pro-immigrant actors $5-9,12-13,80-82$, 220-223, 251-255, 257-252; alliances and conflicts in context $63-65,69-72$; othering of immigrants by $59-62$; in promoting inclusion 37-44

pro-immigrant groups $1,5-13,18-23$, 254-258, 261-263, 266-267; alliances and conflicts in context 57-58, 61-65; political racialization and resistance 220-221

(pro-) immigrant supporters 5-6, 17-18, $222-225,261-264$

protests $2-4,9-10,128-129,152-157$, 170-172, 175-180, 183-185

Provincial Forum of Immigration 82-84, 132-134, 180-181

race $17-18,59-63$

racial discrimination 249

racial Europeanization 17

racialization 7-9, 18-19, 21-22, 58-63, 249-254; see also political racialization racialized/racialized communities $1-5$, $12-16,35-37,249-250,255-256$, 263-267

racism $1-7,14-20,39-41,60-61$, 249-253, 264-267; civic participation 93-95; multiple forms of participation
111-112, 127-128, 138-139; political contention 153-154, 165-167; political racialization and resistance $224-225$, 235-236, 243-244

"racist wave" 34-36

radical left 3-4, 20-21, 40-43, 258-262;

alliances between the immigrant social movement and 172-177; civic participation 104-105; multiple forms of participation 111-113, 122-128, 141-143; obstructing participation 193-194, 203-205; political contention 152-157, 167-173, 175-178, 182-185; political racialization and resistance 223-227; and the politicization of the rights of vulnerable immigrants $168-172$; responses by $40-43$

radical left organizations $3,7,40-42$, $45,205,258$; as ambivalent allies 237-240; civic participation 86,91 , 105; multiple forms of participation $111,113,119,125-126,128,139$, 141-142; political contention 153,156 , 162, 168, 175-176, 184-185; political racialization and resistance 221,223 , 226, 230-231, 242-243

receiving society $9-18,42-43,67-69$, 103-104

reframing resistance 249-254, 265-267

reframing resistance from below 240-244

Reggio Emilia 18-19, 44-46, 80-81, 259-261, 288-289; intercultural dialogue and implications for participation in civic channels 97-102; "Italy is me, too! For the rights of citizenship" 81-84; lessons from 102-105; local realm of immigration and the prevalence of the intercultural approach 86-97; multiple forms of participation 143-144; political continuity and the role of the left-wing administrations in promoting inclusion 84-86; political racialization and resistance 233-236, 243-245

"relational incubators" 63, 255, 259

research design and methodology 44-48, 272-283

resistance 59-62, 221, 224-227, 239, 245; reframing 240-244, 249-254, 265-267 resisting local voting rights $225-227$ resource-poor groups 58 restrictive legislation 32 rights of vulnerable immigrants 168-172 


\section{Index}

right-wing cities/administration 4, 45-47, 71, 276; multiple forms of participation 115-116; obstructing participation 194-196; political contention 154-157, $160-162,167,174,183$

sans-papiers 40, 216, 258, 264

Second Generation 82

securitarian turn 157-162

security threat 58,111

self-criticism 253,266

self-determination 127-131, 171-173, $222,257-258$

separate entities 15, 67-68, 94, 215 , 246, 263

silencing 222-225

skin color 60,250

social movements $55,61-63,128-130$, 165-173, 175-184, 253-254; social movement research $57-59$

socio-political function 61

speak for oneself 137, 240-244

speaking back to power in their own terms 223, 246

strike $111-113$

"Struggle of the crane" 153-157

subordination 15-16, 231-232

substantive representation 233, 235

symbolic and material resources 57, 277

symbolic representation 233-235

Table of Migrants 41, 170-171, 230

theoretical contribution 8-13, 254-257

theoretical model of local dynamics 8-10,

18-19, 62-65, 69-72; approaches to inclusion and implications for participation 65-69; explaining alliances and immigrant activism 55-62; explaining civic and political participation 74

tokenism 67-69, 203-205, 234-237

top-down dynamics 56-57, 62, $142-143,276$

trade unions 177-180; and the assistance approach 200-204; Christian-Democrat
162-164; Communist 94-96, 165-167; leftist 37-40, 94-97, 124-126; see also CISL

treating immigrants as passive subjects 67,253

UIL (Italian Labor Union, Unione Italiana del Lavoro) 37

underground economy 29-32, 152-154

undocumented (immigrants) 4-5, 20-21, 31-34, 39-40, 260-261; civic participation 89-93; extreme form of protest by $153-157$; political contention 152-153, 161-162, 167-169, 171-179, 183-185; political racialization and resistance $220-221$, 237-239

unequal treatment 59-61, 96-97, 223-225, 231-237

Union for Tenants (Unione Inquilini) 205

USB (Base United Unions, Unione Sindacale di Base) 47, 127, 193, 213-215, 222

use immigrants $171,178,213,239$

"us"/"them" dichotomy 9, 15, 132, 233;

civic participation $89,100,103$; political racialization and resistance $240-241,243$

victimizing immigrants 67,128

voting rights $225-227$

vulnerability $33,43,58,66,112,178$, 252,282 ; politicization of the rights of vulnerable immigrants $168-172$

“war against immigrants" 160-162

weak incentives 96-97

weak investment of left-wing administrations $157-162$

weak political participation 100-102 weak role of left-wing organizations 204-205 weak role of the Democratic Party $132-133$ would-be citizens $67,105 \mathrm{n} 1,231,258$

Zonarelli Center 120-121 